An assessment of the influence of orbital forcing on Late Pliocene global sea-level using a shallow-marine sedimentary record from the Wanganui Basin, New

Zealand

\author{
By \\ Juliet Perry Sefton
}

\begin{abstract}
A thesis
Submitted to Victoria University of Wellington

In fulfilment of the requirements for the degree of
\end{abstract}

\title{
Master of Science
}

In Geology

Victoria University of Wellington

Wellington, New Zealand

2015 


\section{Abstract}

Classical Milankovitch Theory suggests variance in the orbital cycles of precession (21,000 year) modulated by eccentricity ( $\sim 100,000$ year) and obliquity $(41,000$ year) should have a profound influence on polar insolation and ice volume. However, the globally-integrated ice volume proxy record (benthic $\delta^{18} 0$ ) during the Late Pliocene (3.0-2.6 Ma) is dominated by obliquity-paced cycles, and lacks a significant precession component. A number of conceptual hypotheses have been proposed to explain this “41,000 year problem", but palaeoclimate records independent of the benthic $\delta^{18} 0$ record are required to test these hypotheses.

The Wanganui Basin, New Zealand, contains a well-dated, shallow-marine Neogene sedimentary succession that is widely recognised as an important site for examining sea-level/ice volume changes at orbital frequencies. In this study, the shallow-marine Late Pliocene Mangaweka Mudstone is examined at an orbital-scale resolution ( 3-5 kyr sampling) along a continuous 672 metre thick (true thickness) outcropping road section on Watershed Road between the Rangitikei and Turakina River valleys.

Two modern analogue-calibrated water depth proxies were used to evaluate palaeobathymetric changes: (i) sediment texture and (ii) benthic foraminifera census data. An overall trend of shallowing to inner-shelf water depths occurs up-section, but is superimposed by higher frequency fluctuations. For the lowermost $\sim 400$ metres of the section, in situ benthic foraminifera assemblages indicate water depths $>100$ metres. As wave-induced sand transport does not occur on the modern Manawatu-Wanganui outer-shelf, and modern wave climates are assumed to be analogous to the Pliocene, it is concluded that the sediment grainsize approach is not an appropriate proxy for reconstruction water depth changes in the lower $\sim 400$ metres of section.

An integrated magneto-, bio- and tephrostratigraphy was developed that constrains the outcrop succession to between $\sim 3.0 \mathrm{Ma}$ and 2.58 Ma. Nine distinct cycles spanning $\sim 400,000$ years are identified in the grainsize and benthic foraminifera assemblages. Within the uncertainty of the age model, the Mangaweka Mudstone grainsize cycles can be matched one-for-one to the $\delta^{18} 0$ glacial-interglacial cycles, as they display a similar 
pattern in terms of frequency and amplitude. The frequency of the Mangaweka Mudstone cycles (and the corresponding interval in the benthic $\delta^{18} 0$ record) are dominated by the $\sim 40,000$ year obliquity cycle, but with a subordinate eccentricity component. Therefore, the fluctuations in the grainsize and benthic foraminifera proxies likely represent an indirect response to global sea-level fluctuations via their effect on continental shelf sediment transport mechanisms (non-wave) with the orbitally-paced transgression and regression of the shoreline on a restricted palaeocontinental shelf.

The implications for the orbital theory of the ice ages are that during the Late Pliocene, global ice volume changes responded primarily to obliquity, and the precession influences were either: (i) too low in amplitude to have influenced the grainsize and benthic foraminifera assemblages in the Mangaweka Mudstone depositional environment, or (ii) cancelled-out in global ice volume and sea-level changes because precession forcing is anti-phased between the hemispheres. 


\section{Acknowledgements}

This thesis is product of a hugely successful collaboration effort. A project spanning such a vast array of disciplines, techniques and understanding can only be possible when those involved are dedicated, enthusiastic and above all passionate about developing a brand new piece of science, however big or small. I have had the pleasure of working with so many people with these qualities.

My supervisors, Tim Naish and Rob McKay, have always been excited to hear about how the project is coming along. They were never too busy, and have provided me with so much knowledge and so many opportunities. I am hugely grateful for the respect they have always given me in any discussions of the project, and it has (truly) instilled in me a passion for the scientific process. You have both made the project a hugely enjoyable experience, especially considering your impeccable tastes in beer. Rob, thanks for still believing in me after Onekaka.

Gillian Turner provided invaluable assistance with the magnetostratigraphy, and has guided me through arguably one of the biggest learning curves I've encountered. Thank you for your support and encouragement, and enthusiasm for field work!

Without the help of Hugh Morgans, this would be a very small benthic foraminifera study. I cannot thank you enough for the assistance with washing, identifying, picking, and counting.. and for always being a cheerful smiling face out at GNS.

Diane Seward conducted the fission-track methodology and analysis, and has been a fantastic mentor for all things tephra but also for academic life. Thank you for always showing an interest and for your encouragement.

Great thanks are also in order for Brent Alloway, who not only conducted the major and trace element measurements for the tephra samples, but also took the Masters students to his stomping ground in Southern Chile. Thanks for the incredible experience, and for always believing in my abilities since undergraduate studies.

Thanks to the rest Wanganui crew - working on a real-life geological drill site was an awesome experience. Thanks especially to Darcy and to Georgia, and may the future be full of only the best bark-ups and trout-tickling. A thanks is also in order for Gavin Dunbar, who provided endless knowledge on all things lab and sediments, help with fine-tuning presentations, and a great interest in the project.

Thanks to the Buchanans (Peter and Wendy) - long-time family friends who have been hiding away in Mangaweka since before I was born. It's funny I came back after all these years to have a look at the rocks right beneath your house. Many thanks for the accommodation and glorious food - I'll be seeing you soon. 
Thanks to the office mates (new and old): Bella and Shaun (for taking me in early!), Georgia, Ari, Molly, Heidi and Richard. You have supplied endless fun and support, and also importantly lots of teas and coffees. Thanks to my fellow Masters students for always being happy to listen, and for understanding!

I am grateful for the support from my family and friends, but mostly I am happy that some of them have finally learned that I am not just studying 'soil'. Thank you!

Lastly, but certainly not least, thank you to Richard. This is a particularly significant thank you considering your help with field work, discussions, and all manners of emotional support during this huge undertaking, all while you are yourself finishing your PhD thesis. You're incredible. Thank you for putting up with me (all the time, office-mate!), and I am so very lucky to have had had your support through it all.

Financial support for this thesis came from the Royal Society Marsden Fund. 


\section{Contents}

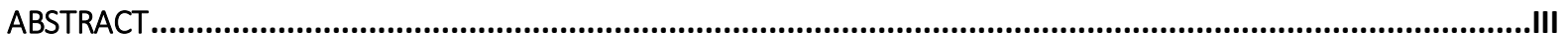

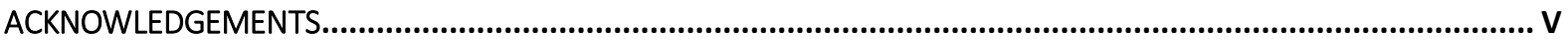

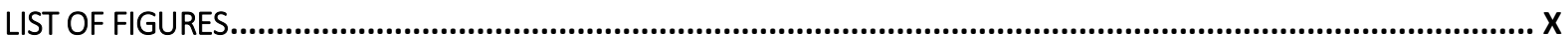

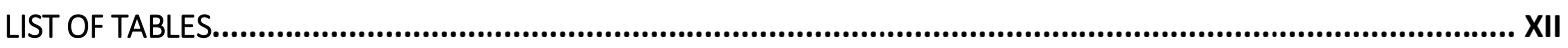

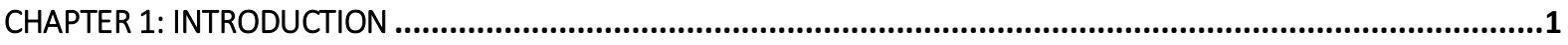

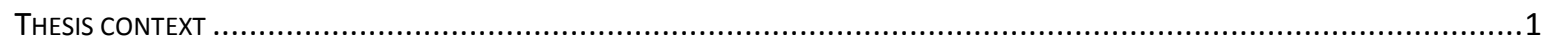

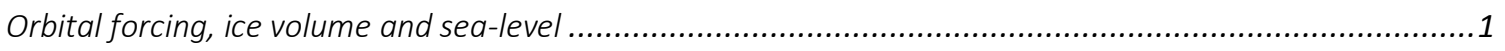

The Late Pliocene transition to a bi-polar glacial world.......................................................................4

A sedimentary record of glacio-eustatic sea-level change: The Wanganui Basin......................................7

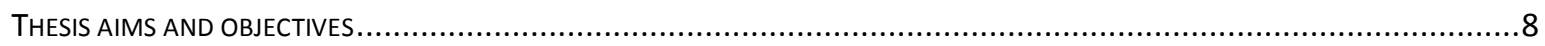

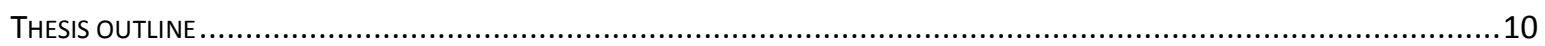

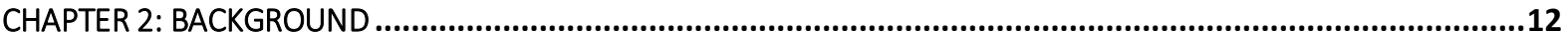

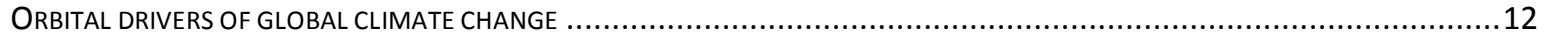

Milankovitch cycles and palaeoclimate records......................................................................... 12

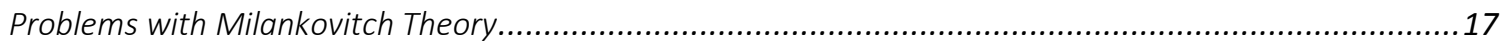

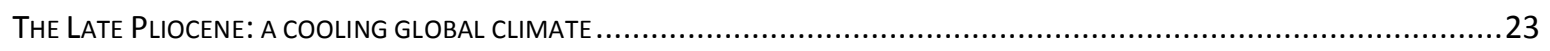

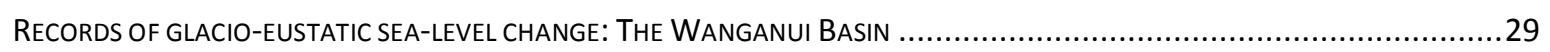

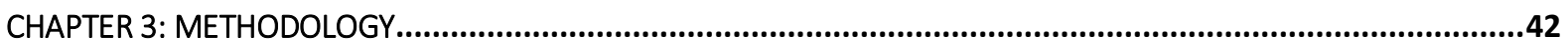

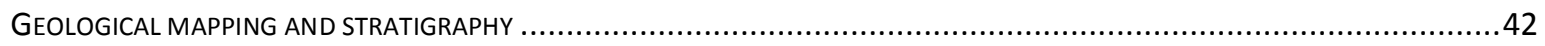

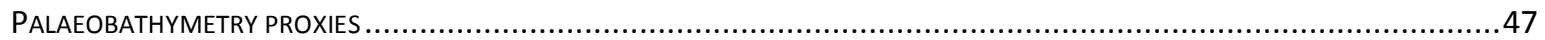

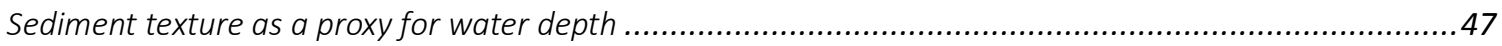

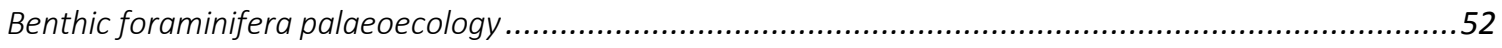

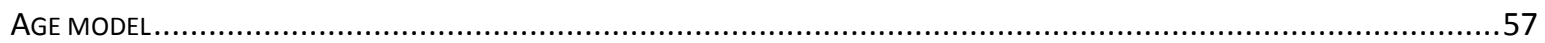

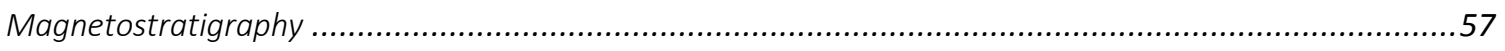

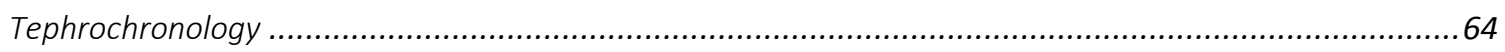

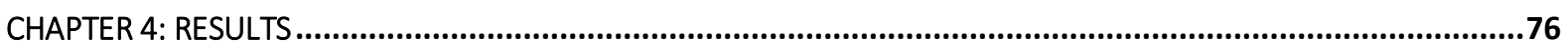

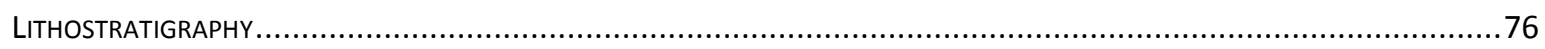

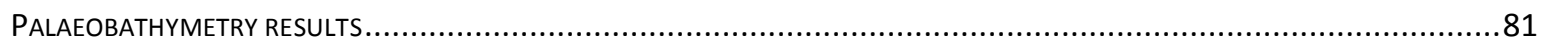

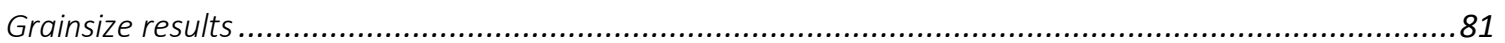

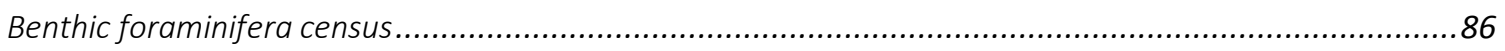

Comparison of grainsize and benthic foraminifera-derived palaeobathymetry ..................................104

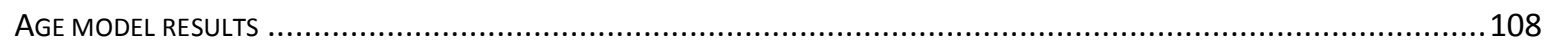

Palaeomagnetic results and magnetostratigraphy ................................................................ 108

Tephrochronology: Fission track dating results ............................................................................ 116

Tephrostratigraphy: Major and trace element geochemical fingerprinting results................................118

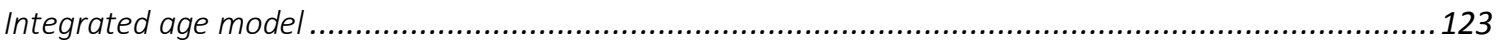




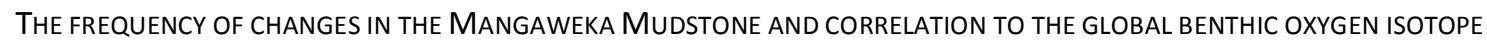
RECORD

DePositionAL PROCESSES ON THE OUTER-SHELF OF THE WANGANUI BASIN IN THE LATE PLIOCENE ................................. 130

AN INDIRECT RECORD OF ORBITALLY-FORCED GLACIO-EUSTATIC SEA LEVEL: IMPLICATIONS......................................... 134

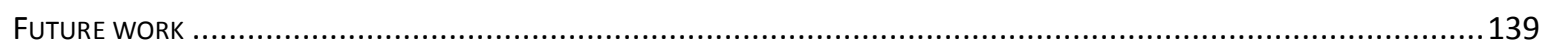

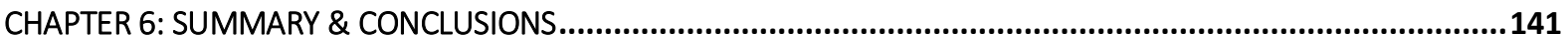

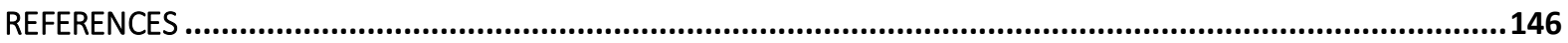

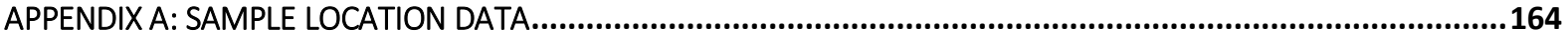

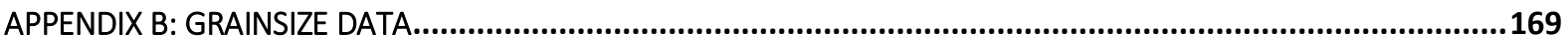

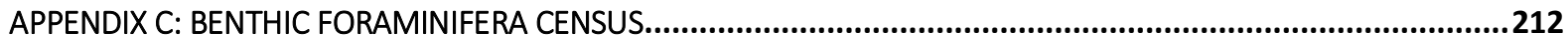

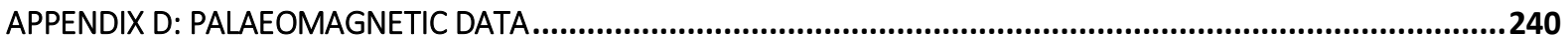

APPENDIX E: FISSION TRACK AND TEPHRA GEOCHEMISTRY DATA ..........................................................245 


\section{List of Figures}

\section{Chapter 1}

Figure 1.1: Benthic $\delta^{18} 0$ record, global climate changes and orbital cycles over the last 5 million years.

Figure 1.2: Benthic $\delta^{18} 0$ record, orbital cycles and insolation during the Late Pliocene..........Page 6

Figure 1.3: The Wanganui Basin setting, New Zealand. Page 8

Chapter 2

Figure 2.1: Schematic representation of the orbital cycles of precession, obliquity and eccentricity

Figure 2.2: Orbital solutions and insolation over the last 5 million years. .Page 14

Figure 2.3: The influence of precession on annual insolation. Page 21

Figure 2.4: Frequencies of total summer temperature and peak insolation over time... Page 22

Figure 2.5: Global changes during the Late Pliocene and Pleistocene Page 24

Figure 2.6: Modelled Pliocene precipitation, land and sea surface temperatures...... Page 27

Figure 2.7: Shallow marine sea level records: The interplay of eustasy, subsidence and sedimentation.

Figure 2.8: Cross-section of the geological structure of the Wanganui Basin Page 32

Figure 2.9: A model of the structural evolution of the Wanganui Basin. ...Page 33

Figure 2.10: Palaeogeography of the lower North Island of New Zealand during the Late Pliocene.

Figure 2.11: Wanganui Basin sequence stratigraphy and links to the global ice volume proxy record. Page 37

Figure 2.12: The Mangaweka Mudstone along Watershed Road, Tiriraukawa. .Page 39

Figure 2.13: The Rangitikei River Mangaweka Mudstone section. .Page 40 Chapter 3

Figure 3.1: The Tiriraukawa Mangaweka Mudstone exposure along Watershed Road Page 42

Figure 3.2: A freshly cut road exposure along Watershed Road. Page 43

Figure 3.3: Field techniques. Page 44

Figure 3.4: Sample localities along Watershed Road...... Page 45

Figure 3.5: (a) Trigonometric method for calculating stratigraphic position. (b) Cross-section line on Digital Elevation Model. (c) Tiriraukawa cross-section.. .Pages 45-46

Figure 3.6: Sediment texture changes on a wave-graded continental shelf. .Page 48

Figure 3.7: Percent mud as a proxy for water depth...... .Page 49

Figure 3.8: The Hjulstrom and Sundborg grainsize and shear stress curves Page 51 
Figure 3.9: Detrital remanent magnetisation

Page 58

Figure 3.10: Orientation of palaeomagnetic samples. Page 63

Figure 3.11: Palaeomagnetic sample field collection. Page 63

Figure 3.12: Otago Palaeomagnetic Research Facility cryogenic magnetometer Page 64

Figure 3.13: Tiriraukawa and Rangitikei River tephra sites Page 65

Figure 3.14: Eagle Hill tephra sample collection in the Rangitikei River Page 67

Figure 3.15: External detector methodology for fission-track dating..... Page 68

Figure 3.16: Zircon crystal images. .Page 69

Figure 3.17: Rangitikei River tephras in outcrop..... Page 73

Figure 3.18: Eagle Hill and Kowhai tephra localities in the Rangitikei River valley...... Page 73 Chapter 4

Figure 4.1: Stratigraphic column for Watershed Road Mangaweka Mudstone. Page 77

Figure 4.2: Field section photography Pages 79-80

Figure 4.3: Example grainsize distributions Page 81

Figure 4.4: Grainsize results: percent mud, mean and standard deviation .Page 82

Figure 4.5: Sediment water depth proxy results Page 84

Figure 4.6: Mica grains and laser particle size measurements. Page 85

Figure 4.7a-d: Percent abundance of common benthic foraminifera species with stratigraphic depth Pages 87-90

Figure 4.8: Q-mode cluster analysis Page 92

Figure 4.9a-f: Taxonomic composition of benthic foraminifera clusters Pages 94-99

Figure 4.10: Foraminifera cluster depth ranges Page 101

Figure 4.11: (a) Grainsize and foraminifera change with stratigraphic depth. (b) Integrated grainsize and benthic foraminifera assemblage palaeobathymetry.... Pages 104-105

Figure 4.12a-d: Palaeomagnetic demagnetisation patterns Page 110

Figure 4.13: Mean site palaeomagnetic directions for development of magnetostratigraphy Page 112

Figure 4.14: Declination and inclination with stratigraphic depth Page 113

Figure 4.15: Magnetostratigraphy interpretations. Page 115

Figure 4.16: Radial plot of individual zircon fission-track ages Page 117

Figure 4.17: Major element plots for Rangitikei and Tiriraukawa tephra samples Page 119

Figure 4.18: Rangitikei and Tiriraukawa Mangaweka Mudstone tephrostratigraphic correlation

Figure 4.19: Trace element plots for Rangitikei and Tiriraukawa tephra samples Page 122 
Figure 4.20: Integrated model for the Tiriraukawa Mangaweka Mudstone.

Page 124

Chapter 5

Figure 5.1: Grainsize and benthic foraminifera assemblage cycles correlated with the benthic $\delta^{180} 0$ record.

Page 127

Figure 5.2: Palaeogeography of the Late Pliocene Wanganui Basin and sediment transport mechanisms. Page 131

Figure 5.3: Benthic $\delta^{18} 0$ record time series analysis. Page 135

Figure 5.4: Grainsize and benthic foraminifera assemblage cycles, benthic $\delta^{18} 0$ record and orbital cycles. Page 137

\section{List of tables}

Chapter 2

Table 2.1: Milankovitch cyclicity in records of palaeoclimate Page 16 Chapter 4

Table 4.1: Foraminifera cluster comparison to previously defined associations. ..Page 102

Table 4.2: Zircon fission-track age data for the Eagle Hill tephra Page 116

Table 4.3: Mean major element data for the Rangitikei and Tiriraukawa tephras Page 118

Table 4.4: Mean trace element data for the Rangitikei and Tiriraukawa tephras Page 120 


\section{Chapter 1: Introduction}

\section{Thesis context}

\section{Orbital forcing, ice volume and sea-level}

The frequency of glacial-interglacial cycles and associated sea level, temperature and carbon dioxide variations documented in the geological record are widely attributed to variations in the geometry of the Earth's orbit (Hays et al., 1976; Berger, 1977; Imbrie, 1985). Termed Milankovitch cycles, these orbital variations directly influence the distribution and magnitude of insolation at the top of the atmosphere (Milankovitch, 1941). Orbital cycles are most apparent in geological climatic records at frequencies of 21,000 years (precession), 41,000 years (obliquity), and 100,000 years (eccentricity). Milankovitch Theory dictates that these orbital cycles influence the amount of insolation reaching high latitudes where large continental ice sheets are located. Critically, changes to the incoming energy, particularly during the summer season regulate the growth and decay of the polar ice sheets.

The first direct evidence of the link between orbital cycles and global ice volume over geological time was revealed by palaeoclimate records over half a century ago, most notably from the global ice volume reconstructions based on the oxygen isotope contents of foraminifera shells in deep ocean sediment cores (Emiliani, 1955; Shackleton and Opdyke, 1973; Hays et al., 1976). These regular variations reflect large climatic changes which are seemingly in-step with orbital cycles, extending as far back as the Early Cenozoic (figure 1.1) (Zachos et al., 2001; Lisiecki and Raymo, 2005; Zachos et al., 2008).

However, there are several well-documented challenges in reconciling Milankovitch orbital theory with geological observations of ice volume change (Raymo and Huybers, 2008). Globally-integrated records of ice volume variability $\left(\delta^{18} 0\right)$ over the last 800,000 years are dominated by asymmetric, high amplitude cycles occurring at a frequency of 100,000 years (figure 1.1). During the Pliocene and Early Pleistocene, inferred ice volume changes are more symmetrical, lower in amplitude, and occurred more frequently (at 41,000 year intervals). The assumptions of a linear relationship between 
ice volume and Milankovitch cycles consequently implies that eccentricity is the primary control on the glacial-interglacial cycles over the past 1 million years, but that obliquity is the primary driver for the glacial-interglacial cycles of the Pliocene and Early Pleistocene (Imbrie and Imbrie, 1980).

If this were the case, then we would also expect to see frequencies pertaining to precession (a 21,000 year frequency) in geological records throughout the Pliocene and Pleistocene. Yet, a precession signal is notably absent in globally-integrated palaeoclimate records for the Pliocene and Early Pleistocene (5.3-0.8 Ma) (Lisiecki and Raymo, 2005). This phenomenon exists despite precession being evident in palaeoclimate records during the last 800,000 years, albeit modulated by 100,000 year eccentricity and thus having a strong influence on insolation received at high latitudes (figure 1.1) (Raymo and Nisancioglu, 2003). This observation challenges our current understanding of Milankovitch Theory, and emphasises the necessity for closer investigation of palaeoclimate records that are independent of the globally-integrated marine oxygen isotope record (Paillard, 2006). This study seeks to explore whether precession had a significant influence on ice volume changes, and thus global sea levels, in the Late Pliocene and Early Pleistocene by using a far-field, shallow-marine sedimentary record of sea-level change from the Wanganui Basin, New Zealand.

There are currently two leading hypotheses that address the lack of a precession signal in the global benthic $\delta^{18} 0$ record from the Late Pliocene and Early Pleistocene. The first suggests that ice sheets do respond to insolation changes controlled by precession and obliquity (Raymo et al., 2006). However, because the seasonal influence of precession is out of phase between the hemispheres, its signal in globally-integrated sea-level (Naish, 1997) and ice volume proxy records (Lisiecki and Raymo, 2005) is cancelled out (i.e. a small amount of precession-regulated ice sheet melt in one hemisphere is offset by precession-regulated growth in the other). This results in the obliquity-regulated component of ice sheet volume changes dominating proxy records of ice volume change, because its influence is in phase between the hemispheres. This hypothesis thus implies that precession does directly influence variations in ice sheet volume during the Late Pliocene, but it is hidden in globally-integrated records of ice volume because its influence is directly anti-phased between hemispheres. However, this cancelling effect requires substantial ice volume in both hemispheres - an important factor considering 
significant northern hemisphere glaciation is thought to have initiated at $\sim 2.7 \mathrm{Ma}$ (Raymo et al., 1992; Ravelo et al., 2004).

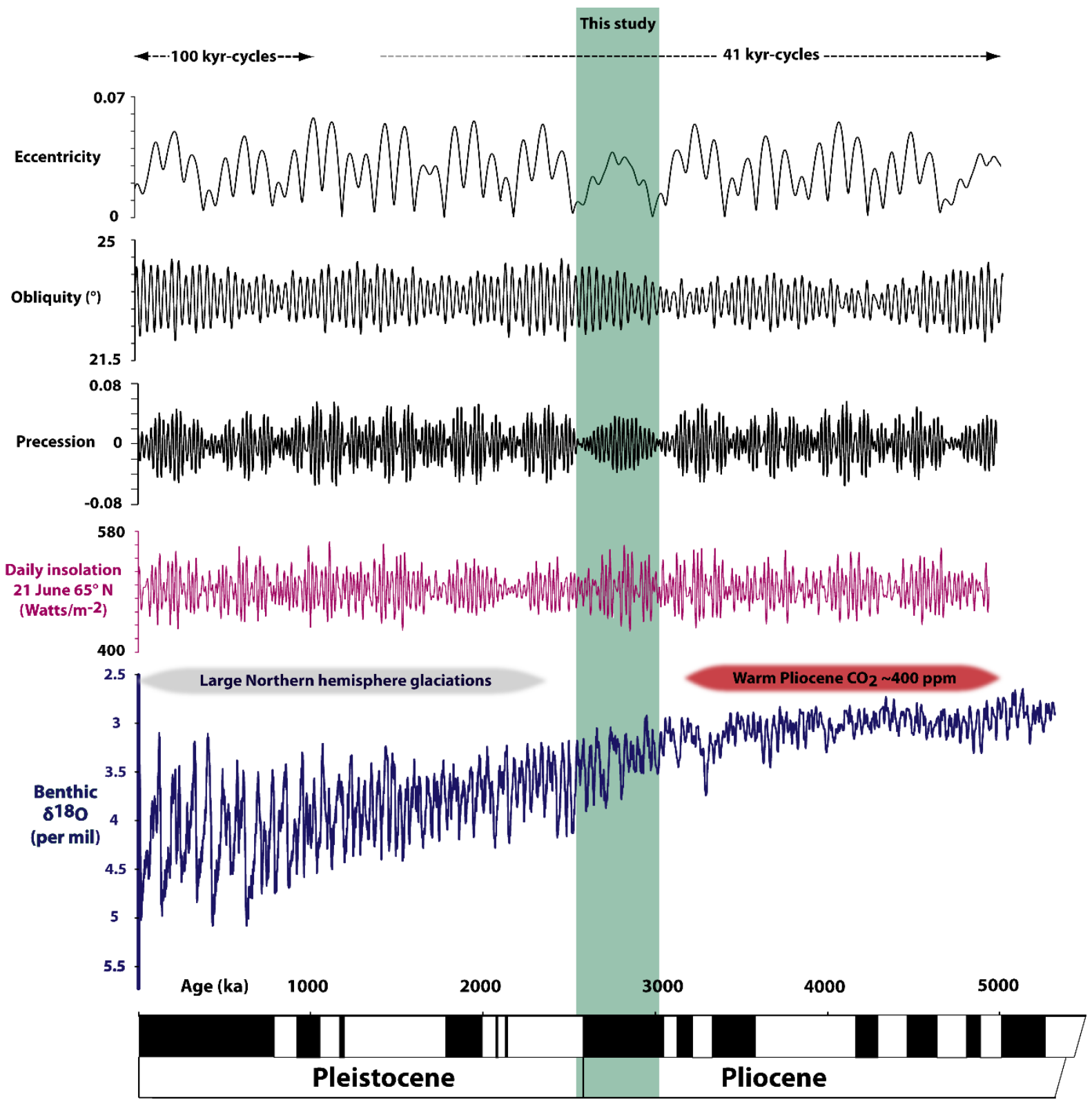

Figure 1.1: The global benthic $\delta^{18} 0$ record, orbital solutions (eccentricity, obliquity and precession), insolation on the summer solstice at $65^{\circ} \mathrm{N}$, and Global Polarity Time Scale for the last 5 million years (Cande and Kent, 1995; Laskar et al., 2004; Lisiecki and Raymo, 2005). The interval for this study is marked in green, which covers roughly 3-2.6 Ma. The insolation parameter shown here is significant because under Milankovitch Theory, the energy received at high northern latitudes during summer is critical to changes in continental ice volume (Milankovitch, 1941; Imbrie and Imbrie, 1980). Importantly, this insolation parameter is also closely tied with the variance in precession over the last 5 million years. 
The second hypothesis suggests that the influence of precession on ice volume is insignificant under certain climate boundary conditions (Huybers, 2006). When the total energy (insolation received by the atmosphere) above the melt threshold required to ablate ice sheets occurs over the majority of the summer season, precession does not exert as much influence (Huybers and Tziperman, 2008). However, this is only valid when ice sheet melt thresholds are lower, which occurs when the overall climate is warmer and atmospheric carbon dioxide higher. Geological records and climate modelling indicate the Pliocene had such a climate (Crowley, 1996; Seki et al., 2010). Under such climates it has been argued that obliquity (which controls mean annual insolation) has more influence on ice sheet ablation than summer insolation intensity, which is determined by precession (Naish et al., 2009).

This study will investigate whether ice sheets in the Late Pliocene and Early Pleistocene (3-2.6 Ma) respond to precession, obliquity or both. A unique opportunity to investigate ice volume changes via their effect on global sea-level is presented in the Wanganui Basin where glacio-eustatic sea level cycles representing recurrent regressions and transgressions of the shoreline across the continental shelf have been recorded in sedimentary strata over the last 4 million years (e.g. Fleming, 1953; Abbott, 1997; Naish, 1997). Water depth changes preserved in the Wanganui Basin sedimentary cycles will be reconstructed using two independent methods (outlined below) within chronostratigraphically-constrained outcropping strata spanning 3.0-2.5 Ma. Critically, this record is independent of the global marine oxygen isotope curve and can provide new insights into the orbital forcing of ice sheets and eustatic sea level.

The Late Pliocene transition to a bi-polar glacial world

The Late Pliocene is of interest to palaeoclimate scientists because it encompasses a major global climate transition (figure 1.1). The Pliocene (5.33 Ma-2.6 Ma) is an epoch characterised by warmer mean surface temperature $\left(2-3^{\circ} \mathrm{C}\right.$ above present global average) (Haywood et al., 2013; IPCC, 2013), a reduced Antarctic ice sheet extent and minimal Northern Hemisphere ice cover (Naish et al., 2009; Cook et al., 2013; Koenig et al., 2014), atmospheric carbon dioxide concentrations consistent with post-industrial levels (>400 ppm) (Seki et al., 2010; Bartoli et al., 2011; Martinez-Boti et al., 2015), and higher interglacial mean sea levels ( $\sim 20 \mathrm{~m}$ above present) (Dowsett et al., 2012; Miller 
et al., 2012). Toward the end of this epoch ( $2.7 \mathrm{Ma}$ ), a sustained major global cooling initiated, and large continental-scale glaciations began to periodically advance and retreat over much of the Northern Hemisphere (Raymo et al., 1989; Jansen et al., 2000; Lawrence et al., 2010; McKay et al., 2012a; Bailey et al., 2013).

Unravelling the signatures of ice sheet variability at either hemisphere from isotopic proxies of ice volume $\left(\delta^{18} 0\right)$ is challenging. Examination of direct records of ice volume across the Late Pliocene climatic transition could therefore provide insights into: (i) the orbital drivers for Antarctic ice sheet variations prior to the onset of Northern Hemisphere glaciation, and (ii) how the cooling climate state of the Late Pliocene and onset of Northern Hemisphere glaciation influence the orbital responses of the glacial cycles.

Archives that are independent of the globally-integrated benthic $\delta^{18} 0$ record are ideal for deciphering the relative responses of ice sheets to orbitally-induced climate changes in different hemispheres. This is because it is difficult to isolate hemisphere-specific ice volumes and their respective frequencies of variability from the $\delta^{18} 0$ record, as: (i) the isotopic signal is complicated by changing temperatures and ocean salinity through time, (ii) the rapid mixing of the ocean (over $\sim 1$ kyrs), and (ii) the isotopic compositions of ice sheets can only be assumed for periods of the geological past (Pillans et al., 1998; Lisiecki and Raymo, 2005; Raymo et al., 2006). Therefore, sea-level records that are a direct indication of global ice volume can provide a clearer understanding of the relative contributions of the polar regions to ice volume variability during the Late Pliocene and Early Pleistocene. 


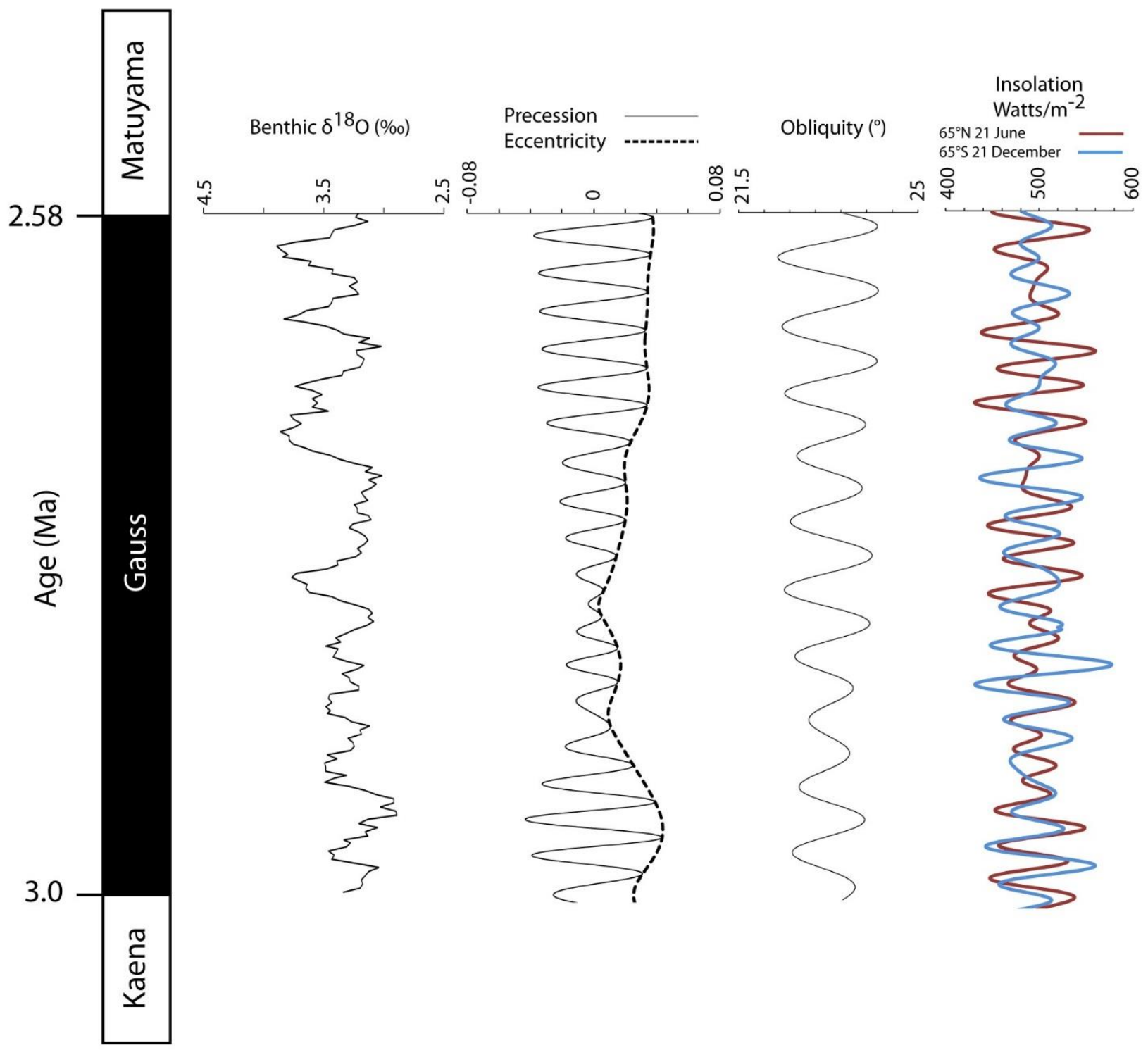

Figure 1.2: Variability in the orbital parameters of eccentricity, obliquity and precession with the benthic $\delta^{18} \mathrm{O}$ record and daily insolation (at $65^{\circ} \mathrm{N}$ and $65^{\circ} \mathrm{S}$ ) during the Late Pliocene. Orbital solutions are by Laskar (2004).

During the Pliocene (3-2.6 Ma), the relative strength of both precession and obliquity varies significantly in palaeoclimate proxy records (figure 1.2). Prior to $3.5 \mathrm{Ma}$, the benthic $\delta^{18} 0$ record exhibits obliquity and minor precession signals, yet proximal geological records of Antarctic ice volume change are dominated by obliquity (Naish et al., 2009; Patterson et al., 2014). Between 3.5 Ma and 2.0 Ma, an Antarctic margin icerafted debris record implies East Antarctic ice sheet changes at precession frequencies (Patterson et al., 2014). However, after $2.8 \mathrm{Ma}$, the benthic $\delta^{18} \mathrm{O}$ record is dominated by obliquity frequencies despite concurrent high precession. At the same time, Antarctic margin ice-rafted debris records suggest ice sheet changes at precession frequencies 
(Patterson et al., 2014). These discrepancies between ice sheet proximal geological records and globally-integrated ice volume proxies is perplexing, and examination of far-field sea-level records that reflect global ice volume changes may provide insights into the role of orbital forcing on polar ice volume variability during the Late Pliocene.

The warmer world of the Pliocene is a particularly important time period because of its similarities with current and future projected climate (Crowley, 1991; Raymo et al., 1996). While not a direct analogue for a future climate forced by anthropogenicallyproduced greenhouse gases, the geological record of the Pliocene provides a means to understand high latitude processes occurring during a warmer climate regime. Therefore, palaeoclimate data from this particular past warm period are necessary for assessing the reliability and sensitivity of climate models for predicting changes in coming centuries (Dowsett et al., 2012).

\section{A sedimentary record of glacio-eustatic sea-level change: The Wanganui Basin}

Questions surrounding ice volume change over time can be directly investigated through records of sea-level change. These expressions of ice volume variability are not limited to the deep ocean, and can be found in previously or presently tectonically active continental settings (Miller et al., 2005; Miller et al., 2012). During glacialinterglacial cycles, sea level rises and falls across continental shelves around the world. These patterns are recorded in the geological record as cyclical changes in the shallow marine sedimentary rocks of sedimentary basins.

One such record is preserved in the shallow marine strata of the Wanganui Basin in New Zealand, a proto-back-arc sedimentary basin resulting from subsidence associated with the Australian-Pacific plate boundary (Proust et al., 2005) (figure 1.3). Because subsidence has largely matched sedimentation rates, this has culminated in the preservation of a $>4 \mathrm{~km}$ thick, near-complete record of Pliocene-Pleistocene eustatic sea-level change (Naish, 1997; Kamp et al., 1998). Uplift along the plate boundary in the last 1 million years has created easily-accessible on-land exposures in river valleys and coastal cliffs. The links between these shallow-marine sedimentary sequences and orbitally-driven sea-level cycles (at an inferred 41,000 year frequency) have been previously demonstrated by an integrated sequence stratigraphic approach that is wellconstrained chronologically by biostratigraphy, magnetostratigraphy, and 
radiometrically-dated tephras (Naish et al., 1996; Alloway et al., 2005; Turner et al., 2005).

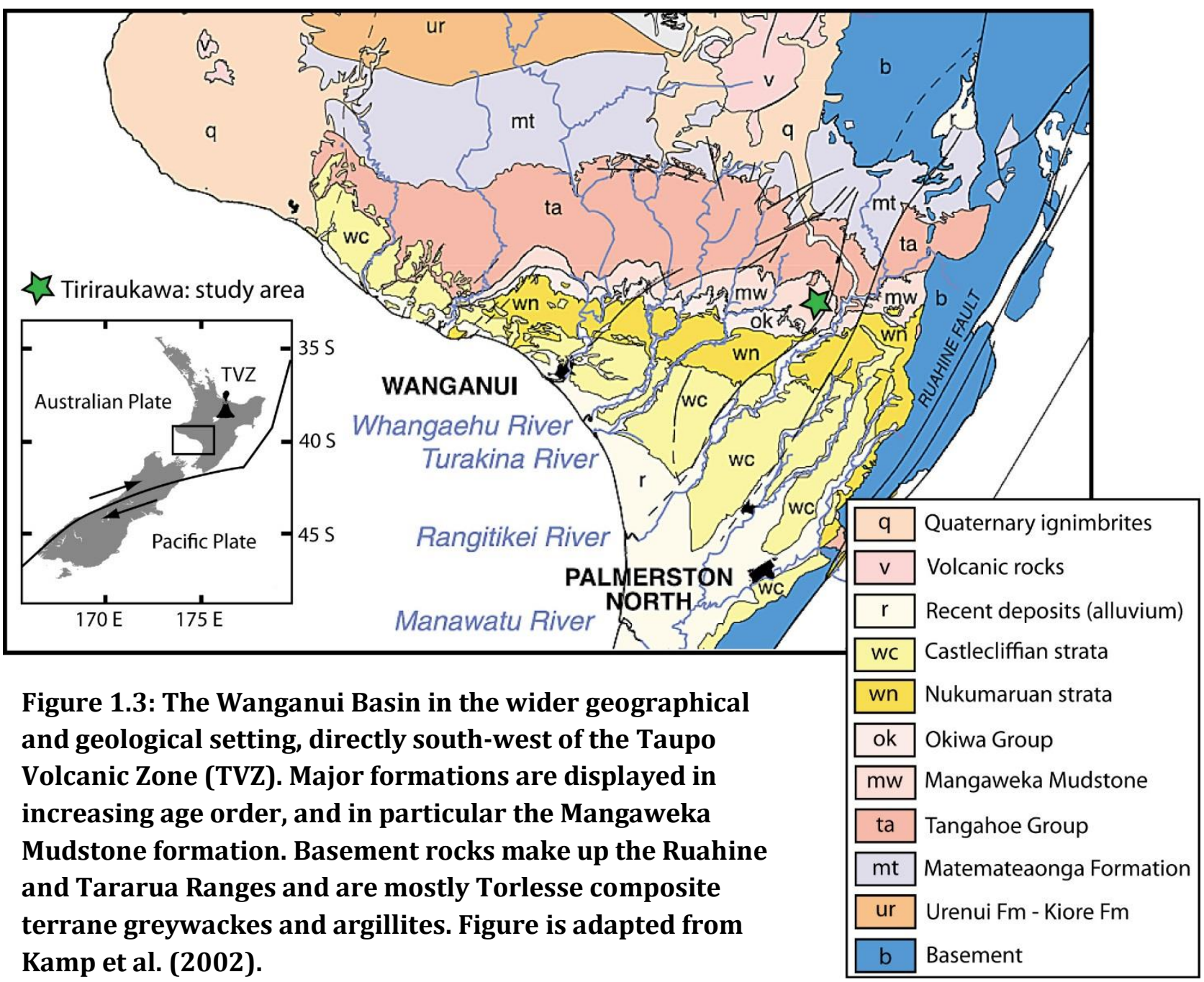

\section{Thesis aims and objectives}

While providing an understanding of this astronomically-tuned lithostratigraphic framework, the resolution of previous studies (Pillans et al., 1994; Naish, 1997; Naish et al., 1998; Saul et al., 1999) has been insufficient to clearly identify subtle water depth changes resulting from higher frequency orbital forcing (specifically 21,000 year precession cycles). Therefore, there is much scope to investigate the valuable archive of the Wanganui Basin in high resolution to evaluate the influence of orbital cycles on eustatic sea-level changes. 
The aim of this thesis is to assess the influence of orbital forcing on sea-level changes in the Late Pliocene (3.0-2.5 Ma) through an investigation of a $700 \mathrm{~m}$-thick, continuous shallow-marine sedimentary sequence (the Mangaweka Mudstone formation) exposed in outcrop in the eastern Wanganui Basin (figure 1.3). Here, detailed analysis of water depth changes using two independent proxy approaches (sediment texture and a benthic foraminifera census) constrain the frequency and relative amplitude of global glacio-eustatic sea-level variations, which largely influenced the relative sea levels recorded in the Wanganui Basin between $\sim 3.0 \mathrm{Ma}$ and $2.5 \mathrm{Ma}$. It is anticipated this investigation will help inform debates regarding ice volume variability during a time period when there was significant climatic change, and it is suited to test hypotheses of orbital theory of the glacial-interglacial cycles outlined above.

Previous studies of the Late Pliocene Mangaweka Mudstone have suggested that the depositional environmental was likely to have been at mid to outer-shelf depths $(>40$ m) (Journeaux et al., 1996; Kamp et al., 1998; McIntyre, 2002). This is ideal for high resolution studies because at this depth range, sediments are not eroded by regressing shorelines during relative sea-level fall and are still sufficiently shallow to record water depth changes in sediment textures and marine fauna assemblages (Kamp et al., 1998).

Evaluation of the water depth changes in the Mangaweka Mudstone will be achieved through high-resolution analysis of sediment textures and the assemblages of benthic foraminifera, which are both proxies for water depth. Reconstructions of water depth changes based on these proxies is supported by modern-analogue studies of: (i) sediment textures off the shallow, wave-graded Manawatu coast (Dunbar and Barrett, 2005), which quantitatively relates percent mud with water depth, and (ii) the depthdistribution of benthic foraminifera species on the modern New Zealand continental shelf (Hayward et al., 1999), which are the same species present in Quaternary and Neogene records.

Recognition of the frequency and relative magnitude of these changes will be constrained by an age model based on an integrated magnetostratigraphy and tephrochronologic framework. These dating techniques will form the basis of an age model, which can be interpreted within the chronostratigraphic framework established in the Wanganui Basin (Naish et al., 1996; Naish et al., 1998; Alloway et al., 2005; Turner et al., 2005). Using this regional age model, the local record of sea-level change recorded 
in the Mangaweka Mudstone can be correlated to other astronomically-tuned local, regional, and farther-field records (e.g. marine sediment cores offshore New Zealand, Antarctic margin sediment cores and the global benthic $\delta^{18} 0$ record). This will allow interpretation of water depth changes seen in this continental shelf setting within a global framework of orbitally-forced ice volume and equivalent global sea-level variability during the warmer world of the Late Pliocene.

While designed to be a standalone study, this project also acts as a pilot study for wider research into the Pliocene records preserved in the Wanganui Basin. Two drill-cores collected during 2014 from mid-Pliocene strata (3.5-3.3 Ma) will use the palaeobathymetry proxies employed in this study to reconstruct peak sea levels during this warmer climate regime, but for older immediately underlying strata. The magnitude of peak sea-level during this time is highly likely to be higher than present $(\sim 20 \pm 10 \mathrm{~m})$, but these values are not well constrained (Naish and Wilson, 2009; Miller et al., 2012). This broader research project aims to determine absolute changes in water depth primarily controlled by orbitally driven, glacio-eustatic changes in global mean sea level.

Absolute amplitudes of eustatic change will not be determined here as further work is required to robustly resolve the additional influence of tectonic subsidence, compaction and hydro-glacio-eustatic adjustments on relative sea-level. The focus of this thesis is to constrain the frequency of sea level change recorded in the Wanganui Basin, which will provide critical insights into the role of orbital forcing on polar ice sheet and global sealevel evolution and variability.

\section{Thesis outline}

This thesis comprises six chapters. Chapter 1 outlines the purpose, aims and objectives of the study, highlighting the key contributions that will be made to this field of enquiry. Chapter 2 explores the background and the state of the science in question, to put into perspective the objectives of the study. Chapter 3 briefly reviews and describes the techniques employed in this study to reconstruct palaeobathymetry and create an age model. Chapter 4 covers: (i) the outcrop stratigraphic section, (ii) the results of 
palaeobathymetry proxies of sediment texture and benthic foraminifera census, including the reconstruction of water depth changes, and (iii) the magnetostratigraphy and tephrochronology for the creation of an age model. Chapter 5 evaluates the characteristics of water depth changes presented by the results and interprets their significance and limitations with respect to other local, regional and global astronomically-tuned sea-level change and ice volume records. Ultimately this chapter addresses the question, "what is the influence of precession on water depth variations recorded in this shallow-marine geological record?" The conclusions and synthesis of the study is provided in Chapter 6. 


\title{
Chapter 2: Background
}

\author{
Orbital drivers of global climate change
}

Milankovitch cycles and palaeoclimate records

The glacial-interglacial cycles of the Late Cenozoic are widely attributed to the changes in the geometry of the Earth's orbit around the Sun (Croll, 1867; Milankovitch, 1941; Hays et al., 1976; Berger, 1977). Changes in the Earth's orbital configuration directly influence the amount of solar radiation received at the top of the atmosphere at a particular latitude and season (Imbrie and Imbrie, 1980). Orbital variations happen at well-known timescales and frequencies, and are a result of complex gravitational influences from the Sun, Moon and other planets (Milankovitch, 1941; Berger and Loutre, 1991; Paillard, 2010). There are three principal orbital parameters that cause

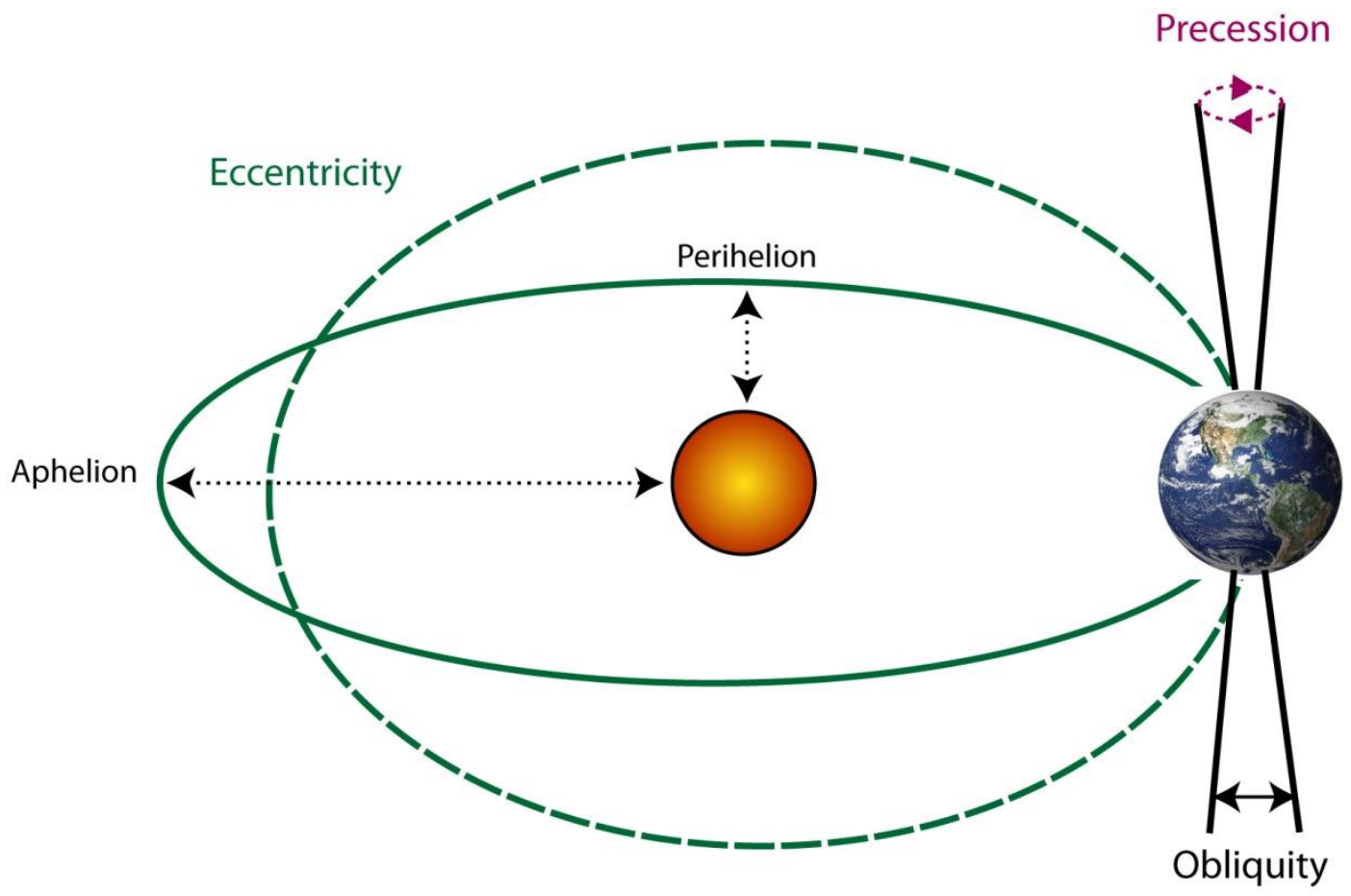

Figure 2.1: A schematic representation of the orbital cycles of eccentricity, obliquity and precession. Eccentricity describes the change in the shape of the orbit (from more elliptical to more spherical). Obliquity describes the change in the tilt angle of the axis of rotation, and precession is the 'wobble' or gyration about that axis. The shortest Earth-Sun distance along the orbit is perihelion, and the longest distance is aphelion. 
variations to incoming solar radiation (or insolation): precession, obliquity and eccentricity (figure 2.1).

Eccentricity defines the change in the shape of the Earth's orbit (figure 2.1). This describes how the orbit changes from a more elliptical to more spherical shape, which varies at a 100,000 year and 400,000 year periodicity (Paillard, 2010). Eccentricity influences the annual mean insolation received, by changing the distances from the Earth to the Sun. For example, a very elliptical orbit will result in significantly less insolation when Earth is at aphelion, and a more spherical orbit will result in only a minor decrease in insolation at aphelion. Overall, eccentricity only results in a $0.03 \%$ change in total annual insolation, but is still significant on the basis of seasonal effects, which can vary from a $6 \%$ to $30 \%$ insolation difference between aphelion and perihelion at low and high eccentricity, respectively (Maslin and Ridgwell, 2005).

Obliquity defines the angle of tilt of the Earth's rotational axis with respect to the orbital plane (figure 2.1). This angle varies between maximums of $21.9^{\circ}$ to $24.5^{\circ}$ at a dominantly 41,000 year periodicity (Paillard, 2010). Obliquity largely influences the latitudinal distribution of insolation, where a larger angle of tilt increases the amount of insolation received at higher latitudes (and therein decreases the amount received at lower latitudes). The change of seasons relies on the Earth's angle of tilt, and thus seasonality also increases with increased obliquity (Paillard, 2010).

Precession describes two orbital motions. The first motion describes the change in orientation of the Earth's angle of tilt, with respect to the stars. The orientation gyrates around a full circle, changing the location of the vernal point (or northern spring equinox) along the Earth's orbit (figure 2.1) (Maslin and Ridgwell, 2005). Therefore, this effect influences the seasonal timing of Earth's position at perihelion, and therefore the strength of a respective season. The second motion describes the change in the location of perihelion with respect to the stars (Paillard, 2010). These combined effects of changing positions of the vernal point and perihelion are combined as "precession" and average at a 21,000 year periodicity. Because precession involves variation in perihelion, it is strongly modulated by changes in eccentricity. For example, high eccentricity results in stronger seasonality associated with the components of precession, and low eccentricity a reduced precession influence (Paillard, 2010). Importantly, unlike obliquity, the effect of precession is not symmetrical with respect to 
the equator, and thus insolation changes are anti-phased between hemispheres (figure 2.2) (Paillard, 2010).

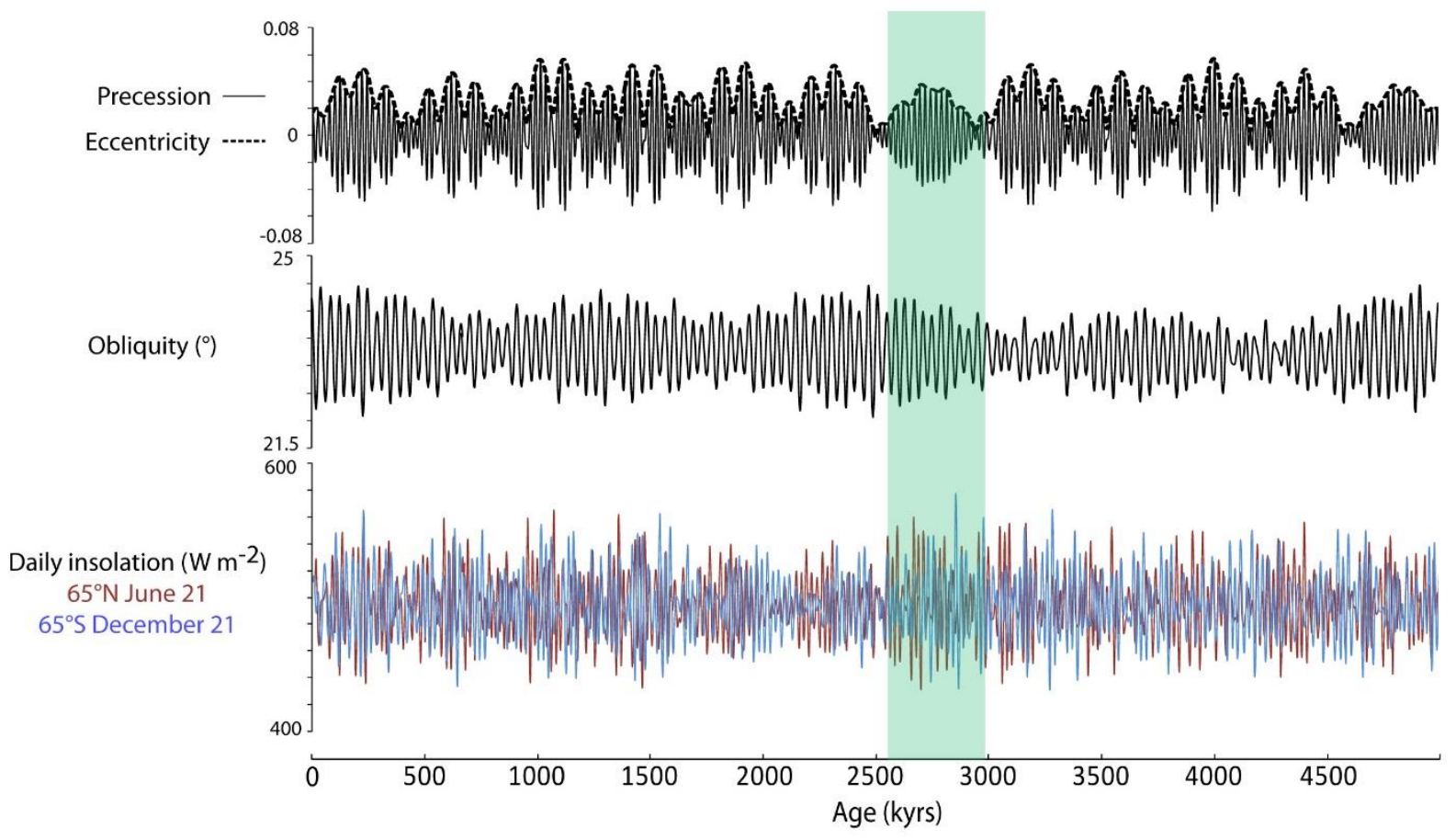

Figure 2.2: Eccentricity, obliquity and precession variation with daily insolation at critical ablation latitudes defined by Milankovitch (1941). Of note is the anti-phased nature of daily insolation between the Northern and Southern Hemispheres during their respective summers. This is a result of precession influenced insolation, which is antiphased between hemispheres. The green rectangle marks the time period of focus in this study. Astronomical solutions are from Laskar (2004).

Joseph Adhémar (1842) is thought to be the first to suggest ice sheet advance and retreat may occur due to orbitally-induced insolation changes. Adhémar proposed glaciations occur when winter coincides with aphelion, when the cold season is longer and more intense (Raymo and Huybers, 2008; Paillard, 2010). James Croll (1867) subsequently argued that glaciations occur when winter coincides with aphelion not because the season is longer and colder, but because insolation is at a minima during this time. Adhémar (1842) and Croll (1867) both inferred that changes in precession and in eccentricity were the drivers of the ice ages (Paillard, 2010).

In 1930, Milutin Milankovtich proposed the orbital theory of the ice ages which is still considered the most compelling today (Milankovitch, 1941). In contrast to Adhémar (1842) and Croll (1867), he proposed that conditions during summer were critical to the initiation of glaciations rather than winters. This was supported by the observation 
that summer melting of mountain glaciers is more important to overall ice mass balance compared to winter snow accumulation (Milankovitch, 1941). Milankovitch's theory states that insolation received at $65^{\circ} \mathrm{N}$ controls the size of Northern Hemisphere ice sheets, and was the combined result of changes in precession, obliquity and eccentricity. If insolation received at this latitude during summer is at a minimum, ice can persist throughout the summer season, and over time coalesces into an ice sheet. For example, ice sheet growth would occur during an extended period of low insolation summers (i.e. summers happen during aphelion), coinciding with an elliptical orbit and shallow tilt of the rotational axis.

The Milankovitch hypothesis is widely accepted as a valid explanation for the pattern of glacial-interglacial cycles over the Quaternary and beyond. The advent of this acceptance began with the recovery of marine sediment cores, which detailed cyclical changes in the stable oxygen isotope composition of foraminifera shells that calcified in equilibrium with the oxygen isotopic composition of the ocean (Hays et al., 1976). Emiliani (1955) had already shown a clear relationship between the oxygen isotope composition of sea water and the volume of ice held in the polar ice sheets. A high ratio of oxygen isotopes $\left({ }^{18} \mathrm{O} /{ }^{16} \mathrm{O}\right)$ preserved in benthic foraminifera shells is an indicator of larger global ice volumes, because the lighter isotope $\left({ }^{16} 0\right)$ is preferentially evaporated from the oceans and incorporated into ice sheets. Globally distributed records of this ice volume proxy (the benthic $\delta^{18} 0$ record) provide clear cyclicity consistent with the Milankovitch cycles, and thus compelling evidence for the theory of the orbital forcing of glacial-interglacial cycles (Lisiecki and Raymo, 2005; Shackleton, 1987).

Evidence for the orbital forcing of glacial-interglacial cycles is not restricted to oxygen isotope-derived ice volume proxies from the deep sea, but by a wide variety of palaeoclimate records across the globe. Some examples are presented in Table 2.1. 
Table 2.1: Examples of orbitally-forced palaeoclimate records from a wide variety of locations.

\begin{tabular}{|c|c|c|c|}
\hline Record & Proxies & Location & Example studies \\
\hline $\begin{array}{l}\text { Continental-derived } \\
\text { dust records }\end{array}$ & $\begin{array}{c}\text { Atmospheric } \\
\text { circulation patterns } \\
\text { and aridification }\end{array}$ & $\begin{array}{l}\text { Low-high latitudes } \\
\text { (marine sedimentary } \\
\text { cores and ice cores) }\end{array}$ & $\begin{array}{c}\text { Basile et al. (1997); } \\
\text { Martinez-Garcia et al. } \\
\text { (2011); } \\
\text { Naafs et al. (2012) }\end{array}$ \\
\hline $\begin{array}{l}\text { Ice-rafted debris } \\
\text { records }\end{array}$ & Ice sheet extent & $\begin{array}{c}\text { Northern and Southern } \\
\text { hemisphere high } \\
\text { latitudes }\end{array}$ & $\begin{array}{l}\text { Kleiven et al. (2002); } \\
\text { Passchier, (2011); } \\
\text { Bailey et al., (2013); } \\
\text { Cook et al., (2014) }\end{array}$ \\
\hline $\begin{array}{c}\text { Antarctic margin } \\
\text { sedimentary records }\end{array}$ & Ice sheet extent & $\begin{array}{l}\text { Southern hemisphere } \\
\text { high latitudes }\end{array}$ & $\begin{array}{l}\text { McKay et al. (2012b); } \\
\text { Fielding et al. (2012); } \\
\text { McKay et al. (2012a); } \\
\text { Naish et al. (2009); } \\
\text { Patterson et al. (2014) }\end{array}$ \\
\hline $\begin{array}{l}\text { Marine sedimentary } \\
\text { cores }\end{array}$ & $\begin{array}{c}\text { Changing } \\
\text { oceanographic } \\
\text { conditions } \\
\text { (sedimentary, } \\
\text { biogeochemical) } \\
\end{array}$ & $\begin{array}{l}\text { Low, mid and high } \\
\text { latitudes }\end{array}$ & $\begin{array}{l}\text { Kershaw et al. (2003); } \\
\text { Ravelo et al. (2004); } \\
\text { (Herbert et al., 2010; } \\
\text { Lawrence et al. (2006) }\end{array}$ \\
\hline Ice cores & $\begin{array}{l}\text { Palaeo- atmospheric } \\
\text { gas concentrations, } \\
\text { hydrological patterns }\end{array}$ & High latitudes & $\begin{array}{l}\text { Jouzel et al. (2007); } \\
\text { Lüthi et al. (2008) }\end{array}$ \\
\hline $\begin{array}{c}\text { Continental loess } \\
\text { deposits }\end{array}$ & $\begin{array}{c}\text { Geochemical and } \\
\text { magnetic }\end{array}$ & Mid-latitudes & $\begin{array}{l}\text { Hovan et al. (1989); } \\
\text { Liu and Ding, (1998) }\end{array}$ \\
\hline $\begin{array}{c}\text { Continental margin } \\
\text { sedimentary sequences }\end{array}$ & Sea level/ice volume & $\begin{array}{l}\text { Mid-latitudes, } \\
\text { tectonically active } \\
\text { margins }\end{array}$ & $\begin{array}{l}\text { Dowsett and Cronin } \\
\text { (1990); Lourens and } \\
\text { Hilgen (1997); Lourens } \\
\text { et al. (1996); Naish et } \\
\text { al. (1998) Murray- } \\
\text { Wallace (2002); } \\
\text { Kuhlmann et al. (2015) }\end{array}$ \\
\hline Lake deposits & $\begin{array}{l}\text { Vegetation and } \\
\text { biogeochemical }\end{array}$ & $\begin{array}{l}\text { Low, mid and high } \\
\text { latitudes }\end{array}$ & $\begin{array}{c}\text { Magee et al. (2004); } \\
\text { Ishiwatari et al. (2009); } \\
\text { Prokopenko et al. } \\
\text { (2006); Melles et al. } \\
\text { (2012); Brigham-Grette } \\
\text { et al. (2013) }\end{array}$ \\
\hline Fossil coral reefs & Sea level & Low latitudes & $\begin{array}{c}\text { Chappell and } \\
\text { Shackleton (1986) }\end{array}$ \\
\hline Speleothems & $\begin{array}{c}\text { Precipitation patterns, } \\
\text { monsoon activity, } \\
\text { Walker and Hadley } \\
\text { atmospheric circulation }\end{array}$ & Low and mid latitudes & $\begin{array}{l}\text { Yuan et al. (2004); } \\
\text { Wang et al. (2008) }\end{array}$ \\
\hline
\end{tabular}

The orbital theory of climate changes over geological time has revolutionised the ability to date sedimentary records (via tuning to astronomical timescales) and the understanding of ice sheet dynamics (Shackleton et al., 1990). However, the vast evidence supplied by the geological record, while displaying distinctly orbital frequencies, lacks information on the physical mechanisms and amplifying feedbacks required to produce these large scale Earth system changes. Scientists have turned to 
geophysical models to help understand the processes behind these large shifts in the Earth's climate system (Imbrie and Imbrie, 1980; Berger, 1988; Imbrie et al., 1992;). It appeared that ice volume change over time recorded in palaeoclimate records could be approximated by using simple models (Imbrie, 1985). Imbrie et al. (1992) identified a lagged linear response of modelled ice volume to precession and obliquity forcing over the last 2 million years, which is largely consistent with Milankovitch Theory. However, modelling results seemed to provide more questions than answers, and reconciling the details of geological observations with Milankovitch Theory proved difficult in many cases. Investigations began into the perplexing dominance of particular orbital cycles (and absence of others) in different periods over geologic time (Raymo and Huybers, 2008). It has become apparent that Milankovitch Theory may not be a 'one-size-fits-all' concept, and that a detailed knowledge of processes and feedbacks within the Earth's climate system is required to robustly explain observed responses to orbital forcing. Problems with Milankovitch Theory

Our understanding of the nature, timing and magnitude of ice sheet response to different orbital cycles over geological time is not complete (Paillard, 2010). Berger (2013) describes the behaviour of the ice-climate system as "not a random walk, but constrained to fluctuations between rather well-defined boundaries, while tending to avoid a central position". Therefore, while Milankovitch forcing is an important external factor, it is only one part of a hugely complex feedback system. The classical theory no longer holds the monopoly on discussions of ice volume change through time (Berger, 2013). Rather, it is a fundamental idea upon which many exceptions are imposed. After all, Milankovitch theory was developed to explain changes to terrestrial-based Northern Hemisphere ice sheets at $65^{\circ} \mathrm{N}$ during the Pleistocene. What is the role of different latitudes, climate-states (greenhouse gas concentrations), ice sheets, continental and ocean configurations, and the carbon cycle? Milankovitch principles evolved at a time when the Antarctic ice sheets were considered largely more stable than their northern counterparts. In recent times, it has become apparent that this is not likely the case (Mercer, 1978; Naish et al., 2001; Naish et al., 2009; Cook et al., 2013; Joughin et al., 2014; Mengel and Levermann, 2014; Patterson et al., 2014). 
Two prominent exceptions to Milankovitch theory are often denoted as the "100,000 year world problem" and the "41,000 year world problem" (figure 1.1) (Raymo and Huybers, 2008). Over the last $\sim 1$ million years, glacial-interglacial cycles have been paced at dominantly 100,000 years, characterised by large glacial build-up over $\sim 90,000$ years, and rapid demise into an interglacial over $\sim 10,000$ years. If a linear response to orbital forcing was assumed, these 100,000 year cycles could be a result of eccentricity and its modulating effect on precession (Hays et al., 1976). However, the effect of eccentricity on total insolation is very weak, and is unlikely the sole reason behind such large amplitude changes in global ice volume. It has been suggested that non-linear internal climate feedbacks related to the ocean, atmosphere and internal ice sheet dynamics play a significant role in the forcing of glacial-interglacial variability, resulting in the 100,000 year cycles (Broecker and Denton, 1989; Imbrie et al., 1993; Shackleton, 2000; Lisiecki, 2010). It has also been speculated that Late Pleistocene glacial variability is a consequence of the increasing intensity of Northern Hemisphere glaciations (Clark et al., 1999; Huybers, 2006; Huybers, 2007). Feedbacks related to ice sheet height mass balance and albedo allowed the larger Late Quaternary ice sheets to persist through higher frequency orbital changes and only decay every two or three obliquity cycles (every 80,000 or 120,000 years, averaging to 100,000 year cycles). However, despite much progress, there is yet to be a consensus on the mechanisms behind the 100,000 year glacial cycles of the last 1 million years.

The "41,000 year world problem" describes the dominance of 41,000 year cycles (obliquity) in records of ice volume change from the Late Pliocene until $\sim 1$ million years ago (figure 1.1) (Piasis and Moore, 1981; Raymo and Nisancioglu, 2003; Lisiecki and Raymo, 2005). Obliquity and precession both strongly modulate high latitude summer insolation, but Late Pliocene and Early Pleistocene glacial-interglacial cycles vary almost at exclusively obliquity frequencies, with a relative absence of precession. What mechanisms explain this missing precession component of ice volume change? Is this an artefact of the ice volume-proxy record, or are there gaps in our understanding? One explanation relies on the different influences imparted by obliquity and precession on insolation. Obliquity controls latitudinal temperature gradients; under increased gradients and seasonality, moisture flux (and therefore snow precipitation) can theoretically increase to higher latitudes (Philander and Fedorov, 2003; Raymo and 
Nisancioglu, 2003; Vettoretti and Peltier, 2011). Therefore, latitudinal temperature gradients resulting from obliquity-forcing control temperature and precipitation at the poles, and thus ice volume. Yet, a precipitation control on ice sheet dynamics is generally considered invalid under classical Milankovitch theory because ice massbalance depends on summer melt, not winter accumulation (Denton et al., 2005; Ruddiman, 2006).

Two new hypotheses for explaining the dominance of 41,000 year cyclicity in Late Pliocene-Early Pleistocene globally-integrated benthic $\delta^{18} 0$ ice volume record have been proposed in the past decade (Huybers, 2006; Raymo et al., 2006). The first suggests that the precession component of ice volume change is masked in such records because it is anti-phased between the hemispheres (Raymo et al., 2006). Ice sheet advance in one hemisphere is offset or "cancelled-out" by ice sheet melt in the other, leaving the obliquity response (which is in phase between hemispheres) to dominate global records. Discrepancy between the relative ice volume contributions from the Northern and Southern Hemisphere (i.e. increasingly more from the North) can be explained assuming their different isotopic compositions: Northern Hemisphere ice sheets have lower $\delta^{18} 0$ values than Antarctic ice sheets. A 20 metre ice-equivalent sealevel contribution from Antarctica and an 80 metre contribution from the Northern Hemisphere sufficiently masks any precession component in the global $\delta^{18} 0$ record. While providing a plausible reason for the absence of precession, this hypothesis does not explain why records that are not subject to the isotopic-cancelling effect exhibit dominantly 41,000 year frequencies (Shackleton et al., 1984; Raymo et al., 1989; Naish et al., 2009; Naafs et al., 2012; Brigham-Grette et al., 2013).

The second hypothesis suggests that ice sheet response to precession during the Late Pliocene and Early Pleistocene is negligible in comparison to obliquity (Huybers, 2006). As Northern Hemisphere ice sheets experience melt, the total amount of insolation over a summer season above an ice melting threshold (i.e. where temperatures exceed $0^{\circ} \mathrm{C}$ ) is the critical factor in determining ice sheet ablation or accumulation. This is in contrast to Milankovitch theory, which states that insolation received at $65^{\circ} \mathrm{N}$ on the summer solstice (21 June), or 'peak' insolation is the most critical indicator of ice sheet mass balance changes (Milankovitch, 1941). When total summer insolation is considered, precession influences are negligible over the course of an annual cycle. This is because 
under certain climate states, the duration and intensity of summer are directly anticorrelated, whereby an intense summer occurring during perihelion is also the shorter summer, due to Kepler's $2^{\text {nd }}$ Law of Planetary Motion, i.e. the conservation of angular momentum. Thus, a short hot summer receives as much precession-influenced insolation as a long cool summer, leaving the obliquity component (which is not influenced by Kepler's $2^{\text {nd }}$ Law and in-phase globally) to regulate the summer insolation (figure 2.3) (Huybers, 2006). Importantly, this depends on the melt threshold of an ice sheet. In climate-states with higher background radiative forcing (e.g. higher carbon dioxide levels, at $\sim 400 \mathrm{ppm}$ ), the insolation energy required to raise the summer temperature sufficiently to melt an ice sheet is lower, and the melt season is extended. When this occurs, total summer insolation is correlated with mean annual insolation, as most insolation at high latitudes is received during the summer season (Huybers and Tziperman, 2008). Mean annual insolation and consequently summer melting is thus modulated by obliquity (figure 2.4a). During times of colder climates without excess radiative forcing (e.g. lower $\mathrm{CO}_{2}$ levels at $\sim 280 \mathrm{ppm}$ ), the influence of precession increases because the length of melt season is lower. When this occurs, peak insolation intensity becomes more important, and is modulated by precession. Thus, warmer climates like the Pliocene and Early Pleistocene (Seki et al., 2010; Dowsett et al., 2012) exhibit obliquity signals, whereas cooler climates like the Late Pleistocene begin to show more precession influence (Lisiecki and Raymo, 2007). Precession is considered to exert considerable influence on summer insolation (figure 2.4b) (Berger, 1978), and precession frequencies are known to be present in palaeoclimate records independent of the globally-integrated benthic $\delta^{18} 0$ (Joyce et al., 1993; Thompson and Goldstein, 2006; Patterson et al., 2014). 

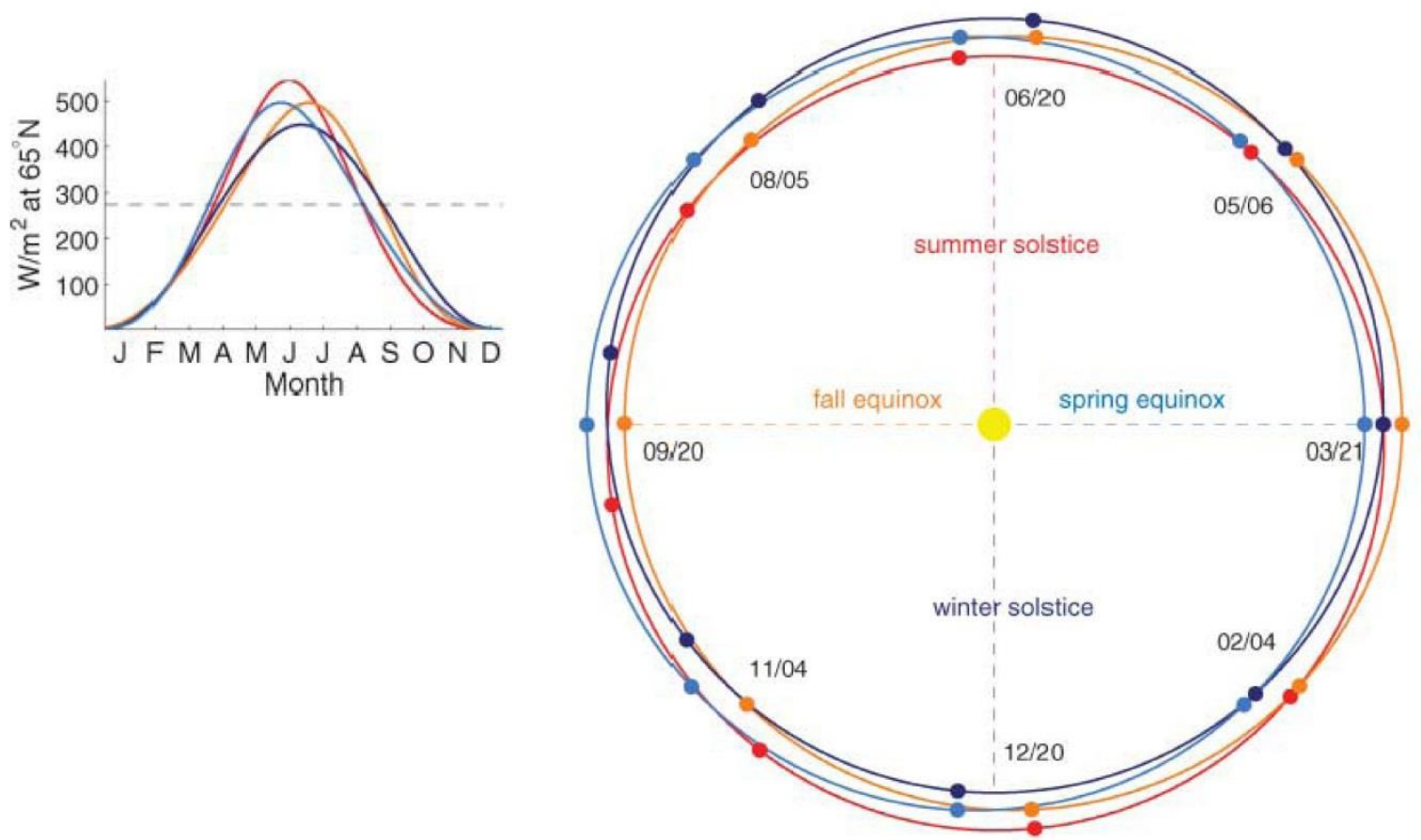

Figure 2.3: The image to the right shows the variation in Earth's orbit around the Sun, to scale, from Huybers (2006). These orbital configurations match those at 220.2, 214.6, 209.2, and $203.5 \mathrm{ka}$, and correspond to perihelion during summer (red), autumn/fall (orange), winter (dark blue), and spring (light blue), respectively. In this case, the spring equinox refers to the northern hemisphere date of $21^{\text {st }}$ March. The image on the left displays monthly variations in insolation at $65^{\circ} \mathrm{N}$, and the inferred insolation threshold for ice sheet ablation at $275 \mathrm{~W} / \mathrm{m}^{2}$ (grey dotted-line). The colours correspond to the orbital configurations to the right. Importantly, the configuration where summer occurs during perihelion (red) has the greatest insolation intensity, but the shortest ablation season.

Indeed, the hypotheses of Raymo et al. (2006) and Huybers (2006) could both be part of the answer (Paillard, 2010). There is no doubt obliquity is a governing signal in palaeoclimate records over the last 3 million years (figure 2.4a), but there is also evidence of precession, although less dominant. A recent study has suggested both of these mechanisms could be operating during the Pliocene and Early Pleistocene (Patterson et al., 2014). In the warmer Pliocene climate prior to 3.3 Ma, frequency spectra of an iceberg-rafted debris (IRD) collected from the East Antarctic continental margin show dominantly 41,000 year cycles, indicating an obliquity response. By 3.0 Ma, spectra are dominated by 100,000 year and 21,000 year signals, indicating an increased precession response. This is consistent with nodes of obliquity and 
precession present in the astronomical solutions and the benthic $\delta^{18} 0$ record, where obliquity variance is low prior to $3.0 \mathrm{Ma}$ and appears again afterwards. Patterson et al. (2014) state the reason obliquity frequencies are strong in the benthic $\delta^{18} 0$ record in contrast to the precession-influenced Antarctic margin IRD record after 3.0 Ma is because the emerging Northern Hemisphere ice sheets are controlled by obliquity and their signal begins to dominate globally-integrated records. Yet, this observation does not rule out the possibility of an out-of-phase precession response being masked in the benthic $\delta^{18} 0$ record.
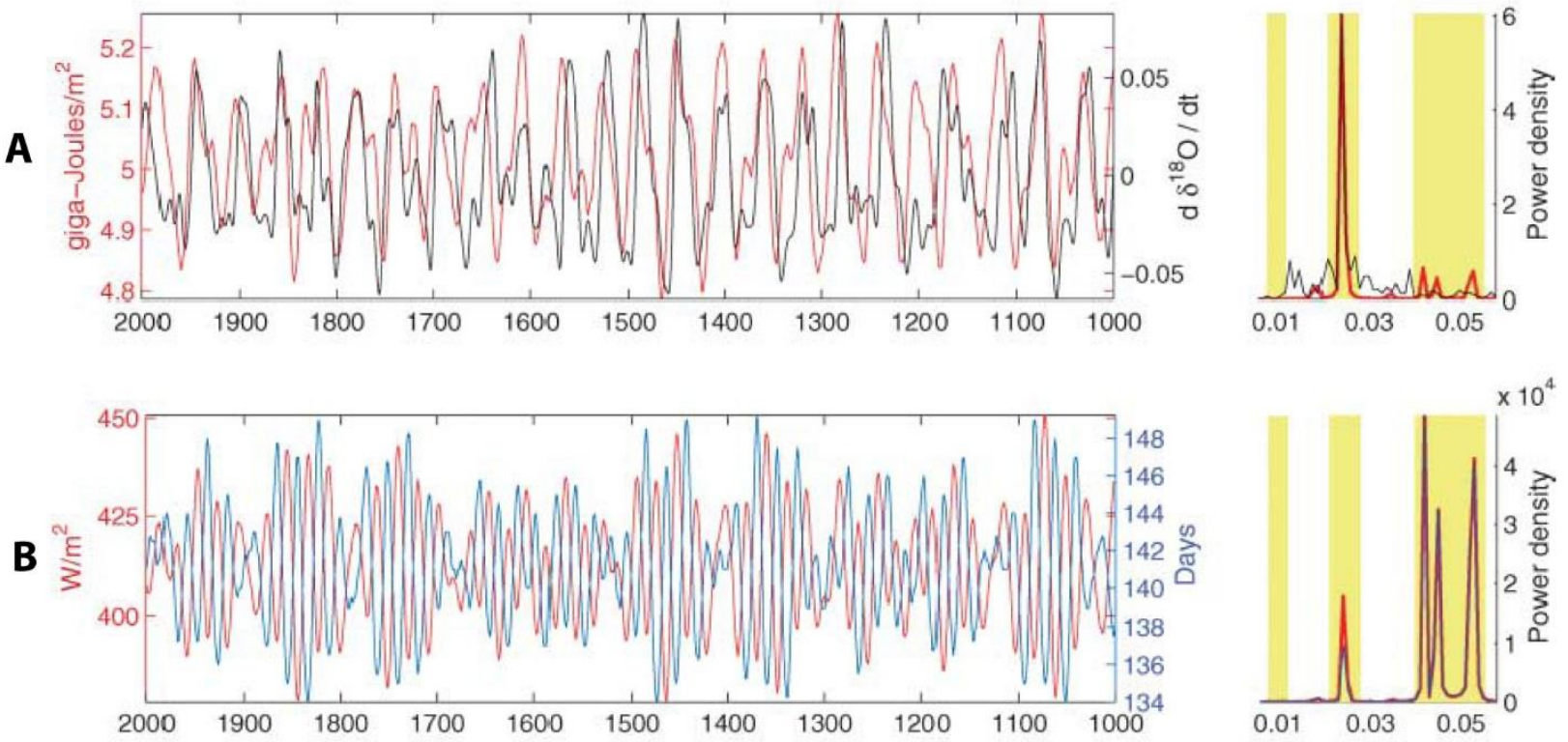

Figure 2.4: Figure A shows the well-correlated records of total summer insolation (in red) and the benthic $\delta^{18} 0$ record for the Late Pliocene and Early Pleistocene from Huybers (2006). To the right is the corresponding spectral analysis, which shows a dominant variance in the 41 kyr (obliquity) period. Figure B, also from Huybers (2006), shows the anti-correlated insolation intensity (red) and the duration of the summer ablation season (blue). The corresponding spectral analysis of these parameters is shown to the right where the dominant variance is in the precession period (19-23 kyr).

There is also yet to be an agreement on the origin of the global cooling (irrespective of orbitally-forced insolation) in the Late Pliocene that led to the onset of Northern Hemisphere glaciation, and the Mid-Pleistocene Transition that saw a switch in the pattern of the glacial-interglacial cycles to large, asymmetrical 100,000 year-paced glaciation at 0.8 Ma (Raymo et al., 1989; Raymo, 1994). Likely, it is difficult to explain any of these palaeoclimate problems on the basis of orbitally-forced insolation alone 
(Paillard, 2006). More studies of high resolution, well-dated palaeoclimate proxy records that are independent of the globally-integrated benthic $\delta^{18} 0$ record are needed to understand the dynamics and feedbacks responsible for these past climate changes (Raymo and Huybers, 2008). This study aims to investigate the problem of the 41,000 year world by examining a record of Late Pliocene sea-level change recorded in shallowmarine sedimentary rocks of the Wanganui Basin, New Zealand. Water depth changes recorded in the well-dated Wanganui Basin sedimentary succession have the potential to provide a record of ice volume variability via its direct effect on global sea levels, independent of the complications associated with inferring hemisphere-specific ice volumes from the benthic $\delta^{18} 0$ record.

\section{The Late Pliocene: a cooling global climate}

The focus of this study is the Late Pliocene (3.0-2.6 Ma), a time period that encompasses a global climate transition from a warmer-than-present climate in the Pliocene to a cooler climate with extensive glaciations occurring at both poles (Ravelo et al., 2004; Lisiecki and Raymo, 2005). This cooling, beginning at $3.5 \mathrm{Ma}$, and intensified at $2.7 \mathrm{Ma}$ (McKay et al., 2012a), is reflected in the development of the first major Northern Hemisphere ice sheets and is the final step in a long-term Cenozoic trend of increasing global ice volume and decreasing atmospheric carbon dioxide concentrations, related to the development of the polar ice sheets (Zachos et al., 2001). The Pliocene-Pleistocene cooling step is prominent in the benthic $\delta^{18} 0$ record, where the long-term trend in global ice volume begins to increase independently of orbitally-forced insolation variations (figure 2.5). Simultaneously, the amplitude of changes at Milankovitch frequencies increases, suggesting heightened ice volume sensitivity and amplified climate system variability (Berger, 2013). A complex interplay of global tectonic processes and climate teleconnections including decreasing atmospheric carbon dioxide (Martinez-Boti et al., 2015) were operating immediately prior to the PliocenePleistocene climate cooling, and identifying one causal mechanism as a sole driver for such sustained period global cooling is challenging (Raymo and Ruddiman, 1992; Lisiecki and Raymo, 2007). Instead, it was possibly a combination of atmospheric, oceanic and ice sheet feedbacks that resulted in gradual cooling into the Pleistocene (Ravelo et al., 2004; Mudelsee and Raymo, 2005). 


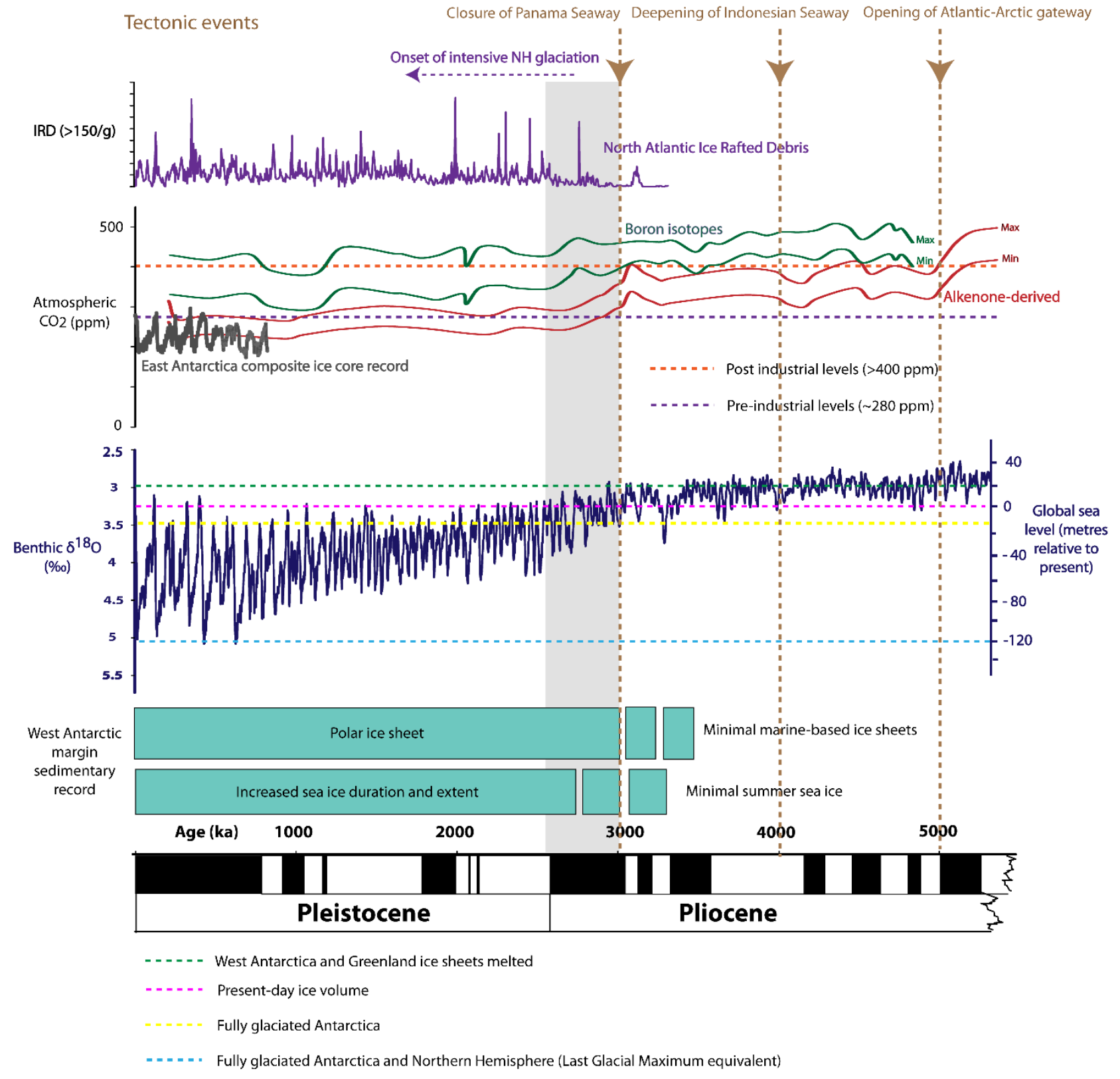

Figure 2.5: Multi-proxy representation of Pliocene-Pleistocene global tectonic, climate and ice volume changes. Timing of tectonic events from Raymo and Ruddiman (1992), Cane and Molnar (2001) and Knies et al. (2014b), respectively. North Atlantic ice-rafted debris record (marking the onset of intensive Northern Hemisphere glaciation) is from (Jansen et al., 2000). Boron isotope and alkenone-derived proxy carbon dioxide concentration ranges are from Seki et al. (2010). The East Antarctic composite ice core carbon dioxide concentrations are from Lüthi et al. (2008). The benthic $\delta^{18} 0$ record is the LR04 stack from Lisiecki and Raymo (2005), and lines denoting ice volume and sea level equivalents are from Naish et al. (2009). The Antarctic margin sedimentary record (detailing changes to the Ross Sea, fed by the West Antarctic Ice Sheet) is the ANDRILL record, with the interpretations from McKay et al. (2012a). The grey shaded area is the time period of focus for this thesis, clearly encompassing a significant change in all displayed records. 
The mid-Pliocene warm period ( $3.5-3.0 \mathrm{Ma})$ spans a period of global climate that was on average $2-3^{\circ} \mathrm{C}$ warmer with respect to present-day levels (figure 2.6) (Crowley, 1991; Haywood and Valdes, 2004; Hill et al., 2014), and is considered the most accessible example of Earth system response to climate projected for the coming decades to centuries (Naish and Zwartz, 2012). Not surprisingly, a warmer climate has several ramifications for the oceans, atmosphere and cryosphere. Carbon dioxide atmospheric concentrations were on average $\sim 400 \mathrm{ppm}$, similar to modern postindustrial levels (Pagani et al., 2010; Seki et al., 2010; Bartoli et al., 2011). Higher global average temperatures and polar amplification processes decreased equator-pole temperature gradients, slowing down latitudinal and meridional atmospheric circulation (Haywood et al., 2000; Brierley et al., 2009; Lunt et al., 2012). The Pliocene oceans were warmer at the surface and at depth, and circulation patterns across the equator and overturning processes at high latitudes operated differently to present (Ravelo and Andreasen, 2000; Fedorov et al., 2006; Ravelo et al., 2006; Herbert et al., 2010;). Global sea level is estimated to be $20 \pm 10$ metres higher than present as a result of reduced terrestrial ice volumes (Wardlaw and Quinn, 1991; Naish and Wilson, 2009; Raymo et al., 2011; Miller et al., 2012). At the same time, significant tectonic changes were occurring, such as the Panama Seaway closure (or Central American Seaway), the Indonesian Seaway deepening and opening of the Arctic-Atlantic gateway (figure 2.5) (Raymo and Ruddiman, 1992; Cane and Molnar, 2001; Knies et al., 2014b). These gradual changes to tectonic configurations had various and wide-ranging consequences for global climate (Raymo and Ruddiman, 1992; Haug and Tiedemann, 1998; Bartoli et al., 2005; Karas et al., 2011).

Reconstructions of the mid-Pliocene warm period provide an opportunity to improve our understanding of physical processes in warmer climates by examining the geological record, to more precisely predict dynamic changes to the atmosphere, ice sheets and sea levels, which are currently exhibiting rapid responses (Joughin et al., 2014). Prior to $2.7 \mathrm{Ma}$, it is widely regarded that there was small-scale glaciation in the Northern Hemisphere, and minimal Arctic sea ice (Jansen and Sjøholm, 1991; Kleiven et al., 2002; Knies et al., 2014a). The Arctic is estimated to have been at least $\sim 8^{\circ} \mathrm{C}$ warmer than present, a result of amplified warming in polar regions compared with global average temperatures (figure 2.6) (Ballantyne et al., 2010; Dowsett et al., 2012; Brigham-Grette et al., 2013). As a result, Pliocene Northern Hemisphere ice extent is 
thought to be mostly limited to Greenland, with some small-scale glaciers in Pacific Alaska and limited Arctic sea ice (Dolan et al., 2011; Koenig et al., 2014; Larsen et al., 1994; Stickley et al., 2009). Vegetation patterns indicate substantially warmer on-land temperatures (Andreev et al., 2014; Melles et al., 2012), and alkenone-derived proxy records and modelling results of Northern Hemisphere sea surface temperatures (SST) exhibit values $2-5^{\circ} \mathrm{C}$ warmer than present (Lawrence et al., 2010; Dowsett et al., 2012; Naafs et al., 2012). The picture of high latitude climate in the mid-Pliocene is considerably different to that of the Late Pleistocene.

The East and West Antarctic Ice Sheets, while relatively extensive, behaved more dynamically (Hepp et al., 2006; Hillenbrand, 2013; Rose et al., 2014). Evidence from Antarctic margin sedimentary records indicate substantial retreat of the West Antarctic Ice Sheet (WAIS) during Pliocene interglacials, which suggests rapid ice sheet response to temperatures $\sim 3^{\circ} \mathrm{C}$ warmer than present, at obliquity frequencies (Naish et al., 2009; Pollard and DeConto, 2009; McKay et al., 2012a). This has long been considered possible due to the marine-based nature and reversed-slope bed of the WAIS (Mercer, 1978). However, more recently it has become clear that the East Antarctic Ice Sheet (EAIS) also demonstrates the possibility of rapid, extensive retreat (up to several hundred kilometres inland) into extensive sub-glacial basins (Fretwell et al., 2013) during Pliocene interglacials (Hambrey and McKelvey, 2000; Cook et al., 2013). Southern Ocean SST were higher and sea ice extent was greatly reduced in comparison to modern configurations (Whitehead et al., 2005; Escutia et al., 2009; McKay et al., 2012a). 

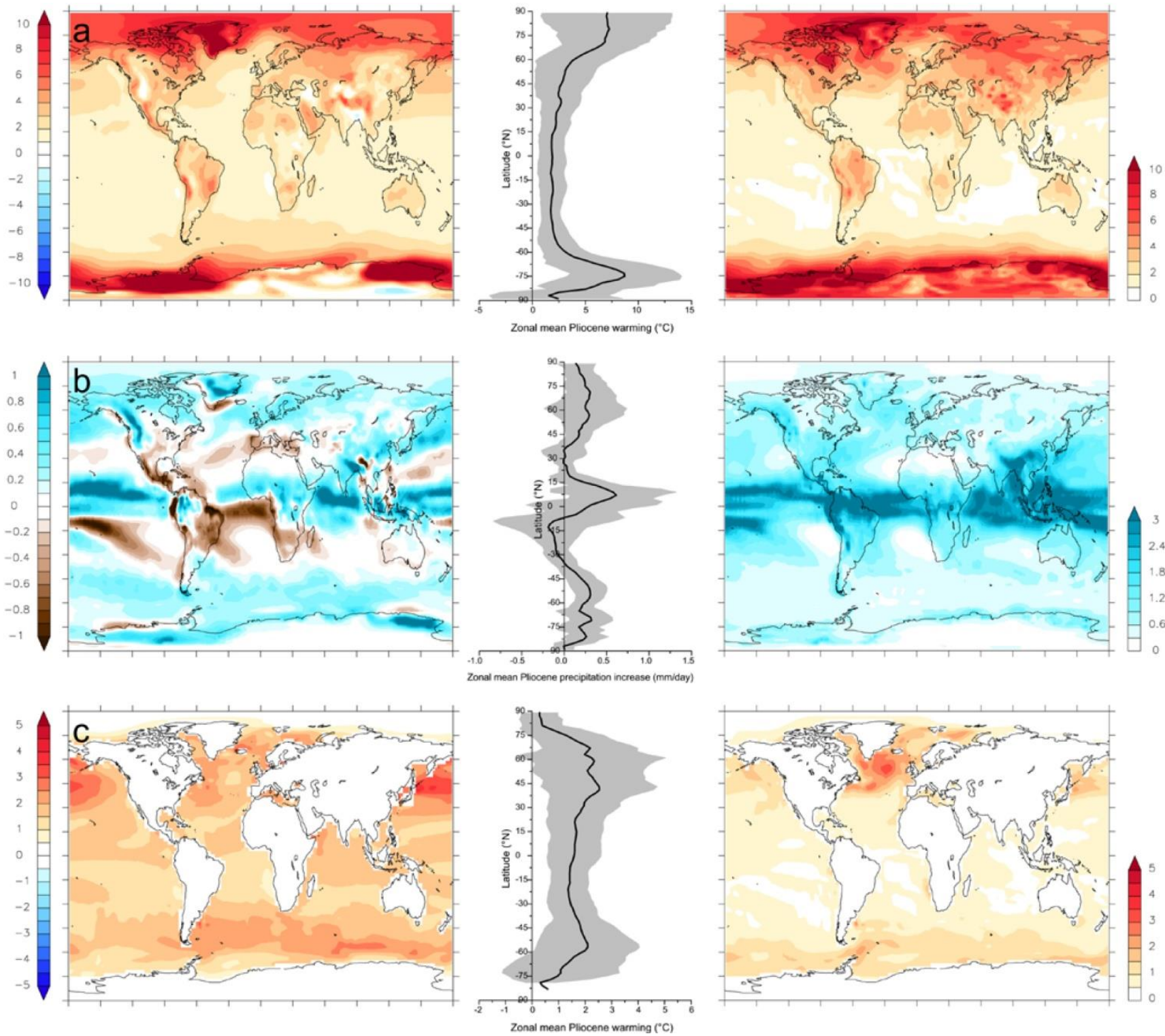

Figure 2.6: Modelled (A) Pliocene mean annual surface air temperatures, (B) mean annual total precipitation (rate anomaly), and (C) mean annual sea surface temperatures from Haywood et al. (2013). The middle graphs display the variability with latitude for each climate parameter. While there is a bias towards Northern Hemisphere records, it is clear than global average temperatures were $\sim 2^{\circ} \mathrm{C}$ warmer, with these global means amplified in high latitude locations $\left(>5^{\circ} \mathrm{C}\right.$ higher $)$.

After 2.7 Ma, glaciation of the Northern Hemisphere intensified. Ice sheets within Greenland and Scandinavia are thought to have expanded initially, with North America and Siberia following shortly afterwards, although the timing of advances in different regions is contested (Raymo et al., 1989; Maslin et al., 1998; Kleiven et al., 2002; Bailey et al., 2013). Prior to this, global climate had been gradually cooling and Antarctic ice volume steadily increasing (Naish et al., 2009; Herbert et al., 2010; Lawrence et al., 2010; Martinez-Garcia et al., 2011; McKay et al., 2012a; Woodard et al., 2014). The 
following complex interplay of ocean-atmosphere-cryosphere feedbacks have been suggested to have occurred driving the climatic deterioration into the bi-polar glacial climate of the Pleistocene:

(i) Atmospheric circulation intensifies (latitudinal and meridional) as equator to pole temperature gradients increase (Lee and Poulsen, 2006; Etourneau et al., 2010).

(ii) North Atlantic Deep Water formation slows and temperatures decrease in response to reduced meridional heat transport, while Antarctic Bottom Water formation intensifies (Driscoll and Haug, 1998; Lawrence et al., 2010; McKay et al., 2012a).

(iii) Polar ocean stratification follows as a result of sea ice growth (Hillenbrand and Cortese, 2006; Nie et al., 2014; Riesselman and Dunbar, 2013; Woodard et al., 2014).

(iv) Polar atmospheric cells and oceanic fronts contract, increasing winds over the Southern Ocean and increasing dust flux (and nutrients) into the surface ocean (Martinez-Garcia et al., 2011).

(v) Increasing winds and dust flux potentially resulted in a decrease in atmospheric carbon dioxide via biogeochemical drawdown into the oceans with increased nutrient input from dust (Raymo and Ruddiman, 1992; Haug et al., 1999; Etourneau et al., 2012).

(vi) Changes to albedo with more land ice and sea ice and concomitant changes in Arctic vegetation cover (Driscoll and Haug, 1998; Melles et al., 2012).

(vii) Reduced ocean ventilation as sea ice acts as a barrier to upwelling water masses, reducing outgassing carbon dioxide into the atmosphere (Sigman et al., 2004; Hillenbrand and Cortese, 2006; Hodell and Venz-Curtis, 2006; Woodard et al., 2014).

(viii) Deep-water upwelling in lower latitudes (Lawrence et al., 2006; Etourneau et al., 2009).

Studying this Late Pliocene interval of significant global change that resulted from complex tectonic, oceanic and atmospheric mechanisms is important in light of current and projected climate changes (Raymo, 1997; Ravelo et al., 2004). 
This study investigates a high resolution record of Late Pliocene sea-level changes recorded in shallow marine sediments of the Wanganui Basin, New Zealand. This record spans 3.0-2.6 Ma, encompassing the interval of the Late Pliocene-Early Pleistocene global cooling, and provides insights into the pattern of changing global ice volume via its direct influence on the magnitude and frequency of global sea level change.

The frequency and amplitude of ice volume changes over geological time can be directly investigated with records of past sea-level, because ice volume and sea level are intrinsically coupled. Records of Quaternary and early Neogene sea-level fluctuations are wide ranging in geographic scope, character and reliability, but nevertheless have been fundamental to the development and calibration of orbitally-forced proxy records of global sea-level change (Chappell and Shackleton, 1986; Hilgen, 1991; Lourens et al., 1996; Naish et al., 1998; Hilgen et al., 2014).

The timing and magnitude of sea-level changes during the last few glacial cycles is well constrained by precisely-dated fossil coral terraces (Chappell and Shackleton, 1986; Fleming et al., 1998; Blanchon et al., 2009; Dutton and Lambeck, 2012), geochemical and sedimentary proxies (Siddall et al., 2003; Rohling et al., 2007), and discrete geomorphic features from stable tectonic settings, such as wave-cut platforms and scarps representative of palaeo-shorelines (Dowsett and Cronin, 1990; Hearty et al., 2007). While these indicators offer much for the assessment of Late Quaternary sealevel variability, records extending into the Neogene are considerably scarcer and are rarely continuous (Grant et al., 2014). In particular, estimates of sea-level changes in the Pliocene are mostly from palaeo-shoreline and marine sediment data, and are often restricted to poorly-dated interglacial periods of unknown duration (Wardlaw and Quinn, 1991; Kaufman and Brigham-Grette, 1993; James et al., 2006; Miller et al., 2012).

Few continuous, well-dated direct sea-level records exist for time intervals beyond the Late Quaternary, but many proxy records have been constructed from discrete geomorphic features and geochemical data (e.g. $\delta^{18} \mathrm{O}$ and $\mathrm{Mg} / \mathrm{Ca}$ ice volume and temperature proxies) (Haq et al., 1987; Shackleton et al., 1990; Pillans et al., 1998; Miller et al., 2005; Dwyer and Chandler, 2009; Miller et al., 2012). Shallow-marine sedimentary sequences are one of the few continuous direct records that have the 
ability to capture glacio-eustatic sea-level changes extending to time periods earlier than the Late Quaternary (Dowsett and Cronin, 1990; Naish, 1997). However, these shallow-marine sequences record relative sea-level changes, and need to be corrected for other influences such as tectonics and sediment compaction before the eustatic component can be calculated (Naish and Wilson, 2009).

Shallow-marine sedimentary sequences exposed on land have the potential to record high resolution water-depth changes, and can be precisely dated with a suite of independent techniques: magnetostratigraphy, tephrochronology, biostratigraphy and astronomical tuning (Hilgen et al., 2014). To preserve the frequency and amplitude of glacio-eustatic sea-level changes, these sequences rely on ample sediment input and accommodation space (resulting from sediment compaction and tectonic subsidence) to record the advance and retreat of shorelines as changing litho- and biofacies (figure 2.7) (Naish and Kamp, 1997b). Thus it is active continental margin basins with relatively simple deformation histories that preserve the most complete archives of past global sea-level change. A number of uplifted shallow-marine continental margins that expose in outcrop continuous successions of facies and water depth changes in response to global glacio-eustatic sea level change have been documented around the world, such as Northern California (Clifton, 1988), Eastern Japan (Ito and Katsura, 1992; Ito et al., 1999), the Mediterranean Sea (Rio et al., 1996; Lourens and Hilgen, 1997; Zecchin et al., 2012) and the Wanganui, Hawke's Bay and Wairarapa Basins in New Zealand (Fleming, 1953; Kennett et al., 1971; Naish, 1997; Bland et al., 2004; Kamp et al., 2004).

Glacio-eustatic sea-level variations have been reconstructed from shallow-marine sedimentary successions using changes in sediment textures and fossil marine faunal changes (macro and micro) (see Chapter 3 for full discussion). High resolution integrated chronostratigraphic frameworks usually based on tephrostratigraphy, biostratigraphy, magnetostratigraphy and astronomical calibration are required to constrain the frequency of water depth changes (Naish et al., 1996; Naish et al., 1998). For the estimation of the amplitude of change, the water depth signals are then corrected for local effects of sediment compaction and water loading (sedimentary backstripping) and tectonic subsidence/uplift (Naish, 1997; Naish and Wilson, 2009 ; Miller et al., 2012). These often presents a challenge, making it difficult to register reconstructed Pliocene sea-level highstands to present-day sea level (Miller et al., 
2012). Additionally, most sea-level records derived from backstripping continental margin sedimentary successions have not been corrected for the influence of hydroglacio-isostatic changes (Raymo et al., 2011), and the influence of dynamic topographic effects. These are variations in the flow of underlying mantle, which affects surface topography and therefore relative of sea level, even on short geological timescales (i.e. since the Pliocene) (Rowley et al., 2013).

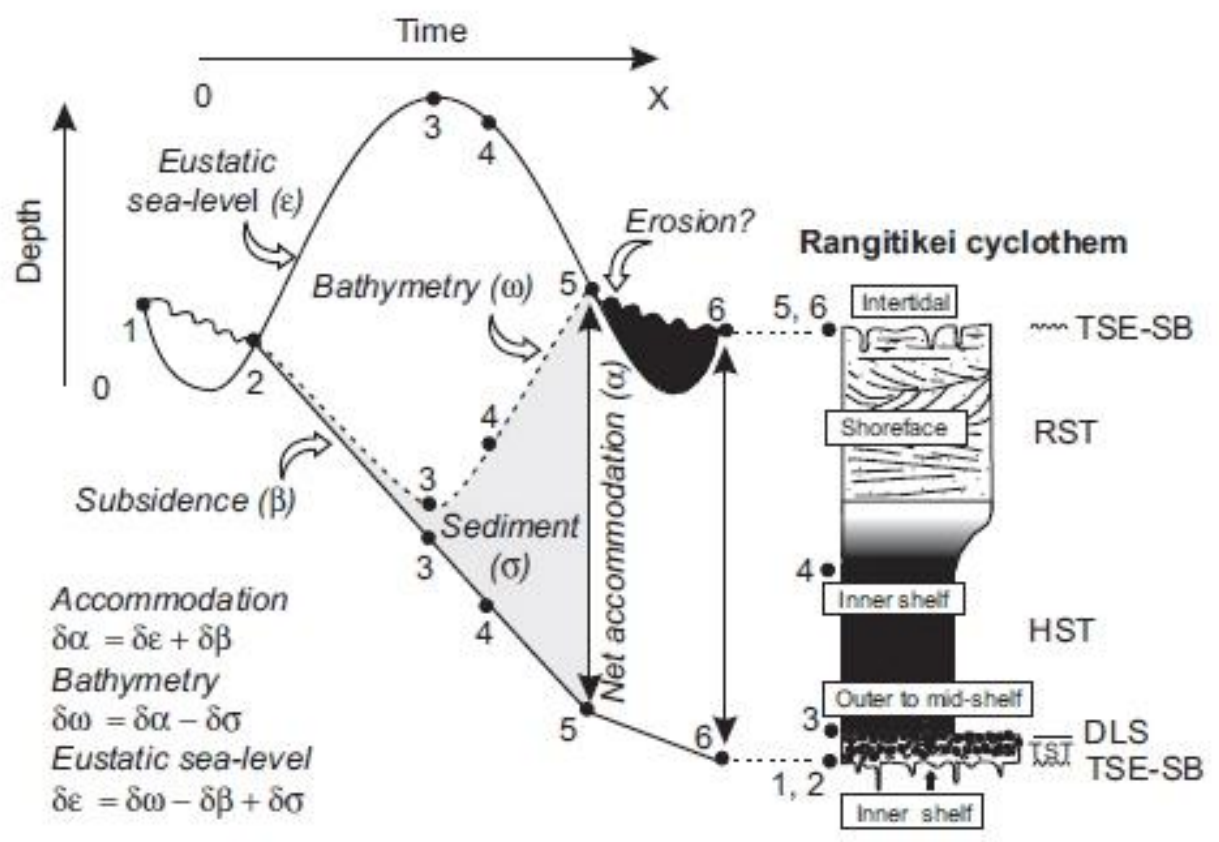

Figure 2.7: Conceptual model detailing the interplay of sedimentation, subsidence and eustasy in the formation of the cyclic shallow-marine sedimentary record of the Wanganui Basin from Naish (1997). An example of what features would be recorded with such processes interacting is shown by the Rangitikei cyclothem. The base is the sequence or cyclothem boundary (TSE-SB), which is often a surface of erosion formed from the transgression of erosive shoreface wave-action due to rising eustatic sea level. Following this surface is the transgressive system tract (TST), an upward deepening sedimentary facies succession. The downlap surface (DLS) describes the deepest bathymetry and the peak of local sea level, characterised by deep-water facies of the highstand system tract (HST). Eustatic sea level drops from this peak and the sedimentary facies begin to shallow into a regressive system tract (RST) until sea level reaches its lowstand. The cycle begins again as sea level rises and creates a transgressive surface of erosion (TSE). The equations detail how eustatic sea level can be calculated if sedimentation, subsidence, erosion and bathymetry can be accurately estimated.

The Wanganui Basin is a Pliocene-Pleistocene proto-back-arc sedimentary basin located in the North Island of New Zealand, directly south of the Taupo Volcanic Zone extensional back-arc basin (Anderton, 1981; Proust et al., 2005) (figure 1.3). The basin 
is emerged to the east towards the Ruahine (Axial) Ranges, and to the west submerged and bounded by the Patea-Tongaporutu High (figure 2.8) (Proust et al., 2005). The PlioPleistocene sedimentary fill overlies Mesozoic basement greywacke (Anderston, 1981, Lamarche et al., 2005; Proust et al., 2005).

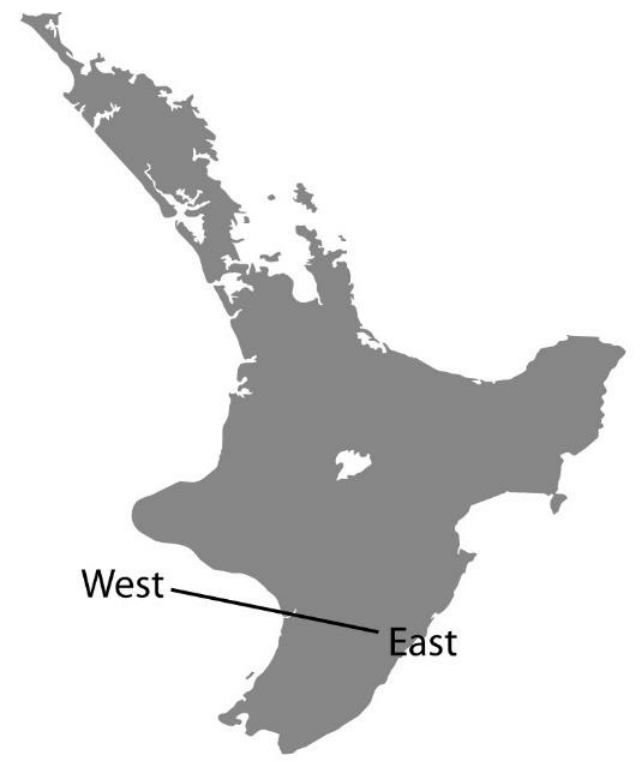

Figure 2.8: The cross-sectional structure of the Wanganui Basin from Proust et al. (2005). The Wanganui Basin sedimentary sequence is bounded on the east by the Kapiti-Manawatu Fault System and the Axial Ranges. To the west, it is bounded by the Patea-Tongaporutu High.

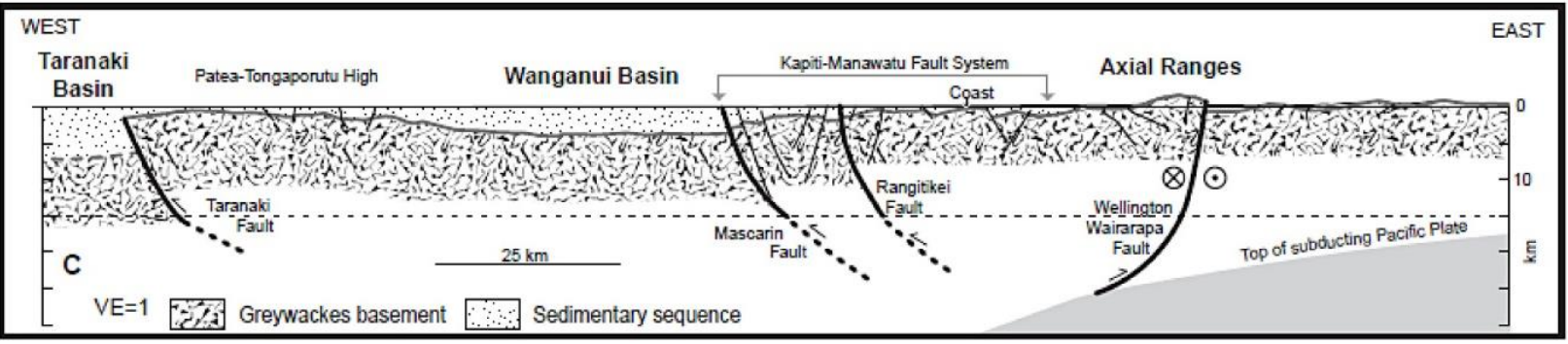

The Wanganui Basin provides a unique opportunity to investigate the anatomy of glacio-eustatic sea-level changes. Basin formation began during the Early Pliocene where mantle-lithosphere interactions related to the Pacific-Indo Australian Plate subduction boundary promoted subsidence (figure 2.9) (Stern et al., 1992; Proust et al., 2005; Stern et al., 2013). This subsidence, largely keeping pace with sedimentation rates, allowed the continuous accumulation of primarily shallow-marine sedimentary succession of over 4 kilometres in thickness (Anderton, 1981; Kamp et al., 2004; Proust et al., 2005). At this time much of the North Island was submerged, and shallow seaways connected the Pliocene Wanganui Basin with the eastern sedimentary basins like Hawke's Bay and the Wairarapa (figure 2.10) (Bland et al., 2004; Trewick and Bland, 2012). 
In the Late Pleistocene the centre of subsidence migrated southwards (Stern et al., 1992; Proust et al., 2005; Nicol, 2011). Models suggest that this was a result of either (i) north-south lithospheric delamination (figure 2.9) (Stern et al., 2013), (ii) strong frictional shear between the Pacific and over-riding Australian Plate, where the lithosphere was down-warped due to the plates locking at the Hikurangi subduction interface (Stern and Davey, 1989; Stern et al., 1992; Proust et al., 2005), (iii) mantle upwelling and crustal doming at the southern margin of the Taupo Volcanic Zone (Kamp et al., 2002, 2004) or (iv) a combination of these processes with subsidence due to sediment loading (Stern et al., 1992; Kamp et al., 2004; Proust et al., 2005).

Subsequently the basin was uplifted (at rates of $\sim 0.3 \mathrm{~mm} /$ year) (Proust et al., 2005; Pulford and Stern, 2004; Stern et al., 2013). Additional uplift along the axial ranges to the east (what is now the Ruahine and Tararua Ranges: i.e. bedrock in figure 1.3) has resulted in exposure of the Plio-Pleistocene shallow-marine sedimentary rocks in incised river valleys and coastal cliff sections (Proust et al., 2005; Pulford and Stern, 2004).

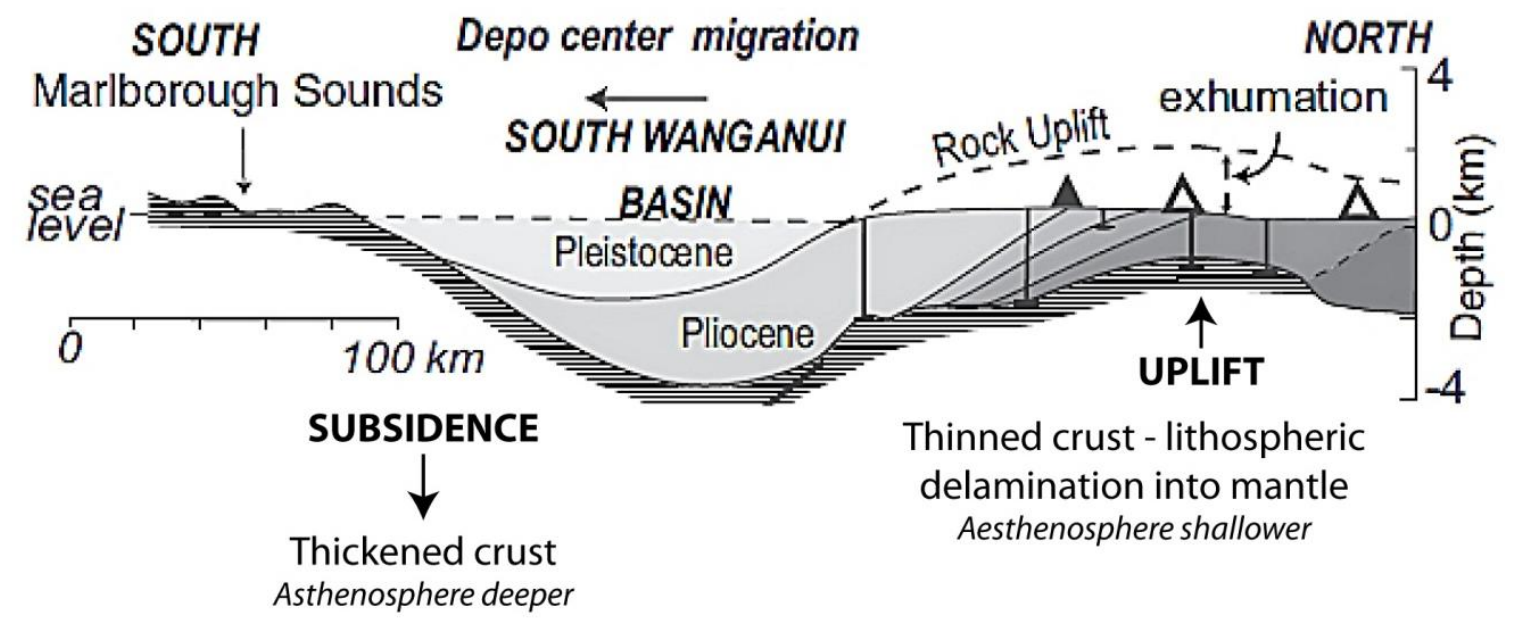

Figure 2.9: A possible model describing the evolution of the Wanganui Basin over time related to complex subduction-zone boundary processes from Stern et al. (2013). To the north (near the Taupo Volcanic Zone), lithospheric delamination occurs (the crust "peels" off) and uplift commences, allowing the aesthenosphere penetrates shallower depths. To the south, the crust is still thick and subsides relative to the uplift occurring to the North. This process of crustal thinning, uplift and subsidence migrates south over time as delamination propagates southwards. This process caused the initial subsidence of the Pliocene and Pleistocene strata, and their subsequent uplift in the Late Quaternary. 
Recognised as a "Tertiary Basin" in the late 1800's (Buchanan, 1869), the strata of the Wanganui Basin were first mapped and described in detail by Feldmeyer et al. (1943) for the Superior Oil Company (New Zealand). This was followed with studies from Te Punga (1953) in the east of the basin, and the landmark New Zealand Geological Survey bulletin by Fleming (1953). The Pliocene and Pleistocene strata were deposited in neritic environments oscillating from near-shore to the continental shelf and slope. Fleming (1953) interpreted more than 30 cyclical lithological and palaeontological changes have formed due to fluctuating sea levels through the Pleistocene, although he could not make the link with global sea level because at the time only four major Northern Hemisphere glacial episodes were recognised. Nevertheless, it was then that the global palaeoclimatic significance of the Wanganui Basin's Pleistocene marine sedimentary rocks were recognised (Fleming, 1953). Subsequent studies began to establish local and regional correlations within an integrated chronostratigraphic framework, and have allowed the interpretation of the cyclic sediments as indicators of orbitally-forced glacio-eustatic sea level variability and global climate change (Beu and Edwards, 1984; Seward et al., 1986; Kamp and Turner, 1990; Alloway et al., 1993; Pillans et al., 1994; Naish et al., 1996; Kamp et al., 1998).

The Wanganui Basin provides a unique opportunity to investigate changes in sea level in response to global climate changes because the active tectonic environment has provided: (i) a framework for the interplay of sedimentation, subsidence and eustasy to continuously record water depth changes responding to changes in global ice volume (Naish and Kamp, 1997b), and (ii) syn-sedimentary rhyolitic volcanism, the products of which provide a means for radiometric dating of tephra horizons preserved within the siliciclastic sequences (Seward, 1976; Alloway et al., 1993; Naish et al., 1996; Seward and Kohn, 1997; McIntyre, 2002; Alloway et al., 2005; Pillans et al., 2005). Quaternary tephras ( $<1.8 \mathrm{Ma}$ ) have a Taupo Volcanic Zone source, while Early Pleistocene and Pliocene tephras are likely sourced from the now inactive Coromandel Volcanic Zone (Wilson et al., 1995; Carter et al., 2003; Carter et al., 2004; Briggs et al., 2005).

Additionally, New Zealand's isolated location in the South Pacific has resulted in the development of a unique biostratigraphic framework based on endemic marine fauna (Collen, 1972; Beu and Edwards, 1984). In conjunction with magnetostratigraphy and tephrochronology, these techniques provide a means to accurately date the shallow 
marine sedimentary succession exposed in the Wanganui Basin (Seward et al., 1986; Kamp and Turner, 1990; Alloway et al., 1993; Pillans et al., 1994; Naish et al., 1996; Alloway et al., 2005; Pillans et al., 2005). Pliocene and Pleistocene water depth changes in the Wanganui Basin have been reconstructed using lithostratigraphy, uplifted palaeomarine terraces, sediment textures, and palaeoecological assessment of assemblages of extant fossil macro and microfauna (see Chapter 3 for discussion of palaeobathymetry proxies of sediment texture and benthic foraminifera palaeoecology) (Fleming, 1953; Beu and Edwards, 1984; Pillans, 1990; Journeaux et al., 1996; Abbott, 1997; Abbott and Carter, 1997; Naish, 1997; Naish and Kamp, 1997a, b; Kamp et al., 1998). Reconciliation of cyclic changes within an integrated chronostratigraphic framework also allows for dating of sedimentary sequences via astronomical tuning, allowing for their interpretation in the context of global climate changes (Hilgen, 1991; Naish et al., 1998; Carter and Naish, 1999). The Wanganui Basin thus contains a key record of palaeoenvironmental change during the Pliocene-Pleistocene, and is considered by many to be a global reference section for outcrop-based sequence stratigraphy, cyclostratigraphy and biostratigraphy (Beu, 1969; Naish and Kamp, 1997b; Carter et al., 1998; Saul et al., 1999).

Outcropping strata of Pleistocene age within the Wanganui Basin have been studied in detail, and are characterised by sedimentary facies and marine fossil micro- and macrofaunal accumulations deposited in alternating paralic (marginal-marine) to mid-outer shelf environments (tidal to >60 metres water depth) (Naish and Kamp, 1995; Abbott, 1997; Abbott and Carter, 1997; Hughes and Kennedy, 2009). With the application of sequence stratigraphic techniques, Naish and Kamp (1997b) found that depositional sequences in the Rangitikei River comprising transgressive and highstand facies assemblages between 2.5-1.6 Ma occur with an average periodicity of 41,000 years (figure 2.11). Within a robust chronostratigraphic framework, they made a one-to-one correlation to the benthic oxygen isotope record, despite the bias towards interglacial preservation and the presence of erosional unconformities representing glacial sealevel lowstands separating each depositional sequence. This has allowed the tuning of depositional sequences to astronomical cycles, which infers that each depositional sequence is the result of obliquity-forced glacio-eustatic sea-level cycles. Sea-level amplitudes calculated from the Rangitikei River record have large errors due to the 
large ranges given by water depth proxies of sediment texture and palaeoecology of marine fauna ( \pm 20 metres), but are likely to be between $15-90$ metres, broadly consistent with benthic $\delta^{18} 0$ estimates (Naish, 1997; Dunbar and Barrett, 2005). For the Late Pleistocene, cyclicity of depositional sequences follows the 100,000 year frequency, also consistent with the benthic $\delta^{18} 0$ record (Pillans et al., 1998; Abbott et al., 2005).

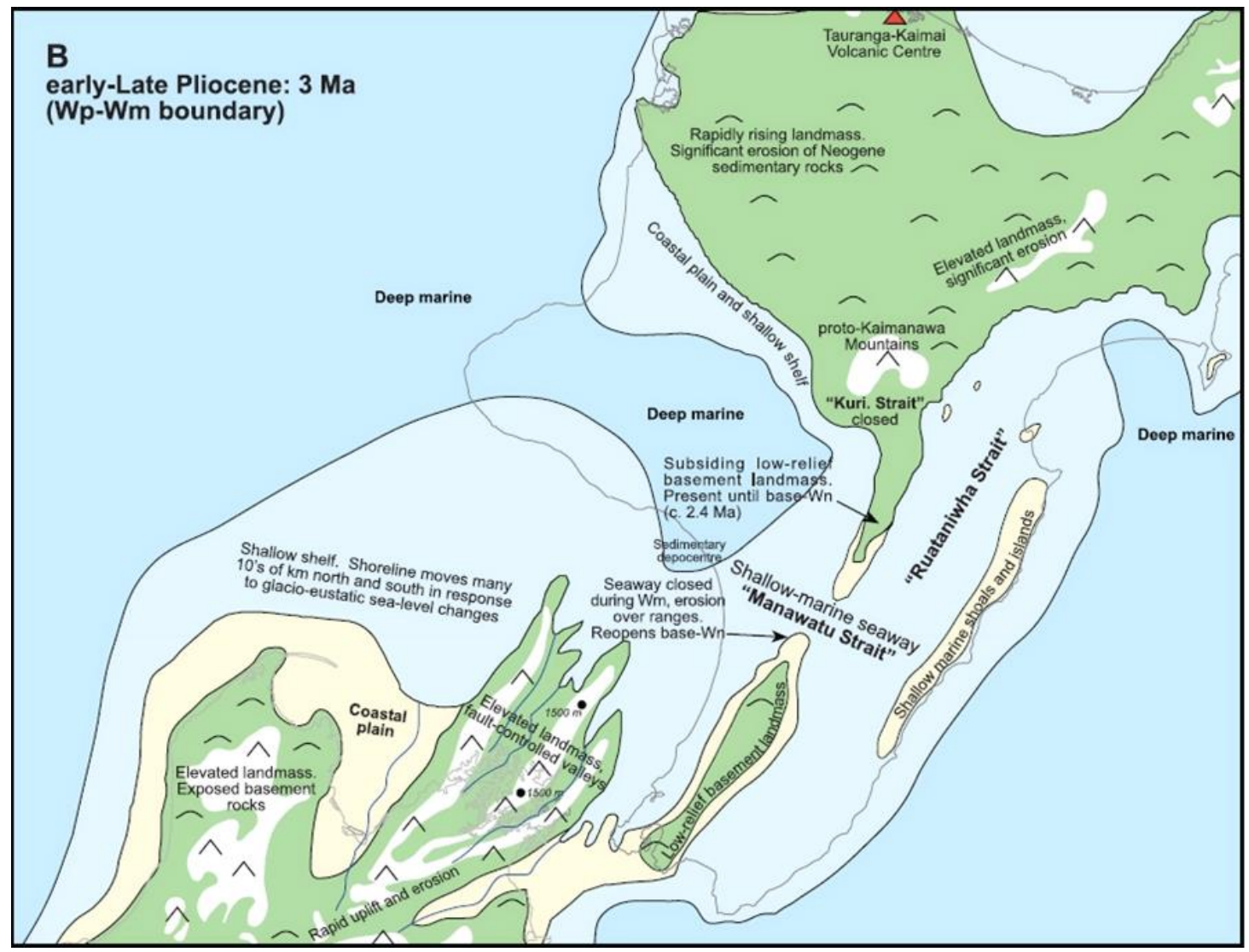

Figure 2.10: The inferred palaeogeography of the southern "North Island" during the Late Pliocene from Trewick and Bland (2012). Much of the Wanganui Basin was either shelf ( $<200$ metres water depth) or deep marine ( $>200$ metres), and a shallow seaway existed between the east and west, before the axial present-day Ruahine and Tararua Ranges were uplifted. It should be noted that during this time, active rhyolitic volcanism was occurring in the north (the red triangle) as part of the now extinct Coromandel Volcanic Zone. The Pliocene precedes the volcanism of the Taupo Volcanic Zone (where uplift of the Kaimanawa Ranges was initiating). Wp and Wm denotes the Waipipian and the Mangapanian New Zealand geological stages (the boundary occurring at 3.0 Ma). 


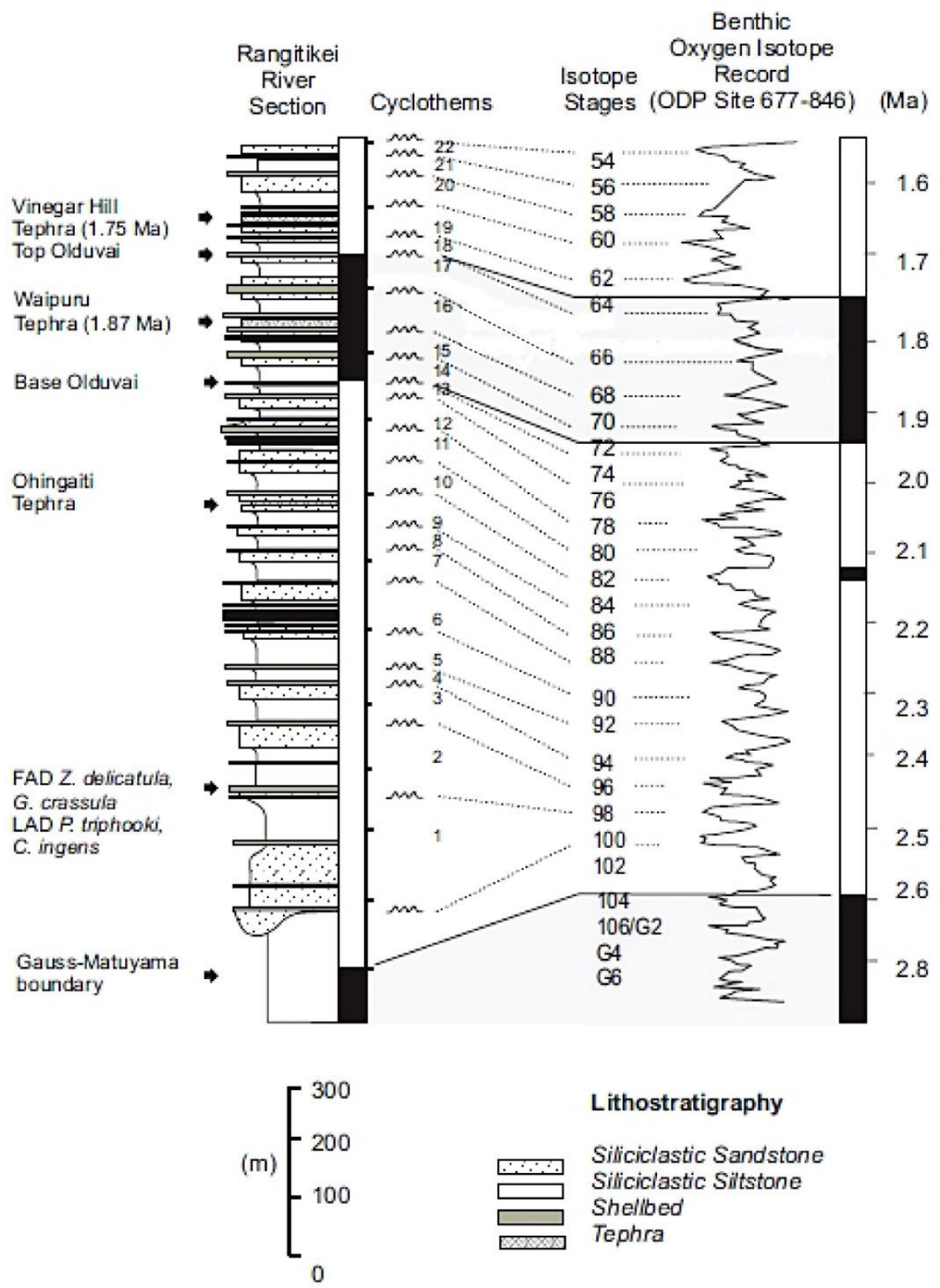

Figure 2.11: The correlation of depositional sequences in the Rangitikei River section to the benthic oxygen isotope record from Naish (1997). Each depositional sequence matches to an interglacial marine isotope stage (as the deepening and high-stand facies are preferentially preserved).

The Pliocene strata of the Wanganui Basin are characterised by continental shelf deposits, with sediment textures and marine fossils suggesting cyclic changes from mid to outer shelf environments ( $\sim 50$ to $>100$ metres water depth) (Journeaux et al., 1996; Kamp et al., 1998; Naish et al., 2005; Naish and Wilson, 2009). To the west of the basin, sedimentary rocks that now crop out along the Southern Taranaki coastline 
accumulated on a structural high point at mid-shelf depths (Naish et al., 2005; Naish and Wilson, 2009). The eastern part of the basin, now exposed in the incised Rangitikei and Turakina River valleys (figure 1.3), was the centre of basin subsidence during the Pliocene and thus accumulated sediments in deeper outer shelf environments (Journeaux et al., 1996; Kamp et al., 1998). While the resolution of these studies is low in comparison to their Pleistocene counterparts, cyclical changes in lithology and fossil marine fauna display pronounced water depth changes, occurring at approximately 41,000 year intervals. Simple sedimentary backstripping has yielded Pliocene sea-level amplitudes of 10-30 metres, notwithstanding the uncertainties discussed above (Naish and Wilson, 2009).

The application of sequence stratigraphy for direct interpretation to glacial-interglacial cycles is not as easily applied to the Pliocene strata in the Wanganui Basin because their environments of accumulation were deeper than those of the Pleistocene succession (Kamp et al., 1998). In general, deposition occurred at or below wave base, and characteristic shell beds, facies successions and unconformities associated with the transgressive and regressive trajectory of the shoreline are not present or not identifiable in the field (Journeaux et al., 1996; Kamp et al., 1998). These such strata are considered to be continuous sedimentary successions (Journeaux et al., 1996; Kamp et al., 1998).

One of these continuous records (the focus of this study) is the Mangaweka Mudstone, a $330-1000 \mathrm{~m}$ thick Late Pliocene ( 3.0-2.6 Ma) mudstone, cropping out in river and road sections in the eastern Wanganui Basin (figures 1.3 and 2.12). The mudstone is thought to have been deposited in a mid-outer shelf environment, encompassing a rapid tectonically-induced basin deepening of $\sim 100 \mathrm{~m}$ at $\sim 3.0$ Ma (figure 2.13) (Feldmeyer et al., 1943; Te Punga, 1953; Hoskins and McGuire, 1990; Journeaux et al., 1996; Kamp et al., 1998; McIntyre, 2002; Naish et al., 2005;). While water depth variability is not obvious in the physical characteristics of the outcrop, which consists of massive, blue-grey mudstone ("papa"), laboratory analysis of sediment textures and microfaunal content (benthic foraminifera) indicate significant cyclical environmental changes corresponding approximately to orbital frequencies (Journeaux et al., 1996; Kamp et al., 1998). 


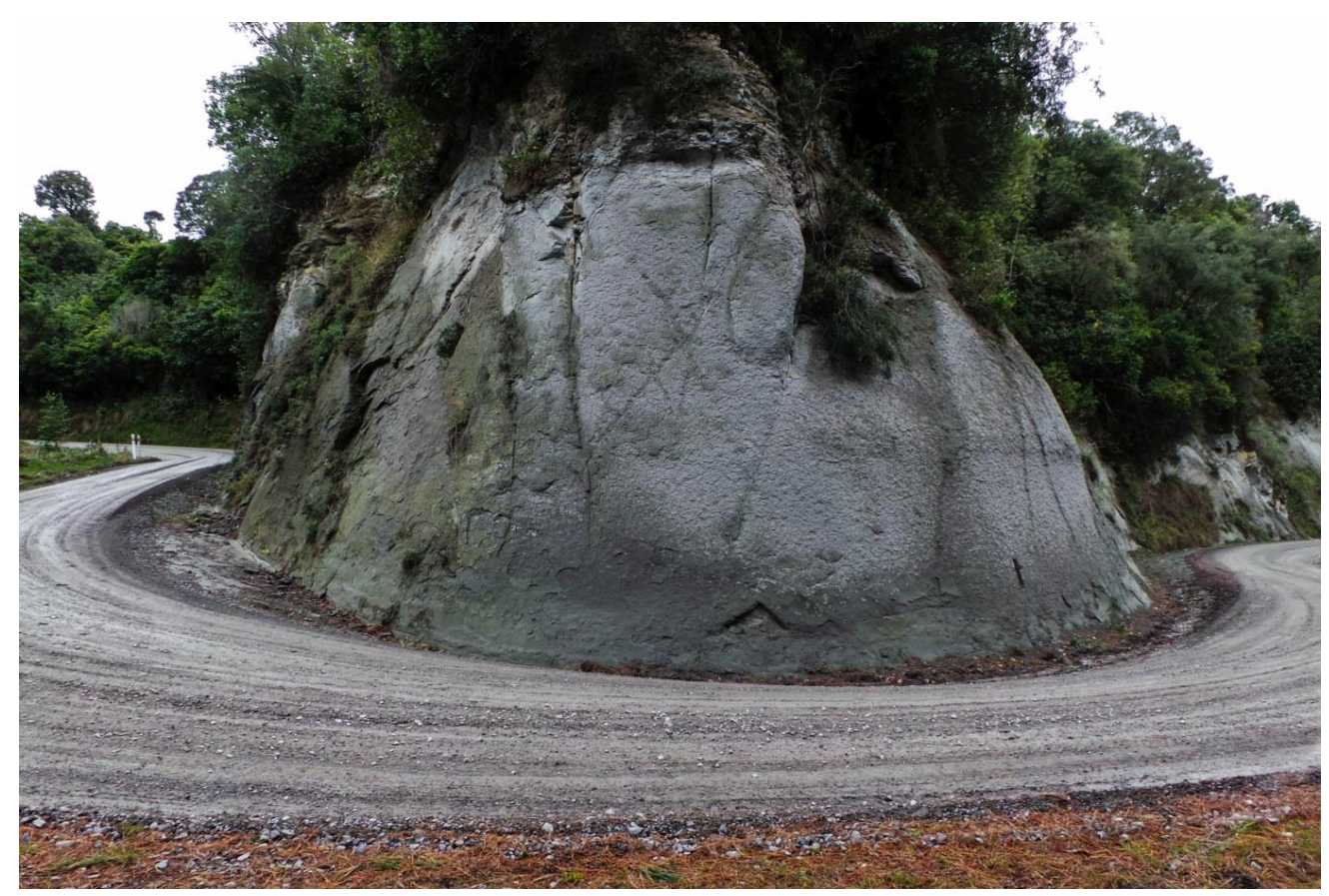

Figure 2.12: The Mangaweka Mudstone in outcrop along Watershed Road near Tiriraukawa, between the Rangitikei and Turakina Rivers.

The Mangaweka Mudstone itself contains three independent age constraints: (i) the Gauss-Matuyama palaeomagnetic reversal (2.58 Ma) at the top of the unit (figure 2.10) and the Kaena subchron reversal (3.01 Ma) immediately below the unit base (Wilson, 1993; Journeaux et al., 1996); (ii) >5 discrete, bioturbated rhyolitic tephra horizons, with the most distinctive being the stratigraphically highest Eagle Hill and the Kowhai Tephras. The Eagle Hill tephra is dated via linear sedimentary interpolation at $2.88 \mathrm{Ma}$, and is chemically distinguishable from the other Mangaweka Mudstone tephras on the basis of major element chemistry (Journeaux et al., 1996; Naish et al., 1996); Three tephra exist stratigraphically below the Eagle Hill and the Kowhai tephras, and are less obvious in outcrop as they are discontinuous and significantly bioturbated (Alloway, personal communication); (iii) A biostratigraphic datum is also provided: the last appearance datum (LAD) of outer-shelf dwelling benthic foraminifera species Cibicides molestus (Hornibrook et al., 1989; Journeaux et al., 1996; Cooper, 2004). This species is present in the lower Mangaweka Mudstone stratigraphically below the tephra members, and absent above. 


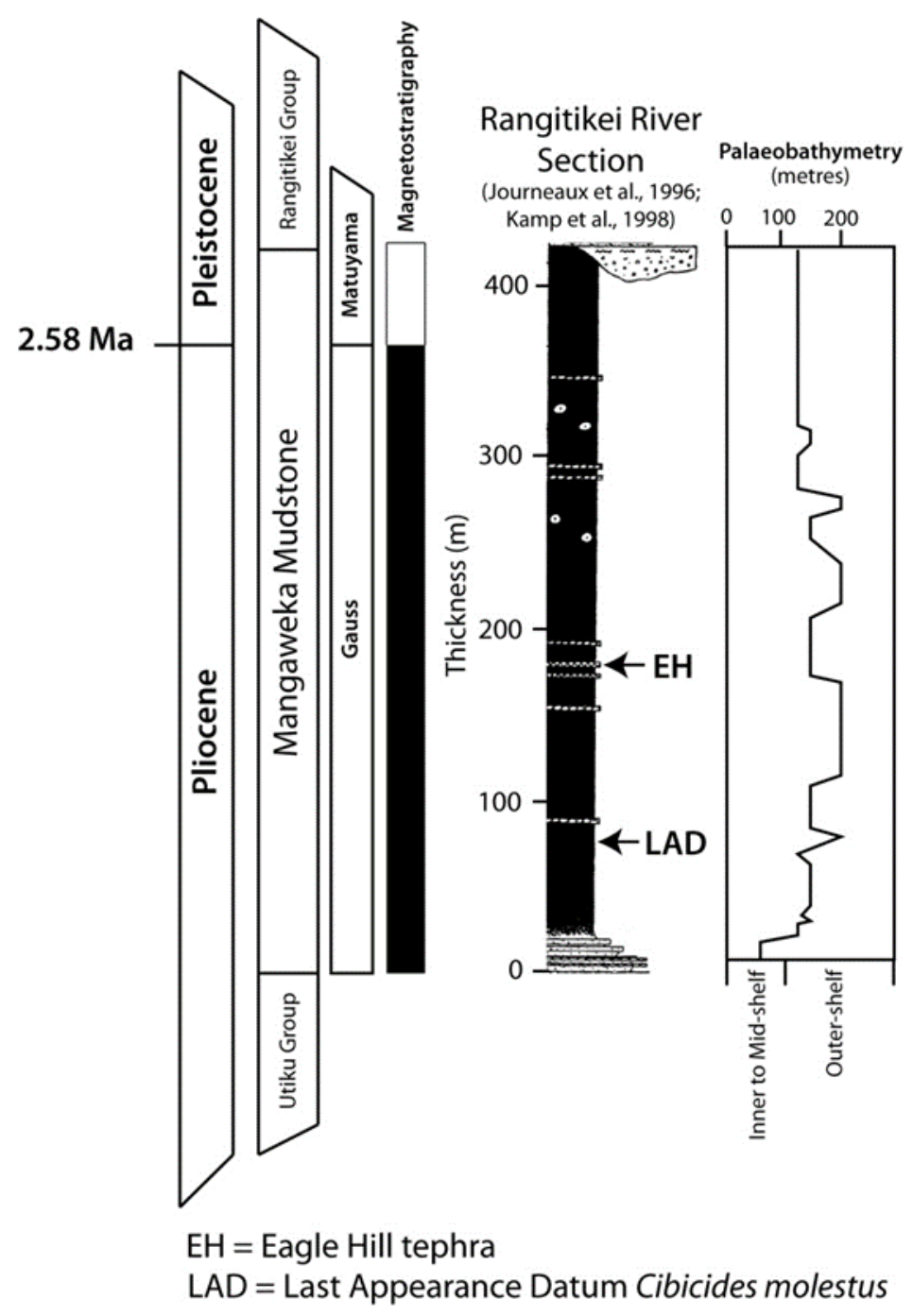

Figure 2.13: The Rangitikei River stratigraphy and age as compiled by Journeaux et al. (1996) and Kamp et al. (1998). The Mangaweka Mudstone encompasses the Gauss chron, with the Matuyama boundary in the top section of the formation. The Kaena reversal occurs in the Utiku Group below the Mangaweka Mudstone. Also presented is the palaeobathymetry derived from benthic foraminifera assemblages and sediment textures by Journeaux et al. (1998), and the location of the Eagle Hill tephra and Last Appearance Datum (LAD) of Cibicides molestus.

While these previous studies of the Mangaweka Mudstone are detailed and robust, they lack the resolution necessary to investigate subtle water depth changes related to high frequency, orbitally-forced glacio-eustatic sea-level cycles (namely precession). Therefore, a unique opportunity is presented in this study to examine in high resolution and continuous neritic sedimentary record within a swell-constrained chronological framework. The Mangaweka Mudstone crops out along a continuous section along Watershed Road near Tiriraukawa (figure 1.3), on a topographic high straddling the 
Rangitikei and Turakina Rivers. In this thesis, this road section has been chosen for investigating the sedimentary and microfaunal changes preserved in the Mangaweka Mudstone at a sampling resolution less than 5000 years. 


\section{Chapter 3: Methodology}

\section{Geological mapping and stratigraphy}

Previous studies of the Mangaweka Mudstone have been largely restricted to exposures along Rangitikei and Turakina Rivers (Feldmeyer et al., 1943; Te Punga, 1953;

Journeaux et al., 1996; Kamp et al., 1998; McIntyre, 2002). A new near-continous exposure of the Mangaweka Mudstone occurs along Watershed Road at Tiriraukawa, approximately $12 \mathrm{~km}$ west of Mangaweka township and the Rangitikei River (figure 1.3 and 3.1). The exposure of the Mangaweka Mudstone along Watershed Road is very accessible and thus ideal for high-resolution sampling and precise stratigraphic measurements. The mudstone is soft and friable, and as a consequence it is eroded very quickly from exposed sites like Watershed Road. In many places, road works were underway and outcrops were fresh, having been very recently cut back with machinery (figure 3.2). This is ideal for geological analysis, as sampling freshly exposed outcrops increases the likelihood of collecting un-weathered material. Additionally, the Watershed Road section is situated geographically between the Rangitikei and Turakina river valleys (figure 1.3) and provides a depositional environment that is intermediate between the shallower and deeper basin equivalents, respectively.

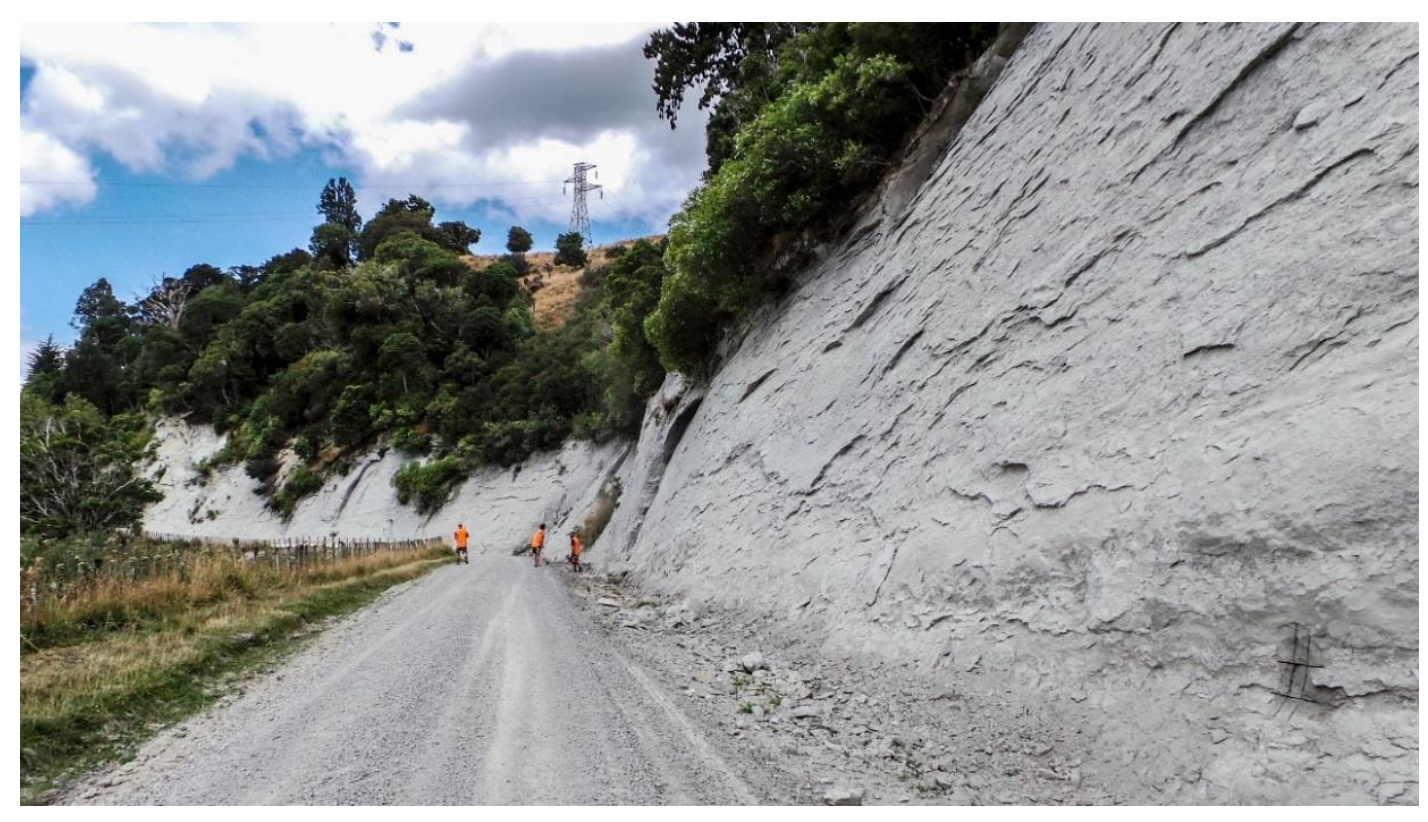

Figure 3.1: Exposure of the upper section of the Mangaweka Mudstone along Watershed Road, looking south. 
Traditional field mapping techniques (Jacob's Staff/Abney Level) and high precision GPS surveying was applied to measure the thickness and sedimentological features of the Mangaweka Mudstone along Watershed Road (figure 3.3). This combination of approaches was required due to a number of field difficulties related to the nature of the geomorphology and geology of the Mangaweka Mudstone, including: (i) the massive and homogenous nature of the formation restricted structural measurements, and therefore the stratigraphic heights of each sample had to be derived from the regional strike and dip of the formation, due to lack of distinctive bedding planes and features; and (ii) the shallow dip of the strata $\left(4-6^{\circ}\right)$ meant larger horizontal distances had to be covered to sample in stratigraphic sequence that when combined with the variable topography of the area along Watershed Road resulted in difficulty in identifying the stratigraphic position of the samples and sedimentary features in the field. Consequently, the field methodology resulted in sample intervals being uneven in some sections, but because the sample locations are precisely located by GPS they were accurately placed into stratigraphic order using the regional strike and dip, subsequent to field measurements.

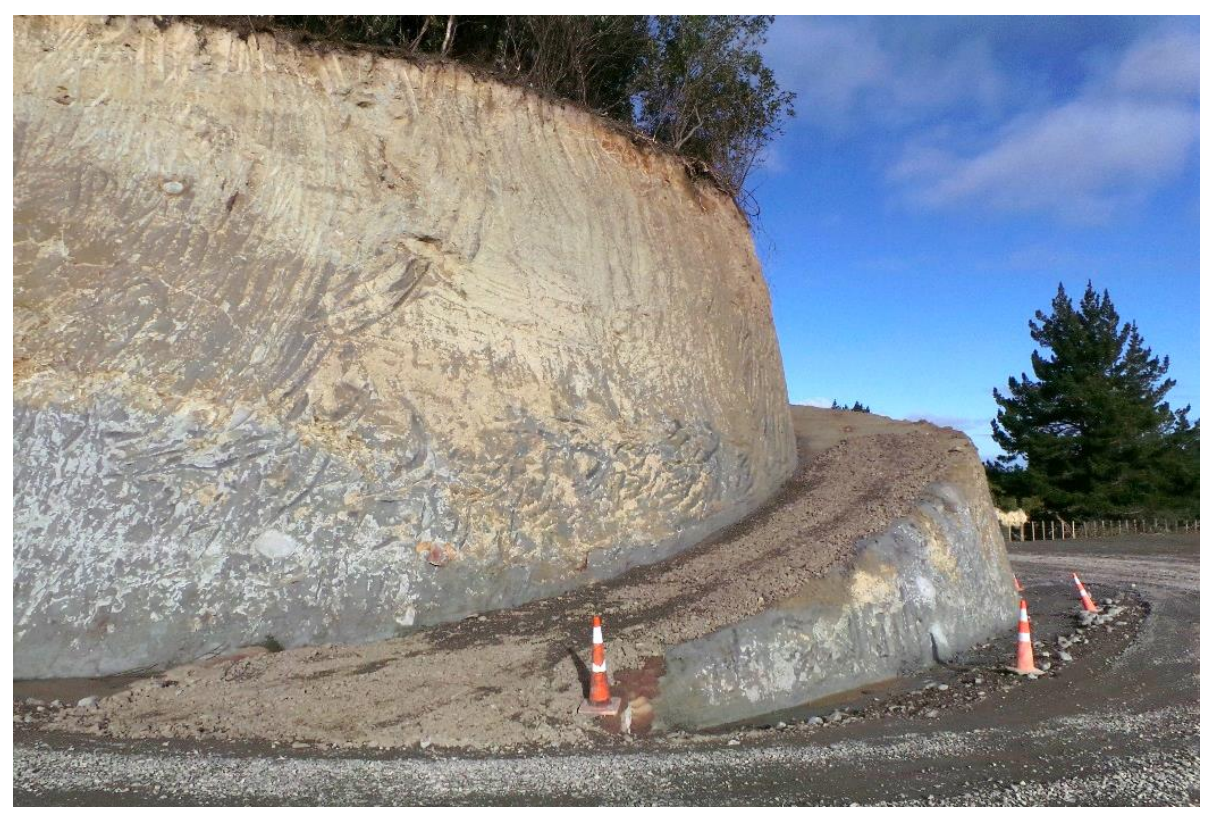

Figure 3.2: A new road cut of the upper part of the Mangaweka Mudstone along Watershed Road, looking south-east.

One hundred and seventy eight bulk sediment samples were collected at 2-5 m stratigraphic intervals from outcrop sections along Watershed Road (figure 3.4). Samples were extracted using a concrete saw and geological hammers, and sampling intervals were initially determined using Jacob's Staff/Abney Level. Each sample site 
was then accurately surveyed using a Trimble RTK differential GPS. Sample sizes ranged from 200 grams for grainsize samples and up to 2 kilograms for paired grainsize (178 samples) and benthic foraminifera (89 samples) studies. Standard lithological descriptions were made for each outcrop throughout the section.

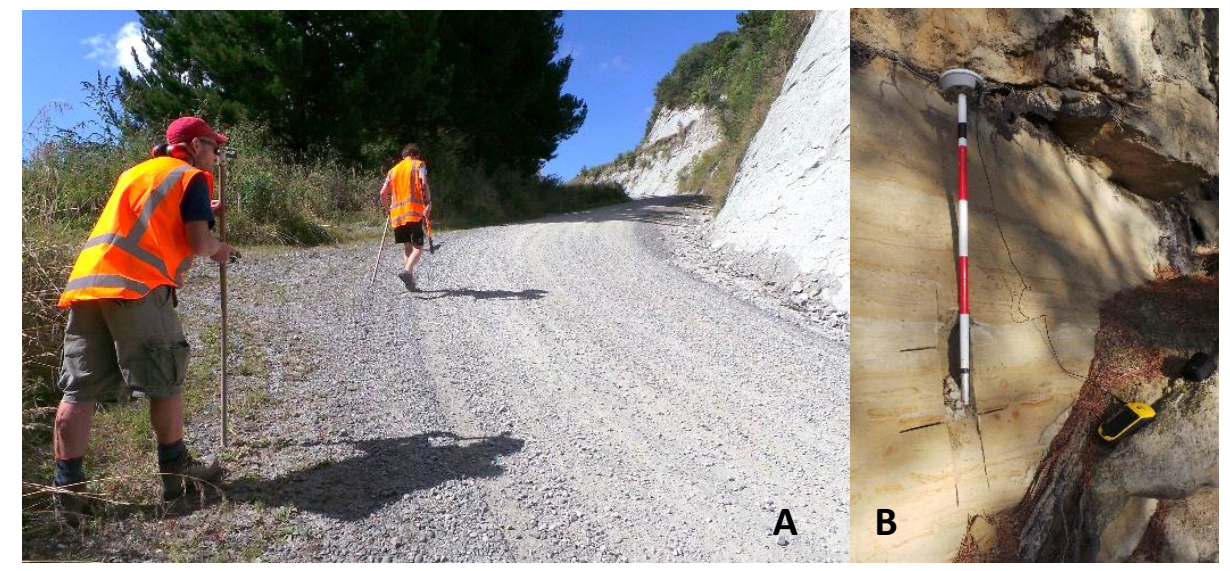

Figure 3.3: Stratigraphic techniques in the field. (A) The stratigraphic height of a sample was estimated during the field collection and mapping using an Abney Level and Jacob's Staff measurements. (B) A GPS unit and a handheld satellite receiver were used to accurately place the sample into the stratigraphic framework subsequent to sampling.

Using structural data collected in the field and from previous studies (Naish and Kamp, 1995; Kamp et al., 1998), the strike and dip for the Mangaweka Mudstone at Tiriraukawa is approximately 115/SW/06. GPS elevations and horizontal positions for each sample were interpolated onto a cross-section parallel to dip direction using Geographic Information Systems (GIS) software ArcMap 10.1. Stratigraphic positions for each sample were determined relative to the upper contact using the equation;

$$
\text { True thickness }=(W \times \operatorname{Sin} D)+(H \times \operatorname{Cos} D)
$$

Where $W$ is cross-sectional distance between sites (in metres), $H$ is elevation difference between sites (in metres) and $D$ is the dip of the strata (in radians) (figures 3.5a and b). 


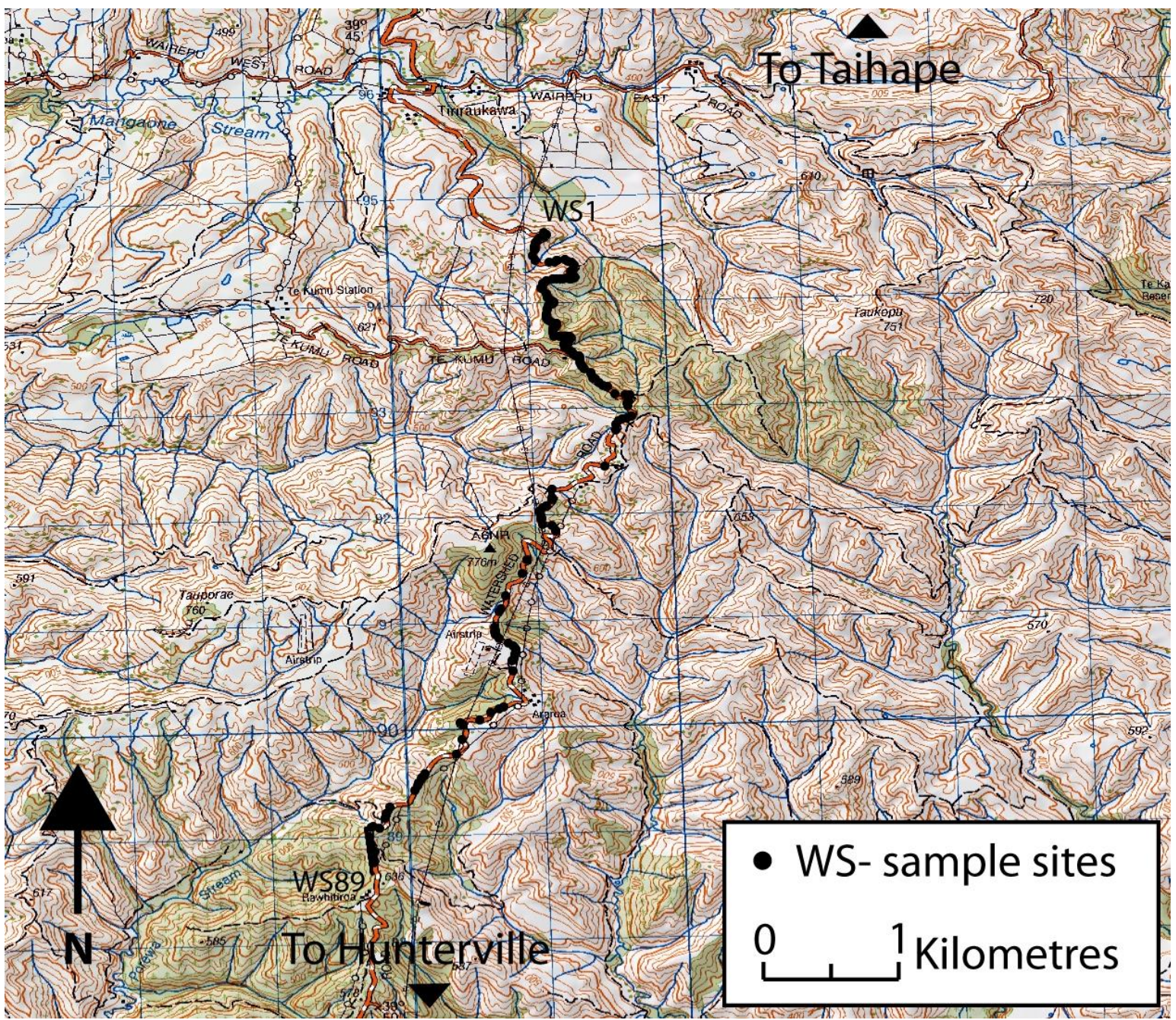

Figure 3.4: GPS locations for grainsize, foraminifera, palaeomagnetic and tephra samples along Watershed Road at Tiriraukawa on the New Zealand Topographic Map. For specific locations of either type of sample, see Chapter 4 and Appendix A for stratigraphic positions.

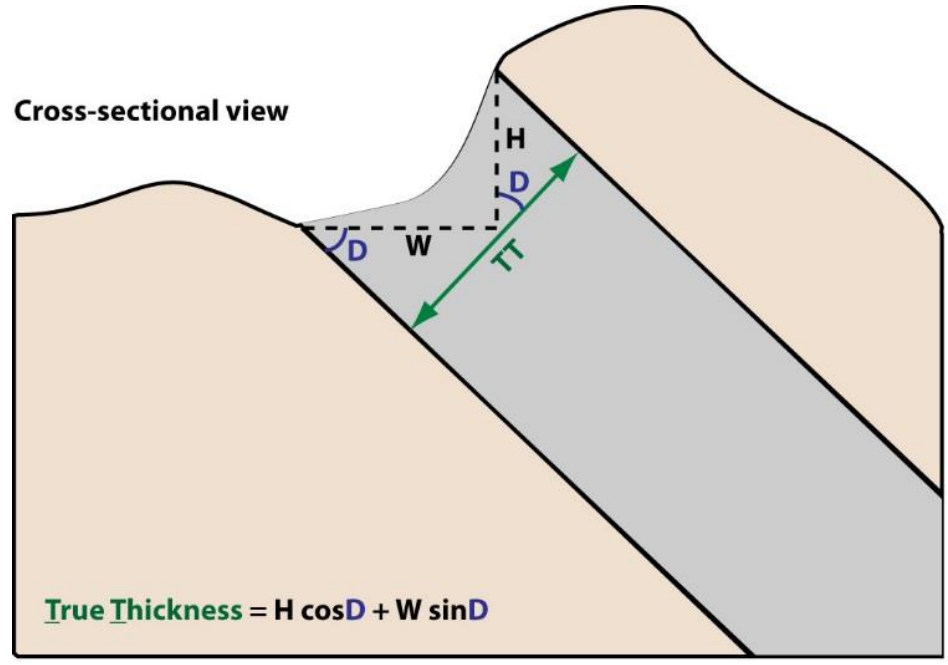

Figure 3.5a: Trigonometric basis for calculating stratigraphic thickness. Sample positions were determined from the top contact, and cumulatively give total stratigraphic thickness. Modified from Lisle (2004). 


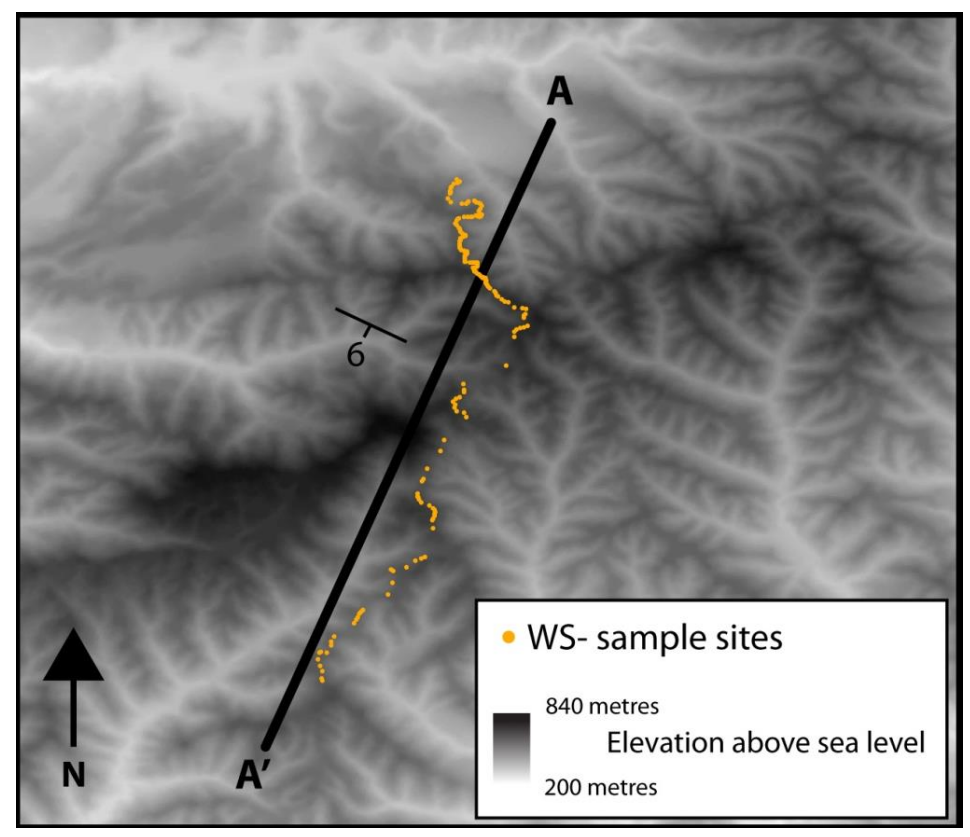

Figure 3.5b: GPS locations as for figure 3.4 (same scale). Sample sites overlain on a digital elevation model for the construction of a cross-section in ArcMap 10.2 software. The dark line shows the cross-section line, with additional structural data used for calculating stratigraphic thicknesses.

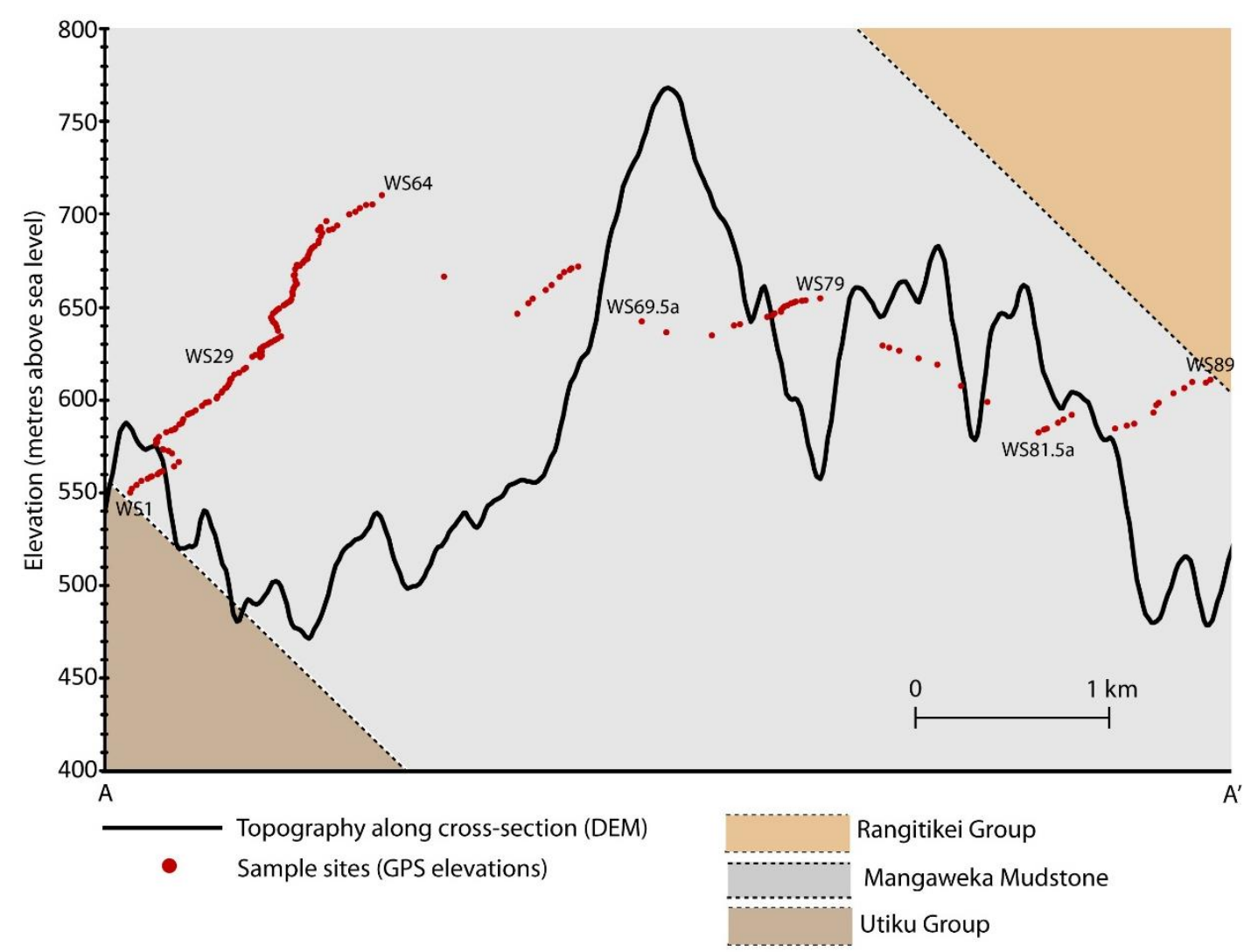

Figure 3.5c: Vertically-exaggerated cross-section of the Watershed Road Mangaweka Mudstone section along cross-section line A-A', with sample locations projected onto the cross-section line (figure 3.5b). Vertical exaggeration is $\mathrm{x} 10$. Also displayed is the 
observed and inferred overlying and underlying formations, respectively. The topography was derived from the New Zealand Digital Elevation Model (DEM) and the sample elevations from post-processed differential GPS.

\section{Palaeobathymetry proxies}

Grainsize analysis and a census of benthic foraminifera was used to identify and to reconstruct any palaeo water-depth changes preserved in the Mangaweka Mudstone. The use of these two independent approaches strengthens the reliability and resolution of past water depth reconstructions. Sedimentological and palaeontological approaches to bathymetric reconstruction are widely applied; however, it should be noted that evidence derived from these proxies rarely directly indicate change in water depths rather, they indicate processes such as wave energy, sediment supply and biological mixing, that are themselves depth-dependent (Clifton, 1988; Boggs, 2011).

Sediment texture as a proxy for water depth

The study of sediment texture preserved in marine sedimentary strata is a fundamental approach to interpreting past depositional environments. Observations of sediment texture across continental shelves show predictable changes from well-sorted sands to poorly-sorted muds with increasing water-depth, a response to decreasing wave energy on the seafloor with increasing water depth (Boggs, 2011). This observation, in addition to other sedimentary-process features such as ripples and cross-bedding, can be used to estimate past water depths (Clifton, 1988; Clifton and Dingler, 1984; Tanner, 1971).

The application of grainsize analysis as a palaeobathymetry proxy for this project is largely based on a study of modern analogue processes along the Manawatu coastline (Dunbar and Barrett, 2005). That study quantitatively examined the relationship between wave climate (height and period), sediment texture and water depth on wavegraded continental shelves. Any changes in sediment texture are inferred to be a direct response to variations in wave-induced shear stress imparted on the seabed, which is a function of wave climate. Percent mud $(<63 \mu \mathrm{m})$ per a given volume of sediment can be directly related to water depth, assuming hydrodynamic equilibrium, where sedimentation, bioturbation, wave energy and water depth are consistent over time. This response produces the distinctive pattern of seaward-fining sediment texture, 
where shallow waters with increased wave energy contain lower percent mud than deeper waters with decreased wave energy (figure 3.6).

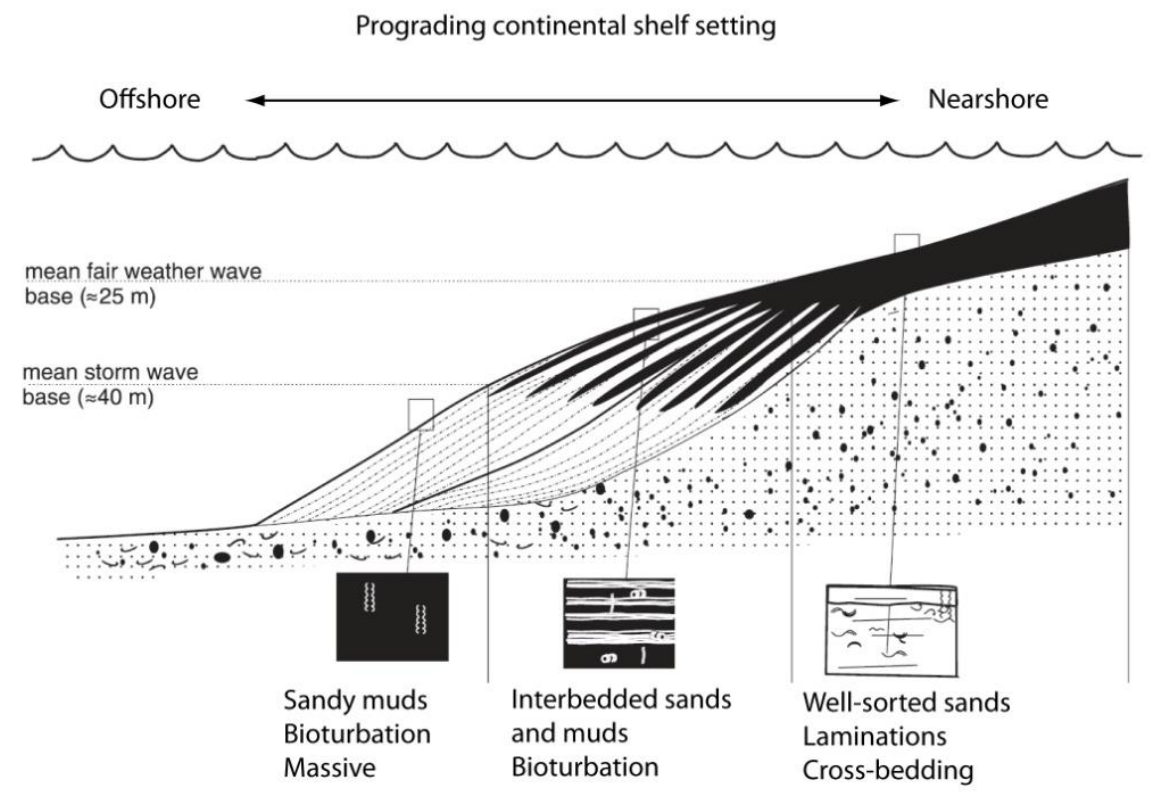

Figure 3.6: Schematic diagram of changing sediment texture with water-depth across the modern Manawatu continental shelf setting, modified from Dunbar and Barrett (2005). While the depths of mean fair weather wave base and storm weather wave base are dependent on the local wave climate, a trend of decreasing sand and increasing mud generally indicates deepening bathymetry.

Sediment texture as a proxy for water-depth is limited to environments of deposition on the shelf where wave processes dominate sediment movement. Fortunately, it is these environments that are preferentially preserved in the geological record, rather than sites of erosion or non-deposition that may not reflect water depth-related processes (Dunbar and Barrett, 2005). Therefore, examining strata deposited in shallow marine sedimentary basins will likely show sediment changes relating to water depth variation over time. There are a couple of previous studies conducted in the Wanganui Basin (see Chapter 2) that have qualitatively related sediment textures and water depths.

Assuming a prevailing wave climate analogous to the modern Manawatu coast, this proxy (figure 3.7) has been successfully applied to Late Pliocene-Early Pleistocene sedimentary sequences from the Rangitikei River in the Wanganui Basin (Dunbar and Barrett, 2005). The palaeobathymetry resulting from this approach was consistent with values derived from depth-sensitive marine micro-fossils, independent of grainsize. 
Therefore, the use of the Dunbar and Barrett water-depth proxy has a number of advantages for investigating the palaeobathymetry recorded in the Mangaweka Mudstone exposed at Tiriraukawa: (i) the depositional environment of the Wanganui Basin is thought to be that of a wave-graded continental shelf (Fleming, 1953; Naish and Kamp, 1995; Naish and Kamp, 1997b): (ii) the palaeogeography of the Wanganui Basin during the deposition of the Mangaweka Mudstone was likely an environment on the shallow continental shelf (or very proximal) (Trewick and Bland, 2012), with marine connections through the central North Island axial ranges to the East Coast Basins (Hawke's Bay and Wairarapa) (figure 2.7); (iii) a wave climate similar to the modern Manawatu coast can be assumed on the basis of (i) and (ii) (Dunbar \& Barrett, 2005).

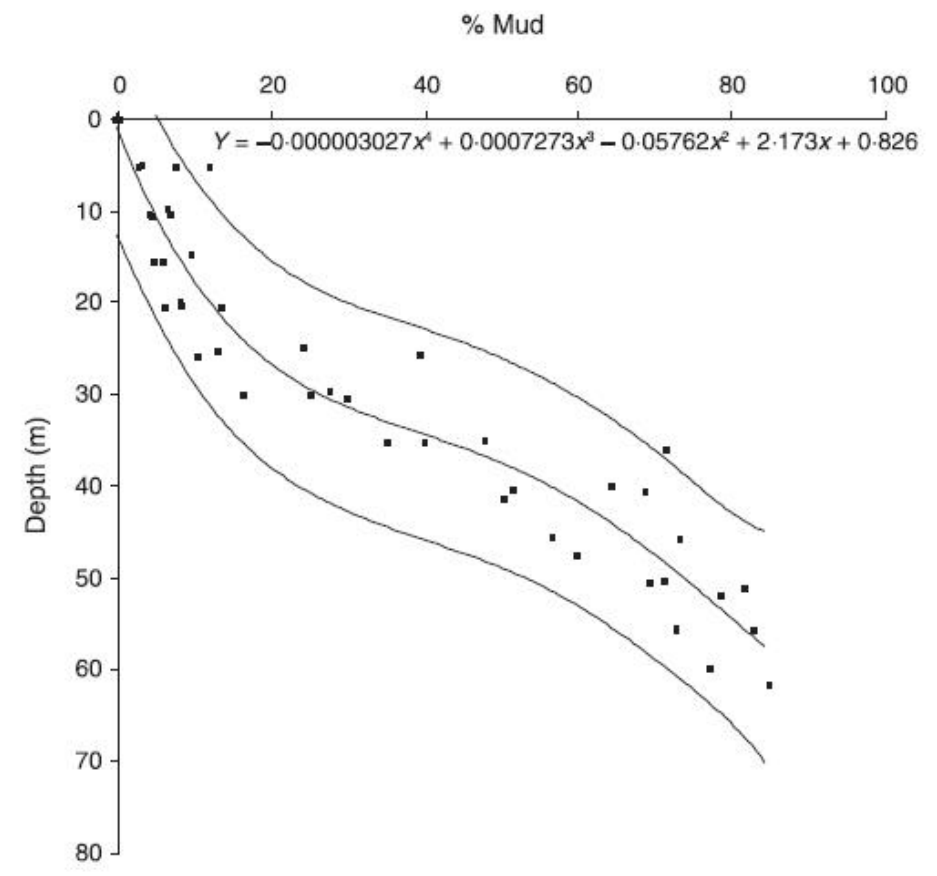

Figure 3.7: The percent mud variation with water depth proxy, based on data from sample transects off the modern Manawatu coast, from Dunbar and Barrett (2005). The percent mud change with water depth can be characterised with a fourth-order polynomial equation.

\section{Limitations}

Interpreting sediment textures for palaeobathymetric reconstruction requires assumptions about the dominant wave climate during the time of deposition. Past wave climates can be estimated by comparing the modern setting of an area to palaeogeographic reconstructions, and the overall climate state during deposition (e.g. 
glacial or interglacial). This is because wave height and period is largely dependent on wind strength and fetch. Based on the current climate state, modern wave climates in the Wanganui Basin are can be assumed to be similar to past interglacials (Dunbar and Barrett, 2005). Estimating wave climates for colder periods presents difficulties, as there is little agreement on whether or not winds in the Southern Hemisphere were stronger than present during past glacial periods (Hesse and McTanish, 1999; Toggweiler and Russell, 2008). Differences between glacial and interglacial wind strengths and consequent wave climates are therefore a limitation to this proxy approach. However, information provided by marine species (macro- or microfauna) that may be preserved in sedimentary rocks can shed light on past wave climate. Some species have an affinity for calmer or more vigorous current activity, and their presence or absence can give an indication of turbulence at the depositional site (Hayward et al., 1999).

The mineralogy and therefore the density of sediments is a fundamental parameter in the physics of how wave-induced shear stress on the seafloor entrains and sorts sediment of various sizes. Many pioneering studies upon which much of modern sedimentology is based on used quartz spheres to calculate energy thresholds for grain entrainment under unidirectional flow, rather than osciallatory flow generated by waves (figure 3.8) (Hjulstrom, 1939; Sundborg, 1956). In natural environments, a dominance of such grains is near impossible; although indicative, such experimental studies should not be applied as a direct proxy. Grain entrainment thresholds rely on grain density, size and shape, the surrounding seafloor morphology and the direction and strength of current flow (Carter and Heath, 1975). Consequently, assumptions of sediment and seafloor characteristics are a limitation to any quantitative grainsize analysis of natural sediments. 


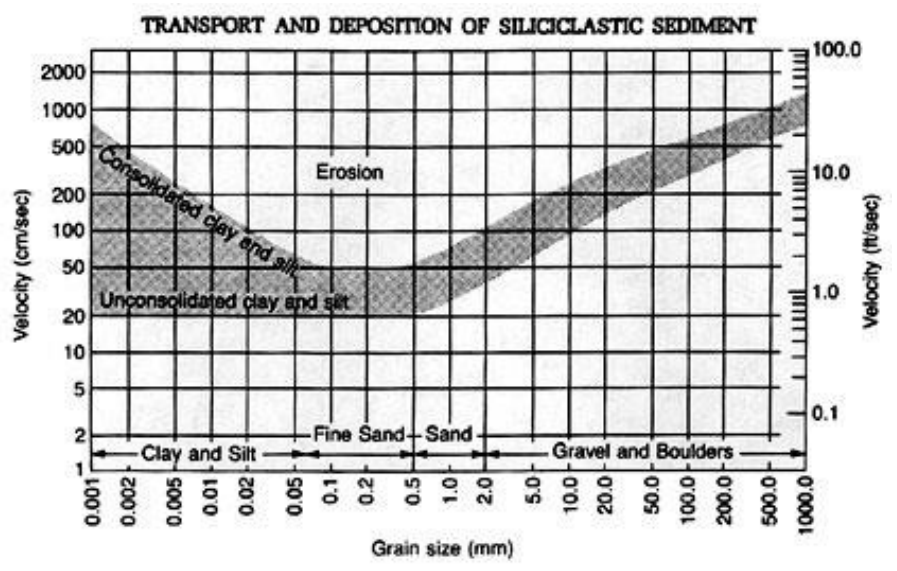

Figure 3.8: Energy thresholds for grains of varying sizes from Sundborg, 1956. The thresholds are specific to a certain density and shape, and therefore mineralogy.

Despite aforementioned uncertainties, this proxy method provides higher precision water depth estimates than more qualitative approaches such as marine fauna palaeoecology (Clifton, 1988). The sediment texture data collected from the modern Manawatu coast quantitatively relates percent mud with water depth, with a $\pm 10 \mathrm{~m}$ uncertainty within the $95 \%$ confidence interval (Dunbar \& Barrett, 2005). However, it should be noted that beyond $\sim 60 \mathrm{~m}$ water depths ( $\sim 80 \%$ mud), energy imparted on the seafloor is very low and only minimum water depths can be estimated.

\section{Laboratory techniques}

Preparation and measurement of sediment for grainsize analysis was undertaken at Victoria University of Wellington and based on the methodology of Dunbar and Barrett (2005). Bulk sediment samples were dried and gently disaggregated using wooden blocks; this methodology is referred over more aggressive methods of disaggregation which may cause grains to break and create artificial grainsize distributions.

Subsamples of 0.5-1 g were taken via the cone and quartering method, where the bulk sample is heaped and quartered to create smaller symmetrical material for subsampling. To remove the organic material, the sediment treated with excess $27 \%$ hydrogen peroxide in $50 \mathrm{~mL}$ plastic centrifuge tubes and incubated in a water bath at $30^{\circ} \mathrm{C}$ for $24-48$ hours. Once the reaction had visibly completed (i.e. vigorous bubbling ceased), the sediment was washed and centrifuged three times with distilled water. Excess $10 \% \mathrm{HCl}_{(\mathrm{aq})}$ (hydrochloric acid) was then added to remove any carbonate material, and left to digest for $<1$ hour. Sediment was again washed and centrifuged three times with distilled water, then freeze-dried. 
Immediately prior to sample measurements, $\sim 30 \mathrm{~mL}$ of $0.5 \mathrm{~g} / \mathrm{L}$ Calgon (sodium hexametaphospate) was added to the samples and stirred and sonicated for 10 minutes in glass beakers. Inspection of samples under an optical microscope after this step proved that 10 minutes was ample time for full disaggregation of the sediments. The samples were then measured using a Beckman Coulter LS 13320 Laser Diffraction Particle Size Analyser with the Polarization Intensity Differential Scattering (PIDS) signal off. The PIDS signal provides the primary information for 0.04-0.4 $\mu \mathrm{m}$ size range, detail that is not necessary for this project which is primarily focusing on the percentage of the $<63 \mu \mathrm{m}$ fraction.

\section{Benthic foraminifera palaeoecology}

Fossil foraminifera shells ('tests') from calcite-secreting marine protozoans have been used widely for reconstructing past environmental changes in shallow-marine strata due to their common occurrence and preservation potential (Van der Zwaan et al., 1999). Foraminifera can contribute to palaeoenvironmental analyses of marine sedimentary successions in two ways: (i) by analysing the major, trace and isotopic geochemistry of their tests (Katz et al., 2010), and (ii) by analysis of species abundance and the composition of foraminifera assemblages (Hayward, 1986; Hayward et al., 1999; Murray, 2001). This study employed the latter approach to estimate past water depths for the Mangaweka Mudstone, as a complimentary and independent measure to grainsize analysis.

Benthic foraminifera, those that live within (infaunal) and on top (epifaunal) of seafloor sediment, are distributed in the marine environment based on affinities for particular environmental variables, such as temperature, salinity, substrate, light, nutrients, current strength, competition, predation, oxygen concentrations, organic material and pH (Vella, 1962; Jorissen et al., 1995; Hayward et al., 1999; Van der Zwaan et al., 1999; Katz et al., 2010). How foraminifera abundances and assemblages change due to the complex variety of interplaying environmental variables is poorly understood. In particular, a direct relationship between benthic assemblages and water depths is difficult to produce (Van der Zwaan et al., 1990; Hayward et al., 1999; Murray, 2001). However, it is widely accepted that two of the most important ecological parameters are oxygen concentrations in sediments and bottom water (Hayward et al., 1999; 
Rosenberg et al., 2001) and organic material flux (food) (Pearson and Rosenberg, 1978), which tend to decrease with increasing water depths (Vella, 1962; Van der Zwaan et al., 1990). These factors change most rapidly within the upper $\sim 100 \mathrm{~m}$ of the ocean surface, and consequently assemblages are more sensitive to change in this shallow environment (Hayward et al., 1999; Hayward et al., 2001). Therefore, the fossil assemblages of benthic foraminifera influenced by decreasing food supply with depth in neritic settings can be used for estimating past water depths.

In contrast to benthic foraminifera, planktic species float within in the upper $\sim 200 \mathrm{~m}$ of the ocean surfaces. Species abundance and assemblages are therefore sensitive to changing environmental variables in the surface of the ocean (Kucera, 2007). They have an affinity for deep oceanic waters, their abundances notably decreasing in neritic environments (Kucera, 2007). This is thought to be due to the decrease in wave turbulence with distance from the shore (Van der Zwaan et al., 1990) and the development of a more complex pelagic nutrient cycle in the deep ocean. The presence of planktic foraminifera in shallow-marine sediments thus provides some information about the 'oceanicity' or characteristics of the overlying water masses (Hayward et al., 1999), leading to the development of the planktic/benthic ratio proxy for water depth (Vella, 1962; Hayward, 1986; Van der Zwaan et al., 1990). While subject to many geographic exceptions and therefore large uncertainties (Hayward et al., 1999), the planktic/benthic ratio (or percentage planktic species) in neritic to deep ocean environments can provide an approximate value for water depths.

Changes in benthic foraminifera productivity and species diversity can also be indirectly related to water depth (Kamp et al., 1998; Hayward et al., 1999). Again, depth alone is not the dominant controlling factor, but many of the environmental factors that do exert an influence are largely depth related. The use of productivity and diversity as palaeobathymetry proxies has however had mixed success, with the Wanganui Basin in particular showing no distinct patterns in Pliocene strata (Kamp et al., 1998).

The foundation for a benthic foraminifera-derived water depth proxy is made possible because many species present in Quaternary and Neogene records still exist on the modern continental shelf and slope (Vella, 1957; Lewis, 1979; Hornibrook et al., 1989; Haywick and Henderson, 1991; Abbott, 1997; Naish and Kamp, 1997a; Hayward et al., 
1999). Using uniformitarian principles, foraminifera can be used to reconstruct palaeobathymetry by comparing the depth-distribution of modern assemblages in the modern environment to those preserved in the geological record (Vella, 1962; Hayward et al., 1999).

New Zealand's broad latitudinal extent gives rise to a very diverse range of marine settings, in response to changes in climate and ocean with latitude (Hayward et al., 1999). In addition, the mostly marine continent Zealandia, of which New Zealand is part, are isolated from other continental areas, and have been for many millions of years. These factors result in a very unique environmental setting for past and present foraminifera, and so exclusive studies specific to New Zealand are required. Vella (1962), Kennett (1962) and Scott (1970) pioneered studies to obtain palaeo-water depths using uniformitarian principles for New Zealand Miocene and Pliocene foraminifera (Hornibrook et al., 1989). These studies were based on the dominant benthic species in an assemblage, and the percentage of planktic foraminifera (Hayward et al., 1999). While robust, these methods were time consuming and more rapid approaches were developed that combined multivariate statistics (Scott, 1970) with dominant benthic and planktic foraminifera, and also depth-data for rarer species (Hayward, 1986; Hayward et al., 1999).

A refined version of this method was completed by Hayward et al. (1999), in which 18 modern shallow-environment New Zealand marine (normal salinity) benthic foraminifera associations were defined for an array of environmental factors, including temperature, wave and current energy and bottom water oxygen concentration. The associations were compiled from cluster analysis of census and environmental data, and can be directly compared to data from fossil assemblages. An equivalent study for deeper benthic foraminifera ( $>100$ metres depth) is also detailed by Hayward (1986). This study applied this method to match benthic foraminifera census data from the Mangaweka Mudstone at Tiriraukawa to the shallow marine species associations defined in Hayward (1986) and Hayward et al. (1999).

There are a number of advantages to using benthic foraminifera as an indicator for water depth in the Mangaweka Mudstone at Tiriraukawa: (i) many foraminifera species present in the Late Pliocene strata of the Wanganui Basin are extant today (Naish and 
Kamp, 1997a), (ii) previous studies have identified abundant and well-preserved foraminifera in the Mangaweka Mudstone (Journeaux et al., 1996; Kamp et al., 1998); (iii) the depositional environment for the Mangaweka Mudstone is likely to be midouter-shelf (< 100 m water depth), and foraminifera are more sensitive to water depth change in shallow marine environments (Hayward et al., 1999); and (iv) foraminiferal content is an independent measure of water depth with respect to grainsize analysis, and substrate has been proven to not be a major control on the distribution of New Zealand foraminifera (Hayward et al., 1999).

\section{Limitations}

While fossil foraminiferal data are often a cornerstone in palaeoenvironmental assessments, they are not without challenges (Clifton, 1988). These challenges stem from gaps in the understanding of modern foraminifera ecology and distribution, and from the assumptions involved with interpreting fossil assemblages.

While it is accepted that food supply and oxygenation of habitats have a large influence on the depth-distribution of benthic foraminifera (Van der Zwaan et al., 1999), many other factors complicate this broad picture of ecology (Murray, 1991). In New Zealand, environmental settings can change vastly in space and time, and the concept that oxygen and food flux are dominant controls may be largely simplistic for complex local systems (Murray, 2001). This results in inconsistencies in depth distribution patterns, and reduced accuracy of palaeobathymetric reconstruction from this uniformitarian approach (Hayward et al., 1999). Contrastingly, many species are not very sensitive to varying environmental conditions and inhabit large depth ranges, and consequently large margins of error exist for water depth reconstructions (Van der Zwaan et al., 1999). This can be amended by the use of species with very narrow depth ranges, but only if they are present in an assemblage.

Using modern foraminifera for interpreting geological problems means that any bias present in studies of modern species are propagated into palaeoenvironment assessments. Bias as a result of sampling only in specific areas, environments or seasons can affect apparent species distributions (Van der Zwaan et al., 1999). Samples of modern foraminifera including both living and a proportion of 'relic' or reworked dead 
specimens may also produce uncertainties in assemblage characteristics (Murray, 2001).

Comparing modern and fossil assemblages requires some assumption as to whether a system is in equilibrium or not - are the features preserved a product of the average conditions or a result of an instantaneous event? Benthic foraminifera assemblages can change as a result of bottom currents and sediment transport mechanisms such as turbidity flows, which winnow out smaller and lighter tests (Jorissen, 2003). Sediment mixing due to bioturbation can also be a problem, depending on sedimentation rates and species present, as this may disturb the nature of assemblage changes preserved, e.g. what was once an abrupt shift appears gradual as a result (Ravelo and HillaireMarcel, 2007). Events like storms may also influence foraminifera distribution, where shallow assemblages are emplaced at deeper environments or vice versa (although the latter is less common) (Hayward et al., 1999). Diagenetic alterations to tests with vulnerable chemical compositions may also influence preserved assemblages (Murray and Alve, 1999; Ravelo and Hillaire-Marcel, 2007).

The method discussed also holds the assumption that modern foraminifera taxa have not changed their ecological necessities over time. This is often difficult to observe, but it is not considered a major concern for Quaternary and Neogene species (Hornibrook et al., 1989; Murray, 1991; Hayward et al., 1999). This is in contrast to the Paleogene, where some species have altered their habitable depth ranges (Hayward et al., 1999).

\section{Laboratory techniques}

The preparation of samples for foraminiferal census was based on the methodology of Naish and Kamp (1997b) and was conducted at the GNS Science Micropalaeontology Lab. Bulk sediment samples of 1-2 kg were collected. Foraminifera samples were prepared for every 2-3 grainsize samples, meaning a total of 63 samples out of the total 89 collected. The use of only two-thirds of the samples collected was decided upon as 63 samples provided sufficient resolution to identify orbital-scale variations within the developed stratigraphic framework, as well as adequately representing the range of facies and depositional environments in the Mangaweka Mudstone. Samples were dried in an oven at $40^{\circ} \mathrm{C}$ (keeping to low temperatures to preserve the isotopic chemistry of foraminifera tests) and disaggregated with a manual rock-crusher. Subsamples of $200 \mathrm{~g}$ 
were weighed and wet sieved through a $63 \mu \mathrm{m}$ mesh. The $>63 \mu \mathrm{m}$ fraction was dried, weighed and then successively split with a sediment splitter until a fraction containing $\sim 200$ specimens remained. The resulting fraction was sieved through a $150 \mu \mathrm{m}$ mesh and all foraminifera collected on the sieve $(>150 \mu \mathrm{m})$ were picked.

\section{Age model}

The Mangaweka Mudstone has been dated in previous studies by an integration of magnetic reversal stratigraphy, radiometric ages on rhyolitic tephras and foraminiferal and molluscan biostratigraphy, and was likely deposited between 3.0 and 2.5 Ma (Beu and Edwards, 1984; Hornibrook et al., 1989; Wilson, 1993; Journeaux et al., 1996; Naish et al., 1996; Hayton, 1998; Kamp et al., 1998; McIntyre, 2002). However, because the section at Tiriraukawa is newly studied in this project, a local age model utilising tephrochronological, magnetostratigraphic and cyclostratigraphic constraints is developed here to allow more precise comparison to other regional and global records, especially the benthic oxygen isotope stack (LR04). This age model is constructed using techniques that have been successfully applied in the Wanganui Basin previously (Seward, 1976; Seward et al., 1986; Kohn et al., 1992; Alloway et al., 1993; Naish et al., 1996; Alloway et al., 2005; Turner et al., 2005).

Magnetostratigraphy

Magnetostratigraphy is a widely applied geochronologic tool that is particularly useful in solving palaeoclimatic, sedimentological, and palaeontological problems (Butler, 1992). Its foundation as a means of dating sedimentary sequences and marine sediment cores lies in the fact that the Earth's magnetic field reverses polarity at well-known, globally- and astronomically-calibrated positions in time (Cande and Kent, 1995; Turner et al., 2005; Tauxe, 2010). In conjunction with independent means of dating (e.g. biostratigraphy or radiometric dating), magnetostratigraphy can be a powerful and robust means of dating. The basis for magnetostratigraphy involves correlating patterns of magnetic reversals recorded in a stratigraphic section with that of the Geomagnetic Polarity Timescale (GPTS). 
Sedimentary rocks can retain a record of magnetisation for long periods of geologic time (Verosub, 1977). However, sedimentary rocks are often formed as a result of many complex geological processes over time, and the interpretation of their magnetic signals is often challenging (Butler, 1992). The natural magnetisation resulting from sedimentary processes (depositional and post-depositional) is termed "detrital remanent magnetisation". This magnetisation is primarily recorded in sediments during deposition and lithification. Magnetic grains in sediments are physically oriented parallel to the magnetising field as they fall through a depositional medium, where they can rotate freely (in most cases, a water column) (figure 3.9) (Verosub, 1977; Tauxe, 2010). At the sediment/water interface, this alignment is often altered at impact. However as sediments are still water-rich upon deposition, magnetic grains can often move freely and are able to rotate to re-align with the magnetic field. Bioturbation also keeps accumulating sediments unconsolidated and water-laden. These postdepositional processes usually occur in the upper 10-20 cm of sediment (Verosub, 1977). Dewatering and consolidation during lithification blocks the motion of the particles and the detrital remanent magnetisation is locked in.

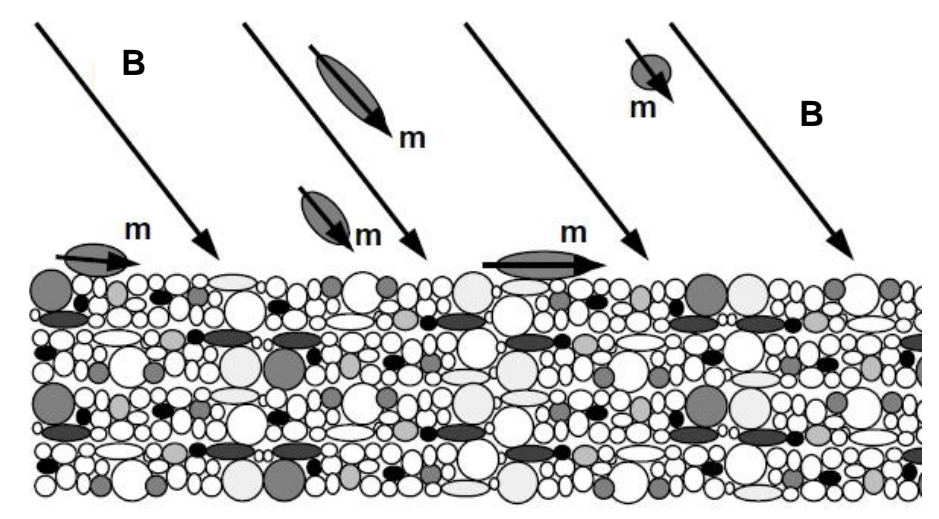

Figure 3.9: Illustration of the process of magnetic grain alignment during deposition. $B$ is the magnetising field at the time of deposition, and $m$ is the magnetic moment of magnetic grains. Upon impact with sediment interface, elongated grains magnetised along their long axis can deviate from the true magnetic field inclination (they are more horizontal). For larger grains, mechanics of falling onto the sediment interface usually dominates over magnetic alignment in the water column. Figure is from Butler (1992).

For a reliable detrital remanent magnetisation to be recorded, these syn- and postdepositional processes are dependent on a number of factors. Firstly, grain size greatly 
influences how easily a magnetic grain is aligned within the water column and sediment. Larger magnetic grains, usually medium sand-size and greater, have more complex internal magnetic properties than smaller grains, which tend to have simpler properties (multi-domain and single domain grains, respectively) (Butler, 1992). Smaller grains (silts and clays) therefore tend to align to the magnetising field in simpler, more predictable ways than their larger counterparts. Larger grains are also heavier and thus more susceptible to gravity and friction forces in the surrounding fluid and sediment, and are more likely to deviate from magnetic field alignment.

Secondly, grain shape also influences how mechanical forces affect a particle as it falls through the water column and impacts the sediment/water interface (Griffiths et al., 1960; Verosub, 1977). For example, an elongate grain will more likely fall onto its long axis (and orient itself horizontally) instead of entering the bulk sediment parallel to the magnetic field (Butler, 1992) (figure 3.9). This phenomenon has been observed in natural and synthetic conditions, where the inclination (angle below horizontal) of the magnetisation of sediments is shallower than that of the magnetising field (Griffiths et al., 1960; Verosub, 1977).

Thirdly, the rate of sediment deposition influences the potential for magnetic grains to record the magnetic field signature. The basis for this is that sedimentation rate determines how long magnetic minerals have been in a water-rich, free-moving environment (Butler, 1992). If sedimentation rate is very high, there is less time for magnetic grains to be re-aligned in a water-rich slurry, and recorded detrital magnetisation will deviate from the true magnetic signal. This is where bioturbation can be an important control on how much post depositional magnetic alignment occurs. However, if the sedimentation rate is very low, then too much sediment mixing may occur and boundaries between reversals of only short duration may be blurred or nonexistent (Butler, 1992). Very low sedimentation rates may also cause significant time lags between a reversal and its recording. Fortunately this is a rare occurrence as geomagnetic polarity reversals take $\sim 5000$ years, and there are not many environments where sedimentation is at the same scale (Turner et al., 2005).

It is therefore apparent that the sediments most likely to carry a reliable detrital remanent magnetism that is a reflection of the magnetising field at the time of 
deposition are: (i) fine-grained sediments (fine sands, silts and clays) with minimal contribution from coarse-sand fractions, (ii) lightly bioturbated, and (iii) those deposited under relatively high sedimentation rates (Butler, 1992). Reliable sediments for palaeomagnetic studies will also ideally have low influence from post-depositional processes like thermal, chemical and structural alteration, processes that may act to change the orientation, composition and magnetisation directions of magnetic grains.

\section{Limitations}

The binary nature of polarity reversals over time means there is always a chance of misidentification of reversal patterns in stratigraphic section, in relation to the GPTS (Turner et al., 2005). In addition, a sedimentary rock can often record many different types of magnetisation, acquired at different points during its geological evolution.

Diagenetic alteration occurs regularly in sedimentary rocks, and commonly results from water infiltration (Elmore et al., 2012). This physically and chemically changes the rock after during and after deposition and lithification. Changes that are important for studies of palaeomagnetism are those that alter the magnetic minerals, but also the sediments surrounding them (Butler, 1992). If the size, shape, internal crystallography, surrounding matrix or composition of a magnetic grain is altered, then the grain will likely take on a new magnetisation. This magnetisation is called "secondary magnetisation" or "chemical remanent magnetisation", and often acts to obscure or totally replace the original or primary magnetisation that was recorded at deposition (Butler, 1992; Tauxe, 2010; Elmore et al., 2012). Such an effect may not be restricted to a single alteration event, as sedimentary rocks can contain many episodes of magnetisation from different processes (Turner et al., 2005). Deciphering the signatures of different phases of magnetisation is challenging, and is rarely the same between different rock types and regions (Turner, 2001). Highly altered sedimentary rocks are therefore problematic for the identification of primary detrital remnant magnetisation and constructing a reliable magnetostratigraphy.

Sedimentary rocks can also obtain secondary magnetisation that can obscure the primary signature without chemical change, called "viscous remnant magnetisation" (Butler, 1992; Tauxe, 2010). This is a gradual effect over time due to exposure to weak magnetic fields, and resides in magnetically-unstable grains (with low blocking 
temperatures and short relaxation times) (Turner et al., 2005). In essence, it is magnetic 'noise' recorded in sediments, and can often be distinguished because it is a very similar direction signal to the present magnetising field (Butler, 1992; Tauxe, 2010).

\section{Palaeomagnetic studies in the Wanganui Basin}

Much of the chronology of the sequences and features preserved in the Wanganui Basin are dependent on magnetostratigraphy (Wilson, 1993; Roberts et al., 1994; Turner et al., 2005). In this section, the development of a theoretical and methodological approach to interpreting the magnetisation present in the sediments of the Wanganui Basin is discussed.

Sediments from the Wanganui Basin are very weakly magnetised, prone to diagenetic alteration from water infiltration (sulphidisation), have enigmatic magnetic mineralogy and exhibit multiple components of magnetisation (Roberts and Pillans, 1993; Turner, 2001; Turner et al., 2005). Much work has gone into deciphering how to recognise the detrital remnant magnetisation component, within the overprints of chemical and viscous remnant magnetisations ((Turner, 2001; Turner et al., 2005). Previously, the detrital remnant magnetisation components have been isolated using a step-wise thermal demagnetisation procedure (Wright and Vella, 1988; Kamp and Turner, 1990; Roberts et al., 1994; Turner et al., 2005).

Thermal demagnetisation relies on the idea that the multiple components of magnetisation present in (the magnetic minerals of) the sediments become thermally unstable at different temperatures (Butler, 1992). Progressive heating and cooling at closely-spaced temperature intervals within a zero magnetic field erases the components of magnetisation that become unstable below certain blocking temperatures, leaving behind the components that are still stable (Butler, 1992). In some cases, the different components of magnetisation may have easily distinguishable blocking temperature ranges. However, in most cases the different magnetisation components have overlapping blocking temperature ranges, and thus their respective recorded magnetic directions are difficult to isolate (Dunlop, 1979).

Turner (2001) defined a model to aid in interpreting thermal demagnetisation data from the Wanganui Basin. Up to three components of magnetisation are identified to be present in these sediments: (i) a viscous remnant magnetisation component that 
resembles the present-day magnetic field direction, which is thermally stable up to $\sim 150^{\circ} \mathrm{C}$, (ii) the original detrital remanent magnetisation, stable above $150-250^{\circ} \mathrm{C}$, but often overprinted by a (iii) a chemical remnant magnetisation resulting from diagenetic alteration, in small grains with a blocking temperature above $250^{\circ} \mathrm{C}$ (Turner, 2001). Above $\sim 350^{\circ} \mathrm{C}$, thermal alteration of clay minerals produces new magnetic minerals that obscure other magnetisations. The chemical remnant magnetisation component is identified on the basis that the magnetic data show a distinct array of magnetic minerals, which likely result from secondary diagenetic processes (Turner, 2001). Application of this model has generated a high-resolution and robust magnetostratigraphy for Pliocene sedimentary rocks exposed in the Wanganui Basin (Turner et al., 2005).

The development of a magnetostratigraphy for the Mangaweka Mudstone at Tiriraukawa is appropriate for a number of reasons. Firstly, the Mangaweka Mudstone is known to be dominantly siltstone (fine-grained) and bioturbated, increasing the likelihood of reliable recording of the magnetic field direction during and shortly after deposition (Journeaux et al., 1996; Kamp et al., 1998). Secondly, the sedimentation rate is estimated to be high, likely exceeding $\sim 1.5 \mathrm{~m} / \mathrm{k}$. y. (Journeaux et al., 1996; Turner et al., 2005). Thirdly, magnetic data from the Mangaweka Mudstone at Tiriraukawa can be (confidently) interpreted within the model supplied by Turner (2001), and correlated within a well-established (across-basin) magnetostratigraphic framework (Turner et al., 2005).

\section{Field and laboratory techniques}

Sixty-eight core-samples were collected from sixteen different stratigraphic positions in the Mangaweka Mudstone at Tiriraukawa (see Chapter 4) (3-5 samples per site). The stratigraphic location of each sample site was decided based on previous magnetostratigraphy reporting polarity reversals at the base and top of the Mangaweka Mudstone (interpreted to be the Kaena/Gauss Chron and Gauss/Matuyama Chron boundaries, respectively) (Journeaux et al., 1996; Kamp et al., 1998; McIntyre, 2002; Turner et al., 2005).

Cylindrical cores $25 \mathrm{~mm}$ in diameter were oriented and collected using a rock drill (figures 3.10 and 3.11). A standard compass and clinometer were used to collect 
orientation measurements, as any local magnetic effects are negligible due to the weak magnetisation of the mudstone sediments. Orientation lines were marked on samples, which were then stored in a magnetic shield until ready for laboratory analysis. Samples were subsequently cut into $22 \mathrm{~mm}$-length specimens, and carefully labelled with original orientation markings and which end of the sample (inner or outer) they were from.
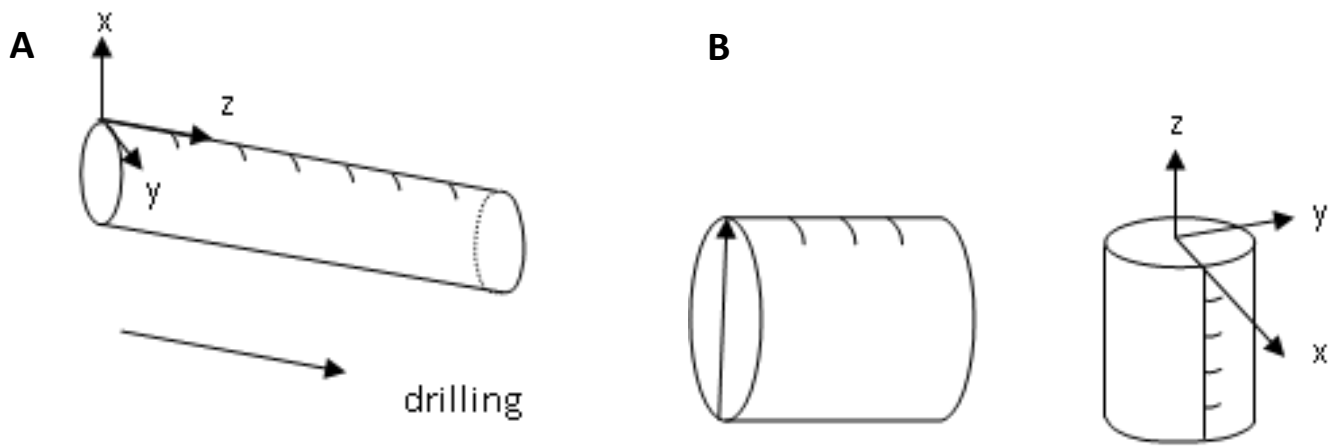

Figure 3.10: Victoria University of Wellington orientation methodology. Measurements collected are: $y$, the azimuth east from north in degrees and $z$, the plunge of $z$ from the horizontal in degrees. The $x$ measurement is drawn on the face of the cylinder to identify the top of the sample, and tick marks are drawn along the $\mathrm{z}$ line to indicate drilling direction. Figure $A$ is a full sample core, and $B$ is a subsequent specimen (image courtesy of Gillian Turner).

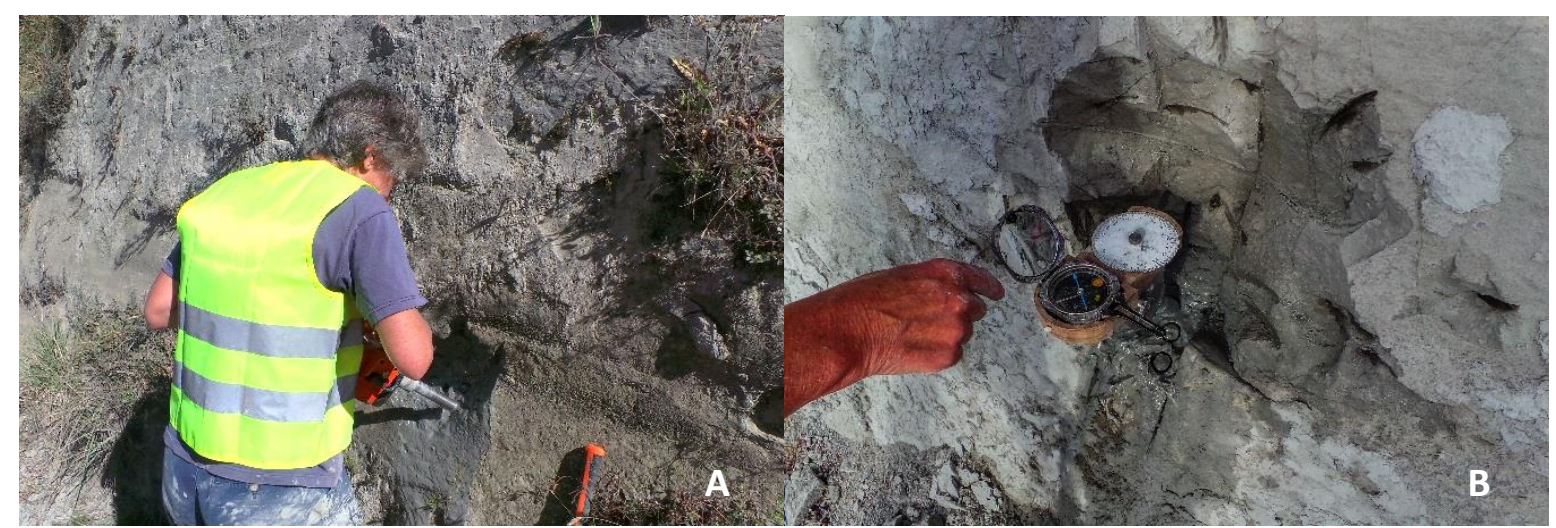

Figure 3.11: Collecting and orienting palaeomagnetic samples in the field. Figure A shows the use of a rock drill to cut sample cores. Figure B shows the measuring of the azimuth (y) of an in situ core with a compass.

The laboratory analysis was undertaken at the Otago Palaeomagnetic Research Facility (Otago University), where specimens underwent stepwise thermal demagnetisation. At each step, specimens were aligned, measured for magnetic susceptibility and then for remanent magnetisation directions $(\mathrm{x}, \mathrm{y}, \mathrm{z}$ as in figure 3.10$)$ using a cryogenic 
magnetometer (figure 3.12). Specimens were first measured with no thermal treatment, then heated and cooled in a rock oven at $\sim 50^{\circ} \mathrm{C}$ increments in zero magnetic field, up to $250-300^{\circ} \mathrm{C}$ (see Appendix D). Specimens were heated slowly in the rock oven and left at each temperature for $\sim 10$ minutes to ensure equal distribution of heat between the surface and interior of the mudstone. After analysis, specimens were stored in magnetic shields.

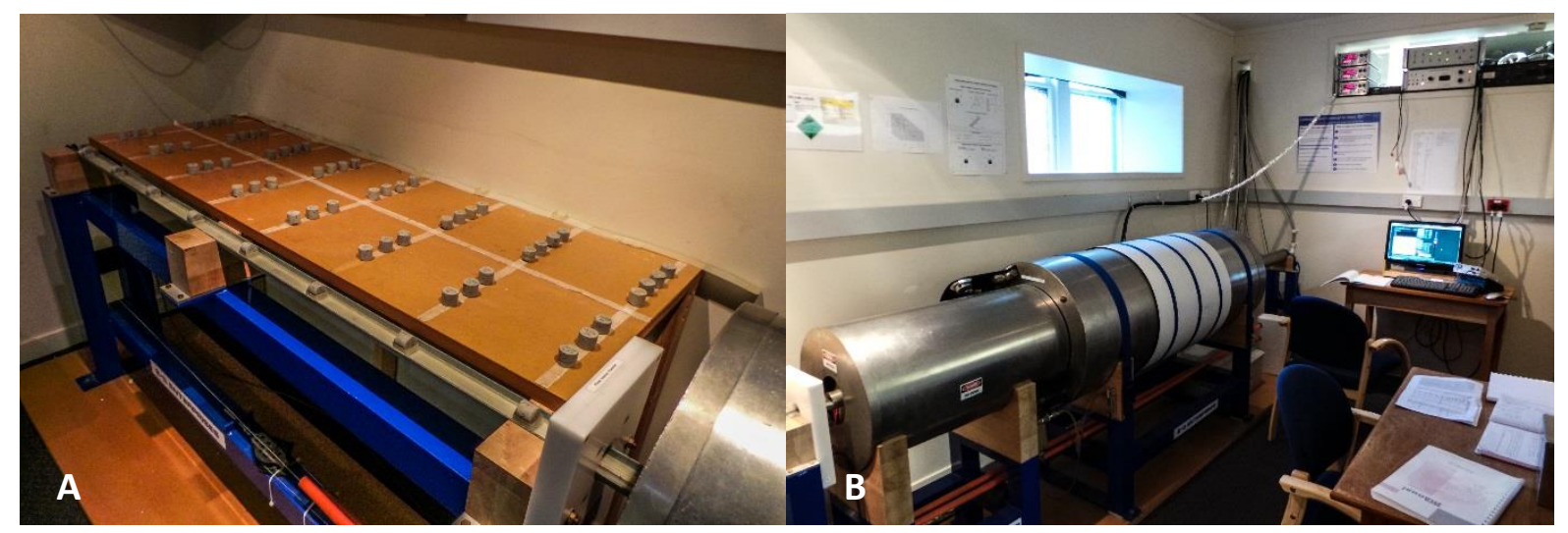

Figure 3.12: Laboratory analysis at Otago University. Figure A shows specimens aligned and ready to be analysed by the cryogenic magnetometer. Figure $B$ shows the magnetically-sensitive cryogenic magnetometer, which is required to measure the weakly magnetised mudstone.

\section{Tephrochronology}

Tephrochronology enables the dating and correlation of stratigraphic features and palaeoenvironmental event. It has been widely applied in New Zealand and in particular the Wanganui Basin (Seward, 1976; Lowe, 1990; Alloway et al., 2005; Lowe, 2011). Tephra deposits are useful for stratigraphic studies because they represent "isochronous" horizons within a sequence: i.e. they represent rapidly emplaced volcanic ashes resulting from an eruption event (Knox, 1993; Lowe, 2011), which in many cases can be traced across local and regional strata (Alloway et al., 2005).

The presence of two rhyolitic tephras (the Eagle Hill and the Kowhai tephras) within the Mangaweka Mudstone at Tiriraukawa and in the same formation in the Rangitikei River section provide a unique opportunity independent from magnetostratigraphy to create an age model and means of correlation between basin-wide, regional and global records. To do this, this project has employed: (i) Fission-track dating of zircons from 
the Eagle Hill tephra, which is known to crop out in the Mangaweka Mudstone in the Rangitikei River valley (Naish et al., 1996), and (ii) major and trace elemental analysis of volcanic glass in both tephra in the Mangaweka Mudstone at Tiriraukawa and the Rangitikei River sections, in order to geochemically fingerprint and confirm correlations of the tephras between these localities (figure 3.13). Fission-track analysis was undertaken with Diane Seward, and geochemical analyses were conducted with Brent Alloway. Work completed solely by either is stated within the text.

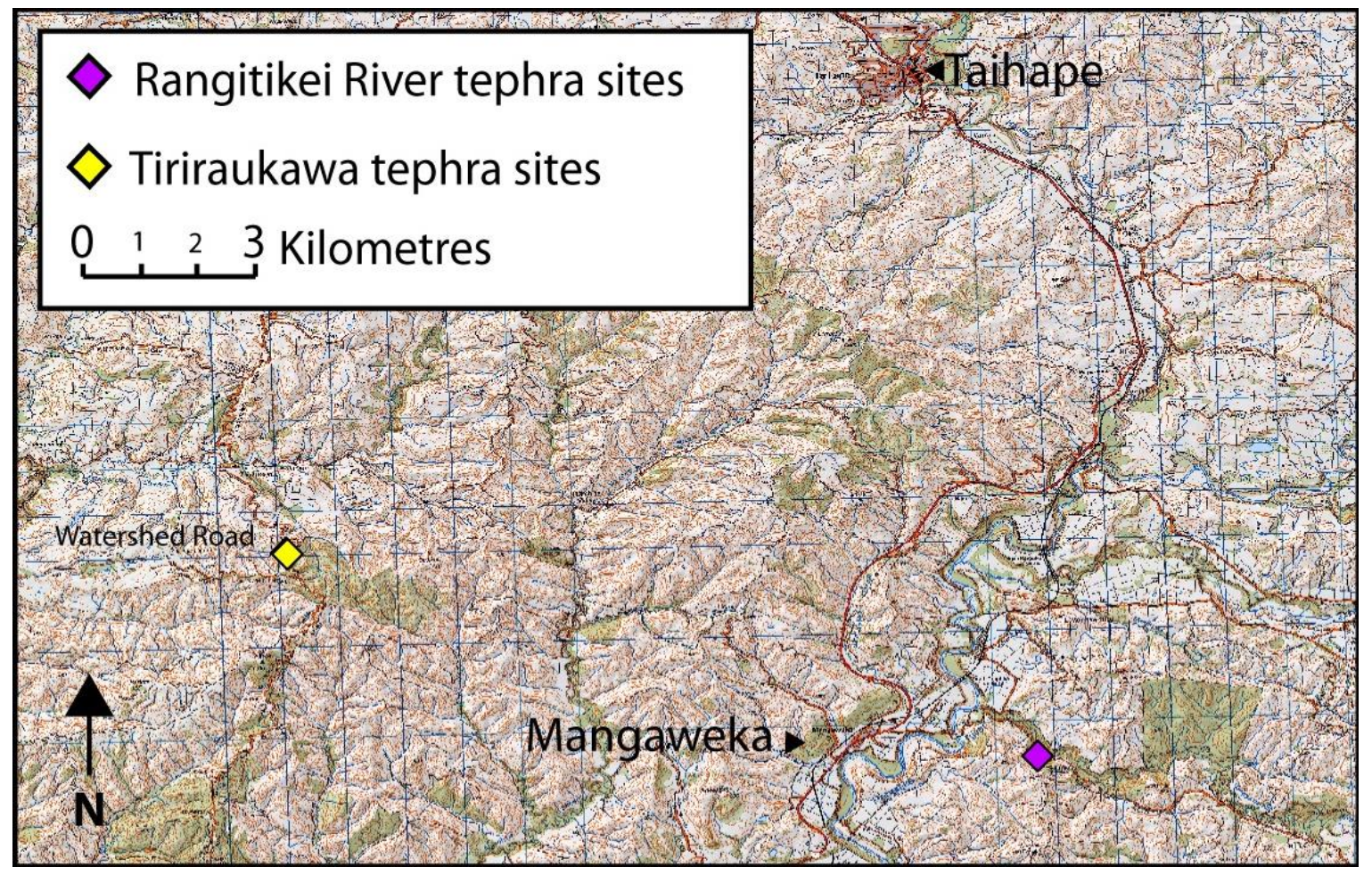

Figure 3.13: Tiriraukawa tephra sites along Watershed Road relative to the tephra sites in the Rangitikei River valley along Ruahine Road (see also figure 3.18).

\section{Zircon fission-track dating}

Fission track dating has been a cornerstone of tephrochronology and stratigraphic studies for over 50 years (Seward, 1976; Naeser et al., 1989; Knox, 1993; Seward and Kohn, 1997). Zircons are stable, durable and common accessory minerals in rhyolitic tephras (MacDougall, 1976; Tagami, 2005), and because they incorporate uranium into their crystal lattice, fission track analysis can be applied to obtain a radiometric age.

While there are various other methods to obtain absolute ages from tephra (e.g. volcanic glass isothermal plateau fission track analysis, K/Ar dating, ${ }^{40} \mathrm{Ar} /{ }^{39} \mathrm{Ar}$ dating, 
luminescence dating, ${ }^{14} \mathrm{C}$ dating), some of these are only useful and more robust for younger, unaltered tephra minerals (Westgate, 1989; Seward and Kohn, 1997; Lowe, 2011). In particular, hydrated volcanic glass present in a lot of rhyolitic tephras is prone to alteration, and erroneous ages have been assigned for tephra in the past (Seward, 1976; Boellstorff and Te Punga, 1977). Additionally, zircons contain vastly more uranium than volcanic glass, and are therefore preferred for fission track analysis (although volcanic glass is also used) (Westgate, 1989; Alloway et al., 1993). Fission track dating of igneous zircons has been applied successfully to Pleistocene and Pliocene tephras preserved in the Wanganui Basin, where these other methods are lessreliable or not applicable (Seward, 1976; Kohn et al., 1992; Seward and Kohn, 1997).

Fission track analysis is based on the natural spontaneous fission of ${ }^{238} \mathrm{U}$, a heavy and unstable radioactive isotope of uranium (Walter, 1989; Tagami, 2005). Critically, this fission happens at a well-known rate through time (MacDougall, 1976; Hurford and Carter, 1991). The ${ }^{238} \mathrm{U}$ atom splits into two nuclei and leaves a trail of damage through the crystal lattice (Tagami, 2005). Simplistically, as time progresses, more spontaneous fission occurs, and more damage trails are formed. The number of spontaneous damage tracks present within a mineral is therefore a measure for mineral age, if the original ${ }^{238} \mathrm{U}$ concentration of the mineral can be determined (MacDougall, 1976). ${ }^{238} \mathrm{U}$ content can be determined by inducing fission of $235 \mathrm{U}$ through irradiation of a sample with neutrons. The number of induced tracks formed is a function of ${ }^{235} \mathrm{U}$ concentration, and because the ratio of ${ }^{235} \mathrm{U} /{ }^{238} \mathrm{U}$ is assumed to be constant over time, ${ }^{238} \mathrm{U}$ content can be calculated.

Zircon has an approximate closure temperature of $240 \pm 40^{\circ} \mathrm{C}$ (Yamada et al., 1995). Above this temperature, spontaneous fission tracks within the crystal lattice can start to "anneal", i.e. the crystal lattice starts to reorder and heal damage trails (Tagami, 2005). Fission track analysis of zircons is suitable for Quaternary and late Neogene tephrochronology because igneous zircons will have passed through the closure temperature immediately after eruption, and are unlikely to have significant thermal overprinting over such a short span of geological time (Tagami, 2005). 


\section{Field and laboratory techniques}

Approximately $3 \mathrm{~kg}$ of sample was collected from the Eagle Hill tephra cropping out in the Mangaweka Mudstone on Ruahine Road in the Rangitikei River valley (figures 3.13 and 3.14). The Eagle Hill tephra is a discrete, $<10 \mathrm{~cm}$-thick layer that is heavily bioturbated, so care was taken to sample tephra with the least amount of detrital material as possible.

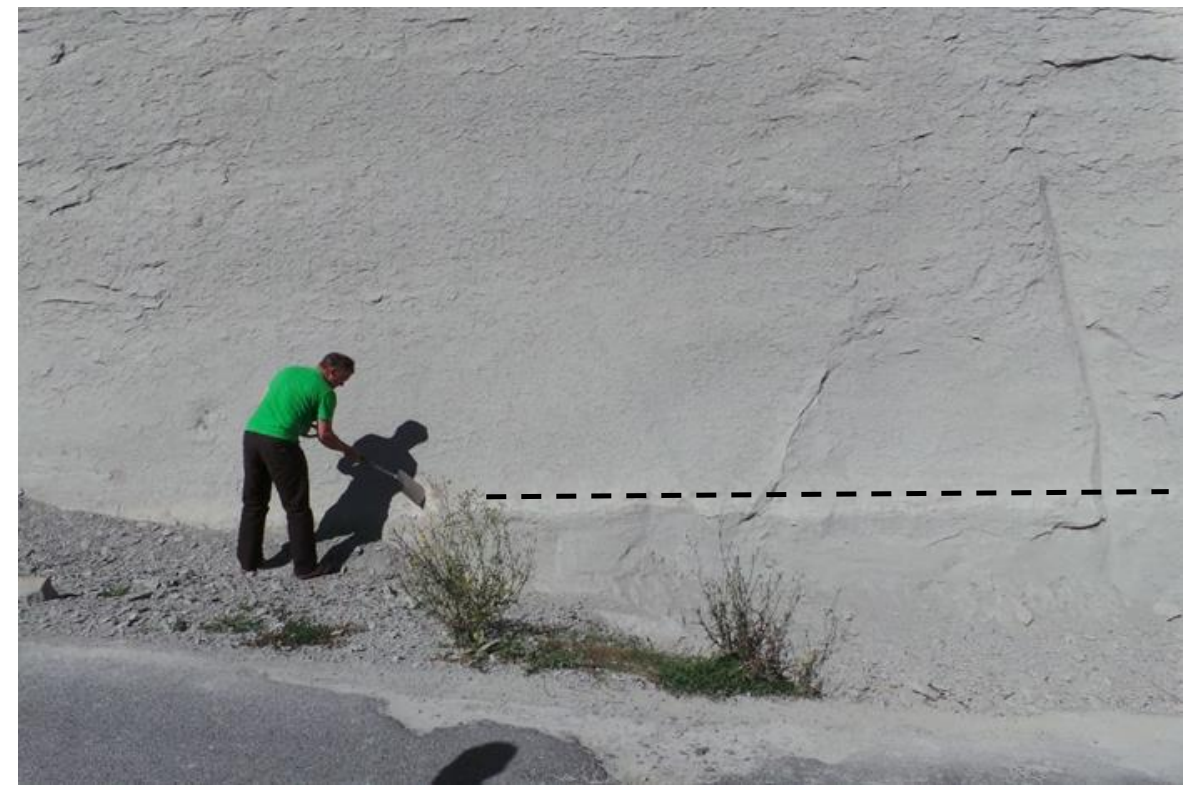

Figure 3.14: The bioturbated Eagle Hill tephra forms a discrete horizon for sampling (shown by black dashed line) within the Mangaweka Mudstone exposure along Ruahine Road in the Rangitikei River valley.

Laboratory preparation was undertaken in the sedimentology lab at Victoria University of Wellington, and follows the external detector methodology (figure 3.15) (Hurford and Carter, 1991). The sample was manually disaggregated in water over 72 hours, and then wet sieved to obtain the 60-250 $\mu \mathrm{m}$ fraction. This size fraction was then separated on a Wilfley Table and the heaviest fractions collected. The heavy fraction was dried and then put through methylene iodide heavy liquid separation (density 3.3), before separation of the magnetic mineral fraction with a Frantz isodynamic separator. The non-magnetic fraction containing zircons was reserved for fission track analysis.

The grains were mounted in Teflon disks, with care being taken to ensure as many grains as possible were oriented along the c-axis. Grain mounts were then polished to an optical finish with sand paper and diamond suspension liquid, and imaged using a 
Trackworks Zeiss M1m microscope (figure 3.16). Grains were etched in a eutectic $\mathrm{NaOH}-\mathrm{KOH}$ melt at $210^{\circ} \mathrm{C}$ for $48-72$ hours until spontaneous damage tracks were revealed.

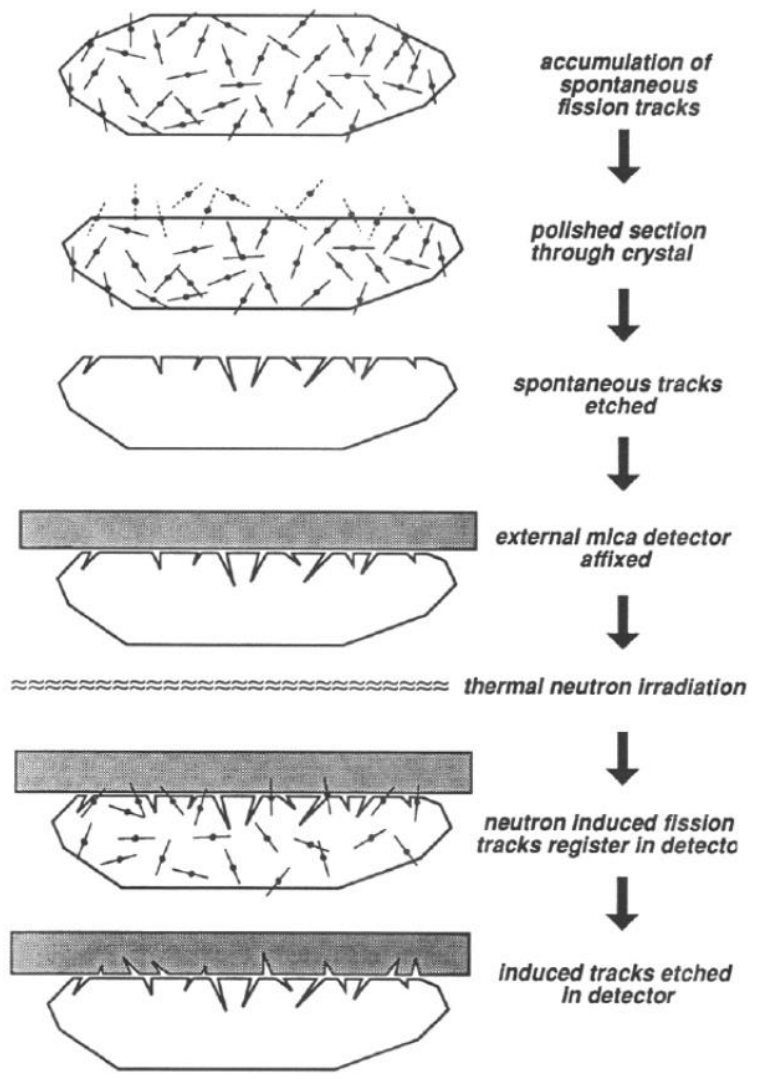

Figure 3.15: The external detector method for zircon fission track analysis from Hurford and Carter (1991). The method is used because uranium concentrations can vary significantly between and within zircon grains. A muscovite 'external detector' is attached to the etched surface of the zircon mount and will record the induced fission tracks (and therefore ${ }^{235} \mathrm{U}$ content) upon neutron irradiation. The ratio between the induced tracks on the muscovite and the original spontaneous tracks within the zircon is used to calculate mineral age.

Muscovite was attached as an external detector to the three etched samples and standard glasses (CN1) and put through thermal neutron irradiation at Oregon State University Reactor, United States of America. The muscovite was then etched in $40 \% \mathrm{HF}$ for 45 minutes at ambient temperature to revel induced damage tracks. Track counts and length measurements were made using a Zeiss M1m microscope with a magnification of x1000. Tracks were only counted on minerals with exposed surfaces 
parallel to their c-axis. The Hurford and Green (1983) zeta calibration was used for age determination.
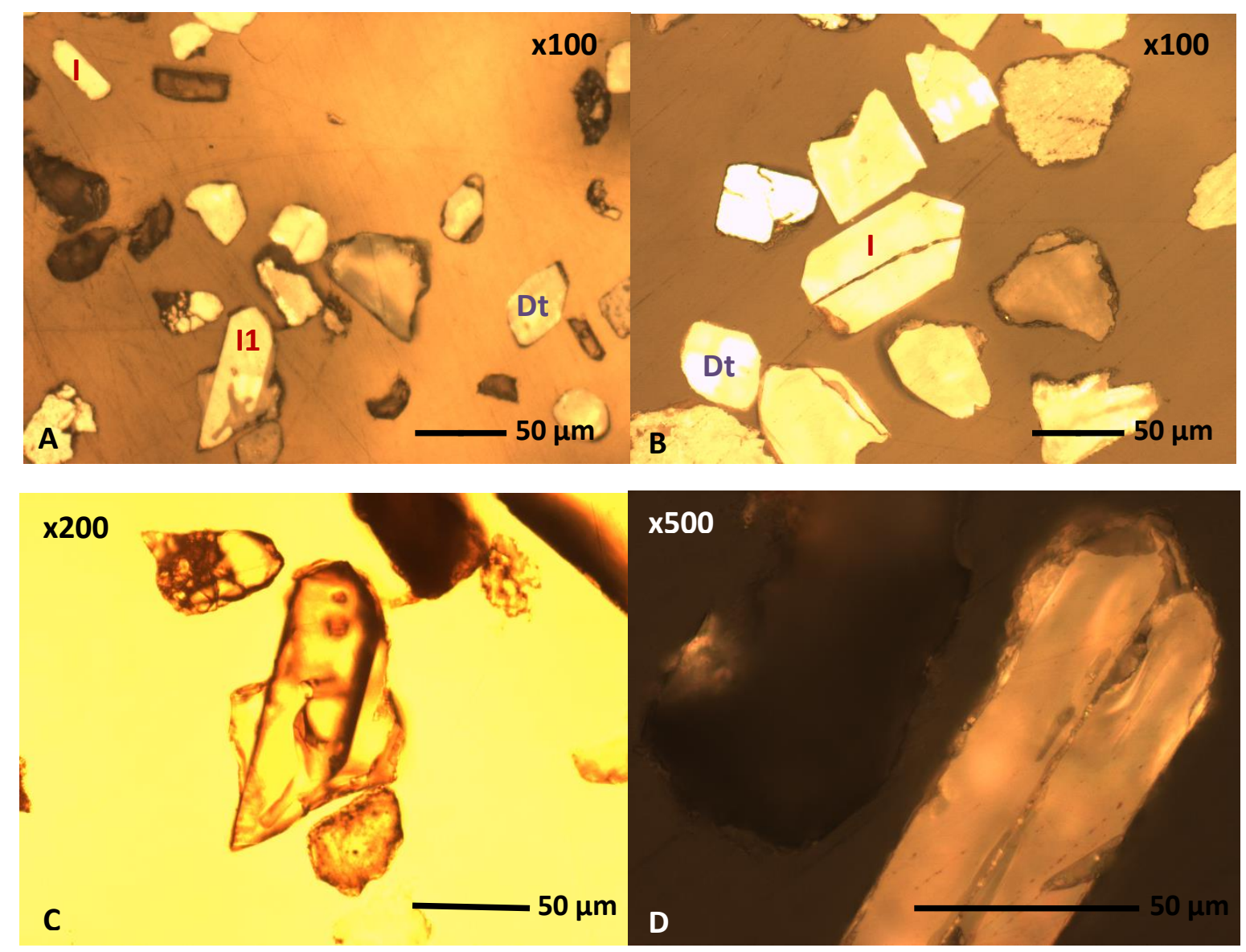

Figure 3.16: Microscope images of zircon mounts prior to chemical etching. Figure $A$ and B show detrital (Dt) and igneous zircons (I) at x100 magnification in reflected light. Figure $C$ shows igneous zircon grain $I 1$ shown in figure $A$ at higher magnification in transmitted light. It is identified as an igneous zircon because of its distinctive euhedral shape, and because there is also glass fringing the rim of the mineral. Detrital zircons are characteristically more rounded and without any glass, such as those in figure $A$ and $B$. Figure $D$ is an igneous zircon grain at x500 magnification in reflected light. It also has a distinctive euhedral shape and glass fringing the outside of the mineral. It is important to identify different mineral populations at an early stage on a physical basis, in order to recognise any individual zircon ages that may be outliers (and thus not volcanic zircon).

Major and trace element analysis: geochemical fingerprinting of volcanic glass

Geochemical fingerprinting of tephra is a valuable stratigraphic tool that allows robust correlations to be made between sites where the same tephra deposit is found. If an age is also determined for a tephra deposit, then the age can be confidently transferred 
between localities that have been matched on physical and geochemical characteristics (Lowe, 2011). This is a valid technique because volcanic ashes destined to be tephra deposits are emplaced almost instantaneously with respect to geological time (Lowe, 2011). Importantly, geochemical characterisation and tephra ages provide a stratigraphic dating and correlating method independent of biostratigraphy, sedimentation-age modelling and magnetostratigraphy (Alloway et al., 1993).

Geochemical fingerprinting involves the chemical characterisation of glass shards and individual crystals that make up tephra deposits (Shane, 2000). Glass shards can be measured for major, trace and rare earth elements, and a combination of these analyses strengthens the ability to distinguish the geochemistry of (i) an eruption centre, (ii) individual tephras and (iii) geochemical heterogeneities within single tephras, even when differences are subtle (Pearce et al., 2007; Lowe, 2011). Eruption and magma chamber fractionation processes together with the composition of magma sources, dictate the major and trace element chemistry of the tephra preserved in the geological record (Froggatt, 1992). The chemistry resulting from individual events and volcanic centres is commonly unique, providing a distinctive elemental signature that can be characterised (Froggatt and Lowe, 1990). In conjunction with other evidence such as stratigraphic position, glass shard and crystal morphology, and mineral assemblages, single tephras can be distinguished and thus are able to be correlated between local and regional localities (Shane, 2000; Lowe, 2011).

Volcanic glass is an amorphous solid, consisting mostly of a spacious $\mathrm{SiO}_{4}$ framework in which major elements (e.g. Fe, Ca, Na, and K) can be incorporated (Froggatt, 1992; Lowe, 2011). Electron probe microanalysis of individual glass shards is the most widely applied approach to obtaining major element compositions, where standard practice measures up to nine different elements (Froggatt, 1992; Shane, 2000; Lowe, 2011). Grain-discrete glass shard analysis is preferred over bulk tephra samples which may incorporate material not characteristic of the eruptive material, such as detrital grains, microfossils, xenocrysts/liths and mineral inclusions (Shane, 2000). Bulk tephra analyses are also problematic because they a prone to amplify the variability associated with distances from volcanic sources (Pearce et al., 2007). 
Trace elements (e.g. Zr, Sr, Nd, Y) are preferentially incorporated or excluded in the $\mathrm{SiO}_{4}$ glass framework based on a complex suite of magma-chamber processes, related to the (i) composition of the parent melt and (ii) the processes and conditions (e.g. temperatures, water content, fractionation) at the time of crystal formation. LaserAblation Inter-coupled Plasma Mass Spectrometry (ICPMS) has been recently applied to the measurement of trace and rare-earth element concentrations in discrete volcanic glass shards (Pearce et al., 2007; Lowe, 2011). While requiring correction of complex fractionation processes during measurement, Laser-Ablation ICPMS provides accurate determination of $\sim 30$ different trace elements (Lowe, 2011).

Geochemical fingerprinting of tephra originally preserved in terrestrial and marine settings within New Zealand has establishment the creation of an extensive temporal and spatial correlation framework, with direct applications to stratigraphic and palaeoclimatic problems (Kyle and Seward, 1984; Froggatt and Lowe, 1990; Lowe, 1990; Wilson et al., 1995; Shane, 2000; Carter et al., 2003; Carter et al., 2004; Alloway et al., 2005; Lowe, 2011). In particular, rhyolitic eruptions throughout the Quaternary are well characterised due to their far-reaching and voluminous nature (Wilson et al., 1995; Shane, 2000; Lowe et al., 2008), and can be dated with a variety of methods (Pillans et al., 1996). Previous studies on major element composition of Quaternary rhyolitic tephras in Wanganui Basin strata have also produced basin-wide and regional tephrostratigraphic frameworks (Alloway et al., 2005; Naish et al., 1996; Pillans et al., 2005; Seward, 1976). However, tephra thought to be older than Quaternary are less well-known because they pre-date the active phase of the Taupo Volcanic Zone (Wilson et al., 1995; Carter et al., 2003). These tephra, recorded in Pliocene and older sedimentary sequences in the Wanganui Basin, are thought to have been sourced from the Coromandel Volcanic Zone (Carter et al., 2003; Briggs et al., 2005). Terrestrial localities containing these older tephras are also less common than those of Quaternary sequences, and therefore Coromandel Volcanic Zone tephras are not as well-studied, with respect to geochemistry or radiometric dating (Shane, 2000).

There are a number of advantages for employing major and trace element analysis on rhyolitic tephras preserved in the Mangaweka Mudstone at Tiriraukawa and the Rangitikei River valley: (i) the theoretical and technical basis for tephrochronology and its application to stratigraphy are well-established within New Zealand and the 
Wanganui Basin; (ii) two rhyolitic tephras, the Eagle Hill and the Kowhai, have been previously analysed for major element analysis and relatively dated via sedimentary age-modelling, providing a foundation for comparison (figure 3.17) (Journeaux et al., 1996; Naish et al., 1996; Kamp et al., 1998); (iii) Although the tephras in the Mangaweka Mudstone are moderately bioturbated, they are thought to exhibit characteristics of primary ash falls rather than secondary deposition via current action, decreasing the chance of contamination from other closely-timed tephra deposits (Manville and Wilson, 2004); (iv) the Mangaweka Mudstone is soft marine mudstone which erodes quickly in river valleys and is cut back frequently for road construction, this means tephra sampled from outcrop is likely fresh, un-weathered material.

\section{Field and laboratory techniques}

This study employs standard grain-discrete glass analysis for major and trace elements on two tephra (Eagle Hill and Kowhai tephra correlatives) from the Tiriraukawa section, and five from the Rangitikei River section (including the Eagle Hill and the Kowhai Tephras). Two tephras $\sim 8 \mathrm{~m}$ stratigraphically apart were sampled from the Mangaweka Mudstone along Watershed Road at Tiriraukawa (figure 3.13). Five additional tephras, including the Eagle Hill that was sampled for fission track analysis, were collected in 2010 by Brent Alloway from the Mangaweka Mudstone along Ruahine Road in the Rangitikei River valley, and are also analysed in this study (figure 3.18). Approximately 200 g samples were collected from discrete but bioturbated layers, and care was taken to ensure sampling of tephra with minimal amounts of detrital material. 


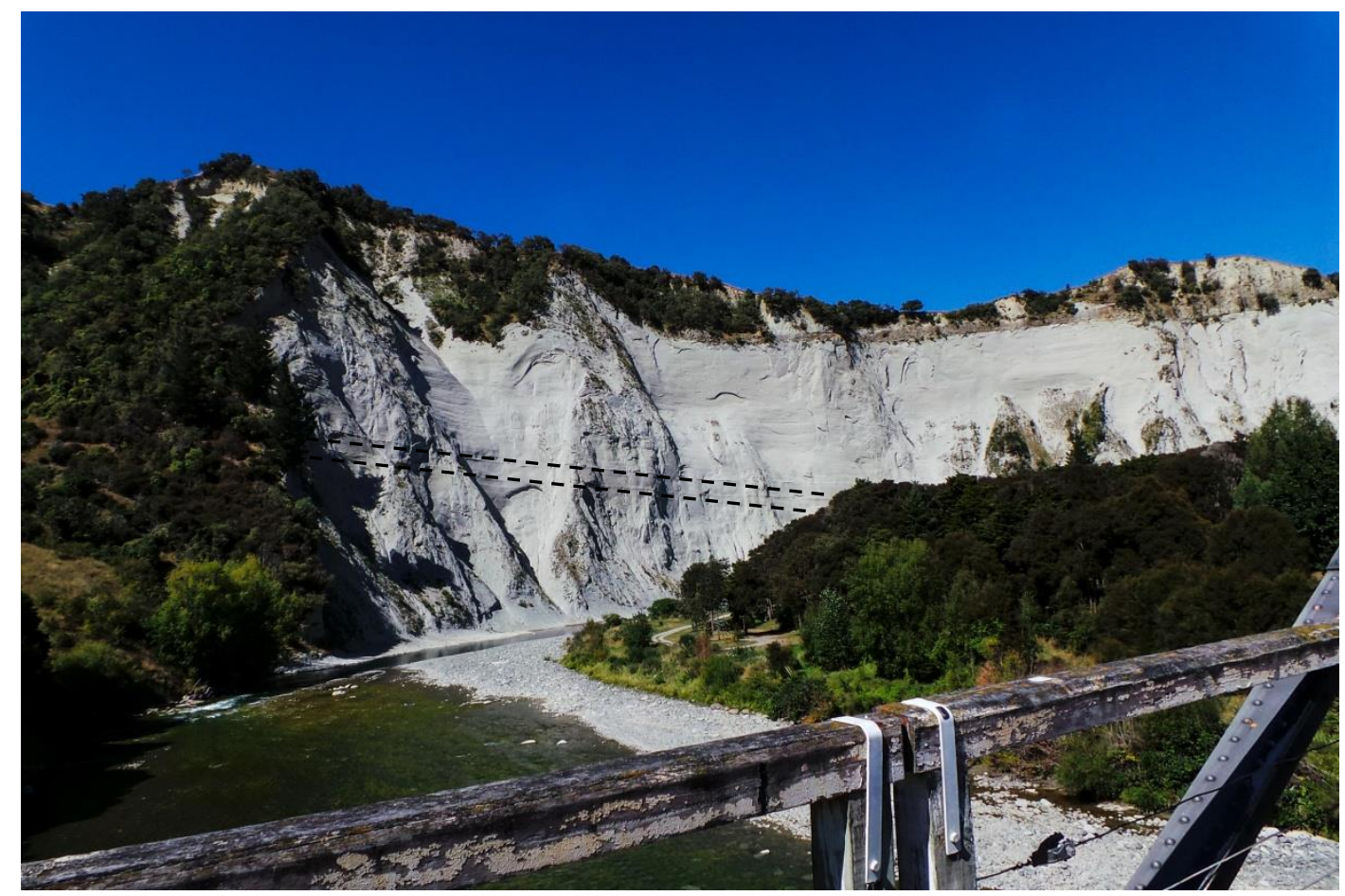

Figure 3.17: This view is the Mangaweka Mudstone cropping out in the Rangitikei River valley, looking approximately east. Two distinct tephra layers can be seen within the section, with at least three other less obvious tephra stratigraphically below. The Eagle Hill tephra and the underlying Kowhai tephra are marked by the two dotted lines.

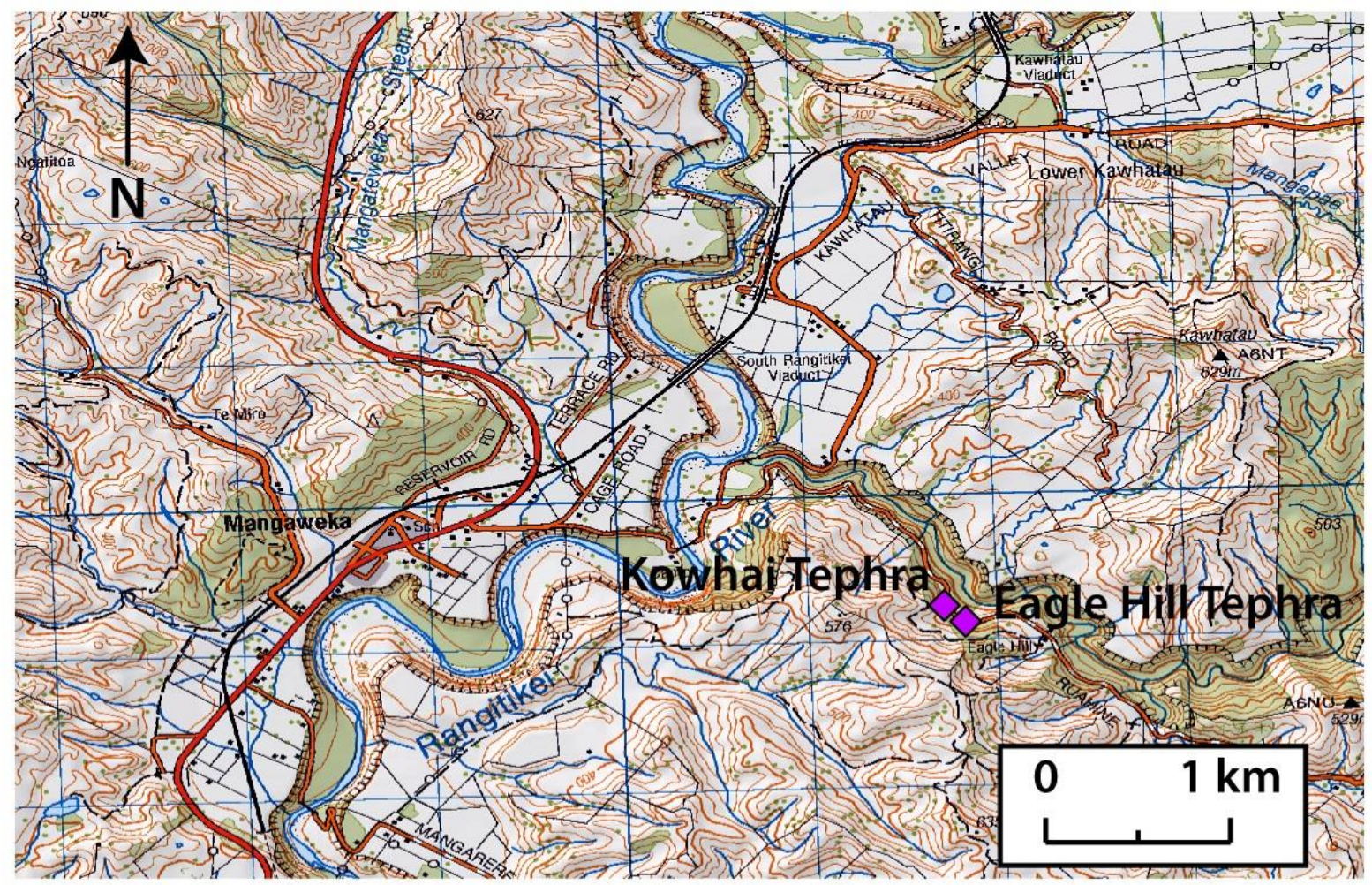

Figure 3.18: GPS locations of two tephra (Eagle Hill and Kowhai) sampled from the Mangaweka Mudstone in the Rangitikei River valley along Ruahine Road. 
Bulk tephra samples were wet sieved into $>125 \mu \mathrm{m}, 125-63 \mu \mathrm{m}$ and 63-32 $\mu \mathrm{m}$ size fractions and dried. The subsequent methods were completed by Brent Alloway. The largest tephra grains ( $>63 \mu \mathrm{m})$ were mounted in an epoxy block, polished to expose grains (by Stewart Bush) and coated with carbon ready for measurement via Electron Probe microanalysis.

Grain-discrete analyses for major elements were made using the Victoria University of Wellington JEOL Superprobe (JXA-8230). The microprobe was operating at $15 \mathrm{kV}$, with a beam current operating at $8 \mathrm{nA}$ and a diameter of $10 \mu \mathrm{m}$, in focussed and scanning mode. Eighteen to twenty glass shards were identified and measured for each tephra sample. Samples were measured interspersed with, and normalised against, the ATHOG glass standard (Jochum et al., 2000).

Grain-discrete analyses for trace elements were made using the Laser Ablation-ICPMS housed at the University of Wales (Aberystwyth, UK), and were measured and data recalculated using the procedure of Pearce et al. (2008).

\section{Limitations}

One of the biggest challenges in tephrochronology is determining whether or not there are "multiple fingerprints" or compositional heterogeneities in a single tephra deposit (Lowe, 2011). During single eruptions, material can be ejected simultaneously from different magma sources and batches (Shane et al., 2008). Factors such as changing wind directions during eruptions can also influence the compositions of single tephra deposits. Compositional heterogeneity can also arise from tephra remobilisation via current actions, as opposed to single emplacement via ash fall from the atmosphere. However, tephras from the Taupo Volcanic Zone and the Coromandel Volcanic Zone have been shown to be relatively homogenous in composition (Shane, 2000).

In contrast, uncertainties in correlation can also be present when numerous tephras from different events have very similar compositions (Pearce et al., 2007). The similarity makes distinguishing individual events on a geochemical basis challenging, and in some instances only possible through stratigraphic positions (Lowe, 2011). Further analysis of trace and rare-earth elements to compliment major elements can also improve the ability to distinguish and correlate tephras. 
Volcanic glass shards are prone to weathering and chemical alteration with exposure (Shane, 2000). Glass can become hydrated over time, or incorporate water present during eruption, a feature seen commonly in rhyolitic tephra from the Taupo Volcanic Zone (Shane, 2000). This results in elemental analysis totals not equalling $100 \%$, where the remainder (usually $5 \%$ ) is attributed to water from either of these two sources. Water is not measured with Electron Probe microanalysis due to loss on ignition via the electron beam, but nonetheless many studies recalculate compositions to $100 \%$ with consistent results, meaning hydrated glasses are likely not compositionally compromised.

Tephra reworking is also a problem for tephrochronology applications. Bioturbation, remobilisation and slumping of sediments in continental shelf and slope settings can disturb and redeposit once discrete tephra layers (Manville and Wilson, 2004; Lowe, 2011). However, if sedimentation rates are high, reworking at the sediment/water interface has a negligible or easily identifiable effect on the preservation of tephra layers (Manville and Wilson, 2004). The process of remobilisation has been shown to occur within the Wanganui Basin (Seward, 1976; Alloway et al., 1993; Shane, 1994), which greatly influences the regional lateral continuity of tephra layers, and therefore correlation potential. Secondary processes such as current action may channelise material, resulting in accumulation in topographic levees and winnowing on ridges. 


\section{Chapter 4: Results}

\section{Lithostratigraphy}

The Mangaweka Mudstone at Tiriraukawa as exposed along Watershed Road, is a 672 metre thick, blue-grey to grey-brown, micaceous, massive, bioturbated siltstone. Overall, the unit is sparsely fossiliferous (articulated and in situ bivalves and gastropods), and contains isolated concretions (metre-sized) and concretionary layers. The unit is comprised of three different facies, distinguished on the basis of sedimentary features, colour and fossil content, and grading into each other stratigraphically upwards (figure 4.1). Two discontinuous and bioturbated tephra beds are also observed (figures 4.1 and 4.2). The base of the Mangaweka Mudstone is not observed, but was inferred from the distinctive change in geomorphology near the base of the road section. Previous studies (Journeaux et al., 1996; Kamp et al., 1998) described a sandstone member at the base of the Mangaweka Mudstone, and along the Watershed Road section the siltstone units form cliff outcrops, where as sandstone units were more slumped and are not cliff-forming. The top contact is observed, which is sharp and undulating at an amplitude of $\sim 50$ centimetres. This separates the underlying grey siltstone from an overlying grey-brown sandstone, inferred to be the Te Rimu Sandstone (or Mangarere Sandstone) which is part of the Rangitikei Group (Naish and Kamp, 1995; McIntyre, 2002). Small scale normal-faulting is evident throughout the section, but any offsets appear to be $<1$ metre (figure 4.2). The Mangaweka Mudstone lithostratigraphy (stratigraphic column and section images) is presented in figures 4.1 and 4.2 .

The mineralogy of the Mangaweka Mudstone is dominantly quartzo-feldspathic, with minor fractions of mica $(<5 \%)$, magnetic minerals $(<1 \%)$, lithics $(<1 \%)$ and accessory minerals $(<1 \%)$. The estimation of the mica content is necessary for assessing the reliability of laser particle size measured sediment texture and the subsequent interpretations (see grainsize results section). 


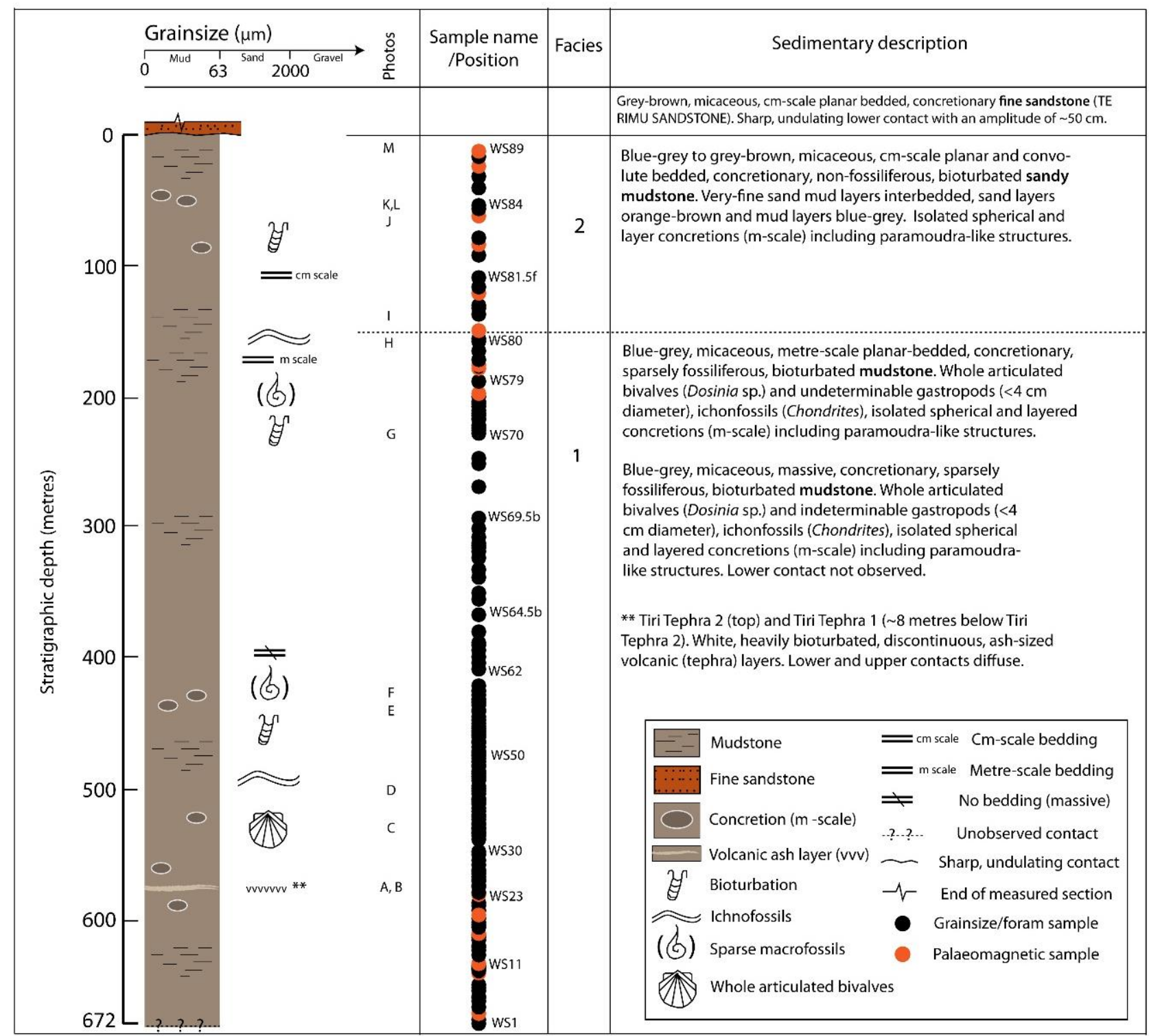

Figure 4.1: Watershed Road stratigraphic column with facies descriptions. Capital letters relate to photos in figure 4.2 A-M.

Facies one (figure 4.1) is exclusively mudstone, and sparse marine bivalves (Dosinia sp.) generally constrain the depositional environment to a neritic, continental-shelf environment (figure 4.2 C) (Beu and Maxwell, 1990). Also present are Chondrites ichnofossils (figure $4.2 \mathrm{G}$ ), which can be found in subtidal continental shelf to abyssal depositional environments, and correlative sedimentary rocks (Bromley and Ekdale, 1984). However, the presence of Chondrites is thought to require oxygen-poor conditions in the seafloor sediments (Bromley and Ekdale, 1984), and oxygen levels can be broadly correlated with bathymetry, where bottom water oxygen decreases with depth (Van der Zwaan et al., 1999). Thus, it is likely that Chondrites in this instance 
represents a deeper continental shelf environment. The massive nature of the marine mudstone likely indicates processes of bioturbation, as well as burrow-like features present below the Tiri-Tephra 2 ash layer (figure 4.2 B, I). The dominance of silt to sand-sized terrigenous sediment suggests deposition via current- and/or wave-action (Boggs, 2011). Therefore, facies one is interpreted to be deposited in a mid-outer-shelf environment.

Facies two (figure 4.1) is characterised by higher sand contents and cm-metre-scale planar laminae and bedding, where in some instances silt-dominated beds alternate with sand-dominated beds (figure $4.2 \mathrm{~J}, \mathrm{~K}, \mathrm{~L}$ ). These bedding features are moderately bioturbated, and also exhibit convolute bedding structures (figure $4.2 \mathrm{~L}$ ). This again indicates deposition via current- and/or wave-action (although likely stronger due to presence of coarser sand-grains), and possibly higher sedimentation, resulting in loading structures (convolute bedding) (Boggs, 2011). Facies two lacks any environmentally-diagnostic macrofossils, possibly due to weathering, or elevated sedimentation rates that result in unfavourable habitats. Using this field-observation data, facies two is interpreted to be an inner to outer-shelf depositional environment, which can be further constrained using grainsize and microfossil analyses.

The upper contact of the Mangaweka Mudstone is sharp and undulating where it abruptly transistions to medium-fine sandstone; interpreted to be the Te Rimu Sandstone (also known as the Mangarere Sandstone) (Naish and Kamp, 1995; McIntyre, 2002). The lack of bioturbation features at this contact and any sediment-texture grading at the base of the Te Rimu Sandstone suggest the contact is an unconformity representing wave-base or slope channel erosion. This is consistent with previous studies in the Rangitikei River section documenting a channelised Te Rimu Sandstone lower contact, with mudstone rip-up clasts overlain by wavy-laminated sandstone (Naish and Kamp, 1995; McIntyre, 2002). 

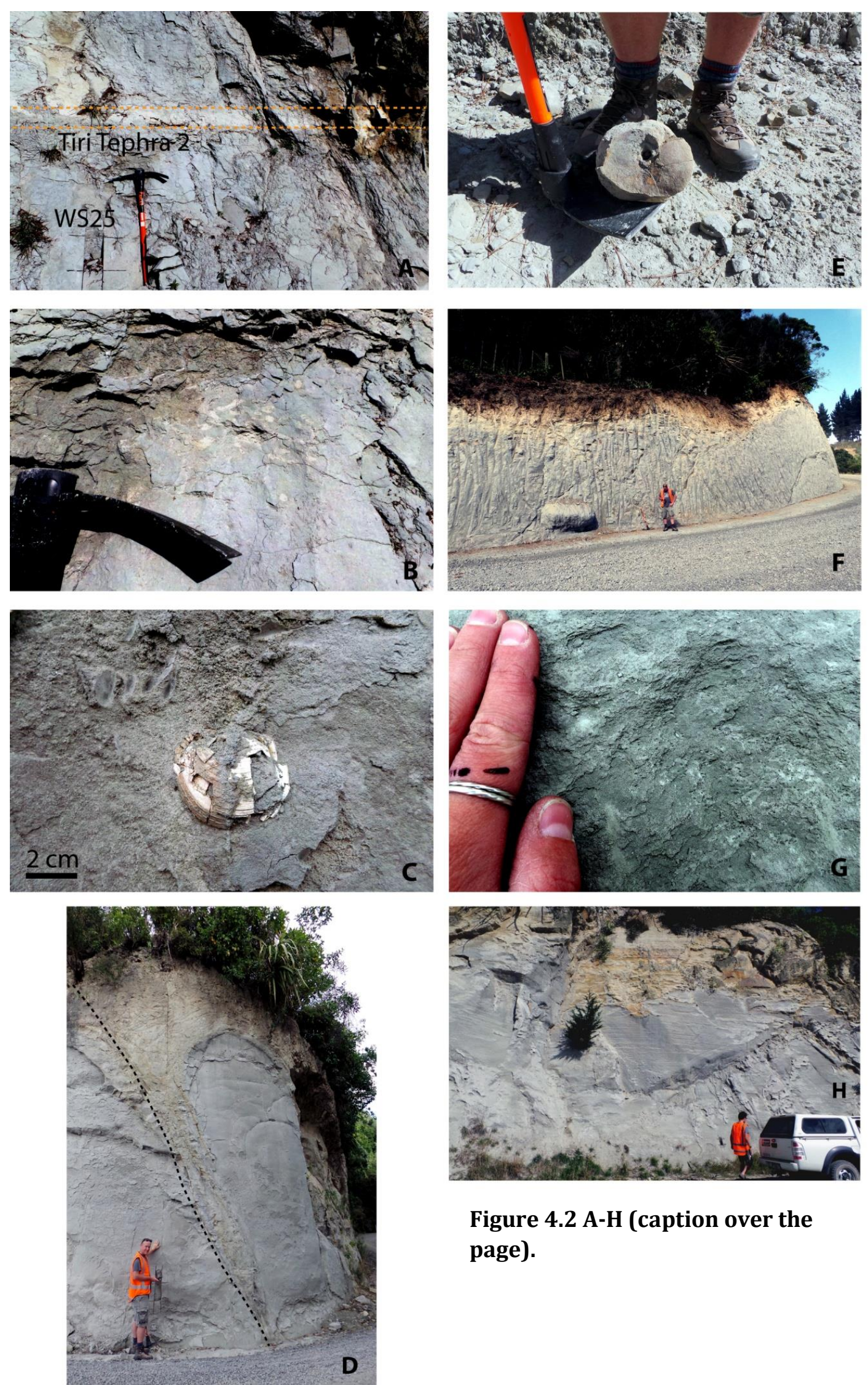

Figure 4.2 A-H (caption over the page). 

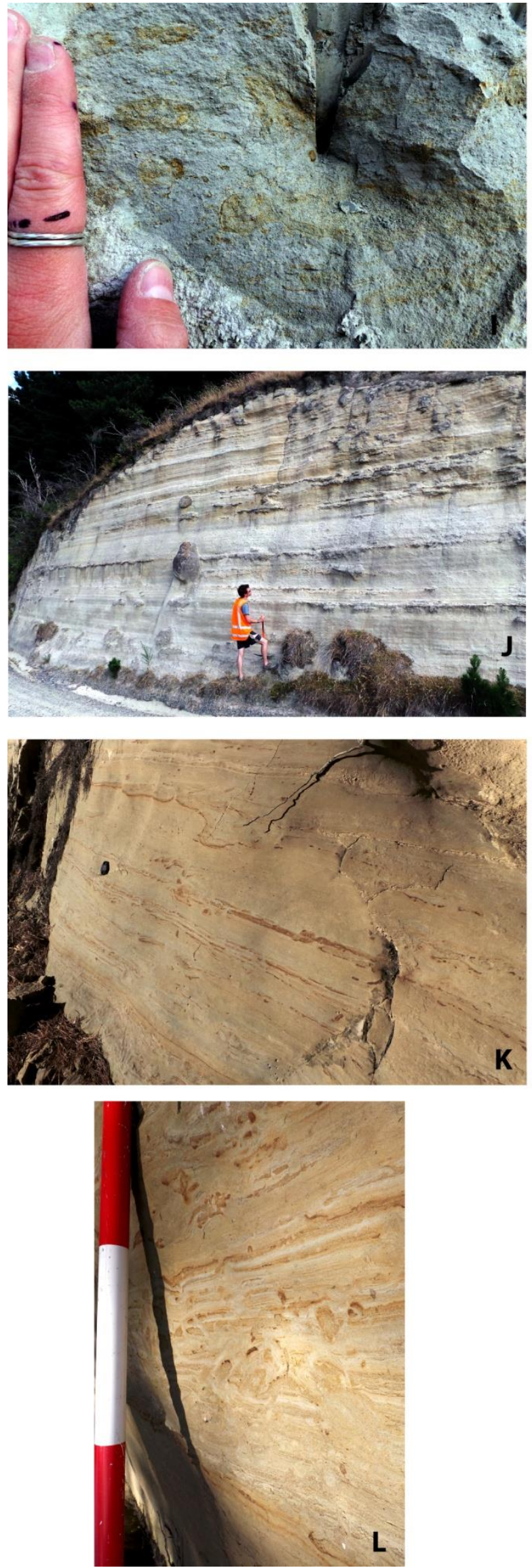

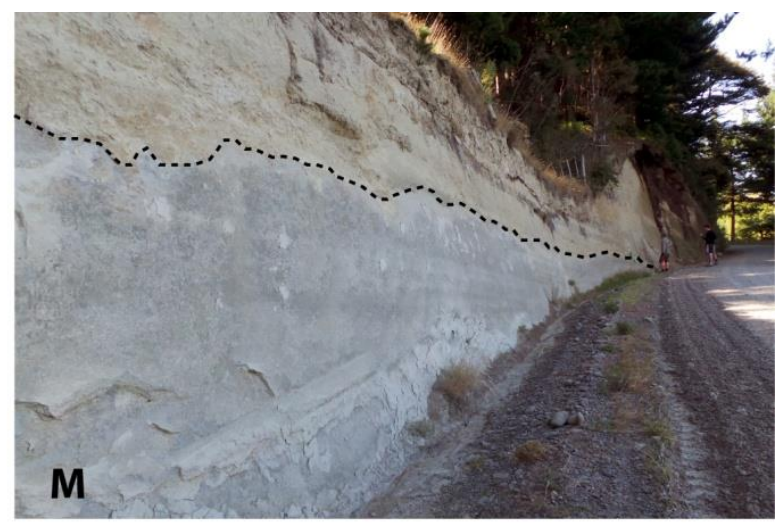

Figure 4.2: (A) Showing Tiri Tephra-2 in outcrop above sample WS25. (B) Bioturbated tephra $<20 \mathrm{~cm}$ below the Tiri Tephra-2 layer. (C) Whole articulated bivalve, Dosinia sp., near sample WS37. (D) The dotted line shows a small scale fault near sample WS43. (E) A paramoudra-like structure taken from in situ near sample WS57. Paramoudra-like concretions have a distinctive funnel shape and hollow conduit running through the middle that may respresent gas escape chimneys or a trace fossil. (F) Metrescale concretion clearly visible in newly cut road section near sample WS61. (G) Chondrites ichnofossils near sample WS70. These are subcentimetre burrows that stand out as darker 'dots' against the lighter mudstone background. (H) A larger outcrop above sample WS80 displays the onset of $\mathrm{cm}$-scale, mud and sand inter-bedding. (I) Evidence of bioturbation, where burrows are filled with fine sand and are weathered to a darker orange in comparison to surrounding blue-grey mud. (J) Centimetre-scale bedding and paramoudra-like structures in situ near sample WS83. (K and L) Sand and mud inter-bedding near sample WS84. Bioturbation and convolute bedding structures are also apparent. Note the white band on the stick is $\sim 15 \mathrm{~cm}$ length. (M) The dotted line showing the top contact of Mangaweka Mudstone (with the Te Rimu Sandstone) at Watershed Road section, above sample WS89. 


\section{Palaeobathymetry results}

\section{Grainsize results}

The laser particle size results indicate all of the Mangaweka Mudstone samples are within the mud to sandy mud textural ranges according to the Folk and Ward (1957) classification. The distributions are characteristically polymodal, and largely poorlysorted (figure 4.3). Sample by sample statistics are available in Appendix B.

WS13.5
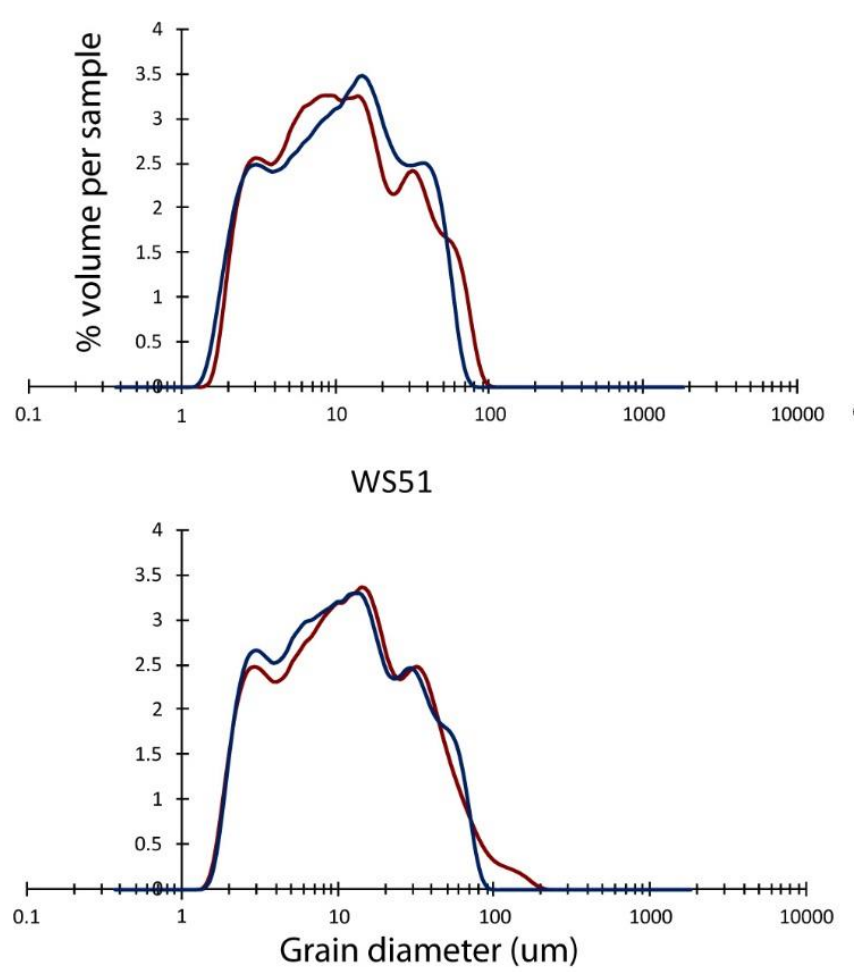

WS21

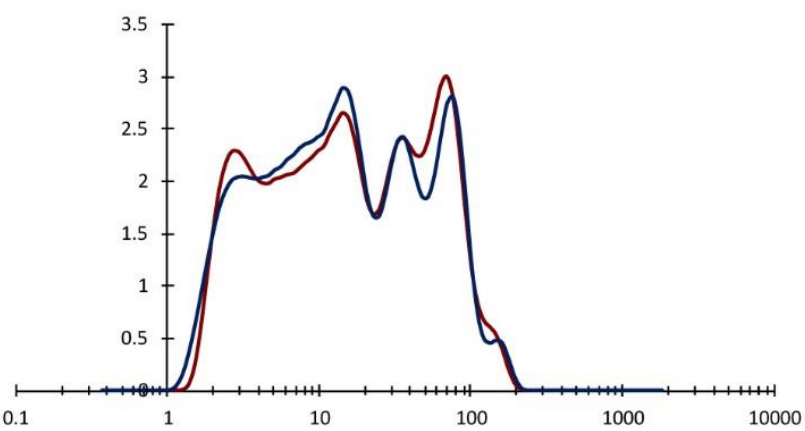

WS76.5

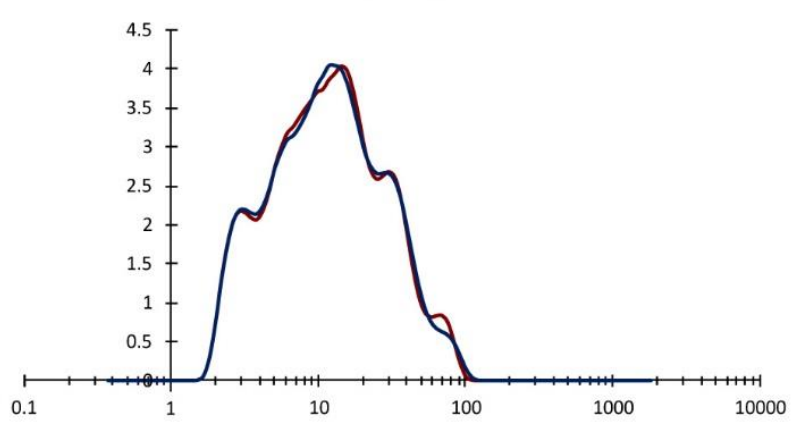

Figure 4.3: Examples of the polymodal, poorly-sorted grainsize distributions from the Mangaweka Mudstone at Watershed Road. The average grainsize is consistently in the silt fraction. Red and blue lines are sample and a repeat, respectively.

While the mean grainsize is largely restricted to the silt fraction $(<63 \mu \mathrm{m})$, there are significant excursions in the percentage mud (percent $<63 \mu \mathrm{m}$ volume) throughout the Mangaweka Mudstone (figure 4.4). Firstly, there is an overall trend of decreasing percent mud up section, ranging from an average of almost $100 \%$ mud in the lower facies one (figure 4.1) and decreasing to $70-80 \%$ mud in the sandier facies two. Superimposed on this trend are cyclical variations in percent mud on the order of 20$30 \%$. These changes are well-defined for the lower $\sim 400 \mathrm{~m}$ of the section, but the 
resolution of sediment texture variability decreases up section (a result of changing outcrop availability and exposure, discussed in Chapter 3).

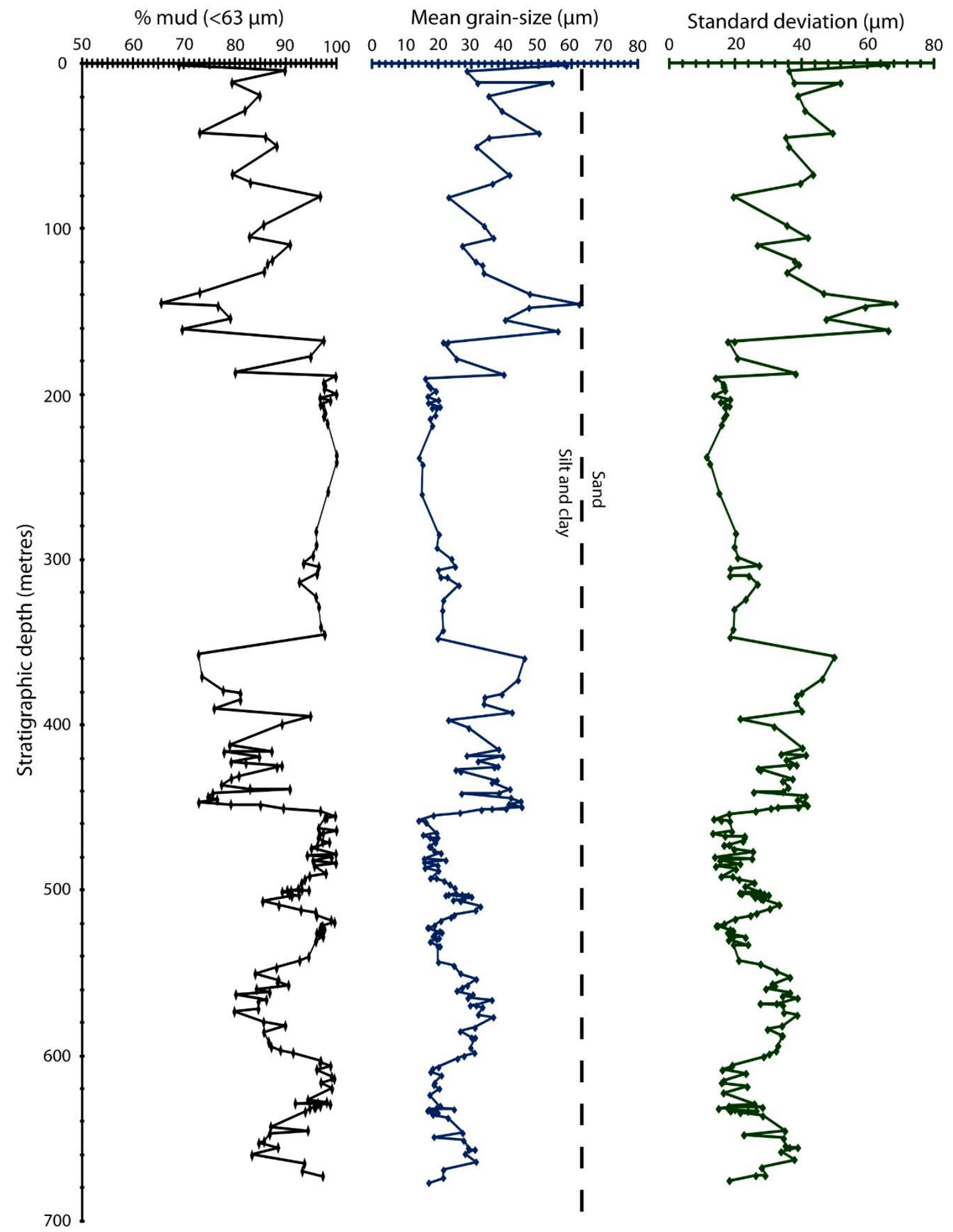

Figure 4.4: Laser particle size results, showing percent mud ( $\%$ of the measured volume under $63 \mu \mathrm{m}$ ), mean grainsize (in $\mu \mathrm{m}$ ) and the standard deviation of the distribution of each sample. Statistics were calculated using the Method of Moments (geometric). 
By applying the sediment grainsize-based water depth proxy approach defined by Dunbar and Barrett (2005) (discussed in Chapter 3), palaeobathymetry can be estimated for the Mangaweka Mudstone from the laser particle sizer results (using the fourth-order polynomial equation in figure 3.7) (figure 4.5). At face-value, if all the assumptions are met, the overall long-term trend of decreasing percent mud is equivalent to approximately 10-15 metres of shallowing, and the higher-frequency superimposed cycles vary from $\sim 10$ metre amplitude water depth changes to as much as 20 metres (figure 4.5). It should be noted that these are palaeobathymetric estimates calculated from grainsize distributions alone, and assume that the critical assumptions and criteria for use of this proxy method outlined for the Dunbar and Barrett (2005) proxy method in Chapter 3, are met in this study. The validity of this assumption is discussed in Chapter 5. 


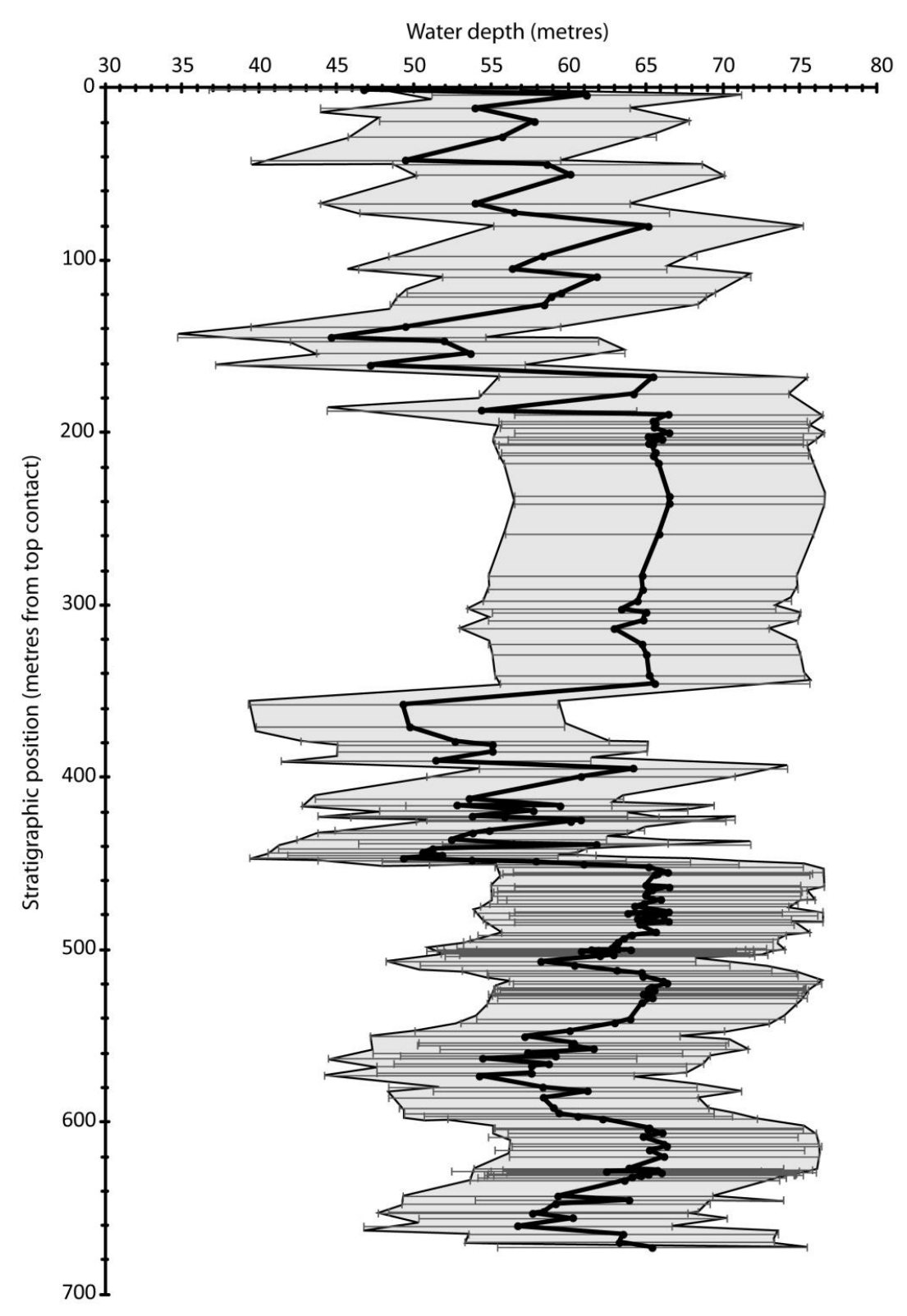

Figure 4.5: Water-depth estimates using the Dunbar and Barrett (2005) sediment grainsize proxy approach. The black line and dots are the calculated water depths, the grey window and error bars accommodate the \pm 10 metre uncertainty, and are within the $\mathbf{9 5 \%}$ confidence interval.

A previous study identified that mica grains significantly alter grainsize distributions when measured with a laser particle sizer, in comparison to traditional sieve analyses (Hayton et al., 2001). Mica grains are significantly different in shape and density in relation to common siliciclastic minerals like quartz. Mica particles are distinctly shaped (flat), and this characteristic influences the scattering of light in laser size analyses to overestimate their relative volume compared to other methods in a grainsize sample. Their low density also means that there are significantly more mica particles per unit 
weight than an equal weight of quartzo-feldspathic grains. Hayton et al. (2001) found that micaceous sands and muds of Pliocene strata from the Wanganui Basin measured in a laser particle sizer generated lower sand contents than the same samples measured by sieve analysis (figure 4.6). This divergence increases with percent sand, to up to $25 \%$ difference. In this study, analysed sediment textures contain a maximum of $\sim 30 \%$ sand, and any mica influence should be minor. Yet, the values yielded for sandier samples can be considered to be minimum percent sand estimates, and could possibly be up to $10 \%$ more per unit weight. This highlights that while laser size measurements provide rapid, precise data, the underlying assumptions (discussed in Chapter 3) surrounding grainsize theory must not be overlooked (Hayton et al., 2001).

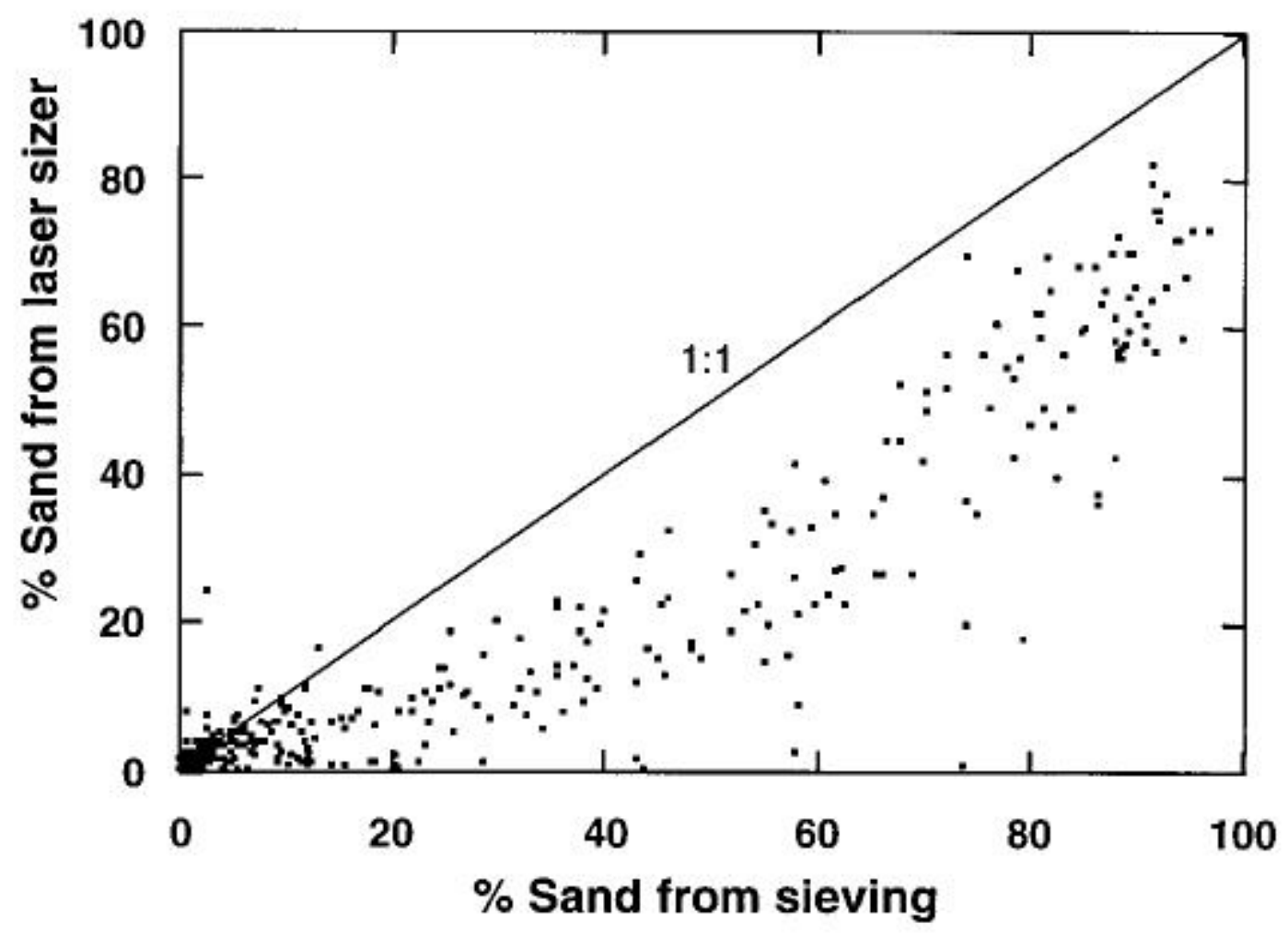

Figure 4.6: Graphical representation of the discrepancy between percent sand measured with laser sizer and sieving using Pliocene sandstones and mudstones from the Wanganui Basin from Hayton et al. (2001).

Some studies have also noted problems of grain flocculation (Konert and Vandenberge, 1997) and sonication damage to grains (Pérez-Maqueda et al., 2003) when measuring micaceous material in laser particle sizers. However, such problems occur when experiments are run over longer periods of time ( $>10$ hours), and the analyses in this study were conducted in much smaller time aliquots ( $<30$ minutes). 


\section{Benthic foraminifera census}

Benthic foraminifera were identified and sorted taxonomically (with assistance from Hugh Morgans, GNS Science), before they were counted and the resulting census data normalised to $100 \%$ (see Appendix C). Planktic foraminifera were also picked and counted for the percent planktic "oceanicity" indicator (discussed in Chapter 3). Eleven samples were completely barren, and two contained less than 200 specimens (out of a total of 63 samples).

Given the primary aim of the benthic foraminifera census in this thesis is to determine palaeo-water depths, some species of the same genus were amalgamated (e.g. Euuvigerina sp. and Bulimina sp.). In many cases, subdivision into different species was unnecessary and did not provide any additional information related to palaeo-water depth, however it is acknowledged that the abundance of different species within a single genus may provide interesting information on palaeoenvironmental indicators other than water depth. These additional palaeoenvironmental factors are not explored in this thesis, but will be considered in future studies.

Overall, 50 benthic foraminifera samples yielded 58 taxonomic divisions (Appendix C). Normalised percent abundance data throughout the stratigraphic section are shown in figure 4.7a-c for common species present in all samples. Percent planktic species and a productivity index are also displayed (figure $4.7 \mathrm{~d}$ ). Wet sieving at $63 \mu \mathrm{m}$ as part of the foraminifera laboratory preparation provides an additional measure of sediment texture, where percent mud can be calculated from the amount of material left on the sieve. However, it should be noted that this grainsize dataset is not directly comparable to the laser particle results as it has not undergone the same laboratory treatment as it measures different grain properties (see Chapter 3). Additionally, samples contained trace amounts of sponge spicules and fragments, diatoms, radiolarians, fish scales, ostrocoda, macro-fossil fragments and echinoderm spines. The presence/absence of these specimens has not been examined further in this thesis. 


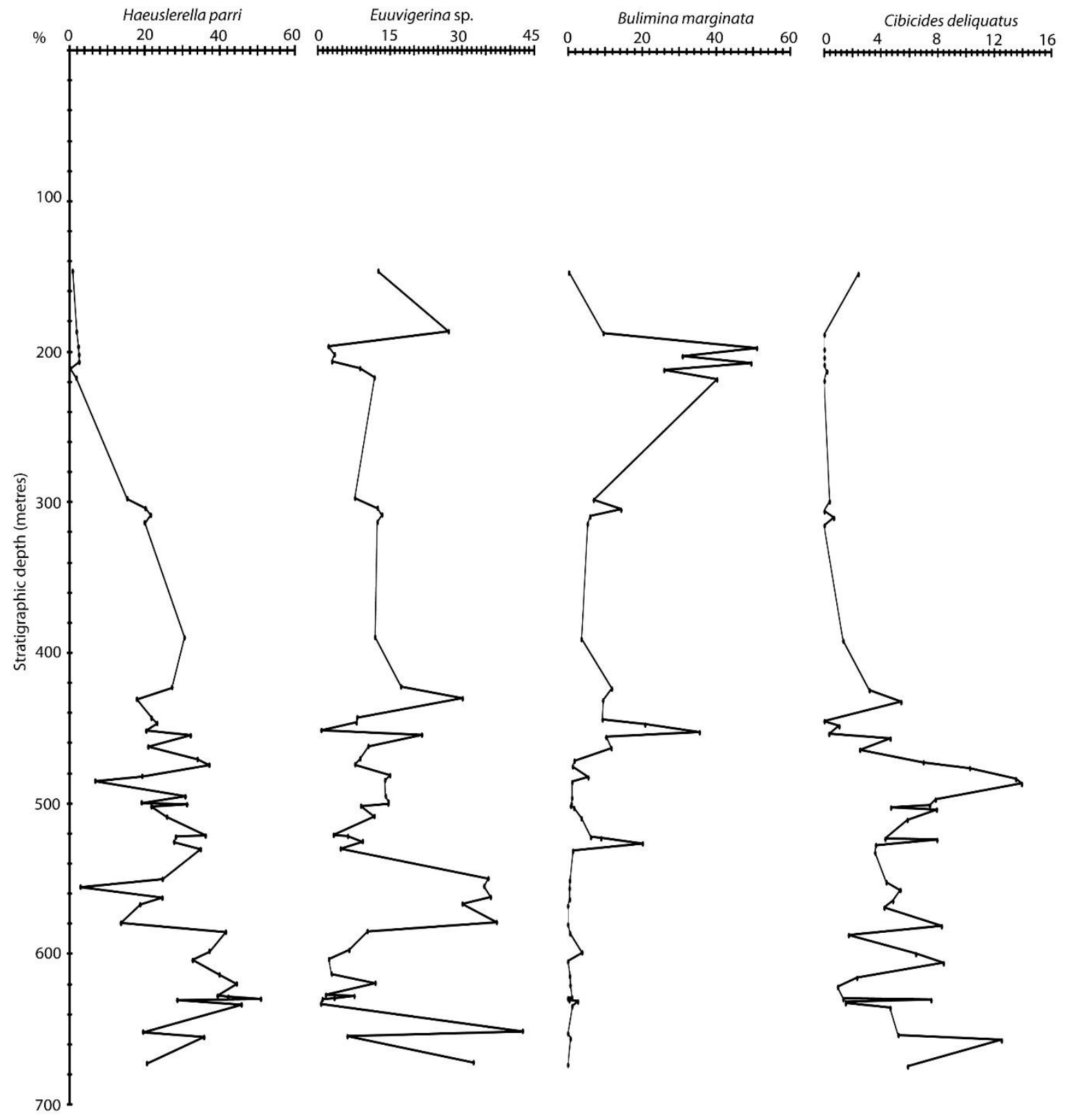

Figure 4.7a-c: The percent abundance of common benthic foraminifera with stratigraphic depth in the Mangaweka Mudstone at Tiriraukawa. 


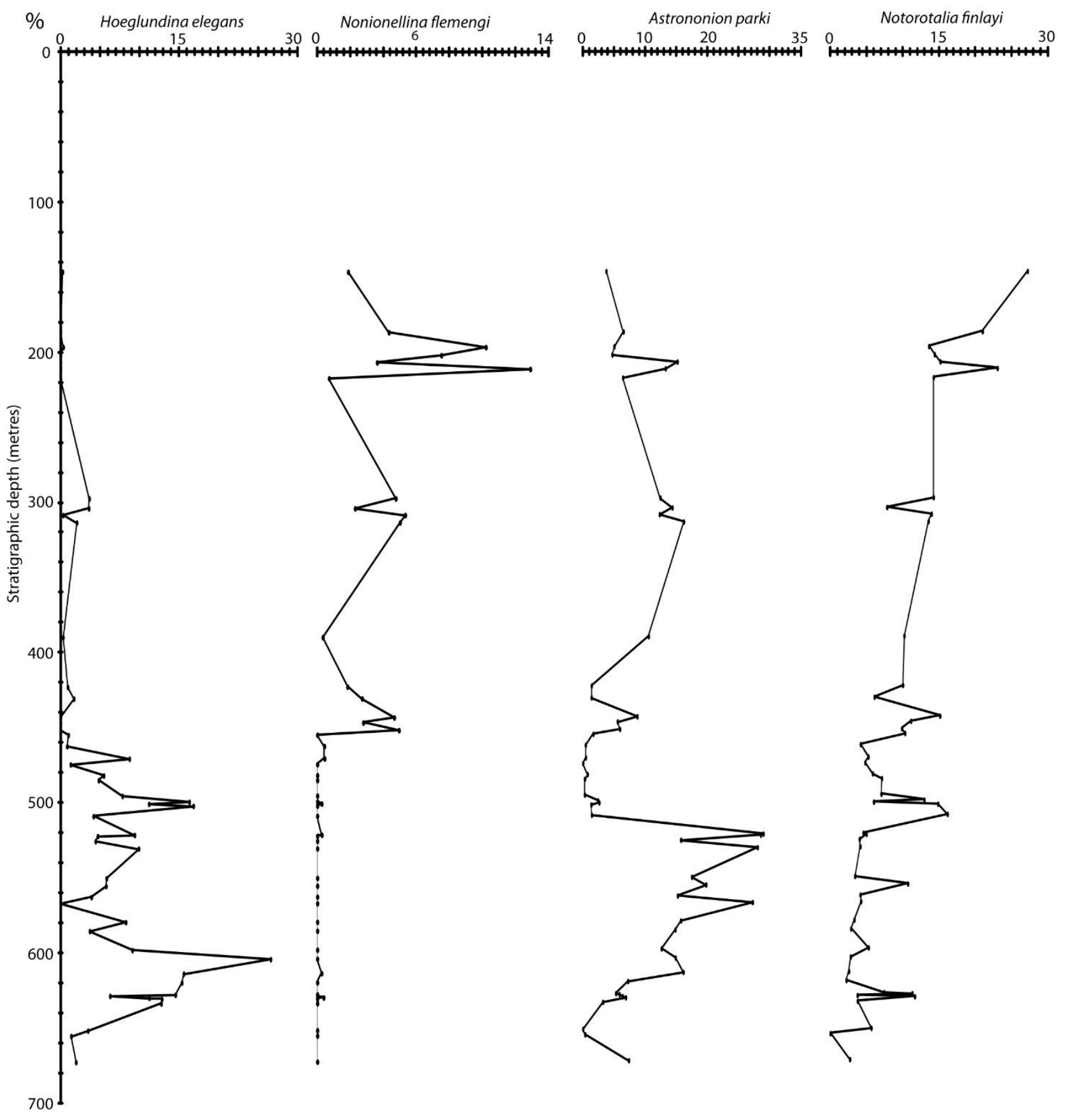

Figure 4.7b 


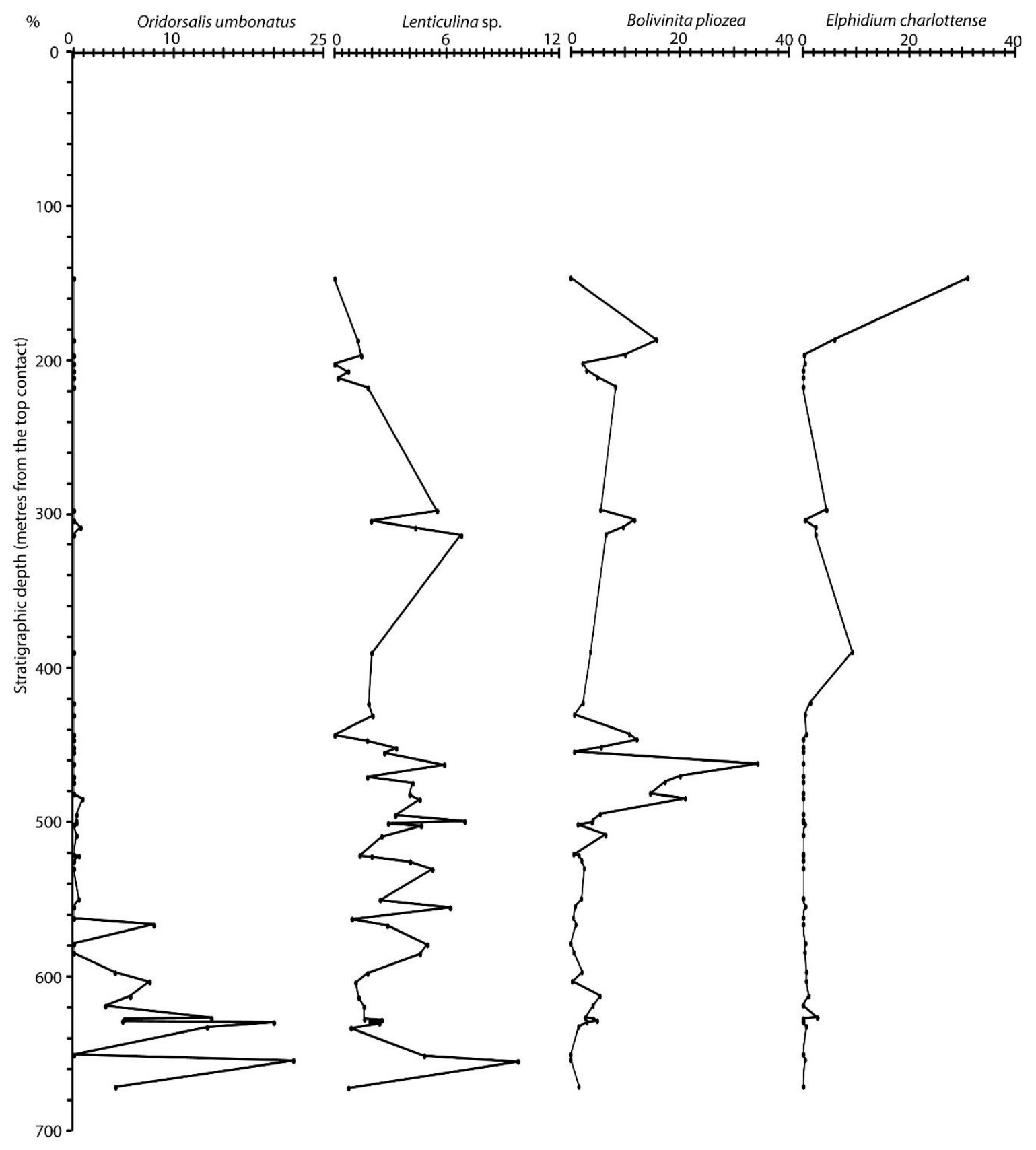

Figure 4.7c 

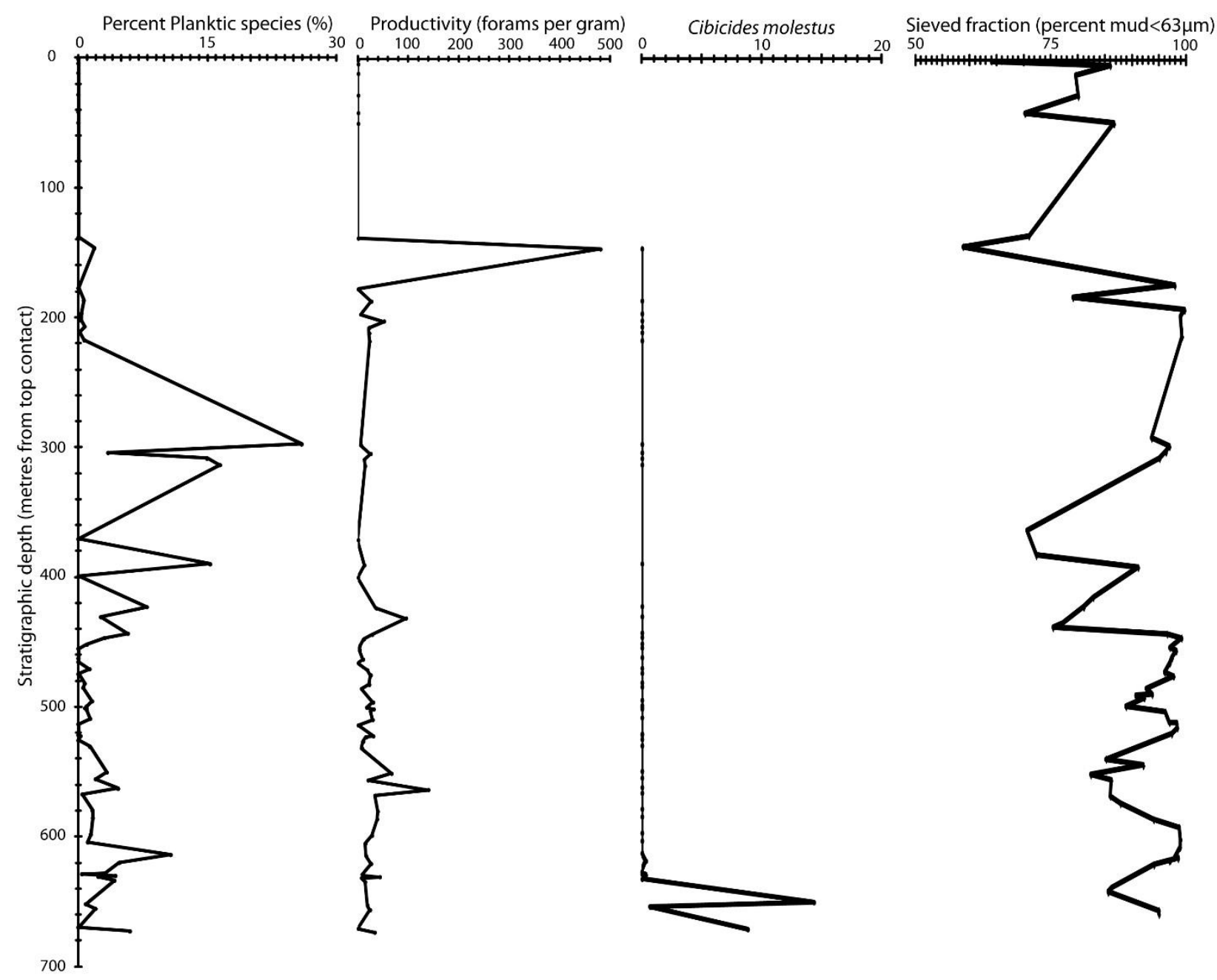

Figure 4.7d: This figure displays percent planktic species (out of total foraminifera content), productivity index (foraminifera specimens greater than $150 \mu \mathrm{m}$ per gram of sediment) and percent mud from sieving during foraminifera sample preparation ( $<63$ $\mu \mathrm{m}$ fraction).

The lower 400 metres of mudstone is dominated by Haeuslerella parri, Euuvigerina sp., Cibicides deliquatus, Hoeglundina elegans, Astrononion parki and Oridorsalis umbonatus, above which their relative abundances decreases. Notorotalia finlayi and Lenticulina sp. maintain relatively consistent abundances throughout the section. The upper $\sim 300$ metres of Mangaweka Mudstone is characterised by higher abundances of Nonionellina flemengi and Bulimina marginata, with increasing Elphidium charlottense, the latter of which sharply increases at $\sim 140$ metres below the top contact. Cibicides molestus is completely absent above $\sim 600$ metres stratigraphic depth. 
The percent planktic species (calculated from total foraminifera species picked per sample) is consistently $<10 \%$ up until 400 metres depth. Above, planktic species abundance increases to almost 30\%, although the resolution provided by these upper samples is not as high as in the lower part of the section. By 200 metres depth, planktic species abundance drops to below 5\%. These results suggest the entire Mangaweka Mudstone was deposited in a dominantly neritic environment (low oceanicity).

Productivity values were calculated using the equation provided in Kamp et al. (1998):

$$
\text { Productivity }=(W / P W)(1 / S) n
$$

Where $W=$ washed residue weight, $P W=$ picked residue weight, $S=$ sample weight (all 200 grams), and $n=$ number of benthic specimens picked. Productivity levels are relatively consistent throughout the section, only peaking above 100 specimens per gram at around $\sim 560$ and $\sim 430$ metres depths. At 140 metres depth, one sample (WS80: see Appendix C) indicates an order of magnitude higher productivity rates (480 specimens per gram) in comparison to all stratigraphically lower samples (figure 4.7). Percent mud $(<63 \mu \mathrm{m})$ calculated from the sieved fraction decreases overall from the bottom to the top of the section. The lower $\sim 400$ metres of the section varies cyclically between $80-95 \%$ mud, with the amplitude of variability increasing in the upper 300 metres to between $60-90 \%$ mud.

Cluster analysis has been used widely on New Zealand and Wanganui Basin foraminiferal data to semi-quantitatively separate distinctive assemblages of benthic foraminifera for palaeo- water depth assessments (Scott, 1970; Hayward, 1986; Haywick and Henderson, 1991; Journeaux et al., 1996; Naish and Kamp, 1997b; Kamp et al., 1998; Hayward et al., 1999). Following the methodology of Hayward (1986) and Hayward et al. (1999), Q-mode cluster analysis (Paired-Group algorithm and BrayCurtis similarity index) was applied to the normalised sample census data using palaeontological statistics software PAST 3.04 (Hammer et al., 2001). Barren and samples with $<200$ specimens were not included. Both stratigraphically constrained and non-constrained methods were used for cluster analysis, to assess the characteristics of each sample's assemblage with respect to the stratigraphically-neighbouring assemblages. The results of both are given in figure 4.8, from which foraminifera 
associations were defined for the Mangaweka Mudstone. The faunal compositions of each foraminifera association are shown in figure 4.9.

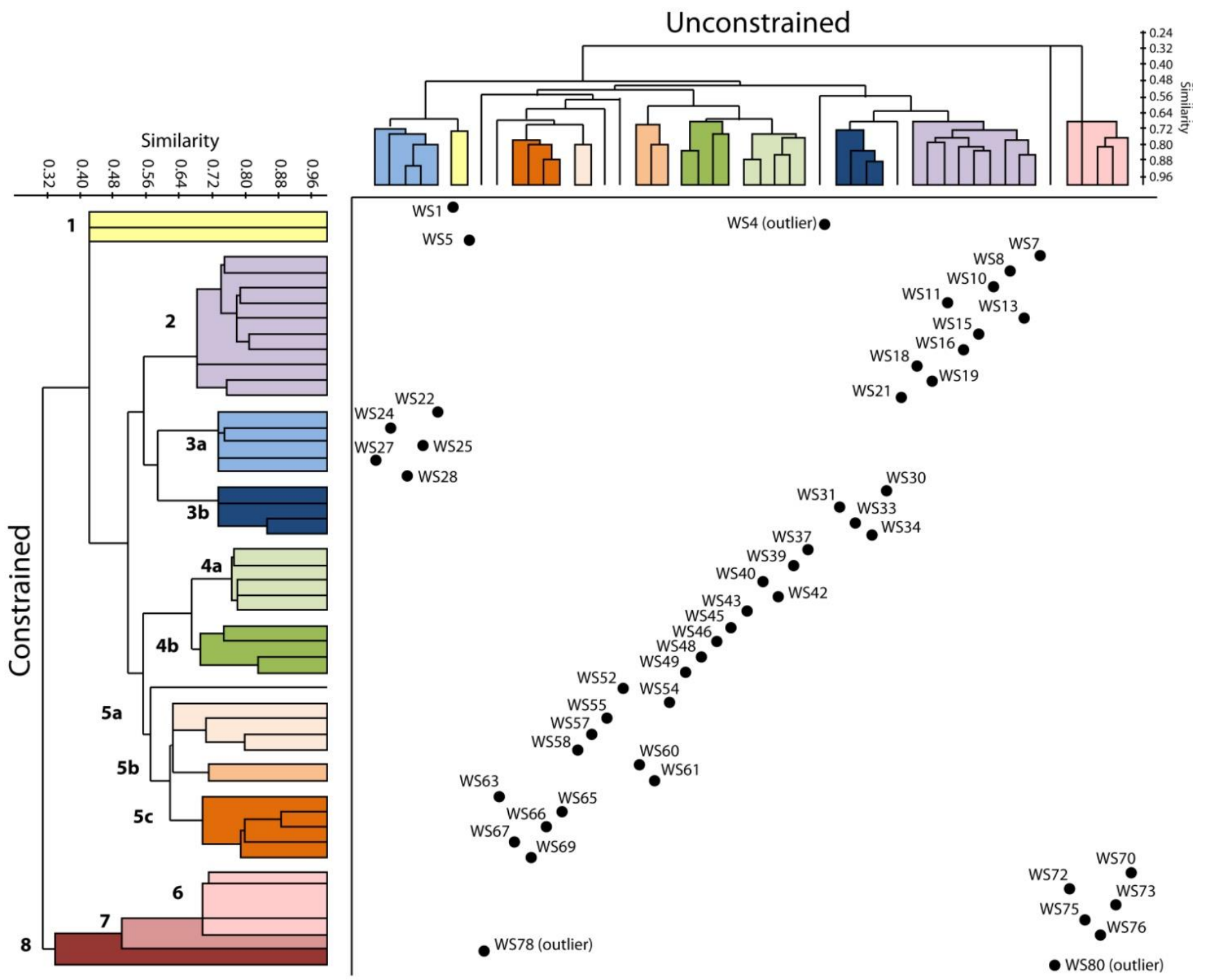

Figure 4.8: Comparison of stratigraphically constrained versus unconstrained Q-mode cluster analysis results. Similarity index indicates high similarity when values approach 1 , limited similarity when values approach 0 . While not uniformly consistent with each other, clusters can be easily identified within the constraints of the stratigraphy because there are no repeating clusters throughout the section (there are stratigraphically continuous faunal changes). The different colours represent individual clusters, numbered 1-8. Clusters $1,6,7,8$ are very distinctive from the bulk of the faunal composition throughout the Watershed Road section. In particular, this difference is caused by the outlying samples WS80, WS78 and WS4.

There is a clear overall trend identifying high similarity between stratigraphically neighbouring samples, with a trend of consistent faunal assemblage change with stratigraphic depth. However, there are a few outliers that can be distinguished as individual clusters. Cluster 1 (yellow) containing samples WS1, WS4 (which is an outlier 
in itself) and WS5 are dominated by the biostratigraphically-constrained Cibicides molestus, which sharply decreases in abundance and is entirely absent above $\sim 600$ metres stratigraphic depth. Cluster 3a (light blue) coincides with the occurrence of the two rhyolitic tephras adjacent to samples WS24 and WS25. It is possible that a shift in the foraminifera assemblages occurred in response to a significant perturbation in the nutrients available, which persisted over some time before returning to assemblages with an affinity for the background nutrient levels (Hamme et al., 2010; Abrajevitch et al., 2014). Similarly, this cluster coincides with a notable peak above background productivity levels (see figure 4.7, 560 metres stratigraphic depth). Clusters 6, 7 and 8 are also identified as outliers on the basis of coinciding with a shift in lithology/facies, likely to represent a shallower depositional environment (facies 3 in figure 4.1). In particular, Clusters 7 and 8 are composed of only one sample each, coinciding with a significant increase in the abundance of assemblages with a shallow-water affinity (figures 4.9a-f and 4.10).

Figure 4.9a-f: Bar graphs of cluster faunal compositions defined from the cluster analysis in figure 4.8 (colour-coded). The compositions of samples within a cluster are averaged, and displayed as averaged abundance percentages. Major species are shown in large font in decreasing order, and minor species are in non-bold. Note Discorbidae sp. is a family grouping, as splitting at the genus and species level would not influence determination of palaeo-water depths. 
Cluster 1

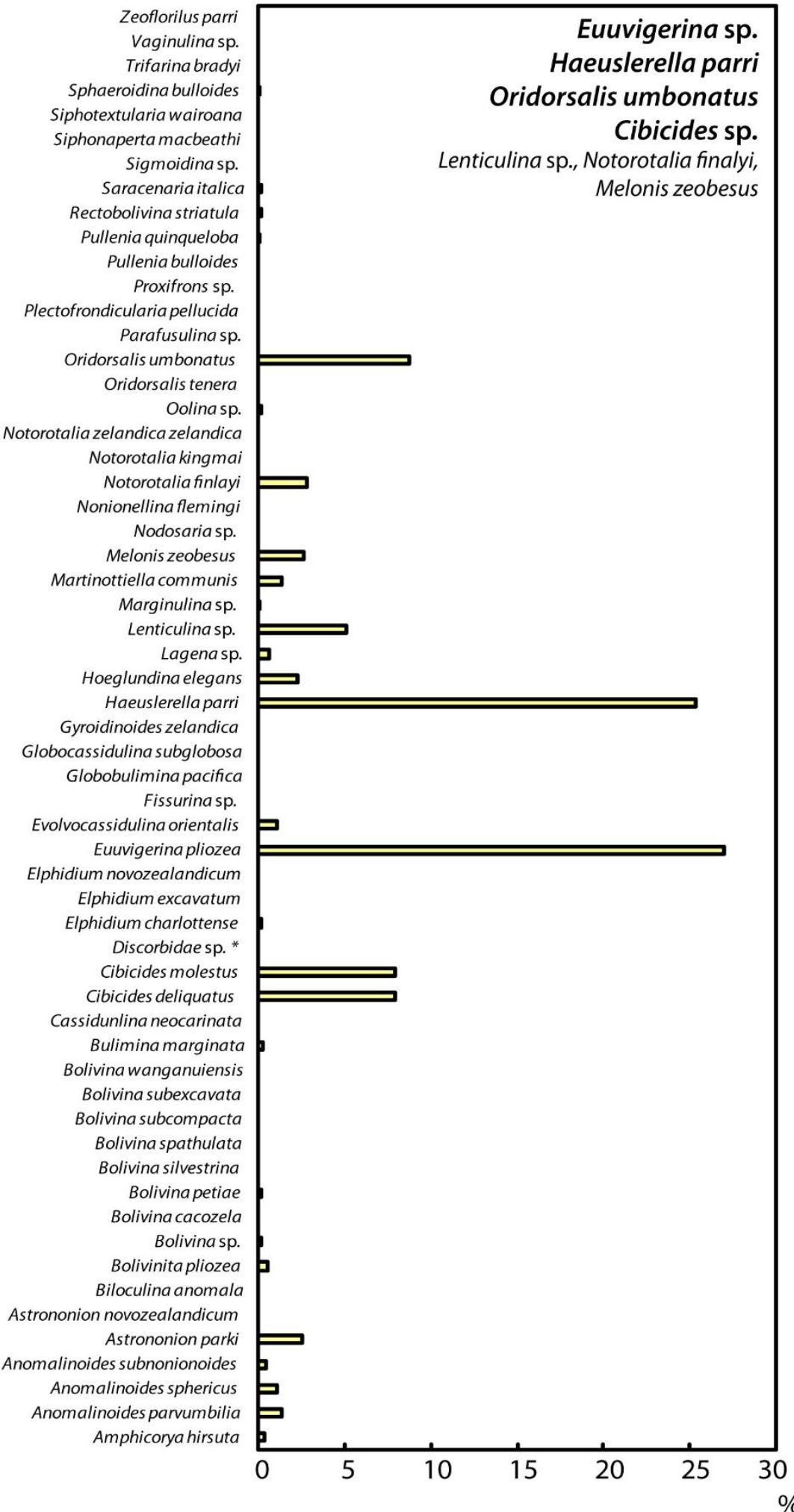

Cluster 2

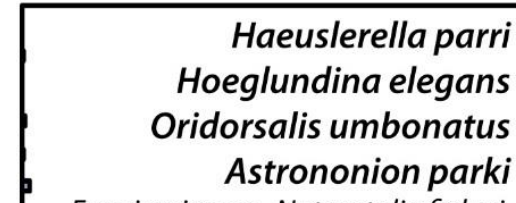

Euuvigerina sp., Notorotalia finlayi, Cibicides deliquatus

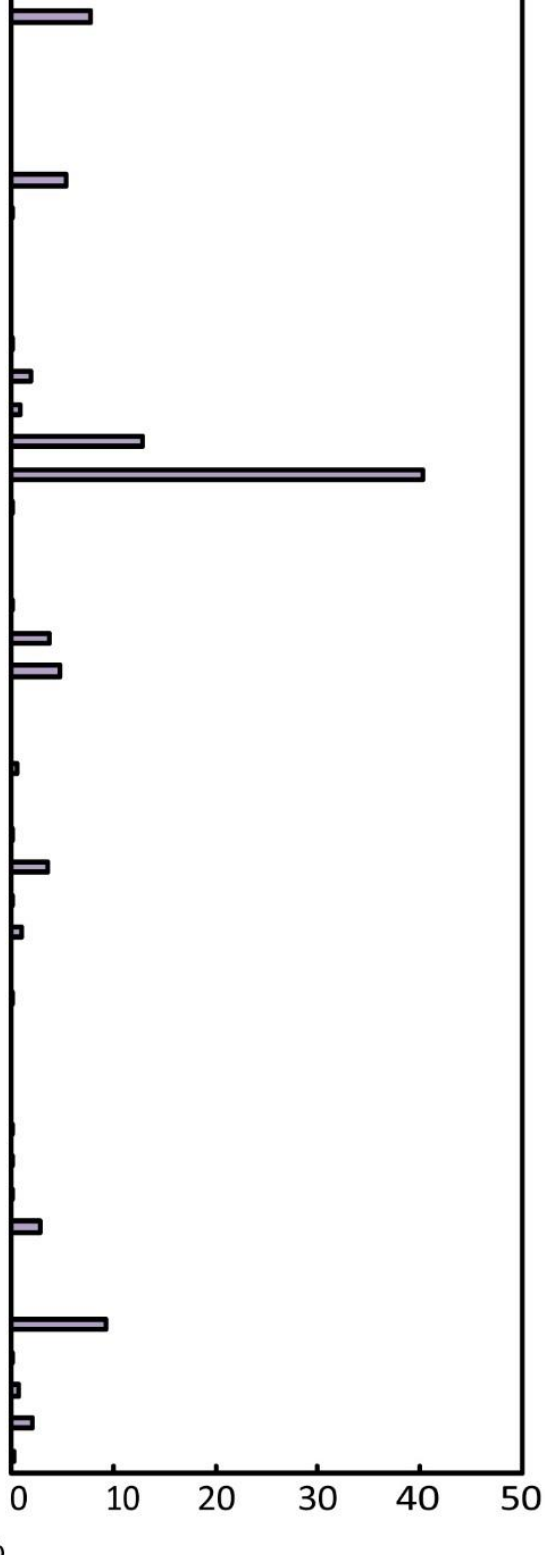

Figure 4.9a: Clusters 1 and 2. 
Cluster $3 a$

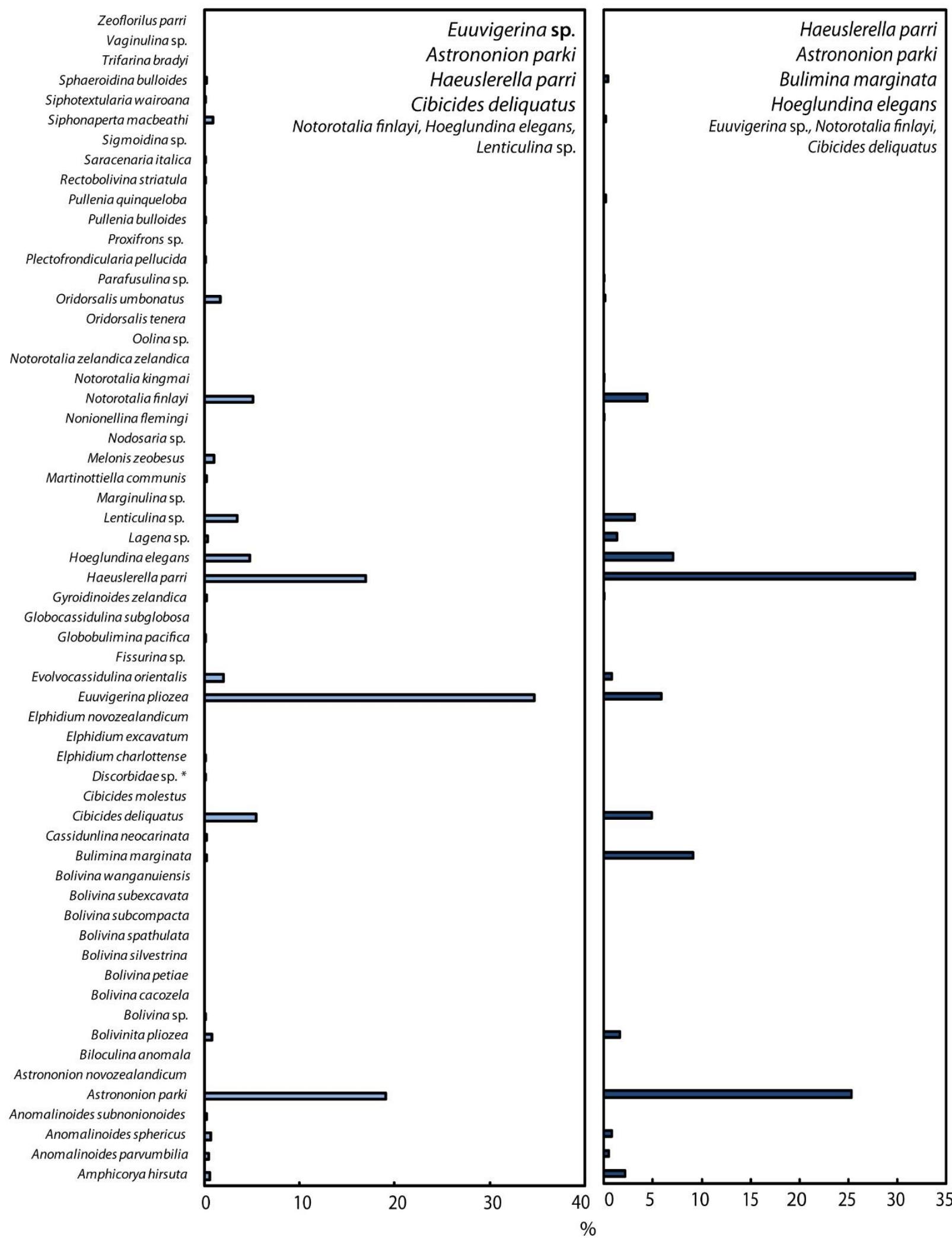

Figure 4.9b: Clusters 3a and $3 b$. 
Cluster 4a

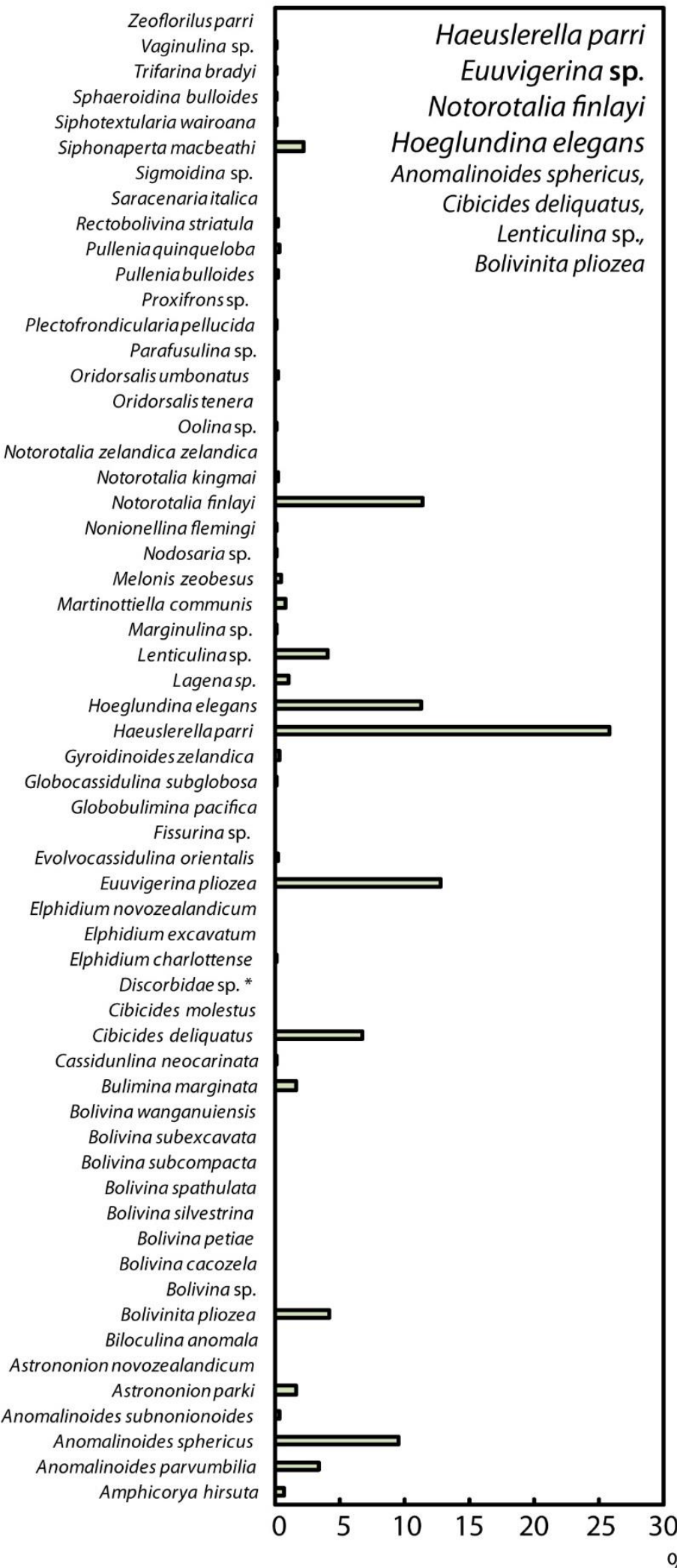

Cluster 4b

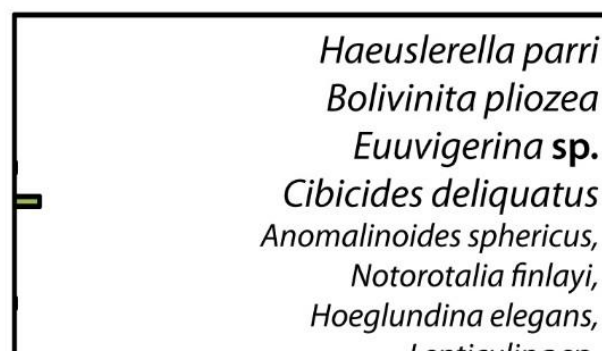

Lenticulina sp.

Figure 4.9c: Clusters 4a and 4b. 
Cluster $5 \mathrm{a}$

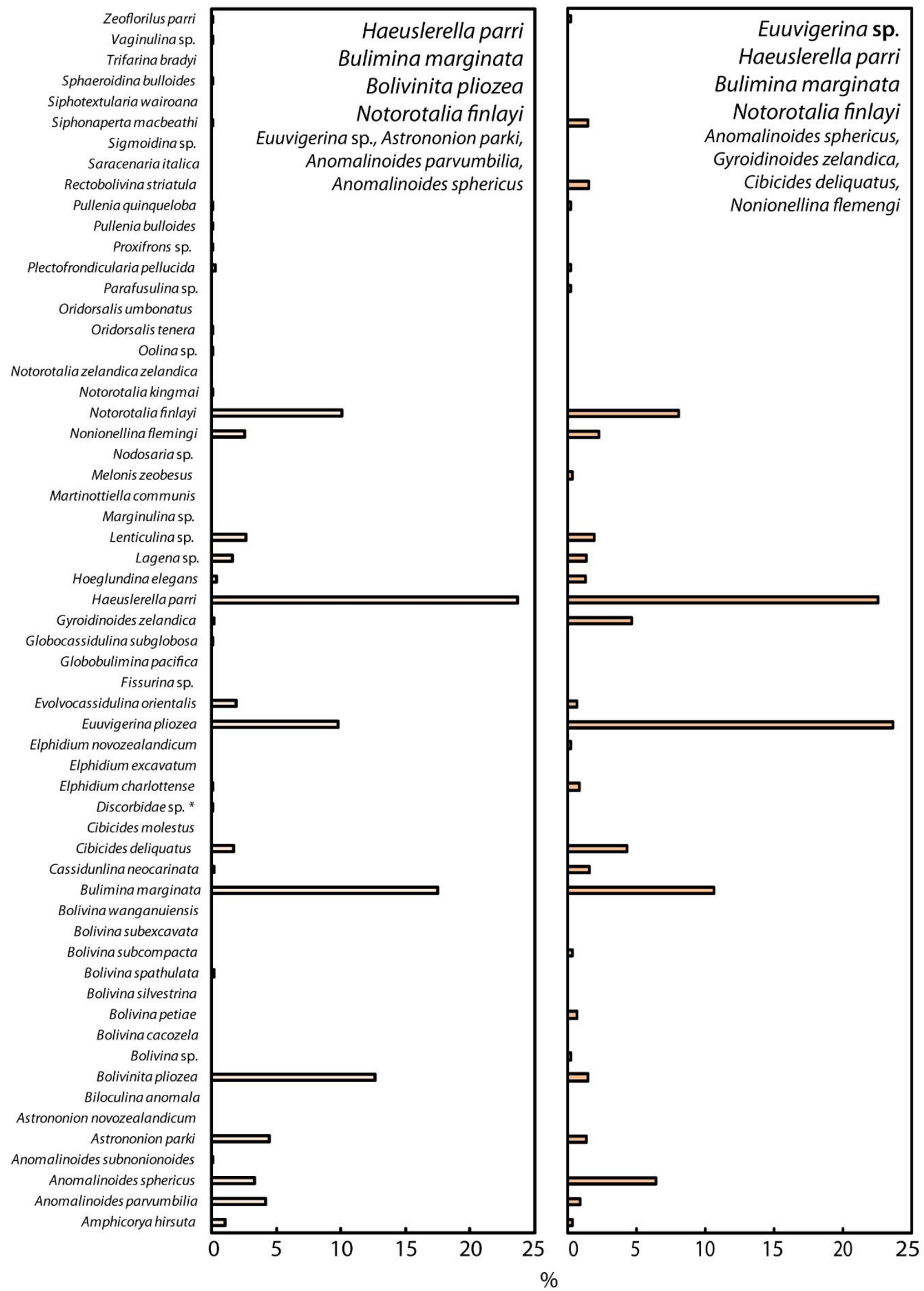

Figure 4.9d: Clusters 5a and $5 b$. 
Cluster 5c

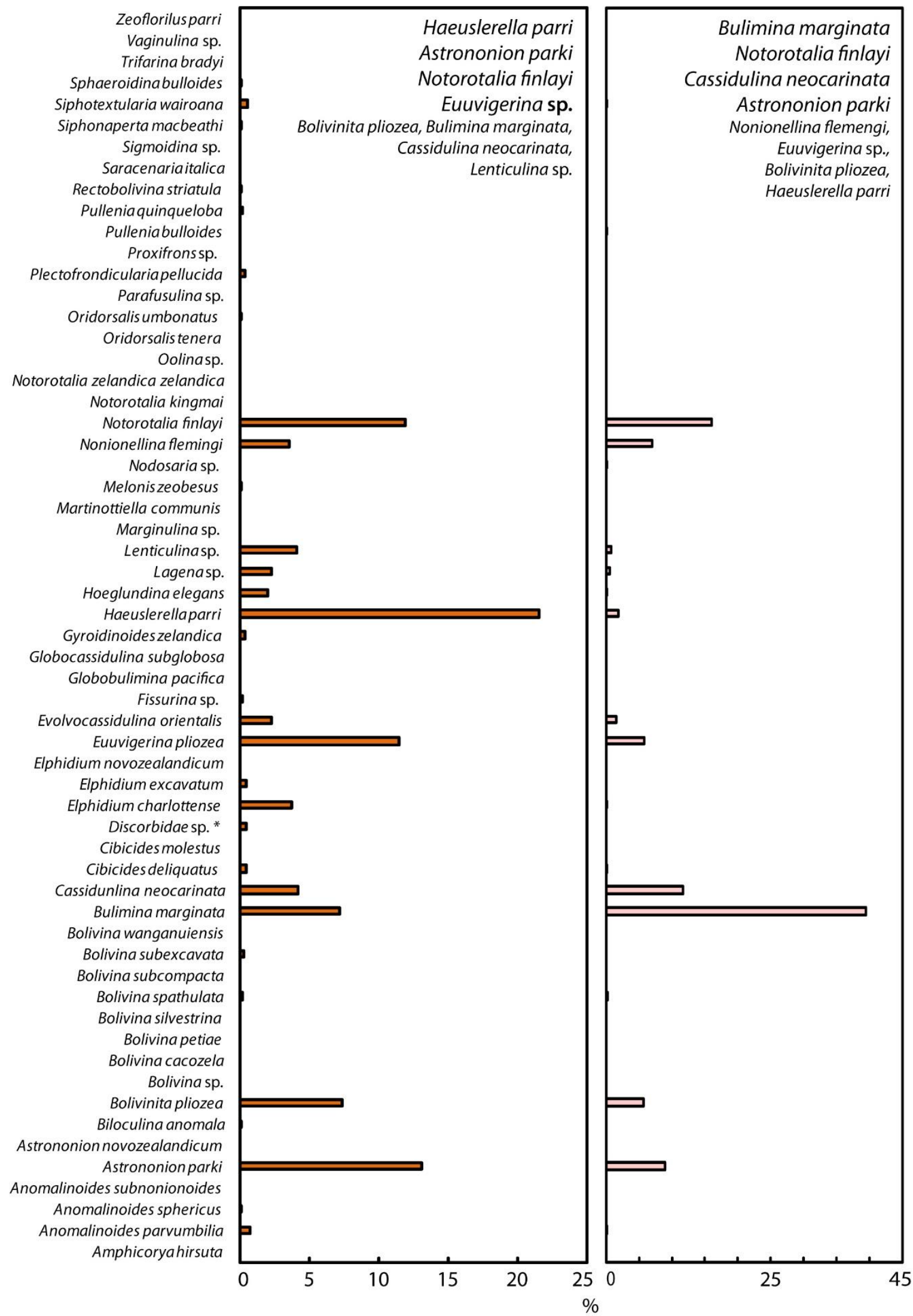

Figure 4.9e: Clusters 5c and 6. 
Cluster 7

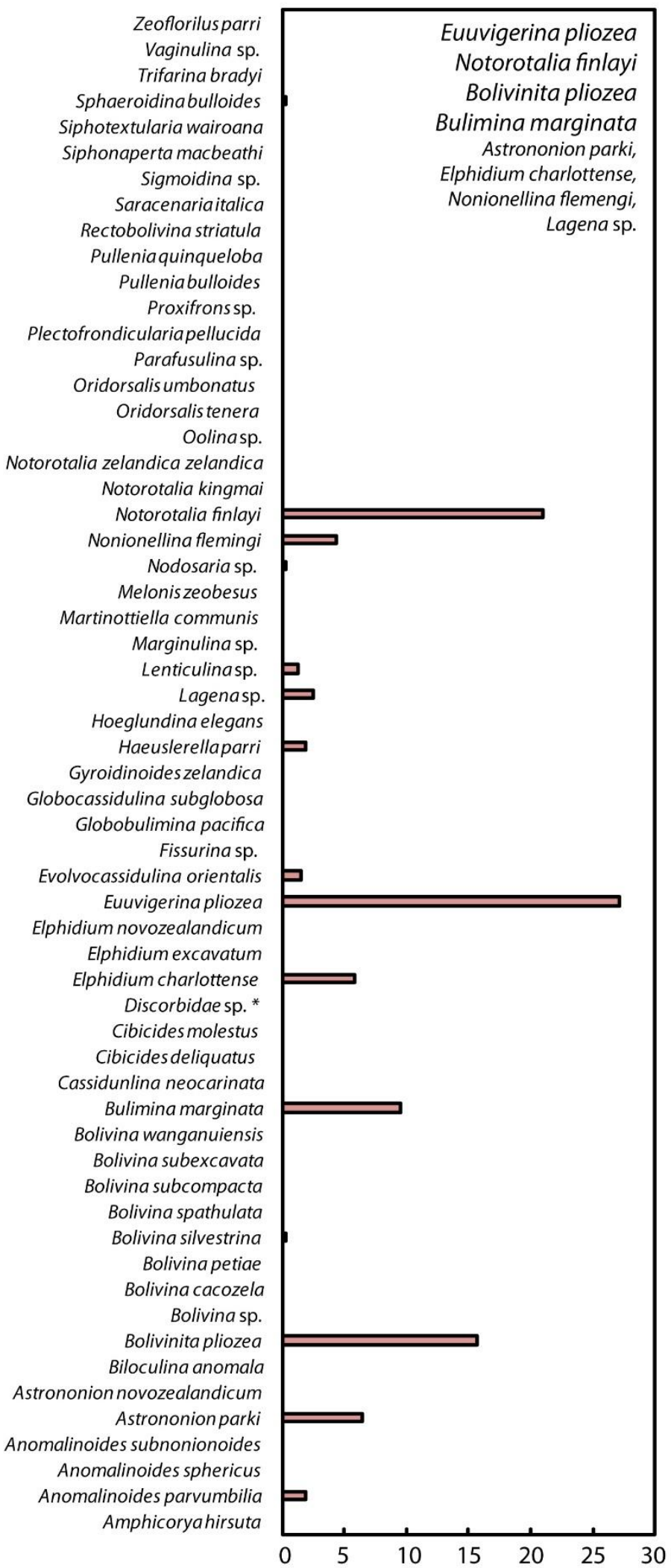

Cluster 8

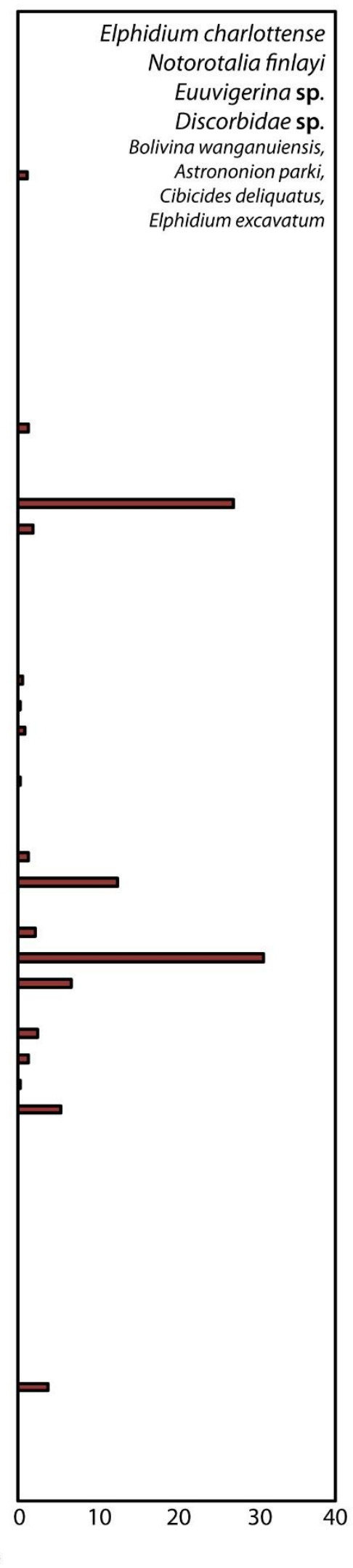

Figure 4.9f: Clusters 7 and 8. 
Palaeo- water depths can be assigned to each association via comparison with previous studies of the modern depth distribution of the same or closely-related taxa. The depth ranges of species and associations from this study are qualitatively compared to those described in Hayward (1986) and Hayward et al. (1999) (figure 4.10), which have also been used in Wanganui Basin studies by Journeaux et al. (1996), Naish and Kamp (1997a) and Kamp et al. (1998). 


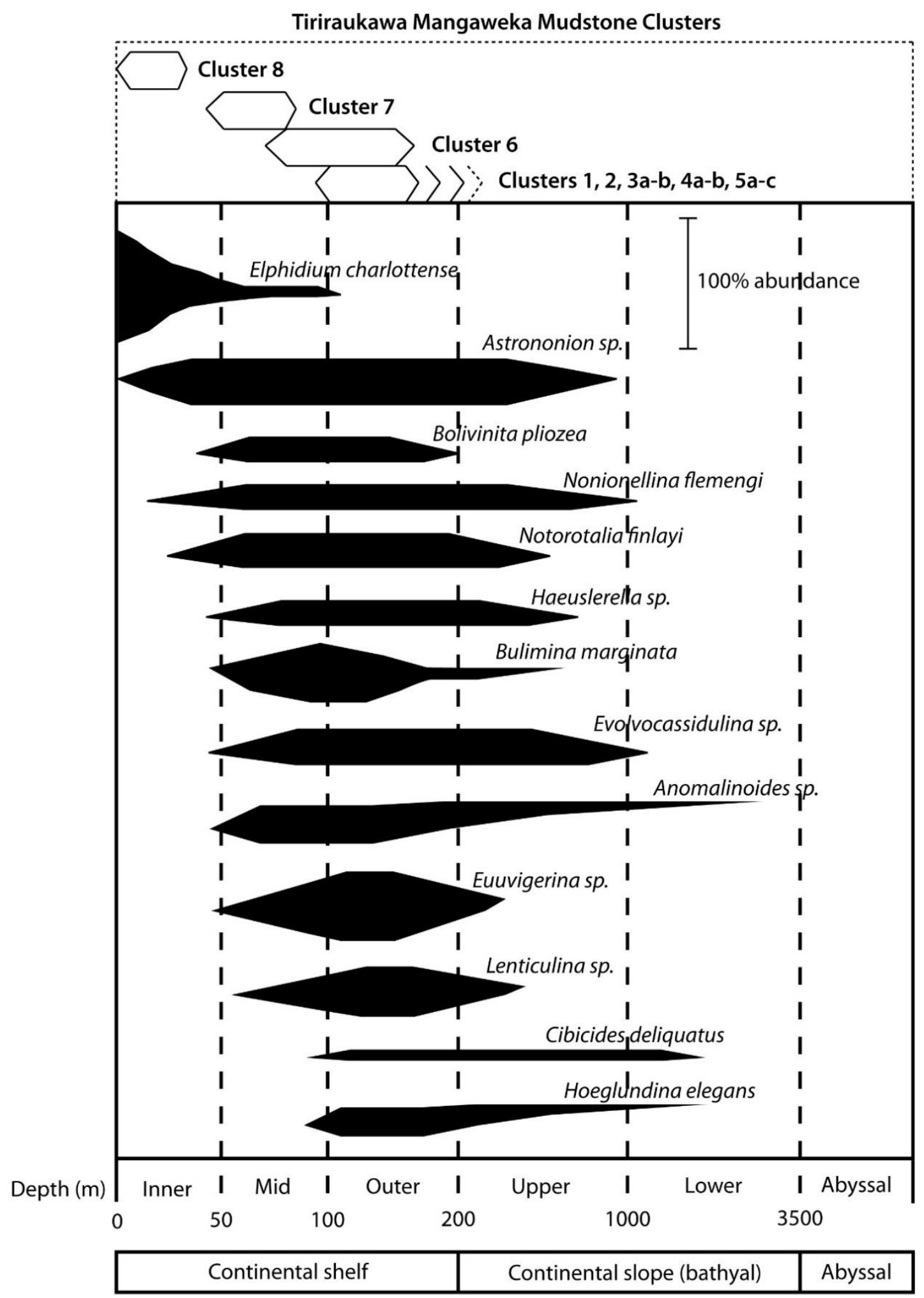

Modern New Zealand marine environment

Figure 4.10: Water depth distribution of modern (normal salinity) New Zealand benthic foraminifera from Hayward (1986) and Hayward et al. (1999). Modern New Zealand configurations compared with the clusters defined in this study (top). Figure after Hayward (1986), Naish \& Kamp (1997b) and Kamp et al. (1998). Arrows indicate the possibility of deeper ranges. 
Table 4.1: Table displaying Tiriraukawa Mangaweka Mudstone cluster depth ranges, depositional environments and comparison to foraminifera associations described in previous studies of the Wanganui Basin (Naish \& Kamp, 1999b; Kamp et al., 1998) and modern New Zealand environments (Hayward et al., 1999).

\begin{tabular}{|c|l|l|l|l|l|}
\hline Cluster & $\begin{array}{c}\text { Assigned } \\
\text { depth } \\
\text { range (m) }\end{array}$ & $\begin{array}{l}\text { Depositional } \\
\text { environment }\end{array}$ & $\begin{array}{c}\text { Hayward et } \\
\text { al. (1999) } \\
\text { association }\end{array}$ & $\begin{array}{l}\text { Naish \& Kamp } \\
\text { (1997b) } \\
\text { association }\end{array}$ & $\begin{array}{l}\text { Kamp et al. } \\
\text { (1998) } \\
\text { association }\end{array}$ \\
\hline $\begin{array}{c}\mathbf{1}, \mathbf{2}, \mathbf{3 a -} \\
\mathbf{b}, \mathbf{4 a - b} \\
\mathbf{5 a - c}\end{array}$ & $\begin{array}{l}100-150 \\
\text { (minimum) }\end{array}$ & Outer-shelf & N/A & $\begin{array}{l}\text { Uvigerina (K), } \\
\text { Bolivinita (L) }\end{array}$ & $\begin{array}{l}\text { Association } \\
\text { C, D and E }\end{array}$ \\
\hline $\mathbf{6}$ & $80-100$ & $\begin{array}{l}\text { Mid- to outer- } \\
\text { shelf }\end{array}$ & N/A & $\begin{array}{l}\text { Notorotalia } \\
\text { finlayi (G-I) }\end{array}$ & $\begin{array}{l}\text { Association } \\
\text { B and C }\end{array}$ \\
\hline $\mathbf{7}$ & $\sim 50$ & Mid-shelf & $\begin{array}{l}\text { Association B } \\
\text { (Bulimina } \\
\text { marginata) } \\
\text { Association C } \\
\text { (Cassidulina } \\
\text { carinata) }\end{array}$ & $\begin{array}{l}\text { Notorotalia } \\
\text { finlayi (G, H) }\end{array}$ & $\begin{array}{l}\text { Association } \\
\text { B }\end{array}$ \\
\hline $\mathbf{8}$ & $<20$ & Inner-shelf & $\begin{array}{l}\text { Association } \\
\text { Ech } \\
\text { (Elphidium } \\
\text { charlottense })\end{array}$ & $\begin{array}{l}\text { Elphidium (C, } \\
\text { D) }\end{array}$ & $\begin{array}{l}\text { Association } \\
\text { A }\end{array}$ \\
\hline
\end{tabular}

Of the 12 benthic foraminifera associations defined in the cluster analysis, nine are of distinctly outer shelf affinity ( $\sim 100-150$ metres water depth), and these characterise the lower 400 metres of the Mangaweka Mudstone at Tiriraukawa (clusters 1-5c) (table 4.1, figures 4.9a-e and 4.10). This is based on the medium to high abundances of Haeuslerella parri, Euuvigerina sp., Hoeglundina elegans, Oridorsalis umbonatus and Lenticulina sp., which define the outer-shelf environment of the modern New Zealand continental shelf (Hayward, 1986). While Haeuslerella parri is not an extant species, its closest living relative has well-resolved water depth distributions, and previously has been used successfully in palaeoenvironmental assessments (Hornibrook et al., 1989; Journeaux et al., 1996). Cluster 6 is characterised as a mid-outer shelf association ( 80100 metres water depth), based on the decreasing abundance of Haeuslerella parri and increasing abundances of mid-shelf species such as Bulimina marginata, Bolivinita pliozea and Notorotalia finlayi (figure 4.9e). Cluster 7 is defined as a mid-shelf association ( $~ 50$ metres water depth) based on the increasing abundances of mid and inner shelf species such as Bulimina marginata and Elphidium charlottense, respectively 
(figure 4.9f). Cluster 8, which is the top sample and notably the most productive, is defined as an inner-shelf association ( $<20$ metres water depth), based on the dominance of shallow species Elphidium charlottense and the presence of Discorbidae sp. and Bolivina wanganuiensis (figure 4.9f) (Hayward et al., 1999).

Overall, this range of associations follows stratigraphic order, and there are no repeating associations up section. This indicates continued faunal changes throughout the section, and displays a persistent shallowing trend from deep, outer shelf depths to shallow inner shelf depths. Superimposed upon this shallowing trend are distinct higher frequency faunal changes (marked by the changing associations of foraminifera) that match the cyclical changes displayed by the sieved grainsize results (figure 4.11).

Clusters 1-5c are identified to be similar to the outer-shelf associations of Naish and Kamp (1997a) and Kamp et al. (1998) (table 4.1) on the basis of: (i) total lack of inner shelf species and (ii) similar common occurrence of Notorotalia finlayi, Astrononion parki, Anomalinoides sp., and Euuvigerina sp., Haeuslerella parri, Cibicides sp., Lenticulina sp. and Hoeglundina elegans. Cluster 6 is reminiscent of association Notorotalia finlayi (Naish \& Kamp, 1996b) and Association B and C (Kamp et al., 1998) on the basis of increasing numbers of inner shelf species of the genus Elphidium, while still containing species with very large depth ranges which encompass mid- and outer-shelf depths (e.g. Nonionellina flemengi, Cassidulina neocarinata, Astrononion parki). The preceding clusters are not able to be identified against the Hayward et al. (1999) associations, as these cover assemblages constrained to the mid-shelf and shallower. Cluster 7 and 8 can be approximately correlated to mid-shelf and very shallow associations of Bulimina marginata and Elphidium charlottense, respectively (Hayward et al., 1999).

Furthermore, the presence of Cibicides molestus at the base of the section and subsequent absence above $\sim 600$ metres stratigraphic depth can be interpreted as the Last Appearance Datum (LAD) Cibicides molestus. This is consistent with previous studies noting the disappearance of Cibicides molestus at the base of the Mangaweka Mudstone in the Late Pliocene, which is a proxy for the Waipipian/Mangapanian New Zealand stage boundary at 3.0 Ma (Collen, 1972; Hornibrook et al., 1989; Journeaux et al., 1996; Cooper, 2004). 
A graphical comparison of grainsize and benthic foraminifera clusters and their respective palaeobathymetries is shown in figures $4.11 \mathrm{a}$ and $\mathrm{b}$.

Figure 4.11: (A) Foraminifera cluster changes with stratigraphic depth compared with grainsize variability. The cluster boundaries are largely consistent with the peaks and lows in the grainsize curve of the lower $\sim 400$ metres of the section. The grainsize measurements from both the Laser Particle Sizer and sieving are also very consistent. (B) Reconstructed water depths for the Mangaweka Mudstone along Watershed Road. Grey area shows likely water depth ranges from both grainsize and foraminifera, colours denote the clusters defined above.

A

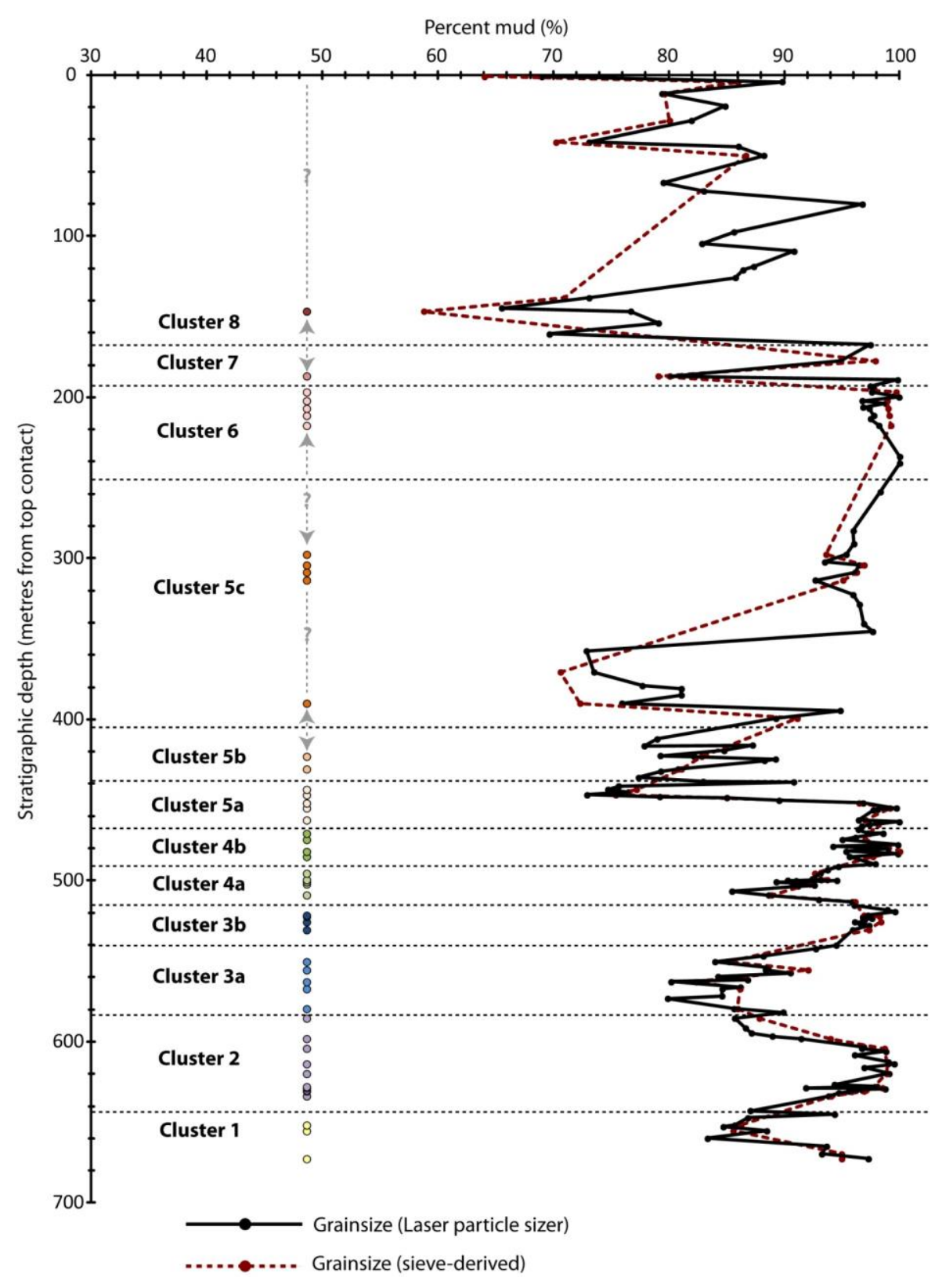


Figure 4.11b

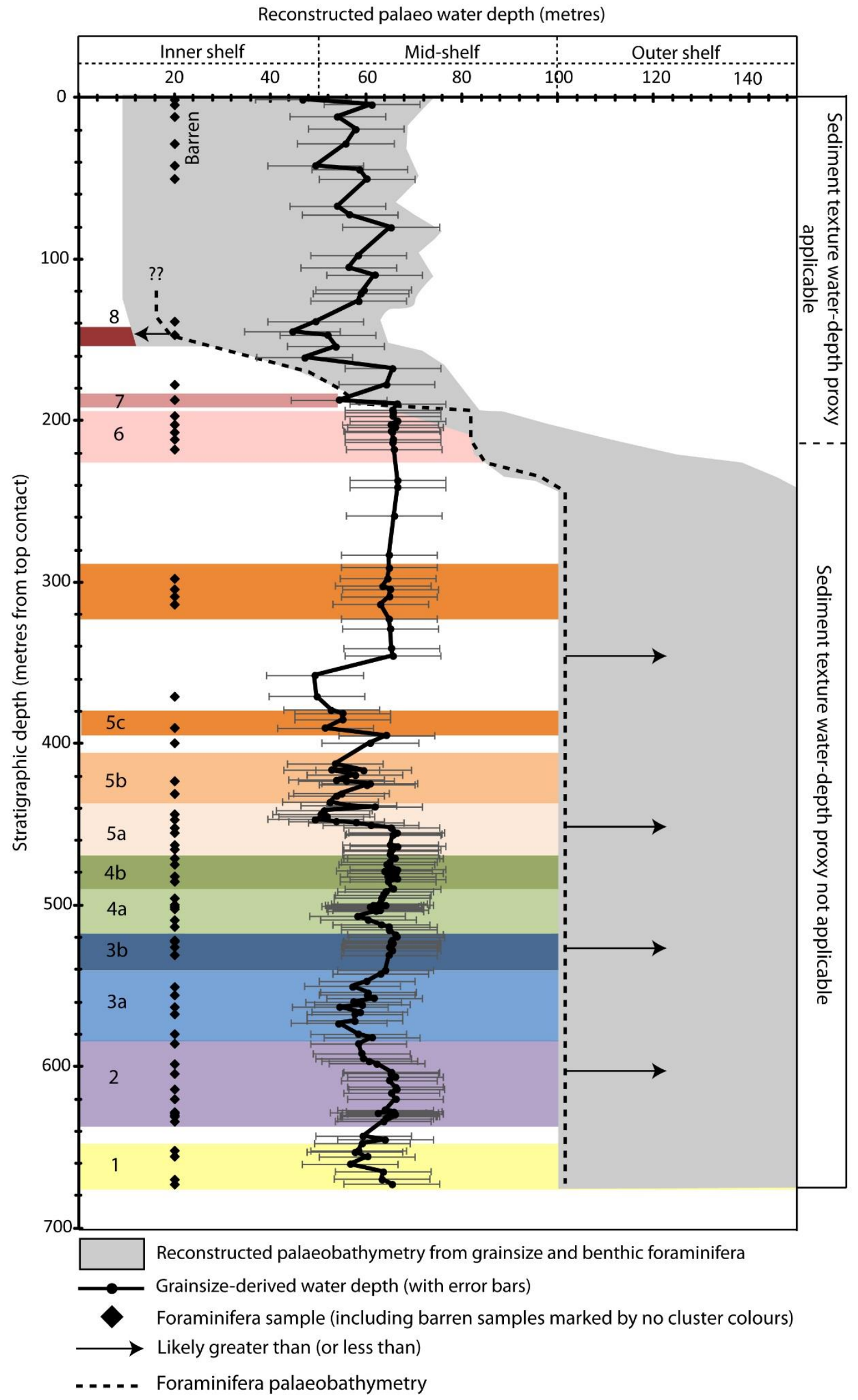


While the possible depth ranges derived from both palaeobathymetry proxies are large, they detail interesting changes in the nature, amplitude and pattern of water depth variability. Both indicate the same overall trend of decreasing water depths, shown by the grainsize as a reduction in percent mud and by the foraminifera associations as an increase in species with the affinity for inner-shelf depths (figures 4.7, 4.10). Similarly, both proxies show small amplitude, higher frequency changes superimposed over this general shallowing trend. The grainsize fluctuations between higher and slightly lower percent mud are largely in-step with the statistically significant changes in the faunal composition of the foraminifera associations (figures $4.11 \mathrm{a}$ and $\mathrm{b}$ ).

The grainsize results suggest approximately mid-shelf ( $\sim 55-65$ metres depth) depths for the lower $\sim 500$ metres of the Mangaweka Mudstone, but in contrast the benthic foraminifera associations indicate outer-shelf depths (>100 metres depth). The discrepancy between these two proxies decreases in the top 200 metres of the section, where they both indicate inner shelf (approximately $<50$ metres) depths.

The outer-shelf foraminifera associations in the lower half of the section demonstrate that the estimates of palaeobathymetry determined from the grainsize proxy are at best minimum estimates, or that grainsize is not in hydrodynamic equilibrium with the contemporary wave environment and that other depositional processes (e.g. tractional currents) are operating. The former is consistent with the study by Dunbar and Barrett (2005) where only minimum estimates can be made for sediments containing over $80 \%$ mud. While the foraminifera associations are changing their composition consistently in phase with the grainsize fluctuations, their implied water-depth variation remains within the outer-shelf range, whereas the grainsize results suggest that the water depths oscillate between mid-shelf and inner-shelf depths. The nature of the foraminifera associations do not imply significant reworking and redeposition. Therefore, it is concluded that grainsize results from the lower $\sim 400$ metres of the Mangaweka Mudstone cannot be interpreted on the basis of the Dunbar and Barrett (2005) water depth proxy for wave-graded continental shelves, and likely reflect the periodic influence of tractional currents (e.g. tidal currents) in the mid- and outer-shelf environments (discussed in Chapter 5).

Above 140 metres stratigraphic depth (Cluster 8), seven foraminifera samples were barren, and characterised by grey-brown colours, bioturbation, fine sand and silt 
laminations with generally decreasing percent mud. It is possible that any foraminifera present in these shallower sandy facies have since been dissolved by interstitial fluids. Based on the grainsize results, sedimentary features and the composition of the closest foraminifera assemblage (dominant Elphidium charlottense and Discorbidae sp.), the top 140 metres of section likely varies between shallow inner-shelf and mid-shelf depths ( $<20$ to 50 metres). At these depths, wave energy is able to interact with the seafloor, and therefore this facies is likely in hydrodynamic equilibrium with a wave-graded inner continental shelf. Therefore, the application of the grainsize water-depth proxy suggests 10-25 metres amplitude of water depth changes in the upper $\sim 140$ metres of section.

In summary, the palaeobathymetry for the Watershed Road section is dominantly outershelf for the lower $\sim 400$ metres of section, which shallows to mid-shelf and ultimately inner-shelf ( $<20$ metres depth) by $\sim 140$ metres from the top contact (figure $4.11 \mathrm{~b}$ ). The section is also characterised by higher-frequency changes in sediment texture and foraminifera associations. However, the grainsize cycles are not the direct results of wave influence on the seabed, and therefore cannot be directly linked to water depth/sea-level changes. However, grainsize variability may be a result of more indirect processes linked to sea-level changes, which is explored further in Chapter 5. 


\section{Age model results}

An age model is constructed here for the studied stratigraphic section based on the integration of a new magnetostratigraphy, foraminiferal biostratigraphic constraints, and tephrochronology and tephrostratigraphy.

Palaeomagnetic results and magnetostratigraphy

Site stratigraphic positions for palaeomagnetic analyses are shown in figure 4.1, and were selected on the basis of previous magnetostratigraphies detailing magnetic reversals at the top and base of the Mangaweka Mudstone (Journeaux et al., 1996; Turner et al., 2005). While five samples were collected from each site, some specimens were lost due to rock oven malfunctions during laboratory analysis, and therefore some sites do not have as many data points as was intended. Site and specimen data for each palaeomagnetic sample are available in Appendix D.

Progressive thermal demagnetisation data were displayed on vector component plots, Z-plots (Zijderveld, 1967), and equal-area stereoplots of the unit vectors (McFadden and McElhinny, 1988; Butler, 1992). Principal component analysis (PCA) to estimate directions of characteristic remanent magnetisation (ChRM) and remagnetisation circle calculations were carried out using the PuffinPlot software of Lurcock and Wilson (2012).

The results are consistent with the characteristics of samples with multiple components of magnetisation as discussed in Turner (2001) and in Chapter 3. Four patterns of demagnetisation are identified on Z-plots and stereoplots (examples displayed in figure 4.12 , numbers on figure denote the numbered bullet points):

A. (Figure 4.12a) Two-components of magnetisation, where the first is a normal thermo-viscous component close to the present-day field direction. The second is an underlying (higher blocking temperature) normal component that trends towards (or close to) the origin $(0,0)$ of a Z-plot and is interpreted to be the primary ChRM.

B. (Figure 4.12b) Three components of magnetisation, where the first is a normal thermo-viscous component close to the present-day field. The second is an underlying normal component, which on demagnetisation does not trend 
towards the origin of a Z-plot and is interpreted to be the primary ChRM, but likely has an underlying chemical remanent magnetisation of undetermined direction. This underlying component cannot be isolated as the samples undergo thermal alteration on further heating and thus masks any remaining remanence.

C. (Figure 4.12c) Two components of magnetisation, where the first is a normal thermo-viscous component close to the present-day field and the second is an underlying reversed component, which is not isolated in the range of demagnetisation temperatures undertaken on stereographic projection of the sequence of direction yields. The arc of a great circle, if extrapolated, terminates in the reversed ChRM direction.

D. (Figure 4.12d) Three components of magnetisation, where the first is a normal thermo-viscous component close to the present-day field, and the second an underlying reversed component, which does not trend towards the origin of a Zplot nor along the arc of a great circle. Therefore this is interpreted to have another underlying chemically-altered component, which is difficult to identify. This pattern of demagnetisation is difficult to distinguish from a pattern (2) that is severely influenced by the chemically-altered underlying component.

Figure 4.12a-d (over page): Examples of multiple-component demagnetisation patterns for the Mangaweka Mudstone palaeomagnetic samples. Specimen examples A-D match the bullet points in text. Equal area stereoplots are displayed on the left, Z-plots in the middle (with vertical and horizontal components displayed) and on the right demagnetisation data (measured magnetisation and magnetic susceptibility with demagnetisation step). Z-plot annotations include the initial natural remanent magnetisation (NRM) measurement and the maximum thermal demagnetisation step measurement $\left(250-290^{\circ} \mathrm{C}\right)$. Declinations (dec) and inclinations (inc) calculated for each of the example specimens are shown directly below the demagnetisation data. Specimen data points highlighted in red indicate the data used to calculate palaeo-directions. PCA denotes the Principal Component Analysis-derived direction, and pole to GC denotes to the direction derived from great circle analysis (the pole to which is shown as the triangle on type $C$ ). Examples $A$ and $B$ are interpreted to be normal polarity, and example $C$ is reversed polarity. As it is difficult to identify the nature of the ChRM of type-D samples, these are regarded as indeterminate directions. 

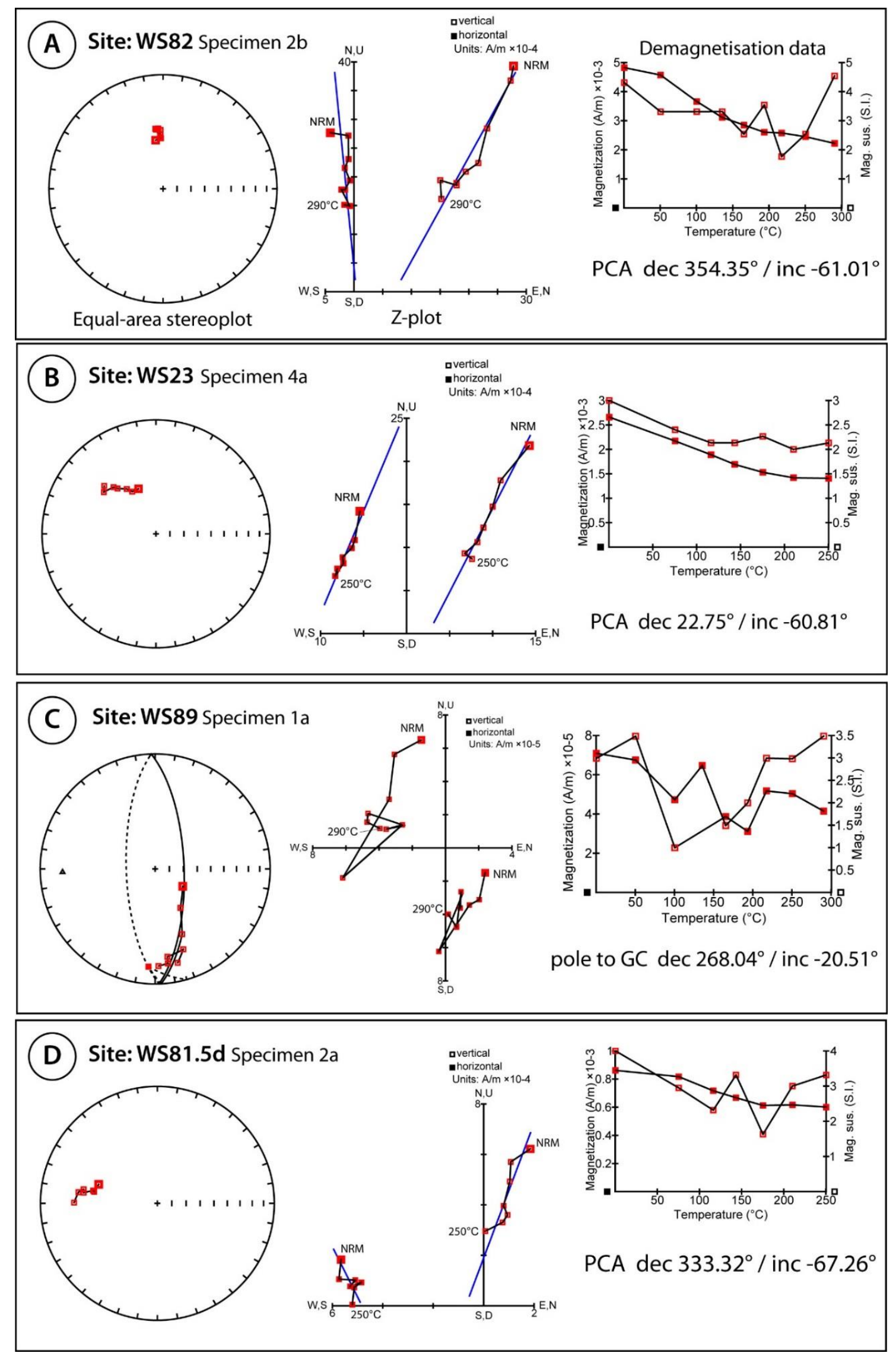
Mean directions for each site were calculated using PuffinPlot software (Lurcock and Wilson, 2012), determined via Fisher means of the Z-plot derived specimen PCA results or from the convergence of specimen remagnetisation circles from the same site. These are displayed (in stratigraphic order) in figure 4.13.

Figure 4.13 shows that the palaeomagnetic samples collected from the Mangaweka Mudstone at Tiriraukawa are dominantly normal polarity. However five samples display likely reversed polarities (WS11, WS79.5a, WS79.5b, WS81 and WS89). Sites WS3, WS79.5a, WS79.5b and WS81.5d have large uncertainties and have indeterminable ChRM (type D), and are thus considered unreliable for the construction of a magnetostratigraphy for the Mangaweka Mudstone. Additionally, samples WS79.5a, WS79.5b and WS81.5d were collected from a weathered outcrop (evidenced by orangebrown discolouration), but all display reversed polarity (Appendix D). The siteaveraged inclinations and declinations are plotted with depth in figure 4.14.

Figure 4.13 (over page): Palaeomagnetic sample site stereoplots used to construct magnetostratigraphy (in stratigraphic order), displaying mean directions derived from PCA and great circle analysis, including their type of demagnetisation pattern (A-D) defined in figure 4.12. Small squares are specimen directions, and the small circle is the mean direction. The larger oval around the squares and small circles is the $\mathbf{9 5 \%}$ confidence interval. Great circle remagnetisation arcs are solid lines for the upper hemisphere and dotted for the lower hemisphere, and the $95 \%$ confidence interval as the dotted oval. The poles to the great circles are plotted as small triangles. Declination (dec), inclination (inc), uncertainty within the $95 \%$ confidence interval (a95) and the number of samples the confidence estimate is calculated from (n) are displayed for each site below the stereoplots. Fisher means were calculated for sites containing specimens analysed using PCA, and the remainder were calculated by observing the convergence of remagnetisation great circles (GC). 


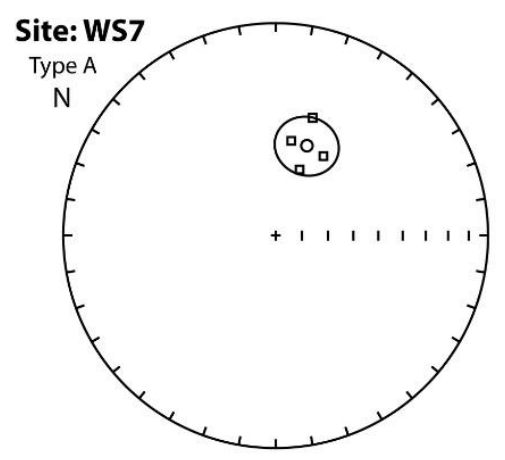

Fisher dec 19.2 / inc -53.1 / a95 11.7/n 4

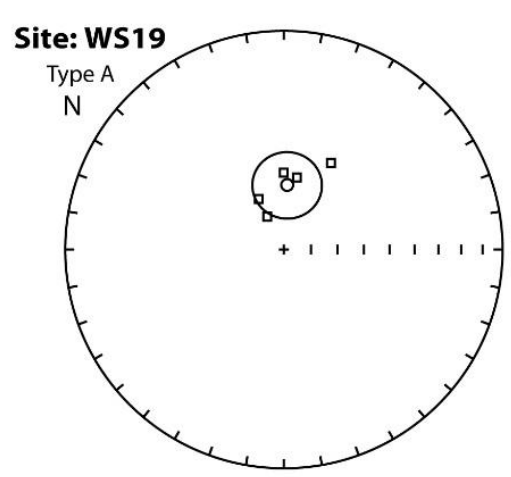

Fisher dec 2.9 / inc - 65.9 / a95 12.6/n 5

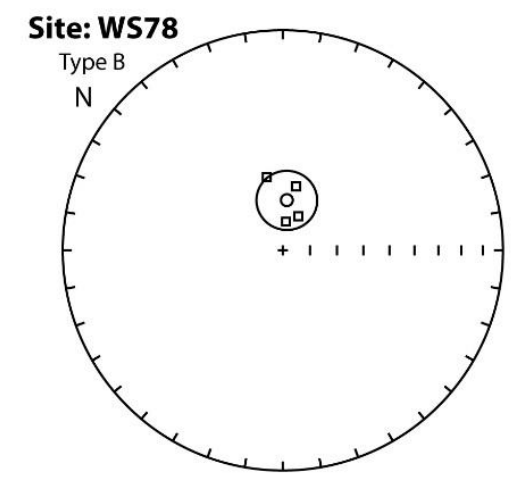

Fisher dec 4.6 / inc -71.4 / a95 11.1 / n 5

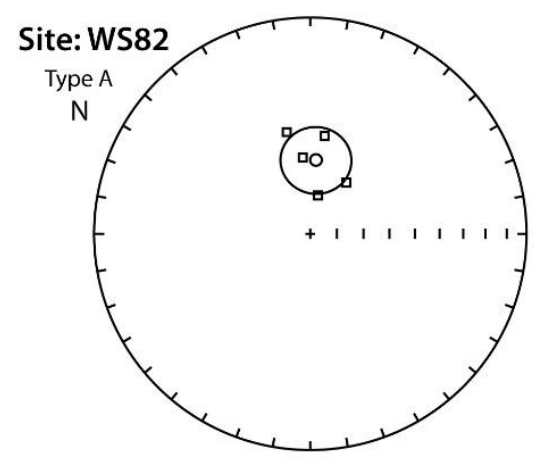

Fisher dec 4.4 / inc -62.0 / a95 12.9/n 5

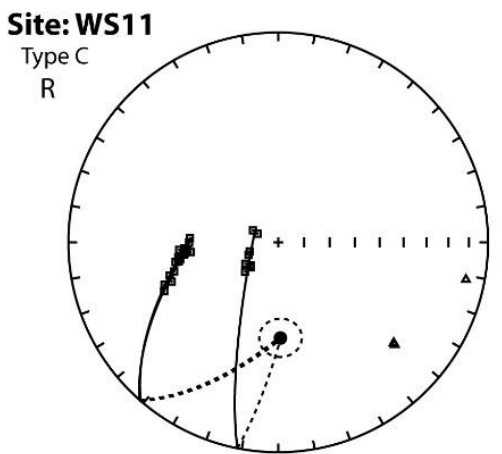

pole to GCs dec 178.6 / inc 52.4 / a95 7.8 / n 3

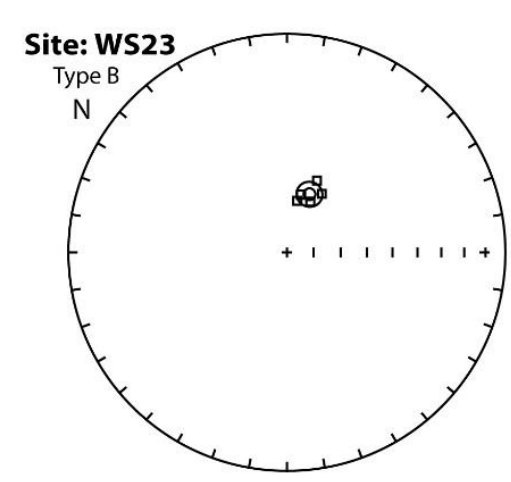

Fisher dec 21.2 / inc - 66.7 / a95 4.7 / n 5

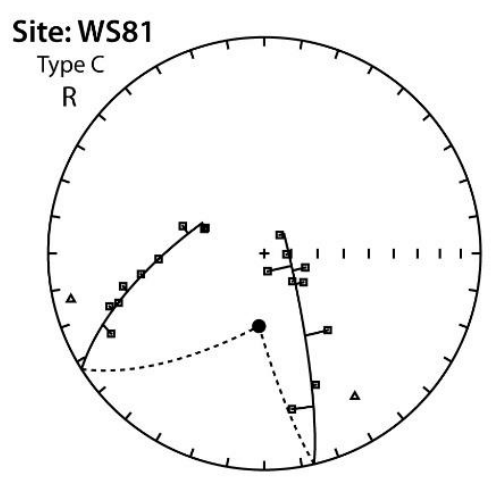

pole to GCs dec 184.2 / inc 62.5 / a95 NaN / n 2

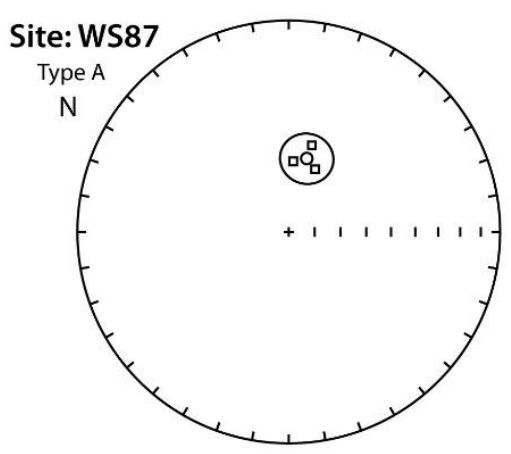

Fisher dec 13.8/inc -60.7 / a95 10.0/n 3

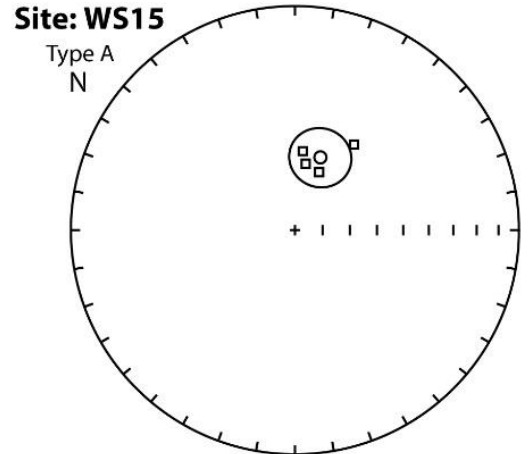

Fisher dec 19.3 / inc -61.8/a95 11.0/n 4

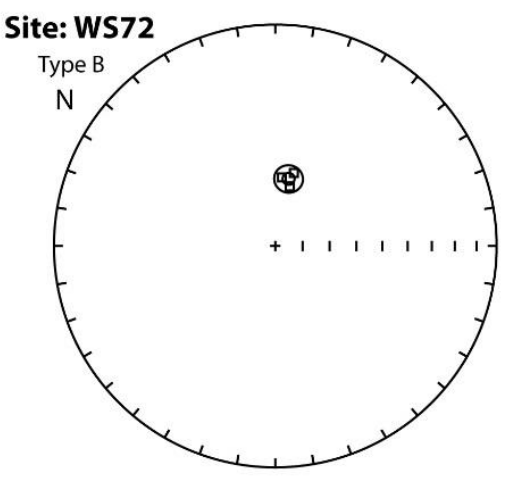

Fisher dec 11.2 / inc -64.8 / a95 5.1 / n 3

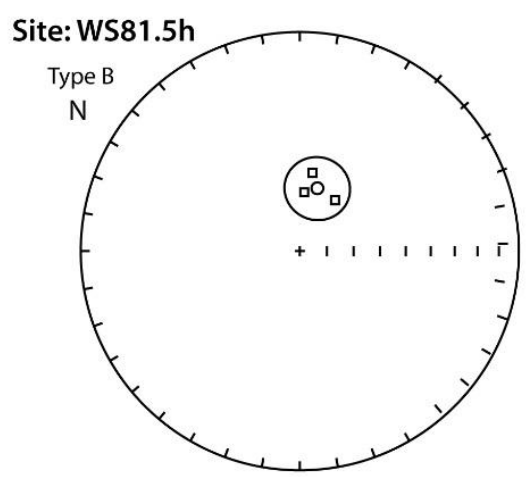

Fisher dec 15.6/inc -65.7 / a95 11.9/n 3

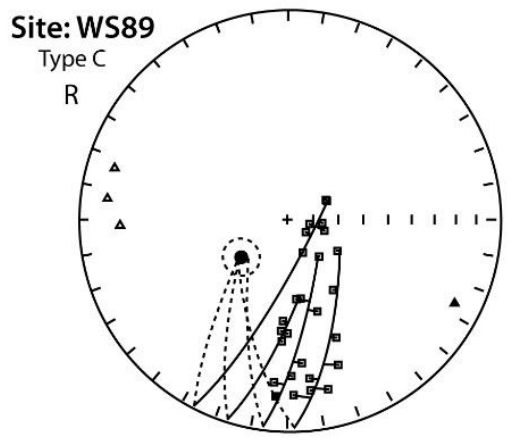

pole to GCs dec 230.9 / inc 66.6 / a95 7.3 / n 4 

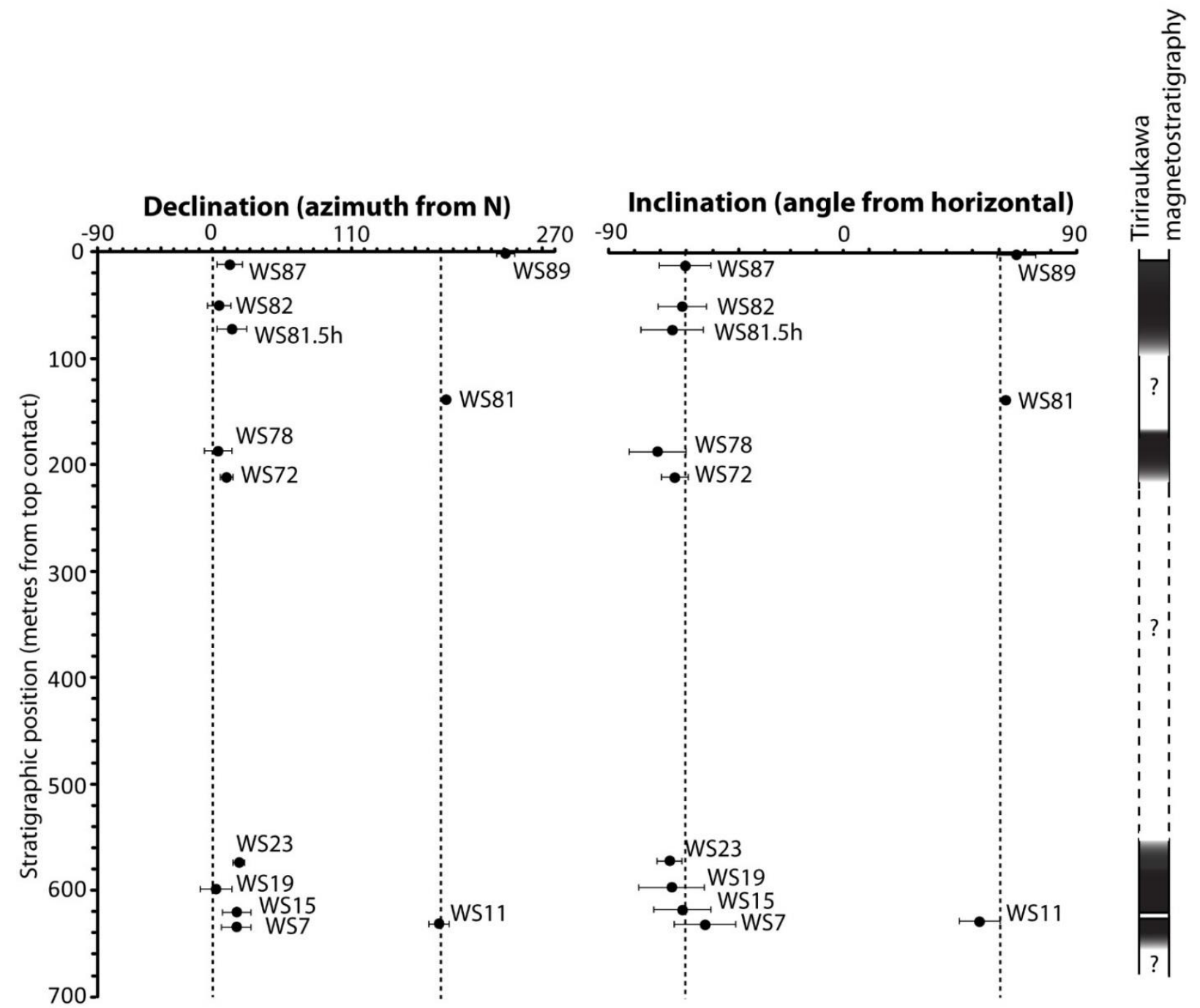

Figure 4.14: Declination and inclination with stratigraphic depth for each palaeomagnetic site (excluding those already determined as unreliable). Error bars display the $95 \%$ uncertainty. The dotted lines highlight where normal and reversed polarity samples would plot, for example the WS89 and WS11 are reversed polarity sites.

The results presented in figure 4.14 and the results of previous magnetostratigraphy of the Mangaweka Mudstone indicate the location of a transition from normal to reversed polarity at the top of the formation. At Watershed Road, this boundary is likely located between $\sim 11$ and $\sim 1$ metres from the top contact, between sites WS87 and WS89. This interpretation is based on reversed site WS89, the top sample of the section at Watershed Road. While there are three reversed sites $\sim 150$ metres below the top contact (WS79.5a, WS79.5b and WS81), they are not interpreted to be reliable enough to form the basis of the magnetostratigraphy because they were also collected from a partially weathered outcrop. It is possible that these samples display a dominant 
secondary (chemical remanent magnetisation) component that was locked in during a reversed polarity interval. Additionally, there are robust polarity sites (WS81.5h, WS82 and WS87) between WS79.5a and WS89 ( 60 metres stratigraphic thickness).

After considering the quality of the samples throughout the section, there are two robust reversely magnetised sites in this suite: WS89 at the very top, and WS11 near the base (figure 4.14). The Matuyama-Gauss boundary at 2.58 Ma (Cande and Kent, 1995) is interpreted to be between samples WS89 and WS87 (the top 11 metres of the section). When this is considered, two interpretations of the magnetostratigraphy are possible (figure 4.15). If a sedimentation rate of 1 metre/ $\mathrm{kyr}^{-1}$ is applied, which is the value obtained for the Mangaweka Mudstone in the Rangitikei River (Turner et al., 2005), then the Kaena reversed polarity subchron would fall in the un-sampled section above WS23 (figure 4.14) and the top of the Mammoth subchron would be near the base of the sampled section. Turner et al. (2005) observed a rapid reverse-normal-reversenormal sequence at the top of the Mammoth in the Turakina River section. It is possible that the reversed polarity site of WS11 is part of this sequence with the main part of the subchron below WS3. If the sedimentation rate at Tiriraukawa was approaching that of the Turakina River at around 1.5 metres/ $\mathrm{kyr}^{-1}$ (Turner et al., 2005), both the Kaena and Mammoth would be below the sampled section. The Mangaweka Mudstone would be entirely in the Gauss normal polarity chron (with the exception of the Matuyama reversal at the top of the section).

The latter interpretation of the magnetostratigraphy is considered the most likely as the sedimentation rates at Tiriraukawa are more likely to be closer to that of the Turakina River record. The total thickness of the Mangaweka Mudstone in the Rangitikei River is 440 metres (Journeaux et al., 1996; Kamp et al., 1998) and is over 700 metres in the Turakina River (Hoskins and McGuire, 1990; Turner et al., 2005). As the measured thickness of the Mangaweka Mudstone at Tiriraukawa is at least 672 metres, sedimentation rates and therefore a magnetostratigraphy comparable to that of the Turakina are most likely. This is also consistent with previous Mangaweka Mudstone magnetostratigraphy that identifies the Kaena and Mammoth subchrons in the underlying formations of the Utiku group (a characteristically sandier, shallower lithology), and the Matuyama-Gauss reversal at the top of the Mangaweka Mudstone formation (Journeaux et al., 1996; Kamp et al., 1998). 


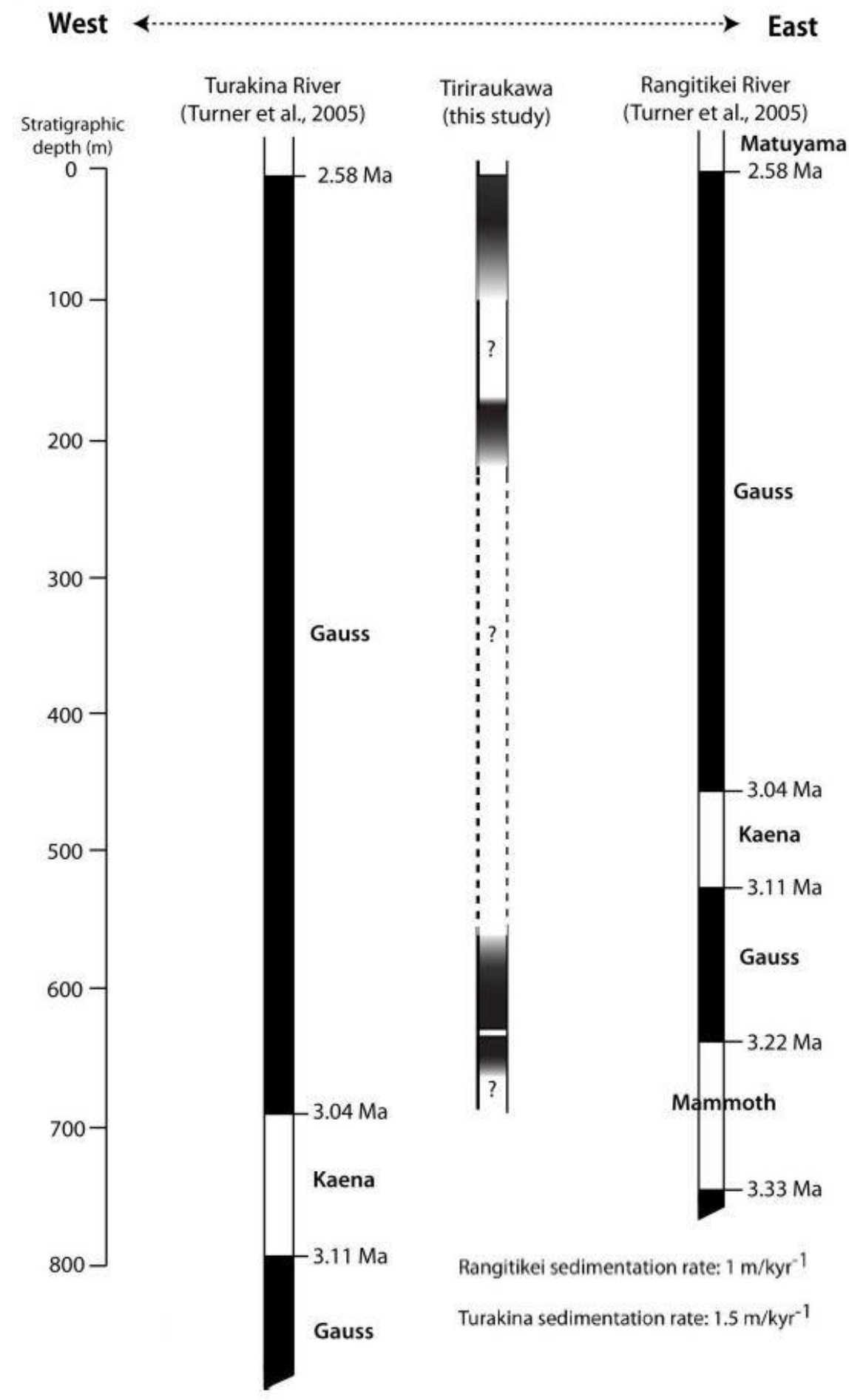

Figure 4.15: Possible interpretations of the Tiriraukawa magnetostratigraphy within the across-basin chronostratigraphic frameworks provided by Turner et al. (2005). It is argued that the Tiriraukawa magnetostratigraphy is more likely to be comparable to that of the Turakina record, which is consistent with previous magnetostratigraphy for the Mangaweka Mudstone. 
The results of the zircon fission track dating of the Eagle Hill tephra from the Rangitikei River are displayed in table 4.2 .

Table 4.2: Zircon fission-track age from the Eagle Hill tephra, Mangaweka Mudstone, Rangitikei River valley. Stratigraphic depth (within the Mangaweka Mudstone measured section) is presented in Journeaux et al. (1996). $\rho$ s and $\rho$ i represent sample spontaneous and induced track densities; $P(\chi 2)$ is the probability of $\chi 2$ for $v$ degrees of freedom where $v=$ no. of crystals -1 . The age is a central age (Galbraith and Laslett, 1993). $\lambda_{D}=1.55125$ $x$ 10-10. Zeta zircon/CN1 $=120 \pm 5$. Samples were irradiated at the Oregon State University reactor facility.

\begin{tabular}{|c|c|c|c|c|c|c|c|c|c|}
\hline $\begin{array}{l}\text { Sample } \\
\text { Number }\end{array}$ & $\begin{array}{l}\text { Stratigraphic } \\
\text { depth(m) }\end{array}$ & $\begin{array}{l}\text { Irradiation } \\
\text { number }\end{array}$ & $\begin{array}{l}\text { Number } \\
\text { of } \\
\text { grains }\end{array}$ & $\begin{array}{l}\text { Standard track } \\
\text { density } \times 10^{5} \\
\mathrm{~cm}^{-2} \\
\text { (counted) }\end{array}$ & $\begin{array}{l}\rho_{s} \times 10^{5} \\
\mathrm{~cm}^{-2} \\
\text { (counted) }\end{array}$ & $\begin{array}{l}\rho_{\mathrm{i}} \times 10^{5} \\
\mathrm{~cm}^{-2} \\
\text { (counted) }\end{array}$ & $\begin{array}{l}\text { U conc } \\
\text { ppm }\end{array}$ & $\begin{array}{l}P\left(\chi^{2}\right) \% \\
\text { (dispersion) }\end{array}$ & $\begin{array}{l}\text { Age } \pm \\
2 \sigma \\
\text { (Ma) }\end{array}$ \\
\hline EH1 & 270 & VUW021 & 16 & $3.186(2383)$ & 3.55 (114) & 24.9 (799) & 306 & 95 & $\begin{array}{l}2.7 \pm \\
0.6\end{array}$ \\
\hline
\end{tabular}

The mean age for the Eagle Hill tephra collected from the Rangitikei River is $2.7 \pm 0.3$ Ma (within one standard deviation). This age is consistent with the age of the Mangaweka Mudstone (Naish and Kamp, 1995; Journeaux et al., 1996), and also with a previously estimated stratigraphic age for the Eagle Hill tephra of 2.88 Ma (Naish et al., 1996), and a Sensitive High Resolution Ion Microprobe U-Pb age of $2.85 \pm 0.2$ Ma by McIntyre (2002). It is acknowledged that this age has a large uncertainty, which limits its use as a precise chronological marker for high resolution grainsize and benthic foraminifera sampling. However, the mean age is consistent with independent dating techniques (magnetostratigraphy and biostratigraphy) and the previously estimated age of Naish et al. (1996), and provides independent constraint and strengthened confidence on the magnetostratigraphic interpretation discussed above.

A value of $95 \%$ for the chi-squared test $\left(x^{2}\right)$ indicates that the zircons analysed are from a single zircon population. However, due to the bioturbated nature of the tephra, volcanic zircons are not as abundant, and there are populations of detrital zircons; these are shown in the radial plot of individual zircon ages (figure 4.16). Additionally, a combination of zircon fission track dating and $\mathrm{U}-\mathrm{Pb}$ dating techniques will provide much higher precision ages (Carter and Moss, 1999), and improve the ability to 
constrain high resolution sedimentary records within magnetostratigraphic and biostratigraphic frameworks.

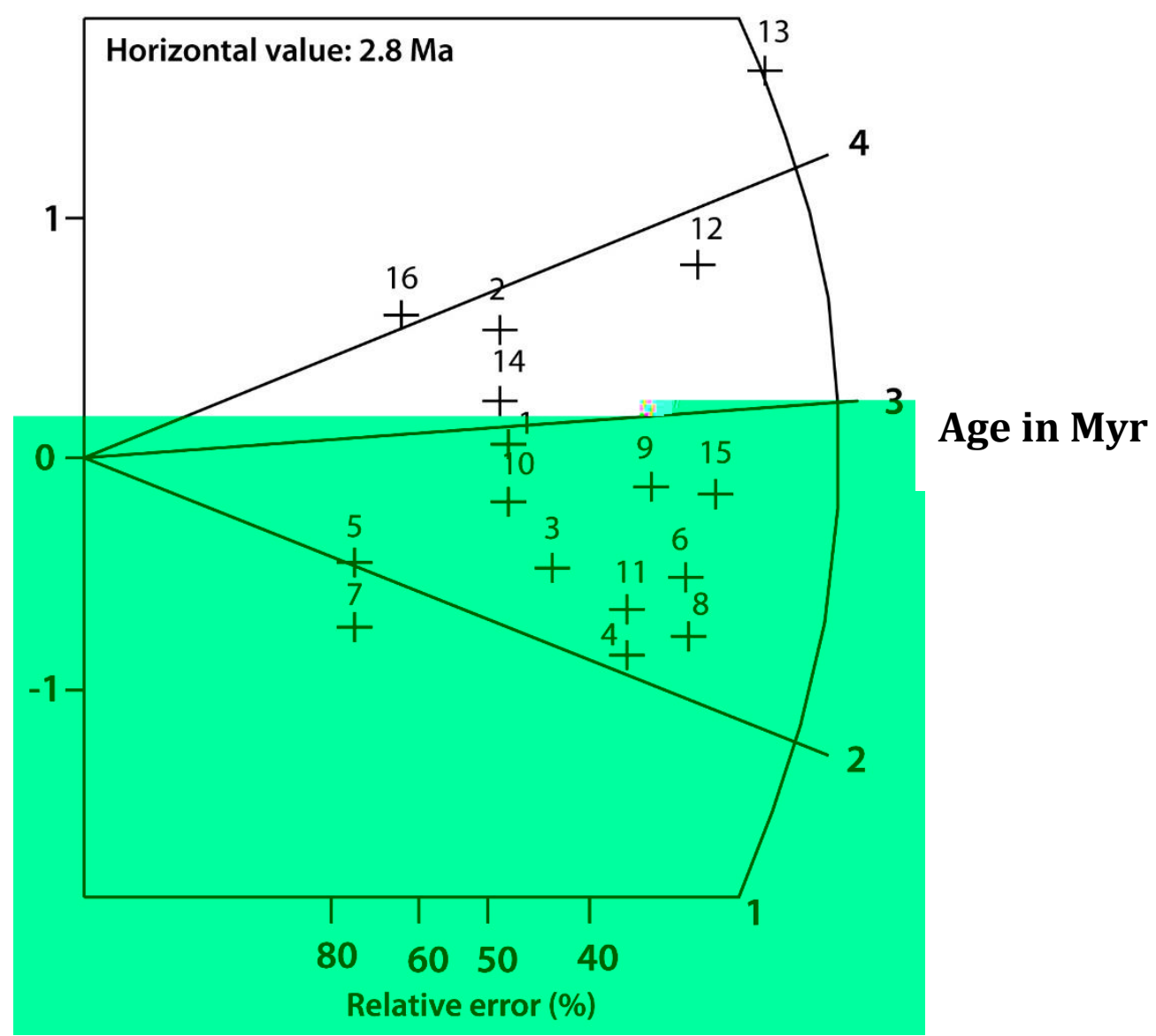

Figure 4.16: Radial plot of single-grain zircon ages (1-16) from the Eagle Hill tephra. Raw data for individual grains is available in Appendix E. The y-axis displays the unit standard error. 
Tephrostratigraphy: Major and trace element geochemical fingerprinting results

Major element data for two tephras collected from the Mangaweka Mudstone at Tiriraukawa and two tephras, the Eagle Hill and Kowhai (Naish et al., 1996) from the Rangitikei section are displayed in table 4.3. Their respective geographic locations and stratigraphic positions are shown in Chapter 3 and in figure 4.1.

Table 4.3: Mean major element composition of glass shards extracted from tephra from the Mangaweka Mudstone near Tiriraukawa and within the Rangitikei River valley. Data displayed are weight percent means calculated on a water-free basis. Standard deviation (in brackets below mean values) is \pm 1 ( $68 \%$ confidence interval) and is derived from the number of analyses ( $n$ ). All Fe is expressed as FeO. All samples are normalised against ATHO-G glass standard. Electron Probe Microanalysis was conducted by Juliet Sefton with the assistance of Brent Alloway. Individual glass major element Electron Probe Microanalysis data for each sample are listed in Appendix E.

\begin{tabular}{|c|c|c|c|c|c|c|c|c|c|c|c|c|}
\hline $\begin{array}{l}\text { Tephra } \\
\text { (probe mount } \\
\text { position) }\end{array}$ & $\mathrm{SiO}_{2}$ & $\mathrm{Al}_{2} \mathrm{O}_{3}$ & $\mathrm{TiO}_{2}$ & FeO & Mg0 & MnO & CaO & $\mathrm{Na}_{2} \mathrm{O}$ & $\mathrm{K}_{2} \mathbf{O}$ & $\mathrm{Cl}$ & $\mathrm{H}_{2} \mathrm{O}$ & $n$ \\
\hline $\begin{array}{l}\text { Tiri Tephra-1 } \\
(14-J 1-4)\end{array}$ & $\begin{array}{l}76.42 \\
(0.90)\end{array}$ & $\begin{array}{l}12.60 \\
(0.12)\end{array}$ & $\begin{array}{c}0.09 \\
(0.02)\end{array}$ & $\begin{array}{c}1.34 \\
(0.06)\end{array}$ & $\begin{array}{c}0.08 \\
(0.06)\end{array}$ & $\begin{array}{c}0.03 \\
(0.02)\end{array}$ & $\begin{array}{c}0.88 \\
(0.02)\end{array}$ & $\begin{array}{c}4.51 \\
(0.74)\end{array}$ & $\begin{array}{c}3.87 \\
(0.27)\end{array}$ & $\begin{array}{c}0.18 \\
(0.01)\end{array}$ & $\begin{array}{c}4.83 \\
(1.23)\end{array}$ & 19 \\
\hline $\begin{array}{l}\text { Tiri Tephra-2 } \\
(14-J 1-5)\end{array}$ & $\begin{array}{l}74.22 \\
(0.41)\end{array}$ & $\begin{array}{l}14.26 \\
(0.13)\end{array}$ & $\begin{array}{c}0.41 \\
(0.01)\end{array}$ & $\begin{array}{c}2.78 \\
(0.08)\end{array}$ & $\begin{array}{c}0.40 \\
(0.07)\end{array}$ & $\begin{array}{c}0.06 \\
(0.02)\end{array}$ & $\begin{array}{c}2.24 \\
(0.10)\end{array}$ & $\begin{array}{c}2.93 \\
(0.43)\end{array}$ & $\begin{array}{c}2.54 \\
(0.11)\end{array}$ & $\begin{array}{c}0.16 \\
(0.01)\end{array}$ & $\begin{array}{c}6.55 \\
(1.02)\end{array}$ & 20 \\
\hline $\begin{array}{l}\text { Eagle Hill } \\
(10-06-03)\end{array}$ & $\begin{array}{l}74.74 \\
(0.53)\end{array}$ & $\begin{array}{l}14.20 \\
(0.12)\end{array}$ & $\begin{array}{c}0.40 \\
(0.02)\end{array}$ & $\begin{array}{c}2.84 \\
(0.11)\end{array}$ & $\begin{array}{c}0.37 \\
(0.07)\end{array}$ & $\begin{array}{c}0.05 \\
(0.01)\end{array}$ & $\begin{array}{c}2.24 \\
(0.07)\end{array}$ & $\begin{array}{c}2.57 \\
(0.67)\end{array}$ & $\begin{array}{c}2.42 \\
(0.20)\end{array}$ & $\begin{array}{c}0.15 \\
(0.02)\end{array}$ & $\begin{array}{c}6.68 \\
(1.66)\end{array}$ & 17 \\
\hline $\begin{array}{l}\text { Kowhai } \\
(10-06-04)\end{array}$ & $\begin{array}{l}77.77 \\
(0.58)\end{array}$ & $\begin{array}{l}12.67 \\
(0.19)\end{array}$ & $\begin{array}{c}0.10 \\
(0.02)\end{array}$ & $\begin{array}{c}1.37 \\
(0.09)\end{array}$ & $\begin{array}{c}0.08 \\
(0.06)\end{array}$ & $\begin{array}{c}0.03 \\
(0.01)\end{array}$ & $\begin{array}{c}0.92 \\
(0.10)\end{array}$ & $\begin{array}{c}3.55 \\
(0.37)\end{array}$ & $\begin{array}{c}3.33 \\
(0.19)\end{array}$ & $\begin{array}{c}0.18 \\
(0.01)\end{array}$ & $\begin{array}{c}3.91 \\
(0.92)\end{array}$ & 20 \\
\hline $\begin{array}{l}\text { Glass } \\
\text { Standard } \\
\text { ATHO-G }\end{array}$ & $\begin{array}{l}75.61 \\
(0.54)\end{array}$ & $\begin{array}{l}12.20 \\
(0.09)\end{array}$ & $\begin{array}{c}0.26 \\
(0.02)\end{array}$ & $\begin{array}{c}3.27 \\
(0.11)\end{array}$ & $\begin{array}{c}0.10 \\
(0.06)\end{array}$ & $\begin{array}{c}0.11 \\
(0.02)\end{array}$ & $\begin{array}{c}1.70 \\
(0.05)\end{array}$ & $\begin{array}{c}3.73 \\
(0.28)\end{array}$ & $\begin{array}{c}2.64 \\
(0.05)\end{array}$ & $\begin{array}{c}0.05 \\
(0.03)\end{array}$ & $\begin{array}{l}99.66 \\
(0.76)\end{array}$ & 73 \\
\hline
\end{tabular}

Major element plots (Le Maitre and $\mathrm{FeO}$ versus $\mathrm{CaO}$ and $\mathrm{K}_{2} \mathrm{O}$ ) of major element glass data displayed in table 4.3 are presented in figure 4.17. 


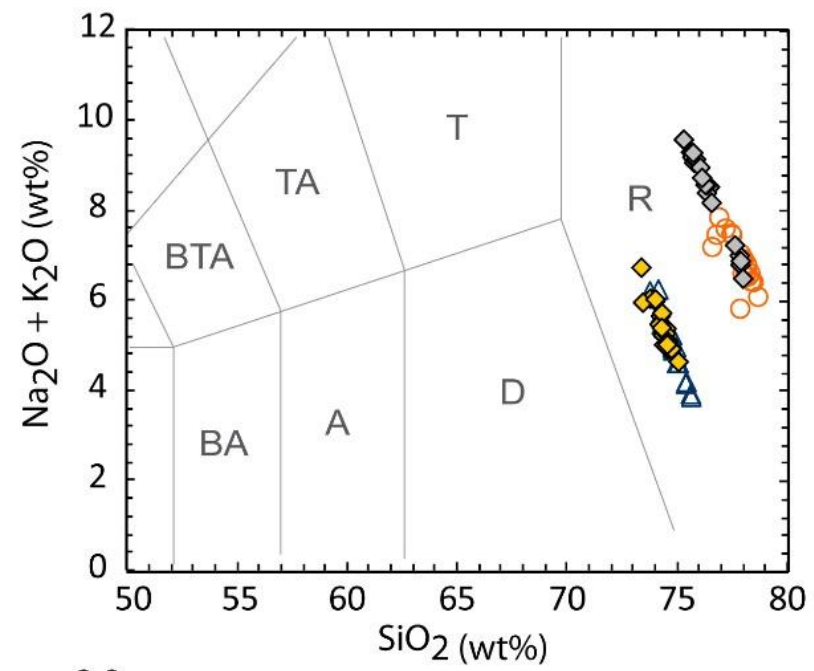

\begin{tabular}{|l|l|}
\hline Rangitikei River & Tiriraukawa \\
\hline$\triangle$ Eagle Hill (010-3) & $\diamond$ Tiri Tephra-2 (14-J1-5) \\
$\circ$ Kowhai (010-4) & $\diamond$ Tiri Tephra-1 (14-J1-4) \\
\hline
\end{tabular}

Figure 4.17: Grain discrete major element plots for correlative tephras- Eagle Hill vs. Tiri Tephra-2, and Kowhai vs. Tiri Tephra-1.
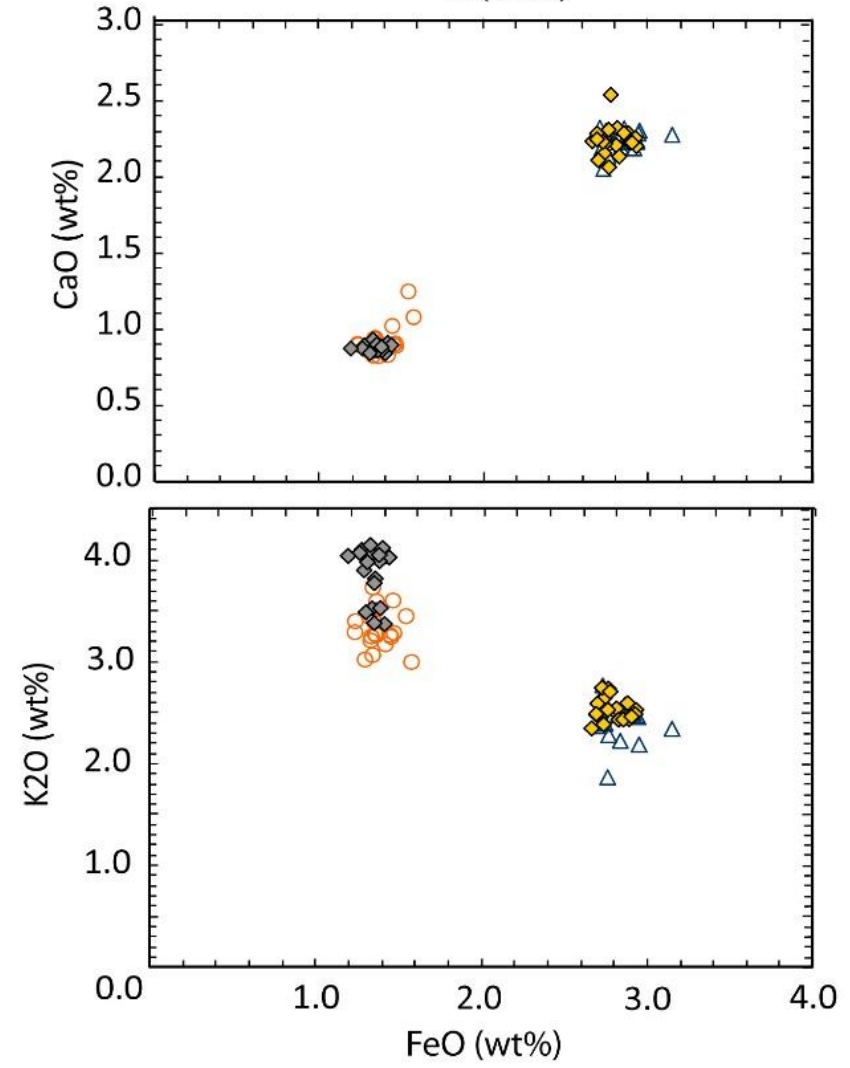

While all tephras are classified as calc-alkaline rhyolitic according to the Le Maitre scheme (Le Maitre, 1984), the Eagle Hill tephra and Tiri Tephra-2 are indistinguishable and are noticeably distinctive from the Kowhai and Tiri-1 population cluster on the basis of weight percent $\mathrm{SiO}_{2}, \mathrm{FeO}, \mathrm{CaO}$ and $\mathrm{K}_{2} \mathrm{O}$ and $\mathrm{Na}_{2} \mathrm{O}$. In comparison to the other tephras, the Eagle Hill tephra and Tiri Tephra-2 contain approximately double the weight percent of $\mathrm{FeO}$ and $\mathrm{CaO}$, approximately 2-6\% less $\mathrm{SiO}_{2}$ per weight volume and distinctly less volatiles (up to half as much). Therefore, on the basis of major elements alone, Tiri Tephra-2 and Tiri Tephra-1 are virtually geochemically indistinguishable 
from the Eagle Hill and Kowhai tephras (respectively) cropping out in the Mangaweka Mudstone at Tiriraukawa and confirms similarities of bedding features, thickness and grainsize observed in the field (figure 4.18). Selected trace element data are is also displayed for the same tephras from Tiriraukawa and the Rangitikei River valley in table 4.4 .

Table 4.4: Mean trace element data in parts per million (ppm) for Tiriraukawa and

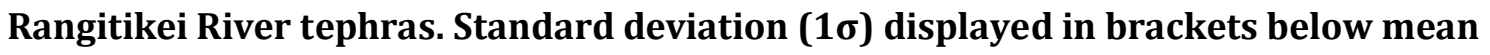
values and is derived from the number of analyses $(n)$. Data recalculated according to standards and methods detailed in Pearce et al. (2008).

\begin{tabular}{|c|c|c|c|c|c|c|c|c|c|c|c|c|}
\hline $\begin{array}{c}\text { Tephra } \\
\text { (probe mount } \\
\text { position) }\end{array}$ & $\mathbf{R b}$ & $\mathrm{Sr}$ & $\mathbf{Y}$ & $\mathrm{Zr}$ & $\mathrm{Nb}$ & Cs & Ba & La & $\mathrm{Ce}$ & Pr & Nd & Sm \\
\hline $\begin{array}{c}\text { Tiri Tephra-1 } \\
(14-J 1-4)\end{array}$ & $\begin{array}{l}152.21 \\
(9.32)\end{array}$ & $\begin{array}{l}81.73 \\
(15.7)\end{array}$ & $\begin{array}{l}37.13 \\
(3.49)\end{array}$ & $\begin{array}{l}143.23 \\
(24.5)\end{array}$ & $\begin{array}{c}8.83 \\
(0.62)\end{array}$ & $\begin{array}{c}6.27 \\
(0.65)\end{array}$ & $\begin{array}{c}1083 \\
(69.1)\end{array}$ & $\begin{array}{l}32.70 \\
(4.82)\end{array}$ & $\begin{array}{r}65.77 \\
(5.26)\end{array}$ & $\begin{array}{c}7.56 \\
(0.94)\end{array}$ & $\begin{array}{l}31.10 \\
(4.46)\end{array}$ & $\begin{array}{c}6.89 \\
(1.76)\end{array}$ \\
\hline $\begin{array}{c}\text { Tiri Tephra-2 } \\
(14-J 1-5) \\
\end{array}$ & $\begin{array}{l}133.96 \\
(20.4) \\
\end{array}$ & $\begin{array}{l}152.7 \\
(35.7) \\
\end{array}$ & $\begin{array}{l}33.90 \\
(2.39) \\
\end{array}$ & $\begin{array}{l}255.2 \\
(26.2) \\
\end{array}$ & $\begin{array}{c}9.38 \\
(0.71) \\
\end{array}$ & $\begin{array}{c}5.65 \\
(0.52) \\
\end{array}$ & $\begin{array}{l}847.3 \\
(61.3) \\
\end{array}$ & $\begin{array}{r}26.00 \\
(1.92) \\
\end{array}$ & $\begin{array}{l}54.82 \\
(2.79) \\
\end{array}$ & $\begin{array}{c}6.25 \\
(0.47) \\
\end{array}$ & $\begin{array}{l}25.42 \\
(3.04) \\
\end{array}$ & $\begin{array}{c}6.33 \\
(1.66) \\
\end{array}$ \\
\hline $\begin{array}{c}\text { Eagle Hill } \\
(10-06-03) \\
\end{array}$ & $\begin{array}{l}117.11 \\
(5.49) \\
\end{array}$ & $\begin{array}{l}180.2 \\
(17.0) \\
\end{array}$ & $\begin{array}{r}37.99 \\
(3.40) \\
\end{array}$ & $\begin{array}{l}299.8 \\
(25.1) \\
\end{array}$ & $\begin{array}{c}9.25 \\
(0.70) \\
\end{array}$ & $\begin{array}{c}5.23 \\
(0.30) \\
\end{array}$ & $\begin{array}{l}852.4 \\
(49.1) \\
\end{array}$ & $\begin{array}{l}27.90 \\
(2.51) \\
\end{array}$ & $\begin{array}{r}55.82 \\
(4.45) \\
\end{array}$ & $\begin{array}{c}6.69 \\
(0.59) \\
\end{array}$ & $\begin{array}{l}28.53 \\
(2.93) \\
\end{array}$ & $\begin{array}{c}6.05 \\
(1.29) \\
\end{array}$ \\
\hline $\begin{array}{c}\text { Kowhai } \\
(10-06-04)\end{array}$ & $\begin{array}{l}152.06 \\
(6.73)\end{array}$ & $\begin{array}{l}78.49 \\
(13.9)\end{array}$ & $\begin{array}{l}37.57 \\
(3.62)\end{array}$ & $\begin{array}{l}158.15 \\
(29.6)\end{array}$ & $\begin{array}{c}9.57 \\
(0.79)\end{array}$ & $\begin{array}{c}6.23 \\
(0.36)\end{array}$ & $\begin{array}{c}1031 \\
(87.7)\end{array}$ & $\begin{array}{l}33.19 \\
(3.14)\end{array}$ & $\begin{array}{l}66.27 \\
(4.22)\end{array}$ & $\begin{array}{c}7.30 \\
(0.75)\end{array}$ & $\begin{array}{l}29.75 \\
(3.16)\end{array}$ & $\begin{array}{l}6.73 \\
1.06\end{array}$ \\
\hline
\end{tabular}

\begin{tabular}{|c|c|c|c|c|c|c|c|c|c|c|c|c|c|c|}
\hline $\begin{array}{l}\text { Tephra } \\
\text { (probe } \\
\text { mount } \\
\text { position) }\end{array}$ & Eu & Gd & $\mathbf{T b}$ & Dy & Ho & Er & Tm & $\mathbf{Y b}$ & Lu & Hf & Ta & Th & $\mathbf{U}$ & $n$ \\
\hline $\begin{array}{c}\text { Tiri } \\
\text { Tephra-1 } \\
(14-J 1-4) \\
\end{array}$ & $\begin{array}{c}0.87 \\
(0.29)\end{array}$ & $\begin{array}{c}6.89 \\
(1.88)\end{array}$ & $\begin{array}{c}1.01 \\
(0.18)\end{array}$ & $\begin{array}{c}6.65 \\
(1.24)\end{array}$ & $\begin{array}{c}1.36 \\
(0.28)\end{array}$ & $\begin{array}{c}4.16 \\
(0.77)\end{array}$ & $\begin{array}{c}0.68 \\
(0.38)\end{array}$ & $\begin{array}{c}4.25 \\
(1.33)\end{array}$ & $\begin{array}{c}0.68 \\
(0.26)\end{array}$ & $\begin{array}{c}5.51 \\
(1.62)\end{array}$ & $\begin{array}{c}0.94 \\
(0.24)\end{array}$ & $\begin{array}{l}17.86 \\
(2.50)\end{array}$ & $\begin{array}{c}6.15 \\
(5.73)\end{array}$ & 20 \\
\hline $\begin{array}{c}\text { Tiri } \\
\text { Tephra-2 } \\
(14-J 1-5)\end{array}$ & $\begin{array}{c}0.98 \\
(0.24)\end{array}$ & $\begin{array}{c}6.01 \\
(1.45)\end{array}$ & $\begin{array}{c}0.93 \\
(0.18)\end{array}$ & $\begin{array}{c}6.08 \\
(0.87)\end{array}$ & $\begin{array}{c}1.26 \\
(0.22)\end{array}$ & $\begin{array}{c}4.03 \\
(0.61)\end{array}$ & $\begin{array}{c}0.57 \\
(0.10)\end{array}$ & $\begin{array}{c}3.71 \\
(0.48)\end{array}$ & $\begin{array}{c}0.59 \\
(0.16)\end{array}$ & $\begin{array}{c}7.74 \\
(0.78)\end{array}$ & $\begin{array}{c}0.80 \\
(0.19)\end{array}$ & $\begin{array}{l}12.63 \\
(1.25)\end{array}$ & $\begin{array}{c}3.46 \\
(0.45)\end{array}$ & 22 \\
\hline $\begin{array}{c}\text { Eagle Hill } \\
(10-06-03)\end{array}$ & $\begin{array}{c}1.11 \\
(0.29) \\
\end{array}$ & $\begin{array}{c}6.87 \\
(1.52) \\
\end{array}$ & $\begin{array}{c}1.02 \\
(0.18) \\
\end{array}$ & $\begin{array}{c}6.99 \\
(0.81) \\
\end{array}$ & $\begin{array}{c}1.41 \\
(0.18) \\
\end{array}$ & $\begin{array}{c}4.18 \\
(0.68) \\
\end{array}$ & $\begin{array}{c}0.60 \\
(0.12) \\
\end{array}$ & $\begin{array}{c}4.02 \\
(0.58) \\
\end{array}$ & $\begin{array}{c}0.67 \\
(0.15) \\
\end{array}$ & $\begin{array}{c}8.13 \\
(0.92) \\
\end{array}$ & $\begin{array}{c}0.76 \\
(0.19) \\
\end{array}$ & $\begin{array}{l}13.48 \\
(0.98) \\
\end{array}$ & $\begin{array}{c}3.17 \\
(0.42) \\
\end{array}$ & 21 \\
\hline $\begin{array}{c}\text { Kowhai } \\
(10-06-04)\end{array}$ & $\begin{array}{c}0.81 \\
(0.25)\end{array}$ & $\begin{array}{c}6.61 \\
(1.60)\end{array}$ & $\begin{array}{c}1.05 \\
(0.20)\end{array}$ & $\begin{array}{c}6.71 \\
(0.84) \\
\end{array}$ & $\begin{array}{c}1.42 \\
(0.23) \\
\end{array}$ & $\begin{array}{c}3.99 \\
(0.78) \\
\end{array}$ & $\begin{array}{c}0.67 \\
(0.15)\end{array}$ & $\begin{array}{c}4.12 \\
(0.59)\end{array}$ & $\begin{array}{c}0.67 \\
(0.17) \\
\end{array}$ & $\begin{array}{c}5.70 \\
(0.95)\end{array}$ & $\begin{array}{c}0.98 \\
(0.19)\end{array}$ & $\begin{array}{l}18.15 \\
(1.63)\end{array}$ & $\begin{array}{c}5.09 \\
(1.86) \\
\end{array}$ & 22 \\
\hline
\end{tabular}

Trace element concentrations are plotted for selected incompatible elements Sr, Y, Zr, versus Nd in the Eagle Hill and Kowhai Tephras, and the Tiri Tephra-1 and Tiri Tephra2 respectively figure 4.19 . 


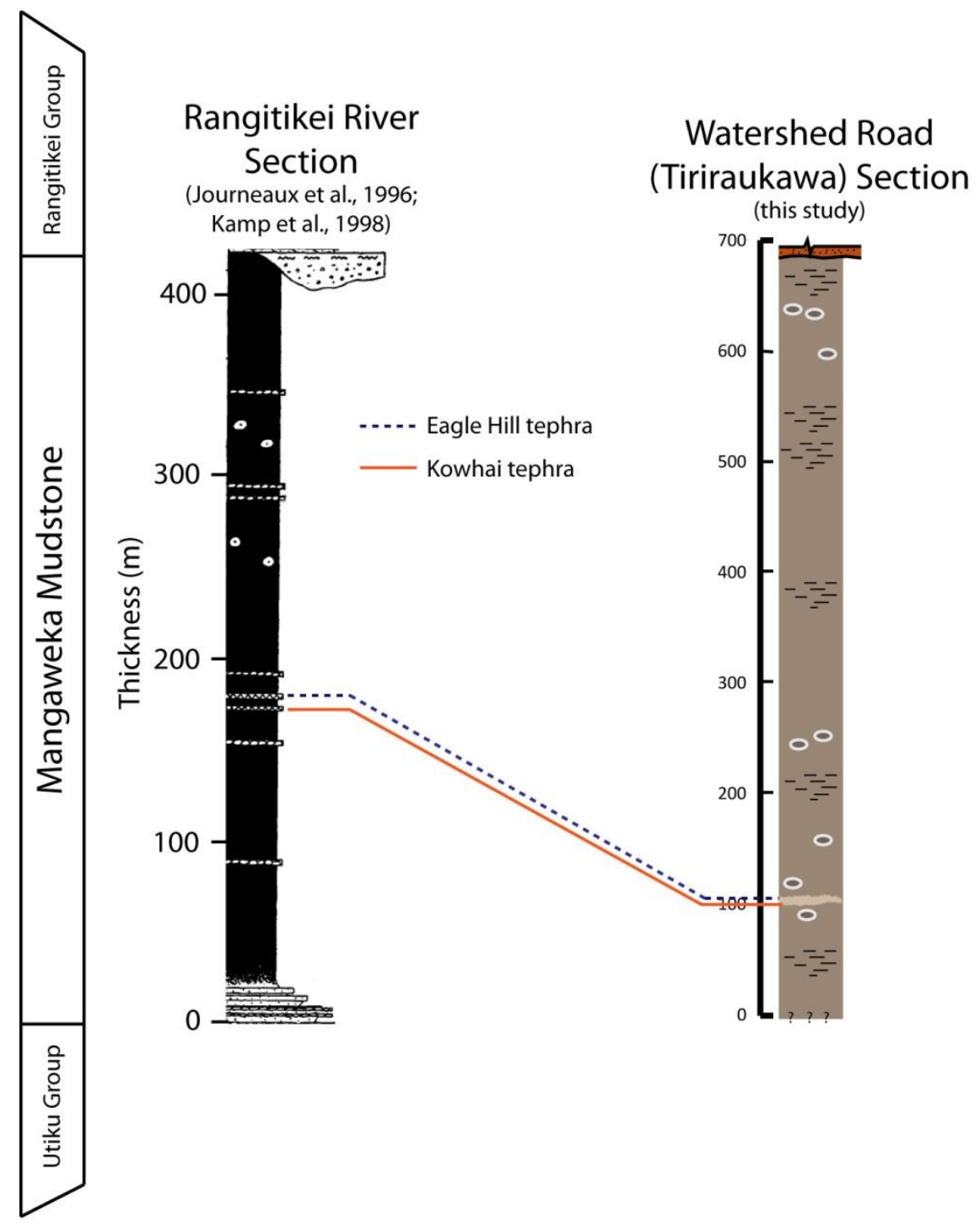

Figure 4.18: Correlation of the Mangaweka Mudstone in the Rangitikei River section with the Tiriraukawa section on the basis of major and trace element geochemistry. The Rangitikei River section stratigraphic column and tephra positions are from Kamp et al. (1998). 

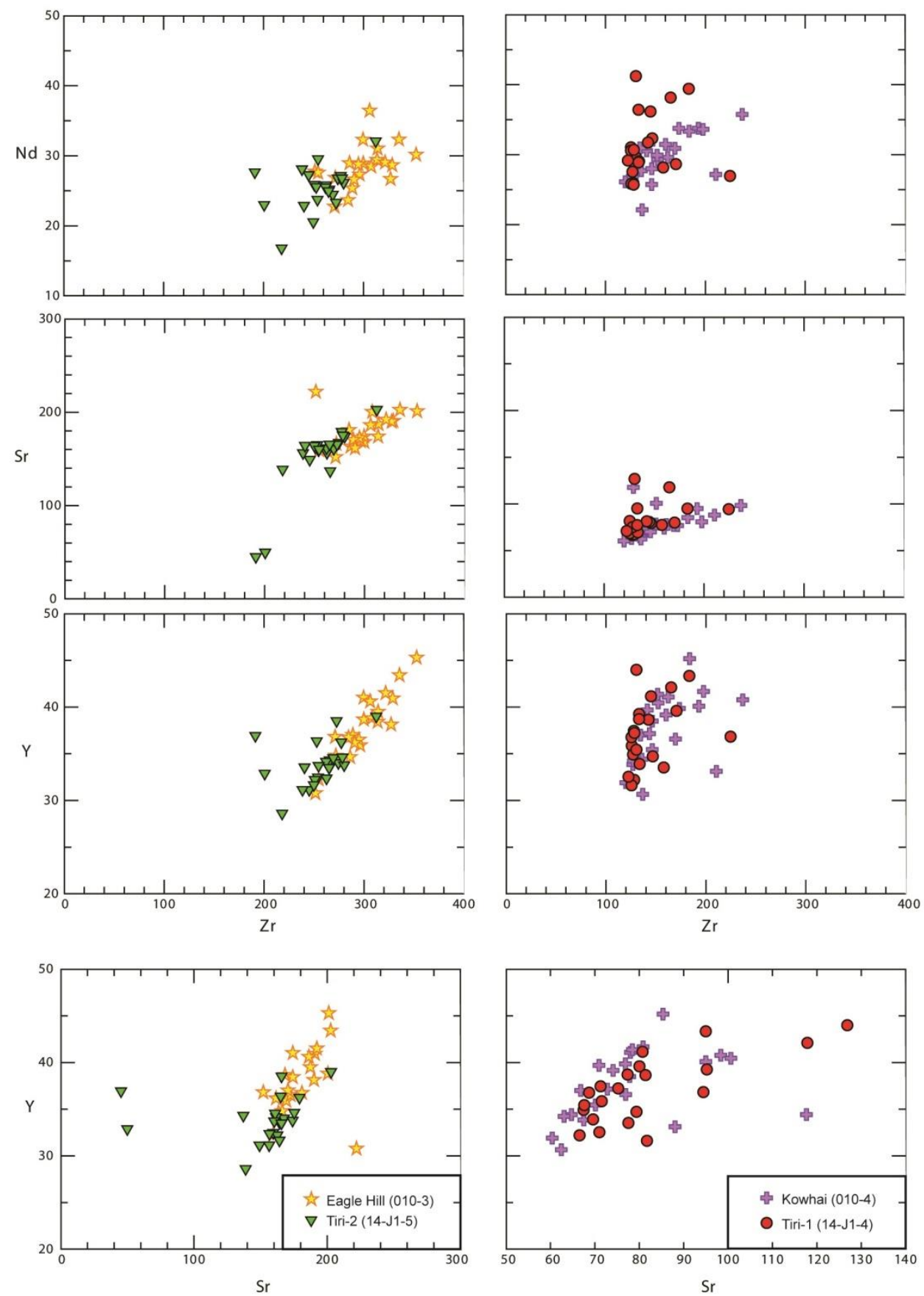

Figure 4.19: Selected trace element data for tephra collected from the Mangaweka Mudstone at Tiriraukawa (Tiri Tephra-2 and Tiri Tephra-1) and the Rangitikei River valley (Eagle Hill tephra and Kowhai tephra). Axes are concentrations in parts per million (ppm) at different scales. The full suite of trace element data is available in Appendix E.

The correlation of Tiri Tephra-2 with Eagle Hill as well as and Tiri Tephra-1 with the Kowhai tephra is affirmed by the closely overlapping clusterings of data points (even in the distribution of sample outliers) presented in figure 4.19. The Eagle Hill and Tiri 
Tephra-2 have consistently higher Sr and $\mathrm{Zr}$ concentrations and lower Nd concentrations than their respective and stratigraphically underlying tephras. These data also indicate that, on the basis of quite different glass geochemistry, the two closely-spaced tephras are likely sourced from different Coromandel Volcanic Zone centres that were erupting at closely in time.

Integrated age model

An age model for the Mangaweka Mudstone at Tiriraukawa is constructed through the integration of (i) magnetostratigraphy, (ii) the Eagle Hill tephra zircon fission track and stratigraphic age transfer via the major and trace element geochemical fingerprinting of the Eagle Hill and Kowhai tephras, and (iii) the Cibicides molestus LAD identified in the benthic foraminifera census (figure 4.20). This age model can only assume linear sedimentation rates between age tie points, which have been constrained to the Matuyama-Gauss polarity reversal at $2.58 \mathrm{Ma}$ (with a depth uncertainty of $\sim 11$ metres), and the biostratigraphic datum of Cibicides molestus, which is a proxy for the Waipipian to Mangapanian New Zealand stage boundary at 3.0 Ma (Hornibrook et al., 1989; Cooper, 2004; Lee et al., 2011). This gives an approximate sedimentation rate of 1.6 metres $/ \mathrm{kyr}^{-1}$, which is consistent with estimates from the neighbouring Turakina River section (Turner et al., 2005). This is also consistent with the thickening of the Mangaweka Mudstone towards the west from the Rangitikei River valley as the basin depo-centre becomes more proximal (Journeaux et al., 1996; Kamp et al., 1998; Nicol, 2011).

The Eagle Hill tephra zircon fission track age has a large uncertainty and is not useful to use as an age tie point, but is an important chronological data point to constrain the Mangaweka Mudstone to the Late Pliocene and the upper part of the Gauss normal chron. Similarly, the stratigraphic age for the Eagle Hill tephra determined by Naish et al. (1996) further constrains the section to the Late Pliocene, (figures 4.15 and 4.19). While the age model does not provide sufficient resolution to resolve the higher resolution variability in grainsize and benthic foraminifera assemblages, it does provide a framework for which the frequency of these changes can be considered in comparison 
to records with well-defined age models, such as the LR04 benthic $\delta^{18} 0$ record (Lisiecki and Raymo, 2005).

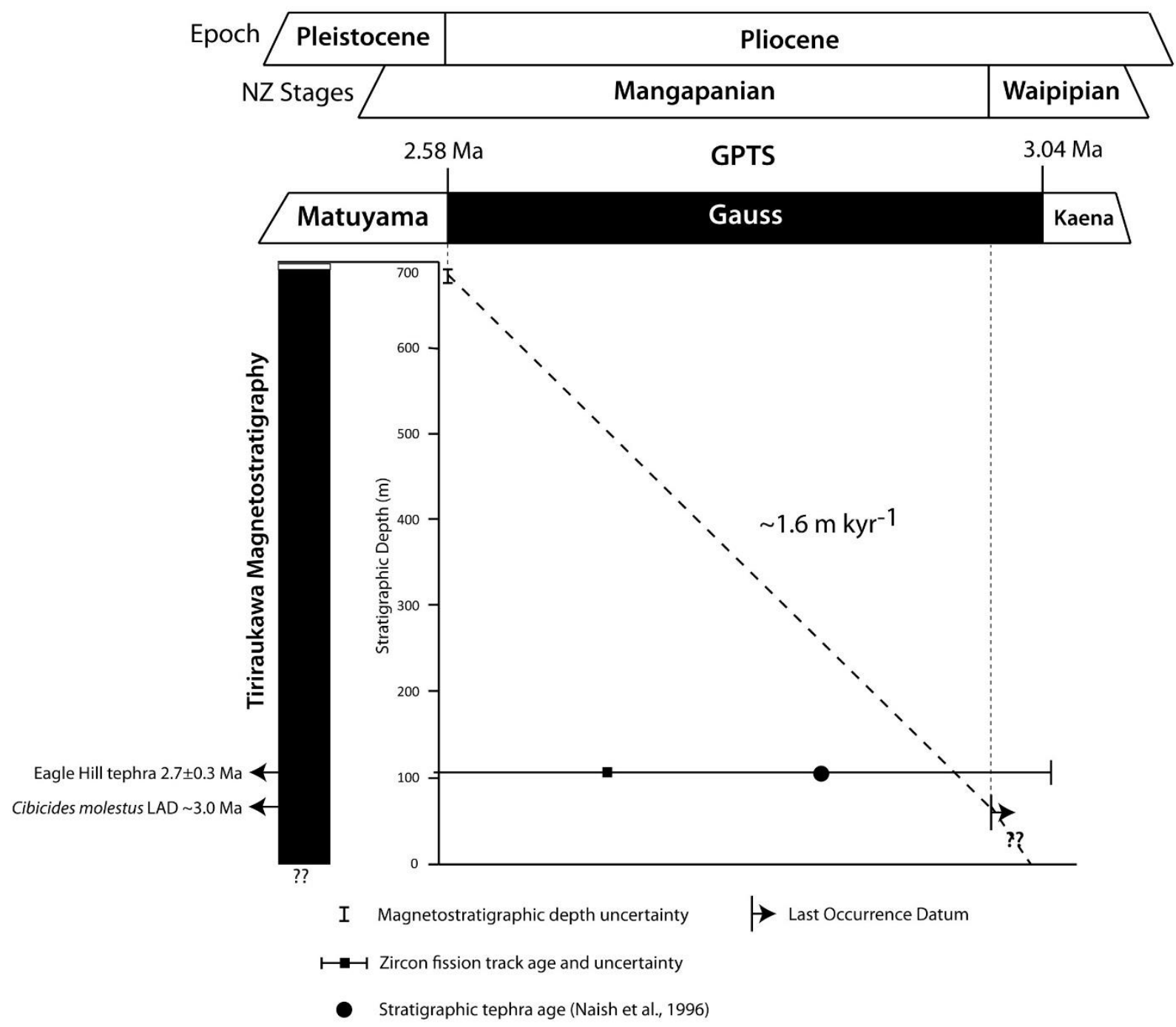

Figure 4.20: Integrated age model and comparison against the Geomagnetic Polarity timescale and the New Zealand and global geological time scale. 


\section{Chapter 5: Discussion}

Palaeobathymetric results from analysis of sediment texture and benthic foraminifera assemblages in the Mangaweka Mudstone at Tiriraukawa indicate a depositional environment that shifted from the outer continental shelf (100-150 metres water depth), shallowing to mid- to inner-shelf depths ( 50 to $<20$ metres) by the latest Pliocene. Superimposed on this overall shallowing trend are higher frequency oscillations in both sediment texture and benthic foraminifera assemblages that appear to relate to sea-level changes. These variations increase in amplitude as the section becomes shallower (figure 5.1).

However, the assumption that sediment texture is directly related to sea-level variations on a wave-graded shallow continental shelf throughout the entire stratigraphic section is under question due to independent constraints on water-depth provided by the in situ benthic foraminifera assemblages. The use of the grainsize-based water depth proxy is not appropriate to apply to the lower 500 metres of the section, because sediment textures imply water depths of mid-shelf ranges ( $\sim 50-60$ metres), and the benthic foraminifera assemblages indicate water depths exceeding 100 metres. Therefore, it is unlikely that the depositional environment is that of a wave-graded continental shelf, primarily because at such depths (>100 metres), wave-induced bedshear stresses capable of transporting sand should not be imparted on the seafloor given the assumed wave climate. A modern dataset from the Manawatu coast with an analogous wave climate suggests that wave-base is restricted to inner- to mid-shelf environments, even in storm dominated conditions (Dunbar and Barrett, 2005). Consequently, more confidence is placed on water depth reconstruction for the lower $\sim 500$ metres of section based on in situ benthic foraminiferal depth assemblages, which are well calibrated based on a robust understanding of the depth palaeoecology of these mostly extant taxa on the modern New Zealand continental shelf. As a result, the amplitudes of the higher-frequency changes in percent mud throughout the Mangaweka Mudstone cannot be directly related to local or global sea-level changes. In this chapter, other local mechanisms that might explain the cyclic occurrence of 5-30\% sand in the outer-shelf sediments during the Late Pliocene ( 3-2.6 Ma) are considered, and 
assessed as an indirect proxy of the frequency and relative amplitude of global sea-level fluctuations.

The age model constructed for the Mangaweka Mudstone at Tiriraukawa is derived from three independent techniques, and constrains the timing of deposition to the Late Pliocene (figure 4.20). The top of the section encompasses the Matuyama-Gauss Chron boundary at $2.58 \mathrm{Ma}$, and the lower part of the section is constrained by the Eagle Hill tephra zircon fission track date and interpolation to the Rangitikei section at $2.7 \pm 0.3 \mathrm{Ma}$ and $2.88 \mathrm{Ma}$, respectively. This is supported by the LAD of benthic foraminifera species Cibicides molestus ( $\sim 3.0 \mathrm{Ma})$ at $\sim 600$ metres stratigraphic depth (figure 4.7$)$. The measured section has an apparently linear sedimentation rate of 1.6 metres $\mathrm{kyr}^{-1}$, and spans $\sim 400,000$ years.

This age model is consistent with magnetostratigraphy, tephrochronology, and biostratigraphy derived from previous studies (Journeaux et al., 1996; Naish et al., 1996; Kamp et al., 1998; McIntyre, 2002; Turner et al., 2005). There remains further potential to refine the resolution and precision of this age model. A possible approach to achieve this is discussed later in this chapter. Nevertheless, the age model presented in this study is sufficiently robust and well-constrained to allow for the examination of the frequency of changes in sediment texture and benthic foraminifera assemblages recorded in the Mangaweka Mudstone.

This chapter will focus on two interpretive outcomes for the Mangaweka Mudstone at Tiriraukawa:

(i) The possible mechanisms for cyclical changes in sediment texture and benthic foraminifera assemblages, and

(ii) How the preserved periodicity relates to orbitally-driven global changes in Late Pliocene ice volume/sea-level.

\section{The frequency of changes in the Mangaweka Mudstone and correlation to the global benthic oxygen isotope record}

Individual cycles in sediment texture and benthic foraminifera clusters are displayed with the age model in figure 5.1. There are nine complete grainsize cycles identified, which are coeval with (albeit with some minor overlap and uncertainty) in the benthic 
foraminifera assemblages defined by clusters. Each grainsize cycle encompasses a rise and fall in percent mud of approximately $15-20 \%$ and nearly all cycles contain two (or in some cases three) foraminifera clusters that correspond to these peaks and troughs. For example, Cycle 2 (figure 5.1) contains two clusters (Clusters 3a and 3b), which align with the lower and higher ranges of percent mud, respectively. Cycle 3 contains three foraminifera clusters, which align with a rise, peak, and fall in percent mud.

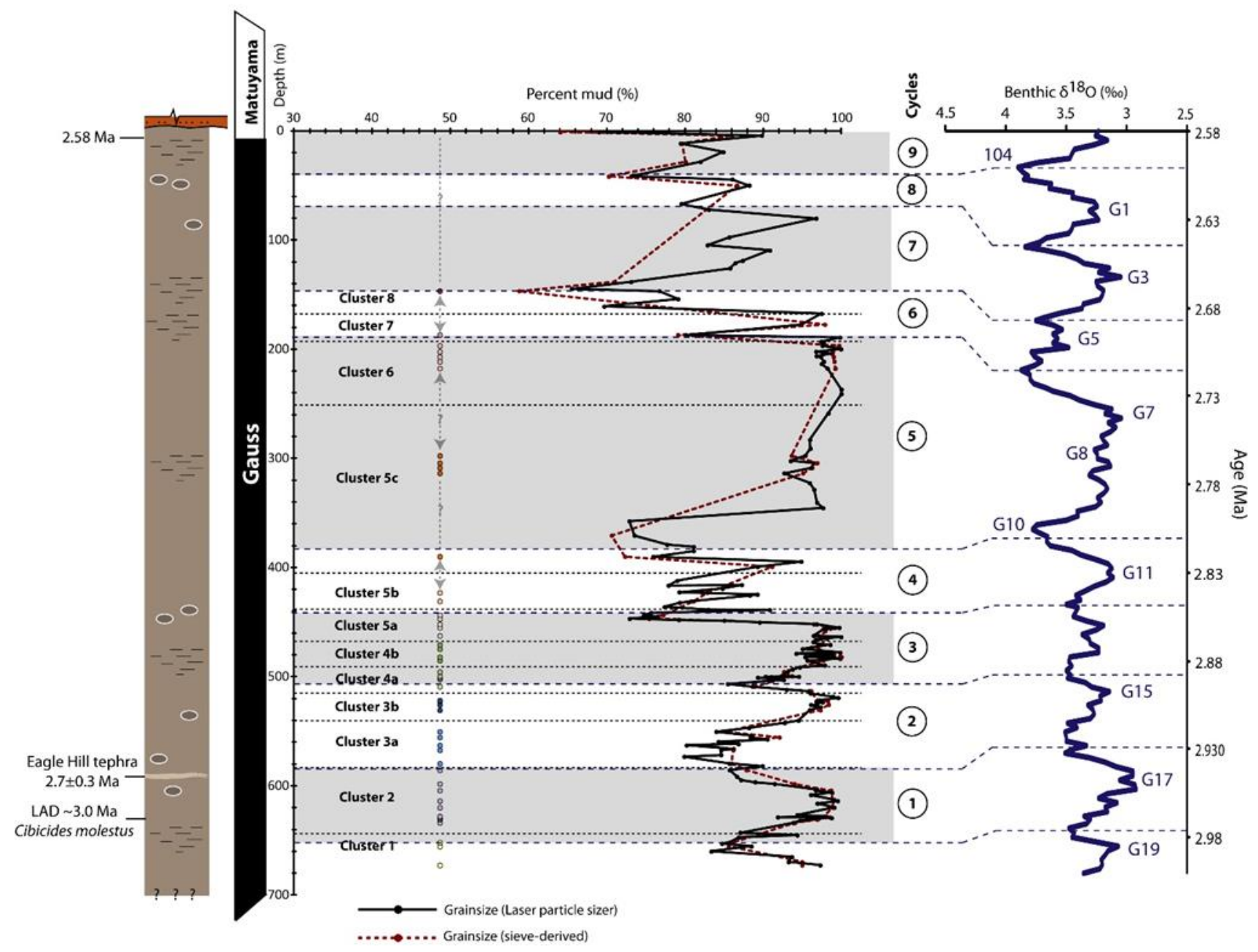

Figure 5.1: Complete cycles identified from sediment texture and benthic foraminifera assemblages constrained by the age model. Nine complete cycles are identified, spanning $<400,000$ years. Additionally, a correlation of the Tiriraukawa grainsize and benthic foraminifera assemblage record with the global benthic $\delta^{180}$ stack (LR04 from Lisiecki and Raymo, 2005) is displayed. This correlation has been made possible due to the visual similarities in the peaks, troughs and amplitudes of the Late Pliocene ice volume proxy record and the Tiriraukawa record, within the chronostratigraphic framework constraints of the age model. 
When the age model is considered (assuming linear sedimentation rates), nine distinct cycles occur in $<400,000$ years. This indicates a frequency of approximately two cycles per 100,000 years, highlighted specifically in the lower half of the section where five distinctive, low-amplitude and symmetrical cycles (1-5) in the lower half of the record occur over $\sim 200,000$ years ( $\sim 2.5$ cycles per 100,000 years).

Visual comparison of the grain size and foraminifera clusters to the global benthic foraminifera $\delta^{18} 0$ record for the Late Pliocene (figure 5.1) suggest there is a direct relationship between the Mangaweka Mudstone cycles and the globally integrated variations in ice volume inferred from the $\delta^{18} 0$ record.

On a visual basis, the Tiriraukawa record is strikingly similar to the Late Pliocene benthic $\delta^{18} 0$ record, particularly in terms of the relative morphology of the correlative cycles. Cycles 1-5, which are largely symmetrical and relatively lower amplitude are consistent with the pattern exhibited in the lower part of the displayed benthic $\delta^{18} \mathrm{O}$ record. Despite the fact that the sampling resolution decreases above $\sim 400$ metres stratigraphic depth, the first excursion in the grainsize record approaching $30 \%$ sand content coincides with the first $\delta^{18} 0$ excursion approaching 4\%o, Marine Isotope Stage (MIS) G10. The prolonged period of lower $\delta^{18} 0$ values (MIS G7 and G8) is also matched in the Tiriraukawa grainsize record by a $\sim 150$ metre-thick interval of $>90 \%$ mud. Overall, the pattern of shallowing and increasing amplitude displayed by both proxies in the Tiriraukawa record coincides with a long-term increase in $\delta^{18} 0$ values and amplitude associated with the build-up of continental ice (especially after $2.7 \mathrm{Ma}$ ) in the Northern Hemisphere. The Late Pliocene benthic $\delta^{18} 0$ record exhibits a dominantly 41,000 year frequency through this period (Lisiecki and Raymo, 2005) and can be matched one for one as described above with the grainsize variability of the Tiriraukawa record.

While the age-depth relationships for the studied record are based on a linear interpolation between magneto-, tephro- and biostratigraphic age constraints, subtle higher-frequency changes in sedimentation rate would have undoubtedly occurred. This makes the correlation of the un-tuned Tiriraukawa record to the orbitally-tuned benthic $\delta^{18} 0$ record quite remarkable. Therefore, it was decided that orbitally-tuning the Tiriraukawa record to the benthic $\delta^{18} 0$ record would be unnecessary, even although this might have allowed intra-cycle variations in sedimentation to be corrected for in 
the age-depth model. Nevertheless, additional age information could be transferred from the well-dated benthic $\delta^{18} 0$ record to the Tiriraukawa record for the maxima and minima of orbital-scale $\delta^{18} 0$ glacial-interglacial ice volume cycles, if $\delta^{18} 0$ can be measured directly on the Mangaweka Mudstone benthic foraminifera. An important caveat is that due to the inherent limitations of the Tiriraukawa age model described above, leads and lags between the two records cannot be identified at present, and such an approach would lead to circular arguments. However, given the compelling evidence for Milankovitch-scale cycles in the Tiriraukawa record, this could potentially be overcome by oxygen isotope analysis of the benthic foraminifera to more rigorously orbitally tune the Tiriraukawa record. This will be a focus of future work, beyond the scope of this thesis.

The correlation between the two records (figure 5.1) suggests that variability observed in the grainsize and benthic foraminifera within the Mangaweka Mudstone is a result of the same mechanisms driving the variability in the Late Pliocene benthic $\delta^{18} 0$ record. In other words, the fluctuations in global ice volume and consequent sea level driven by dominantly 41,000 year obliquity cycles in the Late Pliocene are recorded as cyclical changes in grainsize and benthic foraminifera assemblages in the Wanganui Basin sedimentary record exposed at Tiriraukawa. As discussed above it is clear that the mechanisms driving the variability in the grainsize and foraminifera are not a direct consequence of sea-level changes in a wave-graded inner- to mid-shelf environment. Yet, the visual similarities to the $\delta^{18} 0$ record and occurrence of strong 41,000 year cyclicity modulating the period of variability of the changes strongly suggests a glacioeustatic origin (as opposed to tectonic signals that do no exhibit such high-frequency oscillations). Below, other processes responding to glacio-eustatic sea-level changes that could have influenced the sedimentological and palaeoecological characteristics of deposition of the Mangaweka Mudstone in an outer-shelf depositional environment are discussed. In particular, how did significant quantities of terrigenous sand-sized grains get transported to the outer-shelf environment? 


\section{Depositional processes on the outer-shelf of the Wanganui Basin in the Late Pliocene}

Sediment transport and deposition on the continental shelf is a complex interplay of wave, storm, tidal and ocean current processes (Boggs, 2011). Such processes can bring large amounts of terrigenous sediments to the mid- and outer-shelves, and also to the deep ocean (Carter and Heath, 1975; Carter et al., 2000). Additionally, New Zealand is a tectonically and climatologically active landscape, which enables the transport of globally significant quantities of terrigenous sediment to offshore environments (Carter, 1975; Griffiths and Glasby, 1985). The modern Manawatu-Wanganui coastline is dominated by wave-processes and a very broad low-angle continental shelf, and thus sediment is transported and sorted according to wave direction and strength, which is intimately tied to the prevailing westerly-wind climate setting (Carter and Heath, 1975; Dunbar and Barrett, 2005).

While it is likely that the sediment transport mechanisms for the inner- and mid- parts of the continental shelf of the Late Pliocene are similar to today, the palaeogeography and morphology of the continental shelf was quite different to the modern setting (McIntyre, 2002; Proust et al., 2005; Nicol, 2011; Trewick and Bland, 2012) (figure 5.2). Local sediment transport and depositional patterns can vary significantly, both spatially and temporally when regional or global influences such as tectonics or glacio-eustatic sea-level change are considered. In figure 5.2, the influences on regional sedimentation under Late Pliocene palaeogeography are illustrated (Trewick and Bland, 2012).

Orbitally-paced Late Pliocene fluctuations in glacio-eustatic sea-level were likely only 20-30 metres amplitude (Miller et al., 2012; Naish and Wilson, 2009), but would have had significant influence on outer-shelf sedimentation given the different palaeogeography of the region. The narrow, low angle continental shelf would have promoted periodic large seaward regressions of the shoreline in response to a lowering of glacio-eustatic sea level (Carter et al., 2000), bringing sandy shoreline sediments to the outer-shelf and shelf-break. Indeed, sand-filled slope channels/canyons are described in the Whanganui River section west of the study area (Hayton, 1998; McIntyre, 2002; Kamp et al., 2004). A restricted continental shelf area intensifies the activity of tractional currents (not wave-induced) flowing parallel to the shore (Carter 
and Heath, 1975; Boggs, 2011) and decreases the horizontal distance between the shallow marine and deep marine environments (Carter et al., 1990; Carter et al., 2000). Additionally, a lowered sea level would further confine the narrow, shallow marine connections between the East Coast and the Wanganui Basins and possibly exacerbate tidal flows associated with these seaways (Proctor and Carter, 1989; Carter and Lewis, 1995; Bland et al., 2004).

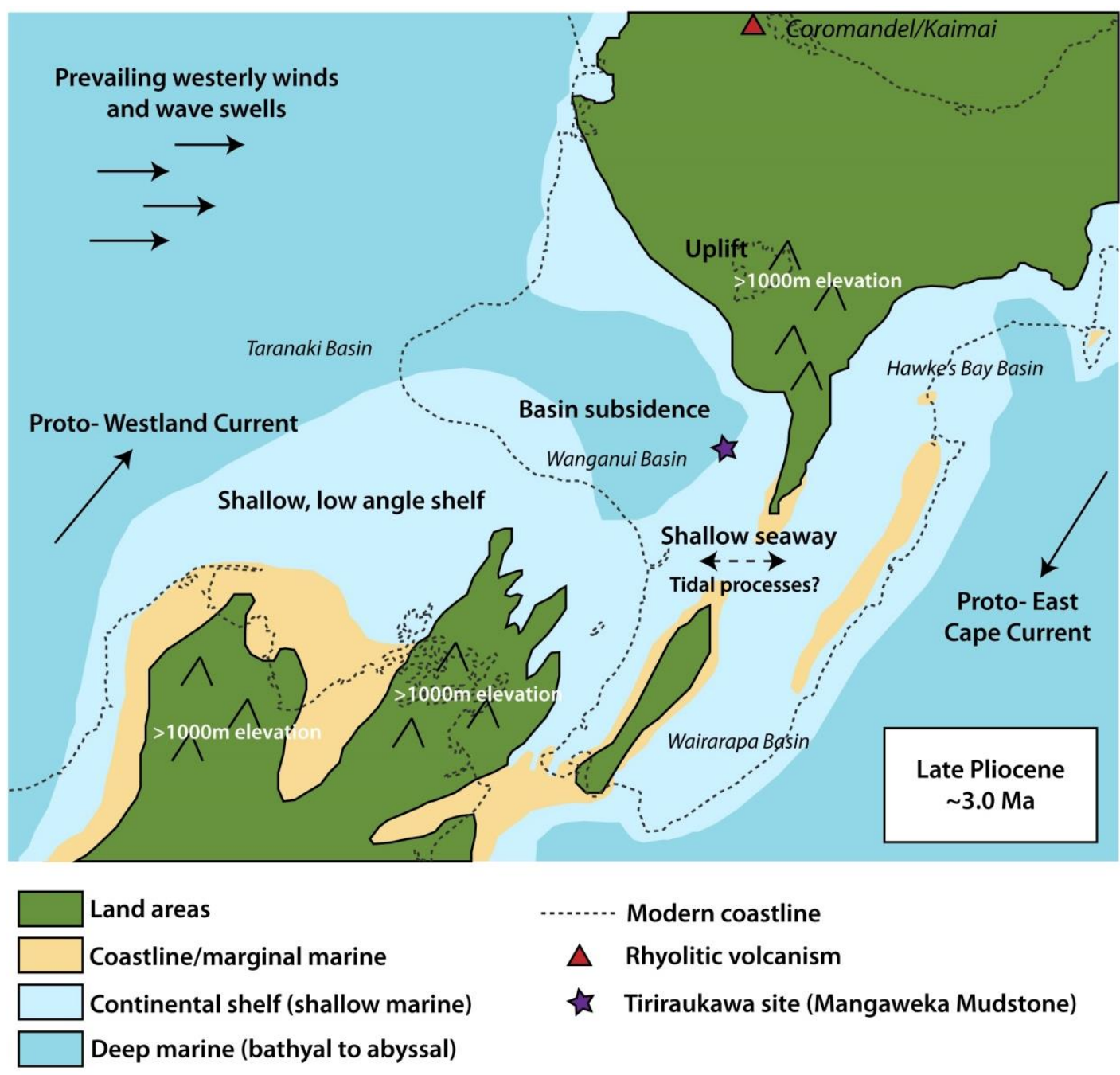

Figure 5.2: Palaeogeographic map of the lower North Island of New Zealand and the dominant environmental parameters operating during the Late Pliocene. Figure modified from Trewick and Bland (2012).

Transport of sand grains requires more shear stress on the seafloor than non-cohesive mud grains, and therefore a higher energy environment extending seawards would favour the deposition of coarser sediments in deeper environments, whereby the measured grainsize distribution is not in hydrodynamic equilibrium with the contemporary wave climate on the outer shelf but represents deposition by these 
additional mechanisms. As discussed, a more energetic continental shelf environment is assumed for sea level lowstands (i.e. glacial intervals), and while specific evidence is lacking for the Late Pliocene, glacial periods may have been associated with intensified and more frequent storm event sedimentation (Pillans et al., 1993). Thus the decrease and increase in sand flux to the outer- continental shelf represents sea-level rising and falling, respectively. So in summary, sand transport to the outer-shelf depositional environment of the Mangaweka Mudstone at Tiriraukawa is therefore interpreted to be a result of:

(i) Increased fine-sand sediment input during a sea-level lowstand due to the closer proximity of the higher-energy shoreline to the outer-shelf. Although 20-30 metre water depth changes paced by obliquity are occurring every 41,000 years, this does not impact outer-shelf water depths sufficiently to affect the foraminiferal depth palaeoecology. At the same time, tidal and along-shelf currents are intensified due to restrictions in the spatial area they operate in. This is exhibited in the modern Cook Strait, where tidal currents can keep sand in suspension for considerable distances and depths (Carter and Lewis, 1995). Increased wind, storm and wave action arguably associated with a colder climate and increased sediment supply from a recently exposed continental shelf are also likely factors (Pillans et al., 1993; Carter et al., 2000).

(ii) Decreased sand input and a dominance of mud sedimentation occurred during sea level highstands due to the shallow inner continental shelf acting as a sediment trap. It is important to note that it is mostly the sand grains that are restricted to the inner continental shelf, as sedimentation rates are still high during highstands. During highstands, the continental shelf was more extensive, the shallow seaways not as restricted, and wind and wave action decreased relative to a cooler climate state.

(iii) Any sedimentary features that indicate tractional currents at deep continental shelf environments, such as laminations or contourites (Carter et al., 2000) are not preserved in the Mangaweka Mudstone due to bioturbation processes.

The overall shallowing trend displayed in the Mangaweka Mudstone is inferred to be a response to a combination of: (i) the shift of the locus of subsidence to the south over 
time, which allows the gradual sediment infilling of the basin in response to reduced subsidence rates (Stern et al., 1992; Kamp et al., 2004; Pulford and Stern, 2004; Proust et al., 2005; Nicol, 2011; Stern et al., 2013), (ii) uplift of the central North Island axial ranges (e.g. Ruahine and Kaimanawa Ranges) and (iii) global cooling during the Late Pliocene and onset of Northern Hemisphere glaciation increases terrestrial ice volume and lowers sea levels (Ravelo et al., 2004; Lisiecki and Raymo, 2005; McKay et al., 2012a; Patterson et al., 2014; Woodard et al., 2014). Additionally, a cooling climate likely results in more intensive glaciation on topographic high points (such as the protoSouthern Alps, and North-west Nelson and Marlborough regions in figure 5.2) (Gage, 1961; Suggate, 1990; Newnham et al., 1999), thus increasing erosion rates and sediment influx into the Mangaweka Mudstone depositional environment. All of these factors result in a shallowing from outer-shelf to mid-shelf, and ultimately the inner-shelf, encompassing a likely bathymetric change of $>50$ metres, and possibly as great as $\sim 100$ metres.

During glacial/interglacial cycles, the significant changes to climate and the surrounding neritic environment have complex influences on the assemblages of benthic foraminifera. While indicating dominantly outer-shelf depths in the lower half of the Tiriraukawa record (and thus not largely sensitive to sea level changes of 20-30 metres), the significant change in species dominance at the same frequency as eustatic variability indicates a response to changing environmental parameters associated with glacial-interglacial cycles. These include but are not restricted to water temperatures, surrounding water turbidity, nutrient availability, oxygen levels and sedimentation rates (Hayward, 1986; Naish et al., 1996; Hayward et al., 1999). However these environmental factors will not be further explored in this thesis, but will be considered in future studies.

As the Tiriraukawa section shallows to mid- to inner-shelf depths, it is likely that wavesorting processes are more influential, and highly depth-sensitive benthic foraminifera assemblages are more common (e.g. the shift from Haeuslerella parri-dominated assemblages to Elphidium charlottense-dominated). The application of the percent mud proxy is potentially valid for the top section, and amplitudes of water-depth changes are similar to those inferred from the benthic $\delta^{18} 0$ record (20-30 metres amplitude). Precise amplitudes are not stated in this thesis as it is likely there are other longer-term 
contributions to the palaeobathymetric signal such as basin subsidence and sediment compaction. While these are not corrected for here, this will be considered in future studies.

In summary, the sediment texture and benthic foraminifera assemblages of the Tiriraukawa record are not responding to direct overhead water-depth changes. Nevertheless, their robust visual match with the glacial-interglacial cycles displayed in the LR04 benthic $\delta^{18} 0$ record and consistent orbital frequency $(41,000$ years) indicate a glacio-eustatic origin. Instead, the grainsize and benthic foraminifera are responding to changes in the proximal neritic environment, which is greatly influenced by glacioeustatic sea-level changes via changes to shoreline configurations and current activity. Thus, the record preserved in the Mangaweka Mudstone at Tiriraukawa provides an indirect proxy for orbitally-driven ice volume/sea-level changes, responding at distinctly obliquity frequencies.

\section{An indirect record of orbitally-forced glacio-eustatic sea level: implications}

The record preserved in the Mangaweka Mudstone interval studied in this thesis provides far-field evidence of global ice volume changes during the Late Pliocene, via their direct effect on global sea levels and subsequent influence on sediment erosion, transport and deposition on the Wanganui Basin continental shelf. Therefore, the Tiriraukawa record provides an opportunity, independent of the global marine oxygen isotope record, to assess the relative influence of three main orbital frequencies ( 100,000 year-eccentricity, $\sim 41,000$ year-obliquity, and $\sim 20,000$ year-precession) contributing to global ice volume and sea-level changes at this time.

The cyclicity presented primarily by the grainsize variability and secondly by the benthic foraminifera exhibits a duration of approximately 41,000 years, which can be matched one-to-one with predominantly 41,000 year cycles in the benthic $\delta^{18} 0$ record. This signal has been attributed to obliquity forcing of the polar ice sheets (figures 5.3) (Lisiecki and Raymo, 2005; Huybers, 2006; Raymo et al., 2006).

Obliquity is predicted to dominate ice volume variability under warmer mean climate states due to its influence on mean annual insolation, and insolation integrated over the summer season (Huybers, 2006). Forty-one thousand year dominated cyclicity is also 
modelled for global sea level and $\delta^{18} 0$ records during the Late Pliocene and Early Pleistocene (Raymo et al., 2006). However, spectral analysis of the LR04 benthic $\delta^{18} \mathrm{O}$ record indicates that while 41,000 year frequencies are dominant, eccentricitymodulated precession frequencies $(100,000$ year and $\sim 20,000$ year, respectively) are present between 3.5 Ma and 2.5 Ma (figure 5.3) (Meyers and Hinnov, 2010; Patterson et al., 2014). Additionally, an East Antarctic margin sedimentary record of iceberg-rafteddebris, which provides direct evidence of periodic deglaciation events, is dominated by eccentricity modulated-precession frequencies from 3.3-2.6 Ma with a noticeable lack of obliquity (Patterson et al., 2014). Prior to 3.3 Ma, obliquity frequencies dominate proximal records of ice volume variability of both the East and West Antarctic Ice Sheets in the warm Pliocene (Naish et al., 2009; Patterson et al., 2014). These observations suggest that globally-integrated records of ice volume/sea-level change may be the product of changing sensitivities of the polar ice sheets through the last 5 million years as the mean climate state changes.

Prior to $3.3 \mathrm{Ma}$, the global climate was on average $2-3^{\circ} \mathrm{C}$ warmer, the polar regions were 4- $5^{\circ} \mathrm{C}$ warmer (McKay et al., 2012a; Haywood et al., 2013), and carbon dioxide levels were $>400$ ppm (Bartoli et al., 2011; Seki et al., 2010). In the ice volume proxy record (Lisiecki and Raymo, 2005), a Southern Ocean aeolian dust record (Martinez-Garcia et al., 2011), and Antarctic margin sedimentary records (Naish et al., 2009; Patterson et al., 2014), obliquity frequencies are dominant. This observational evidence from palaeoclimate proxies is consistent with a leading orbital hypothesis that obliquity forcing should pace polar ice volume and sea-level changes under a warmer climate state (Huybers, 2006; Huybers and Tziperman, 2008) (and discussed in Chapter 2).

After 3.3 Ma, cooling initiated in the Southern Hemisphere, coeval with an orbital configuration that favoured extended intervals of cold summer seasons - a node in obliquity and a minimum in long-term eccentricity (McKay et al., 2012a; Patterson et al., 2014; Woodard et al., 2014). At the same time, precession frequencies became more dominant in the sedimentary record of the East Antarctic Ice Sheet (Patterson et al., 2014). Again, this is consistent with Huybers (2006) hypothesis that predicts a profound increase in precession-driven ablation in a cooler climate state. In a colder climate, ablation (positive degree days) is restricted to the height of summer, as the melt threshold increases and thus the insolation signal progressively shifts towards 
peak summer values, which is precession dominated. Conversely, in a warmer climate state the melt season is extended to cover most of the summer, and the signal approaches that of mean annual insolation, which is obliquity dominated in high latitude regions. This is because insolation is only received in summer months in the high latitudes, and the precession component of insolation cancels itself out over the course of a year (Huybers, 2006).
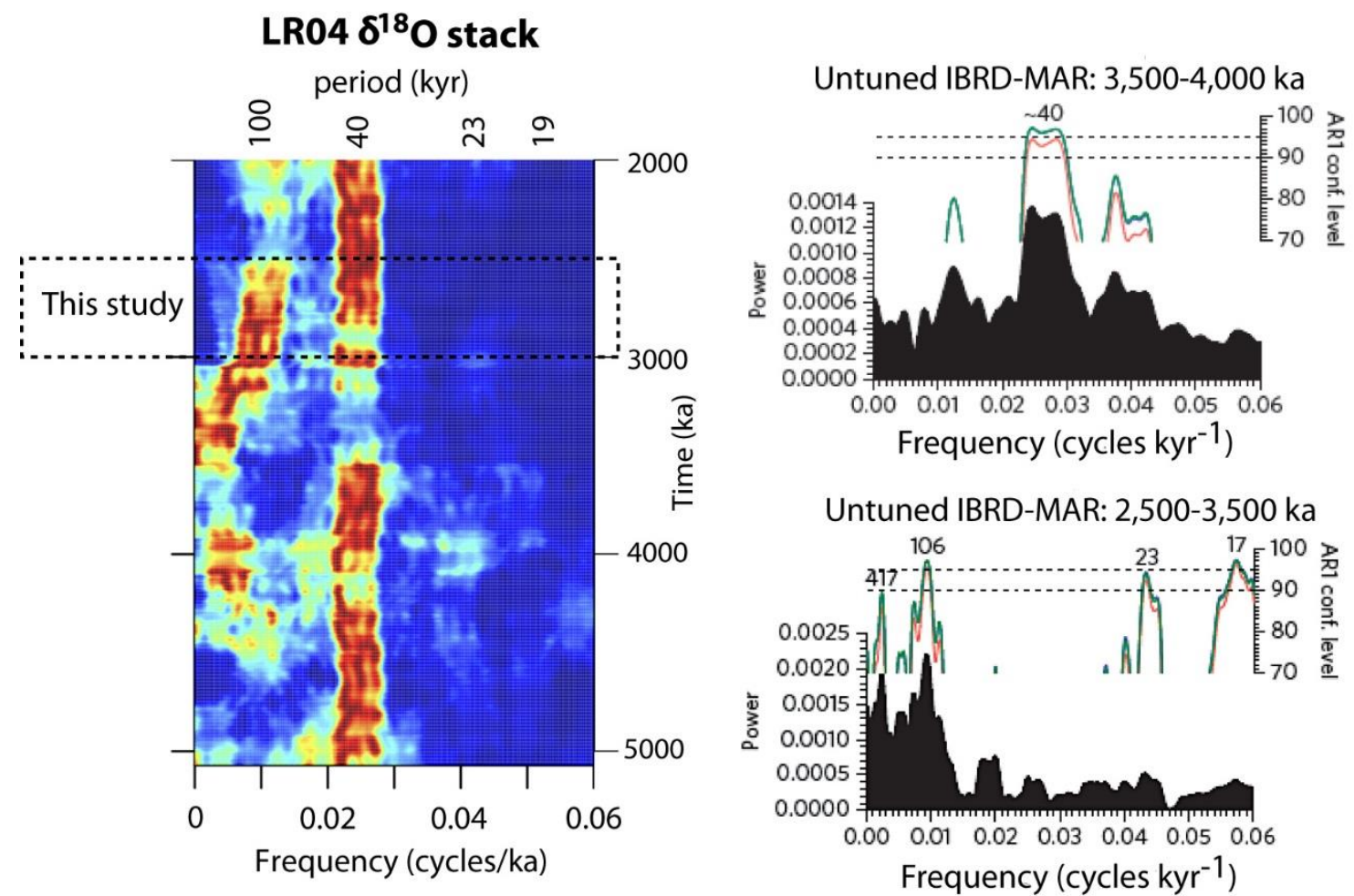

Figure 5.3: The image on the left shows the evolutionary spectral analysis (500-kyr window) of normalised spectral powers from the LR04 benthic $\delta 180$ record from Patterson et al. (2014). Between 3.0 Ma and 2.6 Ma, there is significant power in the 40kyr period (obliquity), and also the $100-\mathrm{kyr}$ period attributed to eccentricity. The images on the right show MTM power spectral analyses of the Antarctic margin IRD record using three different approaches (Patterson et al., 2014). The top image shows a distinct $40 \mathrm{kyr}$ period attributed to obliquity in the 3.5-4.0 Ma time frame, whereas between 2.5-3.5 Ma, there are strong $100 \mathrm{kyr}$ and $23 \mathrm{kyr}$ periods attributed to eccentricity and precession, respectively.

In contrast, the benthic $\delta^{18} 0$ record (and the Tiriraukawa Mangaweka Mudstone record) after $\sim 3.0$ Ma remains dominated by obliquity frequencies (figures 5.3 and 5.4). Patterson et al. (2014) link this observation with a strengthening and dominating obliquity forcing in the astronomical solutions modulating the frequency during the increase in Northern Hemisphere ice volume between 3.0-2.6 Ma. However, an 
alternative hypothesis by Raymo et al. (2006) cannot be rejected on the basis of the Tiriraukawa record either, which explains the dominance of the 40,000 year cycle as a consequence of hemispherically anti-phased precession-forced ice volume change being cancelled out in globally-integrated records, leaving the obliquity signal to dominate. Raymo et al. (2006) modelled an obliquity-paced sea-level curve for the Late Pliocene and Early Pleistocene with a simple ice sheet model. This assumes that the volume of ice sheet variability in the Northern Hemisphere must have been at most twice as large as the interglacial-glacial variability of the Antarctic (or vice versa) to explain the lack of significant precession-paced sea-level variability. Late Pliocene global sea-level amplitudes calculated from the benthic $\delta^{18} 0$ record are on the scale of $\sim 20-30$ metres, and small precession-paced changes in both hemispheres on the order of $\sim 5-10$ metres could be cancelled out, as there is evidence for at least some volume of terrestrial ice in the Northern Hemisphere at this time (Koenig et al., 2014; Larsen et al., 1994; Lunt et al., 2008).

The Tiriraukawa Mangaweka Mudstone record is consistent with ice volume variability at the obliquity frequency as evidenced by correlation in figure 5.4, despite a node in obliquity and a coeval interval of high-amplitude precession variability between 3 and 2.9 Ma. This is why the role of other orbital components as discussed above cannot be ruled out. After Cycle 4 (and above 400 metres stratigraphic depth) the grainsize record deviates from the consistent obliquity response seen in the lower four cycles; this is also a clear signal in the benthic $\delta^{18} 0$ record, and has an apparent eccentricity periodicity, during the prolonged interglacial interval spanning MIS G7, G8 and G9. This prolonged interglacial coincides with a long-term 400,000 year node in eccentricity. This is somewhat at odds with standard Milankovitch theories that low eccentricity, and thus low seasonality is an optimal orbital configuration for ice sheet expansion (Maslin et al., 1998). However, a similar orbital configuration occurs during the Late Pleistocene super-interglacial Marine Isotope Stage 11 (400 ka) highlighting that the strong nonlinear behaviour of the climate system to eccentricity forcing observed in the Late Pleistocene may have also occurred during the Late Pliocene. Thus, Cycle 5 could be interpreted as a 100,000 year cycle responding to eccentricity forcing, but superimposed by a weaker obliquity component. 


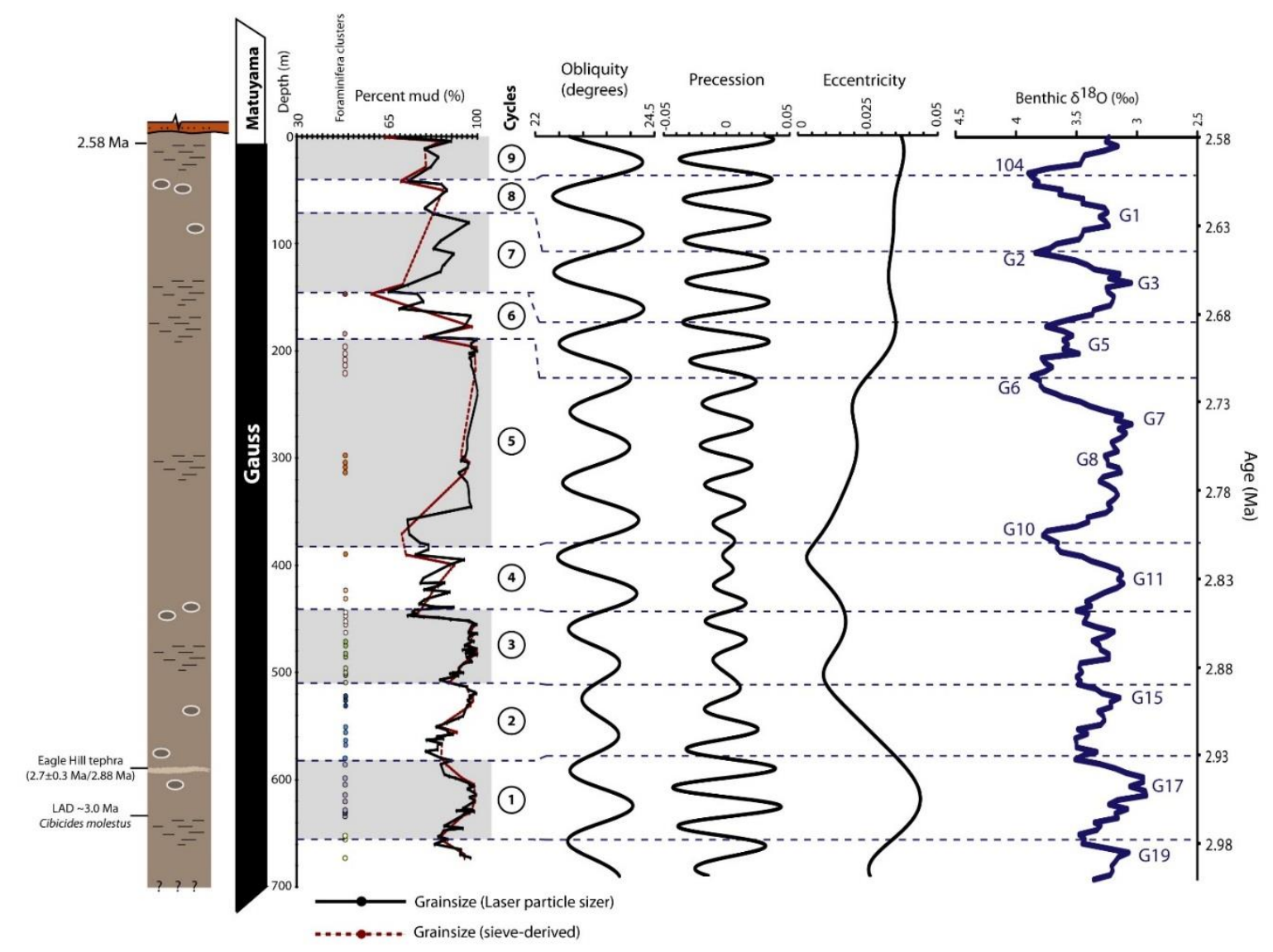

Figure 5.4: The Tiriraukawa Mangaweka Mudstone grainsize and benthic foraminifera record visually correlated to the astronomically-tuned LR04 benthic $\delta^{18} 0$ record (Lisiecki \& Raymo, 2005), constrained by the age model developed in this study, and the orbital solutions (Berger and Loutre, 1991). The grainsize record is consistent with obliquity cyclicity, with the exception of Cycle 5 . However, this deviation from obliquity forcing through this interval is consistent with the benthic $\delta^{180}$ record. While the upper $\sim 200$ metres of the grainsize record can still be matched to obliquity and glacial-interglacial cycles in the $\delta^{180}$ record, it is acknowledged that the resolution of the samples limit the same degree of clear visual comparison that is characteristic of the lower 500 metres.

In conclusion, while direct evidence suggests a strong precession response from the East Antarctic Ice Sheet post $\sim 3.3 \mathrm{Ma}$, the pattern of iceberg rafted debris recorded in high Arctic marine sediment cores suggest a dominant obliquity response of the developing Northern Hemisphere ice sheets at the same (Raymo et al., 1989; Kleiven et al., 2002). The amplitude of polar ice volume change (from the northern and southern hemispheres) and their consequent contribution to global sea level remains unknown. It is possible that ice volume changes at the precession frequency were too small (e.g. $<5$ metres amplitude sea-level equivalent) to be identified, while in grainsize and benthic foraminifera variations preserved in the Mangaweka Mudstone are not sensitive enough 
and only record the higher-amplitude obliquity-forced glacio-eustatic sea-level changes associated with Northern Hemisphere glaciation. As the majority of the Mangaweka Mudstone was deposited in an outer-shelf depositional environment ( $>100$ metres water depth), the variability in grainsize and foraminifera assemblages relies on significant changes in the configuration of the palaeo-shoreline and tractional currents in the proximal shallow neritic environment. Small glacio-eustatic sea-level changes resulting from precession-forced insolation peaks ( $\sim 5$ metres sea level) may not manifest in significant changes to either palaeo-shorelines or tractional currents, and therefore are not represented in the record preserved in the Mangaweka Mudstone. While the absence of precession in globally-integrated records of ice volume change is not completely reconciled here, the likely obliquity-pacing of the grainsize and benthic foraminifera preserved in the Mangaweka Mudstone allow for the following conclusions to be made:

(i) Larger amplitude glacio-eustatic sea-level fluctuations driven by obliquity are recorded in grainsize and foraminifera variability via increasing fine sand flux to the depositional environment, as a result of significant shifts in the configuration of palaeoshorelines and associated tractional currents. Smaller amplitude precession-forced sealevel changes are not of sufficient magnitude to alter the palaeo-shoreline and current activity, and as a result are not recorded as higher-frequency variability in grainsize and benthic foraminifera assemblages.

(ii) The anti-phase nature of the influence of precession in either hemispheres results in the cancelling of its effect on ice volume and global sea level in globally-integrated records. If correct, the Mangaweka Mudstone record infers that land-based ice in the Northern Hemisphere of sufficient volume must have existed in order to influence global sea level prior to the onset of intensive Northern Hemisphere glaciation at $\sim 2.7$ Ma (Lunt et al., 2008; Koenig et al., 2014; Patterson et al., 2014).

\section{Future work}

The compelling visual correlation of the record presented in this thesis to the benthic $\delta^{18} 0$ record can be further constrained with the analysis of the $\delta^{18} 0$ recorded in the shells of the benthic foraminifera from the Tiriraukawa Mangaweka Mudstone. This will 
allow a direct one-to-one comparison with the benthic $\delta^{18} 0$ record, and thus provide a more rigorous orbitally-tuned age model, and would allow a more independent assessment of the grainsize and foraminifera cycles, and their phasing/frequency relative to the orbital cycles.

As discussed in Chapter 4, the zircon fission track age of the Eagle Hill tephra has limited use for chronological constraints in relatively short records like the $\sim 400,000$ year-long Tiriraukawa Mangaweka Mudstone due to the significant uncertainty. However, the application of U-Pb dating of the volcanic zircons can provide much higher precision ages, and will greatly improve the age model and ability to correlate to regional and global records other than the LR04 benthic $\delta^{18} 0$ record (McIntyre, 2002). At the same time, further analysis of the major and trace element data for the Eagle Hill and Kowhai tephras (and also three other rhyolitic tephras stratigraphically below the former) in comparison with tephra geochemistry in the ODP 1123 sediment core record off the East Coast of the North Island could provide a robust correlation to this regional record of palaeoclimate variability (which is also astronomically-tuned). Further grainsize, foraminifera and palaeomagnetic sampling to improve the record and age model resolution could also further constrain the orbital cyclicity preserved in the Mangaweka Mudstone, in particular the top 200 metres of the section.

This thesis is part of a broader study investigating the mid-Pliocene sedimentary record of the Wanganui Basin (as discussed in Chapter 1). It is anticipated that the record of orbitally-forced glacio-eustatic sea-level changes preserved in the Mangaweka Mudstone at Tiriraukawa will compliment and extend the high resolution palaeoclimate records, from the warm mid-Pliocene into the relatively cooler Late Pliocene and Early Pleistocene. This will allow for the interpretation of the influence of orbital forcing on the water-depth changes and thus global ice volume change preserved in the Wanganui Basin over a broader time-scale than presented in this thesis. 


\section{Chapter 6: Summary \& Conclusions}

An evaluation of the influence of orbital forcing on global sea level during the Late Pliocene ( 3.0-2.6 Ma) was undertaken on the Mangaweka Mudstone formation in the Wanganui Basin, New Zealand. This was achieved through: (i) an integrated study of palaeobathymetric proxies of sediment texture and benthic foraminiferal assemblages, and (ii) the application of magneto-, tephro-, and biostratigraphic techniques for the construction of an age model, within a well-constrained local chronostratigraphic framework.

- Standard field-techniques and differential GPS surveying were employed to measure the Mangaweka Mudstone where it is continuously exposed along Watershed Road, near Tiriraukawa in the vicinity of Mangaweka and Taihape townships. At this location at Tiriraukawa, the Mangaweka Mudstone is at least 672 metres thick, 178 grainsize and 63 benthic foraminiferal samples were collected to achieve a sampling resolution of $<5000$ years.

- Grainsize was measured using laser particle size analysis, and the entire Mangaweka Mudstone is classified as poorly-sorted mudstone to sandymudstone. Below 400 metres stratigraphic depth, the section is characterised by cyclic, low-amplitude fluctuations in percent mud. Above $\sim 400$ metres stratigraphic depth, the overall percent mud decreases, and cyclical fluctuations increase in amplitude. An application of a sediment water depth proxy (Dunbar \& Barrett, 2005), assuming a depositional environment of a wave-graded continental shelf, estimates palaeobathymetry ranging $\sim 50-60$ metres water depth, or mid-continental shelf depths, and an overall trend of shallowing water depths up section.

- Benthic foraminifera were prepared and identified using standard procedures, and statistically-distinctive faunal clusters were defined from normalised percent abundance data using Q-mode multivariate cluster analysis. The benthic foraminifera assemblages show a consistent faunal trend up the section, where 
the lower $\sim 400$ metres of section is characterised by species with an outer-shelf (>100 metres water depth) affinity, shallowing to mid- ( $\sim 50$ metres) and innershelf water depths ( $\sim 20$ metres) and associated faunal assemblages by $\sim 140$ metres stratigraphic depth. Superimposed on this long-term faunal trend are higher frequency, distinctive shifts in the abundant benthic species of which the clusters are comprised.

- The in situ benthic foraminifera palaeobathymetries indicate outer-shelf environments, whereas the grainsize water depth proxy estimates are characteristically inner- to mid-shelf for the lower $\sim 400-500$ metres of the section. The robust water depth constraints provided by the depth palaeoecology of extant benthic foraminifera highlights that the results of the grainsize water depth proxy cannot be interpreted as direct overhead water depth changes on a wave-graded continental shelf. This is because wave induced sand transport does not occur on the modern Manawatu-Wanganui outer-shelf, and the Pliocene and modern wave climates are assumed to be analogous. However, in this thesis, an indirect relationship between water depth changes and the higher-frequency variability in grainsize and benthic foraminifera assemblages is argued for the lower $\sim 400$ metres of section, and there is striking consistency between the grainsize and benthic foraminifera variability when the pattern of the higherfrequency changes is considered.

- An age model was developed for the Tiriraukawa section of the Mangaweka Mudstone using: (i) palaeomagnetic analyses constrained by the magnetostratigraphy of previous studies, and identified the Gauss-Matuyama reversal (2.58 Ma) in the upper part of the section, (ii) a zircon fission track age from the rhyolitic Eagle Hill tephra $(2.7 \pm 0.3 \mathrm{Ma})$ cropping-out in the Mangaweka Mudstone in the Rangitikei River valley, which is correlated to the previously unknown tephra in the Tiriraukawa section using (iii) major and trace element characterisation of volcanic glass shards collected from tephra deposits in the studied section. Finally, (iv) a biostratigraphic last appearance datum of the benthic foraminifera Cibicides molestus at $\sim 3.0$ Ma was identified near the base of the section. These three independent dating techniques are consistent with 
previous age models for the Mangaweka Mudstone and constrain the age of the formation to the Late Pliocene between $\sim 3.0 \mathrm{Ma}$ and 2.58 Ma. The construction of the age model enabled the frequency of the variability preserved as cyclical changes in grainsize and benthic foraminifera assemblages to be estimated at approximately 40,000 years.

- There are nine complete cycles identified in the grainsize and benthic foraminifera assemblages within the Mangaweka Mudstone over a 400,000 year interval. When compared to the LR04 benthic $\delta^{18} \mathrm{O}$ record, a strong visual comparison is evident. This observation allows a one-to-one correlation of the grainsize variability and benthic foraminifera clusters to the glacial-interglacial cycles in the ice volume proxy record for the equivalent Late Pliocene time period (spanning Marine Isotope Stage G18-103). While the age models for the Tiriraukawa record and the benthic $\delta^{18} 0$ record are different in approach and precision (e.g. benthic $\delta^{18} 0$ record is an orbitally-tuned global stack), the comparison is robust within the uncertainty of the constructed age model. The correlation between the two records indicates that the frequency of the grainsize and benthic foraminifera cycles is concentrated at $\sim 40,000$ years, which in the LR04 benthic $\delta^{18} 0$ record is attributed to the dominance of obliquity forcing (which has a frequency of $\sim 40,000$ years).

- While the grainsize and foraminifera changes cannot be a result of direct water depth changes on a wave-graded continental shelf (as discussed above), especially in lower $\sim 400$ metres, the distinctive orbital frequency and matching variability between the benthic $\delta^{18} 0$ record strongly suggests a glacio-eustatic origin. When the palaeogeography of the Wanganui Basin during the Late Pliocene is considered, the variability in grainsize can be attributed to periodic fluxes of sand-sized particles to the outer-shelf environment in response to large geographic shifts in palaeo-shorelines across a narrow continental shelf and enhanced tidal current activity across a constricted continental shelf during glacio-eustatic sea-level lowstands. At the same time, the local water depth changes as a consequence of glacio-eustatic water depth changes (of only 20-30 metres amplitude in the Late Pliocene) are not of sufficient amplitude to 
influence the depth palaeoecology of the benthic foraminifera, which remain in a distinct outer-shelf environment. The grainsize and foraminifera variability is therefore interpreted to be an indirect measure of glacio-eustatic sea-level fluctuations influencing the Wanganui Basin during the Late Pliocene.

- The compelling correlation of the Tiriraukawa Mangaweka Mudstone record to the benthic $\delta^{18} 0$ record indicates that the preserved glacio-eustatic sea-level variability is an indirect result of global ice volume response to $\sim 40,000$ year obliquity cycles. Implications for the role of the orbital forcing of the polar ice sheets from this study include:

- Global ice volume/sea-level changes are dominantly forced by obliquity, with likely contributions at the eccentricity-modulated precession frequency $(100,000$ years). The glacial-interglacial cycles represented in the benthic $\delta^{18} 0$ record are also embodied as cycles of global sea-level changes, highlighting that the $\delta^{18} 0$ cycles are likely not artefacts of the isotopic proxy record, or stacking process of these records. In particular the role of anti-phased precession on bi-polar ice volume changes is subordinate to the influence of obliquity during the Late Pliocene.

- However, ice volume changes at the precession frequency cannot be ruled out. It is possible that any glacio-eustatic sea-level changes at precessional frequencies are not of sufficient amplitude to influence the transport of sand to outer-shelf environments via palaeo-shoreline and tractional current shifts. At the same time, precession-forced ice volume and sealevel changes may be cancelled out in the glacio-eustatic sea-level record as its influence is anti-phased between the hemispheres. 


\section{References}

Abbott, S. T., 1997, Foraminiferal paleobathymetry and mid-cycle architecture of midPleistocene depositional sequences, Wanganui Basin, New Zealand: PALAIOS, v. 12, no. 3, p. 267-281.

Abbott, S. T., and Carter, R. M., 1997, Macrofossil associations from mid-Pleistocene cyclothems, Castlecliff section, New Zealand; implications for sequence stratigraphy: PALAIOS, v. 12, no. 2, p. 188-210.

Abbott, S. T., Naish, T. R., Carter, R. M., and Pillans, B. J., 2005, Sequence stratigraphy of Nukumaruan Stratotype (Pliocene-Pleistocene, c. 2.08-1.63 Ma), Wanganui Basin, New Zealand: Journal of the Royal Society of New Zealand, v. 35, no. 1-2, p. 123-150.

Abrajevitch, A., Roberts, A. P., and Kodama, K., 2014, Volcanic iron fertilization of primary productivity at Kerguelen Plateau, Southern Ocean, through the Middle Miocene Climate Transition: Palaeogeography, Palaeoclimatology, Palaeoecology, v. 410, p. 1-13.

Adhemar, J., 1842, Revolutions de la Mer: Deluges Periodiques, Pais.

Alloway, B. V., Pillans, B. J., Sandhu, A. S., and Westgate, J. A., 1993, Revision of the marine chronology in the Wanganui Basin, New Zealand, based on the isothermal plateau fission-track dating of tephra horizons: Sedimentary Geology, v. 82, no. 1, p. 299-310.

Alloway, B. V., Pillans, B. J., Carter, L., Naish, T. R., and Westgate, J. A., 2005, Onshore-offshore correlation of Pleistocene rhyolitic eruptions from New Zealand: implications for TVZ eruptive history and paleoenvironmental construction: Quaternary Science Reviews, v. 24, no. 14-15, p. 1601-1622.

Anderton, P. W., 1981, Structure and evolution of the South Wanganui Basin, New Zealand: New Zealand Journal of Geology and Geophysics, v. 24, no. 1, p. 39-63.

Andreev, A. A., Tarasov, P. E., Wennrich, V., Raschke, E., Herzschuh, U., Nowaczyk, N. R., BrighamGrette, J., and Melles, M., 2014, Late Pliocene and Early Pleistocene vegetation history of northeastern Russian Arctic inferred from the Lake El'gygytgyn pollen record: Climate of the Past, v. 10, no. 3, p. 1017-1039.

Bailey, I., Hole, G. M., Foster, G. L., Wilson, P. A., Storey, C. D., Trueman, C. N., and Raymo, M. E., 2013, An alternative suggestion for the Pliocene onset of major northern hemisphere glaciation based on the geochemical provenance of North Atlantic Ocean ice-rafted debris: Quaternary Science Reviews, v. 75, p. 181-194.

Ballantyne, A. P., Greenwood, D. R., Sinninghe Damste, J. S., Csank, A. Z., Eberle, J. J., and Rybczynski, N., 2010, Significantly warmer Arctic surface temperatures during the Pliocene indicated by multiple independent proxies: Geology, v. 38, no. 7, p. 603-606.

Bartoli, G., Sarnthein, M., Weinelt, M., Erlenkeuser, H., Garbe-Schönberg, D., and Lea, D. W., 2005, Final closure of Panama and the onset of northern hemisphere glaciation: Earth and Planetary Science Letters, v. 237, no. 1-2, p. 33-44.

Bartoli, G., Hönisch, B., and Zeebe, R. E., 2011, Atmospheric CO2 decline during the Pliocene intensification of Northern Hemisphere glaciations: Paleoceanography, v. 26, no. 4, p. 114.

Basile, I., Grousset, F. E., Revel, M., Petit, J. R., Biscaye, P. E., and Barkov, N. I., 1997, Patagonian origin of glacial dust deposited in East Antarctica (Vostok and Dome C) during glacial stages 2, 4 and 6: Earth and Planetary Science Letters, v. 146, no. 3, p. 573-589.

Berger, A., 1977, Support for the astronomical theory of climate change: Nature, v. 269, p. 44-45.

Berger, A., 1978, Long-term variations of daily insolation and Quaternary climatic changes: Journal of the Atmospheric Sciences, v. 35, no. 12, p. 2362-2367.

Berger, A., 1988, Milankovitch theory and climate: Reviews of Geophysics, v. 26, no. 4, p. 624657.

Berger, A., and Loutre, M.-F., 1991, Insolation values for the climate of the last 10 million years: Quaternary Science Reviews, v. 10, no. 4, p. 297-317. 
Berger, W. H., 2013, On the Milankovitch sensitivity of the Quaternary deep-sea record: Climate of the Past, v. 9, no. 4, p. 2003-2011.

Beu, A. G., 1969, Index macrofossils and New Zealand Pliocene and lower Pleistocene timestratigraphy: New Zealand Journal of Geology and Geophysics, v. 12, no. 4, p. 643-658.

Beu, A., and Edwards, A., 1984, New Zealand Pleistocene and late Pliocene glacio-eustatic cycles: Palaeogeography, Palaeoclimatology, Palaeoecology, v. 46, no. 1, p. 119-142.

Beu, A. G., and Maxwell, P. A., 1990, Cenozoic Mollusca of New Zealand: New Zealand Geological Survey Paleontological Bulletin, v. 58.

Blanchon, P., Eisenhauer, A., Fietzke, J., and Liebetrau, V., 2009, Rapid sea-level rise and reef back-stepping at the close of the last interglacial highstand: Nature, v. 458, no. 7240, p. 881-884.

Bland, K. J., Kamp, P. J., Pallentin, A., Graafhuis, R., Nelson, C. S., and Caron, V., 2004, The early Pliocene Titiokura Formation: Stratigraphy of a thick, mixed carbonate-siliciclastic shelf succession in Hawke's Bay Basin, New Zealand: New Zealand Journal of Geology and Geophysics, v. 47, no. 4, p. 675-695.

Blott, S., 2000, A Grainsize Distribution and Statistics Package for the Analysis of Unconsolidated Sediments by Sieving or Laser Granulometer: Royal Holloway University of London, UK.

Boellstorff, J. D., and Te Punga, M. T., 1977, Fission-track ages and correlation of middle and lower pleistocene sequences from Nebraska and New Zealand: New Zealand Journal of Geology and Geophysics, v. 20, no. 1, p. 47-58.

Boggs, S. J., 2011, Principals of Sedimentology and Stratigraphy, Pearson Education Ltd.

Brierley, C. M., Fedorov, A. V., Liu, Z., Herbert, T. D., Lawrence, K. T., and LaRiviere, J. P., 2009, Greatly expanded tropical warm pool and weakened Hadley circulation in the early Pliocene: Science, v. 323, no. 5922, p. 1714-1718.

Briggs, R., Houghton, B., McWilliams, M., and Wilson, C., 2005, 40Ar/39Ar ages of silicic volcanic rocks in the Tauranga-Kaimai area, New Zealand: Dating the transition between volcanism in the Coromandel Arc and the Taupo Volcanic Zone: New Zealand Journal of Geology and Geophysics, v. 48, no. 3, p. 459-469.

Brigham-Grette, J., Melles, M., Minyuk, P., Andreev, A., Tarasov, P., DeConto, R., Koenig, S., Nowaczyk, N., Wennrich, V., and Rosén, P., 2013, Pliocene warmth, polar amplification, and stepped Pleistocene cooling recorded in NE Arctic Russia: Science, v. 340, no. 6139, p. 1421-1427.

Broecker, W. S., and Denton, G. H., 1989, The role of ocean-atmosphere reorganizations in glacial cycles: Geochimica et Cosmochimica Acta, v. 53, no. 10, p. 2465-2501.

Bromley, R. G., and Ekdale, A., 1984, Chondrites: a trace fossil indicator of anoxia in sediments: Science, v. 224, no. 4651, p. 872-874.

Buchanan, J., 1869, On the Wanganui Beds (Upper Tertiary): Transactions of the Royal Society of New Zealand.

Butler, R. F., 1992, Paleomagnetism: magnetic domains to geologic terranes, Blackwell Scientific Publications Boston.

Cande, S. C., and Kent, D. V., 1995, Revised calibration of the geomagnetic polarity timescale for the Late Cretaceous and Cenozoic: Journal of Geophysical Research, v. 100, no. B4, p. 6093.

Cane, M. A., and Molnar, P., 2001, Closing of the Indonesian seaway as a precursor to east African aridification around 3-4 million years ago: Nature, v. 411, no. 6834, p. 157-162.

Carter, A., and Moss, S. J., 1999, Combined detrital-zircon fission-track and U-Pb dating: a new approach to understanding hinterland evolution: Geology, v. 27, no. 3, p. 235-238.

Carter, L., 1975, Sedimentation on the continental terrace around New Zealand: a review: Marine Geology, v. 19, no. 4, p. 209-237.

Carter, L., and Heath, R., 1975, Role of mean circulation, tides, and waves in the transport of bottom sediment on the New Zealand continental shelf: New Zealand Journal of Marine and Freshwater Research, v. 9, no. 4, p. 423-448. 
Carter, L., Carter, R., Nelson, C., Fulthorpe, C., and Neil, H., 1990, Evolution of Pliocene to Recent abyssal sediment waves on Bounty Channel levees, New Zealand: Marine Geology, v. 95, no. 2, p. 97-109.

Carter, L., and Lewis, K., 1995, Variability of the modern sand cover on a tide and storm driven inner shelf, south Wellington, New Zealand: New Zealand Journal of Geology and Geophysics, v. 38, no. 4, p. 451-470.

Carter, L., Neil, H., and McCave, I., 2000, Glacial to interglacial changes in non-carbonate and carbonate accumulation in the SW Pacific Ocean, New Zealand: Palaeogeography, Palaeoclimatology, Palaeoecology, v. 162, no. 3, p. 333-356.

Carter, L., Shane, P., Alloway, B., Hall, I. R., Harris, S. E., and Westgate, J. A., 2003, Demise of one volcanic zone and birth of another-a 12 my marine record of major rhyolitic eruptions from New Zealand: Geology, v. 31, no. 6, p. 493-496.

Carter, L., Alloway, B., Shane, P., and Westgate, J., 2004, Deep-ocean record of major late Cenozoic rhyolitic eruptions from New Zealand: New Zealand Journal of Geology and Geophysics, v. 47, no. 3, p. 481-500.

Carter, R. M., Fulthorpe, C. S., and Naish, T. R., 1998, Sequence concepts at seismic and outcrop scale: the distinction between physical and conceptual stratigraphic surfaces: Sedimentary Geology, v. 122, no. 1, p. 165-179.

Carter, R. M., and Naish, T. R., 1999, The high-resolution chronostratigraphic and sequence stratigraphic record of the Plio-Pleistocene, Wanganui Basin, New Zealand: Institute of Geological \& Nuclear Sciences.

Chamberlain, C., Poage, M., Craw, D., and Reynolds, R., 1999, Topographic development of the Southern Alps recorded by the isotopic composition of authigenic clay minerals, South Island, New Zealand: Chemical Geology, v. 155, no. 3, p. 279-294.

Chappell, J., and Shackleton, N. J., 1986, Oxygen isotopes and sea level: Nature, v. 324, p. 137140.

Clark, P. U., Alley, R., and Pollard, D., 1999, Northern Hemisphere Ice-Sheet Influences on Global Climate Change: Science, v. 286, p. 1104-1111.

Clifton, H. E., 1988, Sedimentologic Approaches to Palaeobathymetry, with Applications to the Merced Formation of Central California: PALAOIS, v. 3, no. 5, p. 507-522.

Clifton, H. E., and Dingler, J. R., 1984, Wave-formed structures and paleoenvironmental reconstruction: Marine Geology, v. 60, no. 1-4, p. 165-198.

Collen, J., 1972, Studies in the Wanganui series: Pliocene foraminifera from Wanganui Basin. Unpublished PhD thesis, Victoria University of Wellingon, Wellington, New Zealand.

Cook, C. P., van de Flierdt, T., Williams, T., Hemming, S. R., Iwai, M., Kobayashi, M., JimenezEspejo, F. J., Escutia, C., González, J. J., Khim, B.-K., McKay, R. M., Passchier, S., Bohaty, S. M., Riesselman, C. R., Tauxe, L., Sugisaki, S., Galindo, A. L., Patterson, M. O., Sangiorgi, F., Pierce, E. L., Brinkhuis, H., Klaus, A., Fehr, A., Bendle, J. A. P., Bijl, P. K., Carr, S. A., Dunbar, R. B., Flores, J. A., Hayden, T. G., Katsuki, K., Kong, G. S., Nakai, M., Olney, M. P., Pekar, S. F., Pross, J., Röhl, U., Sakai, T., Shrivastava, P. K., Stickley, C. E., Tuo, S., Welsh, K., and Yamane, M., 2013, Dynamic behaviour of the East Antarctic ice sheet during Pliocene warmth: Nature Geoscience, v. 6, no. 9, p. 765-769.

Cook, C. P., Hill, D. J., van de Flierdt, T., Williams, T., Hemming, S. R., Dolan, A. M., Pierce, E. L., Escutia, C., Harwood, D., Cortese, G., and Gonzales, J. J., 2014, Sea surface temperature control on the distribution of far-traveled Southern Ocean ice-rafted detritus during the Pliocene: Paleoceanography, v. 29, no. 6, p. 533-548.

Cooper, R. A. (ed), 2004, The New Zealand Geological Timescale: Institute of Geological and Nulcear Sciences Monograph 22, 284pp.

Croll, J., 1867, On the Change in the Obliquity of the Eclipctic; Its Influence on the Climate of the Polar Regions, and the Level of the Sea: Transactions of the Geological Society of Glasgow, p. 177-198.

Crowley, T. J., 1991, Modelling Pliocene Warmth: Quaternary Science Reviews, v. 10, p. 275-282.

Crowley, T. J., 1996, Pliocene climates: the nature of the problem: Marine Micropaleontology, v. 27, p. 3-12. 
Denton, G., Alley, R., Comer, G., and Broecker, W., 2005, The role of seasonality in abrupt climate change: Quaternary Science Reviews, v. 24, no. 10-11, p. 1159-1182.

Dolan, A. M., Haywood, A. M., Hill, D. J., Dowsett, H. J., Hunter, S. J., Lunt, D. J., and Pickering, S. J., 2011, Sensitivity of Pliocene ice sheets to orbital forcing: Palaeogeography, Palaeoclimatology, Palaeoecology, v. 309, no. 1-2, p. 98-110.

Dowsett, H. J., and Cronin, T. M., 1990, High eustatic sea level during the middle Pliocene: Evidence from the southeastern US Atlantic Coastal Plain: Geology, v. 18, no. 5, p. 435438.

Dowsett, H. J., Robinson, M. M., Haywood, A. M., Hill, D. J., Dolan, A. M., Stoll, D. K., Chan, W.-L., Abe-Ouchi, A., Chandler, M. A., Rosenbloom, N. A., Otto-Bliesner, B. L., Bragg, F. J., Lunt, D. J., Foley, K. M., and Riesselman, C. R., 2012, Assessing confidence in Pliocene sea surface temperatures to evaluate predictive models: Nature Climate Change, v. 2, no. 5, p. 365371.

Driscoll, N., and Haug, G., 1998, A short circuit in thermohaline circulation: A cause for Northern Hemisphere glaciation?: Science, v. 282, no. 5388, p. 436-438.

Dunbar, G. B., and Barrett, P. J., 2005, Estimating palaeobathymetry of wave-graded continental shelves from sediment texture: Sedimentology, v. 52, no. 2, p. 253-269.

Dunlop, D. J., 1979, On the use of Zijderveld vector diagrams in multicomponent paleomagnetic studies: Physics of the Earth and Planetary Interiors, v. 20, no. 1, p. 12-24.

Dutton, A., and Lambeck, K., 2012, Ice volume and sea level during the last interglacial: Science, v. 337, no. 6091, p. 216-219.

Dwyer, G. S., and Chandler, M. A., 2009, Mid-Pliocene sea level and continental ice volume based on coupled benthic $\mathrm{Mg} / \mathrm{Ca}$ palaeotemperatures and oxygen isotopes: Philosophical Transations A Mathematical, Physical and Engineering Sciences, v. 367, no. 1886, p. 157 168.

Elmore, R. D., Muxworthy, A. R., and Aldana, M., 2012, Remagnetization and chemical alteration of sedimentary rocks: Geological Society, London, Special Publications, v. 371, no. 1, p. 121.

Emiliani, C., 1955, Pleistocene Temperatures: Journal of Geology, v. 63, p. 538-678.

Escutia, C., Bárcena, M. A., Lucchi, R. G., Romero, O., Ballegeer, A. M., Gonzalez, J. J., and Harwood, D. M., 2009, Circum-Antarctic warming events between 4 and 3.5Ma recorded in marine sediments from the Prydz Bay (ODP Leg 188) and the Antarctic Peninsula (ODP Leg 178) margins: Global and Planetary Change, v. 69, no. 3, p. 170-184.

Etourneau, J., Martinez, P., Blanz, T., and Schneider, R., 2009, Pliocene-Pleistocene variability of upwelling activity, productivity, and nutrient cycling in the Benguela region: Geology, v. 37, no. 10, p. 871-874.

Etourneau, J., Schneider, R., Blanz, T., and Martinez, P., 2010, Intensification of the Walker and Hadley atmospheric circulations during the Pliocene-Pleistocene climate transition: Earth and Planetary Science Letters, v. 297, no. 1-2, p. 103-110.

Etourneau, J., Ehlert, C., Frank, M., Martinez, P., and Schneider, R., 2012, Contribution of changes in opal productivity and nutrient distribution in the coastal upwelling systems to Late Pliocene/Early Pleistocene climate cooling: Climate of the Past, v. 8, no. 5, p. 1435-1445.

Fedorov, A., Dekens, P., McCarthy, M., Ravelo, A., Barreiro, M., Pacanowski, R., and Philander, S., 2006, The Pliocene paradox (mechanisms for a permanent El Niño): Science, v. 312, no. 5779, p. 1485-1489.

Feldmeyer, A. E., Jones, B. C., Firth, C. W., and Knight, J., 1943, Geology of the PalmerstonWanganui Basin, "West Side", North Island, New Zealand.: for the Superior Oil Company of New Zealand, housed at the Institude of Geological and Nuclear Sciences, Lower Hutt.

Fielding, C. R., Harwood, D. M., Winter, D. M., and Francis, J. E., 2012, Neogene stratigraphy of Taylor Valley, Transantarctic Mountains, Antarctica: Evidence for climate dynamism and a vegetated Early Pliocene coastline of McMurdo Sound: Global and Planetary Change, v. 96-97, p. 97-104.

Fleming, C. A., 1953, The geology of the Wanganui Subdivision: New Zealand Geological Survey Bulletin, v. 52. 
Fleming, K., Johnston, P., Zwartz, D., Yokoyama, Y., Lambeck, K., and Chappell, J., 1998, Refining the eustatic sea-level curve since the Last Glacial Maximum using far-and intermediatefield sites: Earth and Planetary Science Letters, v. 163, no. 1, p. 327-342.

Folk, R. L., Ward, W. C., 1957, Brazos River bar: a study of the significance of grain size parameters: Journal of Sedimentary Petrology, v. 27, p. 3-26.

Fretwell, P., Pritchard, H. D., Vaughan, D. G., Bamber, J. L., Barrand, N. E., Bell, R., Bianchi, C., Bingham, R. G., Blankenship, D. D., Casassa, G., Catania, G., Callens, D., Conway, H., Cook, A. J., Corr, H. F. J., Damaske, D., Damm, V., Ferraccioli, F., Forsberg, R., Fujita, S., Gim, Y., Gogineni, P., Griggs, J. A., Hindmarsh, R. C. A., Holmlund, P., Holt, J. W., Jacobel, R. W., Jenkins, A., Jokat, W., Jordan, T., King, E. C., Kohler, J., Krabill, W., Riger-Kusk, M., Langley, K. A., Leitchenkov, G., Leuschen, C., Luyendyk, B. P., Matsuoka, K., Mouginot, J., Nitsche, F. O., Nogi, Y., Nost, O. A., Popov, S. V., Rignot, E., Rippin, D. M., Rivera, A., Roberts, J., Ross, N., Siegert, M. J., Smith, A. M., Steinhage, D., Studinger, M., Sun, B., Tinto, B. K., Welch, B. C., Wilson, D., Young, D. A., Xiangbin, C., and Zirizzotti, A., 2013, Bedmap2: improved ice bed, surface and thickness datasets for Antarctica: The Cryosphere, v. 7, no. 1, p. 375393.

Froggatt, P., 1992, Standardization of the chemical analysis of tephra deposits. Report of the ICCT working group: Quaternary International, v. 13, p. 93-96.

Gage, M., 1961, New Zealand glaciations and the duration of the Pleistocene: Journal of Glaciology, v. 3, no. 29, p. 940-943.

Galbraith, R., and Laslett, G., 1993, Statistical models for mixed fission track ages: Nuclear Tracks and Radiation Measurements, v. 21, no. 4, p. 459-470.

Grant-Taylor, T. L., and de B. Hornibrook, N., 1964, The Makara faulted outlier and the age of Cook Strait: New Zealand Journal of Geology and Geophysics, v. 7, no. 2, p. 299-311.

Grant, K. M., Rohling, E. J., Ramsey, C. B., Cheng, H., Edwards, R. L., Florindo, F., Heslop, D., Marra, F., Roberts, A. P., Tamisiea, M. E., and Williams, F., 2014, Sea-level variability over five glacial cycles: Nature Communications, v. 5, p. 5076.

Griffiths, D., King, R., Rees, A., and Wright, A., 1960, The remanent magnetism of some recent varved sediments: Proceedings of the Royal Society of London. Series A. Mathematical and Physical Sciences, v. 256, no. 1286, p. 359-383.

Griffiths, G., and Glasby, G., 1985, Input of river-derived sediment to the New Zealand continental shelf: I. Mass: Estuarine, Coastal and Shelf Science, v. 21, no. 6, p. 773-787.

Hambrey, M. J., and McKelvey, B., 2000, Major Neogene fluctuations of the East Antarctic ice sheet: Stratigraphic evidence from the Lambert Glacier region: Geology, v. 28, no. 10, p. 887-890.

Hamme, R. C., Webley, P. W., Crawford, W. R., Whitney, F. A., DeGrandpre, M. D., Emerson, S. R., Eriksen, C. C., Giesbrecht, K. E., Gower, J. F. R., Kavanaugh, M. T., Peña, M. A., Sabine, C. L., Batten, S. D., Coogan, L. A., Grundle, D. S., and Lockwood, D., 2010, Volcanic ash fuels anomalous plankton bloom in subarctic northeast Pacific: Geophysical Research Letters, v. 37 , no. 19 , p. $1-5$.

Hammer, Ø., Harper, D. A. T., and Ryan, P. D., 2001, PAST: Paleontological Statistics Software Package for Education and Data Analysis: Palaeontologica Electronica, v. 4, no. 1, p. 9.

Haq, B. U., Hardenbol, J., and Vail, P. R., 1987, Chronology of fluctuating sea levels since the Triassic: Science, v. 235, no. 4793, p. 1156-1167.

Haug, G. H., and Tiedemann, R., 1998, Effect of the formation of the Isthmus of Panama on Atlantic Ocean thermohaline circulation: Nature, v. 393, no. 6686, p. 673-676.

Haug, G. H., Sigman, D. M., Tiedemann, R., Pedersen, T. F., and Sarnthein, M., 1999, Onset of permanent stratification in the subarctic Pacific Ocean: Nature, v. 401, no. 6755, p. 779782.

Hays, J. D., Imbrie, J., and Shackleton, N. J., 1976, Variations in the Earth's Orbit: The Pacemaker of the Ice Ages: Science, v. 194, no. 4270, p. 1121-1132.

Hayton, S., 1998, Sequence stratigraphic, paleoenvironmental, and chronological analysis of the Late Neogene Wanganui River section, Wanganui Basin. Unpublished PhD thesis, University of Waikato, Hamilton, New Zealand. 
Hayton, S., Nelson, C. S., Ricketts, B. D., Cooke, S., and Wedd, M. W., 2001, Effect of mica on particle-size analyses using the laser diffraction technique: Journal of Sedimentary Research, v. 71, no. 3, p. 507-509.

Hayward, B. W., 1986, A guide to paleoenvironmental assessment using New Zealand Cenozoic foraminiferal faunas: New Zealand Geological Survey Report, PAL 109, p. 73.

Hayward, B. W., Grenfell, H. R., Reid, C. M., and Hayward, K. A., 1999, Recent New Zealand shallow-water benthic foraminifera: Taxonomy, ecologic distribution, biogeography, and use in paleoenvironmental assessment: Institute of Geological and Nuclear Sciences monograph 21, Lower Hutt, New Zealand, p. 264.

Hayward, B. W., Carter, R., Grenfell, H. R., and Hayward, J. J., 2001, Depth distribution of Recent deep-sea benthic foraminifera east of New Zealand, and their potential for improving paleobathymetric assessments of Neogene microfaunas: New Zealand Journal of Geology and Geophysics, v. 44, no. 4, p. 555-587.

Haywick, D., and Henderson, R., 1991, Foraminiferal paleobathymetry of Plio-Pleistocene cyclothemic sequences, Petane Group, New Zealand: PALAIOS, p. 586-599.

Haywood, A., Sellwood, B., and Valdes, P., 2000, Regional warming: Pliocene (3 Ma) paleoclimate of Europe and the Mediterranean: Geology, v. 28, no. 12, p. 1063-1066.

Haywood, A. M., and Valdes, P. J., 2004, Modelling Pliocene warmth: contribution of atmosphere, oceans and cryosphere: Earth and Planetary Science Letters, v. 218, no. 3, p. 363-377.

Haywood, A. M., Hill, D. J., Dolan, A. M., Otto-Bliesner, B. L., Bragg, F., Chan, W. L., Chandler, M. A., Contoux, C., Dowsett, H. J., Jost, A., Kamae, Y., Lohmann, G., Lunt, D. J., Abe-Ouchi, A., Pickering, S. J., Ramstein, G., Rosenbloom, N. A., Salzmann, U., Sohl, L., Stepanek, C., Ueda, H., Yan, Q., and Zhang, Z., 2013, Large-scale features of Pliocene climate: results from the Pliocene Model Intercomparison Project: Climate of the Past, v. 9, no. 1, p. 191-209.

Hearty, P. J., Hollin, J. T., Neumann, A. C., O'Leary, M. J., and McCulloch, M., 2007, Global sea-level fluctuations during the Last Interglaciation (MIS 5e): Quaternary Science Reviews, v. 26, no. 17-18, p. 2090-2112.

Hepp, D. A., Mörz, T., and Grützner, J., 2006, Pliocene glacial cyclicity in a deep-sea sediment drift (Antarctic Peninsula Pacific Margin): Palaeogeography, Palaeoclimatology, Palaeoecology, v. 231, no. 1-2, p. 181-198.

Herbert, T. D., Peterson, L. C., Lawrence, K. T., and Liu, Z., 2010, Tropical ocean temperatures over the past 3.5 million years: Science, v. 328, no. 5985, p. 1530-1534.

Hesse, P. P., and McTanish, G. H., 1999, Last Glacial Maximum to Early Holocene Wind Strength in the Mid-latitudes of the Southern Hemisphere from Aeolian Dust in the Tasman Sea: Quaternary Research, v. 52, p. 343-349.

Hilgen, F., 1991, Astronomical calibration of Gauss to Matuyama sapropels in the Mediterranean and implication for the geomagnetic polarity time scale: Earth and Planetary Science Letters, v. 104, no. 2, p. 226-244.

Hilgen, F. J., Hinnov, L. A., Abdul Aziz, H., Abels, H. A., Batenburg, S., Bosmans, J. H. C., de Boer, B., Husing, S. K., Kuiper, K. F., Lourens, L. J., Rivera, T., Tuenter, E., Van de Wal, R. S. W., Wotzlaw, J. F., and Zeeden, C., 2014, Stratigraphic continuity and fragmentary sedimentation: the success of cyclostratigraphy as part of integrated stratigraphy: Geological Society, London, Special Publications.

Hill, D. J., Haywood, A. M., Lunt, D. J., Hunter, S. J., Bragg, F. J., Contoux, C., Stepanek, C., Sohl, L., Rosenbloom, N. A., Chan, W. L., Kamae, Y., Zhang, Z., Abe-Ouchi, A., Chandler, M. A., Jost, A., Lohmann, G., Otto-Bliesner, B. L., Ramstein, G., and Ueda, H., 2014, Evaluating the dominant components of warming in Pliocene climate simulations: Climate of the Past, v. 10, no. 1, p. 79-90.

Hillenbrand, C.-D., 2013, Palaeoclimate: East Antarctica's Achilles' heel: Nature Geoscience, v. 6, no. 9, p. 680-681.

Hillenbrand, C.-D., and Cortese, G., 2006, Polar stratification: A critical view from the Southern Ocean: Palaeogeography, Palaeoclimatology, Palaeoecology, v. 242, no. 3-4, p. 240-252.

Hjulstrom, F., 1939, Transportation of Detritus by Moving Water: Part 1. Transportation: p. 531. 
Hodell, D. A., and Venz-Curtis, K. A., 2006, Late Neogene history of deepwater ventilation in the Southern Ocean: Geochemistry, Geophysics, Geosystems, v. 7, no. 9, p. 1-16.

Hornibrook, N. d. B., Brazier, R. C., and Strong, C. P., 1989, Manual of New Zealand Permian to Pleistocene foraminiferal biostratigraphy.: New Zealand Geological Survey Palaeontological Bulletin, v. 34, no. 1, p. 178.

Hoskins, R. H., and McGuire, D. M., 1990, The Location and Stratigraphy of Samples from the Turakina River Section South Wanganui Basin New Zealand, 0111-7071. New Zealand Geological Survery Palaeontology Report 150.

Hovan, S. A., Rea, D. K., Pisias, N. G., and Shackleton, N. J., 1989, A direct link between the China loess and marine $\delta 180$ records: aeolian flux to the north Pacific: Nature, v. 340, p. 296298.

Hughes, G. R., and Kennedy, D. M., 2009, Late Pleistocene sea-level oscillations (MIS 10-2) recorded in shallow marine and coastal plain sediments of the southern Wanganui Basin, New Zealand: Quaternary Research, v. 71, no. 3, p. 477-489.

Hurford, A. J., and Green, P. F., 1983, The zeta age calibration of fission-track dating: Chemical Geology, v. 41, p. 285-317.

Hurford, A. J., and Carter, A., 1991, The role of fission track dating in discrimination of provenance: Geological Society, London, Special Publications, v. 57, no. 1, p. 67-78.

Huybers, P., 2006, Early Pleistocene glacial cycles and the integrated summer insolation forcing: Science, v. 313, no. 5786, p. 508-511.

Huybers, P., 2007, Glacial variability over the last two million years: an extended depth-derived agemodel, continuous obliquity pacing, and the Pleistocene progression: Quaternary Science Reviews, v. 26, no. 1-2, p. 37-55.

Huybers, P., and Tziperman, E., 2008, Integrated summer insolation forcing and 40,000-year glacial cycles: The perspective from an ice-sheet/energy-balance model: Paleoceanography, v. 23, no. 1, p. n/a-n/a.

Imbrie, J., 1985, A theoretical framework for the Pleistocene ice ages: William Smith Lecture: Journal of the Geological Society, v. 142, no. 3, p. 417-432.

Imbrie, J., and Imbrie, J. Z., 1980, Modeling the climatic response to orbital variations: Science, v. 207, no. 4434, p. 943-953.

Imbrie, J., Berger, A., Boyle, E., Clemens, S., Duffy, A., Howard, W., Kukla, G., Kutzbach, J., Martinson, D., and McIntyre, A., 1993, On the structure and origin of major glaciation cycles 2. The 100,000-year cycle: Paleoceanography, v. 8, no. 6, p. 699-735.

Imbrie, J., Boyle, E. A., Clemens, S. C., Duffy, A., Howard, W. R., Kukla, G., Kutzbach, J., Martinson, D. G., McIntyre, A., Mix, A. C., Molfino, B., Morley, J. J., Peterson, L. C., Pisias, N. G., Prell, W. L., Raymo, M. E., Shackleton, N. J., and Toggweiler, J. R., 1992, On the Structure and Origin of Major Glaciation Cycles: 1. Linear Responses to Milankovitch Forcing: Paleoceanography, v. 7, no. 6, p. 701-738.

IPCC, 2013, Climate Change 2013: The Physical Science Basis, Contribution of Working Group I to the Fifth Assessment Report of the Intergovernmental Panel on Climate Change. Cambridge University Press, 2014.

Ishiwatari, R., Negishi, K., Yoshikawa, H., and Yamamoto, S., 2009, Glacial-interglacial productivity and environmental changes in Lake Biwa, Japan: A sediment core study of organic carbon, chlorins and biomarkers: Organic Geochemistry, v. 40, no. 4, p. 520-530.

Ito, M., and Katsura, Y., 1992, Inferred glacio-eustatic control for high-frequency depositional sequences of the Plio-Pleistocene Kazusa Group, a forearc basin fill in Boso Peninsula, Japan: Sedimentary Geology, v. 80, no. 1, p. 67-75.

Ito, M., Nishikawa, T., and Sugimoto, H., 1999, Tectonic control of high-frequency depositional sequences with durations shorter than Milankovitch cyclicity: An example from the Pleistocene paleo-Tokyo Bay, Japan: Geology, v. 27, no. 8, p. 763-766.

James, N. P., Bone, Y., Carter, R. M., and Murray-Wallace, C. V., 2006, Origin of the Late Neogene Roe Plains and their calcarenite veneer: implications for sedimentology and tectonics in the Great Australian Bight: Australian Journal of Earth Sciences, v. 53, no. 3, p. 407-419. 
Jansen, E., Fronval, T., Rack, F., and Channell, J. E. T., 2000, Pliocene-Pleistocene ice rafting history and cyclicity in the Nordic Seas during the last 3.5 Myr: Paleoceanography, v. 15, no. 6, p. 709-721.

Jansen, E., and Sjøholm, J., 1991, Reconstruction of glaciation over the past 6 Myr from ice-borne deposits in the Norwegian Sea: Nature, v. 349, no. 6310, p. 600-603.

Jochum, K. P., Dingwell, D. B., Rocholl, A., Stoll, B., Hofmann, A. W., Becker, S., Besmehn, A., Bessette, D., Dietze, H. J., Dulski, P., Erzinger, J., Hellebrand, E., Hoppe, P., Horn, I., Janssens, K., Jenner, G. A., Klein, M., McDonough, W. F., Maetz, M., Mezger, K., Münker, C., Nikogosian, I. K., Pickhardt, C., Raczek, I., Rhede, D., Seufert, H. M., Simakin, S. G., Sobolev, A. V., Spettel, B., Straub, S., Vincze, L., Wallianos, A., Weckwerth, G., Weyer, S., Wolf, D., and Zimmer, M., The preparation and preliminary characterisation of eight geological MPI-DING Reference glasses for in-situ microanalysis: The Journal of Geostandards and Geoanalysis, v. 24, p. 87-133.

Jorissen, F. J., 2003, Benthic foraminiferal microhabitats below the sediment-water interface, Modern foraminifera, Springer, p. 161-179.

Jorissen, F. J., de Stigter, H. C., and Widmark, J. G., 1995, A conceptual model explaining benthic foraminiferal microhabitats: Marine Micropaleontology, v. 26, no. 1, p. 3-15.

Joughin, I., Smith, B. E., and Medley, B., 2014, Marine ice sheet collapse potentially under way for the Thwaites Glacier Basin, West Antarctica: Science, v. 344, no. 6185, p. 735-738.

Journeaux, T., Kamp, P. J., and Naish, T., 1996, Middle Pliocene cyclothems, Mangaweka region, Wanganui Basin, New Zealand: a lithostratigraphic framework: New Zealand Journal of Geology and Geophysics, v. 39, no. 1, p. 135-149.

Jouzel, J., Masson-Delmotte, V., Cattani, O., Dreyfus, G., Falourd, S., Hoffmann, G., Minster, B., Nouet, J., Barnola, J. M., Chappellaz, J., Fischer, H., Gallet, J. C., Johnsen, S., Leuenberger, M., Loulergue, L., Luethi, D., Oerter, H., Parrenin, F., Raisbeck, G., Raynaud, D., Schilt, A., Schwander, J., Selmo, E., Souchez, R., Spahni, R., Stauffer, B., Steffensen, J. P., Stenni, B., Stocker, T. F., Tison, J. L., Werner, M., and Wolff, E. W., 2007, Orbital and millennial Antarctic climate variability over the past 800,000 years: Science, v. 317, no. 5839, p. 793-796.

Joyce, J. E., Tjalsma, L. R. C., and Prutzman, J. M., 1993, North American glacial meltwater history for the past 2.3 m.y.: Oxygen isotop evidence from the Gulf of Mexico: Geology, v. 21, p. 483-486.

Kamp, P. J., and Turner, G. M., 1990, Pleistocene unconformity-bounded shelf sequences (Wanganui Basin, New Zealand) correlated with global isotope record: Sedimentary Geology, v. 68, no. 1, p. 155-161.

Kamp, P. J. J., Journeaux, T. D., and Morgans, H. E. G., 1998, Cyclostratigraphy of middle Pliocene mid shelf to upper slope strata, eastern Wanganui Basin (New Zealand): correlations to the deep sea isotope record: Sedimentary Geology, v. 117, p. 165-192.

Kamp, P. J. J., Vonk, A. J., Bland, K. J., Griffin, A. G., Hayton, S., Hendy, A. J. W., McIntyre, A., Nelson, C. S., and Naish, T., Megasequence architecture of Taranaki, Wanganui, and King Country basins and Neogene progradation of two continental margin wedges across western New Zealand, in Proceedings New Zealand Petroleum Conference 24-27 February 2002 2002.

Kamp, P. J. J., Vonk, A. J., Bland, K. J., Hansen, R. J., Hendy, A. J. W., McIntyre, A. P., Ngatai, M., Cartwright, S. J., Hayton, S., and Nelson, C. S., 2004, Neogene stratigraphic architecture and tectonic evolution of Wanganui, King Country, and eastern Taranaki Basins, New Zealand: New Zealand Journal of Geology and Geophysics, v. 47, no. 4, p. 625-644.

Karas, C., Nürnberg, D., Tiedemann, R., and Garbe-Schönberg, D., 2011, Pliocene climate change of the Southwest Pacific and the impact of ocean gateways: Earth and Planetary Science Letters, v. 301, no. 1-2, p. 117-124.

Katz, M. E., Cramer, B. S., Franzese, A., Hönisch, B., Miller, K. G., Rosenthal, Y., and Wright, J. D., 2010, Traditional and emerging geochemical proxies in foraminifera: The Journal of Foraminiferal Research, v. 40, no. 2, p. 165-192. 
Kaufman, D. S., and Brigham-Grette, J., 1993, Aminostratigraphic correlations and paleotemperature implications, Pliocene-Pleistocene high-sea-level deposits, northwestern Alaska: Quaternary Science Reviews, v. 12, no. 1, p. 21-33.

Kennett, J. P., 1962, The Kapitean stage (Upper Miocene) at Cape Foulwind, west coast: New Zealand Journal of Geology and Geophysics, v. 5, no. 4, p. 620-625.

Kennett, J. P., Watkins, N., and Vella, P., 1971, Paleomagnetic chronology of Pliocene-early Pleistocene climates and the Plio-Pleistocene boundary in New Zealand: Science, v. 171, no. 3968, p. 276-279.

Kershaw, A., Van Der Kaars, S., and Moss, P., 2003, Late Quaternary Milankovitch-scale climatic change and variability and its impact on monsoonal Australasia: Marine Geology, v. 201, no. 1, p. 81-95.

Kleiven, H. F., Jansen, E., Fronval, T., and Smith, T., 2002, Intensification of Northern Hemisphere glaciations in the circum Atlantic region (3.5-2.4 Ma)-ice-rafted detritus evidence: Palaeogeography, Palaeoclimatology, Palaeoecology, v. 184, no. 3, p. 213-223.

Knies, J., Cabedo-Sanz, P., Belt, S. T., Baranwal, S., Fietz, S., and Rosell-Mele, A., 2014a, The emergence of modern sea ice cover in the Arctic Ocean: Nature Communications, v. 5, p. 5608.

Knies, J., Mattingsdal, R., Fabian, K., Grøsfjeld, K., Baranwal, S., Husum, K., De Schepper, S., Vogt, C., Andersen, N., Matthiessen, J., Andreassen, K., Jokat, W., Nam, S.-I., and Gaina, C., 2014b, Effect of early Pliocene uplift on late Pliocene cooling in the Arctic-Atlantic gateway: Earth and Planetary Science Letters, v. 387, p. 132-144.

Knox, R. O. B., 1993, Tephra layers as precise chronostratigraphical markers: Geological Society, London, Special Publications, v. 70, no. 1, p. 169-186.

Koenig, S. J., DeConto, R. M., and Pollard, D., 2014, Impact of reduced Arctic sea ice on Greenland ice sheet variability in a warmer than present climate: Geophysical Research Letters, v. 41, no. 11, p. 3933-3942.

Kohn, B., Pillans, B., and McGlone, M., 1992, Zircon fission track age for middle Pleistocene Rangitawa Tephra, New Zealand: stratigraphic and paleoclimatic significance: Palaeogeography, Palaeoclimatology, Palaeoecology, v. 95, no. 1, p. 73-94.

Konert, M., and Vandenberge, J., 1997, Comparison of laser grain size analysis with pipette and sieve analysis: A solution for the underestimation of the clay fraction.: Sedimentology, v. 44, p. 523-536.

Kucera, M., 2007, Chapter six planktonic foraminifera as tracers of past oceanic environments: Developments in Marine Geology, v. 1, p. 213-262.

Kuhlmann, J., Asioli, A., Trincardi, F., Klügel, A., and Huhn, K., 2015, Sedimentary response to Milankovitch-type climatic oscillations and formation of sediment undulations: evidence from a shallow-shelf setting at Gela Basin on the Sicilian continental margin: Quaternary Science Reviews, v. 108, p. 76-94.

Kyle, P. R., and Seward, D., 1984, Dispersed rhyolitic tephra from New Zealand in deep-sea sediments of the Southern Ocean: Geology, v. 12, no. 8, p. 487-490.

Lamarche, G., Proust, J-N., Nodder, S. D., 2005, Long-term slip rates and fault interactions under low contractional strain, Wanganui Basin, New Zealand: Tectonics, v. 24, p. 1-30.

Larsen, H., Saunders, A., Clift, P., Beget, J., Wei, W., and Spezzaferri, S., 1994, Seven million years of glaciation in Greenland: Science, v. 264, no. 5161, p. 952-955.

Laskar, J., Robutel, P., Joutel, F., Gastineau, M., Correia, A. C. M., and Levrard, B., 2004, A longterm numerical solution for the insolation quantities of the Earth: Astronomy and Astrophysics, v. 428, no. 1, p. 261-285.

Lawrence, K. T., Liu, Z., and Herbert, T. D., 2006, Evolution of the eastern tropical Pacific through Plio-Pleistocene glaciation: Science, v. 312, no. 5770, p. 79-83.

Lawrence, K. T., Sosdian, S., White, H. E., and Rosenthal, Y., 2010, North Atlantic climate evolution through the Plio-Pleistocene climate transitions: Earth and Planetary Science Letters, v. 300, no. 3-4, p. 329-342.

Le Maitre, R., 1984, A proposal by the IUGS Subcommission on the Systematics of Igneous Rocks for a chemical classification of volcanic rocks based on the total alkali silica (TAS) 
diagram: (on behalf of the IUGS Subcommission on the Systematics of Igneous Rocks): Australian Journal of Earth Sciences, v. 31, no. 2, p. 243-255.

Lee, J. M., Townsend, D., Bland, K. J., and Kamp, P. J. J., 2011, Geology of the Hawke's Bay area: scale 1:250,000. Institute of Geological and Nuclear Sciences, Lower Hutt, New Zealand.

Lee, S.-Y., and Poulsen, C. J., 2006, Sea ice control of Plio-Pleistocene tropical Pacific climate evolution: Earth and Planetary Science Letters, v. 248, no. 1-2, p. 253-262.

Lewis, K., 1979, Foraminifera on the continental shelf and slope off Southern Hawke's Bay, New Zealand: New Zealand Oceanographic Institute Memoir (New Zealand).

Lewis, K. B., Carter, L., and Davey, F. J., 1994, The opening of Cook Strait: interglacial tidal scour and aligning basins at a subduction to transform plate edge: Marine Geology, v. 116, no. 3, p. 293-312.

Lisiecki, L. E., 2010, Links between eccentricity forcing and the 100,000-year glacial cycle: Nature Geoscience, v. 3, no. 5, p. 349-352.

Lisiecki, L. E., and Raymo, M. E., 2005, A Pliocene-Pleistocene stack of 57 globally distributed benthic $\delta 180$ records: Paleoceanography, v. 20, no. 1, p. n/a-n/a.

Lisiecki, L. E., and Raymo, M. E., 2007, Plio-Pleistocene climate evolution: trends and transitions in glacial cycle dynamics: Quaternary Science Reviews, v. 26, no. 1-2, p. 56-69.

Lisle, R., 2004, Geological Structures and Maps: A Practical Guide, Elsevier ButterworthHeinemann.

Liu, T., and Ding, Z., 1998, Chinese loess and the paleomonsoon: Annual Review of Earth and Planetary Sciences, v. 26, no. 1, p. 111-145.

Lourens, L., and Hilgen, F., 1997, Long-periodic variations in the earth's obliquity and their relation to third-order eustatic cycles and Late Neogene glaciations: Quaternary International, v. 40, p. 43-52.

Lourens, L. J., Antonarakou, A., Hilgen, F. J., Van Hoof, A. A. M., Vergnaud-Grazzini, C., and Zachariasse, W. J., 1996, Evaluation of the Plio-Pleistocene astronomical timescale: Paleoceanography, v. 11, no. 4, p. 391-413.

Lowe, D. J., 1990, Tephra studies in New Zealand: an historical review: Journal of the Royal Society of New Zealand, v. 20, no. 1, p. 119-150.

Lowe, D. J., 2011, Tephrochronology and its application: A review: Quaternary Geochronology, v. 6, no. 2, p. 107-153.

Lowe, D. J., Shane, P. A. R., Alloway, B. V., and Newnham, R. M., 2008, Fingerprints and age models for widespread New Zealand tephra marker beds erupted since 30,000 years ago: a framework for NZ-INTIMATE: Quaternary Science Reviews, v. 27, no. 1-2, p. 95126.

Lunt, D. J., Foster, G. L., Haywood, A. M., and Stone, E. J., 2008, Late Pliocene Greenland glaciation controlled by a decline in atmospheric CO2 levels: Nature, v. 454, no. 7208, p. 11021105.

Lunt, D. J., Haywood, A. M., Schmidt, G. A., Salzmann, U., Valdes, P. J., Dowsett, H. J., and Loptson, C. A., 2012, On the causes of mid-Pliocene warmth and polar amplification: Earth and Planetary Science Letters, v. 321-322, p. 128-138.

Lurcock, P. C., and Wilson, G. S., 2012, PuffinPlot: A versatile, user-friendly program for paleomagnetic analysis: Geochemistry, Geophysics, Geosystems, v. 13, no. 6, p. n/a-n/a.

Lüthi, D., Le Floch, M., Bereiter, B., Blunier, T., Barnola, J.-M., Siegenthaler, U., Raynaud, D., Jouzel, J., Fischer, H., and Kawamura, K., 2008, High-resolution carbon dioxide concentration record 650,000-800,000 years before present: Nature, v. 453, no. 7193, p. 379-382.

MacDougall, J. D., 1976, Fission-Track Dating: Scientific American, p. 114-123.

Magee, J. W., Miller, G. H., Spooner, N. A., and Questiaux, D., 2004, Continuous 150 ky monsoon record from Lake Eyre, Australia: insolation-forcing implications and unexpected Holocene failure: Geology, v. 32, no. 10, p. 885-888.

Manville, V., and Wilson, C., 2004, Vertical density currents: a review of their potential role in the deposition and interpretation of deep-sea ash layers: Journal of the Geological Society, v. 161, no. 6, p. 947-958. 
Martinez-Boti, M. A., Foster, G. L., Chalk, T. B., Rohling, E. J., Sexton, P. F., Lunt, D. J., Pancost, R. D., Badger, M. P., and Schmidt, D. N., 2015, Plio-Pleistocene climate sensitivity evaluated using high-resolution CO2 records: Nature, v. 518, no. 7537, p. 49-54.

Martinez-Garcia, A., Rosell-Mele, A., Jaccard, S. L., Geibert, W., Sigman, D. M., and Haug, G. H., 2011, Southern Ocean dust-climate coupling over the past four million years: Nature, $v$. 476, no. 7360, p. 312-315.

Maslin, M., Li, X., Loutre, M.-F., and Berger, A., 1998, The contribution of orbital forcing to the progressive intensification of Northern Hemisphere glaciation: Quaternary Science Reviews, v. 17, no. 4-5, p. 411-426.

Maslin, M. A., and Ridgwell, A. J., 2005, Mid-Pleistocene revolution and the 'eccentricity myth': Geological Society, London, Special Publications, v. 247, no. 1, p. 19-34.

McFadden, P., and McElhinny, M., 1988, The combined analysis of remagnetization circles and direct observations in palaeomagnetism: Earth and Planetary Science Letters, v. 87, no. 1, p. 161-172.

McIntyre, A. P., 2002, Geology of the Mangapanian (Late Pliocene) strata, Wanganui Basin: lithostratigraphy, paleontology and sequence stratigraphy. Unpublished PhD thesis, University of Waikato, Hamilton, New Zealand.

McKay, R., Naish, T., Carter, L., Riesselman, C., Dunbar, R. B., Sjunneskog, C., Winter, D., Sangiorgi, F., Warren, C., Pagani, M., Schouten, S., Willmott, V., Levy, R., DeConto, R., and Powell, R., 2012a, Antarctic and Southern Ocean influences on Late Pliocene global cooling: Procedings of the National Academy of Sciences, USA, v. 109, no. 17, p. 6423-6428.

McKay, R., Naish, T., Powell, R., Barrett, P., Scherer, R., Talarico, F., Kyle, P., Monien, D., Kuhn, G., Jackolski, C., and Williams, T., 2012b, Pleistocene variability of Antarctic Ice Sheet extent in the Ross Embayment: Quaternary Science Reviews, v. 34, p. 93-112.

Melles, M., Brigham-Grette, J., Minyuk, P. S., Nowaczyk, N. R., Wennrich, V., DeConto, R. M., Anderson, P. M., Andreev, A. A., Coletti, A., and Cook, T. L., 2012, 2.8 million years of Arctic climate change from Lake El'gygytgyn, NE Russia: Science, v. 337, no. 6092, p. 315-320.

Mengel, M., and Levermann, A., 2014, Ice plug prevents irreversible discharge from East Antarctica: Nature Climate Change, v. 4, no. 6, p. 451-455.

Mercer, J. H., 1978, West Antarctic ice sheet and CO 2 greenhouse effect- A threat of disaster: Nature, v. 271, no. 5643, p. 321-325.

Meyers, S. R., and Hinnov, L. A., 2010, Northern Hemisphere glaciation and the evolution of PlioPleistocene climate noise: Paleoceanography, v. 25, no. 3.

Milankovitch, M., 1941, Kanon der Erdbastrahlung und seine Anwendung auf des Eiszeitenproblem.: Royal Serbian Sciences Special Publication 132, v. 33, p. 633. (Canon of Insolation and the Ice Age Problem, English translation by Israel Program for the US Department of Commerce and the National Science Foundation, Washington DC, 1969, and by Zavod za Udzbenike I nastavna Sredstva in cooperation with Muzej nauke I technike Srpske akademije nauka I umetnosti, Beograd, 1998).

Miller, K. G., Kominz, M., Browning, J. V., Wright, J. D., Mountain, G. S., Katz, M. E., Sugarman, P. J., Cramer, B. S., Christie-Blick, N., and Pekar, S. F., 2005, The Phanerozoic Record of Global Sea-Level Change: Science, v. 310, no. 1293-1298.

Miller, K. G., Wright, J. D., Browning, J. V., Kulpecz, A., Kominz, M., Naish, T. R., Cramer, B. S., Rosenthal, Y., Peltier, W. R., and Sosdian, S., 2012, High tide of the warm Pliocene: Implications of global sea level for Antarctic deglaciation: Geology, v. 40, no. 5, p. 407410.

Mudelsee, M., and Raymo, M. E., 2005, Slow dynamics of the Northern Hemisphere glaciation: Paleoceanography, v. 20, no. 4, p. 1-14.

Murray-Wallace, C. V., 2002, Pleistocene coastal stratigraphy, sea-level highstands and neotectonism of the southern Australian passive continental margin?a review: Journal of Quaternary Science, v. 17, no. 5-6, p. 469-489.

Murray, J. W., 1991, Ecology and distribution of benthic foraminifera: Biology of Foraminifera, p. 221-253. 
Murray, J. W., 2001, The niche of benthic foraminifera, critical thresholds and proxies: Marine Micropaleontology, v. 41, no. 1, p. 1-7.

Murray, J. W., and Alve, E., 1999, Natural dissolution of modern shallow water benthic foraminifera: taphonomic effects on the palaeoecological record: Palaeogeography, Palaeoclimatology, Palaeoecology, v. 146, no. 1, p. 195-209.

Naafs, B. D. A., Hefter, J., Acton, G., Haug, G. H., Martínez-Garcia, A., Pancost, R., and Stein, R., 2012, Strengthening of North American dust sources during the late Pliocene (2.7Ma): Earth and Planetary Science Letters, v. 317-318, p. 8-19.

Naeser, N. D., Naeser, C. W., and McCulloh, T. H., 1989, The application of fission-track dating to the depositional and thermal history of rocks in sedimentary basins, Thermal history of sedimentary basins, Springer, p. 157-180.

Naish, T., 1997, Constraints on the amplitude of Late Pliocene eustatic sea-level fluctuations: New evidence from the New Zealand shallow-marine sediment record: Geology, v. 25, no. 12 , p. 1139-1142.

Naish, T., and Kamp, P. J. J., 1995, Pliocene-Pleistocene marine cyclothems, Wanganui Basin, New Zealand: A lithostratigraphic framework: New Zealand Journal of Geology and Geophysics, v. 38, no. 2, p. 223-243.

Naish, T., and Kamp, P. J., 1997a, Sequence stratigraphy of sixth-order (41 ky) PliocenePleistocene cyclothems, Wanganui Basin, New Zealand: a case for the regressive systems tract: Geological Society of America Bulletin, v. 109, no. 8, p. 978-999.

Naish, T., and Kamp, P. J., 1997b, Foraminiferal depth palaeoecology of Late Pliocene shelf sequences and systems tracts, Wanganui Basin, New Zealand: Sedimentary Geology, v. 110 , no. 3, p. 237-255.

Naish, T. R., and Wilson, G. S., 2009, Constraints on the amplitude of Mid-Pliocene (3.6-2.4Ma) eustatic sea-level fluctuations from the New Zealand shallow-marine sediment record: Philosophical Transations of the Royal Society A Mathematical, Physical, and Engineering Sciences, v. 367, no. 1886, p. 169-187.

Naish, T., and Zwartz, D., 2012, Palaeoclimate: Looking back to the future: Nature Climate Change, v. 2, no. 5, p. 317-318.

Naish, T., Kamp, P. J., Alloway, B. V., Pillans, B., Wilson, G. S., and Westgate, J. A., 1996, Integrated tephrochronology and magnetostratigraphy for cyclothemic marine strata, Wanganui Basin: implications for the Pliocene-Pleistocene boundary in New Zealand: Quaternary International, v. 34, p. 29-48.

Naish, T. R., Abbott, S. T., Alloway, V., Beu, A. G., Carter, R. M., Edwards, A. R., Journeaux, T. D., Kamp, P. J., Pillans, B. J., and Saul, G., 1998, Astronomical calibration of a southern hemisphere Plio-Pleistocene reference section, Wanganui Basin, New Zealand: Quaternary Science Reviews, v. 17, no. 8, p. 695-710.

Naish, T. R., Woolfe, K. J., Barrett, P. J., Wilson, G. S., Atkins, C., Bohaty, S. M., Bücker, C. J., Claps, M., Davey, F. J., and Dunbar, G. B., 2001, Orbitally induced oscillations in the East Antarctic ice sheet at the Oligocene/Miocene boundary: Nature, v. 413, no. 6857, p. 719723.

Naish, T. R., Wehland, F., Wilson, G. S., Browne, G. H., Cook, R. A., Morgans, H. E. G., Rosenberg, M., King, P. R., Smale, D., Nelson, C. S., Kamp, P. J. J., and Ricketts, B., 2005, An integrated sequence stratigraphic, palaeoenvironmental, and chronostratigraphic analysis of the Tangahoe Formation, southern Taranaki coast, with implications for mid-Pliocene (c. 3.4-3.0 Ma) glacio-eustatic sea-level changes: Journal of the Royal Society of New Zealand, v. 35, no. 1-2, p. 151-196.

Naish, T., Powell, R., Levy, R., Wilson, G., Scherer, R., Talarico, F., Krissek, L., Niessen, F., Pompilio, M., Wilson, T., Carter, L., DeConto, R., Huybers, P., McKay, R., Pollard, D., Ross, J., Winter, D., Barrett, P., Browne, G., Cody, R., Cowan, E., Crampton, J., Dunbar, G., Dunbar, N., Florindo, F., Gebhardt, C., Graham, I., Hannah, M., Hansaraj, D., Harwood, D., Helling, D., Henrys, S., Hinnov, L., Kuhn, G., Kyle, P., Laufer, A., Maffioli, P., Magens, D., Mandernack, K., McIntosh, W., Millan, C., Morin, R., Ohneiser, C., Paulsen, T., Persico, D., Raine, I., Reed, J., Riesselman, C., Sagnotti, L., Schmitt, D., Sjunneskog, C., Strong, P., Taviani, M., Vogel, S., 
Wilch, T., and Williams, T., 2009, Obliquity-paced Pliocene West Antarctic ice sheet oscillations: Nature, v. 458, no. 7236, p. 322-328.

Newnham, R. M., Lowe, D. J., and Williams, P. W., 1999, Quaternary environmental change in New Zealand: a review: Progress in Physical Geography, v. 23, no. 4, p. 567-610.

Nicol, A., 2011, Landscape history of the Malborough Sounds: New Zealand Journal of Geology and Geophysics, v. 54, no. 2, p. 195-208.

Nie, J., Stevens, T., Song, Y., King, J. W., Zhang, R., Ji, S., Gong, L., and Cares, D., 2014, Pacific freshening drives Pliocene cooling and Asian monsoon intensification: Nature Science Reports, v. 4, p. 5474.

Nodder, S. D., 1995, Late Quaternary transgressive/regressive sequences from Taranaki continental shelf, western New Zealand: Marine Geology, v. 123, p.187-214.

Pagani, M., Liu, Z., LaRiviere, J., and Ravelo, A. C., 2010, High Earth-system climate sensitivity determined from Pliocene carbon dioxide concentrations: Nature Geoscience, v. 3, no. 1, p. 27-30.

Paillard, D., 2006, What drives the ice age cycles?: Science, v. 313, no. 5786, p. 455-456.

Paillard, D., 2010, Climate and the orbital parameters of the Earth: Comptes Rendus Geoscience, v. 342, no. 4-5, p. 273-285.

Passchier, S., 2011, Linkages between East Antarctic Ice Sheet extent and Southern Ocean temperatures based on a Pliocene high-resolution record of ice-rafted debris off Prydz Bay, East Antarctica: Paleoceanography, v. 26, no. 4, p. n/a-n/a.

Patterson, M. O., McKay, R., Naish, T., Escutia, C., Jimenez-Espejo, F. J., Raymo, M. E., Meyers, S. R., Tauxe, L., Brinkhuis, H., Klaus, A., Fehr, A., Bendle, J. A. P., Bijl, P. K., Bohaty, S. M., Carr, S. A., Dunbar, R. B., Flores, J. A., Gonzalez, J. J., Hayden, T. G., Iwai, M., Katsuki, K., Kong, G. S., Nakai, M., Olney, M. P., Passchier, S., Pekar, S. F., Pross, J., Riesselman, C. R., Röhl, U., Sakai, T., Shrivastava, P. K., Stickley, C. E., Sugasaki, S., Tuo, S., van de Flierdt, T., Welsh, K., Williams, T., and Yamane, M., 2014, Orbital forcing of the East Antarctic ice sheet during the Pliocene and Early Pleistocene: Nature Geoscience, v. 7, no. 11, p. 841-847.

Pearce, N. J. G., Alloway, B. V., and Westgate, J. A., 2008, Mid-Pleistocene silicic tephra beds in the Auckland region, New Zealand: Their correlation and origins based on the trace element analyses of single glass shards: Quaternary International, v. 178, no. 1, p. 16-43.

Pearce, N. J. G., Denton, J. S., Perkins, W. T., Westgate, J. A., and Alloway, B. V., 2007, Correlation and characterisation of individual glass shards from tephra deposits using trace element laser ablation ICP-MS analyses: current status and future potential: Journal of Quaternary Science, v. 22, no. 7, p. 721-736.

Pearson, T. H., and Rosenberg, R., 1978, Macrobenthic succession in relation to organic enrichment and pollution of the marine environment: Oceanography and Marine Biology Annual Review, v. 16, p. 229-311.

Pérez-Maqueda, L. A., Franco, F., Avilés, M. A., Poyato, J., and Pérez-Rodríguez, J. L., 2003, Effect of sonication on particle-size distribution in natural muscovite and biotite: Clays and Clay Minerals, v. 51, no. 6, p. 701-708.

Philander, S. G., and Fedorov, A. V., 2003, Role of tropics in changing the response to Milankovich forcing some three million years ago: Paleoceanography, v. 18, no. 2, p. 114.

Piasis, N. G., and Moore, T. C. J., 1981, The Evolution of Pleistocene climate: A Time Series Approach: Earth and Planetary Science Letters, v. 52, p. 450-458.

Pillans, B., 1990, Pleistocene marine terraces in New Zealand: A review: New Zealand Journal of Geology and Geophysics, v. 33, no. 2, p. 219-231.

Pillans, B., McGlone, M., Palmer, A., Mildenhall, D., Alloway, B., and Berger, G., 1993, The Last Glacial Maximum in central and southern North Island, New Zealand: a paleoenvironmental reconstruction using the Kawakawa Tephra Formation as a chronostratigraphic marker: Palaeogeography, Palaeoclimatology, Palaeoecology, v. 101, no. 3, p. 283-304.

Pillans, B. J., Roberts, A. P., Wilson, G. S., Abbott, S. T., and Alloway, B. V., 1994, Magnetostratigraphic, lithostratigraphic and tephrostratigraphic constraints on Lower 
and Middle Pleistocene sea-level changes, Wanganui Basin, New Zealand: Earth and Planetary Science Letters, v. 121, no. 1, p. 81-98.

Pillans, B., Kohn, B. P., Berger, G., Froggatt, P., Duller, G., Alloway, B., and Hesse, P., 1996, Multimethod dating comparison for mid-Pleistocene Rangitawa tephra, New Zealand: Quaternary Science Reviews, v. 15, no. 7, p. 641-653.

Pillans, B., Chappell, J., and Naish, T., 1998, A review of the Milankovitch climatic beat: template for Plio-Pleistocene sea-level changes and sequence stratigraphy: Sedimentary Geology, v. 122 , p. 5-21.

Pillans, B., Alloway, B., Naish, T., Westgate, J., Abbott, S., and Palmer, A., 2005, Silicic tephras in Pleistocene shallow-marine sediments of Wanganui Basin, New Zealand: Journal of the Royal Society of New Zealand, v. 35, no. 1-2, p. 43-90.

Pollard, D., and DeConto, R. M., 2009, Modelling West Antarctic ice sheet growth and collapse through the past five million years: Nature, v. 458, no. 7236, p. 329-332.

Proctor, R., and Carter, L., 1989, Tidal and sedimentary response to the late Quaternary closure and opening of Cook Strait, New Zealand: results from numerical modeling: Paleoceanography, v. 4, no. 2, p. 167-180.

Prokopenko, A. A., Hinnov, L. A., Williams, D. F., and Kuzmin, M. I., 2006, Orbital forcing of continental climate during the Pleistocene: a complete astronomically tuned climatic record from Lake Baikal, SE Siberia: Quaternary Science Reviews, v. 25, no. 23-24, p. 3431-3457.

Proust, J.-N., Lamarche, G., Nodder, S., and Kamp, P. J. J., 2005, Sedimentary architecture of a PlioPleistocene proto-back-arc basin: Wanganui Basin, New Zealand: Sedimentary Geology, v. 181 , no. $3-4$, p. 107-145.

Pulford, A., and Stern, T., 2004, Pliocene exhumation and landscape evolution of central North Island, New Zealand: The role of the upper mantle: Journal of Geophysical Research, v. 109 , no. F1.

Ravelo, A. C., and Andreasen, D. H., 2000, Enhanced circulation during a warm period: Geophysical Research Letters, v. 27, no. 7, p. 1001-1004.

Ravelo, A. C., and Hillaire-Marcel, C., 2007, Chapter Eighteen The Use of Oxygen and Carbon Isotopes of Foraminifera in Paleoceanography: Developments in Marine Geology, v. 1, p. 735-764.

Ravelo, A. C., Andreasen, D. H., Lyle, M., Lyle, A. O., and Wara, M. W., 2004, Regional climate shifts caused by gradual global cooling in the Pliocene epoch: Nature, v. 429, no. 6989, p. 263 267.

Ravelo, C. A., Petra, S. D., and McCarthy, M., 2006, Evidence for El Niño-like conditions during the Pliocene: Geological Society of America Today, v. 16, no. 3, p. 4.

Raymo, M., 1994, The initiation of Northern Hemisphere glaciation: Annual Review of Earth and Planetary Sciences, v. 22, p. 353-383.

Raymo, M. E., 1997, The timing of major climate terminations: Paleoceanography, v. 12, no. 4, p. 577-585.

Raymo, M., and Ruddiman, W. F., 1992, Tectonic forcing of late Cenozoic climate: Nature, v. 359, no. 6391 , p. $117-122$.

Raymo, M. E., and Nisancioglu, K., 2003, The 41 kyr world: Milankovitch's other unsolved mystery: Paleoceanography, v. 18, no. 1, p. 1-14.

Raymo, M. E., and Huybers, P., 2008, Unlocking the mysteries of the ice ages: Nature, v. 451, no. 7176, p. 284-285.

Raymo, M. E., Ruddiman, W. F., Backman, J., Clement, B. M., and Martinson, D. G., 1989, Late Pliocene variation in Northern Hemisphere Ice Sheets and North Atlantic Deep Water Circulation: Paleoceanography, v. 4, no. 4, p. 413-446.

Raymo, M. E., Grant, B., Horowitz, M., and Rau, G. H., 1996, Mid-Pliocene warmth: stronger greenhouse and stronger conveyor: Marine Micropaleontology, v. 27, no. 313-326.

Raymo, M. E., Lisiecki, L., and Nisancioglu, K., 2006, Plio-Pleistocene Ice Volume, Antarctic Climate and the Global d180 record: Science, v. 313, p. 492-495. 
Raymo, M. E., Mitrovica, J. X., O'Leary, M. J., DeConto, R. M., and Hearty, P. J., 2011, Departures from eustasy in Pliocene sea-level records: Nature Geoscience, v. 4, no. 5, p. 328-332.

Riesselman, C. R., and Dunbar, R. B., 2013, Diatom evidence for the onset of Pliocene cooling from AND-1B, McMurdo Sound, Antarctica: Palaeogeography, Palaeoclimatology, Palaeoecology, v. 369, p. 136-153.

Rio, D., Channell, J., Massari, F., Poli, M., Sgavetti, M., D'alessandro, A., and Prosser, G., 1996, Reading Pleistocene eustasy in a tectonically active siliciclastic shelf setting (Crotone peninsula, southern Italy): Geology, v. 24, no. 8, p. 743-746.

Roberts, A. P., and Pillans, B. J., 1993, Rock magnetism of lower/middle Pleistocene marine sediments, Wanganui Basin, New Zealand: Geophysical Research Letters, v. 20, no. 9, p. 839-842.

Roberts, A. P., Turner, G. M., and Vella, P. P., 1994, Magnetostratigraphic chronology of late Miocene to early Pliocene biostratigraphic and oceanographic events in New Zealand: Geological Society of America Bulletin, v. 106, no. 5, p. 665-683.

Rohling, E. J., Grant, K., Hemleben, C., Siddall, M., Hoogakker, B. A. A., Bolshaw, M., and Kucera, M., 2007, High rates of sea-level rise during the last interglacial period: Nature Geoscience, v. 1 , no. 1, p. 38-42.

Rose, K. C., Ross, N., Bingham, R. G., Corr, H. F. J., Ferraccioli, F., Jordan, T. A., Le Brocq, A. M., Rippin, D. M., and Siegert, M. J., 2014, A temperate former West Antarctic ice sheet suggested by an extensive zone of subglacial meltwater channels: Geology, v. 42, no. 11, p. 971-974.

Rosenberg, R., Nilsson, H. C., and Diaz, R. J., 2001, Response of benthic fauna and changing sediment redox profiles over a hypoxic gradient: Estuarine, Coastal and Shelf Science, v. 53, no. 3, p. 343-350.

Rowley, D. B., Forte, A. M., Moucha, R., Mitrovica, J. X., Simmons, N. A., and Grand, S. P., 2013, Dynamic topography change of the eastern United States since 3 million years ago: Science, v. 340, no. 6140, p. 1560-1563.

Ruddiman, W. F., 2006, Orbital changes and climate: Quaternary Science Reviews, v. 25, no. 23 24, p. 3092-3112.

Saul, G., Naish, T., Abbott, S., and Carter, R., 1999, Sedimentary cyclicity in the marine PliocenePleistocene of the Wanganui basin (New Zealand): Sequence stratigraphic motifs characteristic of the past 2.5 my: Geological Society of America Bulletin, v. 111, no. 4, p. 524-537.

Scott, G. H., 1970, Miocene foraminiferal biotopes in New Zealand: Waitemata Group, Kaipara, Northland: New Zealand Journal of Geology and Geophysics, v. 13, no. 2, p. 316-342.

Seki, O., Foster, G. L., Schmidt, D. N., Mackensen, A., Kawamura, K., and Pancost, R. D., 2010, Alkenone and boron-based Pliocene pCO2 records: Earth and Planetary Science Letters, v. 292, no. 1-2, p. 201-211.

Seward, D., 1976, Tephrostratigraphy of the marine sediments in the Wanganui Basin, New Zealand: New Zealand Journal of Geology and Geophysics, v. 19, no. 1, p. 9-20.

Seward, D., Christoffel, D., and Lienert, B., 1986, Magnetic polarity stratigraphy of a PlioPleistocene marine sequence of North Island, New Zealand: Earth and Planetary Science Letters, v. 80, no. 3, p. 353-360.

Seward, D., and Kohn, B. P., 1997, New zircon fission-track ages from New Zealand Quaternary tephra: an interlaboratory experiment and recommendations for the determination of young ages: Chemical Geology, v. 141, no. 1, p. 127-140.

Shackleton, N., 1987, Oxygen isotopes, ice volume and sea level: Quaternary Science Reviews, v. 6, no. 3, p. 183-190.

Shackleton, N. J., 2000, The 100,000-year ice-age cycle identified and found to lag temperature, carbon dioxide, and orbital eccentricity: Science, v. 289, no. 5486, p. 1897-1902.

Shackleton, N. J., and Opdyke, N. D., 1973, Oxygen Isotope and Palaeomagnetic Stratigraphy of Equatorial Pacific Core V28-238: Oxygen Isotope Temperatures and Ice Volumes on a $10^{5}$ Year and $10^{6}$ year Scale: Quaternary Research, v. 3, p. 39-55. 
Shackleton, N. J., Backman, J., Zimmerman, H., Kent, D. V., Hall, M., Roberts, D., Schnitker, D., Baldauf, J., Desprairies, A., and Homrighausen, R., 1984, Oxygen isotope calibration of the onset of ice-rafting and history of glaciation in the North Atlantic region: Nature, v. 307, no. 5952, p. 620-623.

Shackleton, N., Berger, A., and Peltier, W., 1990, An alternative astronomical calibration of the lower Pleistocene timescale based on ODP Site 677: Transactions of the Royal Society of Edinburgh: Earth Sciences, v. 81, no. 04, p. 251-261.

Shane, P. A. R., 1994, A widespread, early Pleistocene tephra (Potaka tephra, $1 \mathrm{Ma}$ ) in New Zealand: Character, distribution, and implications: New Zealand Journal of Geology and Geophysics, v. 37, no. 1, p. 25-35.

Shane, P., 2000, Tephrochronology: a New Zealand case study: Earth-Science Reviews, v. 49, no. 1, p. 223-259.

Shane, P., Nairn, I. A., Martin, S. B., and Smith, V. C., 2008, Compositional heterogeneity in tephra deposits resulting from the eruption of multiple magma bodies: Implications for tephrochronology: Quaternary International, v. 178, no. 1, p. 44-53.

Siddall, M., Rohling, E. J., Almogi-Labin, A., Hemleben, C., Meischner, D., Schmelzer, I., and Smeed, D., 2003, Sea-level fluctuations during the last glacial cycle: Nature, v. 423, no. 6942, p. 853-858.

Sigman, D. M., Jaccard, S. L., and Haug, G. H., 2004, Polar ocean stratification in a cold climate: Nature, v. 428 , no. 6978 , p. 59-63.

Stern, T., and Davey, F. J., 1989, Crustal structure and origin of basins formed behind the Hikurangi subduction zone, New Zealand: Origin and Evolution of Sedimentary Basins and Their Energy and Mineral Resources, v. 48, p. 73-85.

Stern, T., Quinlan, G., and Holt, W., 1992, Basin formation behind an active subduction zone: three-dimensional flexural modelling of Wanganui Basin, New Zealand: Basin Research, v. 4, no. 3-4, p. 197-214.

Stern, T., Houseman, G., Salmon, M., and Evans, L., 2013, Instability of a lithospheric step beneath western North Island, New Zealand: Geology, v. 41, no. 4, p. 423-426.

Stickley, C. E., St John, K., Koc, N., Jordan, R. W., Passchier, S., Pearce, R. B., and Kearns, L. E., 2009, Evidence for middle Eocene Arctic sea ice from diatoms and ice-rafted debris: Nature, v. 460, no. 7253, p. 376-379.

Suggate, R., 1990, Late Pliocene and Quaternary glaciations of New Zealand: Quaternary Science Reviews, v. 9, no. 2, p. 175-197.

Sundborg, Å., 1956, The River Klarälven: a study of fluvial processes: Geografiska Annaler, p. 125-237.

Tagami, T., 2005, Fundamentals of Fission-Track Thermochronology: Reviews in Mineralogy and Geochemistry, v. 58, no. 1, p. 19-47.

Tanner, W. F., 1971, Numerical estimates of ancient waves, water depth and fetch: Sedimentology, v. 16, p. 71-88.

Tauxe, L., 2010, Essentials of paleomagnetism, University of California Press.

Te Punga, M. T., 1953, Geology of the Rangitikei Valley: New Zealand Geological Survey Memoir, v. 8, p. 46.

Thompson, W. G., and Goldstein, S. L., 2006, A radiometric calibration of the SPECMAP timescale: Quaternary Science Reviews, v. 25, no. 23-24, p. 3207-3215.

Toggweiler, J., and Russell, J., 2008, Ocean circulation in a warming climate: Nature, v. 451, no. 7176, p. 286-288.

Trewick, S. A., and Bland, K. J., 2012, Fire and slice: palaeogeography for biogeography at New Zealand's North Island/South Island juncture: Journal of the Royal Society of New Zealand, v. 42, no. 3, p. 153-183.

Turner, G. M., 2001, Toward an understanding of the multicomponent magnetization of uplifted Neogene marine sediments in New Zealand: Journal of Geophysical Research: Solid Earth (1978-2012), v. 106, no. B4, p. 6385-6397. 
Turner, G. M., Kamp, P. J., McIntyre, A. P., Hayton, S., McGuire, D. M., and Wilson, G. S., 2005, A coherent middle Pliocene magnetostratigraphy, Wanganui Basin, New Zealand: Journal of the Royal Society of New Zealand, v. 35, no. 1-2, p. 197-227.

Van der Zwaan, G., Jorissen, F., and De Stigter, H., 1990, The depth dependency of planktonic/benthic foraminiferal ratios: constraints and applications: Marine Geology, v. 95, no. 1, p. 1-16.

Van der Zwaan, G., Duijnstee, I., Den Dulk, M., Ernst, S., Jannink, N., and Kouwenhoven, T., 1999, Benthic foraminifers: proxies or problems?: a review of paleocological concepts: EarthScience Reviews, v. 46, no. 1, p. 213-236.

Vella, P., 1957, Studies in New Zealand Foraminifera, Department of Scientific and Industrial Research, New Zealand Geological Survey, v. 28-33.

Vella, P., 1962, Determining depths of New Zealand Tertiary seas. An introduction to depth paleoecology: Tuatara, v. 10, no. 1, p. 19-40.

Verosub, K. L., 1977, Depositional and postdepositional processes in the magnetization of sediments: Reviews of Geophysics, v. 15, no. 2, p. 129-143.

Vettoretti, G., and Peltier, W. R., 2011, The impact of insolation, greenhouse gas forcing and ocean circulation changes on glacial inception: The Holocene, v. 21, no. 5, p. 803-817.

Walter, R. C., 1989, Application and limitation of fission-track geochronology to Quarternary tephras: Quaternary International, v. 1, p. 35-46.

Wang, Y., Cheng, H., Edwards, R. L., Kong, X., Shao, X., Chen, S., Wu, J., Jiang, X., Wang, X., and An, Z., 2008, Millennial-and orbital-scale changes in the East Asian monsoon over the past 224,000 years: Nature, v. 451, no. 7182, p. 1090-1093.

Wardlaw, B. R., and Quinn, T. M., 1991, The record of Pliocene sea-level change at Enewetak Atoll: Quaternary Science Reviews, v. 10, no. 2, p. 247-258.

Westgate, J. A., 1989, Isothermal plateau fission-track ages of hydrated glass shards from silicic tephra beds: Earth and Planetary Science Letters, v. 95, no. 3, p. 226-234.

Whitehead, J. M., Wotherspoon, S., and Bohaty, S. M., 2005, Minimal Antarctic sea ice during the Pliocene: Geology, v. 33, no. 2, p. 137.

Wilson, C., Houghton, B., McWilliams, M., Lanphere, M., Weaver, S., and Briggs, R., 1995, Volcanic and structural evolution of Taupo Volcanic Zone, New Zealand: a review: Journal of Volcanology and Geothermal Research, v. 68, no. 1, p. 1-28.

Wilson, G. S., 1993, Ice induced sea level change in the late Neogene. Unpublished PhD thesis, Victoria University of Wellington, Wellington, New Zealand.

Woodard, S. C., Rosenthal, Y., Miller, K. G., Wright, J. D., Chiu, B. K., and Lawrence, K. T., 2014, Antarctic role in Northern Hemisphere glaciation: Science, v. 346, no. 6211, p. 847-851.

Wright, I., and Vella, P., 1988, A New Zealand Late Miocene magnetostratigraphy: glacioeustatic and biostratigraphic correlations: Earth and Planetary Science Letters, v. 87, no. 1, p. 193-204.

Yamada, R., Tagami, T., Nishimura, S., and Ito, H., 1995, Annealing kinetics of fission tracks in zircon: an experimental study: Chemical Geology, v. 122, no. 1, p. 249-258.

Yuan, D., Cheng, H., Edwards, R. L., Dykoski, C. A., Kelly, M. J., Zhang, M., Qing, J., Lin, Y., Wang, Y., and $\mathrm{Wu}$, J., 2004, Timing, duration, and transitions of the last interglacial Asian monsoon: Science, v. 304, no. 5670, p. 575-578.

Zachos, J., Pagani, M., Sloan, L., Thomas, E., and Billups, K., 2001, Trends, rhythms, and aberrations in global climate 65 Ma to present: Science, v. 292, no. 5517, p. 686-693.

Zachos, J., Dickens, G., Zeebe, R., 2008, An Early Cenozoic perspective on greenhouse warming and carbon-cycle dynamics: Nature, v. 451, p. 279-283.

Zecchin, M., Caffau, M., Civile, D., Critelli, S., Di Stefano, A., Maniscalco, R., Muto, F., Sturiale, G., and Roda, C., 2012, The Plio-Pleistocene evolution of the Crotone Basin (southern Italy): Interplay between sedimentation, tectonics and eustasy in the frame of Calabrian Arc migration: Earth-Science Reviews, v. 115, no. 4, p. 273-303.

Zijderveld, J., 1967, AC demagnetization of rocks: analysis of results: Methods in Paleomagnetism, v. 3, p. 254. 


\section{Appendix A}

Below is a table containing GPS localities and stratigraphic positions of samples collected for grainsize $(G)$, benthic foraminifera $(F)$ and palaeomagnetic studies $(P)$. The sample localities are presented in stratigraphic order, but the same names may not appear to be in order (e.g. WS12). This is because after GPS surveying and calculation of stratigraphic positions (see Chapter 3), some samples were identified to be reversed. So while they still represent a unique position accurately located within the stratigraphy, they do not appear labelled in order. GPS latitudes and longitudes are in Northings and Eastings, respectively.

\section{Appendix A Table 1: Sample localities and stratigraphic positions}

\begin{tabular}{|c|c|c|c|c|c|}
\hline $\begin{array}{l}\text { Sample } \\
\text { name }\end{array}$ & $\begin{array}{l}\text { Stratigraphic depth } \\
\text { from top contact } \\
(\mathrm{m})\end{array}$ & Latitude & Longitude & $\begin{array}{c}\text { Elevation } \\
\text { (m) }\end{array}$ & $\begin{array}{c}\text { Sample } \\
\text { types }\end{array}$ \\
\hline WS1 & 672.7 & -39.76719 & 175.67522 & 551.92 & $\mathrm{G}, \mathrm{F}$ \\
\hline WS2 & 669.7 & -39.76739 & 175.67548 & 555.10 & $\mathrm{G}, \mathrm{F}$ \\
\hline WS3 & 665.0 & -39.76757 & 175.67528 & 556.85 & $G, F, P$ \\
\hline WS3.5 & 660.1 & -39.76766 & 175.67488 & 559.36 & G \\
\hline WS4 & 655.4 & -39.76791 & 175.67467 & 558.61 & $G, F$ \\
\hline WS4.5 & 652.9 & -39.76803 & 175.67459 & 559.77 & G \\
\hline WS5 & 651.8 & -39.76808 & 175.67454 & 561.44 & $\mathrm{G}, \mathrm{F}$ \\
\hline WS5.5 & 647.4 & -39.76838 & 175.67449 & 562.33 & G \\
\hline WS6 & 645.2 & -39.76853 & 175.67457 & 564.03 & $\mathrm{G}, \mathrm{F}$ \\
\hline WS6.5 & 642.8 & -39.76866 & 175.67449 & 563.96 & G \\
\hline WS7 & 633.8 & -39.76921 & 175.67429 & 567.86 & $G, F, P$ \\
\hline WS12 & 631.8 & -39.76947 & 175.67708 & 575.32 & $\mathrm{G}, \mathrm{F}$ \\
\hline WS11.5 & 631.0 & -39.76955 & 175.67643 & 572.58 & G \\
\hline WS11 & 630.7 & -39.76957 & 175.67637 & 568.47 & $G, F, P$ \\
\hline WS12.5 & 630.3 & -39.76963 & 175.67726 & 574.14 & G \\
\hline WS13 & 630.0 & -39.76970 & 175.67757 & 577.53 & $\mathrm{G}, \mathrm{F}$ \\
\hline WS13.5 & 629.4 & -39.76978 & 175.67768 & 577.89 & G \\
\hline WS10.5 & 628.7 & -39.76976 & 175.67620 & 571.72 & G \\
\hline WS8 & 628.7 & -39.76960 & 175.67457 & 569.68 & $\mathrm{G}, \mathrm{F}$ \\
\hline WS10 & 628.0 & -39.76976 & 175.67574 & 573.82 & $\mathrm{G}, \mathrm{F}$ \\
\hline WS14 & 626.6 & -39.76999 & 175.67786 & 578.50 & $G, F$ \\
\hline WS15 & 619.9 & -39.77034 & 175.67773 & 579.45 & $G, F, P$ \\
\hline WS15.5 & 616.2 & -39.77054 & 175.67755 & 584.72 & G \\
\hline WS16 & 613.8 & -39.77075 & 175.67766 & 585.73 & $G, F$ \\
\hline
\end{tabular}




\begin{tabular}{|c|c|c|c|c|c|}
\hline $\begin{array}{l}\text { Sample } \\
\text { name }\end{array}$ & $\begin{array}{l}\text { Stratigraphic depth } \\
\text { from top contact } \\
\text { (m) }\end{array}$ & Latitude & Longitude & $\begin{array}{l}\text { Elevation } \\
\text { (m) }\end{array}$ & $\begin{array}{c}\text { Sample } \\
\text { types }\end{array}$ \\
\hline WS16.5 & 612.7 & -39.77090 & 175.67784 & 584.10 & G \\
\hline WS17 & 608.2 & -39.77111 & 175.67782 & 599.24 & $G, F$ \\
\hline WS17.5 & 606.1 & -39.77116 & 175.67762 & 593.03 & G \\
\hline WS18 & 604.2 & -39.77112 & 175.67742 & 594.12 & $G, F$ \\
\hline WS18.5 & 603.3 & -39.77104 & 175.67721 & 593.16 & G \\
\hline WS19 & 598.2 & -39.77115 & 175.67688 & 596.52 & $G, F, P$ \\
\hline WS19.5 & 596.6 & -39.77117 & 175.67670 & 596.10 & G \\
\hline WS20 & 594.7 & -39.77116 & 175.67636 & 598.65 & $G, F$ \\
\hline WS20.5 & 591.6 & -39.77118 & 175.67600 & 597.84 & G \\
\hline WS21 & 585.5 & -39.77130 & 175.67547 & 607.93 & $G, F$ \\
\hline WS21.5 & 581.7 & -39.77143 & 175.67531 & 602.75 & G \\
\hline WS22 & 579.6 & -39.77154 & 175.67518 & 605.93 & $G, F$ \\
\hline WS23 & 573.2 & -39.77191 & 175.67502 & 605.88 & $G, F, P$ \\
\hline WS23.5 & 571.6 & -39.77204 & 175.67520 & 603.02 & G \\
\hline WS24 & 567.2 & -39.77238 & 175.67546 & 605.96 & $G, F$ \\
\hline WS24.5 & 566.1 & -39.77245 & 175.67552 & 609.81 & G \\
\hline WS25 & 562.9 & -39.77263 & 175.67555 & 610.36 & $G, F$ \\
\hline WS25.5 & 561.7 & -39.77272 & 175.67559 & 611.04 & G \\
\hline WS26 & 559.6 & -39.77287 & 175.67573 & 612.77 & $\mathrm{G}$ \\
\hline WS26.5 & 557.3 & -39.77306 & 175.67596 & 616.02 & $G, F$ \\
\hline WS27 & 555.5 & -39.77316 & 175.67612 & 614.88 & G \\
\hline WS27.5 & 554.2 & -39.77323 & 175.67610 & 613.55 & $G, F$ \\
\hline WS28 & 550.4 & -39.77330 & 175.67592 & 617.85 & G \\
\hline WS28.5 & 546.9 & -39.77343 & 175.67564 & 619.49 & $G, F$ \\
\hline WS29 & 542.4 & -39.77366 & 175.67557 & 617.32 & $G$ \\
\hline WS29.5 & 540.1 & -39.77377 & 175.67554 & 616.75 & $G, F$ \\
\hline WS30 & 530.6 & -39.77410 & 175.67549 & 628.35 & G \\
\hline WS30.5 & 527.9 & -39.77427 & 175.67548 & 621.73 & $G, F$ \\
\hline WS31 & 525.7 & -39.77447 & 175.67550 & 624.16 & $G, F$ \\
\hline WS31.5 & 526.3 & -39.77458 & 175.67555 & 634.76 & G \\
\hline WS32 & 524.6 & -39.77473 & 175.67569 & 622.44 & $G, F$ \\
\hline WS32.5 & 523.5 & -39.77482 & 175.67598 & 629.50 & G \\
\hline WS33 & 522.3 & -39.77491 & 175.67608 & 630.79 & $G, F$ \\
\hline WS33.5 & 522.7 & -39.77489 & 175.67629 & 630.07 & G \\
\hline WS34 & 521.6 & -39.77494 & 175.67632 & 631.90 & $G, F$ \\
\hline WS34.5 & 519.3 & -39.77508 & 175.67633 & 637.84 & G \\
\hline WS35 & 518.1 & -39.77513 & 175.67628 & 640.11 & $G, F$ \\
\hline WS35.5 & 515.4 & -39.77526 & 175.67615 & 640.21 & G \\
\hline WS36 & 513.2 & -39.77536 & 175.67609 & 640.60 & $\mathrm{G}, \mathrm{F}$ \\
\hline WS36.5 & 511.9 & -39.77543 & 175.67604 & 643.37 & G \\
\hline WS37 & 509.0 & -39.77560 & 175.67603 & 645.10 & $G, F$ \\
\hline
\end{tabular}




\begin{tabular}{|c|c|c|c|c|c|}
\hline $\begin{array}{l}\text { Sample } \\
\text { name }\end{array}$ & $\begin{array}{l}\text { Stratigraphic depth } \\
\text { from top contact } \\
(\mathrm{m})\end{array}$ & Latitude & Longitude & $\begin{array}{l}\text { Elevation } \\
\text { (m) }\end{array}$ & $\begin{array}{c}\text { Sample } \\
\text { types }\end{array}$ \\
\hline WS37.5 & 506.7 & -39.77575 & 175.67602 & 646.05 & G \\
\hline WS38 & 503.4 & -39.77599 & 175.67609 & 638.59 & $G, F$ \\
\hline WS38.5 & 502.9 & -39.77600 & 175.67611 & 639.12 & G \\
\hline WS39 & 502.2 & -39.77603 & 175.67657 & 644.19 & $G, F$ \\
\hline WS39.5 & 501.6 & -39.77604 & 175.67660 & 646.39 & G \\
\hline WS40 & 500.8 & -39.77607 & 175.67683 & 648.95 & $G, F$ \\
\hline WS40.5 & 500.0 & -39.77608 & 175.67699 & 651.77 & G \\
\hline WS41 & 499.9 & -39.77605 & 175.67707 & 651.31 & $G, F$ \\
\hline WS41.5 & 500.2 & -39.77603 & 175.67717 & 649.98 & G \\
\hline WS42 & 499.5 & -39.77601 & 175.67729 & 646.71 & $G, F$ \\
\hline WS42.5 & 499.0 & -39.77603 & 175.67742 & 647.85 & G \\
\hline WS43 & 495.5 & -39.77614 & 175.67740 & 648.00 & $G, F$ \\
\hline WS43.5 & 493.4 & -39.77626 & 175.67741 & 652.51 & G \\
\hline WS44 & 491.4 & -39.77637 & 175.67743 & 654.36 & $G, F$ \\
\hline WS44.5 & 489.6 & -39.77645 & 175.67737 & 655.12 & G \\
\hline WS45 & 485.1 & -39.77661 & 175.67713 & 659.01 & $G, F$ \\
\hline WS45.5 & 483.5 & -39.77663 & 175.67696 & 653.39 & $G$ \\
\hline WS46 & 482.0 & -39.77674 & 175.67701 & 658.62 & $G, F$ \\
\hline WS46.5 & 480.1 & -39.77689 & 175.67706 & 660.20 & G \\
\hline WS47 & 478.8 & -39.77696 & 175.67707 & 659.93 & $G, F$ \\
\hline WS47.5 & 477.9 & -39.77708 & 175.67727 & 662.55 & G \\
\hline WS48 & 474.6 & -39.77723 & 175.67741 & 666.80 & $G, F$ \\
\hline WS48.5 & 473.3 & -39.77727 & 175.67756 & 669.18 & $G$ \\
\hline WS49 & 470.8 & -39.77737 & 175.67765 & 666.63 & $G, F$ \\
\hline WS49.5 & 470.6 & -39.77742 & 175.67772 & 667.41 & G \\
\hline WS50 & 468.3 & -39.77753 & 175.67779 & 666.90 & $\mathrm{G}, \mathrm{F}$ \\
\hline WS50.5 & 466.2 & -39.77770 & 175.67791 & 662.42 & G \\
\hline WS51 & 465.2 & -39.77765 & 175.67801 & 669.42 & $G, F$ \\
\hline WS51.5 & 463.6 & -39.77767 & 175.67826 & 678.20 & G \\
\hline WS52 & 462.5 & -39.77773 & 175.67823 & 673.68 & $G, F$ \\
\hline WS53 & 456.3 & -39.77786 & 175.67830 & 676.65 & $G, F$ \\
\hline WS53.5 & 455.8 & -39.77792 & 175.67832 & 683.98 & $\mathrm{G}$ \\
\hline WS54 & 455.0 & -39.77803 & 175.67832 & 681.22 & $G, F$ \\
\hline WS55 & 451.9 & -39.77819 & 175.67830 & 679.42 & $G, F$ \\
\hline WS55.5 & 450.3 & -39.77827 & 175.67834 & 681.69 & $G$ \\
\hline WS56 & 448.6 & -39.77836 & 175.67836 & 679.03 & $G, F$ \\
\hline WS56.5 & 447.9 & -39.77843 & 175.67839 & 679.10 & G \\
\hline WS57 & 446.8 & -39.77854 & 175.67847 & 679.82 & $G, F$ \\
\hline WS57.5 & 445.0 & -39.77859 & 175.67853 & 682.41 & $\mathrm{G}$ \\
\hline WS58 & 443.4 & -39.77867 & 175.67859 & 683.90 & $G, F$ \\
\hline WS58.5a & 441.3 & -39.77878 & 175.67871 & 685.38 & G \\
\hline
\end{tabular}




\begin{tabular}{|c|c|c|c|c|c|}
\hline $\begin{array}{l}\text { Sample } \\
\text { name }\end{array}$ & $\begin{array}{l}\text { Stratigraphic depth } \\
\text { from top contact } \\
\text { (m) }\end{array}$ & Latitude & Longitude & $\begin{array}{l}\text { Elevation } \\
\text { (m) }\end{array}$ & $\begin{array}{c}\text { Sample } \\
\text { types }\end{array}$ \\
\hline WS58.5b & 438.8 & -39.77912 & 175.67923 & 685.51 & G \\
\hline WS59 & 438.5 & -39.77916 & 175.67928 & 684.56 & $G, F$ \\
\hline WS59.5a & 436.1 & -39.77933 & 175.67935 & 689.15 & G \\
\hline WS59.5b & 432.2 & -39.77959 & 175.67945 & 685.50 & G \\
\hline WS60 & 430.8 & -39.77969 & 175.67962 & 686.66 & $G, F$ \\
\hline WS61.5c & 425.5 & -39.77995 & 175.67996 & 690.28 & G \\
\hline WS60.5a & 424.6 & -39.78018 & 175.68027 & 691.01 & G \\
\hline WS61 & 423.0 & -39.78029 & 175.68068 & 690.33 & $G, F$ \\
\hline WS61.5b & 422.5 & -39.78095 & 175.68217 & 701.78 & G \\
\hline WS60.5d & 419.3 & -39.78099 & 175.68257 & 709.64 & G \\
\hline WS61.5a & 415.9 & -39.78157 & 175.68251 & 686.23 & G \\
\hline WS60.5e & 416.4 & -39.78173 & 175.68236 & 691.30 & G \\
\hline WS61.5f & 412.2 & -39.78197 & 175.68237 & 685.49 & G \\
\hline WS62 & 399.4 & -39.78279 & 175.68271 & 702.36 & $G, F$ \\
\hline WS62.5 & 394.5 & -39.78297 & 175.68235 & 704.54 & G \\
\hline WS63 & 390.0 & -39.78303 & 175.68193 & 705.99 & $G, F$ \\
\hline WS63.5a & 384.8 & -39.78322 & 175.68159 & 708.25 & G \\
\hline WS63.5b & 380.9 & -39.78347 & 175.68137 & 708.23 & G \\
\hline WS64.5a & 379.1 & -39.78703 & 175.68045 & 672.07 & $\mathrm{G}$ \\
\hline WS64 & 370.6 & -39.78399 & 175.68135 & 710.39 & $G, F$ \\
\hline WS64.5b & 357.5 & -39.78904 & 175.67592 & 651.13 & G \\
\hline WS64.5c & 345.5 & -39.78969 & 175.67599 & 657.40 & G \\
\hline WS64.5d & 340.6 & -39.78991 & 175.67595 & 662.37 & G \\
\hline WS64.5e & 328.6 & -39.79044 & 175.67552 & 667.25 & G \\
\hline WS64.5f & 322.6 & -39.79060 & 175.67514 & 667.47 & G \\
\hline WS65 & 313.6 & -39.79091 & 175.67484 & 669.96 & $G, F$ \\
\hline WS66 & 308.6 & -39.79124 & 175.67503 & 671.81 & $G, F$ \\
\hline WS67 & 304.2 & -39.79154 & 175.67499 & 676.34 & $G, F$ \\
\hline WS68 & 302.3 & -39.79208 & 175.67596 & 677.74 & $G, F$ \\
\hline WS69 & 297.6 & -39.79257 & 175.67624 & 676.18 & $G, F$ \\
\hline WS69.5a & 291.0 & -39.79501 & 175.67382 & 646.87 & G \\
\hline WS69.5b & 282.9 & -39.79620 & 175.67344 & 640.87 & G \\
\hline WS69.5c & 258.8 & -39.79809 & 175.67201 & 641.78 & G \\
\hline WS69.5d & 241.0 & -39.79915 & 175.67166 & 643.50 & G \\
\hline WS69.5e & 236.8 & -39.79942 & 175.67150 & 643.86 & G \\
\hline WS70 & 217.6 & -39.80071 & 175.67104 & 647.87 & $G, F$ \\
\hline WS71 & 213.4 & -39.80103 & 175.67104 & 649.46 & $G, F$ \\
\hline WS72 & 211.4 & -39.80115 & 175.67108 & 648.56 & $G, F, P$ \\
\hline WS73 & 206.9 & -39.80167 & 175.67143 & 650.89 & $G, F$ \\
\hline WS74 & 206.2 & -39.80204 & 175.67227 & 652.85 & $G, F$ \\
\hline WS74.5 & 203.8 & -39.80233 & 175.67267 & 651.26 & $G$ \\
\hline WS75 & 202.2 & -39.80250 & 175.67284 & 653.07 & $G, F$ \\
\hline
\end{tabular}




\begin{tabular}{|l|c|c|c|c|c|}
\hline $\begin{array}{l}\text { Sample } \\
\text { name }\end{array}$ & $\begin{array}{c}\text { Stratigraphic depth } \\
\text { from top contact } \\
(\mathbf{m})\end{array}$ & Latitude & Longitude & $\begin{array}{c}\text { Elevation } \\
(\mathbf{m})\end{array}$ & $\begin{array}{c}\text { Sample } \\
\text { types }\end{array}$ \\
\hline WS75.5 & 200.0 & -39.80269 & 175.67290 & 653.64 & G \\
\hline WS76 & 196.8 & -39.80288 & 175.67287 & 654.88 & G, F \\
\hline WS76.5 & 194.7 & -39.80302 & 175.67284 & 656.38 & G \\
\hline WS77 & 193.1 & -39.80312 & 175.67283 & 658.38 & G, F \\
\hline WS77.5 & 189.3 & -39.80340 & 175.67269 & 659.49 & G \\
\hline WS78 & 186.8 & -39.80357 & 175.67260 & 657.03 & G, F, P \\
\hline WS79 & 177.4 & -39.80441 & 175.67265 & 658.04 & G, F \\
\hline WS79.5a & 167.5 & -39.80750 & 175.67183 & 630.34 & G, P \\
\hline WS79.5b & 164.8 & -39.80768 & 175.67143 & 630.06 & P \\
\hline WS79.5c & 160.8 & -39.80794 & 175.67076 & 629.43 & G \\
\hline WS79.5d & 154.0 & -39.80858 & 175.66981 & 625.94 & G \\
\hline WS80 & 146.7 & -39.80887 & 175.66817 & 622.61 & G, F \\
\hline WS80.5 & 144.6 & -39.81026 & 175.66832 & 611.63 & G \\
\hline WS81 & 138.3 & -39.81153 & 175.66789 & 605.72 & G, F, P \\
\hline WS81.5a & 125.8 & -39.81314 & 175.66520 & 586.06 & G \\
\hline WS81.5b & 121.1 & -39.81337 & 175.66502 & 587.23 & G \\
\hline WS81.5c & 118.9 & -39.81349 & 175.66493 & 589.78 & G \\
\hline WS81.5d & 109.4 & -39.81398 & 175.66464 & 596.05 & G, P \\
\hline WS81.5e & 104.7 & -39.81422 & 175.66451 & 593.82 & G \\
\hline WS81.5f & 97.4 & -39.81458 & 175.66429 & 593.99 & G \\
\hline WS81.5g & 80.2 & -39.81602 & 175.66216 & 590.82 & G \\
\hline WS81.5h & 72.1 & -39.81652 & 175.66184 & 600.38 & G, P \\
\hline WS81.5i & 66.8 & -39.81692 & 175.66179 & 594.42 & G \\
\hline WS82 & 49.9 & -39.81778 & 175.66134 & 591.69 & G, F, P \\
\hline WS83 & 44.4 & -39.81766 & 175.66074 & 598.92 & G, F \\
\hline WS84 & 41.7 & -39.81774 & 175.66060 & 602.56 & G, F \\
\hline WS85 & 28.3 & -39.81848 & 175.66043 & 598.46 & G, F \\
\hline WS86 & 19.4 & -39.81917 & 175.66063 & 618.30 & G, F \\
\hline WS87 & 11.6 & -39.81974 & 175.66091 & 629.06 & G,F, P \\
\hline WS88 & 4.2 & -39.82045 & 175.66081 & 615.66 & G,F \\
\hline WS89 & 1.0 & -39.82074 & 175.66087 & 616.48 & G, F, P \\
\hline
\end{tabular}




\section{Appendix B}

Below is a table containing grainsize data for each sample, with mean and standard deviation calculated using Gradistat 4.0 software (Blott, 2000), using Method of Moments (geometric). Also included are the water depths calculated from the percent mud values, using the polynomial equation defined in Dunbar and Barrett (2005). These water depth calculations have a \pm 10 metre uncertainty (displayed in Chapter 4).

\section{Appendix B Table 1: Grainsize data and proxy water-depth calculations}

\begin{tabular}{|c|c|c|c|c|c|}
\hline $\begin{array}{l}\text { Sample } \\
\text { name }\end{array}$ & $\begin{array}{c}\text { Stratigraphic } \\
\text { depth }(\mathrm{m})\end{array}$ & $\begin{array}{l}\text { Percent mud } \\
\quad(<63 \mu \mathrm{m})\end{array}$ & Mean $(\mu \mathrm{m})$ & $\begin{array}{c}\text { Standard } \\
\text { deviation } \\
\text { (um) }\end{array}$ & Water depth (m) \\
\hline WS1 & 672.7 & 97.3 & 16.98 & 18.31 & 65.4 \\
\hline WS2 & 669.7 & 93.3 & 21.30 & 26.29 & 63.3 \\
\hline WS3 & 665.0 & 93.7 & 21.38 & 28.08 & 63.5 \\
\hline WS3.5 & 660.1 & 83.3 & 31.24 & 37.94 & 56.7 \\
\hline WS4 & 655.4 & 88.5 & 27.94 & 33.90 & 60.3 \\
\hline WS4.5 & 652.9 & 84.7 & 30.91 & 38.98 & 57.7 \\
\hline WS5 & 651.8 & 85.7 & 28.89 & 35.23 & 58.4 \\
\hline WS5.5 & 647.4 & 86.8 & 27.50 & 34.71 & 59.2 \\
\hline WS6 & 645.2 & 94.4 & 18.54 & 22.71 & 63.9 \\
\hline WS6.5 & 642.8 & 87.1 & 27.21 & 35.10 & 59.3 \\
\hline WS7 & 633.8 & 93.8 & 22.77 & 28.42 & 63.6 \\
\hline WS12 & 631.8 & 94.7 & 18.22 & 21.61 & 64.1 \\
\hline WS11.5 & 631.0 & 95.8 & 19.28 & 23.95 & 64.7 \\
\hline WS11 & 630.7 & 95.6 & 18.30 & 18.63 & 64.6 \\
\hline WS12.5 & 630.3 & 96.8 & 17.74 & 18.88 & 65.2 \\
\hline WS13 & 630.0 & 96.0 & 17.68 & 19.97 & 64.8 \\
\hline WS13.5 & 629.4 & 98.7 & 17.95 & 18.02 & 66.0 \\
\hline WS10.5 & 628.7 & 96.3 & 17.09 & 18.87 & 64.9 \\
\hline WS8 & 628.7 & 91.9 & 24.63 & 28.34 & 62.5 \\
\hline WS10 & 628.0 & 98.0 & 19.20 & 18.18 & 65.7 \\
\hline WS14 & 626.6 & 94.3 & 20.44 & 25.86 & 63.9 \\
\hline WS15 & 619.9 & 99.1 & 17.27 & 16.52 & 66.2 \\
\hline WS15.5 & 616.2 & 96.9 & 20.16 & 23.70 & 65.2 \\
\hline WS16 & 613.8 & 99.5 & 18.53 & 15.98 & 66.4 \\
\hline WS16.5 & 612.7 & 99.0 & 18.75 & 16.58 & 66.2 \\
\hline WS17 & 608.2 & 96.1 & 20.80 & 23.31 & 64.8 \\
\hline WS17.5 & 606.1 & 98.8 & 17.55 & 16.20 & 66.1 \\
\hline WS18 & 604.2 & 96.7 & 18.16 & 18.91 & 65.1 \\
\hline
\end{tabular}




\begin{tabular}{|c|c|c|c|c|c|}
\hline $\begin{array}{l}\text { Sample } \\
\text { name }\end{array}$ & $\begin{array}{l}\text { Stratigraphic } \\
\text { depth }(m)\end{array}$ & $\begin{array}{l}\text { Percent mud } \\
\quad(<63 \mu \mathrm{m})\end{array}$ & Mean $(\mu \mathrm{m})$ & $\begin{array}{l}\text { Standard } \\
\text { deviation } \\
\text { (um) }\end{array}$ & Water depth (m) \\
\hline WS18.5 & 603.3 & 96.9 & 19.91 & 19.18 & 65.2 \\
\hline WS19 & 598.2 & 91.5 & 25.64 & 28.66 & 62.2 \\
\hline WS19.5 & 596.6 & 89.0 & 27.61 & 30.36 & 60.6 \\
\hline WS20 & 594.7 & 87.2 & 30.78 & 32.44 & 59.4 \\
\hline WS20.5 & 591.6 & 86.6 & 29.61 & 33.01 & 59.0 \\
\hline WS21 & 585.5 & 85.7 & 30.98 & 34.17 & 58.4 \\
\hline WS21.5 & 581.7 & 89.9 & 26.45 & 29.85 & 61.2 \\
\hline WS22 & 579.6 & 85.7 & 30.89 & 34.22 & 58.3 \\
\hline WS23 & 573.2 & 79.9 & 36.47 & 38.83 & 54.2 \\
\hline WS23.5 & 571.6 & 84.6 & 31.92 & 34.78 & 57.6 \\
\hline WS24 & 567.2 & 84.6 & 33.21 & 34.50 & 57.6 \\
\hline WS24.5 & 566.1 & 86.2 & 29.48 & 27.68 & 58.7 \\
\hline WS25 & 562.9 & 80.2 & 36.03 & 38.92 & 54.4 \\
\hline WS25.5 & 561.7 & 86.8 & 28.79 & 34.41 & 59.1 \\
\hline WS26 & 559.6 & 84.3 & 30.29 & 36.64 & 57.3 \\
\hline WS26.5 & 557.3 & 90.5 & 25.46 & 29.35 & 61.6 \\
\hline WS27 & 555.5 & 88.4 & 27.03 & 32.08 & 60.2 \\
\hline WS27.5 & 554.2 & 88.6 & 28.62 & 31.32 & 60.3 \\
\hline WS28 & 550.4 & 84.0 & 31.31 & 36.62 & 57.2 \\
\hline WS28.5 & 546.9 & 88.2 & 26.59 & 32.64 & 60.1 \\
\hline WS29 & 542.4 & 92.7 & 24.62 & 27.76 & 63.0 \\
\hline WS29.5 & 540.1 & 94.5 & 19.88 & 21.18 & 64.0 \\
\hline WS30 & 530.6 & 95.9 & 19.76 & 19.59 & 64.7 \\
\hline WS30.5 & 527.9 & 97.3 & 17.44 & 18.10 & 65.4 \\
\hline WS31 & 525.7 & 96.1 & 20.07 & 19.53 & 64.8 \\
\hline WS31.5 & 526.3 & 96.5 & 19.37 & 23.19 & 65.1 \\
\hline WS32 & 524.6 & 96.9 & 18.25 & 18.49 & 65.2 \\
\hline WS32.5 & 523.5 & 97.6 & 18.70 & 17.84 & 65.5 \\
\hline WS33 & 522.3 & 97.0 & 20.93 & 19.43 & 65.3 \\
\hline WS33.5 & 522.7 & 96.8 & 19.00 & 18.93 & 65.2 \\
\hline WS34 & 521.6 & 97.2 & 20.31 & 18.57 & 65.4 \\
\hline WS34.5 & 519.3 & 99.6 & 16.66 & 14.39 & 66.4 \\
\hline WS35 & 518.1 & 98.9 & 18.66 & 16.74 & 66.1 \\
\hline WS35.5 & 515.4 & 96.1 & 20.62 & 20.06 & 64.8 \\
\hline WS36 & 513.2 & 95.9 & 23.67 & 24.72 & 64.7 \\
\hline WS36.5 & 511.9 & 93.0 & 24.65 & 26.53 & 63.1 \\
\hline WS37 & 509.0 & 88.6 & 31.12 & 30.54 & 60.4 \\
\hline WS37.5 & 506.7 & 85.5 & 32.58 & 33.40 & 58.2 \\
\hline WS38 & 503.4 & 91.2 & 26.60 & 28.50 & 62.0 \\
\hline WS38.5 & 502.9 & 92.6 & 24.34 & 27.86 & 62.9 \\
\hline WS39 & 502.2 & 90.7 & 27.54 & 26.11 & 61.7 \\
\hline
\end{tabular}




\begin{tabular}{|c|c|c|c|c|c|}
\hline $\begin{array}{l}\text { Sample } \\
\text { name }\end{array}$ & $\begin{array}{l}\text { Stratigraphic } \\
\text { depth }(m)\end{array}$ & $\begin{array}{l}\text { Percent mud } \\
\quad(<63 \mu \mathrm{m})\end{array}$ & Mean $(\mu \mathrm{m})$ & $\begin{array}{c}\text { Standard } \\
\text { deviation } \\
\text { (um) }\end{array}$ & Water depth $(\mathrm{m})$ \\
\hline WS39.5 & 501.6 & 91.2 & 27.37 & 28.90 & 62.0 \\
\hline WS40 & 500.8 & 89.3 & 29.89 & 30.18 & 60.8 \\
\hline WS40.5 & 500.0 & 94.6 & 22.10 & 22.11 & 64.0 \\
\hline WS41 & 499.9 & 90.3 & 28.93 & 25.72 & 61.5 \\
\hline WS41.5 & 500.2 & 91.0 & 27.24 & 28.86 & 61.9 \\
\hline WS42 & 499.5 & 93.2 & 27.00 & 25.03 & 63.2 \\
\hline WS42.5 & 499.0 & 92.4 & 25.27 & 27.54 & 62.8 \\
\hline WS43 & 495.5 & 93.1 & 24.86 & 23.08 & 63.2 \\
\hline WS43.5 & 493.4 & 93.7 & 23.36 & 25.87 & 63.6 \\
\hline WS44 & 491.4 & 94.7 & 21.66 & 21.30 & 64.1 \\
\hline WS44.5 & 489.6 & 97.9 & 19.30 & 19.33 & 65.6 \\
\hline WS45 & 485.1 & 95.6 & 19.92 & 20.28 & 64.6 \\
\hline WS45.5 & 483.5 & 99.8 & 15.84 & 14.21 & 66.5 \\
\hline WS46 & 482.0 & 95.4 & 19.68 & 21.57 & 64.4 \\
\hline WS46.5 & 480.1 & 99.0 & 15.67 & 15.54 & 66.1 \\
\hline WS47 & 478.8 & 94.2 & 22.12 & 25.18 & 63.8 \\
\hline WS47.5 & 477.9 & 99.8 & 15.57 & 13.92 & 66.5 \\
\hline WS48 & 474.6 & 95.0 & 20.67 & 25.45 & 64.3 \\
\hline WS48.5 & 473.3 & 96.2 & 18.68 & 19.78 & 64.9 \\
\hline WS49 & 470.8 & 98.6 & 17.61 & 16.71 & 66.0 \\
\hline WS49.5 & 470.6 & 97.3 & 17.15 & 18.28 & 65.4 \\
\hline WS50 & 468.3 & 96.4 & 19.00 & 22.44 & 65.0 \\
\hline WS50.5 & 466.2 & 96.7 & 18.47 & 22.91 & 65.1 \\
\hline WS51 & 465.2 & 97.4 & 19.66 & 22.94 & 65.4 \\
\hline WS51.5 & 463.6 & 100.0 & 15.28 & 13.33 & 66.5 \\
\hline WS52 & 462.5 & 96.4 & 19.34 & 19.06 & 65.0 \\
\hline WS53 & 456.3 & 97.7 & 16.23 & 18.48 & 65.6 \\
\hline WS53.5 & 455.8 & 98.1 & 16.04 & 15.87 & 65.8 \\
\hline WS54 & 455.0 & 99.7 & 13.93 & 13.64 & 66.4 \\
\hline WS55 & 451.9 & 96.8 & 18.39 & 18.24 & 65.2 \\
\hline WS55.5 & 450.3 & 89.5 & 26.39 & 26.27 & 61.0 \\
\hline WS56 & 448.6 & 85.0 & 32.86 & 30.87 & 57.9 \\
\hline WS56.5 & 447.9 & 79.2 & 40.33 & 39.15 & 53.7 \\
\hline WS57 & 446.8 & 72.9 & 45.04 & 41.92 & 49.3 \\
\hline WS57.5 & 445.0 & 76.5 & 41.15 & 40.97 & 51.8 \\
\hline WS58 & 443.4 & 74.7 & 44.75 & 38.92 & 50.6 \\
\hline WS58.5a & 441.3 & 75.7 & 41.76 & 41.37 & 51.2 \\
\hline WS58.5b & 438.8 & 90.8 & 26.87 & 25.67 & 61.8 \\
\hline WS59 & 438.5 & 83.0 & 38.15 & 34.54 & 56.4 \\
\hline WS59.5a & 436.1 & 77.4 & 41.47 & 36.09 & 52.4 \\
\hline WS59.5b & 432.2 & 79.3 & 36.04 & 34.45 & 53.8 \\
\hline
\end{tabular}




\begin{tabular}{|c|c|c|c|c|c|}
\hline $\begin{array}{l}\text { Sample } \\
\text { name }\end{array}$ & $\begin{array}{c}\text { Stratigraphic } \\
\text { depth (m) }\end{array}$ & $\begin{array}{l}\text { Percent mud } \\
\quad(<63 \mu \mathrm{m})\end{array}$ & Mean $(\mu \mathrm{m})$ & $\begin{array}{c}\text { Standard } \\
\text { deviation } \\
\text { (um) }\end{array}$ & Water depth (m) \\
\hline WS60 & 430.8 & 80.8 & 37.52 & 37.43 & 54.9 \\
\hline WS61.5c & 425.5 & 88.3 & 26.62 & 27.74 & 60.1 \\
\hline WS60.5a & 424.6 & 89.2 & 25.13 & 27.06 & 60.8 \\
\hline WS61 & 423.0 & 82.2 & 36.75 & 36.53 & 55.9 \\
\hline WS61.5b & 422.5 & 79.3 & 37.87 & 38.62 & 53.8 \\
\hline WS60.5d & 419.3 & 84.8 & 31.84 & 35.53 & 57.7 \\
\hline WS61.5a & 415.9 & 87.3 & 39.25 & 41.43 & 52.8 \\
\hline WS60.5e & 416.4 & 77.9 & 28.44 & 33.96 & 59.4 \\
\hline WS61.5f & 412.2 & 79.0 & 38.11 & 40.40 & 53.6 \\
\hline WS62 & 399.4 & 89.3 & 29.08 & 31.88 & 60.8 \\
\hline WS62.5 & 394.5 & 94.9 & 22.92 & 21.61 & 64.2 \\
\hline WS63 & 390.0 & 75.9 & 42.11 & 40.20 & 51.4 \\
\hline WS63.5a & 384.8 & 81.1 & 33.63 & 38.47 & 55.1 \\
\hline WS63.5b & 380.9 & 81.1 & 33.88 & 38.68 & 55.1 \\
\hline WS64.5a & 379.1 & 77.7 & 39.02 & 40.12 & 52.6 \\
\hline WS64 & 370.6 & 73.5 & 43.89 & 46.37 & 49.7 \\
\hline WS64.5b & 357.5 & 72.9 & 45.87 & 50.03 & 49.3 \\
\hline WS64.5c & 345.5 & 97.7 & 19.72 & 18.58 & 65.6 \\
\hline WS64.5d & 340.6 & 96.9 & 21.32 & 19.47 & 65.2 \\
\hline WS64.5e & 328.6 & 96.5 & 21.13 & 19.76 & 65.0 \\
\hline WS64.5f & 322.6 & 96.0 & 21.41 & 23.26 & 64.8 \\
\hline WS65 & 313.6 & 92.7 & 26.08 & 26.85 & 62.9 \\
\hline WS66 & 308.6 & 96.1 & 22.58 & 24.23 & 64.8 \\
\hline WS67 & 304.2 & 96.5 & 19.88 & 18.61 & 65.0 \\
\hline WS68 & 302.3 & 93.5 & 24.95 & 27.34 & 63.4 \\
\hline WS69 & 297.6 & 95.4 & 23.89 & 20.83 & 64.5 \\
\hline WS69.5a & 291.0 & 96.0 & 19.47 & 19.84 & 64.8 \\
\hline WS69.5b & 282.9 & 96.0 & 20.10 & 20.26 & 64.8 \\
\hline WS69.5c & 258.8 & 98.3 & 14.94 & 15.22 & 65.9 \\
\hline WS69.5d & 241.0 & 100.0 & 15.19 & 12.43 & 66.5 \\
\hline WS69.5e & 236.8 & 100.0 & 14.08 & 11.45 & 66.5 \\
\hline WS70 & 217.6 & 98.2 & 18.08 & 15.98 & 65.8 \\
\hline WS71 & 213.4 & 97.5 & 17.38 & 16.67 & 65.5 \\
\hline WS72 & 211.4 & 97.8 & 18.98 & 17.34 & 65.6 \\
\hline WS73 & 206.9 & 97.4 & 18.00 & 17.13 & 65.4 \\
\hline WS74 & 206.2 & 96.8 & 20.37 & 16.98 & 65.2 \\
\hline WS74.5 & 203.8 & 98.8 & 16.85 & 18.33 & 66.0 \\
\hline WS75 & 202.2 & 96.8 & 19.91 & 15.69 & 65.2 \\
\hline WS75.5 & 200.0 & 99.9 & 16.68 & 18.54 & 66.5 \\
\hline WS76 & 196.8 & 97.6 & 19.16 & 13.63 & 65.5 \\
\hline WS76.5 & 194.7 & 97.8 & 17.53 & 17.01 & 65.6 \\
\hline WS77 & 193.1 & 97.4 & 16.87 & 16.59 & 65.5 \\
\hline
\end{tabular}




\begin{tabular}{|c|c|c|c|c|c|}
\hline $\begin{array}{l}\text { Sample } \\
\text { name }\end{array}$ & $\begin{array}{c}\text { Stratigraphic } \\
\text { depth }(\mathrm{m})\end{array}$ & $\begin{array}{l}\text { Percent mud } \\
\quad(<63 \mu \mathrm{m})\end{array}$ & Mean $(\mu \mathrm{m})$ & $\begin{array}{c}\text { Standard } \\
\text { deviation } \\
\text { (um) }\end{array}$ & Water depth (m) \\
\hline WS77.5 & 189.3 & 99.8 & 15.97 & 14.17 & 66.5 \\
\hline WS78 & 186.8 & 80.1 & 39.62 & 38.34 & 54.3 \\
\hline WS79 & 177.4 & 94.9 & 25.37 & 20.76 & 64.2 \\
\hline WS79.5a & 167.5 & 97.5 & 21.33 & 17.84 & 65.5 \\
\hline WS79.5c & 160.8 & 69.7 & 55.94 & 66.35 & 47.2 \\
\hline WS79.5d & 154.0 & 79.1 & 40.04 & 47.58 & 53.6 \\
\hline WS80 & 146.7 & 76.7 & 47.19 & 59.36 & 51.9 \\
\hline WS80.5 & 144.6 & 65.5 & 62.34 & 68.51 & 44.6 \\
\hline WS81 & 138.3 & 73.1 & 47.46 & 46.83 & 49.4 \\
\hline WS81.5a & 125.8 & 85.8 & 33.60 & 35.73 & 58.4 \\
\hline WS81.5b & 121.1 & 86.4 & 33.19 & 39.35 & 58.9 \\
\hline WS81.5c & 118.9 & 87.4 & 31.19 & 38.04 & 59.5 \\
\hline WS81.5d & 109.4 & 90.8 & 27.11 & 26.78 & 61.8 \\
\hline WS81.5e & 104.7 & 82.9 & 36.52 & 42.05 & 56.4 \\
\hline WS81.5f & 97.4 & 85.6 & 33.70 & 35.72 & 58.3 \\
\hline WS81.5g & 80.2 & 96.8 & 22.98 & 19.54 & 65.2 \\
\hline WS81.5h & 72.1 & 83.0 & 36.20 & 39.74 & 56.5 \\
\hline WS81.5i & 66.8 & 79.5 & 41.37 & 43.60 & 53.9 \\
\hline WS82 & 49.9 & 88.2 & 31.37 & 36.29 & 60.1 \\
\hline WS83 & 44.4 & 86.0 & 35.17 & 35.39 & 58.6 \\
\hline WS84 & 41.7 & 73.1 & 50.24 & 49.52 & 49.4 \\
\hline WS85 & 28.3 & 82.0 & 39.02 & 41.15 & 55.7 \\
\hline WS86 & 19.4 & 84.9 & 35.04 & 39.02 & 57.8 \\
\hline WS87 & 11.6 & 79.4 & 54.16 & 51.87 & 53.9 \\
\hline WS88 & 4.2 & 89.8 & 28.49 & 36.36 & 61.2 \\
\hline WS89 & 1.0 & 69.0 & 58.51 & 66.08 & 46.7 \\
\hline
\end{tabular}

Table 2 consists of the raw grainsize data collected by the laser particle sizer for each sample and repeats (rep). Diameter $(\mu \mathrm{m})$ is the grainsize channel bins assigned by the laser particle sizer, and values reported for each sample are in percent volume.

Table 2 Appendix B: Raw grainsize data

\begin{tabular}{|l|c|c|c|c|c|c|c|c|c|c|c|c|}
\hline Diameter $(\boldsymbol{\mu m})$ & WS1 & WS2 & WS2rep & WS3 & WS3.5 & WS4 & WS4.5 & WS4.5rep & wS5 & WS5.5 & WS6 & WS6.5 \\
\hline $\mathbf{0 . 3 8}$ & 0.00 & 0.00 & 0.00 & 0.00 & 0.00 & 0.00 & 0.00 & 0.00 & 0.00 & 0.00 & 0.00 & 0.00 \\
\hline $\mathbf{0 . 4 1}$ & 0.00 & 0.00 & 0.00 & 0.00 & 0.00 & 0.00 & 0.00 & 0.00 & 0.00 & 0.00 & 0.00 & 0.00 \\
\hline $\mathbf{0 . 4 5}$ & 0.00 & 0.00 & 0.00 & 0.00 & 0.00 & 0.00 & 0.00 & 0.00 & 0.00 & 0.00 & 0.00 & 0.00 \\
\hline $\mathbf{0 . 5 0}$ & 0.00 & 0.00 & 0.00 & 0.00 & 0.00 & 0.00 & 0.00 & 0.00 & 0.00 & 0.00 & 0.00 & 0.00 \\
\hline $\mathbf{0 . 5 4}$ & 0.00 & 0.00 & 0.00 & 0.00 & 0.00 & 0.00 & 0.00 & 0.00 & 0.00 & 0.00 & 0.00 & 0.00 \\
\hline $\mathbf{0 . 6 0}$ & 0.00 & 0.00 & 0.00 & 0.00 & 0.00 & 0.00 & 0.00 & 0.00 & 0.00 & 0.00 & 0.00 & 0.00 \\
\hline $\mathbf{0 . 6 6}$ & 0.00 & 0.00 & 0.00 & 0.00 & 0.00 & 0.00 & 0.00 & 0.00 & 0.00 & 0.00 & 0.00 & 0.00 \\
\hline $\mathbf{0 . 7 2}$ & 0.00 & 0.00 & 0.00 & 0.00 & 0.00 & 0.00 & 0.00 & 0.00 & 0.00 & 0.00 & 0.00 & 0.00 \\
\hline $\mathbf{0 . 7 9}$ & 0.00 & 0.00 & 0.00 & 0.00 & 0.00 & 0.00 & 0.00 & 0.00 & 0.00 & 0.00 & 0.00 & 0.00 \\
\hline
\end{tabular}




\begin{tabular}{|c|c|c|c|c|c|c|c|c|c|c|c|c|}
\hline Diameter $(\mu \mathrm{m})$ & WS1 & WS2 & WS2rep & WS3 & WS3.5 & WS4 & WS4.5 & WS4.5rep & WS5 & WS5.5 & WS6 & WS6.5 \\
\hline 0.87 & 0.00 & 0.00 & 0.00 & 0.00 & 0.00 & 0.00 & 0.00 & 0.00 & 0.00 & 0.00 & 0.00 & 0.00 \\
\hline 0.95 & 0.00 & 0.00 & 0.00 & 0.00 & 0.00 & 0.00 & 0.00 & 0.00 & 0.00 & 0.00 & 0.00 & 0.00 \\
\hline 1.05 & 0.00 & 0.00 & 0.00 & 0.00 & 0.00 & 0.00 & 0.00 & 0.00 & 0.00 & 0.01 & 0.00 & 0.00 \\
\hline 1.15 & 0.00 & 0.00 & 0.00 & 0.00 & 0.00 & 0.00 & 0.00 & 0.01 & 0.01 & 0.04 & 0.00 & 0.00 \\
\hline 1.26 & 0.04 & 0.02 & 0.00 & 0.00 & 0.00 & 0.01 & 0.00 & 0.08 & 0.08 & 0.17 & 0.03 & 0.00 \\
\hline 1.38 & 0.20 & 0.13 & 0.00 & 0.00 & 0.00 & 0.09 & 0.04 & 0.25 & 0.24 & 0.39 & 0.17 & 0.01 \\
\hline 1.52 & 0.51 & 0.38 & 0.04 & 0.05 & 0.05 & 0.27 & 0.20 & 0.54 & 0.51 & 0.69 & 0.46 & 0.07 \\
\hline 1.67 & 0.94 & 0.80 & 0.25 & 0.26 & 0.26 & 0.56 & 0.55 & 0.89 & 0.83 & 1.02 & 0.86 & 0.28 \\
\hline 1.83 & 1.40 & 1.30 & 0.72 & 0.73 & 0.66 & 0.92 & 1.07 & 1.26 & 1.18 & 1.35 & 1.30 & 0.63 \\
\hline 2.01 & 1.83 & 1.79 & 1.38 & 1.39 & 1.16 & 1.26 & 1.60 & 1.61 & 1.50 & 1.66 & 1.71 & 1.05 \\
\hline 2.21 & 2.18 & 2.17 & 2.04 & 2.02 & 1.60 & 1.55 & 2.05 & 1.91 & 1.78 & 1.93 & 2.06 & 1.44 \\
\hline 2.42 & 2.42 & 2.39 & 2.57 & 2.49 & 1.94 & 1.74 & 2.35 & 2.11 & 1.99 & 2.13 & 2.32 & 1.75 \\
\hline 2.66 & 2.58 & 2.49 & 2.91 & 2.78 & 2.17 & 1.86 & 2.52 & 2.24 & 2.13 & 2.26 & 2.50 & 1.99 \\
\hline 2.92 & 2.65 & 2.47 & 3.05 & 2.86 & 2.31 & 1.92 & 2.57 & 2.29 & 2.20 & 2.32 & 2.59 & 2.15 \\
\hline 3.21 & 2.66 & 2.41 & 3.03 & 2.81 & 2.36 & 1.94 & 2.54 & 2.29 & 2.23 & 2.34 & 2.62 & 2.25 \\
\hline 3.52 & 2.65 & 2.34 & 2.96 & 2.71 & 2.37 & 1.94 & 2.46 & 2.26 & 2.23 & 2.32 & 2.62 & 2.31 \\
\hline 3.86 & 2.65 & 2.28 & 2.90 & 2.64 & 2.37 & 1.95 & 2.40 & 2.24 & 2.22 & 2.30 & 2.62 & 2.35 \\
\hline 4.24 & 2.69 & 2.29 & 2.96 & 2.69 & 2.43 & 2.01 & 2.40 & 2.25 & 2.24 & 2.30 & 2.67 & 2.45 \\
\hline 4.66 & 2.76 & 2.34 & 3.09 & 2.82 & 2.53 & 2.09 & 2.46 & 2.29 & 2.27 & 2.31 & 2.75 & 2.58 \\
\hline 5.11 & 2.86 & 2.45 & 3.26 & 3.01 & 2.66 & 2.23 & 2.57 & 2.37 & 2.33 & 2.36 & 2.87 & 2.75 \\
\hline 5.61 & 2.94 & 2.55 & 3.35 & 3.12 & 2.74 & 2.33 & 2.64 & 2.43 & 2.37 & 2.39 & 2.97 & 2.87 \\
\hline 6.16 & 3.05 & 2.68 & 3.37 & 3.18 & 2.79 & 2.46 & 2.70 & 2.52 & 2.42 & 2.44 & 3.10 & 2.97 \\
\hline 6.76 & 3.12 & 2.78 & 3.30 & 3.15 & 2.79 & 2.56 & 2.73 & 2.60 & 2.46 & 2.49 & 3.20 & 3.03 \\
\hline 7.42 & 3.21 & 2.90 & 3.23 & 3.11 & 2.80 & 2.68 & 2.77 & 2.70 & 2.53 & 2.56 & 3.32 & 3.11 \\
\hline 8.15 & 3.27 & 2.97 & 3.16 & 3.07 & 2.81 & 2.80 & 2.80 & 2.78 & 2.60 & 2.64 & 3.43 & 3.21 \\
\hline 8.94 & 3.29 & 2.98 & 3.06 & 3.00 & 2.81 & 2.89 & 2.79 & 2.81 & 2.65 & 2.69 & 3.50 & 3.28 \\
\hline 9.82 & 3.30 & 2.98 & 2.96 & 2.96 & 2.80 & 2.98 & 2.75 & 2.83 & 2.72 & 2.76 & 3.53 & 3.36 \\
\hline 10.78 & 3.27 & 2.95 & 2.83 & 2.90 & 2.74 & 3.04 & 2.65 & 2.78 & 2.75 & 2.77 & 3.46 & 3.38 \\
\hline 11.83 & 3.31 & 3.04 & 2.77 & 2.91 & 2.70 & 3.17 & 2.58 & 2.79 & 2.83 & 2.83 & 3.39 & 3.42 \\
\hline 12.99 & 3.30 & 3.14 & 2.72 & 2.90 & 2.63 & 3.25 & 2.48 & 2.77 & 2.88 & 2.84 & 3.25 & 3.40 \\
\hline 14.26 & 3.25 & 3.27 & 2.72 & 2.90 & 2.57 & 3.30 & 2.40 & 2.74 & 2.91 & 2.85 & 3.11 & 3.33 \\
\hline 15.65 & 3.07 & 3.26 & 2.65 & 2.81 & 2.45 & 3.19 & 2.28 & 2.62 & 2.81 & 2.75 & 2.91 & 3.14 \\
\hline 17.18 & 2.76 & 3.05 & 2.48 & 2.62 & 2.27 & 2.92 & 2.11 & 2.40 & 2.56 & 2.54 & 2.66 & 2.80 \\
\hline 18.86 & 2.42 & 2.70 & 2.24 & 2.38 & 2.05 & 2.60 & 1.92 & 2.15 & 2.21 & 2.25 & 2.39 & 2.38 \\
\hline 20.71 & 2.14 & 2.31 & 1.97 & 2.13 & 1.82 & 2.31 & 1.71 & 1.91 & 1.84 & 1.95 & 2.12 & 1.95 \\
\hline 22.73 & 2.03 & 2.06 & 1.81 & 1.99 & 1.66 & 2.18 & 1.56 & 1.79 & 1.62 & 1.76 & 1.92 & 1.64 \\
\hline 24.95 & 2.01 & 1.98 & 1.74 & 1.95 & 1.57 & 2.17 & 1.46 & 1.74 & 1.56 & 1.70 & 1.79 & 1.47 \\
\hline 27.39 & 2.04 & 2.07 & 1.76 & 1.99 & 1.57 & 2.26 & 1.44 & 1.75 & 1.70 & 1.77 & 1.77 & 1.45 \\
\hline 30.07 & 2.00 & 2.21 & 1.79 & 2.06 & 1.63 & 2.31 & 1.46 & 1.73 & 1.93 & 1.88 & 1.82 & 1.50 \\
\hline 33.01 & 1.83 & 2.26 & 1.75 & 2.10 & 1.71 & 2.24 & 1.50 & 1.63 & 2.11 & 1.94 & 1.87 & 1.54 \\
\hline 36.24 & 1.59 & 2.16 & 1.62 & 2.06 & 1.77 & 2.05 & 1.54 & 1.51 & 2.12 & 1.88 & 1.86 & 1.51 \\
\hline 39.78 & 1.38 & 1.92 & 1.45 & 1.96 & 1.77 & 1.82 & 1.57 & 1.41 & 1.94 & 1.70 & 1.75 & 1.40 \\
\hline 43.67 & 1.30 & 1.64 & 1.32 & 1.81 & 1.71 & 1.64 & 1.58 & 1.40 & 1.67 & 1.50 & 1.52 & 1.29 \\
\hline
\end{tabular}




\begin{tabular}{|c|c|c|c|c|c|c|c|c|c|c|c|c|}
\hline Diameter $(\mu \mathrm{m})$ & WS1 & WS2 & WS2rep & WS3 & WS3.5 & WS4 & WS4.5 & WS4.5rep & WS5 & WS5.5 & WS6 & WS6.5 \\
\hline 47.94 & 1.38 & 1.43 & 1.29 & 1.63 & 1.63 & 1.60 & 1.58 & 1.53 & 1.47 & 1.36 & 1.21 & 1.23 \\
\hline 52.62 & 1.56 & 1.36 & 1.35 & 1.43 & 1.55 & 1.67 & 1.57 & 1.73 & 1.44 & 1.37 & 0.92 & 1.27 \\
\hline 57.77 & 1.72 & 1.42 & 1.47 & 1.23 & 1.53 & 1.81 & 1.57 & 1.95 & 1.63 & 1.52 & 0.73 & 1.42 \\
\hline 63.41 & 1.70 & 1.54 & 1.54 & 1.04 & 1.61 & 1.91 & 1.59 & 2.05 & 2.00 & 1.78 & 0.69 & 1.63 \\
\hline 69.61 & 1.42 & 1.59 & 1.47 & 0.90 & 1.79 & 1.87 & 1.68 & 2.00 & 2.40 & 2.03 & 0.80 & 1.81 \\
\hline 76.42 & 0.87 & 1.47 & 1.23 & 0.82 & 2.06 & 1.68 & 1.85 & 1.83 & 2.59 & 2.14 & 1.00 & 1.88 \\
\hline 83.89 & 0.35 & 1.13 & 0.90 & 0.80 & 2.30 & 1.41 & 2.05 & 1.64 & 2.43 & 2.03 & 1.16 & 1.80 \\
\hline 92.09 & 0.07 & 0.67 & 0.61 & 0.79 & 2.42 & 1.17 & 2.21 & 1.53 & 1.95 & 1.73 & 1.14 & 1.61 \\
\hline 101.10 & 0.01 & 0.28 & 0.45 & 0.74 & 2.31 & 1.04 & 2.23 & 1.51 & 1.34 & 1.35 & 0.88 & 1.37 \\
\hline 110.98 & 0.00 & 0.11 & 0.41 & 0.64 & 1.97 & 1.00 & 2.04 & 1.52 & 0.86 & 1.03 & 0.48 & 1.16 \\
\hline 121.83 & 0.00 & 0.08 & 0.46 & 0.50 & 1.49 & 0.99 & 1.67 & 1.44 & 0.61 & 0.81 & 0.16 & 0.99 \\
\hline 133.74 & 0.00 & 0.15 & 0.51 & 0.36 & 1.01 & 0.91 & 1.21 & 1.19 & 0.54 & 0.68 & 0.03 & 0.84 \\
\hline 146.82 & 0.00 & 0.26 & 0.48 & 0.26 & 0.62 & 0.72 & 0.77 & 0.82 & 0.54 & 0.57 & 0.00 & 0.67 \\
\hline 161.17 & 0.00 & 0.29 & 0.36 & 0.20 & 0.36 & 0.45 & 0.44 & 0.42 & 0.50 & 0.43 & 0.00 & 0.46 \\
\hline 176.93 & 0.00 & 0.20 & 0.20 & 0.16 & 0.19 & 0.21 & 0.22 & 0.14 & 0.33 & 0.25 & 0.00 & 0.24 \\
\hline 194.22 & 0.00 & 0.09 & 0.07 & 0.10 & 0.09 & 0.06 & 0.09 & 0.02 & 0.14 & 0.10 & 0.00 & 0.09 \\
\hline 213.21 & 0.00 & 0.02 & 0.01 & 0.05 & 0.03 & 0.01 & 0.03 & 0.00 & 0.03 & 0.02 & 0.00 & 0.02 \\
\hline 234.05 & 0.00 & 0.00 & 0.00 & 0.01 & 0.01 & 0.00 & 0.00 & 0.00 & 0.00 & 0.00 & 0.00 & 0.00 \\
\hline 256.94 & 0.00 & 0.00 & 0.00 & 0.00 & 0.00 & 0.00 & 0.00 & 0.00 & 0.00 & 0.00 & 0.00 & 0.00 \\
\hline 282.06 & 0.00 & 0.00 & 0.00 & 0.00 & 0.00 & 0.00 & 0.00 & 0.00 & 0.00 & 0.00 & 0.00 & 0.00 \\
\hline 309.63 & 0.00 & 0.00 & 0.00 & 0.00 & 0.00 & 0.00 & 0.00 & 0.00 & 0.00 & 0.00 & 0.00 & 0.00 \\
\hline 339.90 & 0.00 & 0.00 & 0.00 & 0.00 & 0.00 & 0.00 & 0.00 & 0.00 & 0.00 & 0.00 & 0.00 & 0.00 \\
\hline 373.13 & 0.00 & 0.00 & 0.00 & 0.00 & 0.00 & 0.00 & 0.00 & 0.00 & 0.00 & 0.00 & 0.00 & 0.00 \\
\hline 409.61 & 0.00 & 0.00 & 0.00 & 0.00 & 0.00 & 0.00 & 0.00 & 0.00 & 0.00 & 0.00 & 0.00 & 0.00 \\
\hline 449.66 & 0.00 & 0.00 & 0.00 & 0.00 & 0.00 & 0.00 & 0.00 & 0.00 & 0.00 & 0.00 & 0.00 & 0.00 \\
\hline 493.62 & 0.00 & 0.00 & 0.00 & 0.00 & 0.00 & 0.00 & 0.00 & 0.00 & 0.00 & 0.00 & 0.00 & 0.00 \\
\hline 541.88 & 0.00 & 0.00 & 0.00 & 0.00 & 0.00 & 0.00 & 0.00 & 0.00 & 0.00 & 0.00 & 0.00 & 0.00 \\
\hline 594.85 & 0.00 & 0.00 & 0.00 & 0.00 & 0.00 & 0.00 & 0.00 & 0.00 & 0.00 & 0.00 & 0.00 & 0.00 \\
\hline 653.01 & 0.00 & 0.00 & 0.00 & 0.00 & 0.00 & 0.00 & 0.00 & 0.00 & 0.00 & 0.00 & 0.00 & 0.00 \\
\hline 716.85 & 0.00 & 0.00 & 0.00 & 0.00 & 0.00 & 0.00 & 0.00 & 0.00 & 0.00 & 0.00 & 0.00 & 0.00 \\
\hline 786.93 & 0.00 & 0.00 & 0.00 & 0.00 & 0.00 & 0.00 & 0.00 & 0.00 & 0.00 & 0.00 & 0.00 & 0.00 \\
\hline 863.87 & 0.00 & 0.00 & 0.00 & 0.00 & 0.00 & 0.00 & 0.00 & 0.00 & 0.00 & 0.00 & 0.00 & 0.00 \\
\hline 948.32 & 0.00 & 0.00 & 0.00 & 0.00 & 0.00 & 0.00 & 0.00 & 0.00 & 0.00 & 0.00 & 0.00 & 0.00 \\
\hline 1041.03 & 0.00 & 0.00 & 0.00 & 0.00 & 0.00 & 0.00 & 0.00 & 0.00 & 0.00 & 0.00 & 0.00 & 0.00 \\
\hline 1142.81 & 0.00 & 0.00 & 0.00 & 0.00 & 0.00 & 0.00 & 0.00 & 0.00 & 0.00 & 0.00 & 0.00 & 0.00 \\
\hline 1254.54 & 0.00 & 0.00 & 0.00 & 0.00 & 0.00 & 0.00 & 0.00 & 0.00 & 0.00 & 0.00 & 0.00 & 0.00 \\
\hline 1377.19 & 0.00 & 0.00 & 0.00 & 0.00 & 0.00 & 0.00 & 0.00 & 0.00 & 0.00 & 0.00 & 0.00 & 0.00 \\
\hline 1511.83 & 0.00 & 0.00 & 0.00 & 0.00 & 0.00 & 0.00 & 0.00 & 0.00 & 0.00 & 0.00 & 0.00 & 0.00 \\
\hline 1659.63 & 0.00 & 0.00 & 0.00 & 0.00 & 0.00 & 0.00 & 0.00 & 0.00 & 0.00 & 0.00 & 0.00 & 0.00 \\
\hline 1821.88 & 0.00 & 0.00 & 0.00 & 0.00 & 0.00 & 0.00 & 0.00 & 0.00 & 0.00 & 0.00 & 0.00 & 0.00 \\
\hline 2000 & & & & & & & & & & & & \\
\hline
\end{tabular}




\begin{tabular}{|c|c|c|c|c|c|c|c|c|c|c|c|c|}
\hline $\begin{array}{l}\text { Diameter } \\
(\mu \mathrm{m})\end{array}$ & WS7 & WS12 & WS11.5 & WS11 & WS11rep & WS12.5 & WS13 & WS13.5 & WS13.5rep & WS10.5 & WS8 & WS10 \\
\hline 0.38 & 0.00 & 0.00 & 0.00 & 0.00 & 0.00 & 0.00 & 0.00 & 0.00 & 0.00 & 0.00 & 0.00 & 0.00 \\
\hline 0.41 & 0.00 & 0.00 & 0.00 & 0.00 & 0.00 & 0.00 & 0.00 & 0.00 & 0.00 & 0.00 & 0.00 & 0.00 \\
\hline 0.45 & 0.00 & 0.00 & 0.00 & 0.00 & 0.00 & 0.00 & 0.00 & 0.00 & 0.00 & 0.00 & 0.00 & 0.00 \\
\hline 0.50 & 0.00 & 0.00 & 0.00 & 0.00 & 0.00 & 0.00 & 0.00 & 0.00 & 0.00 & 0.00 & 0.00 & 0.00 \\
\hline 0.54 & 0.00 & 0.00 & 0.00 & 0.00 & 0.00 & 0.00 & 0.00 & 0.00 & 0.00 & 0.00 & 0.00 & 0.00 \\
\hline 0.60 & 0.00 & 0.00 & 0.00 & 0.00 & 0.00 & 0.00 & 0.00 & 0.00 & 0.00 & 0.00 & 0.00 & 0.00 \\
\hline 0.66 & 0.00 & 0.00 & 0.00 & 0.00 & 0.00 & 0.00 & 0.00 & 0.00 & 0.00 & 0.00 & 0.00 & 0.00 \\
\hline 0.72 & 0.00 & 0.00 & 0.00 & 0.00 & 0.00 & 0.00 & 0.00 & 0.00 & 0.00 & 0.00 & 0.00 & 0.00 \\
\hline 0.79 & 0.00 & 0.00 & 0.00 & 0.00 & 0.00 & 0.00 & 0.00 & 0.00 & 0.00 & 0.00 & 0.00 & 0.00 \\
\hline 0.87 & 0.00 & 0.00 & 0.00 & 0.00 & 0.00 & 0.00 & 0.00 & 0.00 & 0.00 & 0.00 & 0.00 & 0.00 \\
\hline 0.95 & 0.00 & 0.00 & 0.00 & 0.00 & 0.00 & 0.00 & 0.00 & 0.00 & 0.00 & 0.00 & 0.00 & 0.00 \\
\hline 1.05 & 0.00 & 0.00 & 0.00 & 0.00 & 0.00 & 0.00 & 0.00 & 0.00 & 0.00 & 0.00 & 0.00 & 0.00 \\
\hline 1.15 & 0.01 & 0.00 & 0.00 & 0.00 & 0.00 & 0.01 & 0.00 & 0.00 & 0.00 & 0.00 & 0.00 & 0.01 \\
\hline 1.26 & 0.06 & 0.00 & 0.00 & 0.00 & 0.00 & 0.06 & 0.00 & 0.00 & 0.02 & 0.00 & 0.02 & 0.07 \\
\hline 1.38 & 0.23 & 0.00 & 0.05 & 0.00 & 0.02 & 0.23 & 0.00 & 0.00 & 0.13 & 0.04 & 0.11 & 0.22 \\
\hline 1.52 & 0.51 & 0.04 & 0.24 & 0.00 & 0.13 & 0.52 & 0.02 & 0.06 & 0.39 & 0.20 & 0.34 & 0.49 \\
\hline 1.67 & 0.87 & 0.23 & 0.62 & 0.06 & 0.46 & 0.88 & 0.13 & 0.31 & 0.78 & 0.56 & 0.69 & 0.83 \\
\hline 1.83 & 1.26 & 0.68 & 1.13 & 0.29 & 1.03 & 1.27 & 0.45 & 0.78 & 1.23 & 1.07 & 1.10 & 1.19 \\
\hline 2.01 & 1.63 & 1.34 & 1.62 & 0.72 & 1.68 & 1.63 & 0.98 & 1.37 & 1.66 & 1.59 & 1.49 & 1.53 \\
\hline 2.21 & 1.93 & 2.00 & 2.04 & 1.24 & 2.27 & 1.93 & 1.58 & 1.88 & 2.02 & 2.06 & 1.81 & 1.81 \\
\hline 2.42 & 2.14 & 2.52 & 2.35 & 1.66 & 2.69 & 2.16 & 2.06 & 2.24 & 2.27 & 2.41 & 2.01 & 2.01 \\
\hline 2.66 & 2.26 & 2.84 & 2.57 & 1.96 & 2.96 & 2.31 & 2.39 & 2.47 & 2.42 & 2.66 & 2.12 & 2.13 \\
\hline 2.92 & 2.31 & 2.97 & 2.68 & 2.11 & 3.05 & 2.39 & 2.54 & 2.55 & 2.48 & 2.80 & 2.14 & 2.19 \\
\hline 3.21 & 2.31 & 2.95 & 2.71 & 2.17 & 3.04 & 2.41 & 2.57 & 2.56 & 2.47 & 2.85 & 2.12 & 2.21 \\
\hline 3.52 & 2.28 & 2.88 & 2.68 & 2.18 & 2.96 & 2.41 & 2.56 & 2.52 & 2.44 & 2.85 & 2.07 & 2.20 \\
\hline 3.86 & 2.25 & 2.83 & 2.65 & 2.21 & 2.88 & 2.40 & 2.57 & 2.49 & 2.40 & 2.84 & 2.04 & 2.20 \\
\hline 4.24 & 2.25 & 2.90 & 2.67 & 2.34 & 2.89 & 2.43 & 2.68 & 2.56 & 2.42 & 2.88 & 2.05 & 2.23 \\
\hline 4.66 & 2.28 & 3.05 & 2.71 & 2.54 & 2.96 & 2.47 & 2.88 & 2.69 & 2.47 & 2.96 & 2.09 & 2.27 \\
\hline 5.11 & 2.36 & 3.27 & 2.79 & 2.81 & 3.08 & 2.57 & 3.14 & 2.88 & 2.56 & 3.07 & 2.18 & 2.36 \\
\hline 5.61 & 2.43 & 3.40 & 2.83 & 3.02 & 3.13 & 2.65 & 3.33 & 3.01 & 2.63 & 3.12 & 2.25 & 2.43 \\
\hline 6.16 & 2.53 & 3.47 & 2.87 & 3.19 & 3.14 & 2.76 & 3.47 & 3.12 & 2.72 & 3.15 & 2.35 & 2.53 \\
\hline 6.76 & 2.61 & 3.44 & 2.89 & 3.28 & 3.10 & 2.85 & 3.52 & 3.16 & 2.79 & 3.15 & 2.42 & 2.61 \\
\hline 7.42 & 2.74 & 3.41 & 2.95 & 3.42 & 3.08 & 2.97 & 3.59 & 3.22 & 2.88 & 3.17 & 2.53 & 2.72 \\
\hline 8.15 & 2.86 & 3.38 & 3.01 & 3.57 & 3.05 & 3.10 & 3.65 & 3.26 & 2.97 & 3.19 & 2.62 & 2.82 \\
\hline 8.94 & 2.96 & 3.35 & 3.07 & 3.73 & 3.01 & 3.21 & 3.70 & 3.26 & 3.03 & 3.18 & 2.69 & 2.90 \\
\hline 9.82 & 3.06 & 3.34 & 3.15 & 3.90 & 2.96 & 3.32 & 3.73 & 3.26 & 3.10 & 3.19 & 2.79 & 3.02 \\
\hline 10.78 & 3.09 & 3.26 & 3.17 & 4.00 & 2.86 & 3.37 & 3.69 & 3.21 & 3.14 & 3.15 & 2.85 & 3.12 \\
\hline 11.83 & 3.15 & 3.21 & 3.22 & 4.15 & 2.82 & 3.46 & 3.67 & 3.23 & 3.26 & 3.17 & 2.99 & 3.29 \\
\hline 12.99 & 3.11 & 3.09 & 3.21 & 4.22 & 2.77 & 3.49 & 3.59 & 3.24 & 3.36 & 3.19 & 3.09 & 3.38 \\
\hline 14.26 & 3.05 & 2.97 & 3.17 & 4.25 & 2.76 & 3.51 & 3.50 & 3.25 & 3.46 & 3.23 & 3.19 & 3.40 \\
\hline 15.65 & 2.88 & 2.77 & 3.03 & 4.07 & 2.70 & 3.40 & 3.32 & 3.15 & 3.45 & 3.17 & 3.14 & 3.25 \\
\hline 17.18 & 2.65 & 2.50 & 2.82 & 3.68 & 2.54 & 3.18 & 3.03 & 2.91 & 3.33 & 2.97 & 2.92 & 2.96 \\
\hline 18.86 & 2.43 & 2.20 & 2.58 & 3.16 & 2.31 & 2.89 & 2.68 & 2.61 & 3.14 & 2.66 & 2.61 & 2.68 \\
\hline
\end{tabular}




\begin{tabular}{|c|c|c|c|c|c|c|c|c|c|c|c|c|}
\hline $\begin{array}{l}\text { Diameter } \\
(\mu \mathrm{m})\end{array}$ & WS7 & WS12 & WS11.5 & WS11 & WS11rep & WS12.5 & WS13 & WS13.5 & WS13.5rep & WS10.5 & WS8 & WS10 \\
\hline 20.71 & 2.25 & 1.91 & 2.35 & 2.60 & 2.05 & 2.58 & 2.30 & 2.32 & 2.90 & 2.30 & 2.29 & 2.48 \\
\hline 22.73 & 2.18 & 1.73 & 2.21 & 2.21 & 1.88 & 2.38 & 2.01 & 2.17 & 2.71 & 2.06 & 2.13 & 2.47 \\
\hline 24.95 & 2.20 & 1.68 & 2.15 & 1.97 & 1.82 & 2.30 & 1.84 & 2.17 & 2.57 & 1.97 & 2.15 & 2.59 \\
\hline 27.39 & 2.28 & 1.76 & 2.16 & 1.90 & 1.89 & 2.35 & 1.82 & 2.29 & 2.50 & 2.03 & 2.35 & 2.76 \\
\hline 30.07 & 2.36 & 1.91 & 2.20 & 1.89 & 2.01 & 2.43 & 1.91 & 2.40 & 2.47 & 2.15 & 2.64 & 2.84 \\
\hline 33.01 & 2.41 & 2.04 & 2.23 & 1.83 & 2.09 & 2.45 & 2.01 & 2.41 & 2.48 & 2.19 & 2.87 & 2.79 \\
\hline 36.24 & 2.41 & 2.05 & 2.20 & 1.68 & 2.05 & 2.34 & 2.04 & 2.28 & 2.50 & 2.06 & 2.92 & 2.62 \\
\hline 39.78 & 2.36 & 1.88 & 2.10 & 1.48 & 1.90 & 2.08 & 1.91 & 2.07 & 2.48 & 1.74 & 2.73 & 2.41 \\
\hline 43.67 & 2.26 & 1.58 & 1.92 & 1.32 & 1.67 & 1.72 & 1.63 & 1.86 & 2.37 & 1.36 & 2.38 & 2.26 \\
\hline 47.94 & 2.10 & 1.23 & 1.67 & 1.26 & 1.45 & 1.34 & 1.26 & 1.73 & 2.10 & 1.05 & 1.99 & 2.16 \\
\hline 52.62 & 1.85 & 0.96 & 1.36 & 1.32 & 1.28 & 1.02 & 0.92 & 1.67 & 1.65 & 0.90 & 1.67 & 2.08 \\
\hline 57.77 & 1.52 & 0.84 & 1.03 & 1.46 & 1.18 & 0.81 & 0.69 & 1.60 & 1.10 & 0.92 & 1.49 & 1.92 \\
\hline 63.41 & 1.17 & 0.88 & 0.75 & 1.55 & 1.13 & 0.73 & 0.62 & 1.44 & 0.55 & 1.04 & 1.47 & 1.60 \\
\hline 69.61 & 0.89 & 1.04 & 0.57 & 1.47 & 1.07 & 0.73 & 0.68 & 1.14 & 0.19 & 1.16 & 1.54 & 1.13 \\
\hline 76.42 & 0.74 & 1.20 & 0.51 & 1.15 & 0.96 & 0.75 & 0.82 & 0.72 & 0.03 & 1.12 & 1.59 & 0.59 \\
\hline 83.89 & 0.71 & 1.21 & 0.54 & 0.66 & 0.78 & 0.71 & 0.91 & 0.33 & 0.00 & 0.84 & 1.49 & 0.20 \\
\hline 92.09 & 0.75 & 0.99 & 0.60 & 0.24 & 0.55 & 0.56 & 0.82 & 0.09 & 0.00 & 0.44 & 1.19 & 0.03 \\
\hline 101.10 & 0.78 & 0.58 & 0.60 & 0.04 & 0.35 & 0.32 & 0.53 & 0.01 & 0.00 & 0.13 & 0.76 & 0.00 \\
\hline 110.98 & 0.71 & 0.22 & 0.49 & 0.00 & 0.23 & 0.12 & 0.22 & 0.00 & 0.00 & 0.02 & 0.39 & 0.00 \\
\hline 121.83 & 0.53 & 0.04 & 0.32 & 0.00 & 0.19 & 0.02 & 0.04 & 0.00 & 0.00 & 0.00 & 0.20 & 0.00 \\
\hline 133.74 & 0.33 & 0.00 & 0.17 & 0.00 & 0.21 & 0.00 & 0.00 & 0.00 & 0.00 & 0.00 & 0.16 & 0.00 \\
\hline 146.82 & 0.20 & 0.00 & 0.09 & 0.00 & 0.25 & 0.00 & 0.00 & 0.00 & 0.00 & 0.00 & 0.21 & 0.00 \\
\hline 161.17 & 0.14 & 0.00 & 0.07 & 0.00 & 0.26 & 0.00 & 0.00 & 0.00 & 0.00 & 0.00 & 0.26 & 0.00 \\
\hline 176.93 & 0.13 & 0.00 & 0.07 & 0.00 & 0.22 & 0.00 & 0.00 & 0.00 & 0.00 & 0.00 & 0.22 & 0.00 \\
\hline 194.22 & 0.12 & 0.00 & 0.07 & 0.00 & 0.13 & 0.00 & 0.00 & 0.00 & 0.00 & 0.00 & 0.11 & 0.00 \\
\hline 213.21 & 0.09 & 0.00 & 0.05 & 0.00 & 0.05 & 0.00 & 0.00 & 0.00 & 0.00 & 0.00 & 0.02 & 0.00 \\
\hline 234.05 & 0.04 & 0.00 & 0.02 & 0.00 & 0.01 & 0.00 & 0.00 & 0.00 & 0.00 & 0.00 & 0.00 & 0.00 \\
\hline 256.94 & 0.01 & 0.00 & 0.00 & 0.00 & 0.00 & 0.00 & 0.00 & 0.00 & 0.00 & 0.00 & 0.00 & 0.00 \\
\hline 282.06 & 0.00 & 0.00 & 0.00 & 0.00 & 0.00 & 0.00 & 0.00 & 0.00 & 0.00 & 0.00 & 0.00 & 0.00 \\
\hline 309.63 & 0.00 & 0.00 & 0.00 & 0.00 & 0.00 & 0.00 & 0.00 & 0.00 & 0.00 & 0.00 & 0.00 & 0.00 \\
\hline 339.90 & 0.00 & 0.00 & 0.00 & 0.00 & 0.00 & 0.00 & 0.00 & 0.00 & 0.00 & 0.00 & 0.00 & 0.00 \\
\hline 373.13 & 0.00 & 0.00 & 0.00 & 0.00 & 0.00 & 0.00 & 0.00 & 0.00 & 0.00 & 0.00 & 0.00 & 0.00 \\
\hline 409.61 & 0.00 & 0.00 & 0.00 & 0.00 & 0.00 & 0.00 & 0.00 & 0.00 & 0.00 & 0.00 & 0.00 & 0.00 \\
\hline 449.66 & 0.00 & 0.00 & 0.00 & 0.00 & 0.00 & 0.00 & 0.00 & 0.00 & 0.00 & 0.00 & 0.00 & 0.00 \\
\hline 493.62 & 0.00 & 0.00 & 0.00 & 0.00 & 0.00 & 0.00 & 0.00 & 0.00 & 0.00 & 0.00 & 0.00 & 0.00 \\
\hline 541.88 & 0.00 & 0.00 & 0.00 & 0.00 & 0.00 & 0.00 & 0.00 & 0.00 & 0.00 & 0.00 & 0.00 & 0.00 \\
\hline 594.85 & 0.00 & 0.00 & 0.00 & 0.00 & 0.00 & 0.00 & 0.00 & 0.00 & 0.00 & 0.00 & 0.00 & 0.00 \\
\hline 653.01 & 0.00 & 0.00 & 0.00 & 0.00 & 0.00 & 0.00 & 0.00 & 0.00 & 0.00 & 0.00 & 0.00 & 0.00 \\
\hline 716.85 & 0.00 & 0.00 & 0.00 & 0.00 & 0.00 & 0.00 & 0.00 & 0.00 & 0.00 & 0.00 & 0.00 & 0.00 \\
\hline 786.93 & 0.00 & 0.00 & 0.00 & 0.00 & 0.00 & 0.00 & 0.00 & 0.00 & 0.00 & 0.00 & 0.00 & 0.00 \\
\hline 863.87 & 0.00 & 0.00 & 0.00 & 0.00 & 0.00 & 0.00 & 0.00 & 0.00 & 0.00 & 0.00 & 0.00 & 0.00 \\
\hline 948.32 & 0.00 & 0.00 & 0.00 & 0.00 & 0.00 & 0.00 & 0.00 & 0.00 & 0.00 & 0.00 & 0.00 & 0.00 \\
\hline 1041.03 & 0.00 & 0.00 & 0.00 & 0.00 & 0.00 & 0.00 & 0.00 & 0.00 & 0.00 & 0.00 & 0.00 & 0.00 \\
\hline
\end{tabular}




\begin{tabular}{|c|c|c|c|c|c|c|c|c|c|c|c|c|}
\hline $\begin{array}{l}\text { Diameter } \\
(\mu \mathrm{m})\end{array}$ & WS7 & WS12 & WS11.5 & WS11 & WS11rep & WS12.5 & WS13 & WS13.5 & WS13.5rep & WS10.5 & WS8 & WS10 \\
\hline 1142.81 & 0.00 & 0.00 & 0.00 & 0.00 & 0.00 & 0.00 & 0.00 & 0.00 & 0.00 & 0.00 & 0.00 & 0.00 \\
\hline 1254.54 & 0.00 & 0.00 & 0.00 & 0.00 & 0.00 & 0.00 & 0.00 & 0.00 & 0.00 & 0.00 & 0.00 & 0.00 \\
\hline 1377.19 & 0.00 & 0.00 & 0.00 & 0.00 & 0.00 & 0.00 & 0.00 & 0.00 & 0.00 & 0.00 & 0.00 & 0.00 \\
\hline 1511.83 & 0.00 & 0.00 & 0.00 & 0.00 & 0.00 & 0.00 & 0.00 & 0.00 & 0.00 & 0.00 & 0.00 & 0.00 \\
\hline 1659.63 & 0.00 & 0.00 & 0.00 & 0.00 & 0.00 & 0.00 & 0.00 & 0.00 & 0.00 & 0.00 & 0.00 & 0.00 \\
\hline 1821.88 & 0.00 & 0.00 & 0.00 & 0.00 & 0.00 & 0.00 & 0.00 & 0.00 & 0.00 & 0.00 & 0.00 & 0.00 \\
\hline 2000 & & & & & & & & & & & & \\
\hline
\end{tabular}

\begin{tabular}{|c|c|c|c|c|c|c|c|c|c|c|c|c|c|}
\hline $\begin{array}{l}\text { Diameter } \\
(\mu \mathrm{m})\end{array}$ & WS14 & WS15 & WS15.5 & WS16 & WS16.5 & WS17 & WS17.5 & WS18 & WS18.5 & WS19 & WS19.5 & WS20 & WS20.5 \\
\hline 0.38 & 0.00 & 0.00 & 0.00 & 0.00 & 0.00 & 0.00 & 0.00 & 0.00 & 0.00 & 0.00 & 0.00 & 0.00 & 0.00 \\
\hline 0.41 & 0.00 & 0.00 & 0.00 & 0.00 & 0.00 & 0.00 & 0.00 & 0.00 & 0.00 & 0.00 & 0.00 & 0.00 & 0.00 \\
\hline 0.45 & 0.00 & 0.00 & 0.00 & 0.00 & 0.00 & 0.00 & 0.00 & 0.00 & 0.00 & 0.00 & 0.00 & 0.00 & 0.00 \\
\hline 0.50 & 0.00 & 0.00 & 0.00 & 0.00 & 0.00 & 0.00 & 0.00 & 0.00 & 0.00 & 0.00 & 0.00 & 0.00 & 0.00 \\
\hline 0.54 & 0.00 & 0.00 & 0.00 & 0.00 & 0.00 & 0.00 & 0.00 & 0.00 & 0.00 & 0.00 & 0.00 & 0.00 & 0.00 \\
\hline 0.60 & 0.00 & 0.00 & 0.00 & 0.00 & 0.00 & 0.00 & 0.00 & 0.00 & 0.00 & 0.00 & 0.00 & 0.00 & 0.00 \\
\hline 0.66 & 0.00 & 0.00 & 0.00 & 0.00 & 0.00 & 0.00 & 0.00 & 0.00 & 0.00 & 0.00 & 0.00 & 0.00 & 0.00 \\
\hline 0.72 & 0.00 & 0.00 & 0.00 & 0.00 & 0.00 & 0.00 & 0.00 & 0.00 & 0.00 & 0.00 & 0.00 & 0.00 & 0.00 \\
\hline 0.79 & 0.00 & 0.00 & 0.00 & 0.00 & 0.00 & 0.00 & 0.00 & 0.00 & 0.00 & 0.00 & 0.00 & 0.00 & 0.00 \\
\hline 0.87 & 0.00 & 0.00 & 0.00 & 0.00 & 0.00 & 0.00 & 0.00 & 0.00 & 0.00 & 0.00 & 0.00 & 0.00 & 0.00 \\
\hline 0.95 & 0.00 & 0.00 & 0.00 & 0.00 & 0.00 & 0.00 & 0.00 & 0.00 & 0.00 & 0.00 & 0.00 & 0.00 & 0.00 \\
\hline 1.05 & 0.00 & 0.00 & 0.00 & 0.00 & 0.00 & 0.00 & 0.00 & 0.00 & 0.00 & 0.00 & 0.00 & 0.00 & 0.00 \\
\hline 1.15 & 0.00 & 0.01 & 0.00 & 0.00 & 0.00 & 0.00 & 0.00 & 0.00 & 0.00 & 0.00 & 0.00 & 0.00 & 0.00 \\
\hline 1.26 & 0.00 & 0.06 & 0.02 & 0.02 & 0.02 & 0.00 & 0.00 & 0.00 & 0.00 & 0.00 & 0.00 & 0.02 & 0.00 \\
\hline 1.38 & 0.00 & 0.22 & 0.12 & 0.13 & 0.12 & 0.03 & 0.02 & 0.00 & 0.03 & 0.01 & 0.01 & 0.12 & 0.02 \\
\hline 1.52 & 0.02 & 0.52 & 0.34 & 0.35 & 0.33 & 0.17 & 0.11 & 0.03 & 0.16 & 0.08 & 0.07 & 0.32 & 0.13 \\
\hline 1.67 & 0.15 & 0.92 & 0.65 & 0.68 & 0.65 & 0.51 & 0.34 & 0.17 & 0.44 & 0.32 & 0.27 & 0.62 & 0.38 \\
\hline 1.83 & 0.47 & 1.34 & 0.99 & 1.05 & 0.99 & 1.02 & 0.72 & 0.53 & 0.84 & 0.76 & 0.62 & 0.93 & 0.76 \\
\hline 2.01 & 0.94 & 1.74 & 1.32 & 1.40 & 1.32 & 1.54 & 1.14 & 1.05 & 1.24 & 1.28 & 1.03 & 1.23 & 1.16 \\
\hline 2.21 & 1.45 & 2.07 & 1.60 & 1.70 & 1.60 & 1.99 & 1.53 & 1.60 & 1.59 & 1.75 & 1.40 & 1.48 & 1.52 \\
\hline 2.42 & 1.86 & 2.29 & 1.82 & 1.91 & 1.81 & 2.30 & 1.84 & 2.05 & 1.87 & 2.10 & 1.68 & 1.64 & 1.80 \\
\hline 2.66 & 2.14 & 2.42 & 1.98 & 2.04 & 1.97 & 2.48 & 2.08 & 2.37 & 2.07 & 2.33 & 1.87 & 1.74 & 2.01 \\
\hline 2.92 & 2.30 & 2.46 & 2.07 & 2.09 & 2.05 & 2.53 & 2.24 & 2.53 & 2.19 & 2.44 & 1.98 & 1.77 & 2.12 \\
\hline 3.21 & 2.35 & 2.46 & 2.12 & 2.10 & 2.08 & 2.49 & 2.34 & 2.59 & 2.25 & 2.46 & 2.03 & 1.77 & 2.17 \\
\hline 3.52 & 2.37 & 2.42 & 2.14 & 2.08 & 2.09 & 2.41 & 2.39 & 2.61 & 2.27 & 2.42 & 2.04 & 1.74 & 2.17 \\
\hline 3.86 & 2.39 & 2.39 & 2.15 & 2.06 & 2.09 & 2.34 & 2.43 & 2.64 & 2.28 & 2.39 & 2.06 & 1.72 & 2.17 \\
\hline 4.24 & 2.51 & 2.39 & 2.20 & 2.08 & 2.13 & 2.35 & 2.52 & 2.76 & 2.35 & 2.41 & 2.13 & 1.73 & 2.21 \\
\hline 4.66 & 2.68 & 2.41 & 2.26 & 2.12 & 2.20 & 2.40 & 2.63 & 2.93 & 2.43 & 2.47 & 2.23 & 1.77 & 2.28 \\
\hline 5.11 & 2.92 & 2.49 & 2.37 & 2.22 & 2.31 & 2.51 & 2.77 & 3.13 & 2.55 & 2.56 & 2.38 & 1.85 & 2.37 \\
\hline 5.61 & 3.10 & 2.55 & 2.46 & 2.30 & 2.39 & 2.57 & 2.86 & 3.25 & 2.63 & 2.59 & 2.48 & 1.91 & 2.41 \\
\hline 6.16 & 3.25 & 2.65 & 2.57 & 2.42 & 2.50 & 2.64 & 2.94 & 3.32 & 2.70 & 2.59 & 2.57 & 2.00 & 2.43 \\
\hline 6.76 & 3.33 & 2.73 & 2.67 & 2.51 & 2.60 & 2.66 & 2.98 & 3.29 & 2.74 & 2.54 & 2.61 & 2.08 & 2.42 \\
\hline 7.42 & 3.43 & 2.85 & 2.81 & 2.65 & 2.74 & 2.72 & 3.05 & 3.25 & 2.82 & 2.51 & 2.67 & 2.19 & 2.44 \\
\hline
\end{tabular}




\begin{tabular}{|c|c|c|c|c|c|c|c|c|c|c|c|c|c|}
\hline $\begin{array}{l}\text { Diameter } \\
(\mu \mathrm{m})\end{array}$ & WS14 & WS15 & WS15.5 & WS16 & WS16.5 & WS17 & WS17.5 & WS18 & WS18.5 & WS19 & WS19.5 & WS20 & WS20.5 \\
\hline 8.15 & 3.55 & 2.97 & 2.96 & 2.79 & 2.88 & 2.78 & 3.14 & 3.20 & 2.90 & 2.47 & 2.72 & 2.30 & 2.45 \\
\hline 8.94 & 3.67 & 3.09 & 3.11 & 2.94 & 3.01 & 2.80 & 3.22 & 3.16 & 2.96 & 2.43 & 2.75 & 2.39 & 2.46 \\
\hline 9.82 & 3.79 & 3.23 & 3.27 & 3.12 & 3.15 & 2.83 & 3.31 & 3.15 & 3.04 & 2.41 & 2.78 & 2.50 & 2.48 \\
\hline 10.78 & 3.83 & 3.32 & 3.38 & 3.25 & 3.25 & 2.84 & 3.37 & 3.15 & 3.08 & 2.40 & 2.77 & 2.57 & 2.48 \\
\hline 11.83 & 3.88 & 3.43 & 3.52 & 3.44 & 3.40 & 2.93 & 3.49 & 3.23 & 3.20 & 2.49 & 2.83 & 2.70 & 2.56 \\
\hline 12.99 & 3.82 & 3.43 & 3.58 & 3.53 & 3.49 & 3.01 & 3.56 & 3.27 & 3.28 & 2.59 & 2.86 & 2.80 & 2.63 \\
\hline 14.26 & 3.69 & 3.36 & 3.60 & 3.57 & 3.56 & 3.11 & 3.60 & 3.31 & 3.36 & 2.72 & 2.90 & 2.90 & 2.72 \\
\hline 15.65 & 3.44 & 3.15 & 3.48 & 3.45 & 3.48 & 3.10 & 3.51 & 3.22 & 3.30 & 2.72 & 2.85 & 2.86 & 2.70 \\
\hline 17.18 & 3.07 & 2.88 & 3.26 & 3.23 & 3.30 & 2.95 & 3.29 & 2.98 & 3.12 & 2.59 & 2.68 & 2.71 & 2.56 \\
\hline 18.86 & 2.67 & 2.64 & 3.02 & 3.03 & 3.09 & 2.73 & 3.04 & 2.67 & 2.86 & 2.37 & 2.45 & 2.48 & 2.32 \\
\hline 20.71 & 2.26 & 2.48 & 2.80 & 2.89 & 2.91 & 2.49 & 2.80 & 2.36 & 2.61 & 2.12 & 2.19 & 2.25 & 2.06 \\
\hline 22.73 & 1.95 & 2.48 & 2.72 & 2.92 & 2.87 & 2.38 & 2.72 & 2.19 & 2.50 & 2.01 & 2.05 & 2.14 & 1.92 \\
\hline 24.95 & 1.74 & 2.55 & 2.71 & 3.04 & 2.92 & 2.39 & 2.72 & 2.17 & 2.52 & 2.03 & 2.03 & 2.14 & 1.91 \\
\hline 27.39 & 1.66 & 2.61 & 2.78 & 3.19 & 3.04 & 2.49 & 2.78 & 2.30 & 2.65 & 2.18 & 2.15 & 2.27 & 2.05 \\
\hline 30.07 & 1.66 & 2.58 & 2.83 & 3.24 & 3.09 & 2.60 & 2.77 & 2.47 & 2.78 & 2.39 & 2.33 & 2.44 & 2.23 \\
\hline 33.01 & 1.71 & 2.45 & 2.81 & 3.17 & 3.03 & 2.63 & 2.63 & 2.56 & 2.80 & 2.54 & 2.48 & 2.59 & 2.36 \\
\hline 36.24 & 1.78 & 2.27 & 2.69 & 2.99 & 2.86 & 2.58 & 2.38 & 2.49 & 2.68 & 2.59 & 2.55 & 2.68 & 2.36 \\
\hline 39.78 & 1.81 & 2.12 & 2.48 & 2.76 & 2.62 & 2.44 & 2.08 & 2.24 & 2.45 & 2.55 & 2.49 & 2.69 & 2.25 \\
\hline 43.67 & 1.76 & 2.03 & 2.20 & 2.52 & 2.38 & 2.28 & 1.84 & 1.87 & 2.19 & 2.48 & 2.37 & 2.68 & 2.12 \\
\hline 47.94 & 1.61 & 1.97 & 1.85 & 2.25 & 2.14 & 2.11 & 1.66 & 1.50 & 1.98 & 2.42 & 2.23 & 2.65 & 2.06 \\
\hline 52.62 & 1.37 & 1.85 & 1.46 & 1.91 & 1.88 & 1.92 & 1.52 & 1.19 & 1.84 & 2.38 & 2.13 & 2.63 & 2.13 \\
\hline 57.77 & 1.09 & 1.60 & 1.05 & 1.48 & 1.55 & 1.68 & 1.36 & 1.01 & 1.73 & 2.33 & 2.11 & 2.60 & 2.32 \\
\hline 63.41 & 0.86 & 1.18 & 0.68 & 0.90 & 1.13 & 1.36 & 1.11 & 0.94 & 1.59 & 2.22 & 2.14 & 2.53 & 2.55 \\
\hline 69.61 & 0.73 & 0.65 & 0.44 & 0.38 & 0.65 & 0.98 & 0.74 & 0.92 & 1.35 & 2.00 & 2.16 & 2.42 & 2.67 \\
\hline 76.42 & 0.72 & 0.24 & 0.32 & 0.08 & 0.27 & 0.63 & 0.35 & 0.89 & 0.98 & 1.66 & 2.11 & 2.23 & 2.57 \\
\hline 83.89 & 0.79 & 0.04 & 0.31 & 0.01 & 0.06 & 0.39 & 0.10 & 0.75 & 0.54 & 1.27 & 1.92 & 1.99 & 2.22 \\
\hline 92.09 & 0.86 & 0.00 & 0.35 & 0.00 & 0.01 & 0.29 & 0.01 & 0.48 & 0.20 & 0.93 & 1.57 & 1.69 & 1.71 \\
\hline 101.10 & 0.83 & 0.00 & 0.37 & 0.00 & 0.00 & 0.29 & 0.00 & 0.20 & 0.04 & 0.68 & 1.14 & 1.37 & 1.21 \\
\hline 110.98 & 0.65 & 0.00 & 0.31 & 0.00 & 0.00 & 0.33 & 0.00 & 0.04 & 0.00 & 0.55 & 0.74 & 1.05 & 0.84 \\
\hline 121.83 & 0.40 & 0.00 & 0.21 & 0.00 & 0.00 & 0.36 & 0.00 & 0.00 & 0.00 & 0.47 & 0.46 & 0.77 & 0.62 \\
\hline 133.74 & 0.21 & 0.00 & 0.13 & 0.00 & 0.00 & 0.31 & 0.00 & 0.00 & 0.00 & 0.41 & 0.30 & 0.54 & 0.51 \\
\hline 146.82 & 0.12 & 0.00 & 0.11 & 0.00 & 0.00 & 0.20 & 0.00 & 0.00 & 0.00 & 0.31 & 0.23 & 0.36 & 0.43 \\
\hline 161.17 & 0.10 & 0.00 & 0.13 & 0.00 & 0.00 & 0.09 & 0.00 & 0.00 & 0.00 & 0.18 & 0.19 & 0.23 & 0.32 \\
\hline 176.93 & 0.10 & 0.00 & 0.16 & 0.00 & 0.00 & 0.02 & 0.00 & 0.00 & 0.00 & 0.07 & 0.13 & 0.13 & 0.18 \\
\hline 194.22 & 0.09 & 0.00 & 0.14 & 0.00 & 0.00 & 0.00 & 0.00 & 0.00 & 0.00 & 0.01 & 0.06 & 0.05 & 0.06 \\
\hline 213.21 & 0.05 & 0.00 & 0.08 & 0.00 & 0.00 & 0.00 & 0.00 & 0.00 & 0.00 & 0.00 & 0.01 & 0.01 & 0.01 \\
\hline 234.05 & 0.01 & 0.00 & 0.02 & 0.00 & 0.00 & 0.00 & 0.00 & 0.00 & 0.00 & 0.00 & 0.00 & 0.00 & 0.00 \\
\hline 256.94 & 0.00 & 0.00 & 0.00 & 0.00 & 0.00 & 0.00 & 0.00 & 0.00 & 0.00 & 0.00 & 0.00 & 0.00 & 0.00 \\
\hline 282.06 & 0.00 & 0.00 & 0.00 & 0.00 & 0.00 & 0.00 & 0.00 & 0.00 & 0.00 & 0.00 & 0.00 & 0.00 & 0.00 \\
\hline 309.63 & 0.00 & 0.00 & 0.00 & 0.00 & 0.00 & 0.00 & 0.00 & 0.00 & 0.00 & 0.00 & 0.00 & 0.00 & 0.00 \\
\hline 339.90 & 0.00 & 0.00 & 0.00 & 0.00 & 0.00 & 0.00 & 0.00 & 0.00 & 0.00 & 0.00 & 0.00 & 0.00 & 0.00 \\
\hline 373.13 & 0.00 & 0.00 & 0.00 & 0.00 & 0.00 & 0.00 & 0.00 & 0.00 & 0.00 & 0.00 & 0.00 & 0.00 & 0.00 \\
\hline 409.61 & 0.00 & 0.00 & 0.00 & 0.00 & 0.00 & 0.00 & 0.00 & 0.00 & 0.00 & 0.00 & 0.00 & 0.00 & 0.00 \\
\hline
\end{tabular}




\begin{tabular}{|c|c|c|c|c|c|c|c|c|c|c|c|c|c|}
\hline $\begin{array}{l}\text { Diameter } \\
(\mu \mathrm{m})\end{array}$ & WS14 & WS15 & WS15.5 & WS16 & WS16.5 & WS17 & WS17.5 & WS18 & WS18.5 & WS19 & WS19.5 & WS20 & WS20.5 \\
\hline 449.66 & 0.00 & 0.00 & 0.00 & 0.00 & 0.00 & 0.00 & 0.00 & 0.00 & 0.00 & 0.00 & 0.00 & 0.00 & 0.00 \\
\hline 493.62 & 0.00 & 0.00 & 0.00 & 0.00 & 0.00 & 0.00 & 0.00 & 0.00 & 0.00 & 0.00 & 0.00 & 0.00 & 0.00 \\
\hline 541.88 & 0.00 & 0.00 & 0.00 & 0.00 & 0.00 & 0.00 & 0.00 & 0.00 & 0.00 & 0.00 & 0.00 & 0.00 & 0.00 \\
\hline 594.85 & 0.00 & 0.00 & 0.00 & 0.00 & 0.00 & 0.00 & 0.00 & 0.00 & 0.00 & 0.00 & 0.00 & 0.00 & 0.00 \\
\hline 653.01 & 0.00 & 0.00 & 0.00 & 0.00 & 0.00 & 0.00 & 0.00 & 0.00 & 0.00 & 0.00 & 0.00 & 0.00 & 0.00 \\
\hline 716.85 & 0.00 & 0.00 & 0.00 & 0.00 & 0.00 & 0.00 & 0.00 & 0.00 & 0.00 & 0.00 & 0.00 & 0.00 & 0.00 \\
\hline 786.93 & 0.00 & 0.00 & 0.00 & 0.00 & 0.00 & 0.00 & 0.00 & 0.00 & 0.00 & 0.00 & 0.00 & 0.00 & 0.00 \\
\hline 863.87 & 0.00 & 0.00 & 0.00 & 0.00 & 0.00 & 0.00 & 0.00 & 0.00 & 0.00 & 0.00 & 0.00 & 0.00 & 0.00 \\
\hline 948.32 & 0.00 & 0.00 & 0.00 & 0.00 & 0.00 & 0.00 & 0.00 & 0.00 & 0.00 & 0.00 & 0.00 & 0.00 & 0.00 \\
\hline 1041.03 & 0.00 & 0.00 & 0.00 & 0.00 & 0.00 & 0.00 & 0.00 & 0.00 & 0.00 & 0.00 & 0.00 & 0.00 & 0.00 \\
\hline 1142.81 & 0.00 & 0.00 & 0.00 & 0.00 & 0.00 & 0.00 & 0.00 & 0.00 & 0.00 & 0.00 & 0.00 & 0.00 & 0.00 \\
\hline 1254.54 & 0.00 & 0.00 & 0.00 & 0.00 & 0.00 & 0.00 & 0.00 & 0.00 & 0.00 & 0.00 & 0.00 & 0.00 & 0.00 \\
\hline 1377.19 & 0.00 & 0.00 & 0.00 & 0.00 & 0.00 & 0.00 & 0.00 & 0.00 & 0.00 & 0.00 & 0.00 & 0.00 & 0.00 \\
\hline 1511.83 & 0.00 & 0.00 & 0.00 & 0.00 & 0.00 & 0.00 & 0.00 & 0.00 & 0.00 & 0.00 & 0.00 & 0.00 & 0.00 \\
\hline 1659.63 & 0.00 & 0.00 & 0.00 & 0.00 & 0.00 & 0.00 & 0.00 & 0.00 & 0.00 & 0.00 & 0.00 & 0.00 & 0.00 \\
\hline 1821.88 & 0.00 & 0.00 & 0.00 & 0.00 & 0.00 & 0.00 & 0.00 & 0.00 & 0.00 & 0.00 & 0.00 & 0.00 & 0.00 \\
\hline 2000 & & & & & & & & & & & & & \\
\hline
\end{tabular}

\begin{tabular}{|c|c|c|c|c|c|c|c|c|c|c|c|c|}
\hline $\begin{array}{l}\text { Diameter } \\
(\mu \mathrm{m})\end{array}$ & WS21 & WS21rep & WS21.5 & WS22 & WS23 & WS23.5 & WS24 & WS24.5 & WS24.5rep & WS25 & WS25.5 & WS26 \\
\hline 0.38 & 0.00 & 0.00 & 0.00 & 0.00 & 0.00 & 0.00 & 0.00 & 0.00 & 0.00 & 0.00 & 0.00 & 0.00 \\
\hline 0.41 & 0.00 & 0.00 & 0.00 & 0.00 & 0.00 & 0.00 & 0.00 & 0.00 & 0.00 & 0.00 & 0.00 & 0.00 \\
\hline 0.45 & 0.00 & 0.00 & 0.00 & 0.00 & 0.00 & 0.00 & 0.00 & 0.00 & 0.00 & 0.00 & 0.00 & 0.00 \\
\hline 0.50 & 0.00 & 0.00 & 0.00 & 0.00 & 0.00 & 0.00 & 0.00 & 0.00 & 0.00 & 0.00 & 0.00 & 0.00 \\
\hline 0.54 & 0.00 & 0.00 & 0.00 & 0.00 & 0.00 & 0.00 & 0.00 & 0.00 & 0.00 & 0.00 & 0.00 & 0.00 \\
\hline 0.60 & 0.00 & 0.00 & 0.00 & 0.00 & 0.00 & 0.00 & 0.00 & 0.00 & 0.00 & 0.00 & 0.00 & 0.00 \\
\hline 0.66 & 0.00 & 0.00 & 0.00 & 0.00 & 0.00 & 0.00 & 0.00 & 0.00 & 0.00 & 0.00 & 0.00 & 0.00 \\
\hline 0.72 & 0.00 & 0.00 & 0.00 & 0.00 & 0.00 & 0.00 & 0.00 & 0.00 & 0.00 & 0.00 & 0.00 & 0.00 \\
\hline 0.79 & 0.00 & 0.00 & 0.00 & 0.00 & 0.00 & 0.00 & 0.00 & 0.00 & 0.00 & 0.00 & 0.00 & 0.00 \\
\hline 0.87 & 0.00 & 0.00 & 0.00 & 0.00 & 0.00 & 0.00 & 0.00 & 0.00 & 0.00 & 0.00 & 0.00 & 0.00 \\
\hline 0.95 & 0.00 & 0.00 & 0.00 & 0.00 & 0.00 & 0.00 & 0.00 & 0.00 & 0.00 & 0.00 & 0.00 & 0.00 \\
\hline 1.05 & 0.00 & 0.01 & 0.00 & 0.00 & 0.00 & 0.00 & 0.00 & 0.00 & 0.00 & 0.00 & 0.00 & 0.00 \\
\hline 1.15 & 0.00 & 0.04 & 0.01 & 0.02 & 0.00 & 0.03 & 0.00 & 0.00 & 0.00 & 0.00 & 0.00 & 0.00 \\
\hline 1.26 & 0.01 & 0.15 & 0.04 & 0.09 & 0.01 & 0.11 & 0.01 & 0.00 & 0.00 & 0.00 & 0.00 & 0.00 \\
\hline 1.38 & 0.05 & 0.34 & 0.17 & 0.27 & 0.06 & 0.28 & 0.07 & 0.00 & 0.00 & 0.01 & 0.05 & 0.00 \\
\hline 1.52 & 0.24 & 0.61 & 0.40 & 0.53 & 0.24 & 0.52 & 0.26 & 0.03 & 0.04 & 0.08 & 0.23 & 0.02 \\
\hline 1.67 & 0.59 & 0.91 & 0.71 & 0.83 & 0.60 & 0.78 & 0.61 & 0.18 & 0.20 & 0.32 & 0.60 & 0.15 \\
\hline 1.83 & 1.08 & 1.22 & 1.03 & 1.15 & 1.08 & 1.05 & 1.04 & 0.47 & 0.54 & 0.75 & 1.09 & 0.45 \\
\hline 2.01 & 1.54 & 1.51 & 1.34 & 1.45 & 1.55 & 1.31 & 1.47 & 0.84 & 0.98 & 1.27 & 1.56 & 0.90 \\
\hline 2.21 & 1.92 & 1.74 & 1.60 & 1.70 & 1.94 & 1.53 & 1.83 & 1.17 & 1.38 & 1.73 & 1.95 & 1.37 \\
\hline 2.42 & 2.17 & 1.91 & 1.80 & 1.87 & 2.20 & 1.70 & 2.05 & 1.42 & 1.66 & 2.04 & 2.24 & 1.74 \\
\hline 2.66 & 2.28 & 2.00 & 1.94 & 1.98 & 2.31 & 1.81 & 2.14 & 1.57 & 1.83 & 2.21 & 2.41 & 1.99 \\
\hline 2.92 & 2.29 & 2.04 & 2.01 & 2.03 & 2.31 & 1.87 & 2.13 & 1.64 & 1.88 & 2.24 & 2.48 & 2.12 \\
\hline
\end{tabular}




\begin{tabular}{|c|c|c|c|c|c|c|c|c|c|c|c|c|}
\hline $\begin{array}{l}\text { Diameter } \\
(\mu \mathrm{m})\end{array}$ & WS21 & WS21rep & WS21.5 & WS22 & WS23 & WS23.5 & WS24 & WS24.5 & WS24.5rep & WS25 & WS25.5 & WS26 \\
\hline 3.21 & 2.22 & 2.04 & 2.04 & 2.03 & 2.24 & 1.89 & 2.05 & 1.66 & 1.86 & 2.19 & 2.47 & 2.16 \\
\hline 3.52 & 2.12 & 2.03 & 2.05 & 2.01 & 2.13 & 1.89 & 1.95 & 1.64 & 1.80 & 2.10 & 2.42 & 2.16 \\
\hline 3.86 & 2.03 & 2.02 & 2.06 & 1.99 & 2.02 & 1.88 & 1.85 & 1.63 & 1.77 & 2.03 & 2.36 & 2.18 \\
\hline 4.24 & 1.99 & 2.04 & 2.11 & 1.99 & 1.96 & 1.90 & 1.80 & 1.68 & 1.80 & 2.03 & 2.35 & 2.29 \\
\hline 4.66 & 1.98 & 2.05 & 2.16 & 2.00 & 1.92 & 1.92 & 1.78 & 1.77 & 1.90 & 2.08 & 2.37 & 2.46 \\
\hline 5.11 & 2.02 & 2.10 & 2.26 & 2.06 & 1.92 & 1.98 & 1.81 & 1.91 & 2.07 & 2.18 & 2.42 & 2.68 \\
\hline 5.61 & 2.04 & 2.14 & 2.33 & 2.10 & 1.89 & 2.02 & 1.81 & 2.01 & 2.19 & 2.22 & 2.43 & 2.83 \\
\hline 6.16 & 2.07 & 2.20 & 2.42 & 2.18 & 1.87 & 2.08 & 1.84 & 2.10 & 2.30 & 2.24 & 2.44 & 2.95 \\
\hline 6.76 & 2.08 & 2.25 & 2.50 & 2.24 & 1.84 & 2.13 & 1.85 & 2.15 & 2.36 & 2.20 & 2.43 & 2.98 \\
\hline 7.42 & 2.12 & 2.31 & 2.60 & 2.33 & 1.84 & 2.21 & 1.90 & 2.23 & 2.45 & 2.16 & 2.45 & 3.02 \\
\hline 8.15 & 2.18 & 2.35 & 2.69 & 2.42 & 1.85 & 2.28 & 1.94 & 2.33 & 2.56 & 2.12 & 2.47 & 3.05 \\
\hline 8.94 & 2.23 & 2.38 & 2.76 & 2.49 & 1.87 & 2.35 & 1.98 & 2.42 & 2.66 & 2.05 & 2.48 & 3.05 \\
\hline 9.82 & 2.29 & 2.42 & 2.83 & 2.56 & 1.93 & 2.42 & 2.05 & 2.55 & 2.77 & 2.01 & 2.50 & 3.05 \\
\hline 10.78 & 2.34 & 2.47 & 2.88 & 2.58 & 2.00 & 2.46 & 2.12 & 2.67 & 2.82 & 1.99 & 2.49 & 3.01 \\
\hline 11.83 & 2.46 & 2.62 & 2.98 & 2.62 & 2.13 & 2.56 & 2.27 & 2.88 & 2.91 & 2.08 & 2.54 & 3.01 \\
\hline 12.99 & 2.56 & 2.76 & 3.04 & 2.60 & 2.22 & 2.63 & 2.38 & 3.08 & 2.93 & 2.19 & 2.57 & 2.99 \\
\hline 14.26 & 2.65 & 2.89 & 3.07 & 2.53 & 2.28 & 2.69 & 2.47 & 3.28 & 2.92 & 2.33 & 2.60 & 2.95 \\
\hline 15.65 & 2.61 & 2.85 & 2.96 & 2.38 & 2.21 & 2.64 & 2.43 & 3.32 & 2.78 & 2.36 & 2.52 & 2.79 \\
\hline 17.18 & 2.40 & 2.62 & 2.72 & 2.17 & 2.00 & 2.46 & 2.27 & 3.17 & 2.53 & 2.22 & 2.34 & 2.49 \\
\hline 18.86 & 2.11 & 2.26 & 2.43 & 1.97 & 1.73 & 2.22 & 2.08 & 2.87 & 2.25 & 1.96 & 2.10 & 2.10 \\
\hline 20.71 & 1.82 & 1.88 & 2.17 & 1.80 & 1.50 & 1.97 & 1.91 & 2.52 & 1.99 & 1.67 & 1.87 & 1.68 \\
\hline 22.73 & 1.69 & 1.67 & 2.04 & 1.74 & 1.43 & 1.84 & 1.89 & 2.31 & 1.86 & 1.51 & 1.77 & 1.42 \\
\hline 24.95 & 1.73 & 1.67 & 2.02 & 1.76 & 1.51 & 1.85 & 1.98 & 2.27 & 1.86 & 1.50 & 1.78 & 1.33 \\
\hline 27.39 & 1.94 & 1.87 & 2.10 & 1.87 & 1.75 & 2.00 & 2.18 & 2.39 & 1.96 & 1.66 & 1.89 & 1.43 \\
\hline 30.07 & 2.20 & 2.16 & 2.19 & 2.02 & 2.01 & 2.23 & 2.38 & 2.57 & 2.10 & 1.89 & 2.01 & 1.64 \\
\hline 33.01 & 2.38 & 2.38 & 2.23 & 2.19 & 2.21 & 2.43 & 2.53 & 2.67 & 2.21 & 2.09 & 2.05 & 1.81 \\
\hline 36.24 & 2.42 & 2.42 & 2.20 & 2.35 & 2.28 & 2.54 & 2.61 & 2.62 & 2.29 & 2.17 & 2.00 & 1.86 \\
\hline 39.78 & 2.34 & 2.26 & 2.14 & 2.48 & 2.26 & 2.52 & 2.66 & 2.43 & 2.34 & 2.14 & 1.90 & 1.75 \\
\hline 43.67 & 2.25 & 2.02 & 2.10 & 2.56 & 2.23 & 2.42 & 2.73 & 2.22 & 2.40 & 2.10 & 1.84 & 1.57 \\
\hline 47.94 & 2.26 & 1.85 & 2.12 & 2.57 & 2.29 & 2.30 & 2.81 & 2.15 & 2.48 & 2.14 & 1.86 & 1.46 \\
\hline 52.62 & 2.40 & 1.85 & 2.18 & 2.50 & 2.47 & 2.23 & 2.89 & 2.30 & 2.56 & 2.32 & 1.99 & 1.50 \\
\hline 57.77 & 2.66 & 2.06 & 2.24 & 2.37 & 2.76 & 2.26 & 2.92 & 2.67 & 2.62 & 2.63 & 2.18 & 1.74 \\
\hline 63.41 & 2.92 & 2.41 & 2.24 & 2.24 & 3.06 & 2.37 & 2.86 & 3.16 & 2.63 & 2.97 & 2.33 & 2.12 \\
\hline 69.61 & 3.01 & 2.73 & 2.12 & 2.16 & 3.27 & 2.51 & 2.70 & 3.51 & 2.57 & 3.20 & 2.35 & 2.50 \\
\hline 76.42 & 2.81 & 2.81 & 1.88 & 2.15 & 3.27 & 2.58 & 2.47 & 3.45 & 2.46 & 3.21 & 2.20 & 2.69 \\
\hline 83.89 & 2.32 & 2.50 & 1.56 & 2.17 & 3.03 & 2.50 & 2.22 & 2.87 & 2.32 & 2.96 & 1.90 & 2.55 \\
\hline 92.09 & 1.71 & 1.90 & 1.23 & 2.14 & 2.62 & 2.23 & 1.99 & 1.92 & 2.13 & 2.54 & 1.56 & 2.13 \\
\hline 101.10 & 1.18 & 1.22 & 0.96 & 1.94 & 2.16 & 1.80 & 1.77 & 0.94 & 1.85 & 2.08 & 1.26 & 1.57 \\
\hline 110.98 & 0.83 & 0.73 & 0.75 & 1.55 & 1.73 & 1.32 & 1.51 & 0.29 & 1.47 & 1.68 & 1.04 & 1.11 \\
\hline 121.83 & 0.67 & 0.50 & 0.59 & 1.04 & 1.37 & 0.90 & 1.19 & 0.05 & 1.01 & 1.36 & 0.89 & 0.82 \\
\hline 133.74 & 0.61 & 0.45 & 0.45 & 0.58 & 1.06 & 0.60 & 0.82 & 0.00 & 0.53 & 1.09 & 0.75 & 0.69 \\
\hline 146.82 & 0.53 & 0.48 & 0.31 & 0.28 & 0.77 & 0.41 & 0.46 & 0.00 & 0.20 & 0.81 & 0.58 & 0.63 \\
\hline 161.17 & 0.39 & 0.45 & 0.17 & 0.14 & 0.49 & 0.28 & 0.19 & 0.00 & 0.04 & 0.52 & 0.38 & 0.53 \\
\hline
\end{tabular}




\begin{tabular}{|c|c|c|c|c|c|c|c|c|c|c|c|c|}
\hline $\begin{array}{l}\text { Diameter } \\
(\mu \mathrm{m})\end{array}$ & WS21 & WS21rep & WS21.5 & WS22 & WS23 & WS23.5 & WS24 & WS24.5 & WS24.5rep & WS25 & WS25.5 & WS26 \\
\hline 176.93 & 0.21 & 0.31 & 0.06 & 0.09 & 0.24 & 0.17 & 0.05 & 0.00 & 0.00 & 0.26 & 0.19 & 0.34 \\
\hline 194.22 & 0.07 & 0.13 & 0.01 & 0.07 & 0.08 & 0.08 & 0.01 & 0.00 & 0.00 & 0.08 & 0.06 & 0.15 \\
\hline 213.21 & 0.01 & 0.03 & 0.00 & 0.04 & 0.01 & 0.02 & 0.00 & 0.00 & 0.00 & 0.01 & 0.01 & 0.03 \\
\hline 234.05 & 0.00 & 0.00 & 0.00 & 0.01 & 0.00 & 0.00 & 0.00 & 0.00 & 0.00 & 0.00 & 0.00 & 0.00 \\
\hline 256.94 & 0.00 & 0.00 & 0.00 & 0.00 & 0.00 & 0.00 & 0.00 & 0.00 & 0.00 & 0.00 & 0.00 & 0.00 \\
\hline 282.06 & 0.00 & 0.00 & 0.00 & 0.00 & 0.00 & 0.00 & 0.00 & 0.00 & 0.00 & 0.00 & 0.00 & 0.00 \\
\hline 309.63 & 0.00 & 0.00 & 0.00 & 0.00 & 0.00 & 0.00 & 0.00 & 0.00 & 0.00 & 0.00 & 0.00 & 0.00 \\
\hline 339.90 & 0.00 & 0.00 & 0.00 & 0.00 & 0.00 & 0.00 & 0.00 & 0.00 & 0.00 & 0.00 & 0.00 & 0.00 \\
\hline 373.13 & 0.00 & 0.00 & 0.00 & 0.00 & 0.00 & 0.00 & 0.00 & 0.00 & 0.00 & 0.00 & 0.00 & 0.00 \\
\hline 409.61 & 0.00 & 0.00 & 0.00 & 0.00 & 0.00 & 0.00 & 0.00 & 0.00 & 0.00 & 0.00 & 0.00 & 0.00 \\
\hline 449.66 & 0.00 & 0.00 & 0.00 & 0.00 & 0.00 & 0.00 & 0.00 & 0.00 & 0.00 & 0.00 & 0.00 & 0.00 \\
\hline 493.62 & 0.00 & 0.00 & 0.00 & 0.00 & 0.00 & 0.00 & 0.00 & 0.00 & 0.00 & 0.00 & 0.00 & 0.00 \\
\hline 541.88 & 0.00 & 0.00 & 0.00 & 0.00 & 0.00 & 0.00 & 0.00 & 0.00 & 0.00 & 0.00 & 0.00 & 0.00 \\
\hline 594.85 & 0.00 & 0.00 & 0.00 & 0.00 & 0.00 & 0.00 & 0.00 & 0.00 & 0.00 & 0.00 & 0.00 & 0.00 \\
\hline 653.01 & 0.00 & 0.00 & 0.00 & 0.00 & 0.00 & 0.00 & 0.00 & 0.00 & 0.00 & 0.00 & 0.00 & 0.00 \\
\hline 716.85 & 0.00 & 0.00 & 0.00 & 0.00 & 0.00 & 0.00 & 0.00 & 0.00 & 0.00 & 0.00 & 0.00 & 0.00 \\
\hline 786.93 & 0.00 & 0.00 & 0.00 & 0.00 & 0.00 & 0.00 & 0.00 & 0.00 & 0.00 & 0.00 & 0.00 & 0.00 \\
\hline 863.87 & 0.00 & 0.00 & 0.00 & 0.00 & 0.00 & 0.00 & 0.00 & 0.00 & 0.00 & 0.00 & 0.00 & 0.00 \\
\hline 948.32 & 0.00 & 0.00 & 0.00 & 0.00 & 0.00 & 0.00 & 0.00 & 0.00 & 0.00 & 0.00 & 0.00 & 0.00 \\
\hline 1041.03 & 0.00 & 0.00 & 0.00 & 0.00 & 0.00 & 0.00 & 0.00 & 0.00 & 0.00 & 0.00 & 0.00 & 0.00 \\
\hline 1142.81 & 0.00 & 0.00 & 0.00 & 0.00 & 0.00 & 0.00 & 0.00 & 0.00 & 0.00 & 0.00 & 0.00 & 0.00 \\
\hline 1254.54 & 0.00 & 0.00 & 0.00 & 0.00 & 0.00 & 0.00 & 0.00 & 0.00 & 0.00 & 0.00 & 0.00 & 0.00 \\
\hline 1377.19 & 0.00 & 0.00 & 0.00 & 0.00 & 0.00 & 0.00 & 0.00 & 0.00 & 0.00 & 0.00 & 0.00 & 0.00 \\
\hline 1511.83 & 0.00 & 0.00 & 0.00 & 0.00 & 0.00 & 0.00 & 0.00 & 0.00 & 0.00 & 0.00 & 0.00 & 0.00 \\
\hline 1659.63 & 0.00 & 0.00 & 0.00 & 0.00 & 0.00 & 0.00 & 0.00 & 0.00 & 0.00 & 0.00 & 0.00 & 0.00 \\
\hline 1821.88 & 0.00 & 0.00 & 0.00 & 0.00 & 0.00 & 0.00 & 0.00 & 0.00 & 0.00 & 0.00 & 0.00 & 0.00 \\
\hline 2000 & & & & & & & & & & & & \\
\hline
\end{tabular}

\begin{tabular}{|c|c|c|c|c|c|c|c|c|c|c|c|c|}
\hline $\begin{array}{l}\text { Diameter } \\
(\mu \mathrm{m})\end{array}$ & WS26.5 & WS27 & WS27.5 & WS28 & WS28.5 & WS29 & WS29.5 & WS30 & WS30rep & WS30.5 & WS31 & WS31.5 \\
\hline 0.38 & 0.00 & 0.00 & 0.00 & 0.00 & 0.00 & 0.00 & 0.00 & 0.00 & 0.00 & 0.00 & 0.00 & 0.00 \\
\hline 0.41 & 0.00 & 0.00 & 0.00 & 0.00 & 0.00 & 0.00 & 0.00 & 0.00 & 0.00 & 0.00 & 0.00 & 0.00 \\
\hline 0.45 & 0.00 & 0.00 & 0.00 & 0.00 & 0.00 & 0.00 & 0.00 & 0.00 & 0.00 & 0.00 & 0.00 & 0.00 \\
\hline 0.50 & 0.00 & 0.00 & 0.00 & 0.00 & 0.00 & 0.00 & 0.00 & 0.00 & 0.00 & 0.00 & 0.00 & 0.00 \\
\hline 0.54 & 0.00 & 0.00 & 0.00 & 0.00 & 0.00 & 0.00 & 0.00 & 0.00 & 0.00 & 0.00 & 0.00 & 0.00 \\
\hline 0.60 & 0.00 & 0.00 & 0.00 & 0.00 & 0.00 & 0.00 & 0.00 & 0.00 & 0.00 & 0.00 & 0.00 & 0.00 \\
\hline 0.66 & 0.00 & 0.00 & 0.00 & 0.00 & 0.00 & 0.00 & 0.00 & 0.00 & 0.00 & 0.00 & 0.00 & 0.00 \\
\hline 0.72 & 0.00 & 0.00 & 0.00 & 0.00 & 0.00 & 0.00 & 0.00 & 0.00 & 0.00 & 0.00 & 0.00 & 0.00 \\
\hline 0.79 & 0.00 & 0.00 & 0.00 & 0.00 & 0.00 & 0.00 & 0.00 & 0.00 & 0.00 & 0.00 & 0.00 & 0.00 \\
\hline 0.87 & 0.00 & 0.00 & 0.00 & 0.00 & 0.00 & 0.00 & 0.00 & 0.00 & 0.00 & 0.00 & 0.00 & 0.00 \\
\hline 0.95 & 0.00 & 0.00 & 0.00 & 0.00 & 0.00 & 0.00 & 0.00 & 0.00 & 0.00 & 0.00 & 0.00 & 0.00 \\
\hline 1.05 & 0.00 & 0.00 & 0.00 & 0.00 & 0.00 & 0.00 & 0.00 & 0.00 & 0.00 & 0.00 & 0.00 & 0.00 \\
\hline 1.15 & 0.00 & 0.00 & 0.00 & 0.00 & 0.00 & 0.00 & 0.00 & 0.00 & 0.00 & 0.00 & 0.00 & 0.00 \\
\hline
\end{tabular}




\begin{tabular}{|c|c|c|c|c|c|c|c|c|c|c|c|c|}
\hline $\begin{array}{l}\text { Diameter } \\
(\mu \mathrm{m})\end{array}$ & WS26.5 & WS27 & WS27.5 & WS28 & WS28.5 & WS29 & WS29.5 & WS30 & WS30rep & WS30.5 & WS31 & WS31.5 \\
\hline 1.26 & 0.03 & 0.00 & 0.02 & 0.00 & 0.00 & 0.00 & 0.00 & 0.00 & 0.01 & 0.00 & 0.00 & 0.00 \\
\hline 1.38 & 0.13 & 0.00 & 0.11 & 0.01 & 0.00 & 0.02 & 0.00 & 0.03 & 0.08 & 0.00 & 0.03 & 0.00 \\
\hline 1.52 & 0.37 & 0.00 & 0.31 & 0.07 & 0.03 & 0.12 & 0.03 & 0.17 & 0.26 & 0.03 & 0.18 & 0.03 \\
\hline 1.67 & 0.70 & 0.05 & 0.60 & 0.31 & 0.19 & 0.37 & 0.19 & 0.48 & 0.58 & 0.17 & 0.49 & 0.19 \\
\hline 1.83 & 1.05 & 0.27 & 0.93 & 0.77 & 0.54 & 0.78 & 0.52 & 0.93 & 0.97 & 0.50 & 0.92 & 0.54 \\
\hline 2.01 & 1.39 & 0.67 & 1.24 & 1.34 & 1.03 & 1.22 & 0.97 & 1.39 & 1.36 & 0.97 & 1.33 & 1.03 \\
\hline 2.21 & 1.68 & 1.17 & 1.50 & 1.84 & 1.53 & 1.61 & 1.42 & 1.77 & 1.69 & 1.44 & 1.67 & 1.51 \\
\hline 2.42 & 1.88 & 1.58 & 1.69 & 2.19 & 1.93 & 1.90 & 1.78 & 2.02 & 1.92 & 1.82 & 1.90 & 1.89 \\
\hline 2.66 & 2.02 & 1.87 & 1.82 & 2.41 & 2.20 & 2.08 & 2.06 & 2.16 & 2.07 & 2.10 & 2.03 & 2.16 \\
\hline 2.92 & 2.09 & 2.02 & 1.89 & 2.49 & 2.34 & 2.16 & 2.22 & 2.20 & 2.14 & 2.26 & 2.09 & 2.30 \\
\hline 3.21 & 2.10 & 2.06 & 1.91 & 2.47 & 2.39 & 2.17 & 2.31 & 2.19 & 2.17 & 2.35 & 2.10 & 2.35 \\
\hline 3.52 & 2.08 & 2.07 & 1.91 & 2.40 & 2.39 & 2.13 & 2.37 & 2.14 & 2.16 & 2.39 & 2.08 & 2.36 \\
\hline 3.86 & 2.06 & 2.09 & 1.90 & 2.33 & 2.40 & 2.10 & 2.42 & 2.09 & 2.15 & 2.44 & 2.08 & 2.37 \\
\hline 4.24 & 2.08 & 2.20 & 1.93 & 2.34 & 2.50 & 2.12 & 2.54 & 2.12 & 2.19 & 2.56 & 2.12 & 2.48 \\
\hline 4.66 & 2.12 & 2.38 & 1.97 & 2.39 & 2.64 & 2.18 & 2.70 & 2.19 & 2.27 & 2.73 & 2.21 & 2.64 \\
\hline 5.11 & 2.20 & 2.61 & 2.06 & 2.50 & 2.82 & 2.29 & 2.90 & 2.32 & 2.40 & 2.96 & 2.34 & 2.86 \\
\hline 5.61 & 2.26 & 2.78 & 2.11 & 2.55 & 2.93 & 2.36 & 3.03 & 2.41 & 2.51 & 3.12 & 2.44 & 3.02 \\
\hline 6.16 & 2.34 & 2.90 & 2.19 & 2.57 & 2.99 & 2.43 & 3.13 & 2.52 & 2.63 & 3.26 & 2.54 & 3.16 \\
\hline 6.76 & 2.41 & 2.96 & 2.26 & 2.53 & 2.98 & 2.46 & 3.17 & 2.58 & 2.73 & 3.33 & 2.61 & 3.23 \\
\hline 7.42 & 2.51 & 3.04 & 2.36 & 2.52 & 2.97 & 2.53 & 3.22 & 2.70 & 2.87 & 3.43 & 2.72 & 3.32 \\
\hline 8.15 & 2.63 & 3.13 & 2.46 & 2.51 & 2.95 & 2.62 & 3.28 & 2.83 & 3.02 & 3.53 & 2.84 & 3.41 \\
\hline 8.94 & 2.74 & 3.21 & 2.56 & 2.51 & 2.90 & 2.71 & 3.32 & 2.95 & 3.16 & 3.62 & 2.95 & 3.49 \\
\hline 9.82 & 2.86 & 3.30 & 2.68 & 2.52 & 2.87 & 2.83 & 3.37 & 3.09 & 3.30 & 3.72 & 3.08 & 3.56 \\
\hline 10.78 & 2.93 & 3.32 & 2.78 & 2.49 & 2.82 & 2.92 & 3.38 & 3.18 & 3.38 & 3.75 & 3.20 & 3.56 \\
\hline 11.83 & 3.05 & 3.35 & 2.92 & 2.49 & 2.86 & 3.07 & 3.45 & 3.36 & 3.50 & 3.79 & 3.42 & 3.58 \\
\hline 12.99 & 3.09 & 3.30 & 3.00 & 2.44 & 2.90 & 3.15 & 3.48 & 3.51 & 3.55 & 3.73 & 3.59 & 3.53 \\
\hline 14.26 & 3.12 & 3.24 & 3.03 & 2.38 & 2.95 & 3.22 & 3.52 & 3.67 & 3.58 & 3.65 & 3.74 & 3.47 \\
\hline 15.65 & 3.04 & 3.07 & 2.91 & 2.25 & 2.88 & 3.15 & 3.41 & 3.68 & 3.49 & 3.45 & 3.69 & 3.30 \\
\hline 17.18 & 2.85 & 2.80 & 2.69 & 2.08 & 2.65 & 2.97 & 3.15 & 3.51 & 3.28 & 3.19 & 3.44 & 3.06 \\
\hline 18.86 & 2.62 & 2.46 & 2.47 & 1.89 & 2.32 & 2.74 & 2.79 & 3.20 & 3.02 & 2.90 & 3.07 & 2.79 \\
\hline 20.71 & 2.38 & 2.09 & 2.32 & 1.70 & 1.98 & 2.50 & 2.40 & 2.84 & 2.74 & 2.61 & 2.70 & 2.53 \\
\hline 22.73 & 2.25 & 1.85 & 2.31 & 1.58 & 1.79 & 2.38 & 2.16 & 2.62 & 2.59 & 2.44 & 2.52 & 2.37 \\
\hline 24.95 & 2.23 & 1.75 & 2.39 & 1.53 & 1.77 & 2.36 & 2.09 & 2.57 & 2.54 & 2.35 & 2.53 & 2.30 \\
\hline 27.39 & 2.33 & 1.80 & 2.50 & 1.57 & 1.89 & 2.43 & 2.20 & 2.71 & 2.61 & 2.36 & 2.71 & 2.30 \\
\hline 30.07 & 2.48 & 1.96 & 2.53 & 1.67 & 2.03 & 2.53 & 2.36 & 2.90 & 2.70 & 2.39 & 2.90 & 2.32 \\
\hline 33.01 & 2.60 & 2.12 & 2.44 & 1.82 & 2.06 & 2.60 & 2.43 & 2.97 & 2.72 & 2.38 & 2.92 & 2.31 \\
\hline 36.24 & 2.61 & 2.19 & 2.28 & 1.97 & 1.91 & 2.62 & 2.31 & 2.83 & 2.62 & 2.29 & 2.72 & 2.25 \\
\hline 39.78 & 2.47 & 2.11 & 2.14 & 2.09 & 1.65 & 2.56 & 1.99 & 2.45 & 2.38 & 2.08 & 2.33 & 2.13 \\
\hline 43.67 & 2.21 & 1.94 & 2.11 & 2.15 & 1.42 & 2.46 & 1.59 & 1.96 & 2.02 & 1.76 & 1.90 & 1.95 \\
\hline 47.94 & 1.91 & 1.74 & 2.19 & 2.14 & 1.35 & 2.30 & 1.26 & 1.49 & 1.61 & 1.37 & 1.58 & 1.71 \\
\hline 52.62 & 1.65 & 1.60 & 2.33 & 2.09 & 1.48 & 2.10 & 1.11 & 1.18 & 1.22 & 0.98 & 1.44 & 1.41 \\
\hline 57.77 & 1.50 & 1.60 & 2.44 & 2.05 & 1.80 & 1.86 & 1.16 & 1.05 & 0.91 & 0.67 & 1.44 & 1.06 \\
\hline 63.41 & 1.49 & 1.73 & 2.40 & 2.06 & 2.17 & 1.60 & 1.35 & 1.07 & 0.72 & 0.49 & 1.50 & 0.72 \\
\hline
\end{tabular}




\begin{tabular}{|c|c|c|c|c|c|c|c|c|c|c|c|c|}
\hline $\begin{array}{l}\text { Diameter } \\
(\mu \mathrm{m})\end{array}$ & WS26.5 & WS27 & WS27.5 & WS28 & WS28.5 & WS29 & WS29.5 & WS30 & WS30rep & WS30.5 & WS31 & WS31.5 \\
\hline 69.61 & 1.59 & 1.93 & 2.19 & 2.15 & 2.40 & 1.36 & 1.54 & 1.13 & 0.65 & 0.45 & 1.46 & 0.48 \\
\hline 76.42 & 1.71 & 2.08 & 1.88 & 2.29 & 2.32 & 1.17 & 1.57 & 1.11 & 0.66 & 0.50 & 1.24 & 0.35 \\
\hline 83.89 & 1.73 & 2.04 & 1.57 & 2.41 & 1.91 & 1.04 & 1.29 & 0.91 & 0.68 & 0.56 & 0.78 & 0.34 \\
\hline 92.09 & 1.53 & 1.75 & 1.34 & 2.38 & 1.35 & 0.94 & 0.76 & 0.55 & 0.64 & 0.55 & 0.33 & 0.40 \\
\hline 101.10 & 1.14 & 1.27 & 1.21 & 2.13 & 0.87 & 0.82 & 0.28 & 0.21 & 0.50 & 0.39 & 0.07 & 0.45 \\
\hline 110.98 & 0.66 & 0.79 & 1.10 & 1.68 & 0.61 & 0.65 & 0.05 & 0.04 & 0.28 & 0.17 & 0.01 & 0.43 \\
\hline 121.83 & 0.32 & 0.46 & 0.93 & 1.16 & 0.53 & 0.46 & 0.00 & 0.00 & 0.13 & 0.04 & 0.00 & 0.34 \\
\hline 133.74 & 0.16 & 0.31 & 0.67 & 0.72 & 0.55 & 0.30 & 0.00 & 0.00 & 0.06 & 0.00 & 0.00 & 0.23 \\
\hline 146.82 & 0.13 & 0.28 & 0.37 & 0.43 & 0.54 & 0.19 & 0.00 & 0.00 & 0.08 & 0.00 & 0.00 & 0.15 \\
\hline 161.17 & 0.15 & 0.28 & 0.13 & 0.28 & 0.42 & 0.13 & 0.00 & 0.00 & 0.13 & 0.00 & 0.00 & 0.11 \\
\hline 176.93 & 0.17 & 0.24 & 0.02 & 0.19 & 0.23 & 0.10 & 0.00 & 0.00 & 0.17 & 0.00 & 0.00 & 0.09 \\
\hline 194.22 & 0.12 & 0.15 & 0.00 & 0.12 & 0.08 & 0.07 & 0.00 & 0.00 & 0.13 & 0.00 & 0.00 & 0.06 \\
\hline 213.21 & 0.05 & 0.05 & 0.00 & 0.05 & 0.01 & 0.03 & 0.00 & 0.00 & 0.06 & 0.00 & 0.00 & 0.03 \\
\hline 234.05 & 0.01 & 0.01 & 0.00 & 0.01 & 0.00 & 0.01 & 0.00 & 0.00 & 0.01 & 0.00 & 0.00 & 0.01 \\
\hline 256.94 & 0.00 & 0.00 & 0.00 & 0.00 & 0.00 & 0.00 & 0.00 & 0.00 & 0.00 & 0.00 & 0.00 & 0.00 \\
\hline 282.06 & 0.00 & 0.00 & 0.00 & 0.00 & 0.00 & 0.00 & 0.00 & 0.00 & 0.00 & 0.00 & 0.00 & 0.00 \\
\hline 309.63 & 0.00 & 0.00 & 0.00 & 0.00 & 0.00 & 0.00 & 0.00 & 0.00 & 0.00 & 0.00 & 0.00 & 0.00 \\
\hline 339.90 & 0.00 & 0.00 & 0.00 & 0.00 & 0.00 & 0.00 & 0.00 & 0.00 & 0.00 & 0.00 & 0.00 & 0.00 \\
\hline 373.13 & 0.00 & 0.00 & 0.00 & 0.00 & 0.00 & 0.00 & 0.00 & 0.00 & 0.00 & 0.00 & 0.00 & 0.00 \\
\hline 409.61 & 0.00 & 0.00 & 0.00 & 0.00 & 0.00 & 0.00 & 0.00 & 0.00 & 0.00 & 0.00 & 0.00 & 0.00 \\
\hline 449.66 & 0.00 & 0.00 & 0.00 & 0.00 & 0.00 & 0.00 & 0.00 & 0.00 & 0.00 & 0.00 & 0.00 & 0.00 \\
\hline 493.62 & 0.00 & 0.00 & 0.00 & 0.00 & 0.00 & 0.00 & 0.00 & 0.00 & 0.00 & 0.00 & 0.00 & 0.00 \\
\hline 541.88 & 0.00 & 0.00 & 0.00 & 0.00 & 0.00 & 0.00 & 0.00 & 0.00 & 0.00 & 0.00 & 0.00 & 0.00 \\
\hline 594.85 & 0.00 & 0.00 & 0.00 & 0.00 & 0.00 & 0.00 & 0.00 & 0.00 & 0.00 & 0.00 & 0.00 & 0.00 \\
\hline 653.01 & 0.00 & 0.00 & 0.00 & 0.00 & 0.00 & 0.00 & 0.00 & 0.00 & 0.00 & 0.00 & 0.00 & 0.00 \\
\hline 716.85 & 0.00 & 0.00 & 0.00 & 0.00 & 0.00 & 0.00 & 0.00 & 0.00 & 0.00 & 0.00 & 0.00 & 0.00 \\
\hline 786.93 & 0.00 & 0.00 & 0.00 & 0.00 & 0.00 & 0.00 & 0.00 & 0.00 & 0.00 & 0.00 & 0.00 & 0.00 \\
\hline 863.87 & 0.00 & 0.00 & 0.00 & 0.00 & 0.00 & 0.00 & 0.00 & 0.00 & 0.00 & 0.00 & 0.00 & 0.00 \\
\hline 948.32 & 0.00 & 0.00 & 0.00 & 0.00 & 0.00 & 0.00 & 0.00 & 0.00 & 0.00 & 0.00 & 0.00 & 0.00 \\
\hline 1041.03 & 0.00 & 0.00 & 0.00 & 0.00 & 0.00 & 0.00 & 0.00 & 0.00 & 0.00 & 0.00 & 0.00 & 0.00 \\
\hline 1142.81 & 0.00 & 0.00 & 0.00 & 0.00 & 0.00 & 0.00 & 0.00 & 0.00 & 0.00 & 0.00 & 0.00 & 0.00 \\
\hline 1254.54 & 0.00 & 0.00 & 0.00 & 0.00 & 0.00 & 0.00 & 0.00 & 0.00 & 0.00 & 0.00 & 0.00 & 0.00 \\
\hline 1377.19 & 0.00 & 0.00 & 0.00 & 0.00 & 0.00 & 0.00 & 0.00 & 0.00 & 0.00 & 0.00 & 0.00 & 0.00 \\
\hline 1511.83 & 0.00 & 0.00 & 0.00 & 0.00 & 0.00 & 0.00 & 0.00 & 0.00 & 0.00 & 0.00 & 0.00 & 0.00 \\
\hline 1659.63 & 0.00 & 0.00 & 0.00 & 0.00 & 0.00 & 0.00 & 0.00 & 0.00 & 0.00 & 0.00 & 0.00 & 0.00 \\
\hline 1821.88 & 0.00 & 0.00 & 0.00 & 0.00 & 0.00 & 0.00 & 0.00 & 0.00 & 0.00 & 0.00 & 0.00 & 0.00 \\
\hline 2000 & & & & & & & & & & & & \\
\hline
\end{tabular}




\begin{tabular}{|c|c|c|c|c|c|c|c|c|c|c|c|c|}
\hline $\begin{array}{l}\text { Diameter } \\
(\mu \mathrm{m})\end{array}$ & WS32 & WS32.5 & WS33 & WS33.5 & WS34 & WS34.5 & WS34.5rep & WS35 & WS35.5 & WS36 & WS36.5 & WS37 \\
\hline 0.38 & 0.00 & 0.00 & 0.00 & 0.00 & 0.00 & 0.00 & 0.00 & 0.00 & 0.00 & 0.00 & 0.00 & 0.00 \\
\hline 0.41 & 0.00 & 0.00 & 0.00 & 0.00 & 0.00 & 0.00 & 0.00 & 0.00 & 0.00 & 0.00 & 0.00 & 0.00 \\
\hline 0.45 & 0.00 & 0.00 & 0.00 & 0.00 & 0.00 & 0.00 & 0.00 & 0.00 & 0.00 & 0.00 & 0.00 & 0.00 \\
\hline 0.50 & 0.00 & 0.00 & 0.00 & 0.00 & 0.00 & 0.00 & 0.00 & 0.00 & 0.00 & 0.00 & 0.00 & 0.00 \\
\hline 0.54 & 0.00 & 0.00 & 0.00 & 0.00 & 0.00 & 0.00 & 0.00 & 0.00 & 0.00 & 0.00 & 0.00 & 0.00 \\
\hline 0.60 & 0.00 & 0.00 & 0.00 & 0.00 & 0.00 & 0.00 & 0.00 & 0.00 & 0.00 & 0.00 & 0.00 & 0.00 \\
\hline 0.66 & 0.00 & 0.00 & 0.00 & 0.00 & 0.00 & 0.00 & 0.00 & 0.00 & 0.00 & 0.00 & 0.00 & 0.00 \\
\hline 0.72 & 0.00 & 0.00 & 0.00 & 0.00 & 0.00 & 0.00 & 0.00 & 0.00 & 0.00 & 0.00 & 0.00 & 0.00 \\
\hline 0.79 & 0.00 & 0.00 & 0.00 & 0.00 & 0.00 & 0.00 & 0.00 & 0.00 & 0.00 & 0.00 & 0.00 & 0.00 \\
\hline 0.87 & 0.00 & 0.00 & 0.00 & 0.00 & 0.00 & 0.00 & 0.00 & 0.00 & 0.00 & 0.00 & 0.00 & 0.00 \\
\hline 0.95 & 0.00 & 0.00 & 0.00 & 0.00 & 0.00 & 0.00 & 0.00 & 0.00 & 0.00 & 0.00 & 0.00 & 0.00 \\
\hline 1.05 & 0.00 & 0.00 & 0.00 & 0.00 & 0.00 & 0.00 & 0.00 & 0.00 & 0.00 & 0.00 & 0.00 & 0.00 \\
\hline 1.15 & 0.00 & 0.00 & 0.00 & 0.00 & 0.00 & 0.00 & 0.00 & 0.00 & 0.00 & 0.00 & 0.00 & 0.00 \\
\hline 1.26 & 0.00 & 0.00 & 0.00 & 0.00 & 0.00 & 0.00 & 0.00 & 0.00 & 0.00 & 0.01 & 0.00 & 0.02 \\
\hline 1.38 & 0.01 & 0.00 & 0.03 & 0.02 & 0.04 & 0.00 & 0.00 & 0.02 & 0.00 & 0.05 & 0.00 & 0.09 \\
\hline 1.52 & 0.11 & 0.04 & 0.18 & 0.14 & 0.18 & 0.02 & 0.02 & 0.12 & 0.02 & 0.18 & 0.04 & 0.24 \\
\hline 1.67 & 0.41 & 0.22 & 0.49 & 0.43 & 0.46 & 0.13 & 0.12 & 0.38 & 0.14 & 0.41 & 0.20 & 0.47 \\
\hline 1.83 & 0.95 & 0.58 & 0.93 & 0.88 & 0.84 & 0.41 & 0.39 & 0.82 & 0.40 & 0.72 & 0.51 & 0.72 \\
\hline 2.01 & 1.57 & 1.04 & 1.37 & 1.36 & 1.22 & 0.86 & 0.81 & 1.31 & 0.79 & 1.02 & 0.90 & 0.97 \\
\hline 2.21 & 2.10 & 1.47 & 1.74 & 1.79 & 1.54 & 1.34 & 1.26 & 1.72 & 1.19 & 1.28 & 1.24 & 1.17 \\
\hline 2.42 & 2.45 & 1.81 & 1.98 & 2.11 & 1.74 & 1.72 & 1.63 & 1.99 & 1.52 & 1.44 & 1.51 & 1.31 \\
\hline 2.66 & 2.62 & 2.06 & 2.10 & 2.32 & 1.86 & 1.99 & 1.89 & 2.14 & 1.76 & 1.55 & 1.71 & 1.39 \\
\hline 2.92 & 2.64 & 2.21 & 2.13 & 2.42 & 1.91 & 2.12 & 2.04 & 2.17 & 1.91 & 1.60 & 1.83 & 1.43 \\
\hline 3.21 & 2.57 & 2.28 & 2.11 & 2.44 & 1.91 & 2.16 & 2.10 & 2.14 & 2.00 & 1.61 & 1.91 & 1.45 \\
\hline 3.52 & 2.46 & 2.32 & 2.05 & 2.42 & 1.89 & 2.16 & 2.12 & 2.08 & 2.05 & 1.60 & 1.95 & 1.45 \\
\hline 3.86 & 2.39 & 2.35 & 2.00 & 2.39 & 1.88 & 2.18 & 2.16 & 2.04 & 2.10 & 1.59 & 1.99 & 1.45 \\
\hline 4.24 & 2.43 & 2.44 & 2.01 & 2.43 & 1.93 & 2.30 & 2.28 & 2.07 & 2.21 & 1.63 & 2.08 & 1.47 \\
\hline 4.66 & 2.52 & 2.57 & 2.07 & 2.51 & 2.03 & 2.48 & 2.46 & 2.17 & 2.37 & 1.69 & 2.20 & 1.52 \\
\hline 5.11 & 2.68 & 2.75 & 2.19 & 2.64 & 2.19 & 2.74 & 2.70 & 2.35 & 2.57 & 1.82 & 2.37 & 1.61 \\
\hline 5.61 & 2.78 & 2.86 & 2.28 & 2.72 & 2.33 & 2.94 & 2.88 & 2.49 & 2.72 & 1.93 & 2.48 & 1.68 \\
\hline 6.16 & 2.86 & 2.95 & 2.38 & 2.79 & 2.49 & 3.12 & 3.05 & 2.63 & 2.85 & 2.06 & 2.58 & 1.79 \\
\hline 6.76 & 2.85 & 2.98 & 2.46 & 2.82 & 2.62 & 3.23 & 3.15 & 2.72 & 2.93 & 2.18 & 2.64 & 1.87 \\
\hline 7.42 & 2.84 & 3.04 & 2.58 & 2.88 & 2.80 & 3.36 & 3.28 & 2.85 & 3.04 & 2.35 & 2.73 & 2.00 \\
\hline 8.15 & 2.82 & 3.10 & 2.72 & 2.95 & 2.95 & 3.51 & 3.43 & 2.98 & 3.16 & 2.55 & 2.82 & 2.12 \\
\hline 8.94 & 2.78 & 3.15 & 2.84 & 2.99 & 3.06 & 3.66 & 3.59 & 3.10 & 3.28 & 2.77 & 2.90 & 2.26 \\
\hline 9.82 & 2.82 & 3.22 & 2.98 & 3.04 & 3.14 & 3.81 & 3.77 & 3.24 & 3.42 & 3.02 & 2.99 & 2.43 \\
\hline 10.78 & 2.90 & 3.26 & 3.08 & 3.06 & 3.17 & 3.89 & 3.89 & 3.34 & 3.50 & 3.22 & 3.04 & 2.59 \\
\hline 11.83 & 3.16 & 3.39 & 3.24 & 3.16 & 3.31 & 3.99 & 4.06 & 3.51 & 3.62 & 3.47 & 3.15 & 2.81 \\
\hline 12.99 & 3.43 & 3.49 & 3.34 & 3.26 & 3.46 & 4.00 & 4.14 & 3.60 & 3.67 & 3.62 & 3.22 & 2.97 \\
\hline 14.26 & 3.66 & 3.58 & 3.41 & 3.39 & 3.63 & 3.98 & 4.18 & 3.66 & 3.69 & 3.72 & 3.30 & 3.09 \\
\hline 15.65 & 3.64 & 3.51 & 3.32 & 3.39 & 3.66 & 3.84 & 4.04 & 3.55 & 3.57 & 3.68 & 3.25 & 3.05 \\
\hline 17.18 & 3.35 & 3.31 & 3.08 & 3.23 & 3.51 & 3.59 & 3.76 & 3.32 & 3.31 & 3.52 & 3.08 & 2.89 \\
\hline 18.86 & 2.90 & 3.02 & 2.79 & 2.96 & 3.24 & 3.29 & 3.42 & 3.07 & 3.00 & 3.34 & 2.84 & 2.68 \\
\hline
\end{tabular}




\begin{tabular}{|c|c|c|c|c|c|c|c|c|c|c|c|c|}
\hline $\begin{array}{l}\text { Diameter } \\
(\mu \mathrm{m})\end{array}$ & WS32 & WS32.5 & WS33 & WS33.5 & WS34 & WS34.5 & WS34.5rep & WS35 & WS35.5 & WS36 & WS36.5 & WS37 \\
\hline 20.71 & 2.45 & 2.75 & 2.55 & 2.66 & 2.94 & 2.97 & 3.06 & 2.86 & 2.69 & 3.19 & 2.59 & 2.48 \\
\hline 22.73 & 2.24 & 2.62 & 2.50 & 2.49 & 2.79 & 2.73 & 2.80 & 2.80 & 2.52 & 3.18 & 2.48 & 2.43 \\
\hline 24.95 & 2.25 & 2.61 & 2.62 & 2.46 & 2.80 & 2.54 & 2.62 & 2.83 & 2.47 & 3.25 & 2.48 & 2.51 \\
\hline 27.39 & 2.46 & 2.70 & 2.84 & 2.54 & 2.93 & 2.43 & 2.51 & 2.90 & 2.52 & 3.39 & 2.61 & 2.72 \\
\hline 30.07 & 2.67 & 2.74 & 3.02 & 2.62 & 3.04 & 2.36 & 2.40 & 2.89 & 2.59 & 3.50 & 2.76 & 2.99 \\
\hline 33.01 & 2.70 & 2.64 & 3.04 & 2.57 & 3.01 & 2.32 & 2.27 & 2.77 & 2.59 & 3.50 & 2.83 & 3.23 \\
\hline 36.24 & 2.49 & 2.39 & 2.88 & 2.36 & 2.79 & 2.29 & 2.13 & 2.58 & 2.49 & 3.38 & 2.79 & 3.38 \\
\hline 39.78 & 2.09 & 2.08 & 2.63 & 2.05 & 2.47 & 2.24 & 1.98 & 2.39 & 2.31 & 3.15 & 2.62 & 3.42 \\
\hline 43.67 & 1.67 & 1.81 & 2.41 & 1.76 & 2.16 & 2.12 & 1.85 & 2.24 & 2.11 & 2.84 & 2.41 & 3.34 \\
\hline 47.94 & 1.37 & 1.64 & 2.28 & 1.59 & 1.95 & 1.88 & 1.70 & 2.12 & 1.94 & 2.44 & 2.21 & 3.16 \\
\hline 52.62 & 1.25 & 1.58 & 2.22 & 1.56 & 1.85 & 1.50 & 1.49 & 1.97 & 1.80 & 1.97 & 2.04 & 2.92 \\
\hline 57.77 & 1.27 & 1.55 & 2.15 & 1.59 & 1.79 & 1.03 & 1.18 & 1.70 & 1.69 & 1.47 & 1.91 & 2.66 \\
\hline 63.41 & 1.31 & 1.46 & 1.95 & 1.58 & 1.67 & 0.54 & 0.79 & 1.28 & 1.55 & 0.98 & 1.79 & 2.41 \\
\hline 69.61 & 1.24 & 1.22 & 1.57 & 1.42 & 1.39 & 0.20 & 0.41 & 0.73 & 1.36 & 0.63 & 1.62 & 2.21 \\
\hline 76.42 & 0.99 & 0.78 & 0.96 & 1.04 & 0.89 & 0.04 & 0.14 & 0.28 & 1.09 & 0.44 & 1.39 & 2.03 \\
\hline 83.89 & 0.58 & 0.33 & 0.40 & 0.55 & 0.39 & 0.00 & 0.03 & 0.05 & 0.77 & 0.39 & 1.10 & 1.85 \\
\hline 92.09 & 0.22 & 0.07 & 0.08 & 0.18 & 0.08 & 0.00 & 0.00 & 0.00 & 0.45 & 0.44 & 0.81 & 1.60 \\
\hline 101.10 & 0.04 & 0.01 & 0.01 & 0.03 & 0.01 & 0.00 & 0.00 & 0.00 & 0.20 & 0.50 & 0.57 & 1.27 \\
\hline 110.98 & 0.00 & 0.00 & 0.00 & 0.00 & 0.00 & 0.00 & 0.00 & 0.00 & 0.06 & 0.49 & 0.40 & 0.89 \\
\hline 121.83 & 0.00 & 0.00 & 0.00 & 0.00 & 0.00 & 0.00 & 0.00 & 0.00 & 0.01 & 0.39 & 0.32 & 0.55 \\
\hline 133.74 & 0.00 & 0.00 & 0.00 & 0.00 & 0.00 & 0.00 & 0.00 & 0.00 & 0.00 & 0.27 & 0.27 & 0.32 \\
\hline 146.82 & 0.00 & 0.00 & 0.00 & 0.00 & 0.00 & 0.00 & 0.00 & 0.00 & 0.00 & 0.18 & 0.23 & 0.20 \\
\hline 161.17 & 0.00 & 0.00 & 0.00 & 0.00 & 0.00 & 0.00 & 0.00 & 0.00 & 0.00 & 0.14 & 0.17 & 0.16 \\
\hline 176.93 & 0.00 & 0.00 & 0.00 & 0.00 & 0.00 & 0.00 & 0.00 & 0.00 & 0.00 & 0.12 & 0.10 & 0.13 \\
\hline 194.22 & 0.00 & 0.00 & 0.00 & 0.00 & 0.00 & 0.00 & 0.00 & 0.00 & 0.00 & 0.08 & 0.04 & 0.09 \\
\hline 213.21 & 0.00 & 0.00 & 0.00 & 0.00 & 0.00 & 0.00 & 0.00 & 0.00 & 0.00 & 0.04 & 0.01 & 0.04 \\
\hline 234.05 & 0.00 & 0.00 & 0.00 & 0.00 & 0.00 & 0.00 & 0.00 & 0.00 & 0.00 & 0.01 & 0.00 & 0.01 \\
\hline 256.94 & 0.00 & 0.00 & 0.00 & 0.00 & 0.00 & 0.00 & 0.00 & 0.00 & 0.00 & 0.00 & 0.00 & 0.00 \\
\hline 282.06 & 0.00 & 0.00 & 0.00 & 0.00 & 0.00 & 0.00 & 0.00 & 0.00 & 0.00 & 0.00 & 0.00 & 0.00 \\
\hline 309.63 & 0.00 & 0.00 & 0.00 & 0.00 & 0.00 & 0.00 & 0.00 & 0.00 & 0.00 & 0.00 & 0.00 & 0.00 \\
\hline 339.90 & 0.00 & 0.00 & 0.00 & 0.00 & 0.00 & 0.00 & 0.00 & 0.00 & 0.00 & 0.00 & 0.00 & 0.00 \\
\hline 373.13 & 0.00 & 0.00 & 0.00 & 0.00 & 0.00 & 0.00 & 0.00 & 0.00 & 0.00 & 0.00 & 0.00 & 0.00 \\
\hline 409.61 & 0.00 & 0.00 & 0.00 & 0.00 & 0.00 & 0.00 & 0.00 & 0.00 & 0.00 & 0.00 & 0.00 & 0.00 \\
\hline 449.66 & 0.00 & 0.00 & 0.00 & 0.00 & 0.00 & 0.00 & 0.00 & 0.00 & 0.00 & 0.00 & 0.00 & 0.00 \\
\hline 493.62 & 0.00 & 0.00 & 0.00 & 0.00 & 0.00 & 0.00 & 0.00 & 0.00 & 0.00 & 0.00 & 0.00 & 0.00 \\
\hline 541.88 & 0.00 & 0.00 & 0.00 & 0.00 & 0.00 & 0.00 & 0.00 & 0.00 & 0.00 & 0.00 & 0.00 & 0.00 \\
\hline 594.85 & 0.00 & 0.00 & 0.00 & 0.00 & 0.00 & 0.00 & 0.00 & 0.00 & 0.00 & 0.00 & 0.00 & 0.00 \\
\hline 653.01 & 0.00 & 0.00 & 0.00 & 0.00 & 0.00 & 0.00 & 0.00 & 0.00 & 0.00 & 0.00 & 0.00 & 0.00 \\
\hline 716.85 & 0.00 & 0.00 & 0.00 & 0.00 & 0.00 & 0.00 & 0.00 & 0.00 & 0.00 & 0.00 & 0.00 & 0.00 \\
\hline 786.93 & 0.00 & 0.00 & 0.00 & 0.00 & 0.00 & 0.00 & 0.00 & 0.00 & 0.00 & 0.00 & 0.00 & 0.00 \\
\hline 863.87 & 0.00 & 0.00 & 0.00 & 0.00 & 0.00 & 0.00 & 0.00 & 0.00 & 0.00 & 0.00 & 0.00 & 0.00 \\
\hline 948.32 & 0.00 & 0.00 & 0.00 & 0.00 & 0.00 & 0.00 & 0.00 & 0.00 & 0.00 & 0.00 & 0.00 & 0.00 \\
\hline 1041.03 & 0.00 & 0.00 & 0.00 & 0.00 & 0.00 & 0.00 & 0.00 & 0.00 & 0.00 & 0.00 & 0.00 & 0.00 \\
\hline
\end{tabular}




\begin{tabular}{|c|c|c|c|c|c|c|c|c|c|c|c|c|}
\hline $\begin{array}{l}\text { Diameter } \\
(\mu \mathrm{m})\end{array}$ & WS32 & WS32.5 & WS33 & WS33.5 & WS34 & WS34.5 & WS34.5rep & WS35 & WS35.5 & WS36 & WS36.5 & WS37 \\
\hline 1142.81 & 0.00 & 0.00 & 0.00 & 0.00 & 0.00 & 0.00 & 0.00 & 0.00 & 0.00 & 0.00 & 0.00 & 0.00 \\
\hline 1254.54 & 0.00 & 0.00 & 0.00 & 0.00 & 0.00 & 0.00 & 0.00 & 0.00 & 0.00 & 0.00 & 0.00 & 0.00 \\
\hline 1377.19 & 0.00 & 0.00 & 0.00 & 0.00 & 0.00 & 0.00 & 0.00 & 0.00 & 0.00 & 0.00 & 0.00 & 0.00 \\
\hline 1511.83 & 0.00 & 0.00 & 0.00 & 0.00 & 0.00 & 0.00 & 0.00 & 0.00 & 0.00 & 0.00 & 0.00 & 0.00 \\
\hline 1659.63 & 0.00 & 0.00 & 0.00 & 0.00 & 0.00 & 0.00 & 0.00 & 0.00 & 0.00 & 0.00 & 0.00 & 0.00 \\
\hline 1821.88 & 0.00 & 0.00 & 0.00 & 0.00 & 0.00 & 0.00 & 0.00 & 0.00 & 0.00 & 0.00 & 0.00 & 0.00 \\
\hline 2000 & & & & & & & & & & & & \\
\hline
\end{tabular}

\begin{tabular}{|c|c|c|c|c|c|c|c|c|c|c|c|c|}
\hline $\begin{array}{l}\text { Diameter } \\
(\mu \mathrm{m})\end{array}$ & WS37.5 & WS38 & WS38.5 & WS39 & WS39.5 & WS40 & WS40.5 & WS41 & WS41.5 & WS42 & WS42rep & WS42.5 \\
\hline 0.38 & 0.00 & 0.00 & 0.00 & 0.00 & 0.00 & 0.00 & 0.00 & 0.00 & 0.00 & 0.00 & 0.00 & 0.00 \\
\hline 0.41 & 0.00 & 0.00 & 0.00 & 0.00 & 0.00 & 0.00 & 0.00 & 0.00 & 0.00 & 0.00 & 0.00 & 0.00 \\
\hline 0.45 & 0.00 & 0.00 & 0.00 & 0.00 & 0.00 & 0.00 & 0.00 & 0.00 & 0.00 & 0.00 & 0.00 & 0.00 \\
\hline 0.50 & 0.00 & 0.00 & 0.00 & 0.00 & 0.00 & 0.00 & 0.00 & 0.00 & 0.00 & 0.00 & 0.00 & 0.00 \\
\hline 0.54 & 0.00 & 0.00 & 0.00 & 0.00 & 0.00 & 0.00 & 0.00 & 0.00 & 0.00 & 0.00 & 0.00 & 0.00 \\
\hline 0.60 & 0.00 & 0.00 & 0.00 & 0.00 & 0.00 & 0.00 & 0.00 & 0.00 & 0.00 & 0.00 & 0.00 & 0.00 \\
\hline 0.66 & 0.00 & 0.00 & 0.00 & 0.00 & 0.00 & 0.00 & 0.00 & 0.00 & 0.00 & 0.00 & 0.00 & 0.00 \\
\hline 0.72 & 0.00 & 0.00 & 0.00 & 0.00 & 0.00 & 0.00 & 0.00 & 0.00 & 0.00 & 0.00 & 0.00 & 0.00 \\
\hline 0.79 & 0.00 & 0.00 & 0.00 & 0.00 & 0.00 & 0.00 & 0.00 & 0.00 & 0.00 & 0.00 & 0.00 & 0.00 \\
\hline 0.87 & 0.00 & 0.00 & 0.00 & 0.00 & 0.00 & 0.00 & 0.00 & 0.00 & 0.00 & 0.00 & 0.00 & 0.00 \\
\hline 0.95 & 0.00 & 0.00 & 0.00 & 0.00 & 0.00 & 0.00 & 0.00 & 0.00 & 0.00 & 0.00 & 0.00 & 0.00 \\
\hline 1.05 & 0.00 & 0.00 & 0.00 & 0.00 & 0.00 & 0.00 & 0.00 & 0.00 & 0.00 & 0.00 & 0.00 & 0.00 \\
\hline 1.15 & 0.00 & 0.00 & 0.00 & 0.00 & 0.00 & 0.00 & 0.00 & 0.00 & 0.00 & 0.00 & 0.00 & 0.00 \\
\hline 1.26 & 0.00 & 0.00 & 0.00 & 0.01 & 0.02 & 0.01 & 0.00 & 0.01 & 0.02 & 0.01 & 0.01 & 0.02 \\
\hline 1.38 & 0.00 & 0.03 & 0.01 & 0.05 & 0.09 & 0.08 & 0.01 & 0.05 & 0.09 & 0.06 & 0.07 & 0.09 \\
\hline 1.52 & 0.03 & 0.17 & 0.08 & 0.18 & 0.25 & 0.23 & 0.09 & 0.17 & 0.25 & 0.21 & 0.22 & 0.27 \\
\hline 1.67 & 0.16 & 0.46 & 0.29 & 0.45 & 0.49 & 0.47 & 0.30 & 0.38 & 0.48 & 0.46 & 0.49 & 0.54 \\
\hline 1.83 & 0.44 & 0.88 & 0.65 & 0.80 & 0.75 & 0.73 & 0.64 & 0.64 & 0.74 & 0.78 & 0.82 & 0.84 \\
\hline 2.01 & 0.80 & 1.28 & 1.06 & 1.14 & 1.00 & 0.98 & 1.02 & 0.90 & 0.99 & 1.09 & 1.14 & 1.13 \\
\hline 2.21 & 1.13 & 1.60 & 1.44 & 1.41 & 1.22 & 1.19 & 1.37 & 1.12 & 1.21 & 1.34 & 1.40 & 1.38 \\
\hline 2.42 & 1.39 & 1.79 & 1.72 & 1.59 & 1.38 & 1.33 & 1.64 & 1.28 & 1.37 & 1.49 & 1.57 & 1.55 \\
\hline 2.66 & 1.58 & 1.88 & 1.93 & 1.68 & 1.50 & 1.42 & 1.83 & 1.39 & 1.49 & 1.58 & 1.68 & 1.68 \\
\hline 2.92 & 1.67 & 1.89 & 2.05 & 1.70 & 1.57 & 1.46 & 1.94 & 1.45 & 1.57 & 1.61 & 1.72 & 1.74 \\
\hline 3.21 & 1.72 & 1.84 & 2.11 & 1.68 & 1.61 & 1.48 & 2.00 & 1.48 & 1.61 & 1.61 & 1.73 & 1.78 \\
\hline 3.52 & 1.73 & 1.78 & 2.12 & 1.64 & 1.63 & 1.48 & 2.02 & 1.48 & 1.64 & 1.59 & 1.72 & 1.78 \\
\hline 3.86 & 1.74 & 1.75 & 2.13 & 1.61 & 1.64 & 1.49 & 2.03 & 1.49 & 1.66 & 1.58 & 1.72 & 1.79 \\
\hline 4.24 & 1.80 & 1.77 & 2.19 & 1.63 & 1.68 & 1.52 & 2.09 & 1.53 & 1.72 & 1.62 & 1.76 & 1.84 \\
\hline 4.66 & 1.90 & 1.84 & 2.28 & 1.68 & 1.74 & 1.58 & 2.17 & 1.58 & 1.79 & 1.68 & 1.83 & 1.91 \\
\hline 5.11 & 2.04 & 1.96 & 2.41 & 1.78 & 1.84 & 1.68 & 2.30 & 1.68 & 1.91 & 1.80 & 1.97 & 2.03 \\
\hline 5.61 & 2.13 & 2.05 & 2.49 & 1.86 & 1.92 & 1.76 & 2.38 & 1.75 & 2.00 & 1.89 & 2.08 & 2.12 \\
\hline 6.16 & 2.21 & 2.16 & 2.57 & 1.95 & 2.01 & 1.88 & 2.47 & 1.84 & 2.12 & 2.00 & 2.22 & 2.24 \\
\hline 6.76 & 2.24 & 2.23 & 2.61 & 2.02 & 2.10 & 1.96 & 2.52 & 1.91 & 2.22 & 2.08 & 2.33 & 2.34 \\
\hline 7.42 & 2.29 & 2.32 & 2.68 & 2.12 & 2.23 & 2.09 & 2.61 & 2.02 & 2.37 & 2.19 & 2.49 & 2.49 \\
\hline
\end{tabular}




\begin{tabular}{|c|c|c|c|c|c|c|c|c|c|c|c|c|}
\hline $\begin{array}{l}\text { Diameter } \\
(\mu \mathrm{m})\end{array}$ & WS37.5 & WS38 & WS38.5 & WS39 & WS39.5 & WS40 & WS40.5 & WS41 & WS41.5 & WS42 & WS42rep & WS42.5 \\
\hline 8.15 & 2.34 & 2.39 & 2.76 & 2.22 & 2.38 & 2.22 & 2.72 & 2.14 & 2.53 & 2.29 & 2.65 & 2.63 \\
\hline 8.94 & 2.39 & 2.42 & 2.85 & 2.33 & 2.52 & 2.34 & 2.85 & 2.27 & 2.69 & 2.38 & 2.82 & 2.77 \\
\hline 9.82 & 2.46 & 2.48 & 2.95 & 2.47 & 2.69 & 2.49 & 3.00 & 2.42 & 2.87 & 2.50 & 3.00 & 2.91 \\
\hline 10.78 & 2.51 & 2.57 & 3.02 & 2.61 & 2.85 & 2.62 & 3.13 & 2.55 & 3.01 & 2.63 & 3.15 & 3.03 \\
\hline 11.83 & 2.63 & 2.82 & 3.13 & 2.85 & 3.08 & 2.85 & 3.33 & 2.76 & 3.21 & 2.87 & 3.35 & 3.21 \\
\hline 12.99 & 2.72 & 3.10 & 3.19 & 3.06 & 3.28 & 3.04 & 3.47 & 2.94 & 3.35 & 3.10 & 3.48 & 3.35 \\
\hline 14.26 & 2.82 & 3.40 & 3.24 & 3.24 & 3.48 & 3.23 & 3.59 & 3.12 & 3.46 & 3.33 & 3.57 & 3.49 \\
\hline 15.65 & 2.79 & 3.50 & 3.18 & 3.26 & 3.51 & 3.27 & 3.58 & 3.16 & 3.41 & 3.38 & 3.50 & 3.47 \\
\hline 17.18 & 2.64 & 3.34 & 3.03 & 3.10 & 3.38 & 3.13 & 3.43 & 3.05 & 3.24 & 3.23 & 3.29 & 3.30 \\
\hline 18.86 & 2.42 & 2.98 & 2.82 & 2.83 & 3.12 & 2.88 & 3.19 & 2.83 & 3.00 & 2.92 & 3.05 & 3.04 \\
\hline 20.71 & 2.20 & 2.58 & 2.60 & 2.54 & 2.84 & 2.59 & 2.92 & 2.56 & 2.75 & 2.58 & 2.83 & 2.75 \\
\hline 22.73 & 2.12 & 2.37 & 2.48 & 2.41 & 2.71 & 2.44 & 2.76 & 2.44 & 2.64 & 2.40 & 2.76 & 2.60 \\
\hline 24.95 & 2.17 & 2.37 & 2.44 & 2.46 & 2.73 & 2.47 & 2.71 & 2.49 & 2.63 & 2.44 & 2.81 & 2.58 \\
\hline 27.39 & 2.34 & 2.59 & 2.50 & 2.70 & 2.89 & 2.70 & 2.79 & 2.78 & 2.73 & 2.70 & 2.95 & 2.69 \\
\hline 30.07 & 2.54 & 2.87 & 2.60 & 3.03 & 3.07 & 3.03 & 2.90 & 3.20 & 2.82 & 3.07 & 3.08 & 2.82 \\
\hline 33.01 & 2.67 & 3.05 & 2.68 & 3.31 & 3.13 & 3.32 & 2.96 & 3.60 & 2.85 & 3.38 & 3.11 & 2.86 \\
\hline 36.24 & 2.69 & 3.00 & 2.67 & 3.43 & 3.01 & 3.46 & 2.88 & 3.83 & 2.79 & 3.49 & 3.03 & 2.76 \\
\hline 39.78 & 2.64 & 2.74 & 2.57 & 3.35 & 2.73 & 3.37 & 2.63 & 3.78 & 2.65 & 3.33 & 2.86 & 2.54 \\
\hline 43.67 & 2.58 & 2.41 & 2.37 & 3.09 & 2.42 & 3.12 & 2.28 & 3.49 & 2.49 & 3.00 & 2.64 & 2.29 \\
\hline 47.94 & 2.57 & 2.15 & 2.09 & 2.75 & 2.19 & 2.80 & 1.89 & 3.09 & 2.35 & 2.63 & 2.41 & 2.08 \\
\hline 52.62 & 2.64 & 2.05 & 1.79 & 2.43 & 2.11 & 2.51 & 1.56 & 2.72 & 2.23 & 2.36 & 2.19 & 1.95 \\
\hline 57.77 & 2.75 & 2.10 & 1.51 & 2.20 & 2.15 & 2.34 & 1.33 & 2.49 & 2.12 & 2.24 & 1.96 & 1.89 \\
\hline 63.41 & 2.83 & 2.22 & 1.30 & 2.09 & 2.22 & 2.28 & 1.23 & 2.42 & 1.99 & 2.25 & 1.73 & 1.84 \\
\hline 69.61 & 2.80 & 2.25 & 1.20 & 2.07 & 2.17 & 2.27 & 1.22 & 2.42 & 1.81 & 2.30 & 1.49 & 1.72 \\
\hline 76.42 & 2.61 & 2.04 & 1.18 & 2.04 & 1.92 & 2.21 & 1.21 & 2.36 & 1.58 & 2.24 & 1.23 & 1.49 \\
\hline 83.89 & 2.28 & 1.57 & 1.18 & 1.88 & 1.45 & 1.97 & 1.13 & 2.09 & 1.33 & 1.92 & 0.95 & 1.16 \\
\hline 92.09 & 1.87 & 0.96 & 1.11 & 1.54 & 0.91 & 1.53 & 0.92 & 1.57 & 1.09 & 1.37 & 0.65 & 0.82 \\
\hline 101.10 & 1.47 & 0.46 & 0.93 & 1.04 & 0.50 & 0.97 & 0.59 & 0.87 & 0.87 & 0.71 & 0.35 & 0.56 \\
\hline 110.98 & 1.13 & 0.22 & 0.64 & 0.52 & 0.30 & 0.48 & 0.28 & 0.33 & 0.69 & 0.25 & 0.13 & 0.41 \\
\hline 121.83 & 0.85 & 0.17 & 0.37 & 0.18 & 0.26 & 0.22 & 0.08 & 0.06 & 0.54 & 0.04 & 0.03 & 0.35 \\
\hline 133.74 & 0.63 & 0.23 & 0.20 & 0.03 & 0.31 & 0.14 & 0.01 & 0.00 & 0.41 & 0.00 & 0.00 & 0.34 \\
\hline 146.82 & 0.44 & 0.32 & 0.13 & 0.00 & 0.37 & 0.18 & 0.00 & 0.00 & 0.30 & 0.00 & 0.00 & 0.31 \\
\hline 161.17 & 0.27 & 0.32 & 0.13 & 0.00 & 0.34 & 0.24 & 0.00 & 0.00 & 0.19 & 0.00 & 0.00 & 0.23 \\
\hline 176.93 & 0.13 & 0.20 & 0.14 & 0.00 & 0.21 & 0.25 & 0.00 & 0.00 & 0.10 & 0.00 & 0.00 & 0.13 \\
\hline 194.22 & 0.04 & 0.08 & 0.11 & 0.00 & 0.09 & 0.16 & 0.00 & 0.00 & 0.04 & 0.00 & 0.00 & 0.04 \\
\hline 213.21 & 0.01 & 0.01 & 0.06 & 0.00 & 0.02 & 0.06 & 0.00 & 0.00 & 0.01 & 0.00 & 0.00 & 0.01 \\
\hline 234.05 & 0.00 & 0.00 & 0.01 & 0.00 & 0.00 & 0.01 & 0.00 & 0.00 & 0.00 & 0.00 & 0.00 & 0.00 \\
\hline 256.94 & 0.00 & 0.00 & 0.00 & 0.00 & 0.00 & 0.00 & 0.00 & 0.00 & 0.00 & 0.00 & 0.00 & 0.00 \\
\hline 282.06 & 0.00 & 0.00 & 0.00 & 0.00 & 0.00 & 0.00 & 0.00 & 0.00 & 0.00 & 0.00 & 0.00 & 0.00 \\
\hline 309.63 & 0.00 & 0.00 & 0.00 & 0.00 & 0.00 & 0.00 & 0.00 & 0.00 & 0.00 & 0.00 & 0.00 & 0.00 \\
\hline 339.90 & 0.00 & 0.00 & 0.00 & 0.00 & 0.00 & 0.00 & 0.00 & 0.00 & 0.00 & 0.00 & 0.00 & 0.00 \\
\hline 373.13 & 0.00 & 0.00 & 0.00 & 0.00 & 0.00 & 0.00 & 0.00 & 0.00 & 0.00 & 0.00 & 0.00 & 0.00 \\
\hline 409.61 & 0.00 & 0.00 & 0.00 & 0.00 & 0.00 & 0.00 & 0.00 & 0.00 & 0.00 & 0.00 & 0.00 & 0.00 \\
\hline
\end{tabular}




\begin{tabular}{|c|c|c|c|c|c|c|c|c|c|c|c|c|}
\hline $\begin{array}{l}\text { Diameter } \\
(\mu \mathrm{m})\end{array}$ & WS37.5 & WS38 & WS38.5 & WS39 & WS39.5 & WS40 & WS40.5 & WS41 & WS41.5 & WS42 & WS42rep & WS42.5 \\
\hline 449.66 & 0.00 & 0.00 & 0.00 & 0.00 & 0.00 & 0.00 & 0.00 & 0.00 & 0.00 & 0.00 & 0.00 & 0.00 \\
\hline 493.62 & 0.00 & 0.00 & 0.00 & 0.00 & 0.00 & 0.00 & 0.00 & 0.00 & 0.00 & 0.00 & 0.00 & 0.00 \\
\hline 541.88 & 0.00 & 0.00 & 0.00 & 0.00 & 0.00 & 0.00 & 0.00 & 0.00 & 0.00 & 0.00 & 0.00 & 0.00 \\
\hline 594.85 & 0.00 & 0.00 & 0.00 & 0.00 & 0.00 & 0.00 & 0.00 & 0.00 & 0.00 & 0.00 & 0.00 & 0.00 \\
\hline 653.01 & 0.00 & 0.00 & 0.00 & 0.00 & 0.00 & 0.00 & 0.00 & 0.00 & 0.00 & 0.00 & 0.00 & 0.00 \\
\hline 716.85 & 0.00 & 0.00 & 0.00 & 0.00 & 0.00 & 0.00 & 0.00 & 0.00 & 0.00 & 0.00 & 0.00 & 0.00 \\
\hline 786.93 & 0.00 & 0.00 & 0.00 & 0.00 & 0.00 & 0.00 & 0.00 & 0.00 & 0.00 & 0.00 & 0.00 & 0.00 \\
\hline 863.87 & 0.00 & 0.00 & 0.00 & 0.00 & 0.00 & 0.00 & 0.00 & 0.00 & 0.00 & 0.00 & 0.00 & 0.00 \\
\hline 948.32 & 0.00 & 0.00 & 0.00 & 0.00 & 0.00 & 0.00 & 0.00 & 0.00 & 0.00 & 0.00 & 0.00 & 0.00 \\
\hline 1041.03 & 0.00 & 0.00 & 0.00 & 0.00 & 0.00 & 0.00 & 0.00 & 0.00 & 0.00 & 0.00 & 0.00 & 0.00 \\
\hline 1142.81 & 0.00 & 0.00 & 0.00 & 0.00 & 0.00 & 0.00 & 0.00 & 0.00 & 0.00 & 0.00 & 0.00 & 0.00 \\
\hline 1254.54 & 0.00 & 0.00 & 0.00 & 0.00 & 0.00 & 0.00 & 0.00 & 0.00 & 0.00 & 0.00 & 0.00 & 0.00 \\
\hline 1377.19 & 0.00 & 0.00 & 0.00 & 0.00 & 0.00 & 0.00 & 0.00 & 0.00 & 0.00 & 0.00 & 0.00 & 0.00 \\
\hline 1511.83 & 0.00 & 0.00 & 0.00 & 0.00 & 0.00 & 0.00 & 0.00 & 0.00 & 0.00 & 0.00 & 0.00 & 0.00 \\
\hline 1659.63 & 0.00 & 0.00 & 0.00 & 0.00 & 0.00 & 0.00 & 0.00 & 0.00 & 0.00 & 0.00 & 0.00 & 0.00 \\
\hline 1821.88 & 0.00 & 0.00 & 0.00 & 0.00 & 0.00 & 0.00 & 0.00 & 0.00 & 0.00 & 0.00 & 0.00 & 0.00 \\
\hline 2000 & & & & & & & & & & & & \\
\hline
\end{tabular}

\begin{tabular}{|c|c|c|c|c|c|c|c|c|c|c|c|c|}
\hline $\begin{array}{l}\text { Diameter } \\
(\mu \mathrm{m})\end{array}$ & WS43 & WS43.5 & WS44 & WS44.5 & WS44.5rep & WS45 & WS45.5 & WS46 & WS46.5 & WS47 & WS47.5 & WS48 \\
\hline 0.38 & 0.00 & 0.00 & 0.00 & 0.00 & 0.00 & 0.00 & 0.00 & 0.00 & 0.00 & 0.00 & 0.00 & 0.00 \\
\hline 0.41 & 0.00 & 0.00 & 0.00 & 0.00 & 0.00 & 0.00 & 0.00 & 0.00 & 0.00 & 0.00 & 0.00 & 0.00 \\
\hline 0.45 & 0.00 & 0.00 & 0.00 & 0.00 & 0.00 & 0.00 & 0.00 & 0.00 & 0.00 & 0.00 & 0.00 & 0.00 \\
\hline 0.50 & 0.00 & 0.00 & 0.00 & 0.00 & 0.00 & 0.00 & 0.00 & 0.00 & 0.00 & 0.00 & 0.00 & 0.00 \\
\hline 0.54 & 0.00 & 0.00 & 0.00 & 0.00 & 0.00 & 0.00 & 0.00 & 0.00 & 0.00 & 0.00 & 0.00 & 0.00 \\
\hline 0.60 & 0.00 & 0.00 & 0.00 & 0.00 & 0.00 & 0.00 & 0.00 & 0.00 & 0.00 & 0.00 & 0.00 & 0.00 \\
\hline 0.66 & 0.00 & 0.00 & 0.00 & 0.00 & 0.00 & 0.00 & 0.00 & 0.00 & 0.00 & 0.00 & 0.00 & 0.00 \\
\hline 0.72 & 0.00 & 0.00 & 0.00 & 0.00 & 0.00 & 0.00 & 0.00 & 0.00 & 0.00 & 0.00 & 0.00 & 0.00 \\
\hline 0.79 & 0.00 & 0.00 & 0.00 & 0.00 & 0.00 & 0.00 & 0.00 & 0.00 & 0.00 & 0.00 & 0.00 & 0.00 \\
\hline 0.87 & 0.00 & 0.00 & 0.00 & 0.00 & 0.00 & 0.00 & 0.00 & 0.00 & 0.00 & 0.00 & 0.00 & 0.00 \\
\hline 0.95 & 0.00 & 0.00 & 0.00 & 0.00 & 0.00 & 0.00 & 0.00 & 0.00 & 0.00 & 0.00 & 0.00 & 0.00 \\
\hline 1.05 & 0.00 & 0.00 & 0.00 & 0.00 & 0.00 & 0.00 & 0.00 & 0.00 & 0.00 & 0.00 & 0.00 & 0.00 \\
\hline 1.15 & 0.00 & 0.00 & 0.00 & 0.00 & 0.00 & 0.00 & 0.00 & 0.00 & 0.00 & 0.00 & 0.00 & 0.00 \\
\hline 1.26 & 0.01 & 0.02 & 0.00 & 0.00 & 0.00 & 0.00 & 0.00 & 0.00 & 0.00 & 0.00 & 0.00 & 0.00 \\
\hline 1.38 & 0.05 & 0.10 & 0.03 & 0.00 & 0.00 & 0.01 & 0.00 & 0.04 & 0.00 & 0.00 & 0.00 & 0.00 \\
\hline 1.52 & 0.19 & 0.29 & 0.17 & 0.02 & 0.03 & 0.10 & 0.03 & 0.21 & 0.03 & 0.06 & 0.03 & 0.06 \\
\hline 1.67 & 0.44 & 0.58 & 0.47 & 0.14 & 0.17 & 0.38 & 0.19 & 0.57 & 0.18 & 0.30 & 0.17 & 0.32 \\
\hline 1.83 & 0.76 & 0.91 & 0.90 & 0.44 & 0.51 & 0.86 & 0.54 & 1.08 & 0.54 & 0.78 & 0.50 & 0.83 \\
\hline 2.01 & 1.07 & 1.22 & 1.33 & 0.89 & 0.99 & 1.41 & 1.03 & 1.58 & 1.06 & 1.40 & 0.98 & 1.47 \\
\hline 2.21 & 1.33 & 1.49 & 1.68 & 1.37 & 1.48 & 1.89 & 1.51 & 2.00 & 1.59 & 1.93 & 1.48 & 2.03 \\
\hline 2.42 & 1.51 & 1.68 & 1.91 & 1.75 & 1.87 & 2.22 & 1.91 & 2.28 & 2.02 & 2.29 & 1.88 & 2.41 \\
\hline 2.66 & 1.62 & 1.81 & 2.04 & 2.02 & 2.14 & 2.41 & 2.20 & 2.45 & 2.33 & 2.47 & 2.18 & 2.62 \\
\hline 2.92 & 1.68 & 1.88 & 2.08 & 2.16 & 2.27 & 2.47 & 2.38 & 2.50 & 2.52 & 2.49 & 2.35 & 2.65 \\
\hline
\end{tabular}




\begin{tabular}{|c|c|c|c|c|c|c|c|c|c|c|c|c|}
\hline $\begin{array}{l}\text { Diameter } \\
(\mu \mathrm{m})\end{array}$ & WS43 & WS43.5 & WS44 & WS44.5 & WS44.5rep & WS45 & WS45.5 & WS46 & WS46.5 & WS47 & WS47.5 & WS48 \\
\hline 3.21 & 1.71 & 1.90 & 2.06 & 2.20 & 2.32 & 2.45 & 2.47 & 2.50 & 2.60 & 2.42 & 2.43 & 2.58 \\
\hline 3.52 & 1.72 & 1.90 & 2.01 & 2.20 & 2.32 & 2.40 & 2.52 & 2.45 & 2.64 & 2.29 & 2.47 & 2.47 \\
\hline 3.86 & 1.73 & 1.90 & 1.97 & 2.23 & 2.34 & 2.37 & 2.57 & 2.41 & 2.69 & 2.18 & 2.51 & 2.37 \\
\hline 4.24 & 1.79 & 1.95 & 2.01 & 2.34 & 2.44 & 2.43 & 2.71 & 2.44 & 2.82 & 2.17 & 2.64 & 2.39 \\
\hline 4.66 & 1.88 & 2.01 & 2.08 & 2.53 & 2.60 & 2.53 & 2.89 & 2.49 & 3.01 & 2.23 & 2.83 & 2.48 \\
\hline 5.11 & 2.01 & 2.14 & 2.22 & 2.77 & 2.82 & 2.67 & 3.12 & 2.60 & 3.26 & 2.38 & 3.08 & 2.65 \\
\hline 5.61 & 2.10 & 2.23 & 2.31 & 2.94 & 2.97 & 2.74 & 3.28 & 2.67 & 3.43 & 2.48 & 3.27 & 2.76 \\
\hline 6.16 & 2.21 & 2.36 & 2.42 & 3.08 & 3.09 & 2.79 & 3.41 & 2.74 & 3.57 & 2.56 & 3.43 & 2.85 \\
\hline 6.76 & 2.29 & 2.47 & 2.49 & 3.15 & 3.14 & 2.77 & 3.47 & 2.76 & 3.63 & 2.59 & 3.51 & 2.87 \\
\hline 7.42 & 2.40 & 2.62 & 2.60 & 3.23 & 3.21 & 2.74 & 3.55 & 2.80 & 3.69 & 2.66 & 3.62 & 2.92 \\
\hline 8.15 & 2.51 & 2.78 & 2.70 & 3.32 & 3.28 & 2.69 & 3.61 & 2.86 & 3.76 & 2.76 & 3.72 & 2.96 \\
\hline 8.94 & 2.59 & 2.92 & 2.78 & 3.39 & 3.36 & 2.64 & 3.65 & 2.92 & 3.81 & 2.87 & 3.81 & 2.98 \\
\hline 9.82 & 2.69 & 3.06 & 2.88 & 3.47 & 3.45 & 2.68 & 3.68 & 3.03 & 3.84 & 2.99 & 3.88 & 3.01 \\
\hline 10.78 & 2.79 & 3.16 & 2.96 & 3.51 & 3.50 & 2.78 & 3.64 & 3.13 & 3.79 & 3.04 & 3.86 & 3.00 \\
\hline 11.83 & 3.01 & 3.33 & 3.16 & 3.60 & 3.60 & 3.06 & 3.63 & 3.30 & 3.74 & 3.15 & 3.85 & 3.08 \\
\hline 12.99 & 3.23 & 3.45 & 3.37 & 3.64 & 3.62 & 3.35 & 3.55 & 3.39 & 3.60 & 3.20 & 3.75 & 3.17 \\
\hline 14.26 & 3.45 & 3.56 & 3.58 & 3.65 & 3.61 & 3.60 & 3.46 & 3.43 & 3.44 & 3.25 & 3.64 & 3.29 \\
\hline 15.65 & 3.48 & 3.52 & 3.63 & 3.51 & 3.46 & 3.59 & 3.30 & 3.29 & 3.19 & 3.20 & 3.43 & 3.28 \\
\hline 17.18 & 3.29 & 3.34 & 3.46 & 3.22 & 3.21 & 3.31 & 3.08 & 3.01 & 2.89 & 3.02 & 3.17 & 3.11 \\
\hline 18.86 & 2.94 & 3.08 & 3.12 & 2.85 & 2.94 & 2.86 & 2.86 & 2.69 & 2.61 & 2.78 & 2.90 & 2.80 \\
\hline 20.71 & 2.56 & 2.82 & 2.72 & 2.50 & 2.70 & 2.40 & 2.62 & 2.38 & 2.38 & 2.52 & 2.62 & 2.44 \\
\hline 22.73 & 2.38 & 2.68 & 2.48 & 2.30 & 2.59 & 2.17 & 2.46 & 2.22 & 2.26 & 2.36 & 2.43 & 2.20 \\
\hline 24.95 & 2.43 & 2.65 & 2.45 & 2.27 & 2.56 & 2.16 & 2.35 & 2.19 & 2.19 & 2.33 & 2.28 & 2.11 \\
\hline 27.39 & 2.71 & 2.72 & 2.63 & 2.37 & 2.58 & 2.36 & 2.30 & 2.28 & 2.16 & 2.41 & 2.21 & 2.18 \\
\hline 30.07 & 3.06 & 2.77 & 2.87 & 2.51 & 2.57 & 2.60 & 2.29 & 2.39 & 2.08 & 2.52 & 2.18 & 2.32 \\
\hline 33.01 & 3.29 & 2.73 & 3.00 & 2.55 & 2.50 & 2.71 & 2.31 & 2.45 & 1.96 & 2.58 & 2.18 & 2.41 \\
\hline 36.24 & 3.28 & 2.57 & 2.90 & 2.45 & 2.40 & 2.59 & 2.32 & 2.40 & 1.81 & 2.53 & 2.18 & 2.37 \\
\hline 39.78 & 3.03 & 2.33 & 2.57 & 2.21 & 2.28 & 2.28 & 2.28 & 2.22 & 1.68 & 2.36 & 2.13 & 2.19 \\
\hline 43.67 & 2.68 & 2.09 & 2.14 & 1.92 & 2.17 & 1.91 & 2.14 & 1.97 & 1.57 & 2.14 & 1.99 & 1.91 \\
\hline 47.94 & 2.38 & 1.88 & 1.76 & 1.66 & 2.02 & 1.63 & 1.84 & 1.67 & 1.46 & 1.91 & 1.71 & 1.63 \\
\hline 52.62 & 2.24 & 1.73 & 1.56 & 1.48 & 1.79 & 1.51 & 1.39 & 1.39 & 1.31 & 1.71 & 1.31 & 1.41 \\
\hline 57.77 & 2.26 & 1.61 & 1.54 & 1.36 & 1.43 & 1.53 & 0.88 & 1.17 & 1.07 & 1.54 & 0.84 & 1.27 \\
\hline 63.41 & 2.34 & 1.48 & 1.63 & 1.28 & 0.97 & 1.61 & 0.42 & 1.03 & 0.77 & 1.40 & 0.41 & 1.18 \\
\hline 69.61 & 2.29 & 1.31 & 1.69 & 1.17 & 0.50 & 1.60 & 0.13 & 0.97 & 0.45 & 1.26 & 0.13 & 1.10 \\
\hline 76.42 & 2.00 & 1.10 & 1.57 & 0.98 & 0.17 & 1.38 & 0.02 & 0.96 & 0.22 & 1.09 & 0.02 & 0.98 \\
\hline 83.89 & 1.45 & 0.87 & 1.18 & 0.71 & 0.03 & 0.90 & 0.00 & 0.91 & 0.11 & 0.90 & 0.00 & 0.78 \\
\hline 92.09 & 0.79 & 0.68 & 0.64 & 0.42 & 0.00 & 0.39 & 0.00 & 0.79 & 0.07 & 0.70 & 0.00 & 0.54 \\
\hline 101.10 & 0.29 & 0.56 & 0.21 & 0.18 & 0.00 & 0.08 & 0.00 & 0.57 & 0.06 & 0.51 & 0.00 & 0.31 \\
\hline 110.98 & 0.05 & 0.48 & 0.03 & 0.05 & 0.00 & 0.01 & 0.00 & 0.31 & 0.05 & 0.37 & 0.00 & 0.18 \\
\hline 121.83 & 0.00 & 0.42 & 0.00 & 0.01 & 0.00 & 0.00 & 0.00 & 0.11 & 0.03 & 0.27 & 0.00 & 0.13 \\
\hline 133.74 & 0.00 & 0.36 & 0.00 & 0.00 & 0.00 & 0.00 & 0.00 & 0.02 & 0.01 & 0.22 & 0.00 & 0.15 \\
\hline 146.82 & 0.00 & 0.26 & 0.00 & 0.00 & 0.00 & 0.00 & 0.00 & 0.00 & 0.00 & 0.18 & 0.00 & 0.20 \\
\hline 161.17 & 0.00 & 0.15 & 0.00 & 0.00 & 0.00 & 0.00 & 0.00 & 0.00 & 0.00 & 0.14 & 0.00 & 0.23 \\
\hline
\end{tabular}




\begin{tabular}{|c|c|c|c|c|c|c|c|c|c|c|c|c|}
\hline $\begin{array}{l}\text { Diameter } \\
(\mu \mathrm{m})\end{array}$ & WS43 & WS43.5 & WS44 & WS44.5 & WS44.5rep & WS45 & WS45.5 & WS46 & WS46.5 & WS47 & WS47.5 & WS48 \\
\hline 176.93 & 0.00 & 0.06 & 0.00 & 0.00 & 0.00 & 0.00 & 0.00 & 0.00 & 0.00 & 0.08 & 0.00 & 0.20 \\
\hline 194.22 & 0.00 & 0.01 & 0.00 & 0.00 & 0.00 & 0.00 & 0.00 & 0.00 & 0.00 & 0.03 & 0.00 & 0.12 \\
\hline 213.21 & 0.00 & 0.00 & 0.00 & 0.00 & 0.00 & 0.00 & 0.00 & 0.00 & 0.00 & 0.01 & 0.00 & 0.04 \\
\hline 234.05 & 0.00 & 0.00 & 0.00 & 0.00 & 0.00 & 0.00 & 0.00 & 0.00 & 0.00 & 0.00 & 0.00 & 0.01 \\
\hline 256.94 & 0.00 & 0.00 & 0.00 & 0.00 & 0.00 & 0.00 & 0.00 & 0.00 & 0.00 & 0.00 & 0.00 & 0.00 \\
\hline 282.06 & 0.00 & 0.00 & 0.00 & 0.00 & 0.00 & 0.00 & 0.00 & 0.00 & 0.00 & 0.00 & 0.00 & 0.00 \\
\hline 309.63 & 0.00 & 0.00 & 0.00 & 0.00 & 0.00 & 0.00 & 0.00 & 0.00 & 0.00 & 0.00 & 0.00 & 0.00 \\
\hline 339.90 & 0.00 & 0.00 & 0.00 & 0.00 & 0.00 & 0.00 & 0.00 & 0.00 & 0.00 & 0.00 & 0.00 & 0.00 \\
\hline 373.13 & 0.00 & 0.00 & 0.00 & 0.00 & 0.00 & 0.00 & 0.00 & 0.00 & 0.00 & 0.00 & 0.00 & 0.00 \\
\hline 409.61 & 0.00 & 0.00 & 0.00 & 0.00 & 0.00 & 0.00 & 0.00 & 0.00 & 0.00 & 0.00 & 0.00 & 0.00 \\
\hline 449.66 & 0.00 & 0.00 & 0.00 & 0.00 & 0.00 & 0.00 & 0.00 & 0.00 & 0.00 & 0.00 & 0.00 & 0.00 \\
\hline 493.62 & 0.00 & 0.00 & 0.00 & 0.00 & 0.00 & 0.00 & 0.00 & 0.00 & 0.00 & 0.00 & 0.00 & 0.00 \\
\hline 541.88 & 0.00 & 0.00 & 0.00 & 0.00 & 0.00 & 0.00 & 0.00 & 0.00 & 0.00 & 0.00 & 0.00 & 0.00 \\
\hline 594.85 & 0.00 & 0.00 & 0.00 & 0.00 & 0.00 & 0.00 & 0.00 & 0.00 & 0.00 & 0.00 & 0.00 & 0.00 \\
\hline 653.01 & 0.00 & 0.00 & 0.00 & 0.00 & 0.00 & 0.00 & 0.00 & 0.00 & 0.00 & 0.00 & 0.00 & 0.00 \\
\hline 716.85 & 0.00 & 0.00 & 0.00 & 0.00 & 0.00 & 0.00 & 0.00 & 0.00 & 0.00 & 0.00 & 0.00 & 0.00 \\
\hline 786.93 & 0.00 & 0.00 & 0.00 & 0.00 & 0.00 & 0.00 & 0.00 & 0.00 & 0.00 & 0.00 & 0.00 & 0.00 \\
\hline 863.87 & 0.00 & 0.00 & 0.00 & 0.00 & 0.00 & 0.00 & 0.00 & 0.00 & 0.00 & 0.00 & 0.00 & 0.00 \\
\hline 948.32 & 0.00 & 0.00 & 0.00 & 0.00 & 0.00 & 0.00 & 0.00 & 0.00 & 0.00 & 0.00 & 0.00 & 0.00 \\
\hline 1041.03 & 0.00 & 0.00 & 0.00 & 0.00 & 0.00 & 0.00 & 0.00 & 0.00 & 0.00 & 0.00 & 0.00 & 0.00 \\
\hline 1142.81 & 0.00 & 0.00 & 0.00 & 0.00 & 0.00 & 0.00 & 0.00 & 0.00 & 0.00 & 0.00 & 0.00 & 0.00 \\
\hline 1254.54 & 0.00 & 0.00 & 0.00 & 0.00 & 0.00 & 0.00 & 0.00 & 0.00 & 0.00 & 0.00 & 0.00 & 0.00 \\
\hline 1377.19 & 0.00 & 0.00 & 0.00 & 0.00 & 0.00 & 0.00 & 0.00 & 0.00 & 0.00 & 0.00 & 0.00 & 0.00 \\
\hline 1511.83 & 0.00 & 0.00 & 0.00 & 0.00 & 0.00 & 0.00 & 0.00 & 0.00 & 0.00 & 0.00 & 0.00 & 0.00 \\
\hline 1659.63 & 0.00 & 0.00 & 0.00 & 0.00 & 0.00 & 0.00 & 0.00 & 0.00 & 0.00 & 0.00 & 0.00 & 0.00 \\
\hline 1821.88 & 0.00 & 0.00 & 0.00 & 0.00 & 0.00 & 0.00 & 0.00 & 0.00 & 0.00 & 0.00 & 0.00 & 0.00 \\
\hline 2000 & & & & & & & & & & & & \\
\hline
\end{tabular}

\begin{tabular}{|c|c|c|c|c|c|c|c|c|c|c|c|c|}
\hline $\begin{array}{l}\text { Diameter } \\
(\mu \mathrm{m})\end{array}$ & WS48.5 & WS49 & WS49.5 & WS50 & WS50.5 & WS51 & WS51rep & WS51.5 & WS52 & WS53 & WS53.5 & WS54 \\
\hline 0.38 & 0.00 & 0.00 & 0.00 & 0.00 & 0.00 & 0.00 & 0.00 & 0.00 & 0.00 & 0.00 & 0.00 & 0.00 \\
\hline 0.41 & 0.00 & 0.00 & 0.00 & 0.00 & 0.00 & 0.00 & 0.00 & 0.00 & 0.00 & 0.00 & 0.00 & 0.00 \\
\hline 0.45 & 0.00 & 0.00 & 0.00 & 0.00 & 0.00 & 0.00 & 0.00 & 0.00 & 0.00 & 0.00 & 0.00 & 0.00 \\
\hline 0.50 & 0.00 & 0.00 & 0.00 & 0.00 & 0.00 & 0.00 & 0.00 & 0.00 & 0.00 & 0.00 & 0.00 & 0.00 \\
\hline 0.54 & 0.00 & 0.00 & 0.00 & 0.00 & 0.00 & 0.00 & 0.00 & 0.00 & 0.00 & 0.00 & 0.00 & 0.00 \\
\hline 0.60 & 0.00 & 0.00 & 0.00 & 0.00 & 0.00 & 0.00 & 0.00 & 0.00 & 0.00 & 0.00 & 0.00 & 0.00 \\
\hline 0.66 & 0.00 & 0.00 & 0.00 & 0.00 & 0.00 & 0.00 & 0.00 & 0.00 & 0.00 & 0.00 & 0.00 & 0.00 \\
\hline 0.72 & 0.00 & 0.00 & 0.00 & 0.00 & 0.00 & 0.00 & 0.00 & 0.00 & 0.00 & 0.00 & 0.00 & 0.00 \\
\hline 0.79 & 0.00 & 0.00 & 0.00 & 0.00 & 0.00 & 0.00 & 0.00 & 0.00 & 0.00 & 0.00 & 0.00 & 0.00 \\
\hline 0.87 & 0.00 & 0.00 & 0.00 & 0.00 & 0.00 & 0.00 & 0.00 & 0.00 & 0.00 & 0.00 & 0.00 & 0.00 \\
\hline 0.95 & 0.00 & 0.00 & 0.00 & 0.00 & 0.00 & 0.00 & 0.00 & 0.00 & 0.00 & 0.00 & 0.00 & 0.00 \\
\hline 1.05 & 0.00 & 0.00 & 0.00 & 0.00 & 0.00 & 0.00 & 0.00 & 0.00 & 0.00 & 0.00 & 0.00 & 0.00 \\
\hline 1.15 & 0.00 & 0.00 & 0.00 & 0.00 & 0.00 & 0.00 & 0.00 & 0.00 & 0.00 & 0.00 & 0.00 & 0.00 \\
\hline
\end{tabular}




\begin{tabular}{|c|c|c|c|c|c|c|c|c|c|c|c|c|}
\hline $\begin{array}{l}\text { Diameter } \\
(\mu \mathrm{m})\end{array}$ & WS48.5 & WS49 & WS49.5 & WS50 & WS50.5 & WS51 & WS51rep & WS51.5 & WS52 & WS53 & WS53.5 & WS54 \\
\hline 1.26 & 0.00 & 0.01 & 0.00 & 0.00 & 0.00 & 0.00 & 0.00 & 0.00 & 0.00 & 0.00 & 0.00 & 0.00 \\
\hline 1.38 & 0.00 & 0.06 & 0.02 & 0.04 & 0.00 & 0.03 & 0.01 & 0.00 & 0.03 & 0.00 & 0.00 & 0.01 \\
\hline 1.52 & 0.04 & 0.24 & 0.15 & 0.19 & 0.04 & 0.17 & 0.11 & 0.05 & 0.16 & 0.05 & 0.03 & 0.07 \\
\hline 1.67 & 0.21 & 0.58 & 0.46 & 0.53 & 0.22 & 0.51 & 0.40 & 0.24 & 0.45 & 0.26 & 0.19 & 0.38 \\
\hline 1.83 & 0.58 & 1.02 & 0.95 & 1.00 & 0.59 & 1.01 & 0.91 & 0.64 & 0.88 & 0.74 & 0.52 & 0.99 \\
\hline 2.01 & 1.07 & 1.45 & 1.47 & 1.45 & 1.08 & 1.53 & 1.49 & 1.14 & 1.32 & 1.42 & 0.99 & 1.76 \\
\hline 2.21 & 1.54 & 1.81 & 1.94 & 1.84 & 1.54 & 1.98 & 2.01 & 1.61 & 1.68 & 2.09 & 1.45 & 2.43 \\
\hline 2.42 & 1.90 & 2.06 & 2.29 & 2.09 & 1.92 & 2.28 & 2.38 & 1.97 & 1.93 & 2.59 & 1.82 & 2.90 \\
\hline 2.66 & 2.16 & 2.21 & 2.52 & 2.24 & 2.21 & 2.44 & 2.60 & 2.24 & 2.08 & 2.89 & 2.10 & 3.17 \\
\hline 2.92 & 2.30 & 2.28 & 2.64 & 2.30 & 2.40 & 2.48 & 2.67 & 2.41 & 2.14 & 2.97 & 2.28 & 3.24 \\
\hline 3.21 & 2.35 & 2.29 & 2.66 & 2.29 & 2.52 & 2.45 & 2.65 & 2.50 & 2.15 & 2.90 & 2.38 & 3.19 \\
\hline 3.52 & 2.37 & 2.27 & 2.64 & 2.25 & 2.59 & 2.38 & 2.58 & 2.55 & 2.12 & 2.77 & 2.44 & 3.08 \\
\hline 3.86 & 2.38 & 2.26 & 2.61 & 2.22 & 2.65 & 2.31 & 2.53 & 2.59 & 2.10 & 2.68 & 2.50 & 2.98 \\
\hline 4.24 & 2.47 & 2.31 & 2.65 & 2.25 & 2.77 & 2.33 & 2.56 & 2.70 & 2.15 & 2.71 & 2.64 & 3.00 \\
\hline 4.66 & 2.61 & 2.40 & 2.74 & 2.35 & 2.93 & 2.40 & 2.65 & 2.85 & 2.24 & 2.86 & 2.81 & 3.09 \\
\hline 5.11 & 2.82 & 2.56 & 2.89 & 2.52 & 3.12 & 2.54 & 2.80 & 3.05 & 2.41 & 3.08 & 3.05 & 3.25 \\
\hline 5.61 & 2.96 & 2.68 & 2.98 & 2.67 & 3.25 & 2.64 & 2.90 & 3.19 & 2.54 & 3.23 & 3.22 & 3.34 \\
\hline 6.16 & 3.08 & 2.82 & 3.06 & 2.84 & 3.34 & 2.75 & 2.98 & 3.31 & 2.68 & 3.34 & 3.37 & 3.40 \\
\hline 6.76 & 3.14 & 2.93 & 3.09 & 2.99 & 3.38 & 2.82 & 3.01 & 3.37 & 2.79 & 3.35 & 3.46 & 3.37 \\
\hline 7.42 & 3.23 & 3.07 & 3.16 & 3.19 & 3.43 & 2.93 & 3.05 & 3.46 & 2.95 & 3.38 & 3.57 & 3.36 \\
\hline 8.15 & 3.34 & 3.21 & 3.23 & 3.40 & 3.49 & 3.04 & 3.11 & 3.55 & 3.11 & 3.43 & 3.70 & 3.36 \\
\hline 8.94 & 3.45 & 3.32 & 3.30 & 3.55 & 3.54 & 3.12 & 3.15 & 3.62 & 3.23 & 3.46 & 3.82 & 3.35 \\
\hline 9.82 & 3.56 & 3.41 & 3.37 & 3.65 & 3.58 & 3.19 & 3.21 & 3.69 & 3.34 & 3.48 & 3.93 & 3.38 \\
\hline 10.78 & 3.61 & 3.44 & 3.38 & 3.62 & 3.58 & 3.20 & 3.22 & 3.69 & 3.38 & 3.42 & 3.98 & 3.36 \\
\hline 11.83 & 3.68 & 3.52 & 3.43 & 3.60 & 3.60 & 3.27 & 3.29 & 3.71 & 3.49 & 3.39 & 4.05 & 3.40 \\
\hline 12.99 & 3.66 & 3.54 & 3.44 & 3.53 & 3.55 & 3.31 & 3.30 & 3.66 & 3.57 & 3.31 & 4.03 & 3.37 \\
\hline 14.26 & 3.60 & 3.55 & 3.43 & 3.50 & 3.46 & 3.37 & 3.29 & 3.62 & 3.67 & 3.26 & 3.99 & 3.30 \\
\hline 15.65 & 3.42 & 3.44 & 3.32 & 3.39 & 3.26 & 3.32 & 3.14 & 3.49 & 3.63 & 3.15 & 3.79 & 3.11 \\
\hline 17.18 & 3.14 & 3.22 & 3.09 & 3.21 & 2.97 & 3.14 & 2.90 & 3.30 & 3.43 & 2.98 & 3.46 & 2.83 \\
\hline 18.86 & 2.82 & 2.96 & 2.80 & 2.98 & 2.67 & 2.87 & 2.63 & 3.06 & 3.12 & 2.76 & 3.06 & 2.54 \\
\hline 20.71 & 2.51 & 2.71 & 2.50 & 2.70 & 2.42 & 2.58 & 2.42 & 2.78 & 2.78 & 2.50 & 2.66 & 2.30 \\
\hline 22.73 & 2.32 & 2.60 & 2.30 & 2.51 & 2.30 & 2.40 & 2.35 & 2.56 & 2.58 & 2.30 & 2.40 & 2.18 \\
\hline 24.95 & 2.24 & 2.58 & 2.20 & 2.38 & 2.24 & 2.34 & 2.38 & 2.39 & 2.53 & 2.16 & 2.24 & 2.12 \\
\hline 27.39 & 2.27 & 2.60 & 2.21 & 2.33 & 2.23 & 2.39 & 2.46 & 2.33 & 2.59 & 2.10 & 2.17 & 2.08 \\
\hline 30.07 & 2.34 & 2.57 & 2.24 & 2.30 & 2.16 & 2.47 & 2.47 & 2.32 & 2.65 & 2.07 & 2.08 & 2.00 \\
\hline 33.01 & 2.35 & 2.44 & 2.22 & 2.23 & 2.01 & 2.48 & 2.37 & 2.35 & 2.59 & 2.04 & 1.91 & 1.85 \\
\hline 36.24 & 2.26 & 2.23 & 2.10 & 2.10 & 1.80 & 2.38 & 2.20 & 2.34 & 2.36 & 1.98 & 1.66 & 1.66 \\
\hline 39.78 & 2.06 & 2.00 & 1.88 & 1.90 & 1.58 & 2.17 & 2.01 & 2.23 & 2.02 & 1.84 & 1.37 & 1.49 \\
\hline 43.67 & 1.77 & 1.83 & 1.62 & 1.68 & 1.43 & 1.91 & 1.89 & 1.98 & 1.70 & 1.62 & 1.13 & 1.35 \\
\hline 47.94 & 1.46 & 1.72 & 1.36 & 1.46 & 1.35 & 1.65 & 1.82 & 1.57 & 1.49 & 1.32 & 0.99 & 1.22 \\
\hline 52.62 & 1.18 & 1.63 & 1.14 & 1.25 & 1.30 & 1.41 & 1.75 & 1.08 & 1.42 & 0.94 & 0.95 & 1.08 \\
\hline 57.77 & 1.00 & 1.50 & 0.97 & 1.05 & 1.20 & 1.19 & 1.61 & 0.57 & 1.46 & 0.57 & 0.97 & 0.86 \\
\hline 63.41 & 0.90 & 1.25 & 0.84 & 0.85 & 1.01 & 1.00 & 1.31 & 0.21 & 1.50 & 0.30 & 0.95 & 0.54 \\
\hline
\end{tabular}




\begin{tabular}{|c|c|c|c|c|c|c|c|c|c|c|c|c|}
\hline $\begin{array}{l}\text { Diameter } \\
(\mu \mathrm{m})\end{array}$ & WS48.5 & WS49 & WS49.5 & WS50 & WS50.5 & WS51 & WS51rep & WS51.5 & WS52 & WS53 & WS53.5 & WS54 \\
\hline 69.61 & 0.88 & 0.86 & 0.74 & 0.68 & 0.72 & 0.81 & 0.87 & 0.04 & 1.43 & 0.19 & 0.84 & 0.23 \\
\hline 76.42 & 0.88 & 0.43 & 0.64 & 0.53 & 0.41 & 0.64 & 0.42 & 0.00 & 1.14 & 0.20 & 0.61 & 0.05 \\
\hline 83.89 & 0.82 & 0.13 & 0.53 & 0.43 & 0.21 & 0.50 & 0.13 & 0.00 & 0.68 & 0.31 & 0.32 & 0.00 \\
\hline 92.09 & 0.66 & 0.02 & 0.40 & 0.37 & 0.14 & 0.39 & 0.02 & 0.00 & 0.26 & 0.46 & 0.11 & 0.00 \\
\hline 101.10 & 0.40 & 0.00 & 0.25 & 0.34 & 0.18 & 0.32 & 0.00 & 0.00 & 0.05 & 0.52 & 0.02 & 0.00 \\
\hline 110.98 & 0.16 & 0.00 & 0.12 & 0.31 & 0.29 & 0.27 & 0.00 & 0.00 & 0.00 & 0.39 & 0.00 & 0.00 \\
\hline 121.83 & 0.03 & 0.00 & 0.04 & 0.28 & 0.40 & 0.24 & 0.00 & 0.00 & 0.00 & 0.18 & 0.00 & 0.00 \\
\hline 133.74 & 0.00 & 0.00 & 0.01 & 0.24 & 0.40 & 0.22 & 0.00 & 0.00 & 0.00 & 0.04 & 0.00 & 0.00 \\
\hline 146.82 & 0.00 & 0.00 & 0.00 & 0.18 & 0.31 & 0.18 & 0.00 & 0.00 & 0.00 & 0.00 & 0.00 & 0.00 \\
\hline 161.17 & 0.00 & 0.00 & 0.00 & 0.13 & 0.17 & 0.14 & 0.00 & 0.00 & 0.00 & 0.00 & 0.00 & 0.00 \\
\hline 176.93 & 0.00 & 0.00 & 0.00 & 0.07 & 0.06 & 0.08 & 0.00 & 0.00 & 0.00 & 0.00 & 0.00 & 0.00 \\
\hline 194.22 & 0.00 & 0.00 & 0.00 & 0.03 & 0.01 & 0.03 & 0.00 & 0.00 & 0.00 & 0.00 & 0.00 & 0.00 \\
\hline 213.21 & 0.00 & 0.00 & 0.00 & 0.01 & 0.00 & 0.01 & 0.00 & 0.00 & 0.00 & 0.00 & 0.00 & 0.00 \\
\hline 234.05 & 0.00 & 0.00 & 0.00 & 0.00 & 0.00 & 0.00 & 0.00 & 0.00 & 0.00 & 0.00 & 0.00 & 0.00 \\
\hline 256.94 & 0.00 & 0.00 & 0.00 & 0.00 & 0.00 & 0.00 & 0.00 & 0.00 & 0.00 & 0.00 & 0.00 & 0.00 \\
\hline 282.06 & 0.00 & 0.00 & 0.00 & 0.00 & 0.00 & 0.00 & 0.00 & 0.00 & 0.00 & 0.00 & 0.00 & 0.00 \\
\hline 309.63 & 0.00 & 0.00 & 0.00 & 0.00 & 0.00 & 0.00 & 0.00 & 0.00 & 0.00 & 0.00 & 0.00 & 0.00 \\
\hline 339.90 & 0.00 & 0.00 & 0.00 & 0.00 & 0.00 & 0.00 & 0.00 & 0.00 & 0.00 & 0.00 & 0.00 & 0.00 \\
\hline 373.13 & 0.00 & 0.00 & 0.00 & 0.00 & 0.00 & 0.00 & 0.00 & 0.00 & 0.00 & 0.00 & 0.00 & 0.00 \\
\hline 409.61 & 0.00 & 0.00 & 0.00 & 0.00 & 0.00 & 0.00 & 0.00 & 0.00 & 0.00 & 0.00 & 0.00 & 0.00 \\
\hline 449.66 & 0.00 & 0.00 & 0.00 & 0.00 & 0.00 & 0.00 & 0.00 & 0.00 & 0.00 & 0.00 & 0.00 & 0.00 \\
\hline 493.62 & 0.00 & 0.00 & 0.00 & 0.00 & 0.00 & 0.00 & 0.00 & 0.00 & 0.00 & 0.00 & 0.00 & 0.00 \\
\hline 541.88 & 0.00 & 0.00 & 0.00 & 0.00 & 0.00 & 0.00 & 0.00 & 0.00 & 0.00 & 0.00 & 0.00 & 0.00 \\
\hline 594.85 & 0.00 & 0.00 & 0.00 & 0.00 & 0.00 & 0.00 & 0.00 & 0.00 & 0.00 & 0.00 & 0.00 & 0.00 \\
\hline 653.01 & 0.00 & 0.00 & 0.00 & 0.00 & 0.00 & 0.00 & 0.00 & 0.00 & 0.00 & 0.00 & 0.00 & 0.00 \\
\hline 716.85 & 0.00 & 0.00 & 0.00 & 0.00 & 0.00 & 0.00 & 0.00 & 0.00 & 0.00 & 0.00 & 0.00 & 0.00 \\
\hline 786.93 & 0.00 & 0.00 & 0.00 & 0.00 & 0.00 & 0.00 & 0.00 & 0.00 & 0.00 & 0.00 & 0.00 & 0.00 \\
\hline 863.87 & 0.00 & 0.00 & 0.00 & 0.00 & 0.00 & 0.00 & 0.00 & 0.00 & 0.00 & 0.00 & 0.00 & 0.00 \\
\hline 948.32 & 0.00 & 0.00 & 0.00 & 0.00 & 0.00 & 0.00 & 0.00 & 0.00 & 0.00 & 0.00 & 0.00 & 0.00 \\
\hline 1041.03 & 0.00 & 0.00 & 0.00 & 0.00 & 0.00 & 0.00 & 0.00 & 0.00 & 0.00 & 0.00 & 0.00 & 0.00 \\
\hline 1142.81 & 0.00 & 0.00 & 0.00 & 0.00 & 0.00 & 0.00 & 0.00 & 0.00 & 0.00 & 0.00 & 0.00 & 0.00 \\
\hline 1254.54 & 0.00 & 0.00 & 0.00 & 0.00 & 0.00 & 0.00 & 0.00 & 0.00 & 0.00 & 0.00 & 0.00 & 0.00 \\
\hline 1377.19 & 0.00 & 0.00 & 0.00 & 0.00 & 0.00 & 0.00 & 0.00 & 0.00 & 0.00 & 0.00 & 0.00 & 0.00 \\
\hline 1511.83 & 0.00 & 0.00 & 0.00 & 0.00 & 0.00 & 0.00 & 0.00 & 0.00 & 0.00 & 0.00 & 0.00 & 0.00 \\
\hline 1659.63 & 0.00 & 0.00 & 0.00 & 0.00 & 0.00 & 0.00 & 0.00 & 0.00 & 0.00 & 0.00 & 0.00 & 0.00 \\
\hline 1821.88 & 0.00 & 0.00 & 0.00 & 0.00 & 0.00 & 0.00 & 0.00 & 0.00 & 0.00 & 0.00 & 0.00 & 0.00 \\
\hline 2000 & & & & & & & & & & & & \\
\hline
\end{tabular}




\begin{tabular}{|c|c|c|c|c|c|c|c|c|c|c|c|c|}
\hline $\begin{array}{l}\text { Diameter } \\
(\mu \mathrm{m})\end{array}$ & WS55 & WS55.5 & WS56 & WS56.5 & WS56.5rep & WS57 & WS57.5 & WS58 & WS58.5a & WS58.5b & WS59 & WS59.5a \\
\hline 0.38 & 0.00 & 0.00 & 0.00 & 0.00 & 0.00 & 0.00 & 0.00 & 0.00 & 0.00 & 0.00 & 0.00 & 0.00 \\
\hline 0.41 & 0.00 & 0.00 & 0.00 & 0.00 & 0.00 & 0.00 & 0.00 & 0.00 & 0.00 & 0.00 & 0.00 & 0.00 \\
\hline 0.45 & 0.00 & 0.00 & 0.00 & 0.00 & 0.00 & 0.00 & 0.00 & 0.00 & 0.00 & 0.00 & 0.00 & 0.00 \\
\hline 0.50 & 0.00 & 0.00 & 0.00 & 0.00 & 0.00 & 0.00 & 0.00 & 0.00 & 0.00 & 0.00 & 0.00 & 0.00 \\
\hline 0.54 & 0.00 & 0.00 & 0.00 & 0.00 & 0.00 & 0.00 & 0.00 & 0.00 & 0.00 & 0.00 & 0.00 & 0.00 \\
\hline 0.60 & 0.00 & 0.00 & 0.00 & 0.00 & 0.00 & 0.00 & 0.00 & 0.00 & 0.00 & 0.00 & 0.00 & 0.00 \\
\hline 0.66 & 0.00 & 0.00 & 0.00 & 0.00 & 0.00 & 0.00 & 0.00 & 0.00 & 0.00 & 0.00 & 0.00 & 0.00 \\
\hline 0.72 & 0.00 & 0.00 & 0.00 & 0.00 & 0.00 & 0.00 & 0.00 & 0.00 & 0.00 & 0.00 & 0.00 & 0.00 \\
\hline 0.79 & 0.00 & 0.00 & 0.00 & 0.00 & 0.00 & 0.00 & 0.00 & 0.00 & 0.00 & 0.00 & 0.00 & 0.00 \\
\hline 0.87 & 0.00 & 0.00 & 0.00 & 0.00 & 0.00 & 0.00 & 0.00 & 0.00 & 0.00 & 0.00 & 0.00 & 0.00 \\
\hline 0.95 & 0.00 & 0.00 & 0.00 & 0.00 & 0.00 & 0.00 & 0.00 & 0.00 & 0.00 & 0.00 & 0.00 & 0.00 \\
\hline 1.05 & 0.00 & 0.00 & 0.00 & 0.00 & 0.00 & 0.00 & 0.00 & 0.00 & 0.00 & 0.00 & 0.00 & 0.00 \\
\hline 1.15 & 0.00 & 0.00 & 0.00 & 0.00 & 0.00 & 0.00 & 0.00 & 0.01 & 0.00 & 0.00 & 0.00 & 0.01 \\
\hline 1.26 & 0.00 & 0.00 & 0.01 & 0.00 & 0.00 & 0.00 & 0.00 & 0.04 & 0.01 & 0.00 & 0.00 & 0.06 \\
\hline 1.38 & 0.02 & 0.02 & 0.05 & 0.01 & 0.02 & 0.01 & 0.02 & 0.15 & 0.06 & 0.01 & 0.02 & 0.17 \\
\hline 1.52 & 0.13 & 0.11 & 0.19 & 0.07 & 0.09 & 0.08 & 0.14 & 0.32 & 0.21 & 0.07 & 0.11 & 0.33 \\
\hline 1.67 & 0.42 & 0.35 & 0.46 & 0.25 & 0.29 & 0.27 & 0.38 & 0.55 & 0.48 & 0.26 & 0.33 & 0.50 \\
\hline 1.83 & 0.88 & 0.73 & 0.82 & 0.54 & 0.60 & 0.62 & 0.71 & 0.79 & 0.81 & 0.59 & 0.66 & 0.67 \\
\hline 2.01 & 1.37 & 1.14 & 1.17 & 0.86 & 0.93 & 1.01 & 1.05 & 1.01 & 1.13 & 0.96 & 0.99 & 0.84 \\
\hline 2.21 & 1.80 & 1.51 & 1.45 & 1.15 & 1.21 & 1.35 & 1.33 & 1.17 & 1.40 & 1.30 & 1.28 & 0.98 \\
\hline 2.42 & 2.09 & 1.79 & 1.61 & 1.34 & 1.41 & 1.58 & 1.54 & 1.25 & 1.60 & 1.55 & 1.45 & 1.08 \\
\hline 2.66 & 2.26 & 1.98 & 1.68 & 1.46 & 1.52 & 1.68 & 1.67 & 1.28 & 1.72 & 1.72 & 1.53 & 1.14 \\
\hline 2.92 & 2.32 & 2.08 & 1.68 & 1.51 & 1.56 & 1.67 & 1.72 & 1.27 & 1.76 & 1.81 & 1.52 & 1.17 \\
\hline 3.21 & 2.31 & 2.12 & 1.64 & 1.51 & 1.55 & 1.61 & 1.72 & 1.25 & 1.75 & 1.84 & 1.47 & 1.18 \\
\hline 3.52 & 2.27 & 2.12 & 1.59 & 1.49 & 1.53 & 1.53 & 1.69 & 1.23 & 1.71 & 1.85 & 1.40 & 1.18 \\
\hline 3.86 & 2.23 & 2.11 & 1.55 & 1.47 & 1.52 & 1.48 & 1.66 & 1.22 & 1.67 & 1.85 & 1.34 & 1.18 \\
\hline 4.24 & 2.27 & 2.17 & 1.55 & 1.50 & 1.56 & 1.47 & 1.67 & 1.22 & 1.67 & 1.90 & 1.32 & 1.20 \\
\hline 4.66 & 2.35 & 2.25 & 1.59 & 1.56 & 1.63 & 1.51 & 1.71 & 1.23 & 1.68 & 1.99 & 1.32 & 1.22 \\
\hline 5.11 & 2.51 & 2.37 & 1.67 & 1.67 & 1.74 & 1.58 & 1.77 & 1.26 & 1.72 & 2.12 & 1.37 & 1.27 \\
\hline 5.61 & 2.61 & 2.45 & 1.73 & 1.74 & 1.82 & 1.61 & 1.79 & 1.28 & 1.72 & 2.21 & 1.39 & 1.31 \\
\hline 6.16 & 2.72 & 2.51 & 1.81 & 1.82 & 1.90 & 1.63 & 1.82 & 1.33 & 1.73 & 2.30 & 1.43 & 1.38 \\
\hline 6.76 & 2.77 & 2.53 & 1.86 & 1.86 & 1.94 & 1.61 & 1.83 & 1.34 & 1.72 & 2.35 & 1.44 & 1.43 \\
\hline 7.42 & 2.87 & 2.58 & 1.93 & 1.92 & 2.00 & 1.59 & 1.85 & 1.35 & 1.74 & 2.42 & 1.49 & 1.52 \\
\hline 8.15 & 2.98 & 2.63 & 1.99 & 1.99 & 2.05 & 1.57 & 1.89 & 1.32 & 1.76 & 2.50 & 1.54 & 1.60 \\
\hline 8.94 & 3.10 & 2.66 & 2.03 & 2.06 & 2.07 & 1.54 & 1.91 & 1.31 & 1.76 & 2.58 & 1.60 & 1.68 \\
\hline 9.82 & 3.26 & 2.69 & 2.10 & 2.15 & 2.12 & 1.56 & 1.96 & 1.37 & 1.79 & 2.67 & 1.70 & 1.78 \\
\hline 10.78 & 3.39 & 2.68 & 2.18 & 2.22 & 2.17 & 1.61 & 2.00 & 1.51 & 1.83 & 2.74 & 1.82 & 1.88 \\
\hline 11.83 & 3.60 & 2.75 & 2.37 & 2.35 & 2.30 & 1.76 & 2.11 & 1.78 & 1.95 & 2.86 & 2.04 & 2.07 \\
\hline 12.99 & 3.74 & 2.80 & 2.55 & 2.44 & 2.42 & 1.92 & 2.19 & 2.05 & 2.09 & 2.95 & 2.23 & 2.26 \\
\hline 14.26 & 3.85 & 2.85 & 2.72 & 2.51 & 2.55 & 2.09 & 2.28 & 2.27 & 2.24 & 3.03 & 2.40 & 2.45 \\
\hline 15.65 & 3.76 & 2.79 & 2.74 & 2.46 & 2.56 & 2.14 & 2.26 & 2.27 & 2.29 & 2.98 & 2.42 & 2.52 \\
\hline 17.18 & 3.49 & 2.57 & 2.60 & 2.28 & 2.43 & 2.02 & 2.13 & 2.08 & 2.19 & 2.79 & 2.29 & 2.43 \\
\hline 18.86 & 3.13 & 2.26 & 2.37 & 2.03 & 2.19 & 1.80 & 1.92 & 1.79 & 1.96 & 2.53 & 2.10 & 2.23 \\
\hline
\end{tabular}




\begin{tabular}{|c|c|c|c|c|c|c|c|c|c|c|c|c|}
\hline $\begin{array}{l}\text { Diameter } \\
(\mu \mathrm{m})\end{array}$ & WS55 & WS55.5 & WS56 & WS56.5 & WS56.5rep & WS57 & WS57.5 & WS58 & WS58.5a & WS58.5b & WS59 & WS59.5a \\
\hline 20.71 & 2.77 & 1.93 & 2.13 & 1.79 & 1.91 & 1.54 & 1.71 & 1.54 & 1.69 & 2.27 & 1.92 & 2.00 \\
\hline 22.73 & 2.59 & 1.77 & 2.02 & 1.70 & 1.75 & 1.42 & 1.62 & 1.47 & 1.55 & 2.17 & 1.92 & 1.91 \\
\hline 24.95 & 2.57 & 1.79 & 2.08 & 1.75 & 1.76 & 1.47 & 1.66 & 1.61 & 1.58 & 2.23 & 2.10 & 1.98 \\
\hline 27.39 & 2.66 & 2.02 & 2.32 & 1.97 & 1.97 & 1.73 & 1.87 & 1.98 & 1.81 & 2.46 & 2.48 & 2.23 \\
\hline 30.07 & 2.71 & 2.32 & 2.67 & 2.26 & 2.32 & 2.13 & 2.15 & 2.47 & 2.14 & 2.75 & 2.95 & 2.57 \\
\hline 33.01 & 2.60 & 2.54 & 3.02 & 2.54 & 2.70 & 2.52 & 2.42 & 2.96 & 2.44 & 3.00 & 3.40 & 2.90 \\
\hline 36.24 & 2.29 & 2.58 & 3.27 & 2.72 & 2.98 & 2.80 & 2.60 & 3.32 & 2.60 & 3.10 & 3.74 & 3.12 \\
\hline 39.78 & 1.86 & 2.46 & 3.35 & 2.79 & 3.08 & 2.89 & 2.64 & 3.50 & 2.59 & 3.04 & 3.90 & 3.20 \\
\hline 43.67 & 1.47 & 2.29 & 3.26 & 2.78 & 3.01 & 2.84 & 2.60 & 3.54 & 2.48 & 2.88 & 3.94 & 3.20 \\
\hline 47.94 & 1.22 & 2.22 & 3.06 & 2.76 & 2.85 & 2.76 & 2.54 & 3.49 & 2.40 & 2.69 & 3.87 & 3.20 \\
\hline 52.62 & 1.14 & 2.35 & 2.84 & 2.77 & 2.74 & 2.76 & 2.54 & 3.45 & 2.46 & 2.55 & 3.75 & 3.27 \\
\hline 57.77 & 1.20 & 2.67 & 2.68 & 2.85 & 2.77 & 2.92 & 2.63 & 3.49 & 2.69 & 2.48 & 3.60 & 3.43 \\
\hline 63.41 & 1.27 & 3.04 & 2.65 & 2.98 & 2.99 & 3.22 & 2.80 & 3.61 & 3.06 & 2.47 & 3.43 & 3.65 \\
\hline 69.61 & 1.25 & 3.22 & 2.74 & 3.12 & 3.37 & 3.61 & 3.02 & 3.79 & 3.42 & 2.44 & 3.21 & 3.83 \\
\hline 76.42 & 1.02 & 2.98 & 2.86 & 3.21 & 3.75 & 3.93 & 3.21 & 3.92 & 3.62 & 2.28 & 2.94 & 3.87 \\
\hline 83.89 & 0.62 & 2.30 & 2.85 & 3.18 & 3.86 & 4.02 & 3.28 & 3.89 & 3.55 & 1.93 & 2.60 & 3.71 \\
\hline 92.09 & 0.24 & 1.33 & 2.57 & 3.02 & 3.51 & 3.81 & 3.19 & 3.63 & 3.23 & 1.40 & 2.21 & 3.32 \\
\hline 101.10 & 0.04 & 0.52 & 1.99 & 2.71 & 2.68 & 3.31 & 2.91 & 3.13 & 2.76 & 0.78 & 1.80 & 2.77 \\
\hline 110.98 & 0.00 & 0.10 & 1.23 & 2.29 & 1.54 & 2.67 & 2.49 & 2.47 & 2.27 & 0.30 & 1.40 & 2.12 \\
\hline 121.83 & 0.00 & 0.01 & 0.56 & 1.79 & 0.61 & 2.03 & 1.99 & 1.79 & 1.83 & 0.06 & 1.05 & 1.48 \\
\hline 133.74 & 0.00 & 0.00 & 0.16 & 1.29 & 0.12 & 1.48 & 1.47 & 1.20 & 1.44 & 0.00 & 0.75 & 0.90 \\
\hline 146.82 & 0.00 & 0.00 & 0.02 & 0.83 & 0.01 & 1.03 & 0.99 & 0.74 & 1.06 & 0.00 & 0.51 & 0.44 \\
\hline 161.17 & 0.00 & 0.00 & 0.00 & 0.45 & 0.00 & 0.67 & 0.57 & 0.42 & 0.68 & 0.00 & 0.32 & 0.15 \\
\hline 176.93 & 0.00 & 0.00 & 0.00 & 0.19 & 0.00 & 0.36 & 0.27 & 0.20 & 0.34 & 0.00 & 0.16 & 0.03 \\
\hline 194.22 & 0.00 & 0.00 & 0.00 & 0.05 & 0.00 & 0.14 & 0.09 & 0.07 & 0.11 & 0.00 & 0.06 & 0.00 \\
\hline 213.21 & 0.00 & 0.00 & 0.00 & 0.01 & 0.00 & 0.03 & 0.01 & 0.01 & 0.02 & 0.00 & 0.01 & 0.00 \\
\hline 234.05 & 0.00 & 0.00 & 0.00 & 0.00 & 0.00 & 0.00 & 0.00 & 0.00 & 0.00 & 0.00 & 0.00 & 0.00 \\
\hline 256.94 & 0.00 & 0.00 & 0.00 & 0.00 & 0.00 & 0.00 & 0.00 & 0.00 & 0.00 & 0.00 & 0.00 & 0.00 \\
\hline 282.06 & 0.00 & 0.00 & 0.00 & 0.00 & 0.00 & 0.00 & 0.00 & 0.00 & 0.00 & 0.00 & 0.00 & 0.00 \\
\hline 309.63 & 0.00 & 0.00 & 0.00 & 0.00 & 0.00 & 0.00 & 0.00 & 0.00 & 0.00 & 0.00 & 0.00 & 0.00 \\
\hline 339.90 & 0.00 & 0.00 & 0.00 & 0.00 & 0.00 & 0.00 & 0.00 & 0.00 & 0.00 & 0.00 & 0.00 & 0.00 \\
\hline 373.13 & 0.00 & 0.00 & 0.00 & 0.00 & 0.00 & 0.00 & 0.00 & 0.00 & 0.00 & 0.00 & 0.00 & 0.00 \\
\hline 409.61 & 0.00 & 0.00 & 0.00 & 0.00 & 0.00 & 0.00 & 0.00 & 0.00 & 0.00 & 0.00 & 0.00 & 0.00 \\
\hline 449.66 & 0.00 & 0.00 & 0.00 & 0.00 & 0.00 & 0.00 & 0.00 & 0.00 & 0.00 & 0.00 & 0.00 & 0.00 \\
\hline 493.62 & 0.00 & 0.00 & 0.00 & 0.00 & 0.00 & 0.00 & 0.00 & 0.00 & 0.00 & 0.00 & 0.00 & 0.00 \\
\hline 541.88 & 0.00 & 0.00 & 0.00 & 0.00 & 0.00 & 0.00 & 0.00 & 0.00 & 0.00 & 0.00 & 0.00 & 0.00 \\
\hline 594.85 & 0.00 & 0.00 & 0.00 & 0.00 & 0.00 & 0.00 & 0.00 & 0.00 & 0.00 & 0.00 & 0.00 & 0.00 \\
\hline 653.01 & 0.00 & 0.00 & 0.00 & 0.00 & 0.00 & 0.00 & 0.00 & 0.00 & 0.00 & 0.00 & 0.00 & 0.00 \\
\hline 716.85 & 0.00 & 0.00 & 0.00 & 0.00 & 0.00 & 0.00 & 0.00 & 0.00 & 0.00 & 0.00 & 0.00 & 0.00 \\
\hline 786.93 & 0.00 & 0.00 & 0.00 & 0.00 & 0.00 & 0.00 & 0.00 & 0.00 & 0.00 & 0.00 & 0.00 & 0.00 \\
\hline 863.87 & 0.00 & 0.00 & 0.00 & 0.00 & 0.00 & 0.00 & 0.00 & 0.00 & 0.00 & 0.00 & 0.00 & 0.00 \\
\hline 948.32 & 0.00 & 0.00 & 0.00 & 0.00 & 0.00 & 0.00 & 0.00 & 0.00 & 0.00 & 0.00 & 0.00 & 0.00 \\
\hline 1041.03 & 0.00 & 0.00 & 0.00 & 0.00 & 0.00 & 0.00 & 0.00 & 0.00 & 0.00 & 0.00 & 0.00 & 0.00 \\
\hline
\end{tabular}




\begin{tabular}{|c|c|c|c|c|c|c|c|c|c|c|c|c|}
\hline $\begin{array}{l}\text { Diameter } \\
(\mu \mathrm{m})\end{array}$ & WS55 & WS55.5 & WS56 & WS56.5 & WS56.5rep & WS57 & WS57.5 & WS58 & WS58.5a & WS58.5b & WS59 & WS59.5a \\
\hline 1142.81 & 0.00 & 0.00 & 0.00 & 0.00 & 0.00 & 0.00 & 0.00 & 0.00 & 0.00 & 0.00 & 0.00 & 0.00 \\
\hline 1254.54 & 0.00 & 0.00 & 0.00 & 0.00 & 0.00 & 0.00 & 0.00 & 0.00 & 0.00 & 0.00 & 0.00 & 0.00 \\
\hline 1377.19 & 0.00 & 0.00 & 0.00 & 0.00 & 0.00 & 0.00 & 0.00 & 0.00 & 0.00 & 0.00 & 0.00 & 0.00 \\
\hline 1511.83 & 0.00 & 0.00 & 0.00 & 0.00 & 0.00 & 0.00 & 0.00 & 0.00 & 0.00 & 0.00 & 0.00 & 0.00 \\
\hline 1659.63 & 0.00 & 0.00 & 0.00 & 0.00 & 0.00 & 0.00 & 0.00 & 0.00 & 0.00 & 0.00 & 0.00 & 0.00 \\
\hline 1821.88 & 0.00 & 0.00 & 0.00 & 0.00 & 0.00 & 0.00 & 0.00 & 0.00 & 0.00 & 0.00 & 0.00 & 0.00 \\
\hline 2000 & & & & & & & & & & & & \\
\hline
\end{tabular}

\begin{tabular}{|c|c|c|c|c|c|c|c|c|c|c|c|c|}
\hline $\begin{array}{l}\text { Diameter } \\
(\mu \mathrm{m})\end{array}$ & WS59.5b & WS60 & WS61.5c & WS60.5a & WS61 & WS61.5b & WS61.5d & WS61.5e & WS61.5a & WS61.5f & WS62 & WS62.5 \\
\hline 0.38 & 0.00 & 0.00 & 0.00 & 0.00 & 0.00 & 0.00 & 0.00 & 0.00 & 0.00 & 0.00 & 0.00 & 0.00 \\
\hline 0.41 & 0.00 & 0.00 & 0.00 & 0.00 & 0.00 & 0.00 & 0.00 & 0.00 & 0.00 & 0.00 & 0.00 & 0.00 \\
\hline 0.45 & 0.00 & 0.00 & 0.00 & 0.00 & 0.00 & 0.00 & 0.00 & 0.00 & 0.00 & 0.00 & 0.00 & 0.00 \\
\hline 0.50 & 0.00 & 0.00 & 0.00 & 0.00 & 0.00 & 0.00 & 0.00 & 0.00 & 0.00 & 0.00 & 0.00 & 0.00 \\
\hline 0.54 & 0.00 & 0.00 & 0.00 & 0.00 & 0.00 & 0.00 & 0.00 & 0.00 & 0.00 & 0.00 & 0.00 & 0.00 \\
\hline 0.60 & 0.00 & 0.00 & 0.00 & 0.00 & 0.00 & 0.00 & 0.00 & 0.00 & 0.00 & 0.00 & 0.00 & 0.00 \\
\hline 0.66 & 0.00 & 0.00 & 0.00 & 0.00 & 0.00 & 0.00 & 0.00 & 0.00 & 0.00 & 0.00 & 0.00 & 0.00 \\
\hline 0.72 & 0.00 & 0.00 & 0.00 & 0.00 & 0.00 & 0.00 & 0.00 & 0.00 & 0.00 & 0.00 & 0.00 & 0.00 \\
\hline 0.79 & 0.00 & 0.00 & 0.00 & 0.00 & 0.00 & 0.00 & 0.00 & 0.00 & 0.00 & 0.00 & 0.00 & 0.00 \\
\hline 0.87 & 0.00 & 0.00 & 0.00 & 0.00 & 0.00 & 0.00 & 0.00 & 0.00 & 0.00 & 0.00 & 0.00 & 0.00 \\
\hline 0.95 & 0.00 & 0.00 & 0.00 & 0.00 & 0.00 & 0.00 & 0.00 & 0.00 & 0.00 & 0.00 & 0.00 & 0.00 \\
\hline 1.05 & 0.00 & 0.00 & 0.00 & 0.00 & 0.00 & 0.00 & 0.00 & 0.00 & 0.00 & 0.00 & 0.00 & 0.00 \\
\hline 1.15 & 0.00 & 0.01 & 0.00 & 0.00 & 0.00 & 0.00 & 0.00 & 0.00 & 0.00 & 0.00 & 0.00 & 0.00 \\
\hline 1.26 & 0.01 & 0.04 & 0.00 & 0.02 & 0.01 & 0.00 & 0.00 & 0.00 & 0.03 & 0.00 & 0.01 & 0.00 \\
\hline 1.38 & 0.09 & 0.15 & 0.00 & 0.11 & 0.05 & 0.00 & 0.00 & 0.00 & 0.14 & 0.01 & 0.07 & 0.00 \\
\hline 1.52 & 0.27 & 0.34 & 0.04 & 0.33 & 0.17 & 0.04 & 0.04 & 0.04 & 0.38 & 0.07 & 0.23 & 0.04 \\
\hline 1.67 & 0.56 & 0.59 & 0.21 & 0.65 & 0.40 & 0.20 & 0.19 & 0.19 & 0.70 & 0.23 & 0.53 & 0.18 \\
\hline 1.83 & 0.90 & 0.87 & 0.54 & 1.01 & 0.69 & 0.51 & 0.49 & 0.48 & 1.04 & 0.52 & 0.91 & 0.49 \\
\hline 2.01 & 1.23 & 1.12 & 0.97 & 1.36 & 0.98 & 0.89 & 0.88 & 0.84 & 1.35 & 0.86 & 1.27 & 0.88 \\
\hline 2.21 & 1.51 & 1.31 & 1.35 & 1.66 & 1.21 & 1.23 & 1.22 & 1.15 & 1.62 & 1.16 & 1.57 & 1.25 \\
\hline 2.42 & 1.71 & 1.42 & 1.64 & 1.87 & 1.36 & 1.47 & 1.48 & 1.38 & 1.81 & 1.39 & 1.77 & 1.53 \\
\hline 2.66 & 1.83 & 1.47 & 1.84 & 2.01 & 1.44 & 1.64 & 1.66 & 1.54 & 1.94 & 1.55 & 1.87 & 1.75 \\
\hline 2.92 & 1.87 & 1.47 & 1.95 & 2.08 & 1.46 & 1.72 & 1.77 & 1.62 & 2.00 & 1.64 & 1.89 & 1.88 \\
\hline 3.21 & 1.86 & 1.46 & 2.00 & 2.10 & 1.46 & 1.74 & 1.82 & 1.66 & 2.02 & 1.69 & 1.87 & 1.95 \\
\hline 3.52 & 1.82 & 1.45 & 2.01 & 2.09 & 1.44 & 1.73 & 1.84 & 1.66 & 2.02 & 1.70 & 1.82 & 1.98 \\
\hline 3.86 & 1.78 & 1.45 & 2.02 & 2.07 & 1.43 & 1.72 & 1.86 & 1.66 & 2.01 & 1.71 & 1.79 & 2.01 \\
\hline 4.24 & 1.77 & 1.48 & 2.09 & 2.10 & 1.46 & 1.76 & 1.94 & 1.72 & 2.05 & 1.77 & 1.79 & 2.09 \\
\hline 4.66 & 1.78 & 1.53 & 2.20 & 2.15 & 1.51 & 1.83 & 2.05 & 1.81 & 2.10 & 1.86 & 1.83 & 2.21 \\
\hline 5.11 & 1.83 & 1.63 & 2.37 & 2.25 & 1.61 & 1.94 & 2.21 & 1.95 & 2.20 & 1.99 & 1.91 & 2.37 \\
\hline 5.61 & 1.84 & 1.71 & 2.48 & 2.32 & 1.69 & 2.01 & 2.32 & 2.05 & 2.27 & 2.08 & 1.97 & 2.48 \\
\hline 6.16 & 1.87 & 1.83 & 2.58 & 2.42 & 1.79 & 2.06 & 2.42 & 2.14 & 2.36 & 2.17 & 2.05 & 2.58 \\
\hline 6.76 & 1.88 & 1.90 & 2.63 & 2.49 & 1.86 & 2.07 & 2.48 & 2.20 & 2.44 & 2.22 & 2.10 & 2.63 \\
\hline 7.42 & 1.92 & 1.98 & 2.71 & 2.60 & 1.97 & 2.11 & 2.57 & 2.28 & 2.54 & 2.30 & 2.19 & 2.72 \\
\hline
\end{tabular}




\begin{tabular}{|c|c|c|c|c|c|c|c|c|c|c|c|c|}
\hline $\begin{array}{l}\text { Diameter } \\
(\mu \mathrm{m})\end{array}$ & WS59.5b & WS60 & WS61.5c & WS60.5a & WS61 & WS61.5b & WS61.5d & WS61.5e & WS61.5a & WS61.5f & WS62 & WS62.5 \\
\hline 8.15 & 1.95 & 2.01 & 2.81 & 2.71 & 2.05 & 2.15 & 2.66 & 2.36 & 2.64 & 2.38 & 2.27 & 2.83 \\
\hline 8.94 & 1.98 & 2.00 & 2.89 & 2.81 & 2.11 & 2.19 & 2.73 & 2.43 & 2.71 & 2.46 & 2.34 & 2.93 \\
\hline 9.82 & 2.01 & 2.03 & 2.98 & 2.91 & 2.19 & 2.25 & 2.81 & 2.50 & 2.78 & 2.54 & 2.45 & 3.05 \\
\hline 10.78 & 2.02 & 2.10 & 3.03 & 2.96 & 2.26 & 2.29 & 2.83 & 2.53 & 2.82 & 2.59 & 2.55 & 3.14 \\
\hline 11.83 & 2.11 & 2.30 & 3.12 & 3.07 & 2.44 & 2.39 & 2.91 & 2.60 & 2.94 & 2.66 & 2.76 & 3.30 \\
\hline 12.99 & 2.19 & 2.50 & 3.18 & 3.12 & 2.60 & 2.46 & 2.95 & 2.62 & 3.05 & 2.68 & 2.94 & 3.40 \\
\hline 14.26 & 2.30 & 2.67 & 3.22 & 3.18 & 2.76 & 2.53 & 2.99 & 2.64 & 3.16 & 2.68 & 3.10 & 3.48 \\
\hline 15.65 & 2.33 & 2.67 & 3.14 & 3.12 & 2.77 & 2.50 & 2.93 & 2.56 & 3.13 & 2.57 & 3.08 & 3.40 \\
\hline 17.18 & 2.24 & 2.49 & 2.91 & 2.94 & 2.61 & 2.36 & 2.74 & 2.38 & 2.93 & 2.38 & 2.89 & 3.15 \\
\hline 18.86 & 2.06 & 2.22 & 2.57 & 2.66 & 2.36 & 2.17 & 2.47 & 2.16 & 2.62 & 2.16 & 2.60 & 2.82 \\
\hline 20.71 & 1.82 & 1.96 & 2.19 & 2.33 & 2.11 & 1.96 & 2.18 & 1.91 & 2.27 & 1.93 & 2.32 & 2.50 \\
\hline 22.73 & 1.66 & 1.86 & 1.94 & 2.11 & 2.02 & 1.87 & 2.01 & 1.76 & 2.07 & 1.80 & 2.20 & 2.35 \\
\hline 24.95 & 1.63 & 1.92 & 1.83 & 2.02 & 2.10 & 1.89 & 1.97 & 1.70 & 2.02 & 1.75 & 2.26 & 2.35 \\
\hline 27.39 & 1.78 & 2.13 & 1.90 & 2.07 & 2.33 & 2.03 & 2.07 & 1.77 & 2.11 & 1.81 & 2.47 & 2.49 \\
\hline 30.07 & 2.04 & 2.40 & 2.08 & 2.21 & 2.60 & 2.21 & 2.23 & 1.93 & 2.22 & 1.93 & 2.73 & 2.63 \\
\hline 33.01 & 2.34 & 2.62 & 2.24 & 2.32 & 2.81 & 2.37 & 2.35 & 2.11 & 2.23 & 2.07 & 2.90 & 2.67 \\
\hline 36.24 & 2.56 & 2.75 & 2.30 & 2.31 & 2.90 & 2.45 & 2.36 & 2.26 & 2.07 & 2.20 & 2.92 & 2.59 \\
\hline 39.78 & 2.65 & 2.79 & 2.21 & 2.15 & 2.89 & 2.45 & 2.25 & 2.33 & 1.81 & 2.28 & 2.81 & 2.45 \\
\hline 43.67 & 2.61 & 2.78 & 2.04 & 1.90 & 2.83 & 2.41 & 2.11 & 2.32 & 1.57 & 2.31 & 2.64 & 2.35 \\
\hline 47.94 & 2.54 & 2.77 & 1.89 & 1.65 & 2.80 & 2.37 & 1.98 & 2.24 & 1.48 & 2.29 & 2.49 & 2.35 \\
\hline 52.62 & 2.52 & 2.80 & 1.86 & 1.53 & 2.82 & 2.36 & 1.94 & 2.14 & 1.58 & 2.23 & 2.40 & 2.47 \\
\hline 57.77 & 2.66 & 2.86 & 2.00 & 1.60 & 2.89 & 2.41 & 1.99 & 2.10 & 1.85 & 2.19 & 2.37 & 2.59 \\
\hline 63.41 & 2.98 & 2.93 & 2.29 & 1.87 & 2.94 & 2.49 & 2.09 & 2.15 & 2.16 & 2.18 & 2.35 & 2.55 \\
\hline 69.61 & 3.44 & 2.97 & 2.61 & 2.22 & 2.93 & 2.61 & 2.20 & 2.33 & 2.33 & 2.27 & 2.26 & 2.23 \\
\hline 76.42 & 3.85 & 2.95 & 2.75 & 2.47 & 2.80 & 2.74 & 2.24 & 2.60 & 2.24 & 2.46 & 2.04 & 1.63 \\
\hline 83.89 & 3.99 & 2.84 & 2.56 & 2.40 & 2.56 & 2.84 & 2.19 & 2.89 & 1.89 & 2.69 & 1.68 & 0.90 \\
\hline 92.09 & 3.66 & 2.61 & 1.99 & 1.93 & 2.27 & 2.88 & 2.02 & 3.06 & 1.43 & 2.88 & 1.25 & 0.33 \\
\hline 101.10 & 2.86 & 2.27 & 1.19 & 1.16 & 1.95 & 2.78 & 1.78 & 2.99 & 1.06 & 2.88 & 0.85 & 0.06 \\
\hline 110.98 & 1.80 & 1.84 & 0.50 & 0.47 & 1.64 & 2.49 & 1.50 & 2.65 & 0.86 & 2.62 & 0.57 & 0.00 \\
\hline 121.83 & 0.83 & 1.40 & 0.11 & 0.09 & 1.33 & 1.99 & 1.20 & 2.11 & 0.78 & 2.11 & 0.43 & 0.00 \\
\hline 133.74 & 0.24 & 0.98 & 0.01 & 0.01 & 1.01 & 1.37 & 0.90 & 1.50 & 0.75 & 1.48 & 0.39 & 0.00 \\
\hline 146.82 & 0.03 & 0.65 & 0.00 & 0.00 & 0.70 & 0.73 & 0.61 & 0.96 & 0.65 & 0.89 & 0.39 & 0.00 \\
\hline 161.17 & 0.00 & 0.39 & 0.00 & 0.00 & 0.41 & 0.27 & 0.35 & 0.56 & 0.45 & 0.46 & 0.37 & 0.00 \\
\hline 176.93 & 0.00 & 0.20 & 0.00 & 0.00 & 0.18 & 0.05 & 0.16 & 0.29 & 0.22 & 0.19 & 0.28 & 0.00 \\
\hline 194.22 & 0.00 & 0.08 & 0.00 & 0.00 & 0.05 & 0.00 & 0.05 & 0.12 & 0.07 & 0.07 & 0.15 & 0.00 \\
\hline 213.21 & 0.00 & 0.02 & 0.00 & 0.00 & 0.01 & 0.00 & 0.01 & 0.04 & 0.01 & 0.02 & 0.05 & 0.00 \\
\hline 234.05 & 0.00 & 0.00 & 0.00 & 0.00 & 0.00 & 0.00 & 0.00 & 0.01 & 0.00 & 0.00 & 0.01 & 0.00 \\
\hline 256.94 & 0.00 & 0.00 & 0.00 & 0.00 & 0.00 & 0.00 & 0.00 & 0.00 & 0.00 & 0.00 & 0.00 & 0.00 \\
\hline 282.06 & 0.00 & 0.00 & 0.00 & 0.00 & 0.00 & 0.00 & 0.00 & 0.00 & 0.00 & 0.00 & 0.00 & 0.00 \\
\hline 309.63 & 0.00 & 0.00 & 0.00 & 0.00 & 0.00 & 0.00 & 0.00 & 0.00 & 0.00 & 0.00 & 0.00 & 0.00 \\
\hline 339.90 & 0.00 & 0.00 & 0.00 & 0.00 & 0.00 & 0.00 & 0.00 & 0.00 & 0.00 & 0.00 & 0.00 & 0.00 \\
\hline 373.13 & 0.00 & 0.00 & 0.00 & 0.00 & 0.00 & 0.00 & 0.00 & 0.00 & 0.00 & 0.00 & 0.00 & 0.00 \\
\hline 409.61 & 0.00 & 0.00 & 0.00 & 0.00 & 0.00 & 0.00 & 0.00 & 0.00 & 0.00 & 0.00 & 0.00 & 0.00 \\
\hline
\end{tabular}




\begin{tabular}{|c|c|c|c|c|c|c|c|c|c|c|c|c|}
\hline $\begin{array}{l}\text { Diameter } \\
(\mu \mathrm{m})\end{array}$ & WS59.5b & WS60 & WS61.5c & WS60.5a & WS61 & WS61.5b & WS61.5d & WS61.5e & WS61.5a & WS61.5f & WS62 & WS62.5 \\
\hline 449.66 & 0.00 & 0.00 & 0.00 & 0.00 & 0.00 & 0.00 & 0.00 & 0.00 & 0.00 & 0.00 & 0.00 & 0.00 \\
\hline 493.62 & 0.00 & 0.00 & 0.00 & 0.00 & 0.00 & 0.00 & 0.00 & 0.00 & 0.00 & 0.00 & 0.00 & 0.00 \\
\hline 541.88 & 0.00 & 0.00 & 0.00 & 0.00 & 0.00 & 0.00 & 0.00 & 0.00 & 0.00 & 0.00 & 0.00 & 0.00 \\
\hline 594.85 & 0.00 & 0.00 & 0.00 & 0.00 & 0.00 & 0.00 & 0.00 & 0.00 & 0.00 & 0.00 & 0.00 & 0.00 \\
\hline 653.01 & 0.00 & 0.00 & 0.00 & 0.00 & 0.00 & 0.00 & 0.00 & 0.00 & 0.00 & 0.00 & 0.00 & 0.00 \\
\hline 716.85 & 0.00 & 0.00 & 0.00 & 0.00 & 0.00 & 0.00 & 0.00 & 0.00 & 0.00 & 0.00 & 0.00 & 0.00 \\
\hline 786.93 & 0.00 & 0.00 & 0.00 & 0.00 & 0.00 & 0.00 & 0.00 & 0.00 & 0.00 & 0.00 & 0.00 & 0.00 \\
\hline 863.87 & 0.00 & 0.00 & 0.00 & 0.00 & 0.00 & 0.00 & 0.00 & 0.00 & 0.00 & 0.00 & 0.00 & 0.00 \\
\hline 948.32 & 0.00 & 0.00 & 0.00 & 0.00 & 0.00 & 0.00 & 0.00 & 0.00 & 0.00 & 0.00 & 0.00 & 0.00 \\
\hline 1041.03 & 0.00 & 0.00 & 0.00 & 0.00 & 0.00 & 0.00 & 0.00 & 0.00 & 0.00 & 0.00 & 0.00 & 0.00 \\
\hline 1142.81 & 0.00 & 0.00 & 0.00 & 0.00 & 0.00 & 0.00 & 0.00 & 0.00 & 0.00 & 0.00 & 0.00 & 0.00 \\
\hline 1254.54 & 0.00 & 0.00 & 0.00 & 0.00 & 0.00 & 0.00 & 0.00 & 0.00 & 0.00 & 0.00 & 0.00 & 0.00 \\
\hline 1377.19 & 0.00 & 0.00 & 0.00 & 0.00 & 0.00 & 0.00 & 0.00 & 0.00 & 0.00 & 0.00 & 0.00 & 0.00 \\
\hline 1511.83 & 0.00 & 0.00 & 0.00 & 0.00 & 0.00 & 0.00 & 0.00 & 0.00 & 0.00 & 0.00 & 0.00 & 0.00 \\
\hline 1659.63 & 0.00 & 0.00 & 0.00 & 0.00 & 0.00 & 0.00 & 0.00 & 0.00 & 0.00 & 0.00 & 0.00 & 0.00 \\
\hline 1821.88 & 0.00 & 0.00 & 0.00 & 0.00 & 0.00 & 0.00 & 0.00 & 0.00 & 0.00 & 0.00 & 0.00 & 0.00 \\
\hline 2000 & & & & & & & & & & & & \\
\hline
\end{tabular}

\begin{tabular}{|c|c|c|c|c|c|c|c|c|c|c|c|c|}
\hline $\begin{array}{l}\text { Diameter } \\
(\mu \mathrm{m})\end{array}$ & WS63 & WS63.5a & WS63.5b & WS64.5a & WS64 & WS64.5b & WS64.5c & WS64.5d & WS64.5e & WS64.5f & WS65 & WS66 \\
\hline 0.38 & 0.00 & 0.00 & 0.00 & 0.00 & 0.00 & 0.00 & 0.00 & 0.00 & 0.00 & 0.00 & 0.00 & 0.00 \\
\hline 0.41 & 0.00 & 0.00 & 0.00 & 0.00 & 0.00 & 0.00 & 0.00 & 0.00 & 0.00 & 0.00 & 0.00 & 0.00 \\
\hline 0.45 & 0.00 & 0.00 & 0.00 & 0.00 & 0.00 & 0.00 & 0.00 & 0.00 & 0.00 & 0.00 & 0.00 & 0.00 \\
\hline 0.50 & 0.00 & 0.00 & 0.00 & 0.00 & 0.00 & 0.00 & 0.00 & 0.00 & 0.00 & 0.00 & 0.00 & 0.00 \\
\hline 0.54 & 0.00 & 0.00 & 0.00 & 0.00 & 0.00 & 0.00 & 0.00 & 0.00 & 0.00 & 0.00 & 0.00 & 0.00 \\
\hline 0.60 & 0.00 & 0.00 & 0.00 & 0.00 & 0.00 & 0.00 & 0.00 & 0.00 & 0.00 & 0.00 & 0.00 & 0.00 \\
\hline 0.66 & 0.00 & 0.00 & 0.00 & 0.00 & 0.00 & 0.00 & 0.00 & 0.00 & 0.00 & 0.00 & 0.00 & 0.00 \\
\hline 0.72 & 0.00 & 0.00 & 0.00 & 0.00 & 0.00 & 0.00 & 0.00 & 0.00 & 0.00 & 0.00 & 0.00 & 0.00 \\
\hline 0.79 & 0.00 & 0.00 & 0.00 & 0.00 & 0.00 & 0.00 & 0.00 & 0.00 & 0.00 & 0.00 & 0.00 & 0.00 \\
\hline 0.87 & 0.00 & 0.00 & 0.00 & 0.00 & 0.00 & 0.00 & 0.00 & 0.00 & 0.00 & 0.00 & 0.00 & 0.00 \\
\hline 0.95 & 0.00 & 0.00 & 0.00 & 0.00 & 0.00 & 0.00 & 0.00 & 0.00 & 0.00 & 0.00 & 0.00 & 0.00 \\
\hline 1.05 & 0.00 & 0.00 & 0.00 & 0.00 & 0.00 & 0.00 & 0.00 & 0.00 & 0.00 & 0.00 & 0.00 & 0.00 \\
\hline 1.15 & 0.00 & 0.00 & 0.00 & 0.00 & 0.00 & 0.00 & 0.00 & 0.00 & 0.00 & 0.00 & 0.00 & 0.00 \\
\hline 1.26 & 0.01 & 0.00 & 0.00 & 0.00 & 0.01 & 0.01 & 0.01 & 0.02 & 0.00 & 0.00 & 0.01 & 0.02 \\
\hline 1.38 & 0.07 & 0.00 & 0.00 & 0.01 & 0.06 & 0.05 & 0.07 & 0.11 & 0.01 & 0.01 & 0.08 & 0.10 \\
\hline 1.52 & 0.20 & 0.05 & 0.05 & 0.05 & 0.21 & 0.19 & 0.27 & 0.31 & 0.09 & 0.10 & 0.24 & 0.29 \\
\hline 1.67 & 0.42 & 0.24 & 0.25 & 0.22 & 0.47 & 0.43 & 0.60 & 0.63 & 0.31 & 0.32 & 0.48 & 0.58 \\
\hline 1.83 & 0.67 & 0.63 & 0.65 & 0.52 & 0.80 & 0.73 & 1.02 & 0.99 & 0.66 & 0.70 & 0.77 & 0.90 \\
\hline 2.01 & 0.91 & 1.13 & 1.16 & 0.88 & 1.13 & 1.02 & 1.43 & 1.34 & 1.06 & 1.11 & 1.04 & 1.21 \\
\hline 2.21 & 1.11 & 1.58 & 1.60 & 1.21 & 1.40 & 1.27 & 1.78 & 1.64 & 1.43 & 1.50 & 1.27 & 1.47 \\
\hline 2.42 & 1.24 & 1.90 & 1.92 & 1.45 & 1.56 & 1.45 & 2.03 & 1.84 & 1.71 & 1.79 & 1.43 & 1.65 \\
\hline 2.66 & 1.31 & 2.10 & 2.11 & 1.61 & 1.64 & 1.57 & 2.20 & 1.98 & 1.91 & 2.01 & 1.53 & 1.76 \\
\hline 2.92 & 1.33 & 2.18 & 2.17 & 1.69 & 1.64 & 1.63 & 2.28 & 2.03 & 2.03 & 2.13 & 1.58 & 1.80 \\
\hline
\end{tabular}




\begin{tabular}{|c|c|c|c|c|c|c|c|c|c|c|c|c|}
\hline $\begin{array}{l}\text { Diameter } \\
(\mu \mathrm{m})\end{array}$ & WS63 & WS63.5a & WS63.5b & WS64.5a & WS64 & WS64.5b & WS64.5c & WS64.5d & WS64.5e & WS64.5f & WS65 & WS66 \\
\hline 3.21 & 1.34 & 2.17 & 2.16 & 1.72 & 1.62 & 1.65 & 2.29 & 2.04 & 2.09 & 2.19 & 1.61 & 1.82 \\
\hline 3.52 & 1.33 & 2.12 & 2.10 & 1.72 & 1.57 & 1.64 & 2.27 & 2.01 & 2.11 & 2.21 & 1.62 & 1.81 \\
\hline 3.86 & 1.33 & 2.09 & 2.06 & 1.72 & 1.55 & 1.63 & 2.23 & 1.97 & 2.12 & 2.21 & 1.63 & 1.81 \\
\hline 4.24 & 1.36 & 2.14 & 2.09 & 1.76 & 1.57 & 1.66 & 2.25 & 1.98 & 2.18 & 2.27 & 1.68 & 1.86 \\
\hline 4.66 & 1.40 & 2.24 & 2.18 & 1.84 & 1.62 & 1.72 & 2.29 & 2.01 & 2.27 & 2.36 & 1.75 & 1.93 \\
\hline 5.11 & 1.48 & 2.39 & 2.32 & 1.95 & 1.73 & 1.80 & 2.37 & 2.09 & 2.40 & 2.49 & 1.86 & 2.06 \\
\hline 5.61 & 1.53 & 2.50 & 2.42 & 2.02 & 1.81 & 1.86 & 2.42 & 2.14 & 2.48 & 2.56 & 1.94 & 2.16 \\
\hline 6.16 & 1.61 & 2.57 & 2.49 & 2.07 & 1.92 & 1.94 & 2.48 & 2.21 & 2.55 & 2.63 & 2.05 & 2.30 \\
\hline 6.76 & 1.66 & 2.58 & 2.50 & 2.09 & 2.01 & 1.99 & 2.51 & 2.27 & 2.58 & 2.66 & 2.13 & 2.41 \\
\hline 7.42 & 1.73 & 2.61 & 2.53 & 2.13 & 2.11 & 2.07 & 2.60 & 2.38 & 2.64 & 2.72 & 2.25 & 2.57 \\
\hline 8.15 & 1.80 & 2.62 & 2.56 & 2.17 & 2.18 & 2.16 & 2.69 & 2.50 & 2.72 & 2.80 & 2.36 & 2.72 \\
\hline 8.94 & 1.88 & 2.62 & 2.57 & 2.20 & 2.20 & 2.24 & 2.78 & 2.62 & 2.80 & 2.88 & 2.48 & 2.86 \\
\hline 9.82 & 1.98 & 2.62 & 2.59 & 2.24 & 2.20 & 2.32 & 2.89 & 2.77 & 2.91 & 2.98 & 2.66 & 3.01 \\
\hline 10.78 & 2.09 & 2.59 & 2.57 & 2.26 & 2.17 & 2.37 & 2.98 & 2.90 & 3.00 & 3.05 & 2.84 & 3.13 \\
\hline 11.83 & 2.29 & 2.63 & 2.62 & 2.35 & 2.24 & 2.47 & 3.16 & 3.11 & 3.17 & 3.20 & 3.14 & 3.33 \\
\hline 12.99 & 2.46 & 2.64 & 2.64 & 2.44 & 2.32 & 2.54 & 3.30 & 3.29 & 3.30 & 3.32 & 3.39 & 3.50 \\
\hline 14.26 & 2.61 & 2.65 & 2.67 & 2.54 & 2.46 & 2.59 & 3.42 & 3.45 & 3.43 & 3.42 & 3.59 & 3.67 \\
\hline 15.65 & 2.61 & 2.56 & 2.60 & 2.54 & 2.50 & 2.54 & 3.38 & 3.45 & 3.41 & 3.39 & 3.59 & 3.68 \\
\hline 17.18 & 2.46 & 2.37 & 2.42 & 2.42 & 2.39 & 2.37 & 3.19 & 3.28 & 3.24 & 3.23 & 3.39 & 3.52 \\
\hline 18.86 & 2.21 & 2.12 & 2.17 & 2.20 & 2.16 & 2.14 & 2.93 & 3.02 & 2.99 & 3.00 & 3.09 & 3.25 \\
\hline 20.71 & 1.95 & 1.86 & 1.90 & 1.95 & 1.86 & 1.93 & 2.69 & 2.75 & 2.73 & 2.77 & 2.80 & 2.94 \\
\hline 22.73 & 1.83 & 1.69 & 1.72 & 1.79 & 1.65 & 1.83 & 2.60 & 2.65 & 2.62 & 2.68 & 2.69 & 2.77 \\
\hline 24.95 & 1.87 & 1.63 & 1.65 & 1.76 & 1.59 & 1.83 & 2.64 & 2.71 & 2.65 & 2.71 & 2.77 & 2.76 \\
\hline 27.39 & 2.07 & 1.66 & 1.69 & 1.88 & 1.69 & 1.91 & 2.76 & 2.93 & 2.84 & 2.82 & 3.01 & 2.89 \\
\hline 30.07 & 2.36 & 1.73 & 1.77 & 2.08 & 1.88 & 1.96 & 2.84 & 3.17 & 3.04 & 2.91 & 3.28 & 3.06 \\
\hline 33.01 & 2.61 & 1.78 & 1.84 & 2.25 & 2.06 & 1.91 & 2.80 & 3.30 & 3.14 & 2.86 & 3.43 & 3.13 \\
\hline 36.24 & 2.74 & 1.77 & 1.85 & 2.34 & 2.14 & 1.76 & 2.64 & 3.24 & 3.08 & 2.68 & 3.38 & 3.04 \\
\hline 39.78 & 2.73 & 1.71 & 1.80 & 2.31 & 2.08 & 1.56 & 2.42 & 3.01 & 2.85 & 2.40 & 3.13 & 2.75 \\
\hline 43.67 & 2.63 & 1.64 & 1.72 & 2.22 & 1.93 & 1.43 & 2.24 & 2.69 & 2.54 & 2.12 & 2.76 & 2.36 \\
\hline 47.94 & 2.55 & 1.62 & 1.67 & 2.15 & 1.79 & 1.42 & 2.14 & 2.38 & 2.22 & 1.91 & 2.37 & 1.95 \\
\hline 52.62 & 2.55 & 1.66 & 1.67 & 2.16 & 1.74 & 1.55 & 2.09 & 2.11 & 1.95 & 1.76 & 2.06 & 1.61 \\
\hline 57.77 & 2.68 & 1.77 & 1.74 & 2.29 & 1.82 & 1.76 & 1.97 & 1.89 & 1.73 & 1.63 & 1.84 & 1.37 \\
\hline 63.41 & 2.93 & 1.94 & 1.89 & 2.53 & 2.04 & 1.98 & 1.71 & 1.65 & 1.53 & 1.45 & 1.71 & 1.23 \\
\hline 69.61 & 3.23 & 2.15 & 2.10 & 2.82 & 2.36 & 2.14 & 1.27 & 1.34 & 1.30 & 1.17 & 1.61 & 1.13 \\
\hline 76.42 & 3.47 & 2.37 & 2.33 & 3.06 & 2.72 & 2.23 & 0.72 & 0.96 & 1.01 & 0.80 & 1.46 & 1.01 \\
\hline 83.89 & 3.54 & 2.57 & 2.53 & 3.18 & 3.02 & 2.31 & 0.28 & 0.54 & 0.68 & 0.46 & 1.23 & 0.83 \\
\hline 92.09 & 3.37 & 2.68 & 2.65 & 3.11 & 3.21 & 2.48 & 0.05 & 0.21 & 0.35 & 0.24 & 0.92 & 0.60 \\
\hline 101.10 & 2.99 & 2.64 & 2.62 & 2.84 & 3.23 & 2.78 & 0.00 & 0.05 & 0.13 & 0.16 & 0.60 & 0.35 \\
\hline 110.98 & 2.46 & 2.37 & 2.37 & 2.41 & 3.10 & 3.12 & 0.00 & 0.00 & 0.02 & 0.18 & 0.37 & 0.19 \\
\hline 121.83 & 1.88 & 1.89 & 1.92 & 1.90 & 2.80 & 3.31 & 0.00 & 0.00 & 0.00 & 0.25 & 0.25 & 0.13 \\
\hline 133.74 & 1.35 & 1.28 & 1.33 & 1.36 & 2.33 & 3.16 & 0.00 & 0.00 & 0.00 & 0.30 & 0.21 & 0.13 \\
\hline 146.82 & 0.89 & 0.67 & 0.72 & 0.87 & 1.75 & 2.59 & 0.00 & 0.00 & 0.00 & 0.26 & 0.22 & 0.17 \\
\hline 161.17 & 0.53 & 0.24 & 0.28 & 0.48 & 1.14 & 1.76 & 0.00 & 0.00 & 0.00 & 0.15 & 0.21 & 0.19 \\
\hline
\end{tabular}




\begin{tabular}{|c|c|c|c|c|c|c|c|c|c|c|c|c|}
\hline $\begin{array}{l}\text { Diameter } \\
(\mu \mathrm{m})\end{array}$ & WS63 & WS63.5a & WS63.5b & WS64.5a & WS64 & WS64.5b & WS64.5c & WS64.5d & WS64.5e & WS64.5f & WS65 & WS66 \\
\hline 176.93 & 0.26 & 0.04 & 0.06 & 0.20 & 0.58 & 0.89 & 0.00 & 0.00 & 0.00 & 0.06 & 0.15 & 0.14 \\
\hline 194.22 & 0.09 & 0.00 & 0.01 & 0.06 & 0.20 & 0.31 & 0.00 & 0.00 & 0.00 & 0.01 & 0.07 & 0.07 \\
\hline 213.21 & 0.02 & 0.00 & 0.00 & 0.01 & 0.04 & 0.05 & 0.00 & 0.00 & 0.00 & 0.00 & 0.01 & 0.01 \\
\hline 234.05 & 0.00 & 0.00 & 0.00 & 0.00 & 0.00 & 0.00 & 0.00 & 0.00 & 0.00 & 0.00 & 0.00 & 0.00 \\
\hline 256.94 & 0.00 & 0.00 & 0.00 & 0.00 & 0.00 & 0.00 & 0.00 & 0.00 & 0.00 & 0.00 & 0.00 & 0.00 \\
\hline 282.06 & 0.00 & 0.00 & 0.00 & 0.00 & 0.00 & 0.00 & 0.00 & 0.00 & 0.00 & 0.00 & 0.00 & 0.00 \\
\hline 309.63 & 0.00 & 0.00 & 0.00 & 0.00 & 0.00 & 0.00 & 0.00 & 0.00 & 0.00 & 0.00 & 0.00 & 0.00 \\
\hline 339.90 & 0.00 & 0.00 & 0.00 & 0.00 & 0.00 & 0.00 & 0.00 & 0.00 & 0.00 & 0.00 & 0.00 & 0.00 \\
\hline 373.13 & 0.00 & 0.00 & 0.00 & 0.00 & 0.00 & 0.00 & 0.00 & 0.00 & 0.00 & 0.00 & 0.00 & 0.00 \\
\hline 409.61 & 0.00 & 0.00 & 0.00 & 0.00 & 0.00 & 0.00 & 0.00 & 0.00 & 0.00 & 0.00 & 0.00 & 0.00 \\
\hline 449.66 & 0.00 & 0.00 & 0.00 & 0.00 & 0.00 & 0.00 & 0.00 & 0.00 & 0.00 & 0.00 & 0.00 & 0.00 \\
\hline 493.62 & 0.00 & 0.00 & 0.00 & 0.00 & 0.00 & 0.00 & 0.00 & 0.00 & 0.00 & 0.00 & 0.00 & 0.00 \\
\hline 541.88 & 0.00 & 0.00 & 0.00 & 0.00 & 0.00 & 0.00 & 0.00 & 0.00 & 0.00 & 0.00 & 0.00 & 0.00 \\
\hline 594.85 & 0.00 & 0.00 & 0.00 & 0.00 & 0.00 & 0.00 & 0.00 & 0.00 & 0.00 & 0.00 & 0.00 & 0.00 \\
\hline 653.01 & 0.00 & 0.00 & 0.00 & 0.00 & 0.00 & 0.00 & 0.00 & 0.00 & 0.00 & 0.00 & 0.00 & 0.00 \\
\hline 716.85 & 0.00 & 0.00 & 0.00 & 0.00 & 0.00 & 0.00 & 0.00 & 0.00 & 0.00 & 0.00 & 0.00 & 0.00 \\
\hline 786.93 & 0.00 & 0.00 & 0.00 & 0.00 & 0.00 & 0.00 & 0.00 & 0.00 & 0.00 & 0.00 & 0.00 & 0.00 \\
\hline 863.87 & 0.00 & 0.00 & 0.00 & 0.00 & 0.00 & 0.00 & 0.00 & 0.00 & 0.00 & 0.00 & 0.00 & 0.00 \\
\hline 948.32 & 0.00 & 0.00 & 0.00 & 0.00 & 0.00 & 0.00 & 0.00 & 0.00 & 0.00 & 0.00 & 0.00 & 0.00 \\
\hline 1041.03 & 0.00 & 0.00 & 0.00 & 0.00 & 0.00 & 0.00 & 0.00 & 0.00 & 0.00 & 0.00 & 0.00 & 0.00 \\
\hline 1142.81 & 0.00 & 0.00 & 0.00 & 0.00 & 0.00 & 0.00 & 0.00 & 0.00 & 0.00 & 0.00 & 0.00 & 0.00 \\
\hline 1254.54 & 0.00 & 0.00 & 0.00 & 0.00 & 0.00 & 0.00 & 0.00 & 0.00 & 0.00 & 0.00 & 0.00 & 0.00 \\
\hline 1377.19 & 0.00 & 0.00 & 0.00 & 0.00 & 0.00 & 0.00 & 0.00 & 0.00 & 0.00 & 0.00 & 0.00 & 0.00 \\
\hline 1511.83 & 0.00 & 0.00 & 0.00 & 0.00 & 0.00 & 0.00 & 0.00 & 0.00 & 0.00 & 0.00 & 0.00 & 0.00 \\
\hline 1659.63 & 0.00 & 0.00 & 0.00 & 0.00 & 0.00 & 0.00 & 0.00 & 0.00 & 0.00 & 0.00 & 0.00 & 0.00 \\
\hline 1821.88 & 0.00 & 0.00 & 0.00 & 0.00 & 0.00 & 0.00 & 0.00 & 0.00 & 0.00 & 0.00 & 0.00 & 0.00 \\
\hline 2000 & & & & & & & & & & & & \\
\hline
\end{tabular}

\begin{tabular}{|c|c|c|c|c|c|c|c|c|c|c|c|c|}
\hline $\begin{array}{l}\text { Diameter } \\
(\mu \mathrm{m})\end{array}$ & WS66rep & WS67 & WS68 & WS69 & WS69.5a & WS69.5b & WS69.5c & WS69.5d & WS69.5e & WS70 & WS71 & WS72 \\
\hline 0.38 & 0.00 & 0.00 & 0.00 & 0.00 & 0.00 & 0.00 & 0.00 & 0.00 & 0.00 & 0.00 & 0.00 & 0.00 \\
\hline 0.41 & 0.00 & 0.00 & 0.00 & 0.00 & 0.00 & 0.00 & 0.00 & 0.00 & 0.00 & 0.00 & 0.00 & 0.00 \\
\hline 0.45 & 0.00 & 0.00 & 0.00 & 0.00 & 0.00 & 0.00 & 0.00 & 0.00 & 0.00 & 0.00 & 0.00 & 0.00 \\
\hline 0.50 & 0.00 & 0.00 & 0.00 & 0.00 & 0.00 & 0.00 & 0.00 & 0.00 & 0.00 & 0.00 & 0.00 & 0.00 \\
\hline 0.54 & 0.00 & 0.00 & 0.00 & 0.00 & 0.00 & 0.00 & 0.00 & 0.00 & 0.00 & 0.00 & 0.00 & 0.00 \\
\hline 0.60 & 0.00 & 0.00 & 0.00 & 0.00 & 0.00 & 0.00 & 0.00 & 0.00 & 0.00 & 0.00 & 0.00 & 0.00 \\
\hline 0.66 & 0.00 & 0.00 & 0.00 & 0.00 & 0.00 & 0.00 & 0.00 & 0.00 & 0.00 & 0.00 & 0.00 & 0.00 \\
\hline 0.72 & 0.00 & 0.00 & 0.00 & 0.00 & 0.00 & 0.00 & 0.00 & 0.00 & 0.00 & 0.00 & 0.00 & 0.00 \\
\hline 0.79 & 0.00 & 0.00 & 0.00 & 0.00 & 0.00 & 0.00 & 0.00 & 0.00 & 0.00 & 0.00 & 0.00 & 0.00 \\
\hline 0.87 & 0.00 & 0.00 & 0.00 & 0.00 & 0.00 & 0.00 & 0.00 & 0.00 & 0.00 & 0.00 & 0.00 & 0.00 \\
\hline 0.95 & 0.00 & 0.00 & 0.00 & 0.00 & 0.00 & 0.00 & 0.00 & 0.00 & 0.00 & 0.00 & 0.00 & 0.00 \\
\hline 1.05 & 0.00 & 0.00 & 0.00 & 0.00 & 0.00 & 0.00 & 0.00 & 0.00 & 0.00 & 0.00 & 0.00 & 0.00 \\
\hline 1.15 & 0.00 & 0.00 & 0.00 & 0.00 & 0.00 & 0.00 & 0.00 & 0.00 & 0.00 & 0.00 & 0.00 & 0.00 \\
\hline
\end{tabular}




\begin{tabular}{|c|c|c|c|c|c|c|c|c|c|c|c|c|}
\hline $\begin{array}{l}\text { Diameter } \\
(\mu \mathrm{m})\end{array}$ & WS66rep & WS67 & WS68 & WS69 & WS69.5a & WS69.5b & WS69.5c & WS69.5d & WS69.5e & WS70 & WS71 & WS72 \\
\hline 1.26 & 0.01 & 0.00 & 0.00 & 0.00 & 0.02 & 0.02 & 0.00 & 0.00 & 0.00 & 0.00 & 0.00 & 0.00 \\
\hline 1.38 & 0.08 & 0.02 & 0.03 & 0.02 & 0.10 & 0.12 & 0.03 & 0.02 & 0.01 & 0.00 & 0.00 & 0.01 \\
\hline 1.52 & 0.25 & 0.13 & 0.14 & 0.13 & 0.30 & 0.35 & 0.18 & 0.15 & 0.09 & 0.04 & 0.04 & 0.09 \\
\hline 1.67 & 0.52 & 0.38 & 0.39 & 0.36 & 0.63 & 0.69 & 0.50 & 0.43 & 0.35 & 0.23 & 0.23 & 0.31 \\
\hline 1.83 & 0.85 & 0.75 & 0.76 & 0.70 & 1.01 & 1.07 & 0.99 & 0.87 & 0.82 & 0.59 & 0.62 & 0.68 \\
\hline 2.01 & 1.17 & 1.12 & 1.11 & 1.03 & 1.38 & 1.43 & 1.49 & 1.33 & 1.36 & 1.03 & 1.12 & 1.11 \\
\hline 2.21 & 1.43 & 1.45 & 1.42 & 1.29 & 1.70 & 1.75 & 1.93 & 1.75 & 1.86 & 1.42 & 1.57 & 1.48 \\
\hline 2.42 & 1.61 & 1.66 & 1.62 & 1.45 & 1.94 & 1.98 & 2.27 & 2.06 & 2.22 & 1.68 & 1.90 & 1.72 \\
\hline 2.66 & 1.73 & 1.80 & 1.74 & 1.54 & 2.11 & 2.14 & 2.51 & 2.28 & 2.48 & 1.85 & 2.09 & 1.87 \\
\hline 2.92 & 1.79 & 1.87 & 1.80 & 1.57 & 2.20 & 2.22 & 2.64 & 2.40 & 2.62 & 1.91 & 2.16 & 1.92 \\
\hline 3.21 & 1.81 & 1.89 & 1.82 & 1.57 & 2.25 & 2.25 & 2.70 & 2.45 & 2.67 & 1.93 & 2.16 & 1.93 \\
\hline 3.52 & 1.81 & 1.90 & 1.82 & 1.57 & 2.26 & 2.25 & 2.72 & 2.45 & 2.66 & 1.91 & 2.12 & 1.91 \\
\hline 3.86 & 1.83 & 1.92 & 1.82 & 1.60 & 2.26 & 2.24 & 2.72 & 2.44 & 2.65 & 1.91 & 2.10 & 1.90 \\
\hline 4.24 & 1.89 & 2.00 & 1.87 & 1.68 & 2.31 & 2.28 & 2.80 & 2.50 & 2.71 & 1.99 & 2.16 & 1.97 \\
\hline 4.66 & 1.97 & 2.11 & 1.94 & 1.80 & 2.37 & 2.34 & 2.91 & 2.59 & 2.82 & 2.13 & 2.30 & 2.09 \\
\hline 5.11 & 2.12 & 2.28 & 2.06 & 1.96 & 2.48 & 2.45 & 3.07 & 2.74 & 2.98 & 2.35 & 2.53 & 2.28 \\
\hline 5.61 & 2.23 & 2.41 & 2.14 & 2.08 & 2.56 & 2.52 & 3.18 & 2.84 & 3.08 & 2.52 & 2.70 & 2.43 \\
\hline 6.16 & 2.36 & 2.54 & 2.25 & 2.21 & 2.65 & 2.62 & 3.29 & 2.93 & 3.16 & 2.69 & 2.86 & 2.59 \\
\hline 6.76 & 2.47 & 2.63 & 2.31 & 2.29 & 2.72 & 2.69 & 3.35 & 2.98 & 3.19 & 2.80 & 2.96 & 2.69 \\
\hline 7.42 & 2.62 & 2.75 & 2.41 & 2.38 & 2.83 & 2.80 & 3.45 & 3.07 & 3.26 & 2.95 & 3.10 & 2.85 \\
\hline 8.15 & 2.76 & 2.87 & 2.53 & 2.42 & 2.95 & 2.91 & 3.56 & 3.18 & 3.35 & 3.11 & 3.26 & 3.00 \\
\hline 8.94 & 2.88 & 2.96 & 2.68 & 2.44 & 3.06 & 3.00 & 3.64 & 3.29 & 3.43 & 3.26 & 3.41 & 3.14 \\
\hline 9.82 & 3.02 & 3.09 & 2.87 & 2.51 & 3.19 & 3.09 & 3.72 & 3.43 & 3.54 & 3.42 & 3.57 & 3.30 \\
\hline 10.78 & 3.15 & 3.21 & 3.06 & 2.64 & 3.28 & 3.13 & 3.73 & 3.52 & 3.60 & 3.55 & 3.66 & 3.41 \\
\hline 11.83 & 3.40 & 3.48 & 3.31 & 2.96 & 3.42 & 3.23 & 3.77 & 3.69 & 3.73 & 3.79 & 3.82 & 3.63 \\
\hline 12.99 & 3.61 & 3.75 & 3.48 & 3.31 & 3.50 & 3.29 & 3.75 & 3.81 & 3.84 & 4.00 & 3.94 & 3.82 \\
\hline 14.26 & 3.80 & 4.02 & 3.58 & 3.65 & 3.57 & 3.35 & 3.72 & 3.95 & 3.95 & 4.23 & 4.07 & 4.02 \\
\hline 15.65 & 3.80 & 4.08 & 3.49 & 3.72 & 3.49 & 3.28 & 3.57 & 3.96 & 3.91 & 4.26 & 4.07 & 4.05 \\
\hline 17.18 & 3.59 & 3.89 & 3.23 & 3.53 & 3.26 & 3.07 & 3.29 & 3.80 & 3.67 & 4.08 & 3.89 & 3.87 \\
\hline 18.86 & 3.30 & 3.52 & 2.94 & 3.18 & 2.96 & 2.79 & 2.94 & 3.48 & 3.27 & 3.73 & 3.57 & 3.53 \\
\hline 20.71 & 3.02 & 3.12 & 2.70 & 2.86 & 2.65 & 2.49 & 2.58 & 3.06 & 2.81 & 3.34 & 3.16 & 3.15 \\
\hline 22.73 & 2.94 & 2.90 & 2.65 & 2.78 & 2.47 & 2.34 & 2.32 & 2.74 & 2.53 & 3.11 & 2.87 & 2.92 \\
\hline 24.95 & 3.02 & 2.88 & 2.74 & 2.93 & 2.42 & 2.32 & 2.16 & 2.58 & 2.46 & 3.03 & 2.72 & 2.89 \\
\hline 27.39 & 3.20 & 3.04 & 2.92 & 3.26 & 2.51 & 2.44 & 2.09 & 2.62 & 2.61 & 3.09 & 2.74 & 3.03 \\
\hline 30.07 & 3.30 & 3.18 & 3.02 & 3.56 & 2.62 & 2.58 & 2.01 & 2.77 & 2.81 & 3.12 & 2.80 & 3.21 \\
\hline 33.01 & 3.21 & 3.14 & 2.96 & 3.65 & 2.64 & 2.64 & 1.85 & 2.90 & 2.85 & 2.96 & 2.77 & 3.23 \\
\hline 36.24 & 2.91 & 2.82 & 2.74 & 3.48 & 2.50 & 2.56 & 1.60 & 2.81 & 2.58 & 2.58 & 2.52 & 2.98 \\
\hline 39.78 & 2.51 & 2.29 & 2.44 & 3.13 & 2.21 & 2.35 & 1.29 & 2.44 & 1.99 & 2.05 & 2.04 & 2.48 \\
\hline 43.67 & 2.14 & 1.73 & 2.21 & 2.76 & 1.87 & 2.10 & 1.01 & 1.83 & 1.26 & 1.53 & 1.44 & 1.87 \\
\hline 47.94 & 1.91 & 1.33 & 2.10 & 2.49 & 1.56 & 1.88 & 0.82 & 1.13 & 0.60 & 1.17 & 0.90 & 1.33 \\
\hline 52.62 & 1.81 & 1.15 & 2.11 & 2.36 & 1.35 & 1.73 & 0.73 & 0.52 & 0.19 & 0.99 & 0.56 & 1.00 \\
\hline 57.77 & 1.77 & 1.16 & 2.16 & 2.31 & 1.26 & 1.65 & 0.72 & 0.16 & 0.03 & 0.95 & 0.44 & 0.86 \\
\hline 63.41 & 1.66 & 1.26 & 2.12 & 2.22 & 1.24 & 1.57 & 0.72 & 0.02 & 0.00 & 0.94 & 0.49 & 0.86 \\
\hline
\end{tabular}




\begin{tabular}{|c|c|c|c|c|c|c|c|c|c|c|c|c|}
\hline $\begin{array}{l}\text { Diameter } \\
(\mu \mathrm{m})\end{array}$ & WS66rep & WS67 & WS68 & WS69 & WS69.5a & WS69.5b & WS69.5c & WS69.5d & WS69.5e & WS70 & WS71 & WS72 \\
\hline 69.61 & 1.39 & 1.29 & 1.87 & 1.96 & 1.21 & 1.43 & 0.67 & 0.00 & 0.00 & 0.86 & 0.62 & 0.88 \\
\hline 76.42 & 0.89 & 1.13 & 1.39 & 1.47 & 1.10 & 1.17 & 0.53 & 0.00 & 0.00 & 0.59 & 0.71 & 0.82 \\
\hline 83.89 & 0.38 & 0.72 & 0.81 & 0.83 & 0.85 & 0.81 & 0.32 & 0.00 & 0.00 & 0.28 & 0.63 & 0.57 \\
\hline 92.09 & 0.08 & 0.31 & 0.37 & 0.31 & 0.52 & 0.43 & 0.13 & 0.00 & 0.00 & 0.06 & 0.39 & 0.26 \\
\hline 101.10 & 0.01 & 0.06 & 0.17 & 0.06 & 0.22 & 0.16 & 0.03 & 0.00 & 0.00 & 0.01 & 0.15 & 0.06 \\
\hline 110.98 & 0.00 & 0.01 & 0.16 & 0.00 & 0.06 & 0.03 & 0.00 & 0.00 & 0.00 & 0.00 & 0.03 & 0.01 \\
\hline 121.83 & 0.00 & 0.00 & 0.27 & 0.00 & 0.01 & 0.00 & 0.00 & 0.00 & 0.00 & 0.00 & 0.00 & 0.00 \\
\hline 133.74 & 0.00 & 0.00 & 0.41 & 0.00 & 0.00 & 0.00 & 0.00 & 0.00 & 0.00 & 0.00 & 0.00 & 0.00 \\
\hline 146.82 & 0.00 & 0.00 & 0.45 & 0.00 & 0.00 & 0.00 & 0.00 & 0.00 & 0.00 & 0.00 & 0.00 & 0.00 \\
\hline 161.17 & 0.00 & 0.00 & 0.34 & 0.00 & 0.00 & 0.00 & 0.00 & 0.00 & 0.00 & 0.00 & 0.00 & 0.00 \\
\hline 176.93 & 0.00 & 0.00 & 0.18 & 0.00 & 0.00 & 0.00 & 0.00 & 0.00 & 0.00 & 0.00 & 0.00 & 0.00 \\
\hline 194.22 & 0.00 & 0.00 & 0.05 & 0.00 & 0.00 & 0.00 & 0.00 & 0.00 & 0.00 & 0.00 & 0.00 & 0.00 \\
\hline 213.21 & 0.00 & 0.00 & 0.01 & 0.00 & 0.00 & 0.00 & 0.00 & 0.00 & 0.00 & 0.00 & 0.00 & 0.00 \\
\hline 234.05 & 0.00 & 0.00 & 0.00 & 0.00 & 0.00 & 0.00 & 0.00 & 0.00 & 0.00 & 0.00 & 0.00 & 0.00 \\
\hline 256.94 & 0.00 & 0.00 & 0.00 & 0.00 & 0.00 & 0.00 & 0.00 & 0.00 & 0.00 & 0.00 & 0.00 & 0.00 \\
\hline 282.06 & 0.00 & 0.00 & 0.00 & 0.00 & 0.00 & 0.00 & 0.00 & 0.00 & 0.00 & 0.00 & 0.00 & 0.00 \\
\hline 309.63 & 0.00 & 0.00 & 0.00 & 0.00 & 0.00 & 0.00 & 0.00 & 0.00 & 0.00 & 0.00 & 0.00 & 0.00 \\
\hline 339.90 & 0.00 & 0.00 & 0.00 & 0.00 & 0.00 & 0.00 & 0.00 & 0.00 & 0.00 & 0.00 & 0.00 & 0.00 \\
\hline 373.13 & 0.00 & 0.00 & 0.00 & 0.00 & 0.00 & 0.00 & 0.00 & 0.00 & 0.00 & 0.00 & 0.00 & 0.00 \\
\hline 409.61 & 0.00 & 0.00 & 0.00 & 0.00 & 0.00 & 0.00 & 0.00 & 0.00 & 0.00 & 0.00 & 0.00 & 0.00 \\
\hline 449.66 & 0.00 & 0.00 & 0.00 & 0.00 & 0.00 & 0.00 & 0.00 & 0.00 & 0.00 & 0.00 & 0.00 & 0.00 \\
\hline 493.62 & 0.00 & 0.00 & 0.00 & 0.00 & 0.00 & 0.00 & 0.00 & 0.00 & 0.00 & 0.00 & 0.00 & 0.00 \\
\hline 541.88 & 0.00 & 0.00 & 0.00 & 0.00 & 0.00 & 0.00 & 0.00 & 0.00 & 0.00 & 0.00 & 0.00 & 0.00 \\
\hline 594.85 & 0.00 & 0.00 & 0.00 & 0.00 & 0.00 & 0.00 & 0.00 & 0.00 & 0.00 & 0.00 & 0.00 & 0.00 \\
\hline 653.01 & 0.00 & 0.00 & 0.00 & 0.00 & 0.00 & 0.00 & 0.00 & 0.00 & 0.00 & 0.00 & 0.00 & 0.00 \\
\hline 716.85 & 0.00 & 0.00 & 0.00 & 0.00 & 0.00 & 0.00 & 0.00 & 0.00 & 0.00 & 0.00 & 0.00 & 0.00 \\
\hline 786.93 & 0.00 & 0.00 & 0.00 & 0.00 & 0.00 & 0.00 & 0.00 & 0.00 & 0.00 & 0.00 & 0.00 & 0.00 \\
\hline 863.87 & 0.00 & 0.00 & 0.00 & 0.00 & 0.00 & 0.00 & 0.00 & 0.00 & 0.00 & 0.00 & 0.00 & 0.00 \\
\hline 948.32 & 0.00 & 0.00 & 0.00 & 0.00 & 0.00 & 0.00 & 0.00 & 0.00 & 0.00 & 0.00 & 0.00 & 0.00 \\
\hline 1041.03 & 0.00 & 0.00 & 0.00 & 0.00 & 0.00 & 0.00 & 0.00 & 0.00 & 0.00 & 0.00 & 0.00 & 0.00 \\
\hline 1142.81 & 0.00 & 0.00 & 0.00 & 0.00 & 0.00 & 0.00 & 0.00 & 0.00 & 0.00 & 0.00 & 0.00 & 0.00 \\
\hline 1254.54 & 0.00 & 0.00 & 0.00 & 0.00 & 0.00 & 0.00 & 0.00 & 0.00 & 0.00 & 0.00 & 0.00 & 0.00 \\
\hline 1377.19 & 0.00 & 0.00 & 0.00 & 0.00 & 0.00 & 0.00 & 0.00 & 0.00 & 0.00 & 0.00 & 0.00 & 0.00 \\
\hline 1511.83 & 0.00 & 0.00 & 0.00 & 0.00 & 0.00 & 0.00 & 0.00 & 0.00 & 0.00 & 0.00 & 0.00 & 0.00 \\
\hline 1659.63 & 0.00 & 0.00 & 0.00 & 0.00 & 0.00 & 0.00 & 0.00 & 0.00 & 0.00 & 0.00 & 0.00 & 0.00 \\
\hline 1821.88 & 0.00 & 0.00 & 0.00 & 0.00 & 0.00 & 0.00 & 0.00 & 0.00 & 0.00 & 0.00 & 0.00 & 0.00 \\
\hline 2000 & & & & & & & & & & & & \\
\hline
\end{tabular}




\begin{tabular}{|c|c|c|c|c|c|c|c|c|c|c|c|c|}
\hline $\begin{array}{l}\text { Diameter } \\
(\mu \mathrm{m})\end{array}$ & WS72rep & WS73 & WS74 & WS74.5 & WS75 & WS75.5 & WS76 & WS76.5 & WS76.5rep & WS77 & WS77.5 & WS78 \\
\hline 0.38 & 0.00 & 0.00 & 0.00 & 0.00 & 0.00 & 0.00 & 0.00 & 0.00 & 0.00 & 0.00 & 0.00 & 0.00 \\
\hline 0.41 & 0.00 & 0.00 & 0.00 & 0.00 & 0.00 & 0.00 & 0.00 & 0.00 & 0.00 & 0.00 & 0.00 & 0.00 \\
\hline 0.45 & 0.00 & 0.00 & 0.00 & 0.00 & 0.00 & 0.00 & 0.00 & 0.00 & 0.00 & 0.00 & 0.00 & 0.00 \\
\hline 0.50 & 0.00 & 0.00 & 0.00 & 0.00 & 0.00 & 0.00 & 0.00 & 0.00 & 0.00 & 0.00 & 0.00 & 0.00 \\
\hline 0.54 & 0.00 & 0.00 & 0.00 & 0.00 & 0.00 & 0.00 & 0.00 & 0.00 & 0.00 & 0.00 & 0.00 & 0.00 \\
\hline 0.60 & 0.00 & 0.00 & 0.00 & 0.00 & 0.00 & 0.00 & 0.00 & 0.00 & 0.00 & 0.00 & 0.00 & 0.00 \\
\hline 0.66 & 0.00 & 0.00 & 0.00 & 0.00 & 0.00 & 0.00 & 0.00 & 0.00 & 0.00 & 0.00 & 0.00 & 0.00 \\
\hline 0.72 & 0.00 & 0.00 & 0.00 & 0.00 & 0.00 & 0.00 & 0.00 & 0.00 & 0.00 & 0.00 & 0.00 & 0.00 \\
\hline 0.79 & 0.00 & 0.00 & 0.00 & 0.00 & 0.00 & 0.00 & 0.00 & 0.00 & 0.00 & 0.00 & 0.00 & 0.00 \\
\hline 0.87 & 0.00 & 0.00 & 0.00 & 0.00 & 0.00 & 0.00 & 0.00 & 0.00 & 0.00 & 0.00 & 0.00 & 0.00 \\
\hline 0.95 & 0.00 & 0.00 & 0.00 & 0.00 & 0.00 & 0.00 & 0.00 & 0.00 & 0.00 & 0.00 & 0.00 & 0.00 \\
\hline 1.05 & 0.00 & 0.00 & 0.00 & 0.00 & 0.00 & 0.00 & 0.00 & 0.00 & 0.00 & 0.00 & 0.00 & 0.00 \\
\hline 1.15 & 0.00 & 0.00 & 0.00 & 0.00 & 0.00 & 0.00 & 0.00 & 0.00 & 0.00 & 0.00 & 0.00 & 0.00 \\
\hline 1.26 & 0.00 & 0.00 & 0.00 & 0.00 & 0.00 & 0.00 & 0.00 & 0.00 & 0.00 & 0.00 & 0.00 & 0.02 \\
\hline 1.38 & 0.03 & 0.00 & 0.00 & 0.00 & 0.01 & 0.00 & 0.02 & 0.00 & 0.00 & 0.01 & 0.00 & 0.10 \\
\hline 1.52 & 0.15 & 0.05 & 0.05 & 0.04 & 0.07 & 0.03 & 0.10 & 0.00 & 0.00 & 0.08 & 0.02 & 0.27 \\
\hline 1.67 & 0.42 & 0.23 & 0.23 & 0.21 & 0.29 & 0.19 & 0.32 & 0.06 & 0.06 & 0.33 & 0.16 & 0.51 \\
\hline 1.83 & 0.80 & 0.60 & 0.58 & 0.58 & 0.68 & 0.50 & 0.68 & 0.30 & 0.29 & 0.77 & 0.54 & 0.76 \\
\hline 2.01 & 1.18 & 1.06 & 1.02 & 1.06 & 1.15 & 0.92 & 1.06 & 0.74 & 0.73 & 1.30 & 1.13 & 1.00 \\
\hline 2.21 & 1.51 & 1.44 & 1.37 & 1.51 & 1.54 & 1.33 & 1.39 & 1.30 & 1.29 & 1.75 & 1.77 & 1.18 \\
\hline 2.42 & 1.72 & 1.71 & 1.61 & 1.88 & 1.81 & 1.65 & 1.61 & 1.75 & 1.73 & 2.05 & 2.25 & 1.28 \\
\hline 2.66 & 1.86 & 1.87 & 1.75 & 2.14 & 1.96 & 1.90 & 1.74 & 2.05 & 2.04 & 2.22 & 2.53 & 1.34 \\
\hline 2.92 & 1.91 & 1.93 & 1.79 & 2.30 & 2.00 & 2.05 & 1.78 & 2.17 & 2.18 & 2.27 & 2.59 & 1.34 \\
\hline 3.21 & 1.93 & 1.95 & 1.80 & 2.38 & 1.99 & 2.14 & 1.80 & 2.15 & 2.19 & 2.27 & 2.50 & 1.34 \\
\hline 3.52 & 1.92 & 1.96 & 1.77 & 2.41 & 1.94 & 2.19 & 1.79 & 2.08 & 2.15 & 2.22 & 2.36 & 1.33 \\
\hline 3.86 & 1.92 & 2.00 & 1.76 & 2.44 & 1.91 & 2.24 & 1.80 & 2.06 & 2.14 & 2.20 & 2.29 & 1.34 \\
\hline 4.24 & 1.97 & 2.14 & 1.83 & 2.54 & 1.96 & 2.35 & 1.87 & 2.19 & 2.25 & 2.27 & 2.36 & 1.36 \\
\hline 4.66 & 2.07 & 2.33 & 1.94 & 2.68 & 2.06 & 2.49 & 2.00 & 2.43 & 2.45 & 2.40 & 2.57 & 1.40 \\
\hline 5.11 & 2.22 & 2.58 & 2.12 & 2.87 & 2.24 & 2.68 & 2.19 & 2.75 & 2.73 & 2.62 & 2.87 & 1.46 \\
\hline 5.61 & 2.33 & 2.78 & 2.26 & 3.00 & 2.38 & 2.81 & 2.34 & 2.98 & 2.94 & 2.78 & 3.10 & 1.51 \\
\hline 6.16 & 2.46 & 2.97 & 2.40 & 3.10 & 2.51 & 2.93 & 2.51 & 3.17 & 3.09 & 2.94 & 3.27 & 1.58 \\
\hline 6.76 & 2.55 & 3.07 & 2.49 & 3.15 & 2.59 & 3.00 & 2.62 & 3.25 & 3.14 & 3.03 & 3.31 & 1.62 \\
\hline 7.42 & 2.68 & 3.17 & 2.62 & 3.22 & 2.73 & 3.09 & 2.77 & 3.36 & 3.25 & 3.16 & 3.37 & 1.66 \\
\hline 8.15 & 2.82 & 3.23 & 2.76 & 3.31 & 2.87 & 3.20 & 2.92 & 3.48 & 3.39 & 3.29 & 3.41 & 1.66 \\
\hline 8.94 & 2.95 & 3.26 & 2.90 & 3.39 & 3.02 & 3.31 & 3.04 & 3.58 & 3.57 & 3.41 & 3.44 & 1.66 \\
\hline 9.82 & 3.12 & 3.34 & 3.10 & 3.50 & 3.18 & 3.44 & 3.20 & 3.69 & 3.78 & 3.54 & 3.48 & 1.72 \\
\hline 10.78 & 3.28 & 3.45 & 3.29 & 3.56 & 3.30 & 3.54 & 3.34 & 3.73 & 3.91 & 3.62 & 3.46 & 1.84 \\
\hline 11.83 & 3.54 & 3.75 & 3.60 & 3.68 & 3.51 & 3.71 & 3.62 & 3.85 & 4.04 & 3.78 & 3.52 & 2.13 \\
\hline 12.99 & 3.76 & 4.05 & 3.88 & 3.73 & 3.69 & 3.85 & 3.90 & 3.93 & 4.04 & 3.91 & 3.53 & 2.43 \\
\hline 14.26 & 3.93 & 4.32 & 4.13 & 3.77 & 3.87 & 3.99 & 4.19 & 4.02 & 4.00 & 4.04 & 3.56 & 2.71 \\
\hline 15.65 & 3.90 & 4.34 & 4.18 & 3.65 & 3.89 & 4.01 & 4.29 & 3.98 & 3.83 & 4.01 & 3.52 & 2.79 \\
\hline 17.18 & 3.67 & 4.04 & 3.97 & 3.42 & 3.70 & 3.89 & 4.13 & 3.74 & 3.55 & 3.79 & 3.38 & 2.62 \\
\hline 18.86 & 3.35 & 3.55 & 3.60 & 3.13 & 3.36 & 3.66 & 3.78 & 3.38 & 3.24 & 3.42 & 3.18 & 2.30 \\
\hline
\end{tabular}




\begin{tabular}{|c|c|c|c|c|c|c|c|c|c|c|c|c|}
\hline $\begin{array}{l}\text { Diameter } \\
(\mu \mathrm{m})\end{array}$ & WS72rep & WS73 & WS74 & WS74.5 & WS75 & WS75.5 & WS76 & WS76.5 & WS76.5rep & WS77 & WS77.5 & WS78 \\
\hline 20.71 & 3.06 & 3.00 & 3.19 & 2.84 & 2.97 & 3.34 & 3.36 & 2.97 & 2.93 & 2.98 & 2.94 & 1.97 \\
\hline 22.73 & 2.97 & 2.67 & 2.97 & 2.68 & 2.74 & 3.09 & 3.09 & 2.69 & 2.75 & 2.69 & 2.75 & 1.82 \\
\hline 24.95 & 3.04 & 2.57 & 2.96 & 2.62 & 2.71 & 2.89 & 3.03 & 2.58 & 2.66 & 2.57 & 2.59 & 1.92 \\
\hline 27.39 & 3.21 & 2.68 & 3.14 & 2.61 & 2.89 & 2.81 & 3.16 & 2.62 & 2.66 & 2.61 & 2.48 & 2.27 \\
\hline 30.07 & 3.31 & 2.84 & 3.34 & 2.56 & 3.13 & 2.79 & 3.33 & 2.67 & 2.66 & 2.70 & 2.40 & 2.74 \\
\hline 33.01 & 3.21 & 2.86 & 3.39 & 2.40 & 3.23 & 2.77 & 3.36 & 2.61 & 2.57 & 2.67 & 2.33 & 3.17 \\
\hline 36.24 & 2.89 & 2.61 & 3.17 & 2.15 & 3.08 & 2.69 & 3.11 & 2.36 & 2.35 & 2.40 & 2.26 & 3.40 \\
\hline 39.78 & 2.46 & 2.11 & 2.69 & 1.86 & 2.65 & 2.50 & 2.59 & 1.93 & 2.01 & 1.89 & 2.16 & 3.37 \\
\hline 43.67 & 2.04 & 1.53 & 2.10 & 1.60 & 2.10 & 2.17 & 1.94 & 1.47 & 1.61 & 1.28 & 2.00 & 3.19 \\
\hline 47.94 & 1.74 & 1.05 & 1.59 & 1.41 & 1.59 & 1.71 & 1.35 & 1.10 & 1.24 & 0.77 & 1.73 & 2.99 \\
\hline 52.62 & 1.56 & 0.78 & 1.25 & 1.28 & 1.25 & 1.18 & 0.95 & 0.88 & 0.95 & 0.48 & 1.35 & 2.89 \\
\hline 57.77 & 1.43 & 0.72 & 1.12 & 1.15 & 1.11 & 0.64 & 0.77 & 0.81 & 0.76 & 0.41 & 0.90 & 2.95 \\
\hline 63.41 & 1.26 & 0.79 & 1.10 & 0.96 & 1.10 & 0.25 & 0.75 & 0.83 & 0.67 & 0.51 & 0.46 & 3.13 \\
\hline 69.61 & 0.99 & 0.87 & 1.11 & 0.69 & 1.12 & 0.05 & 0.79 & 0.83 & 0.62 & 0.67 & 0.16 & 3.33 \\
\hline 76.42 & 0.60 & 0.84 & 1.00 & 0.38 & 1.02 & 0.00 & 0.76 & 0.73 & 0.58 & 0.76 & 0.03 & 3.36 \\
\hline 83.89 & 0.24 & 0.59 & 0.68 & 0.14 & 0.70 & 0.00 & 0.55 & 0.48 & 0.48 & 0.64 & 0.00 & 3.10 \\
\hline 92.09 & 0.05 & 0.27 & 0.32 & 0.02 & 0.33 & 0.00 & 0.26 & 0.22 & 0.32 & 0.36 & 0.00 & 2.58 \\
\hline 101.10 & 0.00 & 0.06 & 0.07 & 0.00 & 0.07 & 0.00 & 0.06 & 0.05 & 0.14 & 0.12 & 0.00 & 1.95 \\
\hline 110.98 & 0.00 & 0.01 & 0.01 & 0.00 & 0.01 & 0.00 & 0.01 & 0.00 & 0.04 & 0.02 & 0.00 & 1.42 \\
\hline 121.83 & 0.00 & 0.00 & 0.00 & 0.00 & 0.00 & 0.00 & 0.00 & 0.00 & 0.00 & 0.00 & 0.00 & 1.08 \\
\hline 133.74 & 0.00 & 0.00 & 0.00 & 0.00 & 0.00 & 0.00 & 0.00 & 0.00 & 0.00 & 0.00 & 0.00 & 0.91 \\
\hline 146.82 & 0.00 & 0.00 & 0.00 & 0.00 & 0.00 & 0.00 & 0.00 & 0.00 & 0.00 & 0.00 & 0.00 & 0.82 \\
\hline 161.17 & 0.00 & 0.00 & 0.00 & 0.00 & 0.00 & 0.00 & 0.00 & 0.00 & 0.00 & 0.00 & 0.00 & 0.69 \\
\hline 176.93 & 0.00 & 0.00 & 0.00 & 0.00 & 0.00 & 0.00 & 0.00 & 0.00 & 0.00 & 0.00 & 0.00 & 0.44 \\
\hline 194.22 & 0.00 & 0.00 & 0.00 & 0.00 & 0.00 & 0.00 & 0.00 & 0.00 & 0.00 & 0.00 & 0.00 & 0.19 \\
\hline 213.21 & 0.00 & 0.00 & 0.00 & 0.00 & 0.00 & 0.00 & 0.00 & 0.00 & 0.00 & 0.00 & 0.00 & 0.04 \\
\hline 234.05 & 0.00 & 0.00 & 0.00 & 0.00 & 0.00 & 0.00 & 0.00 & 0.00 & 0.00 & 0.00 & 0.00 & 0.00 \\
\hline 256.94 & 0.00 & 0.00 & 0.00 & 0.00 & 0.00 & 0.00 & 0.00 & 0.00 & 0.00 & 0.00 & 0.00 & 0.00 \\
\hline 282.06 & 0.00 & 0.00 & 0.00 & 0.00 & 0.00 & 0.00 & 0.00 & 0.00 & 0.00 & 0.00 & 0.00 & 0.00 \\
\hline 309.63 & 0.00 & 0.00 & 0.00 & 0.00 & 0.00 & 0.00 & 0.00 & 0.00 & 0.00 & 0.00 & 0.00 & 0.00 \\
\hline 339.90 & 0.00 & 0.00 & 0.00 & 0.00 & 0.00 & 0.00 & 0.00 & 0.00 & 0.00 & 0.00 & 0.00 & 0.00 \\
\hline 373.13 & 0.00 & 0.00 & 0.00 & 0.00 & 0.00 & 0.00 & 0.00 & 0.00 & 0.00 & 0.00 & 0.00 & 0.00 \\
\hline 409.61 & 0.00 & 0.00 & 0.00 & 0.00 & 0.00 & 0.00 & 0.00 & 0.00 & 0.00 & 0.00 & 0.00 & 0.00 \\
\hline 449.66 & 0.00 & 0.00 & 0.00 & 0.00 & 0.00 & 0.00 & 0.00 & 0.00 & 0.00 & 0.00 & 0.00 & 0.00 \\
\hline 493.62 & 0.00 & 0.00 & 0.00 & 0.00 & 0.00 & 0.00 & 0.00 & 0.00 & 0.00 & 0.00 & 0.00 & 0.00 \\
\hline 541.88 & 0.00 & 0.00 & 0.00 & 0.00 & 0.00 & 0.00 & 0.00 & 0.00 & 0.00 & 0.00 & 0.00 & 0.00 \\
\hline 594.85 & 0.00 & 0.00 & 0.00 & 0.00 & 0.00 & 0.00 & 0.00 & 0.00 & 0.00 & 0.00 & 0.00 & 0.00 \\
\hline 653.01 & 0.00 & 0.00 & 0.00 & 0.00 & 0.00 & 0.00 & 0.00 & 0.00 & 0.00 & 0.00 & 0.00 & 0.00 \\
\hline 716.85 & 0.00 & 0.00 & 0.00 & 0.00 & 0.00 & 0.00 & 0.00 & 0.00 & 0.00 & 0.00 & 0.00 & 0.00 \\
\hline 786.93 & 0.00 & 0.00 & 0.00 & 0.00 & 0.00 & 0.00 & 0.00 & 0.00 & 0.00 & 0.00 & 0.00 & 0.00 \\
\hline 863.87 & 0.00 & 0.00 & 0.00 & 0.00 & 0.00 & 0.00 & 0.00 & 0.00 & 0.00 & 0.00 & 0.00 & 0.00 \\
\hline 948.32 & 0.00 & 0.00 & 0.00 & 0.00 & 0.00 & 0.00 & 0.00 & 0.00 & 0.00 & 0.00 & 0.00 & 0.00 \\
\hline 1041.03 & 0.00 & 0.00 & 0.00 & 0.00 & 0.00 & 0.00 & 0.00 & 0.00 & 0.00 & 0.00 & 0.00 & 0.00 \\
\hline
\end{tabular}




\begin{tabular}{|c|c|c|c|c|c|c|c|c|c|c|c|c|}
\hline $\begin{array}{l}\text { Diameter } \\
(\mu \mathrm{m})\end{array}$ & WS72rep & WS73 & WS74 & WS74.5 & WS75 & WS75.5 & WS76 & WS76.5 & WS76.5rep & WS77 & WS77.5 & WS78 \\
\hline 1142.81 & 0.00 & 0.00 & 0.00 & 0.00 & 0.00 & 0.00 & 0.00 & 0.00 & 0.00 & 0.00 & 0.00 & 0.00 \\
\hline 1254.54 & 0.00 & 0.00 & 0.00 & 0.00 & 0.00 & 0.00 & 0.00 & 0.00 & 0.00 & 0.00 & 0.00 & 0.00 \\
\hline 1377.19 & 0.00 & 0.00 & 0.00 & 0.00 & 0.00 & 0.00 & 0.00 & 0.00 & 0.00 & 0.00 & 0.00 & 0.00 \\
\hline 1511.83 & 0.00 & 0.00 & 0.00 & 0.00 & 0.00 & 0.00 & 0.00 & 0.00 & 0.00 & 0.00 & 0.00 & 0.00 \\
\hline 1659.63 & 0.00 & 0.00 & 0.00 & 0.00 & 0.00 & 0.00 & 0.00 & 0.00 & 0.00 & 0.00 & 0.00 & 0.00 \\
\hline 1821.88 & 0.00 & 0.00 & 0.00 & 0.00 & 0.00 & 0.00 & 0.00 & 0.00 & 0.00 & 0.00 & 0.00 & 0.00 \\
\hline 2000 & & & & & & & & & & & & \\
\hline
\end{tabular}

\begin{tabular}{|c|c|c|c|c|c|c|c|c|c|c|c|c|}
\hline $\begin{array}{l}\text { Diameter } \\
(\mu \mathrm{m})\end{array}$ & WS79 & WS79.5a & $\begin{array}{c}\text { WS79.5a } \\
\text { rep }\end{array}$ & WS79.5c & WS79.5d & WS80 & WS80.5 & WS81 & WS81.5a & WS81.5b & WS81.5c & WS81.5d \\
\hline 0.38 & 0.00 & 0.00 & 0.00 & 0.00 & 0.00 & 0.00 & 0.00 & 0.00 & 0.00 & 0.00 & 0.00 & 0.00 \\
\hline 0.41 & 0.00 & 0.00 & 0.00 & 0.00 & 0.00 & 0.00 & 0.00 & 0.00 & 0.00 & 0.00 & 0.00 & 0.00 \\
\hline 0.45 & 0.00 & 0.00 & 0.00 & 0.00 & 0.00 & 0.00 & 0.00 & 0.00 & 0.00 & 0.00 & 0.00 & 0.00 \\
\hline 0.50 & 0.00 & 0.00 & 0.00 & 0.00 & 0.00 & 0.00 & 0.00 & 0.00 & 0.00 & 0.00 & 0.00 & 0.00 \\
\hline 0.54 & 0.00 & 0.00 & 0.00 & 0.00 & 0.00 & 0.00 & 0.00 & 0.00 & 0.00 & 0.00 & 0.00 & 0.00 \\
\hline 0.60 & 0.00 & 0.00 & 0.00 & 0.00 & 0.00 & 0.00 & 0.00 & 0.00 & 0.00 & 0.00 & 0.00 & 0.00 \\
\hline 0.66 & 0.00 & 0.00 & 0.00 & 0.00 & 0.00 & 0.00 & 0.00 & 0.00 & 0.00 & 0.00 & 0.00 & 0.00 \\
\hline 0.72 & 0.00 & 0.00 & 0.00 & 0.00 & 0.00 & 0.00 & 0.00 & 0.00 & 0.00 & 0.00 & 0.00 & 0.00 \\
\hline 0.79 & 0.00 & 0.00 & 0.00 & 0.00 & 0.00 & 0.00 & 0.00 & 0.00 & 0.00 & 0.00 & 0.00 & 0.00 \\
\hline 0.87 & 0.00 & 0.00 & 0.00 & 0.00 & 0.00 & 0.00 & 0.00 & 0.00 & 0.00 & 0.00 & 0.00 & 0.00 \\
\hline 0.95 & 0.00 & 0.00 & 0.00 & 0.00 & 0.00 & 0.00 & 0.00 & 0.00 & 0.00 & 0.00 & 0.00 & 0.00 \\
\hline 1.05 & 0.00 & 0.00 & 0.00 & 0.00 & 0.00 & 0.00 & 0.00 & 0.00 & 0.00 & 0.00 & 0.00 & 0.00 \\
\hline 1.15 & 0.00 & 0.00 & 0.00 & 0.00 & 0.00 & 0.00 & 0.00 & 0.00 & 0.00 & 0.00 & 0.00 & 0.00 \\
\hline 1.26 & 0.00 & 0.00 & 0.00 & 0.00 & 0.00 & 0.00 & 0.00 & 0.00 & 0.00 & 0.00 & 0.00 & 0.00 \\
\hline 1.38 & 0.00 & 0.00 & 0.00 & 0.00 & 0.00 & 0.00 & 0.02 & 0.00 & 0.00 & 0.00 & 0.00 & 0.00 \\
\hline 1.52 & 0.01 & 0.03 & 0.02 & 0.02 & 0.02 & 0.01 & 0.13 & 0.00 & 0.00 & 0.00 & 0.00 & 0.02 \\
\hline 1.67 & 0.08 & 0.17 & 0.13 & 0.15 & 0.15 & 0.04 & 0.36 & 0.05 & 0.03 & 0.04 & 0.05 & 0.13 \\
\hline 1.83 & 0.25 & 0.48 & 0.40 & 0.47 & 0.48 & 0.16 & 0.69 & 0.22 & 0.15 & 0.21 & 0.27 & 0.37 \\
\hline 2.01 & 0.51 & 0.88 & 0.80 & 0.95 & 0.96 & 0.39 & 1.03 & 0.53 & 0.42 & 0.54 & 0.67 & 0.73 \\
\hline 2.21 & 0.78 & 1.26 & 1.20 & 1.43 & 1.45 & 0.75 & 1.32 & 0.90 & 0.80 & 0.96 & 1.15 & 1.09 \\
\hline 2.42 & 0.99 & 1.55 & 1.52 & 1.78 & 1.79 & 1.19 & 1.49 & 1.18 & 1.15 & 1.31 & 1.52 & 1.36 \\
\hline 2.66 & 1.13 & 1.74 & 1.73 & 1.94 & 1.95 & 1.68 & 1.59 & 1.34 & 1.41 & 1.55 & 1.76 & 1.52 \\
\hline 2.92 & 1.20 & 1.83 & 1.82 & 1.94 & 1.94 & 2.12 & 1.61 & 1.39 & 1.52 & 1.65 & 1.83 & 1.58 \\
\hline 3.21 & 1.23 & 1.84 & 1.83 & 1.83 & 1.82 & 2.41 & 1.61 & 1.34 & 1.51 & 1.65 & 1.80 & 1.57 \\
\hline 3.52 & 1.24 & 1.81 & 1.80 & 1.68 & 1.67 & 2.54 & 1.59 & 1.27 & 1.44 & 1.60 & 1.73 & 1.55 \\
\hline 3.86 & 1.27 & 1.79 & 1.79 & 1.59 & 1.58 & 2.52 & 1.59 & 1.21 & 1.43 & 1.60 & 1.70 & 1.55 \\
\hline 4.24 & 1.36 & 1.84 & 1.84 & 1.63 & 1.63 & 2.39 & 1.63 & 1.24 & 1.54 & 1.69 & 1.78 & 1.64 \\
\hline 4.66 & 1.49 & 1.94 & 1.95 & 1.79 & 1.81 & 2.17 & 1.70 & 1.34 & 1.73 & 1.87 & 1.94 & 1.78 \\
\hline 5.11 & 1.68 & 2.09 & 2.11 & 2.03 & 2.07 & 1.98 & 1.81 & 1.49 & 1.96 & 2.09 & 2.17 & 1.97 \\
\hline 5.61 & 1.82 & 2.20 & 2.21 & 2.21 & 2.27 & 1.88 & 1.89 & 1.61 & 2.10 & 2.23 & 2.33 & 2.11 \\
\hline 6.16 & 1.96 & 2.30 & 2.29 & 2.32 & 2.38 & 1.91 & 1.98 & 1.70 & 2.18 & 2.33 & 2.44 & 2.22 \\
\hline 6.76 & 2.04 & 2.35 & 2.32 & 2.32 & 2.32 & 2.07 & 2.03 & 1.74 & 2.16 & 2.34 & 2.45 & 2.26 \\
\hline 7.42 & 2.15 & 2.45 & 2.38 & 2.28 & 2.23 & 2.26 & 2.10 & 1.80 & 2.18 & 2.37 & 2.48 & 2.31 \\
\hline
\end{tabular}




\begin{tabular}{|c|c|c|c|c|c|c|c|c|c|c|c|c|}
\hline $\begin{array}{l}\text { Diameter } \\
(\mu \mathrm{m})\end{array}$ & WS79 & WS79.5a & $\begin{array}{c}\text { WS79.5a } \\
\text { rep }\end{array}$ & WS79.5c & WS79.5d & WS80 & WS80.5 & WS81 & WS81.5a & WS81.5b & WS81.5c & WS81.5d \\
\hline 8.15 & 2.27 & 2.57 & 2.47 & 2.22 & 2.16 & 2.48 & 2.14 & 1.88 & 2.22 & 2.42 & 2.51 & 2.35 \\
\hline 8.94 & 2.40 & 2.71 & 2.57 & 2.15 & 2.19 & 2.60 & 2.15 & 1.97 & 2.30 & 2.48 & 2.57 & 2.42 \\
\hline 9.82 & 2.59 & 2.89 & 2.73 & 2.13 & 2.37 & 2.69 & 2.17 & 2.09 & 2.47 & 2.60 & 2.69 & 2.55 \\
\hline 10.78 & 2.82 & 3.06 & 2.90 & 2.13 & 2.62 & 2.69 & 2.16 & 2.17 & 2.64 & 2.75 & 2.82 & 2.73 \\
\hline 11.83 & 3.21 & 3.32 & 3.17 & 2.25 & 2.94 & 2.61 & 2.21 & 2.31 & 2.91 & 3.00 & 3.06 & 3.06 \\
\hline 12.99 & 3.60 & 3.52 & 3.41 & 2.38 & 3.11 & 2.51 & 2.24 & 2.41 & 3.10 & 3.24 & 3.26 & 3.36 \\
\hline 14.26 & 3.97 & 3.69 & 3.63 & 2.51 & 3.13 & 2.38 & 2.27 & 2.50 & 3.25 & 3.44 & 3.44 & 3.64 \\
\hline 15.65 & 4.11 & 3.68 & 3.64 & 2.51 & 2.91 & 2.35 & 2.21 & 2.48 & 3.22 & 3.46 & 3.43 & 3.68 \\
\hline 17.18 & 3.98 & 3.54 & 3.48 & 2.33 & 2.57 & 2.34 & 2.06 & 2.36 & 3.06 & 3.27 & 3.23 & 3.50 \\
\hline 18.86 & 3.67 & 3.33 & 3.22 & 2.03 & 2.27 & 2.38 & 1.87 & 2.21 & 2.83 & 2.95 & 2.92 & 3.19 \\
\hline 20.71 & 3.33 & 3.16 & 2.97 & 1.69 & 2.07 & 2.37 & 1.66 & 2.06 & 2.64 & 2.62 & 2.61 & 2.89 \\
\hline 22.73 & 3.21 & 3.14 & 2.91 & 1.46 & 2.06 & 2.28 & 1.55 & 2.02 & 2.60 & 2.46 & 2.48 & 2.79 \\
\hline 24.95 & 3.32 & 3.21 & 3.00 & 1.40 & 2.16 & 2.14 & 1.52 & 2.08 & 2.70 & 2.47 & 2.53 & 2.89 \\
\hline 27.39 & 3.65 & 3.33 & 3.22 & 1.49 & 2.30 & 1.97 & 1.57 & 2.24 & 2.92 & 2.64 & 2.72 & 3.15 \\
\hline 30.07 & 4.01 & 3.38 & 3.40 & 1.66 & 2.36 & 1.87 & 1.64 & 2.41 & 3.15 & 2.83 & 2.92 & 3.40 \\
\hline 33.01 & 4.19 & 3.31 & 3.43 & 1.79 & 2.28 & 1.81 & 1.65 & 2.53 & 3.29 & 2.90 & 2.96 & 3.48 \\
\hline 36.24 & 4.07 & 3.15 & 3.28 & 1.78 & 2.09 & 1.81 & 1.58 & 2.57 & 3.27 & 2.77 & 2.77 & 3.33 \\
\hline 39.78 & 3.64 & 2.97 & 3.00 & 1.60 & 1.85 & 1.80 & 1.44 & 2.54 & 3.08 & 2.48 & 2.39 & 2.96 \\
\hline 43.67 & 3.08 & 2.85 & 2.72 & 1.35 & 1.64 & 1.75 & 1.27 & 2.48 & 2.78 & 2.16 & 1.96 & 2.50 \\
\hline 47.94 & 2.55 & 2.73 & 2.51 & 1.12 & 1.50 & 1.62 & 1.12 & 2.42 & 2.42 & 1.92 & 1.62 & 2.10 \\
\hline 52.62 & 2.17 & 2.55 & 2.36 & 1.01 & 1.40 & 1.45 & 1.00 & 2.37 & 2.04 & 1.82 & 1.45 & 1.82 \\
\hline 57.77 & 1.97 & 2.20 & 2.23 & 1.05 & 1.33 & 1.25 & 0.94 & 2.33 & 1.70 & 1.83 & 1.44 & 1.68 \\
\hline 63.41 & 1.87 & 1.66 & 2.00 & 1.23 & 1.27 & 1.08 & 0.91 & 2.30 & 1.44 & 1.89 & 1.52 & 1.64 \\
\hline 69.61 & 1.76 & 0.98 & 1.62 & 1.49 & 1.21 & 1.00 & 0.93 & 2.32 & 1.31 & 1.86 & 1.60 & 1.65 \\
\hline 76.42 & 1.51 & 0.41 & 1.12 & 1.71 & 1.20 & 0.99 & 1.00 & 2.41 & 1.32 & 1.68 & 1.56 & 1.65 \\
\hline 83.89 & 1.07 & 0.09 & 0.59 & 1.81 & 1.30 & 1.07 & 1.14 & 2.59 & 1.48 & 1.37 & 1.37 & 1.59 \\
\hline 92.09 & 0.56 & 0.01 & 0.21 & 1.79 & 1.58 & 1.22 & 1.38 & 2.86 & 1.74 & 1.06 & 1.13 & 1.44 \\
\hline 101.10 & 0.18 & 0.00 & 0.04 & 1.78 & 2.06 & 1.45 & 1.81 & 3.13 & 1.98 & 0.89 & 0.95 & 1.20 \\
\hline 110.98 & 0.03 & 0.00 & 0.00 & 1.90 & 2.61 & 1.76 & 2.47 & 3.28 & 2.05 & 0.91 & 0.92 & 0.88 \\
\hline 121.83 & 0.00 & 0.00 & 0.00 & 2.23 & 3.01 & 2.14 & 3.35 & 3.17 & 1.84 & 1.08 & 1.01 & 0.50 \\
\hline 133.74 & 0.00 & 0.00 & 0.00 & 2.73 & 2.98 & 2.53 & 4.26 & 2.75 & 1.38 & 1.28 & 1.13 & 0.20 \\
\hline 146.82 & 0.00 & 0.00 & 0.00 & 3.22 & 2.45 & 2.80 & 4.83 & 2.09 & 0.78 & 1.32 & 1.13 & 0.04 \\
\hline 161.17 & 0.00 & 0.00 & 0.00 & 3.42 & 1.57 & 2.79 & 4.76 & 1.35 & 0.30 & 1.11 & 0.94 & 0.00 \\
\hline 176.93 & 0.00 & 0.00 & 0.00 & 3.17 & 0.71 & 2.41 & 3.96 & 0.67 & 0.06 & 0.68 & 0.59 & 0.00 \\
\hline 194.22 & 0.00 & 0.00 & 0.00 & 2.49 & 0.19 & 1.75 & 2.69 & 0.23 & 0.00 & 0.28 & 0.25 & 0.00 \\
\hline 213.21 & 0.00 & 0.00 & 0.00 & 1.59 & 0.03 & 0.96 & 1.35 & 0.04 & 0.00 & 0.06 & 0.06 & 0.00 \\
\hline 234.05 & 0.00 & 0.00 & 0.00 & 0.75 & 0.00 & 0.36 & 0.45 & 0.00 & 0.00 & 0.00 & 0.01 & 0.00 \\
\hline 256.94 & 0.00 & 0.00 & 0.00 & 0.23 & 0.00 & 0.07 & 0.08 & 0.00 & 0.00 & 0.00 & 0.00 & 0.00 \\
\hline 282.06 & 0.00 & 0.00 & 0.00 & 0.04 & 0.00 & 0.01 & 0.00 & 0.00 & 0.00 & 0.00 & 0.00 & 0.00 \\
\hline 309.63 & 0.00 & 0.00 & 0.00 & 0.00 & 0.00 & 0.00 & 0.00 & 0.00 & 0.00 & 0.00 & 0.00 & 0.00 \\
\hline 339.90 & 0.00 & 0.00 & 0.00 & 0.00 & 0.00 & 0.00 & 0.00 & 0.00 & 0.00 & 0.00 & 0.00 & 0.00 \\
\hline 373.13 & 0.00 & 0.00 & 0.00 & 0.00 & 0.00 & 0.00 & 0.00 & 0.00 & 0.00 & 0.00 & 0.00 & 0.00 \\
\hline 409.61 & 0.00 & 0.00 & 0.00 & 0.00 & 0.00 & 0.00 & 0.00 & 0.00 & 0.00 & 0.00 & 0.00 & 0.00 \\
\hline
\end{tabular}




\begin{tabular}{|c|c|c|c|c|c|c|c|c|c|c|c|c|}
\hline $\begin{array}{l}\text { Diameter } \\
(\mu \mathrm{m})\end{array}$ & WS79 & WS79.5a & $\begin{array}{c}\text { WS79.5a } \\
\text { rep }\end{array}$ & WS79.5c & WS79.5d & WS80 & WS80.5 & WS81 & WS81.5a & WS81.5b & WS81.5c & WS81.5d \\
\hline 449.66 & 0.00 & 0.00 & 0.00 & 0.00 & 0.00 & 0.00 & 0.00 & 0.00 & 0.00 & 0.00 & 0.00 & 0.00 \\
\hline 493.62 & 0.00 & 0.00 & 0.00 & 0.00 & 0.00 & 0.00 & 0.00 & 0.00 & 0.00 & 0.00 & 0.00 & 0.00 \\
\hline 541.88 & 0.00 & 0.00 & 0.00 & 0.00 & 0.00 & 0.00 & 0.00 & 0.00 & 0.00 & 0.00 & 0.00 & 0.00 \\
\hline 594.85 & 0.00 & 0.00 & 0.00 & 0.00 & 0.00 & 0.00 & 0.00 & 0.00 & 0.00 & 0.00 & 0.00 & 0.00 \\
\hline 653.01 & 0.00 & 0.00 & 0.00 & 0.00 & 0.00 & 0.00 & 0.00 & 0.00 & 0.00 & 0.00 & 0.00 & 0.00 \\
\hline 716.85 & 0.00 & 0.00 & 0.00 & 0.00 & 0.00 & 0.00 & 0.00 & 0.00 & 0.00 & 0.00 & 0.00 & 0.00 \\
\hline 786.93 & 0.00 & 0.00 & 0.00 & 0.00 & 0.00 & 0.00 & 0.00 & 0.00 & 0.00 & 0.00 & 0.00 & 0.00 \\
\hline 863.87 & 0.00 & 0.00 & 0.00 & 0.00 & 0.00 & 0.00 & 0.00 & 0.00 & 0.00 & 0.00 & 0.00 & 0.00 \\
\hline 948.32 & 0.00 & 0.00 & 0.00 & 0.00 & 0.00 & 0.00 & 0.00 & 0.00 & 0.00 & 0.00 & 0.00 & 0.00 \\
\hline 1041.03 & 0.00 & 0.00 & 0.00 & 0.00 & 0.00 & 0.00 & 0.00 & 0.00 & 0.00 & 0.00 & 0.00 & 0.00 \\
\hline 1142.81 & 0.00 & 0.00 & 0.00 & 0.00 & 0.00 & 0.00 & 0.00 & 0.00 & 0.00 & 0.00 & 0.00 & 0.00 \\
\hline 1254.54 & 0.00 & 0.00 & 0.00 & 0.00 & 0.00 & 0.00 & 0.00 & 0.00 & 0.00 & 0.00 & 0.00 & 0.00 \\
\hline 1377.19 & 0.00 & 0.00 & 0.00 & 0.00 & 0.00 & 0.00 & 0.00 & 0.00 & 0.00 & 0.00 & 0.00 & 0.00 \\
\hline 1511.83 & 0.00 & 0.00 & 0.00 & 0.00 & 0.00 & 0.00 & 0.00 & 0.00 & 0.00 & 0.00 & 0.00 & 0.00 \\
\hline 1659.63 & 0.00 & 0.00 & 0.00 & 0.00 & 0.00 & 0.00 & 0.00 & 0.00 & 0.00 & 0.00 & 0.00 & 0.00 \\
\hline 1821.88 & 0.00 & 0.00 & 0.00 & 0.00 & 0.00 & 0.00 & 0.00 & 0.00 & 0.00 & 0.00 & 0.00 & 0.00 \\
\hline 2000 & & & & & & & & & & & & \\
\hline
\end{tabular}

\begin{tabular}{|c|c|c|c|c|c|c|c|}
\hline Diameter $(\mu \mathrm{m})$ & WS81.5e & WS81.5f & WS81.5g & WS81.5h & WS81.5i & WS82 & WS83 \\
\hline 0.38 & 0.00 & 0.00 & 0.00 & 0.00 & 0.00 & 0.00 & 0.00 \\
\hline 0.41 & 0.00 & 0.00 & 0.00 & 0.00 & 0.00 & 0.00 & 0.00 \\
\hline 0.45 & 0.00 & 0.00 & 0.00 & 0.00 & 0.00 & 0.00 & 0.00 \\
\hline 0.50 & 0.00 & 0.00 & 0.00 & 0.00 & 0.00 & 0.00 & 0.00 \\
\hline 0.54 & 0.00 & 0.00 & 0.00 & 0.00 & 0.00 & 0.00 & 0.00 \\
\hline 0.60 & 0.00 & 0.00 & 0.00 & 0.00 & 0.00 & 0.00 & 0.00 \\
\hline 0.66 & 0.00 & 0.00 & 0.00 & 0.00 & 0.00 & 0.00 & 0.00 \\
\hline 0.72 & 0.00 & 0.00 & 0.00 & 0.00 & 0.00 & 0.00 & 0.00 \\
\hline 0.79 & 0.00 & 0.00 & 0.00 & 0.00 & 0.00 & 0.00 & 0.00 \\
\hline 0.87 & 0.00 & 0.00 & 0.00 & 0.00 & 0.00 & 0.00 & 0.00 \\
\hline 0.95 & 0.00 & 0.00 & 0.00 & 0.00 & 0.00 & 0.00 & 0.00 \\
\hline 1.05 & 0.00 & 0.00 & 0.00 & 0.00 & 0.00 & 0.00 & 0.00 \\
\hline 1.15 & 0.00 & 0.00 & 0.00 & 0.00 & 0.00 & 0.00 & 0.00 \\
\hline 1.26 & 0.00 & 0.00 & 0.00 & 0.00 & 0.00 & 0.00 & 0.00 \\
\hline 1.38 & 0.00 & 0.00 & 0.00 & 0.00 & 0.00 & 0.00 & 0.01 \\
\hline 1.52 & 0.00 & 0.00 & 0.00 & 0.00 & 0.02 & 0.02 & 0.06 \\
\hline 1.67 & 0.05 & 0.03 & 0.05 & 0.03 & 0.11 & 0.10 & 0.21 \\
\hline 1.83 & 0.24 & 0.15 & 0.24 & 0.17 & 0.33 & 0.35 & 0.49 \\
\hline 2.01 & 0.60 & 0.42 & 0.61 & 0.46 & 0.66 & 0.73 & 0.82 \\
\hline 2.21 & 1.04 & 0.80 & 1.08 & 0.87 & 0.99 & 1.15 & 1.10 \\
\hline 2.42 & 1.39 & 1.15 & 1.46 & 1.25 & 1.23 & 1.48 & 1.28 \\
\hline 2.66 & 1.62 & 1.41 & 1.72 & 1.52 & 1.37 & 1.68 & 1.37 \\
\hline 2.92 & 1.71 & 1.51 & 1.81 & 1.62 & 1.40 & 1.74 & 1.39 \\
\hline 3.21 & 1.69 & 1.49 & 1.77 & 1.59 & 1.37 & 1.70 & 1.38 \\
\hline
\end{tabular}




\begin{tabular}{|c|c|c|c|c|c|c|c|}
\hline Diameter $(\mu \mathrm{m})$ & WS81.5e & WS81.5f & WS81.5g & WS81.5h & WS81.5i & WS82 & WS83 \\
\hline 3.52 & 1.64 & 1.42 & 1.68 & 1.48 & 1.32 & 1.62 & 1.34 \\
\hline 3.86 & 1.62 & 1.40 & 1.64 & 1.45 & 1.29 & 1.55 & 1.32 \\
\hline 4.24 & 1.71 & 1.51 & 1.72 & 1.55 & 1.33 & 1.57 & 1.35 \\
\hline 4.66 & 1.87 & 1.71 & 1.90 & 1.76 & 1.44 & 1.66 & 1.43 \\
\hline 5.11 & 2.08 & 1.96 & 2.14 & 2.02 & 1.60 & 1.82 & 1.55 \\
\hline 5.61 & 2.22 & 2.11 & 2.29 & 2.18 & 1.72 & 1.94 & 1.64 \\
\hline 6.16 & 2.31 & 2.20 & 2.39 & 2.27 & 1.81 & 2.04 & 1.74 \\
\hline 6.76 & 2.32 & 2.19 & 2.39 & 2.26 & 1.84 & 2.08 & 1.79 \\
\hline 7.42 & 2.33 & 2.21 & 2.42 & 2.29 & 1.88 & 2.19 & 1.88 \\
\hline 8.15 & 2.35 & 2.24 & 2.46 & 2.34 & 1.92 & 2.34 & 1.94 \\
\hline 8.94 & 2.39 & 2.30 & 2.54 & 2.41 & 1.99 & 2.52 & 2.01 \\
\hline 9.82 & 2.49 & 2.43 & 2.70 & 2.53 & 2.13 & 2.73 & 2.12 \\
\hline 10.78 & 2.62 & 2.57 & 2.88 & 2.63 & 2.28 & 2.88 & 2.25 \\
\hline 11.83 & 2.83 & 2.82 & 3.18 & 2.80 & 2.53 & 3.06 & 2.49 \\
\hline 12.99 & 2.99 & 3.04 & 3.42 & 2.94 & 2.75 & 3.16 & 2.72 \\
\hline 14.26 & 3.10 & 3.24 & 3.62 & 3.06 & 2.92 & 3.27 & 2.93 \\
\hline 15.65 & 3.03 & 3.27 & 3.61 & 3.05 & 2.92 & 3.28 & 2.97 \\
\hline 17.18 & 2.82 & 3.14 & 3.43 & 2.88 & 2.76 & 3.19 & 2.85 \\
\hline 18.86 & 2.57 & 2.91 & 3.20 & 2.62 & 2.52 & 3.04 & 2.64 \\
\hline 20.71 & 2.38 & 2.68 & 3.01 & 2.33 & 2.29 & 2.86 & 2.45 \\
\hline 22.73 & 2.35 & 2.60 & 3.04 & 2.18 & 2.22 & 2.78 & 2.43 \\
\hline 24.95 & 2.43 & 2.67 & 3.21 & 2.17 & 2.30 & 2.80 & 2.58 \\
\hline 27.39 & 2.59 & 2.88 & 3.46 & 2.33 & 2.51 & 2.93 & 2.90 \\
\hline 30.07 & 2.68 & 3.12 & 3.60 & 2.54 & 2.76 & 3.08 & 3.26 \\
\hline 33.01 & 2.65 & 3.27 & 3.55 & 2.72 & 2.94 & 3.15 & 3.53 \\
\hline 36.24 & 2.50 & 3.27 & 3.31 & 2.77 & 2.99 & 3.08 & 3.65 \\
\hline 39.78 & 2.30 & 3.09 & 3.00 & 2.68 & 2.90 & 2.86 & 3.60 \\
\hline 43.67 & 2.13 & 2.79 & 2.73 & 2.51 & 2.73 & 2.53 & 3.43 \\
\hline 47.94 & 2.00 & 2.42 & 2.58 & 2.32 & 2.54 & 2.19 & 3.19 \\
\hline 52.62 & 1.89 & 2.04 & 2.49 & 2.19 & 2.39 & 1.88 & 2.92 \\
\hline 57.77 & 1.76 & 1.72 & 2.37 & 2.13 & 2.28 & 1.66 & 2.65 \\
\hline 63.41 & 1.59 & 1.48 & 2.09 & 2.13 & 2.22 & 1.51 & 2.37 \\
\hline 69.61 & 1.41 & 1.36 & 1.62 & 2.13 & 2.18 & 1.42 & 2.11 \\
\hline 76.42 & 1.30 & 1.37 & 1.01 & 2.09 & 2.16 & 1.35 & 1.89 \\
\hline 83.89 & 1.33 & 1.52 & 0.46 & 1.99 & 2.13 & 1.28 & 1.71 \\
\hline 92.09 & 1.54 & 1.76 & 0.13 & 1.84 & 2.10 & 1.20 & 1.57 \\
\hline 101.10 & 1.88 & 1.98 & 0.02 & 1.70 & 2.08 & 1.12 & 1.45 \\
\hline 110.98 & 2.19 & 2.04 & 0.00 & 1.60 & 2.07 & 1.05 & 1.34 \\
\hline 121.83 & 2.29 & 1.83 & 0.00 & 1.51 & 2.01 & 1.02 & 1.20 \\
\hline 133.74 & 2.07 & 1.37 & 0.00 & 1.39 & 1.86 & 0.97 & 1.00 \\
\hline 146.82 & 1.57 & 0.77 & 0.00 & 1.17 & 1.58 & 0.88 & 0.77 \\
\hline 161.17 & 0.96 & 0.29 & 0.00 & 0.85 & 1.17 & 0.70 & 0.52 \\
\hline 176.93 & 0.44 & 0.06 & 0.00 & 0.47 & 0.71 & 0.47 & 0.28 \\
\hline
\end{tabular}




\begin{tabular}{|c|c|c|c|c|c|c|c|}
\hline Diameter $(\mu \mathrm{m})$ & WS81.5e & WS81.5f & WS81.5g & WS81.5h & WS81.5i & WS82 & WS83 \\
\hline 194.22 & 0.13 & 0.00 & 0.00 & 0.18 & 0.32 & 0.23 & 0.10 \\
\hline 213.21 & 0.02 & 0.00 & 0.00 & 0.03 & 0.09 & 0.07 & 0.02 \\
\hline 234.05 & 0.00 & 0.00 & 0.00 & 0.00 & 0.01 & 0.01 & 0.00 \\
\hline 256.94 & 0.00 & 0.00 & 0.00 & 0.00 & 0.00 & 0.00 & 0.00 \\
\hline 282.06 & 0.00 & 0.00 & 0.00 & 0.00 & 0.00 & 0.00 & 0.00 \\
\hline 309.63 & 0.00 & 0.00 & 0.00 & 0.00 & 0.00 & 0.00 & 0.00 \\
\hline 339.90 & 0.00 & 0.00 & 0.00 & 0.00 & 0.00 & 0.00 & 0.00 \\
\hline 373.13 & 0.00 & 0.00 & 0.00 & 0.00 & 0.00 & 0.00 & 0.00 \\
\hline 409.61 & 0.00 & 0.00 & 0.00 & 0.00 & 0.00 & 0.00 & 0.00 \\
\hline 449.66 & 0.00 & 0.00 & 0.00 & 0.00 & 0.00 & 0.00 & 0.00 \\
\hline 493.62 & 0.00 & 0.00 & 0.00 & 0.00 & 0.00 & 0.00 & 0.00 \\
\hline 541.88 & 0.00 & 0.00 & 0.00 & 0.00 & 0.00 & 0.00 & 0.00 \\
\hline 594.85 & 0.00 & 0.00 & 0.00 & 0.00 & 0.00 & 0.00 & 0.00 \\
\hline 653.01 & 0.00 & 0.00 & 0.00 & 0.00 & 0.00 & 0.00 & 0.00 \\
\hline 716.85 & 0.00 & 0.00 & 0.00 & 0.00 & 0.00 & 0.00 & 0.00 \\
\hline 786.93 & 0.00 & 0.00 & 0.00 & 0.00 & 0.00 & 0.00 & 0.00 \\
\hline 863.87 & 0.00 & 0.00 & 0.00 & 0.00 & 0.00 & 0.00 & 0.00 \\
\hline 948.32 & 0.00 & 0.00 & 0.00 & 0.00 & 0.00 & 0.00 & 0.00 \\
\hline 1041.03 & 0.00 & 0.00 & 0.00 & 0.00 & 0.00 & 0.00 & 0.00 \\
\hline 1142.81 & 0.00 & 0.00 & 0.00 & 0.00 & 0.00 & 0.00 & 0.00 \\
\hline 1254.54 & 0.00 & 0.00 & 0.00 & 0.00 & 0.00 & 0.00 & 0.00 \\
\hline 1377.19 & 0.00 & 0.00 & 0.00 & 0.00 & 0.00 & 0.00 & 0.00 \\
\hline 1511.83 & 0.00 & 0.00 & 0.00 & 0.00 & 0.00 & 0.00 & 0.00 \\
\hline 1659.63 & 0.00 & 0.00 & 0.00 & 0.00 & 0.00 & 0.00 & 0.00 \\
\hline 1821.88 & 0.00 & 0.00 & 0.00 & 0.00 & 0.00 & 0.00 & 0.00 \\
\hline 2000 & & & & & & & \\
\hline
\end{tabular}

\begin{tabular}{|l|l|l|l|l|l|l|l|}
\hline Diameter $(\boldsymbol{\mu m})$ & WS84 & WS85 & WS86 & WS87 & WS87rep & WS88 & WS89 \\
\hline $\mathbf{0 . 3 8}$ & 0.00 & 0.00 & 0.00 & 0.00 & 0.00 & 0.00 & 0.00 \\
\hline $\mathbf{0 . 4 1}$ & 0.00 & 0.00 & 0.00 & 0.00 & 0.00 & 0.00 & 0.00 \\
\hline $\mathbf{0 . 4 5}$ & 0.00 & 0.00 & 0.00 & 0.00 & 0.00 & 0.00 & 0.00 \\
\hline $\mathbf{0 . 5 0}$ & 0.00 & 0.00 & 0.00 & 0.00 & 0.00 & 0.00 & 0.00 \\
\hline $\mathbf{0 . 5 4}$ & 0.00 & 0.00 & 0.00 & 0.00 & 0.00 & 0.00 & 0.00 \\
\hline $\mathbf{0 . 6 0}$ & 0.00 & 0.00 & 0.00 & 0.00 & 0.00 & 0.00 & 0.00 \\
\hline $\mathbf{0 . 6 6}$ & 0.00 & 0.00 & 0.00 & 0.00 & 0.00 & 0.00 & 0.00 \\
\hline $\mathbf{0 . 7 2}$ & 0.00 & 0.00 & 0.00 & 0.00 & 0.00 & 0.00 & 0.00 \\
\hline $\mathbf{0 . 7 9}$ & 0.00 & 0.00 & 0.00 & 0.00 & 0.00 & 0.00 & 0.00 \\
\hline $\mathbf{0 . 8 7}$ & 0.00 & 0.00 & 0.00 & 0.00 & 0.00 & 0.00 & 0.00 \\
\hline $\mathbf{0 . 9 5}$ & 0.00 & 0.00 & 0.00 & 0.00 & 0.00 & 0.00 & 0.00 \\
\hline $\mathbf{1 . 0 5}$ & 0.00 & 0.00 & 0.00 & 0.00 & 0.00 & 0.00 & 0.00 \\
\hline $\mathbf{1 . 1 5}$ & 0.00 & 0.00 & 0.00 & 0.00 & 0.00 & 0.00 & 0.00 \\
\hline $\mathbf{1 . 2 6}$ & 0.00 & 0.00 & 0.00 & 0.00 & 0.00 & 0.00 & 0.00 \\
\hline $\mathbf{1 . 3 8}$ & 0.00 & 0.00 & 0.00 & 0.00 & 0.00 & 0.02 & 0.01 \\
\hline
\end{tabular}




\begin{tabular}{|c|c|c|c|c|c|c|c|}
\hline Diameter $(\mu \mathrm{m})$ & WS84 & WS85 & WS86 & WS87 & WS87rep & WS88 & WS89 \\
\hline 1.52 & 0.00 & 0.01 & 0.01 & 0.00 & 0.03 & 0.12 & 0.07 \\
\hline 1.67 & 0.03 & 0.07 & 0.06 & 0.03 & 0.17 & 0.34 & 0.25 \\
\hline 1.83 & 0.14 & 0.26 & 0.25 & 0.15 & 0.46 & 0.69 & 0.56 \\
\hline 2.01 & 0.37 & 0.58 & 0.58 & 0.39 & 0.85 & 1.04 & 0.90 \\
\hline 2.21 & 0.67 & 0.93 & 0.94 & 0.67 & 1.21 & 1.34 & 1.18 \\
\hline 2.42 & 0.94 & 1.20 & 1.23 & 0.88 & 1.48 & 1.54 & 1.35 \\
\hline 2.66 & 1.13 & 1.36 & 1.40 & 1.02 & 1.65 & 1.65 & 1.43 \\
\hline 2.92 & 1.20 & 1.41 & 1.47 & 1.06 & 1.72 & 1.68 & 1.44 \\
\hline 3.21 & 1.17 & 1.38 & 1.45 & 1.03 & 1.72 & 1.69 & 1.43 \\
\hline 3.52 & 1.11 & 1.32 & 1.41 & 0.97 & 1.69 & 1.67 & 1.40 \\
\hline 3.86 & 1.08 & 1.29 & 1.39 & 0.94 & 1.68 & 1.67 & 1.40 \\
\hline 4.24 & 1.15 & 1.34 & 1.46 & 0.97 & 1.74 & 1.72 & 1.46 \\
\hline 4.66 & 1.27 & 1.44 & 1.59 & 1.06 & 1.84 & 1.81 & 1.56 \\
\hline 5.11 & 1.44 & 1.60 & 1.79 & 1.20 & 2.00 & 1.96 & 1.72 \\
\hline 5.61 & 1.53 & 1.71 & 1.94 & 1.31 & 2.11 & 2.09 & 1.85 \\
\hline 6.16 & 1.59 & 1.79 & 2.06 & 1.40 & 2.20 & 2.24 & 1.97 \\
\hline 6.76 & 1.57 & 1.81 & 2.12 & 1.45 & 2.24 & 2.36 & 2.04 \\
\hline 7.42 & 1.57 & 1.86 & 2.21 & 1.52 & 2.29 & 2.53 & 2.12 \\
\hline 8.15 & 1.59 & 1.92 & 2.31 & 1.58 & 2.35 & 2.71 & 2.20 \\
\hline 8.94 & 1.65 & 2.01 & 2.41 & 1.64 & 2.42 & 2.88 & 2.26 \\
\hline 9.82 & 1.77 & 2.17 & 2.56 & 1.72 & 2.55 & 3.05 & 2.35 \\
\hline 10.78 & 1.92 & 2.36 & 2.69 & 1.80 & 2.68 & 3.17 & 2.41 \\
\hline 11.83 & 2.16 & 2.65 & 2.91 & 1.97 & 2.94 & 3.36 & 2.54 \\
\hline 12.99 & 2.37 & 2.89 & 3.09 & 2.15 & 3.18 & 3.51 & 2.61 \\
\hline 14.26 & 2.55 & 3.08 & 3.25 & 2.34 & 3.40 & 3.66 & 2.64 \\
\hline 15.65 & 2.57 & 3.09 & 3.27 & 2.41 & 3.43 & 3.67 & 2.56 \\
\hline 17.18 & 2.46 & 2.92 & 3.13 & 2.33 & 3.25 & 3.52 & 2.37 \\
\hline 18.86 & 2.26 & 2.70 & 2.90 & 2.16 & 2.93 & 3.27 & 2.15 \\
\hline 20.71 & 2.07 & 2.50 & 2.67 & 1.98 & 2.60 & 2.98 & 1.97 \\
\hline 22.73 & 2.02 & 2.49 & 2.56 & 1.95 & 2.45 & 2.82 & 1.90 \\
\hline 24.95 & 2.13 & 2.63 & 2.60 & 2.07 & 2.49 & 2.78 & 1.91 \\
\hline 27.39 & 2.42 & 2.88 & 2.76 & 2.34 & 2.70 & 2.86 & 1.95 \\
\hline 30.07 & 2.77 & 3.09 & 2.96 & 2.65 & 2.94 & 2.94 & 1.95 \\
\hline 33.01 & 3.07 & 3.15 & 3.09 & 2.90 & 3.02 & 2.91 & 1.86 \\
\hline 36.24 & 3.23 & 3.05 & 3.08 & 3.02 & 2.88 & 2.72 & 1.70 \\
\hline 39.78 & 3.19 & 2.84 & 2.91 & 3.01 & 2.55 & 2.37 & 1.53 \\
\hline 43.67 & 3.01 & 2.62 & 2.63 & 2.97 & 2.19 & 1.94 & 1.39 \\
\hline 47.94 & 2.76 & 2.47 & 2.31 & 2.95 & 1.93 & 1.52 & 1.29 \\
\hline 52.62 & 2.52 & 2.41 & 2.01 & 2.98 & 1.84 & 1.18 & 1.22 \\
\hline 57.77 & 2.36 & 2.38 & 1.78 & 3.04 & 1.92 & 0.97 & 1.12 \\
\hline 63.41 & 2.30 & 2.31 & 1.63 & 3.05 & 2.05 & 0.87 & 0.99 \\
\hline 69.61 & 2.33 & 2.17 & 1.58 & 2.96 & 2.07 & 0.87 & 0.86 \\
\hline 76.42 & 2.40 & 1.97 & 1.59 & 2.74 & 1.85 & 0.92 & 0.79 \\
\hline
\end{tabular}




\begin{tabular}{|c|c|c|c|c|c|c|c|}
\hline Diameter $(\mu \mathrm{m})$ & WS84 & WS85 & WS86 & WS87 & WS87rep & WS88 & WS89 \\
\hline 83.89 & 2.48 & 1.77 & 1.62 & 2.46 & 1.39 & 0.98 & 0.87 \\
\hline 92.09 & 2.54 & 1.67 & 1.65 & 2.24 & 0.90 & 1.01 & 1.15 \\
\hline 101.10 & 2.59 & 1.70 & 1.64 & 2.20 & 0.59 & 0.99 & 1.68 \\
\hline 110.98 & 2.64 & 1.82 & 1.58 & 2.36 & 0.53 & 0.96 & 2.42 \\
\hline 121.83 & 2.69 & 1.90 & 1.47 & 2.65 & 0.68 & 0.93 & 3.25 \\
\hline 133.74 & 2.64 & 1.81 & 1.32 & 2.89 & 0.95 & 0.92 & 3.97 \\
\hline 146.82 & 2.41 & 1.49 & 1.10 & 2.87 & 1.12 & 0.87 & 4.33 \\
\hline 161.17 & 1.94 & 1.01 & 0.81 & 2.46 & 1.03 & 0.75 & 4.16 \\
\hline 176.93 & 1.31 & 0.51 & 0.49 & 1.75 & 0.70 & 0.55 & 3.44 \\
\hline 194.22 & 0.67 & 0.17 & 0.22 & 0.94 & 0.33 & 0.30 & 2.36 \\
\hline 213.21 & 0.23 & 0.03 & 0.06 & 0.34 & 0.09 & 0.11 & 1.23 \\
\hline 234.05 & 0.04 & 0.00 & 0.01 & 0.06 & 0.01 & 0.02 & 0.43 \\
\hline 256.94 & 0.00 & 0.00 & 0.00 & 0.00 & 0.00 & 0.00 & 0.08 \\
\hline 282.06 & 0.00 & 0.00 & 0.00 & 0.00 & 0.00 & 0.00 & 0.01 \\
\hline 309.63 & 0.00 & 0.00 & 0.00 & 0.00 & 0.00 & 0.00 & 0.00 \\
\hline 339.90 & 0.00 & 0.00 & 0.00 & 0.00 & 0.00 & 0.00 & 0.00 \\
\hline 373.13 & 0.00 & 0.00 & 0.00 & 0.00 & 0.00 & 0.00 & 0.00 \\
\hline 409.61 & 0.00 & 0.00 & 0.00 & 0.00 & 0.00 & 0.00 & 0.00 \\
\hline 449.66 & 0.00 & 0.00 & 0.00 & 0.00 & 0.00 & 0.00 & 0.00 \\
\hline 493.62 & 0.00 & 0.00 & 0.00 & 0.00 & 0.00 & 0.00 & 0.00 \\
\hline 541.88 & 0.00 & 0.00 & 0.00 & 0.00 & 0.00 & 0.00 & 0.00 \\
\hline 594.85 & 0.00 & 0.00 & 0.00 & 0.00 & 0.00 & 0.00 & 0.00 \\
\hline 653.01 & 0.00 & 0.00 & 0.00 & 0.00 & 0.00 & 0.00 & 0.00 \\
\hline 716.85 & 0.00 & 0.00 & 0.00 & 0.00 & 0.00 & 0.00 & 0.00 \\
\hline 786.93 & 0.00 & 0.00 & 0.00 & 0.00 & 0.00 & 0.00 & 0.00 \\
\hline 863.87 & 0.00 & 0.00 & 0.00 & 0.00 & 0.00 & 0.00 & 0.00 \\
\hline 948.32 & 0.00 & 0.00 & 0.00 & 0.00 & 0.00 & 0.00 & 0.00 \\
\hline 1041.03 & 0.00 & 0.00 & 0.00 & 0.00 & 0.00 & 0.00 & 0.00 \\
\hline 1142.81 & 0.00 & 0.00 & 0.00 & 0.00 & 0.00 & 0.00 & 0.00 \\
\hline 1254.54 & 0.00 & 0.00 & 0.00 & 0.00 & 0.00 & 0.00 & 0.00 \\
\hline 1377.19 & 0.00 & 0.00 & 0.00 & 0.00 & 0.00 & 0.00 & 0.00 \\
\hline 1511.83 & 0.00 & 0.00 & 0.00 & 0.00 & 0.00 & 0.00 & 0.00 \\
\hline 1659.63 & 0.00 & 0.00 & 0.00 & 0.00 & 0.00 & 0.00 & 0.00 \\
\hline 1821.88 & 0.00 & 0.00 & 0.00 & 0.00 & 0.00 & 0.00 & 0.00 \\
\hline 2000 & & & & & & & \\
\hline
\end{tabular}




\section{Appendix C}

The table below presents the benthic foraminifera census data, including percentage of planktic species, productivity index calculations and sieve-derived percent mud (see Chapter 4).

\section{Appendix C Table 1: Benthic foraminifera census data}

\begin{tabular}{|c|c|c|c|c|c|c|c|c|c|c|}
\hline Species name & WS1 & WS2 & WS4 & WS5 & WS7 & WS8 & WS10 & WS11 & WS13 & WS15 \\
\hline Amphicorya hirsuta & 1 & 0 & 2 & 0 & 1 & 0 & 0 & 0 & 1 & 4 \\
\hline $\begin{array}{l}\text { Anomalinoides } \\
\text { parvumbilia }\end{array}$ & 8 & 0 & 2 & 3 & 12 & 9 & 6 & 9 & 17 & 7 \\
\hline $\begin{array}{l}\text { Anomalinoides } \\
\text { sphericus }\end{array}$ & 10 & 1 & 2 & 0 & 0 & 1 & 6 & 1 & 1 & 3 \\
\hline $\begin{array}{l}\text { Anomalinoides } \\
\text { subnonionoides }\end{array}$ & 0 & 0 & 0 & 3 & 2 & 0 & 0 & 0 & 0 & 0 \\
\hline Astrononion parki & 30 & 0 & 1 & 0 & 11 & 23 & 17 & 14 & 20 & 23 \\
\hline Biloculina anomala & 0 & 0 & 0 & 0 & 0 & 0 & 0 & 0 & 0 & 0 \\
\hline Bolivinita pliozea & 6 & 0 & 0 & 0 & 5 & 10 & 13 & 10 & 10 & 13 \\
\hline Bolivina sp. & 0 & 0 & 0 & 1 & 1 & 0 & 0 & 0 & 0 & 0 \\
\hline Bolivina cacozela & 0 & 0 & 0 & 0 & 0 & 0 & 0 & 0 & 0 & 0 \\
\hline Bolivina petiae & 0 & 0 & 1 & 0 & 0 & 0 & 0 & 0 & 0 & 0 \\
\hline Bolivina silvestrina & 0 & 0 & 0 & 0 & 0 & 0 & 0 & 0 & 0 & 0 \\
\hline Bolivina spathulata & 0 & 0 & 0 & 0 & 0 & 0 & 0 & 0 & 0 & 0 \\
\hline Bolivina subcompacta & 0 & 0 & 0 & 0 & 0 & 0 & 0 & 0 & 0 & 0 \\
\hline Bolivina subexcavata & 0 & 0 & 0 & 0 & 0 & 0 & 0 & 0 & 0 & 0 \\
\hline Bolivina wanganuiensis & 0 & 0 & 0 & 0 & 0 & 0 & 0 & 0 & 0 & 0 \\
\hline Bulimina marginata & 0 & 1 & 2 & 0 & 4 & 9 & 1 & 0 & 4 & 2 \\
\hline $\begin{array}{l}\text { Cassidunlina } \\
\text { neocarinata }\end{array}$ & 0 & 0 & 0 & 0 & 0 & 0 & 0 & 0 & 1 & 0 \\
\hline Cibicides deliquatus & 24 & 1 & 37 & 12 & 16 & 5 & 4 & 18 & 5 & 3 \\
\hline Cibicides molestus & 36 & 0 & 2 & 33 & 0 & 1 & 0 & 0 & 0 & 1 \\
\hline Discorbidae sp. & 0 & 0 & 0 & 0 & 0 & 0 & 0 & 0 & 0 & 0 \\
\hline Elphidium charlottense & 0 & 0 & 1 & 0 & 2 & 0 & 0 & 0 & 10 & 0 \\
\hline Elphidium excavatum & 0 & 0 & 0 & 0 & 0 & 0 & 0 & 0 & 0 & 0 \\
\hline $\begin{array}{l}\text { Elphidium } \\
\text { novozealandicum }\end{array}$ & 0 & 0 & 0 & 0 & 0 & 0 & 0 & 0 & 0 & 0 \\
\hline Euuvigerina pliozea & 132 & 3 & 18 & 98 & 2 & 3 & 9 & 18 & 6 & 38 \\
\hline $\begin{array}{l}\text { Evolvocassidulina } \\
\text { orientalis }\end{array}$ & 2 & 0 & 7 & 1 & 10 & 12 & 11 & 5 & 9 & 5 \\
\hline Fissurina sp. & 0 & 0 & 0 & 0 & 0 & 1 & 0 & 0 & 0 & 0 \\
\hline Globobulimina pacifica & 0 & 0 & 0 & 0 & 0 & 0 & 0 & 0 & 0 & 0 \\
\hline $\begin{array}{l}\text { Globocassidulina } \\
\text { subglobosa }\end{array}$ & 0 & 0 & 0 & 0 & 0 & 0 & 0 & 0 & 0 & 0 \\
\hline
\end{tabular}




\begin{tabular}{|c|c|c|c|c|c|c|c|c|c|c|}
\hline Species name & WS1 & WS2 & WS4 & WS5 & WS7 & WS8 & WS10 & WS11 & WS13 & WS15 \\
\hline $\begin{array}{l}\text { Gyroidinoides } \\
\text { zelandica }\end{array}$ & 0 & 0 & 0 & 0 & 0 & 0 & 0 & 0 & 0 & 2 \\
\hline Haeuslerella parri & 84 & 0 & 106 & 45 & 158 & 96 & 136 & 101 & 149 & 142 \\
\hline Hoeglundina elegans & 8 & 0 & 4 & 8 & 44 & 43 & 30 & 15 & 55 & 49 \\
\hline Lagena sp. & 1 & 0 & 2 & 2 & 8 & 3 & 0 & 3 & 2 & 1 \\
\hline Lenticulina sp. & 3 & 0 & 29 & 11 & 3 & 8 & 5 & 6 & 6 & 5 \\
\hline Marginulina sp. & 1 & 0 & 0 & 0 & 0 & 0 & 0 & 0 & 0 & 0 \\
\hline $\begin{array}{l}\text { Martinottiella } \\
\text { communis }\end{array}$ & 0 & 0 & 12 & 0 & 0 & 0 & 0 & 0 & 0 & 0 \\
\hline Melonis zeobesus & 32 & 0 & 0 & 0 & 0 & 0 & 0 & 0 & 0 & 0 \\
\hline Nodosaria sp. & 0 & 0 & 0 & 0 & 0 & 0 & 0 & 0 & 0 & 0 \\
\hline Nonionellina flemingi & 0 & 0 & 0 & 0 & 0 & 0 & 1 & 0 & 0 & 0 \\
\hline Notorotalia finlayi & 11 & 4 & 0 & 13 & 13 & 39 & 10 & 27 & 28 & 7 \\
\hline Notorotalia kingmai & 0 & 0 & 0 & 0 & 0 & 0 & 0 & 0 & 0 & 0 \\
\hline $\begin{array}{l}\text { Notorotalia zelandica } \\
\text { zelandica }\end{array}$ & 0 & 0 & 0 & 0 & 0 & 0 & 0 & 0 & 0 & 0 \\
\hline Oolina sp. & 0 & 0 & 1 & 0 & 0 & 0 & 0 & 0 & 0 & 0 \\
\hline Oridorsalis tenera & 0 & 0 & 0 & 0 & 0 & 0 & 0 & 0 & 0 & 0 \\
\hline Oridorsalis umbonatus & 17 & 0 & 65 & 0 & 46 & 67 & 13 & 12 & 52 & 10 \\
\hline Parafusulina sp. & 0 & 0 & 0 & 0 & 0 & 0 & 0 & 0 & 0 & 0 \\
\hline $\begin{array}{l}\text { Plectofrondicularia } \\
\text { pellucida }\end{array}$ & 0 & 0 & 0 & 0 & 0 & 0 & 0 & 0 & 0 & 0 \\
\hline Proxifrons sp. & 0 & 0 & 0 & 0 & 0 & 0 & 0 & 0 & 0 & 0 \\
\hline Pullenia bulloides & 0 & 0 & 0 & 0 & 2 & 0 & 0 & 0 & 0 & 0 \\
\hline Pullenia quinqueloba & 1 & 0 & 0 & 0 & 0 & 0 & 1 & 0 & 0 & 1 \\
\hline Rectobolivina striatula & 0 & 0 & 1 & 0 & 0 & 0 & 0 & 0 & 0 & 0 \\
\hline Saracenaria italica & 0 & 0 & 1 & 0 & 0 & 0 & 0 & 0 & 0 & 0 \\
\hline Sigmoidina sp. & 0 & 0 & 0 & 0 & 0 & 0 & 0 & 0 & 0 & 0 \\
\hline $\begin{array}{l}\text { Siphonaperta } \\
\text { macbeathi }\end{array}$ & 0 & 0 & 0 & 0 & 0 & 0 & 2 & 0 & 1 & 3 \\
\hline $\begin{array}{l}\text { Siphotextularia } \\
\text { wairoana }\end{array}$ & 0 & 0 & 0 & 0 & 3 & 2 & 0 & 0 & 1 & 0 \\
\hline Sphaeroidina bulloides & 1 & 0 & 0 & 0 & 2 & 3 & 2 & 0 & 0 & 0 \\
\hline Trifarina bradyi & 0 & 0 & 0 & 0 & 0 & 0 & 0 & 0 & 0 & 0 \\
\hline Vaginulina sp. & 0 & 0 & 0 & 0 & 0 & 0 & 0 & 0 & 0 & 0 \\
\hline Zeoflorilus parri & 0 & 0 & 0 & 0 & 0 & 0 & 0 & 0 & 0 & 0 \\
\hline \multicolumn{11}{|l|}{ Totals } \\
\hline Benthic foraminifera & 408 & 10 & 296 & 230 & 345 & 335 & 267 & 239 & 378 & 319 \\
\hline $\begin{array}{l}\text { Planktonic } \\
\text { foraminifera }\end{array}$ & 26 & 0 & 6 & 2 & 15 & 8 & 12 & 1 & 12 & 16 \\
\hline Total forams & 434 & 10 & 302 & 232 & 360 & 343 & 279 & 240 & 390 & 335 \\
\hline $\begin{array}{l}\text { Percentage planktonic } \\
\text { forams }\end{array}$ & 6.0 & 0.0 & 2.0 & 0.9 & 4.2 & 2.3 & 4.3 & 0.4 & 3.1 & 4.8 \\
\hline Productivity Index & 32.6 & 0.1 & 23.7 & 18.4 & 13.8 & 6.7 & 42.7 & 9.6 & 7.6 & 25.5 \\
\hline $\begin{array}{l}\text { Percent mud (<63 um } \\
\text { sieved) }\end{array}$ & 95.0 & 95.0 & 85.6 & 86.2 & 94.1 & 96.9 & 97.1 & 98.5 & 97.8 & 98.9 \\
\hline
\end{tabular}




\begin{tabular}{|c|c|c|c|c|c|c|c|c|c|c|}
\hline Species name & WS16 & WS18 & WS19 & WS21 & WS22 & WS24 & WS25 & WS27 & WS28 & WS30 \\
\hline Amphicorya hirsuta & 0 & 1 & 2 & 1 & 0 & 2 & 1 & 4 & 0 & 12 \\
\hline $\begin{array}{l}\text { Anomalinoides } \\
\text { parvumbilia }\end{array}$ & 2 & 1 & 1 & 3 & 1 & 0 & 0 & 5 & 0 & 0 \\
\hline $\begin{array}{l}\text { Anomalinoides } \\
\text { sphericus }\end{array}$ & 0 & 0 & 0 & 10 & 1 & 0 & 5 & 5 & 0 & 0 \\
\hline $\begin{array}{l}\text { Anomalinoides } \\
\text { subnonionoides }\end{array}$ & 0 & 0 & 0 & 0 & 0 & 0 & 0 & 1 & 1 & 0 \\
\hline Astrononion parki & 63 & 53 & 43 & 52 & 38 & 58 & 66 & 48 & 36 & 102 \\
\hline Biloculina anomala & 0 & 0 & 0 & 0 & 0 & 0 & 0 & 0 & 0 & 0 \\
\hline Bolivinita pliozea & 21 & 1 & 7 & 2 & 0 & 2 & 2 & 2 & 4 & 9 \\
\hline Bolivina sp. & 0 & 0 & 1 & 0 & 0 & 1 & 1 & 0 & 0 & 0 \\
\hline Bolivina cacozela & 0 & 0 & 1 & 0 & 0 & 0 & 0 & 0 & 0 & 0 \\
\hline Bolivina petiae & 0 & 0 & 1 & 0 & 0 & 0 & 0 & 0 & 0 & 0 \\
\hline Bolivina silvestrina & 0 & 0 & 0 & 0 & 0 & 0 & 0 & 0 & 0 & 0 \\
\hline Bolivina spathulata & 0 & 0 & 0 & 0 & 0 & 0 & 0 & 0 & 0 & 0 \\
\hline $\begin{array}{l}\text { Bolivina } \\
\text { subcompacta }\end{array}$ & 0 & 0 & 0 & 0 & 0 & 0 & 0 & 0 & 0 & 0 \\
\hline Bolivina subexcavata & 0 & 1 & 1 & 0 & 0 & 0 & 0 & 0 & 0 & 0 \\
\hline $\begin{array}{l}\text { Bolivina } \\
\text { wanganuiensis }\end{array}$ & 0 & 0 & 0 & 0 & 0 & 0 & 0 & 0 & 0 & 0 \\
\hline Bulimina marginata & 2 & 0 & 13 & 2 & 0 & 0 & 2 & 1 & 1 & 5 \\
\hline $\begin{array}{l}\text { Cassidunlina } \\
\text { neocarinata }\end{array}$ & 0 & 0 & 1 & 0 & 1 & 1 & 0 & 0 & 0 & 0 \\
\hline Cibicides deliquatus & 9 & 30 & 22 & 6 & 20 & 9 & 21 & 13 & 9 & 13 \\
\hline Cibicides molestus & 0 & 0 & 0 & 0 & 0 & 0 & 0 & 0 & 0 & 0 \\
\hline Discorbidae sp. & 0 & 0 & 0 & 0 & 0 & 0 & 1 & 0 & 0 & 0 \\
\hline $\begin{array}{l}\text { Elphidium } \\
\text { charlottense }\end{array}$ & 4 & 2 & 2 & 1 & 1 & 0 & 0 & 1 & 0 & 0 \\
\hline Elphidium excavatum & 0 & 0 & 0 & 0 & 0 & 0 & 0 & 0 & 0 & 0 \\
\hline $\begin{array}{l}\text { Elphidium } \\
\text { novozealandicum }\end{array}$ & 0 & 0 & 0 & 0 & 0 & 0 & 0 & 0 & 0 & 0 \\
\hline Euuvigerina pliozea & 11 & 8 & 22 & 36 & 90 & 64 & 156 & 84 & 73 & 17 \\
\hline $\begin{array}{l}\text { Evolvocassidulina } \\
\text { orientalis }\end{array}$ & 12 & 3 & 16 & 42 & 14 & 2 & 2 & 6 & 1 & 1 \\
\hline Fissurina sp. & 0 & 0 & 0 & 0 & 0 & 0 & 0 & 0 & 0 & 0 \\
\hline $\begin{array}{l}\text { Globobulimina } \\
\text { pacifica }\end{array}$ & 0 & 0 & 0 & 0 & 1 & 0 & 0 & 0 & 0 & 0 \\
\hline $\begin{array}{l}\text { Globocassidulina } \\
\text { subglobosa }\end{array}$ & 0 & 0 & 0 & 0 & 0 & 0 & 0 & 0 & 0 & 0 \\
\hline $\begin{array}{l}\text { Gyroidinoides } \\
\text { zelandica }\end{array}$ & 1 & 0 & 1 & 0 & 0 & 0 & 2 & 0 & 1 & 0 \\
\hline Haeuslerella parri & 156 & 117 & 127 & 146 & 33 & 40 & 107 & 7 & 51 & 127 \\
\hline Hoeglundina elegans & 61 & 95 & 31 & 13 & 20 & 0 & 17 & 14 & 12 & 36 \\
\hline Lagena sp. & 0 & 0 & 6 & 4 & 1 & 1 & 1 & 2 & 0 & 7 \\
\hline Lenticulina sp. & 5 & 4 & 6 & 16 & 12 & 6 & 4 & 15 & 5 & 19 \\
\hline Marginulina sp. & 0 & 0 & 0 & 1 & 0 & 0 & 0 & 0 & 0 & 0 \\
\hline $\begin{array}{l}\text { Martinottiella } \\
\text { communis }\end{array}$ & 0 & 0 & 0 & 0 & 0 & 0 & 0 & 0 & 2 & 0 \\
\hline Melonis zeobesus & 0 & 0 & 0 & 0 & 0 & 0 & 18 & 2 & 0 & 0 \\
\hline
\end{tabular}




\begin{tabular}{|c|c|c|c|c|c|c|c|c|c|c|}
\hline Species name & WS16 & WS18 & WS19 & WS21 & WS22 & WS24 & WS25 & WS27 & WS28 & WS30 \\
\hline Nodosaria sp. & 1 & 0 & 0 & 0 & 0 & 0 & 0 & 0 & 0 & 0 \\
\hline Nonionellina flemingi & 10 & 10 & 18 & 10 & 8 & 9 & 0 & 0 & 0 & 0 \\
\hline Notorotalia finlayi & 0 & 0 & 0 & 0 & 0 & 0 & 18 & 26 & 7 & 15 \\
\hline Notorotalia kingmai & 0 & 0 & 0 & 0 & 0 & 0 & 0 & 0 & 0 & 0 \\
\hline $\begin{array}{l}\text { Notorotalia zelandica } \\
\text { zelandica }\end{array}$ & 0 & 0 & 0 & 0 & 0 & 0 & 0 & 0 & 0 & 0 \\
\hline Oolina sp. & 0 & 0 & 0 & 0 & 0 & 0 & 0 & 0 & 0 & 0 \\
\hline Oridorsalis tenera & 22 & 27 & 14 & 0 & 0 & 17 & 0 & 0 & 0 & 0 \\
\hline $\begin{array}{l}\text { Oridorsalis } \\
\text { umbonatus }\end{array}$ & 0 & 0 & 0 & 0 & 0 & 0 & 0 & 0 & 1 & 0 \\
\hline Parafusulina sp. & 0 & 0 & 0 & 0 & 0 & 0 & 0 & 0 & 0 & 0 \\
\hline $\begin{array}{l}\text { Plectofrondicularia } \\
\text { pellucida }\end{array}$ & 0 & 0 & 0 & 0 & 0 & 0 & 0 & 0 & 1 & 0 \\
\hline Proxifrons sp. & 0 & 0 & 0 & 1 & 0 & 0 & 0 & 0 & 0 & 0 \\
\hline Pullenia bulloides & 2 & 0 & 0 & 0 & 0 & 0 & 1 & 0 & 0 & 0 \\
\hline Pullenia quinqueloba & 1 & 0 & 0 & 1 & 0 & 0 & 0 & 0 & 0 & 0 \\
\hline $\begin{array}{l}\text { Rectobolivina } \\
\text { striatula }\end{array}$ & 0 & 0 & 1 & 0 & 0 & 0 & 1 & 0 & 0 & 0 \\
\hline Saracenaria italica & 0 & 0 & 0 & 0 & 0 & 0 & 0 & 1 & 0 & 0 \\
\hline Sigmoidina sp. & 7 & 2 & 4 & 4 & 0 & 0 & 0 & 0 & 0 & 0 \\
\hline $\begin{array}{l}\text { Siphonaperta } \\
\text { macbeathi }\end{array}$ & 1 & 0 & 0 & 0 & 0 & 0 & 6 & 6 & 1 & 1 \\
\hline $\begin{array}{l}\text { Siphotextularia } \\
\text { wairoana }\end{array}$ & 0 & 1 & 0 & 0 & 1 & 1 & 2 & 0 & 0 & 0 \\
\hline $\begin{array}{l}\text { Sphaeroidina } \\
\text { bulloides }\end{array}$ & 0 & 0 & 0 & 0 & 0 & 0 & 0 & 0 & 0 & 0 \\
\hline Trifarina bradyi & 0 & 1 & 0 & 0 & 0 & 0 & 0 & 0 & 0 & 0 \\
\hline Vaginulina sp. & 0 & 0 & 0 & 0 & 0 & 0 & 0 & 0 & 0 & 0 \\
\hline Zeoflorilus parri & & & & & & & 0 & 0 & 0 & 0 \\
\hline \multicolumn{11}{|l|}{ Totals } \\
\hline Benthic foraminifera & 391 & 357 & 341 & 351 & 242 & 213 & 434 & 243 & 206 & 364 \\
\hline $\begin{array}{l}\text { Planktonic } \\
\text { foraminifera }\end{array}$ & 47 & 4 & 5 & 6 & 4 & 1 & 21 & 5 & 7 & 5 \\
\hline Total forams & 438 & 361 & 346 & 357 & 246 & 214 & 455 & 248 & 213 & 369 \\
\hline $\begin{array}{l}\text { Percentage } \\
\text { planktonic forams }\end{array}$ & 10.7 & 1.1 & 1.4 & 1.7 & 1.6 & 0.5 & 4.6 & 2.0 & 3.3 & 1.4 \\
\hline Productivity Index & 15.6 & 14.3 & 27.3 & 37.4 & 38.7 & 34.1 & 138.9 & 19.4 & 65.9 & 7.3 \\
\hline $\begin{array}{l}\text { Percent mud (<63 um } \\
\text { sieved) }\end{array}$ & 99.0 & 98.7 & 94.0 & 87.9 & 86.0 & 86.2 & 82.4 & 92.1 & 85.2 & 97.3 \\
\hline
\end{tabular}




\begin{tabular}{|c|c|c|c|c|c|c|c|c|c|c|}
\hline Species name & WS31 & WS33 & WS34 & WS36 & WS37 & WS39 & WS40 & WS42 & WS43 & WS45 \\
\hline Amphicorya hirsuta & 6 & 5 & 6 & 1 & 4 & 4 & 1 & 2 & 1 & 6 \\
\hline $\begin{array}{l}\text { Anomalinoides } \\
\text { parvumbilia }\end{array}$ & 2 & 1 & 4 & 0 & 20 & 7 & 17 & 13 & 4 & 4 \\
\hline $\begin{array}{l}\text { Anomalinoides } \\
\text { sphericus }\end{array}$ & 0 & 7 & 5 & 0 & 24 & 29 & 47 & 28 & 46 & 72 \\
\hline $\begin{array}{l}\text { Anomalinoides } \\
\text { subnonionoides }\end{array}$ & 0 & 0 & 0 & 0 & 0 & 0 & 0 & 0 & 5 & 0 \\
\hline Astrononion parki & 39 & 115 & 108 & 0 & 5 & 4 & 10 & 10 & 1 & 1 \\
\hline Biloculina anomala & 0 & 0 & 0 & 0 & 0 & 0 & 0 & 0 & 0 & 0 \\
\hline Bolivinita pliozea & 5 & 6 & 2 & 1 & 23 & 4 & 15 & 17 & 20 & 74 \\
\hline Bolivina sp. & 0 & 0 & 0 & 0 & 0 & 0 & 0 & 0 & 0 & 0 \\
\hline Bolivina cacozela & 0 & 0 & 0 & 0 & 0 & 0 & 0 & 0 & 0 & 0 \\
\hline Bolivina petiae & 0 & 0 & 0 & 0 & 0 & 0 & 0 & 0 & 0 & 0 \\
\hline Bolivina silvestrina & 0 & 0 & 0 & 0 & 0 & 0 & 0 & 0 & 0 & 0 \\
\hline Bolivina spathulata & 0 & 0 & 0 & 0 & 0 & 0 & 0 & 0 & 0 & 0 \\
\hline $\begin{array}{l}\text { Bolivina } \\
\text { subcompacta }\end{array}$ & 0 & 0 & 0 & 0 & 0 & 0 & 0 & 0 & 0 & 0 \\
\hline $\begin{array}{l}\text { Bolivina } \\
\text { subexcavata }\end{array}$ & 0 & 0 & 0 & 0 & 0 & 0 & 0 & 0 & 0 & 0 \\
\hline $\begin{array}{l}\text { Bolivina } \\
\text { wanganuiensis }\end{array}$ & 0 & 0 & 0 & 0 & 0 & 0 & 0 & 0 & 0 & 0 \\
\hline Bulimina marginata & 50 & 36 & 23 & 0 & 13 & 5 & 3 & 4 & 4 & 4 \\
\hline $\begin{array}{l}\text { Cassidunlina } \\
\text { neocarinata }\end{array}$ & 0 & 0 & 0 & 0 & 0 & 0 & 0 & 1 & 0 & 0 \\
\hline Cibicides deliquatus & 9 & 32 & 16 & 0 & 21 & 24 & 18 & 31 & 29 & 49 \\
\hline Cibicides molestus & 0 & 0 & 0 & 0 & 0 & 0 & 0 & 0 & 0 & 0 \\
\hline Discorbidae sp. & 0 & 0 & 0 & 0 & 0 & 0 & 0 & 0 & 0 & 0 \\
\hline $\begin{array}{l}\text { Elphidium } \\
\text { charlottense }\end{array}$ & 0 & 0 & 0 & 0 & 0 & 1 & 0 & 0 & 0 & 0 \\
\hline $\begin{array}{l}\text { Elphidium } \\
\text { excavatum }\end{array}$ & 0 & 0 & 0 & 0 & 0 & 0 & 0 & 0 & 0 & 0 \\
\hline $\begin{array}{l}\text { Elphidium } \\
\text { novozealandicum }\end{array}$ & 0 & 0 & 0 & 0 & 0 & 0 & 0 & 0 & 0 & 0 \\
\hline Euuvigerina pliozea & 23 & 25 & 12 & 1 & 42 & 27 & 56 & 61 & 52 & 49 \\
\hline $\begin{array}{l}\text { Evolvocassidulina } \\
\text { orientalis }\end{array}$ & 4 & 4 & 1 & 2 & 0 & 1 & 1 & 0 & 1 & 0 \\
\hline Fissurina sp. & 0 & 0 & 0 & 0 & 0 & 0 & 0 & 0 & 0 & 0 \\
\hline $\begin{array}{l}\text { Globobulimina } \\
\text { pacifica }\end{array}$ & 0 & 0 & 0 & 0 & 0 & 0 & 0 & 0 & 0 & 0 \\
\hline $\begin{array}{l}\text { Globocassidulina } \\
\text { subglobosa }\end{array}$ & 0 & 0 & 0 & 0 & 0 & 0 & 0 & 1 & 0 & 1 \\
\hline $\begin{array}{l}\text { Gyroidinoides } \\
\text { zelandica }\end{array}$ & 0 & 1 & 0 & 0 & 1 & 2 & 1 & 0 & 1 & 0 \\
\hline Haeuslerella parri & 69 & 114 & 135 & 2 & 93 & 66 & 120 & 80 & 114 & 24 \\
\hline $\begin{array}{l}\text { Hoeglundina } \\
\text { elegans }\end{array}$ & 11 & 19 & 35 & 0 & 15 & 51 & 43 & 68 & 29 & 17 \\
\hline Lagena sp. & 6 & 3 & 1 & 1 & 3 & 7 & 2 & 3 & 2 & 4 \\
\hline Lenticulina sp. & 10 & 8 & 5 & 4 & 9 & 14 & 11 & 29 & 12 & 16 \\
\hline Marginulina sp. & 0 & 0 & 0 & 0 & 0 & 1 & 0 & 0 & 0 & 0 \\
\hline
\end{tabular}




\begin{tabular}{|c|c|c|c|c|c|c|c|c|c|c|}
\hline Species name & WS31 & WS33 & WS34 & WS36 & WS37 & WS39 & WS40 & WS42 & WS43 & WS45 \\
\hline $\begin{array}{l}\text { Martinottiella } \\
\text { communis }\end{array}$ & 0 & 0 & 0 & 0 & 4 & 1 & 0 & 3 & 7 & 0 \\
\hline Melonis zeobesus & 0 & 0 & 0 & 0 & 0 & 0 & 0 & 1 & 8 & 2 \\
\hline Nodosaria sp. & 0 & 0 & 0 & 0 & 1 & 0 & 0 & 0 & 0 & 0 \\
\hline $\begin{array}{l}\text { Nonionellina } \\
\text { flemingi }\end{array}$ & 0 & 0 & 1 & 0 & 0 & 0 & 1 & 0 & 0 & 0 \\
\hline Notorotalia finlayi & 10 & 20 & 17 & 1 & 58 & 45 & 23 & 54 & 26 & 25 \\
\hline Notorotalia kingmai & 0 & 0 & 1 & 0 & 2 & 0 & 2 & 0 & 0 & 0 \\
\hline $\begin{array}{l}\text { Notorotalia } \\
\text { zelandica zelandica }\end{array}$ & 0 & 0 & 0 & 0 & 0 & 0 & 0 & 0 & 0 & 0 \\
\hline Oolina sp. & 0 & 0 & 0 & 0 & 1 & 0 & 0 & 0 & 1 & 0 \\
\hline Oridorsalis tenera & 0 & 0 & 0 & 0 & 0 & 0 & 0 & 0 & 0 & 0 \\
\hline $\begin{array}{l}\text { Oridorsalis } \\
\text { umbonatus }\end{array}$ & 0 & 2 & 0 & 0 & 1 & 0 & 1 & 1 & 1 & 3 \\
\hline Parafusulina sp. & 0 & 1 & 0 & 0 & 0 & 0 & 0 & 0 & 0 & 0 \\
\hline $\begin{array}{l}\text { Plectofrondicularia } \\
\text { pellucida }\end{array}$ & 0 & 0 & 0 & 0 & 0 & 0 & 1 & 0 & 0 & 0 \\
\hline Proxifrons sp. & 0 & 0 & 0 & 0 & 0 & 0 & 0 & 0 & 0 & 0 \\
\hline Pullenia bulloides & 0 & 0 & 0 & 0 & 1 & 1 & 0 & 1 & 0 & 0 \\
\hline $\begin{array}{l}\text { Pullenia } \\
\text { quinqueloba }\end{array}$ & 0 & 2 & 1 & 0 & 1 & 1 & 2 & 2 & 0 & 0 \\
\hline $\begin{array}{l}\text { Rectobolivina } \\
\text { striatula }\end{array}$ & 0 & 0 & 0 & 0 & 2 & 0 & 0 & 1 & 0 & 0 \\
\hline Saracenaria italica & 0 & 0 & 0 & 0 & 0 & 0 & 0 & 0 & 0 & 0 \\
\hline Sigmoidina sp. & 0 & 0 & 0 & 0 & 0 & 0 & 0 & 0 & 0 & 0 \\
\hline $\begin{array}{l}\text { Siphonaperta } \\
\text { macbeathi }\end{array}$ & 0 & 2 & 0 & 0 & 13 & 8 & 8 & 4 & 6 & 1 \\
\hline $\begin{array}{l}\text { Siphotextularia } \\
\text { wairoana }\end{array}$ & 0 & 0 & 0 & 0 & 1 & 0 & 0 & 0 & 0 & 0 \\
\hline $\begin{array}{l}\text { Sphaeroidina } \\
\text { bulloides }\end{array}$ & 4 & 0 & 0 & 0 & 1 & 0 & 0 & 0 & 0 & 0 \\
\hline Trifarina bradyi & 0 & 0 & 0 & 0 & 0 & 0 & 0 & 1 & 0 & 0 \\
\hline Vaginulina sp. & 0 & 0 & 0 & 0 & 0 & 0 & 1 & 1 & 0 & 0 \\
\hline Zeoflorilus parri & 0 & 0 & 0 & 0 & 0 & 0 & 0 & 0 & 0 & 0 \\
\hline \multicolumn{11}{|l|}{ Totals } \\
\hline Benthic foraminifera & 248 & 403 & 373 & 13 & 359 & 303 & 384 & 417 & 370 & 352 \\
\hline $\begin{array}{l}\text { Planktonic } \\
\text { foraminifera }\end{array}$ & 0 & 1 & 0 & 0 & 5 & 3 & 3 & 4 & 6 & 2 \\
\hline Total forams & 248 & 404 & 373 & 13 & 364 & 306 & 387 & 421 & 376 & 354 \\
\hline $\begin{array}{l}\text { Percentage } \\
\text { planktonic forams }\end{array}$ & 0.0 & 0.2 & 0.0 & 0.0 & 1.4 & 1.0 & 0.8 & 1.0 & 1.6 & 0.6 \\
\hline Productivity Index & 9.9 & 16.1 & 29.8 & 0.1 & 28.7 & 24.2 & 30.7 & 16.7 & 29.6 & 7.0 \\
\hline $\begin{array}{l}\text { Percent mud ( }<63 \\
\text { um sieved) }\end{array}$ & 98.4 & 98.3 & 96.9 & 96.1 & 88.9 & 92.3 & 90.7 & 93.7 & 92.6 & 97.7 \\
\hline
\end{tabular}




\begin{tabular}{|c|c|c|c|c|c|c|c|c|c|c|c|}
\hline Species name & WS46 & WS48 & WS49 & WS51 & WS52 & WS54 & WS55 & WS57 & WS58 & WS60 & WS61 \\
\hline $\begin{array}{l}\text { Amphicorya } \\
\text { hirsuta }\end{array}$ & 3 & 4 & 3 & 0 & 5 & 2 & 6 & 1 & 0 & 2 & 0 \\
\hline $\begin{array}{l}\text { Anomalinoides } \\
\text { parvumbilia }\end{array}$ & 11 & 4 & 1 & 0 & 0 & 19 & 17 & 11 & 18 & 0 & 4 \\
\hline $\begin{array}{l}\text { Anomalinoides } \\
\text { sphericus }\end{array}$ & 16 & 37 & 12 & 0 & 4 & 11 & 2 & 13 & 22 & 19 & 14 \\
\hline $\begin{array}{l}\text { Anomalinoides } \\
\text { subnonionoides }\end{array}$ & 0 & 0 & 0 & 0 & 0 & 0 & 0 & 0 & 1 & 0 & 0 \\
\hline Astrononion parki & 2 & 0 & 1 & 0 & 1 & 5 & 18 & 16 & 30 & 4 & 3 \\
\hline $\begin{array}{l}\text { Biloculina } \\
\text { anomala }\end{array}$ & 0 & 0 & 0 & 0 & 0 & 0 & 0 & 0 & 0 & 0 & 0 \\
\hline Bolivinita pliozea & 40 & 54 & 46 & 0 & 82 & 2 & 17 & 35 & 37 & 2 & 5 \\
\hline Bolivina sp. & 0 & 0 & 0 & 0 & 0 & 0 & 0 & 0 & 0 & 0 & 1 \\
\hline Bolivina cacozela & 0 & 0 & 0 & 0 & 0 & 0 & 0 & 0 & 0 & 0 & 0 \\
\hline Bolivina petiae & 0 & 0 & 0 & 0 & 0 & 0 & 0 & 0 & 0 & 4 & 0 \\
\hline Bolivina silvestrina & 0 & 0 & 0 & 0 & 0 & 0 & 0 & 0 & 0 & 0 & 0 \\
\hline $\begin{array}{l}\text { Bolivina } \\
\text { spathulata }\end{array}$ & 0 & 0 & 0 & 0 & 0 & 0 & 0 & 2 & 1 & 0 & 0 \\
\hline $\begin{array}{l}\text { Bolivina } \\
\text { subcompacta }\end{array}$ & 0 & 0 & 0 & 0 & 0 & 0 & 0 & 0 & 0 & 2 & 0 \\
\hline $\begin{array}{l}\text { Bolivina } \\
\text { subexcavata }\end{array}$ & 0 & 0 & 0 & 0 & 0 & 0 & 0 & 0 & 0 & 0 & 0 \\
\hline $\begin{array}{l}\text { Bolivina } \\
\text { wanganuiensis }\end{array}$ & 0 & 0 & 0 & 0 & 0 & 0 & 0 & 0 & 0 & 0 & 0 \\
\hline $\begin{array}{l}\text { Bulimina } \\
\text { marginata }\end{array}$ & 15 & 4 & 4 & 0 & 28 & 31 & 108 & 60 & 32 & 28 & 26 \\
\hline $\begin{array}{l}\text { Cassidunlina } \\
\text { neocarinata }\end{array}$ & 0 & 0 & 0 & 0 & 0 & 0 & 0 & 0 & 4 & 4 & 4 \\
\hline $\begin{array}{l}\text { Cibicides } \\
\text { deliquatus }\end{array}$ & 37 & 32 & 16 & 0 & 6 & 14 & 1 & 3 & 0 & 16 & 7 \\
\hline Cibicides molestus & 0 & 0 & 0 & 0 & 0 & 0 & 0 & 0 & 0 & 0 & 0 \\
\hline Discorbidae sp. & 0 & 0 & 0 & 0 & 0 & 0 & 0 & 1 & 1 & 0 & 0 \\
\hline $\begin{array}{l}\text { Elphidium } \\
\text { charlottense }\end{array}$ & 0 & 0 & 0 & 0 & 0 & 0 & 0 & 0 & 2 & 1 & 3 \\
\hline $\begin{array}{l}\text { Elphidium } \\
\text { excavatum }\end{array}$ & 0 & 0 & 0 & 0 & 0 & 0 & 0 & 0 & 0 & 0 & 0 \\
\hline $\begin{array}{l}\text { Elphidium } \\
\text { novozealandicum }\end{array}$ & 0 & 0 & 0 & 0 & 0 & 0 & 0 & 0 & 0 & 0 & 1 \\
\hline $\begin{array}{l}\text { Euuvigerina } \\
\text { pliozea }\end{array}$ & 41 & 24 & 20 & 0 & 25 & 65 & 2 & 23 & 28 & 89 & 38 \\
\hline $\begin{array}{l}\text { Evolvocassidulina } \\
\text { orientalis }\end{array}$ & 0 & 0 & 0 & 0 & 2 & 8 & 8 & 7 & 3 & 0 & 3 \\
\hline Fissurina sp. & 0 & 0 & 0 & 0 & 0 & 0 & 0 & 0 & 0 & 0 & 0 \\
\hline $\begin{array}{l}\text { Globobulimina } \\
\text { pacifica }\end{array}$ & 0 & 0 & 0 & 0 & 0 & 0 & 0 & 0 & 0 & 0 & 0 \\
\hline $\begin{array}{l}\text { Globocassidulina } \\
\text { subglobosa }\end{array}$ & 0 & 0 & 0 & 0 & 0 & 0 & 0 & 0 & 1 & 0 & 0 \\
\hline $\begin{array}{l}\text { Gyroidinoides } \\
\text { zelandica }\end{array}$ & 0 & 1 & 1 & 0 & 0 & 0 & 0 & 0 & 3 & 26 & 1 \\
\hline Haeuslerella parri & 53 & 116 & 78 & 0 & 50 & 97 & 62 & 67 & 75 & 53 & 60 \\
\hline $\begin{array}{l}\text { Hoeglundina } \\
\text { elegans }\end{array}$ & 15 & 4 & 20 & 0 & 2 & 3 & 0 & 0 & 0 & 5 & 2 \\
\hline
\end{tabular}




\begin{tabular}{|c|c|c|c|c|c|c|c|c|c|c|c|}
\hline Species name & WS46 & WS48 & WS49 & WS51 & WS52 & WS54 & WS55 & WS57 & WS58 & WS60 & WS61 \\
\hline Lagena sp. & 5 & 2 & 0 & 0 & 7 & 2 & 6 & 1 & 8 & 0 & 6 \\
\hline Lenticulina sp. & 11 & 13 & 4 & 0 & 14 & 8 & 10 & 5 & 0 & 6 & 4 \\
\hline Marginulina sp. & 1 & 0 & 0 & 0 & 0 & 0 & 0 & 0 & 0 & 0 & 0 \\
\hline $\begin{array}{l}\text { Martinottiella } \\
\text { communis }\end{array}$ & 0 & 0 & 0 & 0 & 0 & 0 & 0 & 0 & 0 & 0 & 0 \\
\hline Melonis zeobesus & 1 & 0 & 0 & 0 & 0 & 0 & 0 & 0 & 0 & 2 & 0 \\
\hline Nodosaria sp. & 0 & 0 & 1 & 0 & 0 & 0 & 0 & 0 & 0 & 0 & 0 \\
\hline $\begin{array}{l}\text { Nonionellina } \\
\text { flemingi }\end{array}$ & 0 & 0 & 1 & 0 & 1 & 0 & 15 & 8 & 16 & 8 & 4 \\
\hline Notorotalia finlayi & 16 & 15 & 12 & 0 & 10 & 31 & 30 & 32 & 52 & 18 & 22 \\
\hline $\begin{array}{l}\text { Notorotalia } \\
\text { kingmai }\end{array}$ & 1 & 0 & 0 & 0 & 0 & 2 & 0 & 0 & 0 & 0 & 0 \\
\hline $\begin{array}{l}\text { Notorotalia } \\
\text { zelandica } \\
\text { zelandica }\end{array}$ & 1 & 0 & 0 & 0 & 0 & 0 & 0 & 0 & 0 & 0 & 0 \\
\hline Oolina sp. & 0 & 0 & 2 & 0 & 0 & 0 & 0 & 1 & 0 & 0 & 0 \\
\hline Oridorsalis tenera & 0 & 0 & 0 & 0 & 0 & 0 & 0 & 0 & 1 & 0 & 0 \\
\hline $\begin{array}{l}\text { Oridorsalis } \\
\text { umbonatus }\end{array}$ & 0 & 0 & 0 & 0 & 0 & 0 & 0 & 0 & 0 & 0 & 0 \\
\hline Parafusulina sp. & 0 & 0 & 0 & 0 & 0 & 0 & 0 & 0 & 0 & 0 & 1 \\
\hline $\begin{array}{l}\text { Plectofrondicularia } \\
\text { pellucida }\end{array}$ & 0 & 0 & 0 & 0 & 1 & 0 & 0 & 1 & 3 & 0 & 1 \\
\hline Proxifrons sp. & 0 & 0 & 0 & 0 & 0 & 0 & 0 & 0 & 1 & 0 & 0 \\
\hline Pullenia bulloides & 0 & 0 & 0 & 0 & 0 & 0 & 0 & 0 & 1 & 0 & 0 \\
\hline $\begin{array}{l}\text { Pullenia } \\
\text { quinqueloba }\end{array}$ & 0 & 0 & 0 & 0 & 0 & 1 & 0 & 1 & 0 & 0 & 1 \\
\hline $\begin{array}{l}\text { Rectobolivina } \\
\text { striatula }\end{array}$ & 1 & 0 & 0 & 0 & 0 & 0 & 0 & 0 & 0 & 5 & 3 \\
\hline Saracenaria italica & 0 & 0 & 0 & 0 & 0 & 0 & 0 & 0 & 0 & 0 & 0 \\
\hline Sigmoidina sp. & 0 & 0 & 0 & 0 & 0 & 0 & 0 & 0 & 0 & 0 & 0 \\
\hline $\begin{array}{l}\text { Siphonaperta } \\
\text { macbeathi }\end{array}$ & 4 & 2 & 6 & 0 & 0 & 0 & 0 & 0 & 2 & 2 & 5 \\
\hline $\begin{array}{l}\text { Siphotextularia } \\
\text { wairoana }\end{array}$ & 0 & 0 & 1 & 0 & 0 & 0 & 0 & 0 & 0 & 0 & 0 \\
\hline $\begin{array}{l}\text { Sphaeroidina } \\
\text { bulloides }\end{array}$ & 0 & 0 & 0 & 0 & 1 & 0 & 0 & 0 & 1 & 0 & 0 \\
\hline Trifarina bradyi & 0 & 0 & 0 & 0 & 0 & 0 & 0 & 0 & 0 & 0 & 0 \\
\hline Vaginulina sp. & 0 & 0 & 0 & 0 & 0 & 0 & 0 & 0 & 1 & 0 & 0 \\
\hline Zeoflorilus parri & 0 & 0 & 0 & 0 & 0 & 0 & 2 & 0 & 0 & 0 & 1 \\
\hline \multicolumn{12}{|l|}{ Totals } \\
\hline $\begin{array}{l}\text { Benthic } \\
\text { foraminifera }\end{array}$ & 274 & 312 & 229 & 0 & 239 & 301 & 304 & 288 & 344 & 296 & 220 \\
\hline $\begin{array}{l}\text { Planktonic } \\
\text { foraminifera }\end{array}$ & 2 & 0 & 3 & 0 & 0 & 0 & 3 & 9 & 21 & 8 & 19 \\
\hline Total forams & 276 & 312 & 232 & 0 & 239 & 301 & 307 & 297 & 365 & 304 & 239 \\
\hline $\begin{array}{l}\text { Percentage } \\
\text { planktonic forams }\end{array}$ & 0.7 & 0.0 & 1.3 & 0.0 & 0.0 & 0.0 & 1.0 & 3.0 & 5.8 & 2.6 & 7.9 \\
\hline Productivity Index & 21.9 & 25.0 & 18.3 & 0.0 & 9.6 & 3.0 & 3.0 & 11.5 & 27.5 & 94.7 & 35.2 \\
\hline $\begin{array}{l}\text { Percent mud (<63 } \\
\text { um sieved) }\end{array}$ & 96.0 & 97.0 & 97.4 & 98.1 & 97.0 & 99.2 & 96.5 & 75.4 & 77.2 & 81.1 & 82.8 \\
\hline
\end{tabular}




\begin{tabular}{|c|c|c|c|c|c|c|c|c|c|c|c|}
\hline Species name & WS62 & WS63 & WS64 & WS65 & WS66 & WS67 & WS69 & WS70 & WS72 & WS73 & WS75 \\
\hline $\begin{array}{l}\text { Amphicorya } \\
\text { hirsuta }\end{array}$ & 0 & 0 & 0 & 0 & 0 & 0 & 0 & 0 & 0 & 0 & 0 \\
\hline $\begin{array}{l}\text { Anomalinoides } \\
\text { parvumbilia }\end{array}$ & 0 & 2 & 0 & 2 & 5 & 2 & 1 & 0 & 0 & 0 & 1 \\
\hline $\begin{array}{l}\text { Anomalinoides } \\
\text { sphericus }\end{array}$ & 0 & 1 & 0 & 0 & 0 & 0 & 0 & 0 & 0 & 0 & 0 \\
\hline $\begin{array}{l}\text { Anomalinoides } \\
\text { subnonionoides }\end{array}$ & 0 & 0 & 0 & 0 & 0 & 0 & 0 & 0 & 0 & 0 & 0 \\
\hline Astrononion parki & 0 & 32 & 0 & 55 & 37 & 44 & 34 & 18 & 73 & 42 & 15 \\
\hline $\begin{array}{l}\text { Biloculina } \\
\text { anomala }\end{array}$ & 0 & 0 & 0 & 0 & 0 & 0 & 1 & 0 & 0 & 0 & 0 \\
\hline Bolivinita pliozea & 0 & 11 & 0 & 22 & 29 & 36 & 15 & 23 & 27 & 8 & 7 \\
\hline Bolivina sp. & 0 & 0 & 0 & 0 & 0 & 0 & 0 & 0 & 0 & 0 & 0 \\
\hline Bolivina cacozela & 0 & 0 & 0 & 0 & 0 & 0 & 0 & 0 & 0 & 0 & 0 \\
\hline Bolivina petiae & 0 & 0 & 0 & 0 & 0 & 0 & 0 & 0 & 0 & 0 & 0 \\
\hline Bolivina silvestrina & 0 & 0 & 0 & 0 & 0 & 0 & 0 & 0 & 0 & 0 & 0 \\
\hline $\begin{array}{l}\text { Bolivina } \\
\text { spathulata }\end{array}$ & 0 & 1 & 0 & 0 & 0 & 2 & 0 & 1 & 3 & 0 & 0 \\
\hline $\begin{array}{l}\text { Bolivina } \\
\text { subcompacta }\end{array}$ & 0 & 0 & 0 & 0 & 0 & 0 & 0 & 0 & 0 & 0 & 0 \\
\hline $\begin{array}{l}\text { Bolivina } \\
\text { subexcavata }\end{array}$ & 0 & 0 & 0 & 0 & 1 & 0 & 3 & 0 & 0 & 0 & 0 \\
\hline $\begin{array}{l}\text { Bolivina } \\
\text { wanganuiensis }\end{array}$ & 0 & 0 & 0 & 0 & 0 & 0 & 0 & 0 & 0 & 0 & 0 \\
\hline $\begin{array}{l}\text { Bulimina } \\
\text { marginata }\end{array}$ & 0 & 11 & 0 & 18 & 18 & 44 & 19 & 113 & 143 & 137 & 99 \\
\hline $\begin{array}{l}\text { Cassidunlina } \\
\text { neocarinata }\end{array}$ & 0 & 4 & 0 & 14 & 7 & 14 & 24 & 35 & 43 & 18 & 99 \\
\hline $\begin{array}{l}\text { Cibicides } \\
\text { deliquatus }\end{array}$ & 0 & 4 & 0 & 0 & 2 & 0 & 1 & 0 & 1 & 0 & 0 \\
\hline Cibicides molestus & 0 & 0 & 0 & 0 & 0 & 0 & 0 & 0 & 0 & 0 & 0 \\
\hline Discorbidae sp. & 0 & 2 & 0 & 3 & 3 & 0 & 0 & 0 & 0 & 0 & 0 \\
\hline $\begin{array}{l}\text { Elphidium } \\
\text { charlottense }\end{array}$ & 0 & 28 & 0 & 8 & 7 & 1 & 12 & 0 & 0 & 0 & 1 \\
\hline $\begin{array}{l}\text { Elphidium } \\
\text { excavatum }\end{array}$ & 0 & 2 & 0 & 0 & 1 & 0 & 4 & 0 & 0 & 0 & 0 \\
\hline $\begin{array}{l}\text { Elphidium } \\
\text { novozealandicum }\end{array}$ & 0 & 0 & 0 & 0 & 0 & 0 & 0 & 0 & 0 & 0 & 0 \\
\hline $\begin{array}{l}\text { Euuvigerina } \\
\text { pliozea }\end{array}$ & 0 & 36 & 0 & 42 & 40 & 38 & 21 & 33 & 48 & 8 & 11 \\
\hline $\begin{array}{l}\text { Evolvocassidulina } \\
\text { orientalis }\end{array}$ & 0 & 8 & 0 & 9 & 6 & 5 & 7 & 2 & 13 & 2 & 8 \\
\hline Fissurina sp. & 0 & 1 & 0 & 0 & 0 & 1 & 1 & 0 & 0 & 0 & 0 \\
\hline $\begin{array}{l}\text { Globobulimina } \\
\text { pacifica }\end{array}$ & 0 & 0 & 0 & 0 & 0 & 0 & 0 & 0 & 0 & 0 & 0 \\
\hline $\begin{array}{l}\text { Globocassidulina } \\
\text { subglobosa }\end{array}$ & 0 & 0 & 0 & 0 & 0 & 0 & 0 & 0 & 0 & 0 & 0 \\
\hline $\begin{array}{l}\text { Gyroidinoides } \\
\text { zelandica }\end{array}$ & 0 & 6 & 0 & 0 & 0 & 0 & 0 & 0 & 0 & 0 & 0 \\
\hline Haeuslerella parri & 0 & 93 & 0 & 68 & 65 & 62 & 42 & 5 & 1 & 7 & 8 \\
\hline
\end{tabular}




\begin{tabular}{|c|c|c|c|c|c|c|c|c|c|c|c|}
\hline Species name & WS62 & WS63 & WS64 & WS65 & WS66 & WS67 & WS69 & WS70 & WS72 & WS73 & WS75 \\
\hline $\begin{array}{l}\text { Hoeglundina } \\
\text { elegans }\end{array}$ & 1 & 1 & 0 & 7 & 1 & 11 & 10 & 0 & 0 & 0 & 0 \\
\hline Lagena sp. & 0 & 13 & 0 & 2 & 3 & 8 & 8 & 3 & 0 & 1 & 1 \\
\hline Lenticulina sp. & 0 & 6 & 0 & 23 & 13 & 6 & 15 & 5 & 1 & 2 & 0 \\
\hline Marginulina sp. & 0 & 0 & 0 & 0 & 0 & 0 & 0 & 0 & 0 & 0 & 0 \\
\hline $\begin{array}{l}\text { Martinottiella } \\
\text { communis }\end{array}$ & 0 & 0 & 0 & 0 & 0 & 0 & 0 & 0 & 0 & 0 & 0 \\
\hline Melonis zeobesus & 0 & 1 & 0 & 0 & 0 & 0 & 0 & 0 & 0 & 0 & 0 \\
\hline Nodosaria sp. & 0 & 0 & 0 & 0 & 0 & 0 & 0 & 0 & 0 & 0 & 0 \\
\hline $\begin{array}{l}\text { Nonionellina } \\
\text { flemingi }\end{array}$ & 0 & 1 & 0 & 17 & 16 & 7 & 13 & 2 & 71 & 10 & 24 \\
\hline Notorotalia finlayi & 0 & 31 & 0 & 46 & 42 & 24 & 39 & 40 & 127 & 42 & 46 \\
\hline $\begin{array}{l}\text { Notorotalia } \\
\text { kingmai }\end{array}$ & 0 & 0 & 0 & 0 & 0 & 0 & 0 & 0 & 0 & 0 & 0 \\
\hline $\begin{array}{l}\text { Notorotalia } \\
\text { zelandica } \\
\text { zelandica }\end{array}$ & 0 & 0 & 0 & 0 & 0 & 0 & 0 & 0 & 0 & 0 & 0 \\
\hline Oolina sp. & 0 & 0 & 0 & 0 & 0 & 0 & 0 & 0 & 0 & 0 & 0 \\
\hline Oridorsalis tenera & 0 & 0 & 0 & 0 & 0 & 0 & 0 & 0 & 0 & 0 & 0 \\
\hline $\begin{array}{l}\text { Oridorsalis } \\
\text { umbonatus }\end{array}$ & 0 & 0 & 0 & 0 & 2 & 0 & 0 & 0 & 0 & 0 & 0 \\
\hline Parafusulina sp. & 0 & 0 & 0 & 0 & 0 & 0 & 0 & 0 & 0 & 0 & 0 \\
\hline $\begin{array}{l}\text { Plectofrondicularia } \\
\text { pellucida }\end{array}$ & 0 & 6 & 0 & 0 & 0 & 0 & 0 & 0 & 0 & 0 & 0 \\
\hline Proxifrons sp. & 0 & 0 & 0 & 0 & 0 & 0 & 0 & 0 & 0 & 0 & 0 \\
\hline Pullenia bulloides & 0 & 0 & 0 & 0 & 0 & 0 & 0 & 0 & 0 & 0 & 0 \\
\hline $\begin{array}{l}\text { Pullenia } \\
\text { quinqueloba }\end{array}$ & 0 & 2 & 0 & 0 & 1 & 0 & 0 & 0 & 0 & 0 & 0 \\
\hline $\begin{array}{l}\text { Rectobolivina } \\
\text { striatula }\end{array}$ & 0 & 1 & 0 & 0 & 0 & 0 & 0 & 0 & 0 & 0 & 0 \\
\hline Saracenaria italica & 0 & 0 & 0 & 0 & 0 & 0 & 0 & 0 & 0 & 0 & 0 \\
\hline Sigmoidina sp. & 0 & 0 & 0 & 0 & 0 & 0 & 0 & 0 & 0 & 0 & 0 \\
\hline $\begin{array}{l}\text { Siphonaperta } \\
\text { macbeathi }\end{array}$ & 0 & 0 & 0 & 0 & 1 & 0 & 0 & 0 & 0 & 0 & 0 \\
\hline $\begin{array}{l}\text { Siphotextularia } \\
\text { wairoana }\end{array}$ & 0 & 0 & 0 & 3 & 1 & 2 & 3 & 1 & 0 & 0 & 0 \\
\hline $\begin{array}{l}\text { Sphaeroidina } \\
\text { bulloides }\end{array}$ & 0 & 0 & 0 & 1 & 0 & 0 & 1 & 0 & 0 & 0 & 0 \\
\hline Trifarina bradyi & 0 & 0 & 0 & 0 & 0 & 0 & 0 & 0 & 0 & 0 & 0 \\
\hline Vaginulina sp. & 0 & 0 & 0 & 0 & 0 & 0 & 0 & 0 & 0 & 0 & 0 \\
\hline Zeoflorilus parri & 0 & 0 & 0 & 0 & 0 & 0 & 0 & 0 & 0 & 0 & 0 \\
\hline \multicolumn{12}{|l|}{ Totals } \\
\hline $\begin{array}{l}\text { Benthic } \\
\text { foraminifera }\end{array}$ & 1 & 304 & 0 & 340 & 301 & 307 & 274 & 281 & 551 & 277 & 320 \\
\hline $\begin{array}{l}\text { Planktonic } \\
\text { foraminifera }\end{array}$ & 0 & 55 & 0 & 67 & 53 & 11 & 96 & 2 & 1 & 2 & 1 \\
\hline Total forams & 1 & 359 & 0 & 407 & 354 & 318 & 370 & 283 & 552 & 279 & 321 \\
\hline $\begin{array}{l}\text { Percentage } \\
\text { planktonic forams }\end{array}$ & 0.0 & 15.3 & 0.0 & 16.5 & 15.0 & 3.5 & 25.9 & 0.7 & 0.2 & 0.7 & 0.3 \\
\hline Productivity Index & 0.0 & 12.2 & 0.0 & 13.6 & 12.0 & 24.6 & 5.5 & 22.5 & 22.0 & 22.2 & 51.2 \\
\hline
\end{tabular}




\begin{tabular}{|l|c|c|c|c|c|c|c|c|c|c|c|}
\hline Species name & WS62 & WS63 & WS64 & WS65 & WS66 & WS67 & WS69 & WS70 & WS72 & WS73 & WS75 \\
\hline $\begin{array}{l}\text { Percent mud (<63 } \\
\text { um sieved) }\end{array}$ & 91.1 & 72.3 & 70.6 & 95.1 & 96.3 & 96.9 & 93.6 & 99.2 & 99.1 & 99.0 & 98.9 \\
\hline
\end{tabular}

\begin{tabular}{|c|c|c|c|c|c|c|c|c|c|c|c|}
\hline Species name & WS76 & WS78 & WS79 & WS80 & WS81 & WS82 & WS84 & WS85 & WS87 & WS88 & WS89 \\
\hline $\begin{array}{l}\text { Amphicorya } \\
\text { hirsuta }\end{array}$ & 0 & 0 & 0 & 0 & 0 & 0 & 0 & 0 & 0 & 0 & 0 \\
\hline $\begin{array}{l}\text { Anomalinoides } \\
\text { parvumbilia }\end{array}$ & 2 & 6 & 0 & 0 & 0 & 0 & 0 & 0 & 0 & 0 & 0 \\
\hline $\begin{array}{l}\text { Anomalinoides } \\
\text { sphericus }\end{array}$ & 0 & 0 & 0 & 0 & 0 & 0 & 0 & 0 & 0 & 0 & 0 \\
\hline $\begin{array}{l}\text { Anomalinoides } \\
\text { subnonionoides }\end{array}$ & 0 & 0 & 0 & 0 & 0 & 0 & 0 & 0 & 0 & 0 & 0 \\
\hline Astrononion parki & 28 & 21 & 0 & 14 & 0 & 0 & 0 & 0 & 0 & 0 & 0 \\
\hline $\begin{array}{l}\text { Biloculina } \\
\text { anomala }\end{array}$ & 0 & 0 & 0 & 0 & 0 & 0 & 0 & 0 & 0 & 0 & 0 \\
\hline Bolivinita pliozea & 56 & 51 & 0 & 0 & 0 & 0 & 0 & 0 & 0 & 0 & 0 \\
\hline Bolivina sp. & 0 & 0 & 0 & 0 & 0 & 0 & 0 & 0 & 0 & 0 & 0 \\
\hline Bolivina cacozela & 0 & 0 & 0 & 0 & 0 & 0 & 0 & 0 & 0 & 0 & 0 \\
\hline Bolivina petiae & 0 & 0 & 0 & 0 & 0 & 0 & 0 & 0 & 0 & 0 & 0 \\
\hline Bolivina silvestrina & 0 & 1 & 0 & 0 & 0 & 0 & 0 & 0 & 0 & 0 & 0 \\
\hline $\begin{array}{l}\text { Bolivina } \\
\text { spathulata }\end{array}$ & 0 & 0 & 0 & 0 & 0 & 0 & 0 & 0 & 0 & 0 & 0 \\
\hline $\begin{array}{l}\text { Bolivina } \\
\text { subcompacta }\end{array}$ & 0 & 0 & 0 & 0 & 0 & 0 & 0 & 0 & 0 & 0 & 0 \\
\hline $\begin{array}{l}\text { Bolivina } \\
\text { subexcavata }\end{array}$ & 0 & 0 & 0 & 0 & 0 & 0 & 0 & 0 & 0 & 0 & 0 \\
\hline $\begin{array}{l}\text { Bolivina } \\
\text { wanganuiensis }\end{array}$ & 0 & 0 & 0 & 20 & 0 & 0 & 0 & 0 & 0 & 0 & 0 \\
\hline $\begin{array}{l}\text { Bulimina } \\
\text { marginata }\end{array}$ & 285 & 31 & 0 & 1 & 0 & 0 & 0 & 0 & 0 & 0 & 0 \\
\hline $\begin{array}{l}\text { Cassidunlina } \\
\text { neocarinata }\end{array}$ & 3 & 0 & 0 & 5 & 0 & 0 & 0 & 0 & 0 & 0 & 0 \\
\hline $\begin{array}{l}\text { Cibicides } \\
\text { deliquatus }\end{array}$ & 0 & 0 & 0 & 9 & 0 & 0 & 0 & 0 & 0 & 0 & 0 \\
\hline Cibicides molestus & 0 & 0 & 0 & 0 & 0 & 0 & 0 & 0 & 0 & 0 & 0 \\
\hline Discorbidae sp. & 0 & 0 & 0 & 25 & 0 & 0 & 0 & 0 & 0 & 0 & 0 \\
\hline $\begin{array}{l}\text { Elphidium } \\
\text { charlottense }\end{array}$ & 1 & 19 & 0 & 116 & 0 & 0 & 0 & 0 & 0 & 0 & 0 \\
\hline $\begin{array}{l}\text { Elphidium } \\
\text { excavatum }\end{array}$ & 0 & 0 & 0 & 8 & 0 & 0 & 0 & 0 & 0 & 0 & 0 \\
\hline $\begin{array}{l}\text { Elphidium } \\
\text { novozealandicum }\end{array}$ & 0 & 0 & 0 & 0 & 0 & 0 & 0 & 0 & 0 & 0 & 0 \\
\hline $\begin{array}{l}\text { Euuvigerina } \\
\text { pliozea }\end{array}$ & 12 & 88 & 0 & 47 & 0 & 0 & 0 & 0 & 0 & 0 & 0 \\
\hline $\begin{array}{l}\text { Evolvocassidulina } \\
\text { orientalis }\end{array}$ & 8 & 5 & 0 & 5 & 0 & 0 & 0 & 0 & 0 & 0 & 0 \\
\hline Fissurina sp. & 0 & 0 & 0 & 0 & 0 & 0 & 0 & 0 & 0 & 0 & 0 \\
\hline $\begin{array}{l}\text { Globobulimina } \\
\text { pacifica }\end{array}$ & 0 & 0 & 0 & 0 & 0 & 0 & 0 & 0 & 0 & 0 & 0 \\
\hline $\begin{array}{l}\text { Globocassidulina } \\
\text { subglobosa }\end{array}$ & 0 & 0 & 0 & 1 & 0 & 0 & 0 & 0 & 0 & 0 & 0 \\
\hline
\end{tabular}




\begin{tabular}{|c|c|c|c|c|c|c|c|c|c|c|c|}
\hline Species name & WS76 & WS78 & WS79 & WS80 & WS81 & WS82 & WS84 & WS85 & WS87 & WS88 & WS89 \\
\hline $\begin{array}{l}\text { Gyroidinoides } \\
\text { zelandica }\end{array}$ & 0 & 0 & 0 & 0 & 0 & 0 & 0 & 0 & 0 & 0 & 0 \\
\hline Haeuslerella parri & 13 & 6 & 0 & 3 & 0 & 0 & 0 & 0 & 0 & 0 & 0 \\
\hline $\begin{array}{l}\text { Hoeglundina } \\
\text { elegans }\end{array}$ & 2 & 0 & 0 & 1 & 0 & 0 & 0 & 0 & 0 & 0 & 0 \\
\hline Lagena sp. & 5 & 8 & 0 & 2 & 0 & 0 & 0 & 0 & 0 & 0 & 0 \\
\hline Lenticulina sp. & 8 & 4 & 0 & 0 & 0 & 0 & 0 & 0 & 0 & 0 & 0 \\
\hline Marginulina sp. & 0 & 0 & 0 & 0 & 0 & 0 & 0 & 0 & 0 & 0 & 0 \\
\hline $\begin{array}{l}\text { Martinottiella } \\
\text { communis }\end{array}$ & 0 & 0 & 0 & 0 & 0 & 0 & 0 & 0 & 0 & 0 & 0 \\
\hline Melonis zeobesus & 0 & 0 & 0 & 0 & 0 & 0 & 0 & 0 & 0 & 0 & 0 \\
\hline Nodosaria sp. & 1 & 1 & 0 & 0 & 0 & 0 & 0 & 0 & 0 & 0 & 0 \\
\hline $\begin{array}{l}\text { Nonionellina } \\
\text { flemingi }\end{array}$ & 57 & 14 & 0 & 7 & 0 & 0 & 0 & 0 & 0 & 0 & 0 \\
\hline Notorotalia finlayi & 76 & 68 & 0 & 102 & 0 & 0 & 0 & 0 & 0 & 0 & 0 \\
\hline $\begin{array}{l}\text { Notorotalia } \\
\text { kingmai }\end{array}$ & 0 & 0 & 0 & 0 & 0 & 0 & 0 & 0 & 0 & 0 & 0 \\
\hline $\begin{array}{l}\text { Notorotalia } \\
\text { zelandica } \\
\text { zelandica }\end{array}$ & 0 & 0 & 0 & 0 & 0 & 0 & 0 & 0 & 0 & 0 & 0 \\
\hline Oolina sp. & 0 & 0 & 0 & 5 & 0 & 0 & 0 & 0 & 0 & 0 & 0 \\
\hline Oridorsalis tenera & 0 & 0 & 0 & 0 & 0 & 0 & 0 & 0 & 0 & 0 & 0 \\
\hline $\begin{array}{l}\text { Oridorsalis } \\
\text { umbonatus }\end{array}$ & 0 & 0 & 0 & 0 & 0 & 0 & 0 & 0 & 0 & 0 & 0 \\
\hline Parafusulina sp. & 0 & 0 & 0 & 0 & 0 & 0 & 0 & 0 & 0 & 0 & 0 \\
\hline $\begin{array}{l}\text { Plectofrondicularia } \\
\text { pellucida }\end{array}$ & 0 & 0 & 0 & 0 & 0 & 0 & 0 & 0 & 0 & 0 & 0 \\
\hline Proxifrons sp. & 0 & 0 & 0 & 0 & 0 & 0 & 0 & 0 & 0 & 0 & 0 \\
\hline Pullenia bulloides & 1 & 0 & 0 & 0 & 0 & 0 & 0 & 0 & 0 & 0 & 0 \\
\hline $\begin{array}{l}\text { Pullenia } \\
\text { quinqueloba }\end{array}$ & 0 & 0 & 0 & 0 & 0 & 0 & 0 & 0 & 0 & 0 & 0 \\
\hline $\begin{array}{l}\text { Rectobolivina } \\
\text { striatula }\end{array}$ & 0 & 0 & 0 & 0 & 0 & 0 & 0 & 0 & 0 & 0 & 0 \\
\hline Saracenaria italica & 0 & 0 & 0 & 0 & 0 & 0 & 0 & 0 & 0 & 0 & 0 \\
\hline Sigmoidina sp. & 0 & 0 & 0 & 4 & 0 & 0 & 0 & 0 & 0 & 0 & 0 \\
\hline $\begin{array}{l}\text { Siphonaperta } \\
\text { macbeathi }\end{array}$ & 0 & 0 & 0 & 0 & 0 & 0 & 0 & 0 & 0 & 0 & 0 \\
\hline $\begin{array}{l}\text { Siphotextularia } \\
\text { wairoana }\end{array}$ & 1 & 0 & 0 & 0 & 0 & 0 & 0 & 0 & 0 & 0 & 0 \\
\hline $\begin{array}{l}\text { Sphaeroidina } \\
\text { bulloides }\end{array}$ & 0 & 1 & 0 & 0 & 0 & 0 & 0 & 0 & 0 & 0 & 0 \\
\hline Trifarina bradyi & 0 & 0 & 0 & 0 & 0 & 0 & 0 & 0 & 0 & 0 & 0 \\
\hline Vaginulina sp. & 0 & 0 & 0 & 0 & 0 & 0 & 0 & 0 & 0 & 0 & 0 \\
\hline Zeoflorilus parri & 0 & 0 & 0 & 0 & 0 & 0 & 0 & 0 & 0 & 0 & 0 \\
\hline \multicolumn{12}{|l|}{ Totals } \\
\hline $\begin{array}{l}\text { Benthic } \\
\text { foraminifera }\end{array}$ & 559 & 324 & 0 & 375 & 0 & 0 & 0 & 0 & 0 & 0 & 0 \\
\hline $\begin{array}{l}\text { Planktonic } \\
\text { foraminifera }\end{array}$ & 2 & 2 & 0 & 7 & 0 & 0 & 0 & 0 & 0 & 0 & 0 \\
\hline Total forams & 561 & 326 & 0 & 382 & 0 & 0 & 0 & 0 & 0 & 0 & 0 \\
\hline
\end{tabular}




\begin{tabular}{|l|c|c|c|c|c|c|c|c|c|c|c|}
\hline Species name & WS76 & WS78 & WS79 & WS80 & WS81 & WS82 & WS84 & WS85 & WS87 & WS88 & WS89 \\
\hline $\begin{array}{l}\text { Percentage } \\
\text { planktonic forams }\end{array}$ & 0.4 & 0.6 & 0.0 & 1.8 & 0.0 & 0.0 & 0.0 & 0.0 & 0.0 & 0.0 & 0.0 \\
\hline Productivity Index & 5.6 & 25.9 & 0.0 & 480.0 & 0.0 & 0.0 & 0.0 & 0.0 & 0.0 & 0.0 & 0.0 \\
\hline $\begin{array}{l}\text { Percent mud (<63 } \\
\text { um sieved) }\end{array}$ & 99.7 & 79.1 & 97.9 & 58.8 & 71.0 & 86.7 & 70.2 & 80.1 & 79.6 & 86.0 & 64.0 \\
\hline
\end{tabular}

The table below displays the sample and faunal compositions of the clusters defined in Chapter 4. Data are displayed as normalised values (\% abundance).

\section{Appendix C Table 2: Taxonomic composition of clusters defined in Chapter 4}

\begin{tabular}{|l|c|c|c|c|}
\hline CLUSTER 1 & WS1 & WS4 & WS5 & Mean \\
\hline Amphicorya hirsuta & 0.2 & 0.7 & 0.0 & 0.306925 \\
\hline Anomalinoides parvumbilia & 2.0 & 0.7 & 1.3 & 1.313603 \\
\hline Anomalinoides sphericus & 2.5 & 0.7 & 0.0 & 1.042219 \\
\hline $\begin{array}{l}\text { Anomalinoides } \\
\text { subnonionoides }\end{array}$ & 0.0 & 0.0 & 1.3 & 0.434783 \\
\hline Astrononion parki & 7.4 & 0.3 & 0.0 & 2.563593 \\
\hline Biloculina anomala & 0.0 & 0.0 & 0.0 & 0 \\
\hline Bolivinita pliozea & 1.5 & 0.0 & 0.0 & 0.490196 \\
\hline Bolivina sp. & 0.0 & 0.0 & 0.4 & 0.144928 \\
\hline Bolivina cacozela & 0.0 & 0.0 & 0.0 & 0 \\
\hline Bolivina petiae & 0.0 & 0.3 & 0.0 & 0.112613 \\
\hline Bolivina silvestrina & 0.0 & 0.0 & 0.0 & 0 \\
\hline Bolivina spathulata & 0.0 & 0.0 & 0.0 & 0 \\
\hline Bolivina subcompacta & 0.0 & 0.0 & 0.0 & 0 \\
\hline Bolivina subexcavata & 0.0 & 0.0 & 0.0 & 0 \\
\hline Bolivina wanganuiensis & 0.0 & 0.0 & 0.0 & 0 \\
\hline Bulimina marginata & 0.0 & 0.7 & 0.0 & 0.225225 \\
\hline Cassidunlina neocarinata & 0.0 & 0.0 & 0.0 & 0 \\
\hline Cibicides deliquatus & 5.9 & 12.5 & 5.2 & 7.866581 \\
\hline Cibicides molestus & 8.8 & 0.7 & 14.3 & 7.94901 \\
\hline Discorbidae sp. & 0.0 & 0.0 & 0.0 & 0 \\
\hline Elphidium charlottense & 0.0 & 0.3 & 0.0 & 0.112613 \\
\hline Elphidium excavatum & 0.0 & 0.0 & 0.0 & 0 \\
\hline Elphidium novozealandicum & 0.0 & 0.0 & 0.0 & 0 \\
\hline Euuvigerina pliozea & 32.4 & 6.1 & 42.6 & 27.01424 \\
\hline Evolvocassidulina orientalis & 0.5 & 2.4 & 0.4 & 1.096615 \\
\hline Fissurina sp. & 0.0 & 0.0 & 0.0 & 0 \\
\hline Globobulimina pacifica & 0.0 & 0.0 & 0.0 & 0 \\
\hline Globocassidulina subglobosa & 0.0 & 0.0 & 0.0 & 0 \\
\hline Gyroidinoides zelandica & 0.0 & 0.0 & 0.0 & 0 \\
\hline Haeuslerella parri & 20.6 & 35.8 & 19.6 & 25.32142 \\
\hline Hoeglundina elegans & 2.0 & 1.4 & 3.5 & 2.263466 \\
\hline & & & & \\
\hline
\end{tabular}




\begin{tabular}{|l|c|c|c|c|}
\hline CLUSTER 1 & WS1 & WS4 & WS5 & Mean \\
\hline Lagena sp. & 0.2 & 0.7 & 0.9 & 0.59678 \\
\hline Lenticulina sp. & 0.7 & 9.8 & 4.8 & 5.105067 \\
\hline Marginulina sp. & 0.2 & 0.0 & 0.0 & 0.081699 \\
\hline Martinottiella communis & 0.0 & 4.1 & 0.0 & 1.351351 \\
\hline Melonis zeobesus & 7.8 & 0.0 & 0.0 & 2.614379 \\
\hline Nodosaria sp. & 0.0 & 0.0 & 0.0 & 0 \\
\hline Nonionellina flemingi & 0.0 & 0.0 & 0.0 & 0 \\
\hline Notorotalia finlayi & 2.7 & 0.0 & 5.7 & 2.782751 \\
\hline Notorotalia kingmai & 0.0 & 0.0 & 0.0 & 0 \\
\hline Notorotalia zelandica & 0.0 & 0.0 & 0.0 & 0 \\
\hline zelandica & 0.0 & 0.3 & 0.0 & 0.112613 \\
\hline Oolina sp. & 0.0 & 0.0 & 0.0 & 0 \\
\hline Oridorsalis tenera & 4.2 & 22.0 & 0.0 & 8.708709 \\
\hline Oridorsalis umbonatus & 0.0 & 0.0 & 0.0 & 0 \\
\hline Parafusulina sp. & 0.0 & 0.0 & 0.0 & 0 \\
\hline Plectofrondicularia pellucida & 0.0 & 0.0 & 0.0 & 0 \\
\hline Proxifrons sp. & 0.0 & 0.0 & 0.0 & 0 \\
\hline Pullenia bulloides & 0.2 & 0.0 & 0.0 & 0.081699 \\
\hline Pullenia quinqueloba & 0.0 & 0.3 & 0.0 & 0.112613 \\
\hline Rectobolivina striatula & 0.0 & 0.3 & 0.0 & 0.112613 \\
\hline Saracenaria italica & 0.0 & 0.0 & 0.0 & 0 \\
\hline Sigmoidina sp. & 0.0 & 0.0 & 0.0 & 0 \\
\hline Siphonaperta macbeathi & 0.0 & 0.0 & 0.0 & 0 \\
\hline Siphotextularia wairoana & 0.2 & 0.0 & 0.0 & 0.081699 \\
\hline Sphaeroidina bulloides & 0.0 & 0.0 & 0.0 & 0 \\
\hline Trifarina bradyi & 0.0 & 0.0 & 0.0 & 0 \\
\hline Vaginulina sp. & 0.0 & 0.0 & 0.0 & 0 \\
\hline Zeoflorilus parri & & & & \\
\hline & & & \\
\hline
\end{tabular}

\begin{tabular}{|l|c|c|c|c|c|c|c|c|c|c|c|}
\hline CLUSTER 2 & WS7 & WS8 & WS10 & WS11 & WS13 & WS15 & WS16 & WS18 & WS19 & WS21 & Mean \\
\hline Amphicorya hirsuta & 0.29 & 0.00 & 0.00 & 0.00 & 0.26 & 1.25 & 0.00 & 0.28 & 0.59 & 0.28 & 0.30 \\
\hline $\begin{array}{l}\text { Anomalinoides } \\
\text { parvumbilia }\end{array}$ & 3.48 & 2.69 & 2.25 & 3.77 & 4.50 & 2.19 & 0.51 & 0.28 & 0.29 & 0.85 & 2.08 \\
\hline $\begin{array}{l}\text { Anomalinoides } \\
\text { sphericus }\end{array}$ & 0.00 & 0.30 & 2.25 & 0.42 & 0.26 & 0.94 & 0.00 & 0.00 & 0.00 & 2.85 & 0.70 \\
\hline $\begin{array}{l}\text { Anomalinoides } \\
\text { subnonionoides }\end{array}$ & 0.58 & 0.00 & 0.00 & 0.00 & 0.00 & 0.00 & 0.00 & 0.00 & 0.00 & 0.00 & 0.06 \\
\hline Astrononion parki & 3.19 & 6.87 & 6.37 & 5.86 & 5.29 & 7.21 & 16.11 & 14.85 & 12.61 & 14.81 & 9.32 \\
\hline Biloculina anomala & 0.00 & 0.00 & 0.00 & 0.00 & 0.00 & 0.00 & 0.00 & 0.00 & 0.00 & 0.00 & 0.00 \\
\hline Bolivinita pliozea & 1.45 & 2.99 & 4.87 & 4.18 & 2.65 & 4.08 & 5.37 & 0.28 & 2.05 & 0.57 & 2.85 \\
\hline Bolivina sp. & 0.29 & 0.00 & 0.00 & 0.00 & 0.00 & 0.00 & 0.00 & 0.00 & 0.29 & 0.00 & 0.06 \\
\hline Bolivina cacozela & 0.00 & 0.00 & 0.00 & 0.00 & 0.00 & 0.00 & 0.00 & 0.00 & 0.29 & 0.00 & 0.03 \\
\hline Bolivina petiae & 0.00 & 0.00 & 0.00 & 0.00 & 0.00 & 0.00 & 0.00 & 0.00 & 0.29 & 0.00 & 0.03 \\
\hline Bolivina silvestrina & 0.00 & 0.00 & 0.00 & 0.00 & 0.00 & 0.00 & 0.00 & 0.00 & 0.00 & 0.00 & 0.00 \\
\hline Bolivina spathulata & 0.00 & 0.00 & 0.00 & 0.00 & 0.00 & 0.00 & 0.00 & 0.00 & 0.00 & 0.00 & 0.00 \\
\hline
\end{tabular}




\begin{tabular}{|c|c|c|c|c|c|c|c|c|c|c|c|}
\hline CLUSTER 2 & WS7 & WS8 & WS10 & WS11 & WS13 & WS15 & WS16 & WS18 & WS19 & WS21 & Mean \\
\hline $\begin{array}{l}\text { Bolivina } \\
\text { subcompacta }\end{array}$ & 0.00 & 0.00 & 0.00 & 0.00 & 0.00 & 0.00 & 0.00 & 0.00 & 0.00 & 0.00 & 0.00 \\
\hline $\begin{array}{l}\text { Bolivina } \\
\text { subexcavata }\end{array}$ & 0.00 & 0.00 & 0.00 & 0.00 & 0.00 & 0.00 & 0.00 & 0.28 & 0.29 & 0.00 & 0.06 \\
\hline $\begin{array}{l}\text { Bolivina } \\
\text { wanganuiensis }\end{array}$ & 0.00 & 0.00 & 0.00 & 0.00 & 0.00 & 0.00 & 0.00 & 0.00 & 0.00 & 0.00 & 0.00 \\
\hline Bulimina marginata & 1.16 & 2.69 & 0.37 & 0.00 & 1.06 & 0.63 & 0.51 & 0.00 & 3.81 & 0.57 & 1.08 \\
\hline $\begin{array}{l}\text { Cassidunlina } \\
\text { neocarinata }\end{array}$ & 0.00 & 0.00 & 0.00 & 0.00 & 0.26 & 0.00 & 0.00 & 0.00 & 0.29 & 0.00 & 0.06 \\
\hline Cibicides deliquatus & 4.64 & 1.49 & 1.50 & 7.53 & 1.32 & 0.94 & 2.30 & 8.40 & 6.45 & 1.71 & 3.63 \\
\hline Cibicides molestus & 0.00 & 0.30 & 0.00 & 0.00 & 0.00 & 0.31 & 0.00 & 0.00 & 0.00 & 0.00 & 0.06 \\
\hline Discorbidae sp. & 0.00 & 0.00 & 0.00 & 0.00 & 0.00 & 0.00 & 0.00 & 0.00 & 0.00 & 0.00 & 0.00 \\
\hline $\begin{array}{l}\text { Elphidium } \\
\text { charlottense }\end{array}$ & 0.58 & 0.00 & 0.00 & 0.00 & 2.65 & 0.00 & 1.02 & 0.56 & 0.59 & 0.28 & 0.57 \\
\hline $\begin{array}{l}\text { Elphidium } \\
\text { excavatum }\end{array}$ & 0.00 & 0.00 & 0.00 & 0.00 & 0.00 & 0.00 & 0.00 & 0.00 & 0.00 & 0.00 & 0.00 \\
\hline $\begin{array}{l}\text { Elphidium } \\
\text { novozealandicum }\end{array}$ & 0.00 & 0.00 & 0.00 & 0.00 & 0.00 & 0.00 & 0.00 & 0.00 & 0.00 & 0.00 & 0.00 \\
\hline Euuvigerina pliozea & 0.58 & 0.90 & 3.37 & 7.53 & 1.59 & 11.91 & 2.81 & 2.24 & 6.45 & 10.26 & 4.76 \\
\hline $\begin{array}{l}\text { Evolvocassidulina } \\
\text { orientalis }\end{array}$ & 2.90 & 3.58 & 4.12 & 2.09 & 2.38 & 1.57 & 3.07 & 0.84 & 4.69 & 11.97 & 3.72 \\
\hline Fissurina sp. & 0.00 & 0.30 & 0.00 & 0.00 & 0.00 & 0.00 & 0.00 & 0.00 & 0.00 & 0.00 & 0.03 \\
\hline $\begin{array}{l}\text { Globobulimina } \\
\text { pacifica }\end{array}$ & 0.00 & 0.00 & 0.00 & 0.00 & 0.00 & 0.00 & 0.00 & 0.00 & 0.00 & 0.00 & 0.00 \\
\hline $\begin{array}{l}\text { Globocassidulina } \\
\text { subglobosa }\end{array}$ & 0.00 & 0.00 & 0.00 & 0.00 & 0.00 & 0.00 & 0.00 & 0.00 & 0.00 & 0.00 & 0.00 \\
\hline $\begin{array}{l}\text { Gyroidinoides } \\
\text { zelandica }\end{array}$ & 0.00 & 0.00 & 0.00 & 0.00 & 0.00 & 0.63 & 0.26 & 0.00 & 0.29 & 0.00 & 0.12 \\
\hline Haeuslerella parri & 45.80 & 28.66 & 50.94 & 42.26 & 39.42 & 44.51 & 39.90 & 32.77 & 37.24 & 41.60 & 40.31 \\
\hline $\begin{array}{l}\text { Hoeglundina } \\
\text { elegans }\end{array}$ & 12.75 & 12.84 & 11.24 & 6.28 & 14.55 & 15.36 & 15.60 & 26.61 & 9.09 & 3.70 & 12.80 \\
\hline Lagena sp. & 2.32 & 0.90 & 0.00 & 1.26 & 0.53 & 0.31 & 0.00 & 0.00 & 1.76 & 1.14 & 0.82 \\
\hline Lenticulina sp. & 0.87 & 2.39 & 1.87 & 2.51 & 1.59 & 1.57 & 1.28 & 1.12 & 1.76 & 4.56 & 1.95 \\
\hline Marginulina sp. & 0.00 & 0.00 & 0.00 & 0.00 & 0.00 & 0.00 & 0.00 & 0.00 & 0.00 & 0.28 & 0.03 \\
\hline $\begin{array}{l}\text { Martinottiella } \\
\text { communis }\end{array}$ & 0.00 & 0.00 & 0.00 & 0.00 & 0.00 & 0.00 & 0.00 & 0.00 & 0.00 & 0.00 & 0.00 \\
\hline Melonis zeobesus & 0.00 & 0.00 & 0.00 & 0.00 & 0.00 & 0.00 & 0.00 & 0.00 & 0.00 & 0.00 & 0.00 \\
\hline Nodosaria sp. & 0.00 & 0.00 & 0.00 & 0.00 & 0.00 & 0.00 & 0.00 & 0.00 & 0.00 & 0.00 & 0.00 \\
\hline $\begin{array}{l}\text { Nonionellina } \\
\text { flemingi }\end{array}$ & 0.00 & 0.00 & 0.37 & 0.00 & 0.00 & 0.00 & 0.26 & 0.00 & 0.00 & 0.00 & 0.06 \\
\hline Notorotalia finlayi & 3.77 & 11.64 & 3.75 & 11.30 & 7.41 & 2.19 & 2.56 & 2.80 & 5.28 & 2.85 & 5.35 \\
\hline $\begin{array}{l}\text { Notorotalia } \\
\text { kingmai }\end{array}$ & 0.00 & 0.00 & 0.00 & 0.00 & 0.00 & 0.00 & 0.00 & 0.00 & 0.00 & 0.00 & 0.00 \\
\hline $\begin{array}{l}\text { Notorotalia } \\
\text { zelandica zelandica }\end{array}$ & 0.00 & 0.00 & 0.00 & 0.00 & 0.00 & 0.00 & 0.00 & 0.00 & 0.00 & 0.00 & 0.00 \\
\hline Oolina sp. & 0.00 & 0.00 & 0.00 & 0.00 & 0.00 & 0.00 & 0.00 & 0.00 & 0.00 & 0.00 & 0.00 \\
\hline Oridorsalis tenera & 0.00 & 0.00 & 0.00 & 0.00 & 0.00 & 0.00 & 0.00 & 0.00 & 0.00 & 0.00 & 0.00 \\
\hline $\begin{array}{l}\text { Oridorsalis } \\
\text { umbonatus }\end{array}$ & 13.33 & 20.00 & 4.87 & 5.02 & 13.76 & 3.13 & 5.63 & 7.56 & 4.11 & 0.00 & 7.74 \\
\hline Parafusulina sp. & 0.00 & 0.00 & 0.00 & 0.00 & 0.00 & 0.00 & 0.00 & 0.00 & 0.00 & 0.00 & 0.00 \\
\hline
\end{tabular}




\begin{tabular}{|l|c|c|c|c|c|c|c|c|c|c|c|}
\hline CLUSTER 2 & WS7 & WS8 & WS10 & WS11 & WS13 & WS15 & WS16 & WS18 & WS19 & WS21 & Mean \\
\hline $\begin{array}{l}\text { Plectofrondicularia } \\
\text { pellucida }\end{array}$ & 0.00 & 0.00 & 0.00 & 0.00 & 0.00 & 0.00 & 0.00 & 0.00 & 0.00 & 0.00 & 0.00 \\
\hline Proxifrons sp. & 0.00 & 0.00 & 0.00 & 0.00 & 0.00 & 0.00 & 0.00 & 0.00 & 0.00 & 0.00 & 0.00 \\
\hline Pullenia bulloides & 0.58 & 0.00 & 0.00 & 0.00 & 0.00 & 0.00 & 0.00 & 0.00 & 0.00 & 0.28 & 0.09 \\
\hline $\begin{array}{l}\text { Pullenia } \\
\text { quinqueloba }\end{array}$ & 0.00 & 0.00 & 0.37 & 0.00 & 0.00 & 0.31 & 0.51 & 0.00 & 0.00 & 0.00 & 0.12 \\
\hline $\begin{array}{l}\text { Rectobolivina } \\
\text { striatula }\end{array}$ & 0.00 & 0.00 & 0.00 & 0.00 & 0.00 & 0.00 & 0.26 & 0.00 & 0.00 & 0.28 & 0.05 \\
\hline Saracenaria italica & 0.00 & 0.00 & 0.00 & 0.00 & 0.00 & 0.00 & 0.00 & 0.00 & 0.29 & 0.00 & 0.03 \\
\hline Sigmoidina sp. & 0.00 & 0.00 & 0.00 & 0.00 & 0.00 & 0.00 & 0.00 & 0.00 & 0.00 & 0.00 & 0.00 \\
\hline $\begin{array}{l}\text { Siphonaperta } \\
\text { macbeathi }\end{array}$ & 0.00 & 0.00 & 0.75 & 0.00 & 0.26 & 0.94 & 1.79 & 0.56 & 1.17 & 1.14 & 0.66 \\
\hline $\begin{array}{l}\text { Siphotextularia } \\
\text { wairoana }\end{array}$ & 0.87 & 0.60 & 0.00 & 0.00 & 0.26 & 0.00 & 0.26 & 0.00 & 0.00 & 0.00 & 0.20 \\
\hline $\begin{array}{l}\text { Sphaeroidina } \\
\text { bulloides }\end{array}$ & 0.58 & 0.90 & 0.75 & 0.00 & 0.00 & 0.00 & 0.00 & 0.28 & 0.00 & 0.00 & 0.25 \\
\hline Trifarina bradyi & 0.00 & 0.00 & 0.00 & 0.00 & 0.00 & 0.00 & 0.00 & 0.00 & 0.00 & 0.00 & 0.00 \\
\hline Vaginulina sp. & 0.00 & 0.00 & 0.00 & 0.00 & 0.00 & 0.00 & 0.00 & 0.28 & 0.00 & 0.00 & 0.03 \\
\hline Zeoflorilus parri & 0.00 & 0.00 & 0.00 & 0.00 & 0.00 & 0.00 & 0.00 & 0.00 & 0.00 & 0.00 & 0.00 \\
\hline
\end{tabular}

\begin{tabular}{|l|c|c|c|c|c|c|}
\hline CLUSTER 3a & WS22 & WS24 & WS25 & WS27 & WS28 & Mean \\
\hline Amphicorya hirsuta & 0.00 & 0.94 & 0.23 & 1.65 & 0.00 & 0.56 \\
\hline Anomalinoides parvumbilia & 0.41 & 0.00 & 0.00 & 2.06 & 0.00 & 0.49 \\
\hline Anomalinoides sphericus & 0.41 & 0.00 & 1.15 & 2.06 & 0.00 & 0.72 \\
\hline Anomalinoides subnonionoides & 0.00 & 0.00 & 0.00 & 0.41 & 0.49 & 0.18 \\
\hline Astrononion parki & 15.70 & 27.23 & 15.21 & 19.75 & 17.48 & 19.07 \\
\hline Biloculina anomala & 0.00 & 0.00 & 0.00 & 0.00 & 0.00 & 0.00 \\
\hline Bolivinita pliozea & 0.00 & 0.94 & 0.46 & 0.82 & 1.94 & 0.83 \\
\hline Bolivina sp. & 0.00 & 0.47 & 0.23 & 0.00 & 0.00 & 0.14 \\
\hline Bolivina cacozela & 0.00 & 0.00 & 0.00 & 0.00 & 0.00 & 0.00 \\
\hline Bolivina petiae & 0.00 & 0.00 & 0.00 & 0.00 & 0.00 & 0.00 \\
\hline Bolivina silvestrina & 0.00 & 0.00 & 0.00 & 0.00 & 0.00 & 0.00 \\
\hline Bolivina spathulata & 0.00 & 0.00 & 0.00 & 0.00 & 0.00 & 0.00 \\
\hline Bolivina subcompacta & 0.00 & 0.00 & 0.00 & 0.00 & 0.00 & 0.00 \\
\hline Bolivina subexcavata & 0.00 & 0.00 & 0.00 & 0.00 & 0.00 & 0.00 \\
\hline Bolivina wanganuiensis & 0.00 & 0.00 & 0.00 & 0.00 & 0.00 & 0.00 \\
\hline Bulimina marginata & 0.00 & 0.00 & 0.46 & 0.41 & 0.49 & 0.27 \\
\hline Cassidunlina neocarinata & 0.41 & 0.47 & 0.00 & 0.00 & 0.00 & 0.18 \\
\hline Cibicides deliquatus & 8.26 & 4.23 & 4.84 & 5.35 & 4.37 & 5.41 \\
\hline Cibicides molestus & 0.00 & 0.00 & 0.00 & 0.00 & 0.00 & 0.00 \\
\hline Discorbidae sp. & 0.00 & 0.00 & 0.23 & 0.00 & 0.00 & 0.05 \\
\hline Elphidium charlottense & 0.41 & 0.00 & 0.00 & 0.41 & 0.00 & 0.16 \\
\hline Elphidium excavatum & 0.00 & 0.00 & 0.00 & 0.00 & 0.00 & 0.00 \\
\hline Elphidium novozealandicum & 0.00 & 0.00 & 0.00 & 0.00 & 0.00 & 0.00 \\
\hline Euuvigerina pliozea & 37.19 & 30.05 & 35.94 & 34.57 & 35.44 & 34.64 \\
\hline
\end{tabular}




\begin{tabular}{|c|c|c|c|c|c|c|}
\hline CLUSTER $3 a$ & WS22 & WS24 & WS25 & WS27 & WS28 & Mean \\
\hline Evolvocassidulina orientalis & 5.79 & 0.94 & 0.46 & 2.47 & 0.49 & 2.03 \\
\hline Fissurina sp. & 0.00 & 0.00 & 0.00 & 0.00 & 0.00 & 0.00 \\
\hline Globobulimina pacifica & 0.41 & 0.00 & 0.00 & 0.00 & 0.00 & 0.08 \\
\hline Globocassidulina subglobosa & 0.00 & 0.00 & 0.00 & 0.00 & 0.00 & 0.00 \\
\hline Gyroidinoides zelandica & 0.00 & 0.00 & 0.46 & 0.00 & 0.49 & 0.19 \\
\hline Haeuslerella parri & 13.64 & 18.78 & 24.65 & 2.88 & 24.76 & 16.94 \\
\hline Hoeglundina elegans & 8.26 & 0.00 & 3.92 & 5.76 & 5.83 & 4.75 \\
\hline Lagena sp. & 0.41 & 0.47 & 0.23 & 0.82 & 0.00 & 0.39 \\
\hline Lenticulina sp. & 4.96 & 2.82 & 0.92 & 6.17 & 2.43 & 3.46 \\
\hline Marginulina sp. & 0.00 & 0.00 & 0.00 & 0.00 & 0.00 & 0.00 \\
\hline Martinottiella communis & 0.00 & 0.00 & 0.00 & 0.00 & 0.97 & 0.19 \\
\hline Melonis zeobesus & 0.00 & 0.00 & 4.15 & 0.82 & 0.00 & 0.99 \\
\hline Nodosaria sp. & 0.00 & 0.00 & 0.00 & 0.00 & 0.00 & 0.00 \\
\hline Nonionellina flemingi & 0.00 & 0.00 & 0.00 & 0.00 & 0.00 & 0.00 \\
\hline Notorotalia finlayi & 3.31 & 4.23 & 4.15 & 10.70 & 3.40 & 5.16 \\
\hline Notorotalia kingmai & 0.00 & 0.00 & 0.00 & 0.00 & 0.00 & 0.00 \\
\hline Notorotalia zelandica zelandica & 0.00 & 0.00 & 0.00 & 0.00 & 0.00 & 0.00 \\
\hline Oolina sp. & 0.00 & 0.00 & 0.00 & 0.00 & 0.00 & 0.00 \\
\hline Oridorsalis tenera & 0.00 & 0.00 & 0.00 & 0.00 & 0.00 & 0.00 \\
\hline Oridorsalis umbonatus & 0.00 & 7.98 & 0.00 & 0.00 & 0.49 & 1.69 \\
\hline Parafusulina sp. & 0.00 & 0.00 & 0.00 & 0.00 & 0.00 & 0.00 \\
\hline Plectofrondicularia pellucida & 0.00 & 0.00 & 0.00 & 0.00 & 0.49 & 0.10 \\
\hline Proxifrons sp. & 0.00 & 0.00 & 0.00 & 0.00 & 0.00 & 0.00 \\
\hline Pullenia bulloides & 0.00 & 0.00 & 0.23 & 0.00 & 0.00 & 0.05 \\
\hline Pullenia quinqueloba & 0.00 & 0.00 & 0.00 & 0.00 & 0.00 & 0.00 \\
\hline Rectobolivina striatula & 0.00 & 0.00 & 0.23 & 0.00 & 0.00 & 0.05 \\
\hline Saracenaria italica & 0.00 & 0.00 & 0.00 & 0.41 & 0.00 & 0.08 \\
\hline Sigmoidina sp. & 0.00 & 0.00 & 0.00 & 0.00 & 0.00 & 0.00 \\
\hline Siphonaperta macbeathi & 0.00 & 0.00 & 1.38 & 2.47 & 0.49 & 0.87 \\
\hline Siphotextularia wairoana & 0.00 & 0.00 & 0.46 & 0.00 & 0.00 & 0.09 \\
\hline Sphaeroidina bulloides & 0.41 & 0.47 & 0.00 & 0.00 & 0.00 & 0.18 \\
\hline Trifarina bradyi & 0.00 & 0.00 & 0.00 & 0.00 & 0.00 & 0.00 \\
\hline Vaginulina sp. & 0.00 & 0.00 & 0.00 & 0.00 & 0.00 & 0.00 \\
\hline Zeoflorilus parri & 0.00 & 0.00 & 0.00 & 0.00 & 0.00 & 0.00 \\
\hline
\end{tabular}

\begin{tabular}{|l|c|c|c|c|c|}
\hline CLUSTER 3b & WS30 & WS31 & WS33 & WS34 & Mean \\
\hline Amphicorya hirsuta & 3.30 & 2.42 & 1.24 & 1.61 & 2.14 \\
\hline Anomalinoides parvumbilia & 0.00 & 0.81 & 0.25 & 1.07 & 0.53 \\
\hline Anomalinoides sphericus & 0.00 & 0.00 & 1.74 & 1.34 & 0.77 \\
\hline Anomalinoides subnonionoides & 0.00 & 0.00 & 0.00 & 0.00 & 0.00 \\
\hline Astrononion parki & 28.02 & 15.73 & 28.54 & 28.95 & 25.31 \\
\hline Biloculina anomala & 0.00 & 0.00 & 0.00 & 0.00 & 0.00 \\
\hline Bolivinita pliozea & 2.47 & 2.02 & 1.49 & 0.54 & 1.63 \\
\hline
\end{tabular}




\begin{tabular}{|c|c|c|c|c|c|}
\hline CLUSTER 3b & WS30 & WS31 & WS33 & WS34 & Mean \\
\hline Bolivina sp. & 0.00 & 0.00 & 0.00 & 0.00 & 0.00 \\
\hline Bolivina cacozela & 0.00 & 0.00 & 0.00 & 0.00 & 0.00 \\
\hline Bolivina petiae & 0.00 & 0.00 & 0.00 & 0.00 & 0.00 \\
\hline Bolivina silvestrina & 0.00 & 0.00 & 0.00 & 0.00 & 0.00 \\
\hline Bolivina spathulata & 0.00 & 0.00 & 0.00 & 0.00 & 0.00 \\
\hline Bolivina subcompacta & 0.00 & 0.00 & 0.00 & 0.00 & 0.00 \\
\hline Bolivina subexcavata & 0.00 & 0.00 & 0.00 & 0.00 & 0.00 \\
\hline Bolivina wanganuiensis & 0.00 & 0.00 & 0.00 & 0.00 & 0.00 \\
\hline Bulimina marginata & 1.37 & 20.16 & 8.93 & 6.17 & 9.16 \\
\hline Cassidunlina neocarinata & 0.00 & 0.00 & 0.00 & 0.00 & 0.00 \\
\hline Cibicides deliquatus & 3.57 & 3.63 & 7.94 & 4.29 & 4.86 \\
\hline Cibicides molestus & 0.00 & 0.00 & 0.00 & 0.00 & 0.00 \\
\hline Discorbidae sp. & 0.00 & 0.00 & 0.00 & 0.00 & 0.00 \\
\hline Elphidium charlottense & 0.00 & 0.00 & 0.00 & 0.00 & 0.00 \\
\hline Elphidium excavatum & 0.00 & 0.00 & 0.00 & 0.00 & 0.00 \\
\hline Elphidium novozealandicum & 0.00 & 0.00 & 0.00 & 0.00 & 0.00 \\
\hline Euuvigerina pliozea & 4.67 & 9.27 & 6.20 & 3.22 & 5.84 \\
\hline Evolvocassidulina orientalis & 0.27 & 1.61 & 0.99 & 0.27 & 0.79 \\
\hline Fissurina sp. & 0.00 & 0.00 & 0.00 & 0.00 & 0.00 \\
\hline Globobulimina pacifica & 0.00 & 0.00 & 0.00 & 0.00 & 0.00 \\
\hline Globocassidulina subglobosa & 0.00 & 0.00 & 0.00 & 0.00 & 0.00 \\
\hline Gyroidinoides zelandica & 0.00 & 0.00 & 0.25 & 0.00 & 0.06 \\
\hline Haeuslerella parri & 34.89 & 27.82 & 28.29 & 36.19 & 31.80 \\
\hline Hoeglundina elegans & 9.89 & 4.44 & 4.71 & 9.38 & 7.11 \\
\hline Lagena sp. & 1.92 & 2.42 & 0.74 & 0.27 & 1.34 \\
\hline Lenticulina sp. & 5.22 & 4.03 & 1.99 & 1.34 & 3.14 \\
\hline Marginulina sp. & 0.00 & 0.00 & 0.00 & 0.00 & 0.00 \\
\hline Martinottiella communis & 0.00 & 0.00 & 0.00 & 0.00 & 0.00 \\
\hline Melonis zeobesus & 0.00 & 0.00 & 0.00 & 0.00 & 0.00 \\
\hline Nodosaria sp. & 0.00 & 0.00 & 0.00 & 0.00 & 0.00 \\
\hline Nonionellina flemingi & 0.00 & 0.00 & 0.00 & 0.27 & 0.07 \\
\hline Notorotalia finlayi & 4.12 & 4.03 & 4.96 & 4.56 & 4.42 \\
\hline Notorotalia kingmai & 0.00 & 0.00 & 0.00 & 0.27 & 0.07 \\
\hline Notorotalia zelandica zelandica & 0.00 & 0.00 & 0.00 & 0.00 & 0.00 \\
\hline Oolina sp. & 0.00 & 0.00 & 0.00 & 0.00 & 0.00 \\
\hline Oridorsalis tenera & 0.00 & 0.00 & 0.00 & 0.00 & 0.00 \\
\hline Oridorsalis umbonatus & 0.00 & 0.00 & 0.50 & 0.00 & 0.12 \\
\hline Parafusulina sp. & 0.00 & 0.00 & 0.25 & 0.00 & 0.06 \\
\hline Plectofrondicularia pellucida & 0.00 & 0.00 & 0.00 & 0.00 & 0.00 \\
\hline Proxifrons sp. & 0.00 & 0.00 & 0.00 & 0.00 & 0.00 \\
\hline Pullenia bulloides & 0.00 & 0.00 & 0.00 & 0.00 & 0.00 \\
\hline Pullenia quinqueloba & 0.00 & 0.00 & 0.50 & 0.27 & 0.19 \\
\hline Rectobolivina striatula & 0.00 & 0.00 & 0.00 & 0.00 & 0.00 \\
\hline
\end{tabular}




\begin{tabular}{|l|c|c|c|c|c|}
\hline CLUSTER 3b & WS30 & WS31 & WS33 & WS34 & Mean \\
\hline Saracenaria italica & 0.00 & 0.00 & 0.00 & 0.00 & 0.00 \\
\hline Sigmoidina sp. & 0.00 & 0.00 & 0.00 & 0.00 & 0.00 \\
\hline Siphonaperta macbeathi & 0.27 & 0.00 & 0.50 & 0.00 & 0.19 \\
\hline Siphotextularia wairoana & 0.00 & 0.00 & 0.00 & 0.00 & 0.00 \\
\hline Sphaeroidina bulloides & 0.00 & 1.61 & 0.00 & 0.00 & 0.40 \\
\hline Trifarina bradyi & 0.00 & 0.00 & 0.00 & 0.00 & 0.00 \\
\hline Vaginulina sp. & 0.00 & 0.00 & 0.00 & 0.00 & 0.00 \\
\hline Zeoflorilus parri & 0.00 & 0.00 & 0.00 & 0.00 & 0.00 \\
\hline
\end{tabular}

\begin{tabular}{|c|c|c|c|c|c|c|}
\hline CLUSTER 4a & WS37 & WS39 & WS40 & WS42 & WS43 & Mean \\
\hline Amphicorya hirsuta & 1.11 & 1.32 & 0.26 & 0.48 & 0.27 & 0.69 \\
\hline Anomalinoides parvumbilia & 5.57 & 2.31 & 4.43 & 3.12 & 1.08 & 3.30 \\
\hline Anomalinoides sphericus & 6.69 & 9.57 & 12.24 & 6.71 & 12.43 & 9.53 \\
\hline Anomalinoides subnonionoides & 0.00 & 0.00 & 0.00 & 0.00 & 1.35 & 0.27 \\
\hline Astrononion parki & 1.39 & 1.32 & 2.60 & 2.40 & 0.27 & 1.60 \\
\hline Biloculina anomala & 0.00 & 0.00 & 0.00 & 0.00 & 0.00 & 0.00 \\
\hline Bolivinita pliozea & 6.41 & 1.32 & 3.91 & 4.08 & 5.41 & 4.22 \\
\hline Bolivina sp. & 0.00 & 0.00 & 0.00 & 0.00 & 0.00 & 0.00 \\
\hline Bolivina cacozela & 0.00 & 0.00 & 0.00 & 0.00 & 0.00 & 0.00 \\
\hline Bolivina petiae & 0.00 & 0.00 & 0.00 & 0.00 & 0.00 & 0.00 \\
\hline Bolivina silvestrina & 0.00 & 0.00 & 0.00 & 0.00 & 0.00 & 0.00 \\
\hline Bolivina spathulata & 0.00 & 0.00 & 0.00 & 0.00 & 0.00 & 0.00 \\
\hline Bolivina subcompacta & 0.00 & 0.00 & 0.00 & 0.00 & 0.00 & 0.00 \\
\hline Bolivina subexcavata & 0.00 & 0.00 & 0.00 & 0.00 & 0.00 & 0.00 \\
\hline Bolivina wanganuiensis & 0.00 & 0.00 & 0.00 & 0.00 & 0.00 & 0.00 \\
\hline Bulimina marginata & 3.62 & 1.65 & 0.78 & 0.96 & 1.08 & 1.62 \\
\hline Cassidunlina neocarinata & 0.00 & 0.00 & 0.00 & 0.24 & 0.00 & 0.05 \\
\hline Cibicides deliquatus & 5.85 & 7.92 & 4.69 & 7.43 & 7.84 & 6.75 \\
\hline Cibicides molestus & 0.00 & 0.00 & 0.00 & 0.00 & 0.00 & 0.00 \\
\hline Discorbidae sp. & 0.00 & 0.00 & 0.00 & 0.00 & 0.00 & 0.00 \\
\hline Elphidium charlottense & 0.00 & 0.33 & 0.00 & 0.00 & 0.00 & 0.07 \\
\hline Elphidium excavatum & 0.00 & 0.00 & 0.00 & 0.00 & 0.00 & 0.00 \\
\hline Elphidium novozealandicum & 0.00 & 0.00 & 0.00 & 0.00 & 0.00 & 0.00 \\
\hline Euuvigerina pliozea & 11.70 & 8.91 & 14.58 & 14.63 & 14.05 & 12.78 \\
\hline Evolvocassidulina orientalis & 0.00 & 0.33 & 0.26 & 0.00 & 0.27 & 0.17 \\
\hline Fissurina sp. & 0.00 & 0.00 & 0.00 & 0.00 & 0.00 & 0.00 \\
\hline Globobulimina pacifica & 0.00 & 0.00 & 0.00 & 0.00 & 0.00 & 0.00 \\
\hline Globocassidulina subglobosa & 0.00 & 0.00 & 0.00 & 0.24 & 0.00 & 0.05 \\
\hline Gyroidinoides zelandica & 0.28 & 0.66 & 0.26 & 0.00 & 0.27 & 0.29 \\
\hline Haeuslerella parri & 25.91 & 21.78 & 31.25 & 19.18 & 30.81 & 25.79 \\
\hline Hoeglundina elegans & 4.18 & 16.83 & 11.20 & 16.31 & 7.84 & 11.27 \\
\hline Lagena sp. & 0.84 & 2.31 & 0.52 & 0.72 & 0.54 & 0.99 \\
\hline Lenticulina sp. & 2.51 & 4.62 & 2.86 & 6.95 & 3.24 & 4.04 \\
\hline
\end{tabular}




\begin{tabular}{|l|c|c|c|c|c|c|}
\hline CLUSTER 4a & WS37 & WS39 & WS40 & WS42 & WS43 & Mean \\
\hline Marginulina sp. & 0.00 & 0.33 & 0.00 & 0.00 & 0.00 & 0.07 \\
\hline Martinottiella communis & 1.11 & 0.33 & 0.00 & 0.72 & 1.89 & 0.81 \\
\hline Melonis zeobesus & 0.00 & 0.00 & 0.00 & 0.24 & 2.16 & 0.48 \\
\hline Nodosaria sp. & 0.28 & 0.00 & 0.00 & 0.00 & 0.00 & 0.06 \\
\hline Nonionellina flemingi & 0.00 & 0.00 & 0.26 & 0.00 & 0.00 & 0.05 \\
\hline Notorotalia finlayi & 16.16 & 14.85 & 5.99 & 12.95 & 7.03 & 11.39 \\
\hline Notorotalia kingmai & 0.56 & 0.00 & 0.52 & 0.00 & 0.00 & 0.22 \\
\hline Notorotalia zelandica zelandica & 0.00 & 0.00 & 0.00 & 0.00 & 0.00 & 0.00 \\
\hline Oolina sp. & 0.28 & 0.00 & 0.00 & 0.00 & 0.27 & 0.11 \\
\hline Oridorsalis tenera & 0.00 & 0.00 & 0.00 & 0.00 & 0.00 & 0.00 \\
\hline Oridorsalis umbonatus & 0.28 & 0.00 & 0.26 & 0.24 & 0.27 & 0.21 \\
\hline Parafusulina sp. & 0.00 & 0.00 & 0.00 & 0.00 & 0.00 & 0.00 \\
\hline Plectofrondicularia pellucida & 0.00 & 0.00 & 0.26 & 0.00 & 0.00 & 0.05 \\
\hline Proxifrons sp. & 0.00 & 0.00 & 0.00 & 0.00 & 0.00 & 0.00 \\
\hline Pullenia bulloides & 0.28 & 0.33 & 0.00 & 0.24 & 0.00 & 0.17 \\
\hline Pullenia quinqueloba & 0.28 & 0.33 & 0.52 & 0.48 & 0.00 & 0.32 \\
\hline Rectobolivina striatula & 0.56 & 0.00 & 0.00 & 0.24 & 0.00 & 0.16 \\
\hline Saracenaria italica & 0.00 & 0.00 & 0.00 & 0.00 & 0.00 & 0.00 \\
\hline Sigmoidina sp. & 0.00 & 0.00 & 0.00 & 0.00 & 0.00 & 0.00 \\
\hline Siphonaperta macbeathi & 3.62 & 2.64 & 2.08 & 0.96 & 1.62 & 2.19 \\
\hline Siphotextularia wairoana & 0.28 & 0.00 & 0.00 & 0.00 & 0.00 & 0.06 \\
\hline Sphaeroidina bulloides & 0.28 & 0.00 & 0.00 & 0.00 & 0.00 & 0.06 \\
\hline Trifarina bradyi & 0.00 & 0.00 & 0.00 & 0.24 & 0.00 & 0.05 \\
\hline Vaginulina sp. & 0.00 & 0.00 & 0.26 & 0.24 & 0.00 & 0.10 \\
\hline Zeoflorilus parri & 0.00 & 0.00 & 0.00 & 0.00 & 0.00 & 0.00 \\
\hline
\end{tabular}

\begin{tabular}{|l|c|c|c|c|c|}
\hline CLUSTER 4b & WS45 & WS46 & WS48 & WS49 & Mean \\
\hline Amphicorya hirsuta & 1.70 & 1.09 & 1.28 & 1.31 & 1.35 \\
\hline Anomalinoides parvumbilia & 1.14 & 4.01 & 1.28 & 0.44 & 1.72 \\
\hline Anomalinoides sphericus & 20.45 & 5.84 & 11.86 & 5.24 & 10.85 \\
\hline Anomalinoides subnonionoides & 0.00 & 0.00 & 0.00 & 0.00 & 0.00 \\
\hline Astrononion parki & 0.28 & 0.73 & 0.00 & 0.44 & 0.36 \\
\hline Biloculina anomala & 0.00 & 0.00 & 0.00 & 0.00 & 0.00 \\
\hline Bolivinita pliozea & 21.02 & 14.60 & 17.31 & 20.09 & 18.25 \\
\hline Bolivina sp. & 0.00 & 0.00 & 0.00 & 0.00 & 0.00 \\
\hline Bolivina cacozela & 0.00 & 0.00 & 0.00 & 0.00 & 0.00 \\
\hline Bolivina petiae & 0.00 & 0.00 & 0.00 & 0.00 & 0.00 \\
\hline Bolivina silvestrina & 0.00 & 0.00 & 0.00 & 0.00 & 0.00 \\
\hline Bolivina spathulata & 0.00 & 0.00 & 0.00 & 0.00 & 0.00 \\
\hline Bolivina subcompacta & 0.00 & 0.00 & 0.00 & 0.00 & 0.00 \\
\hline Bolivina subexcavata & 0.00 & 0.00 & 0.00 & 0.00 & 0.00 \\
\hline Bolivina wanganuiensis & 0.00 & 0.00 & 0.00 & 0.00 & 0.00 \\
\hline Bulimina marginata & 1.14 & 5.47 & 1.28 & 1.75 & 2.41 \\
\hline
\end{tabular}




\begin{tabular}{|c|c|c|c|c|c|}
\hline CLUSTER 4b & WS45 & WS46 & WS48 & WS49 & Mean \\
\hline Cassidunlina neocarinata & 0.00 & 0.00 & 0.00 & 0.00 & 0.00 \\
\hline Cibicides deliquatus & 13.92 & 13.50 & 10.26 & 6.99 & 11.17 \\
\hline Cibicides molestus & 0.00 & 0.00 & 0.00 & 0.00 & 0.00 \\
\hline Discorbidae sp. & 0.00 & 0.00 & 0.00 & 0.00 & 0.00 \\
\hline Elphidium charlottense & 0.00 & 0.00 & 0.00 & 0.00 & 0.00 \\
\hline Elphidium excavatum & 0.00 & 0.00 & 0.00 & 0.00 & 0.00 \\
\hline Elphidium novozealandicum & 0.00 & 0.00 & 0.00 & 0.00 & 0.00 \\
\hline Euuvigerina pliozea & 13.92 & 14.96 & 7.69 & 8.73 & 11.33 \\
\hline Evolvocassidulina orientalis & 0.00 & 0.00 & 0.00 & 0.00 & 0.00 \\
\hline Fissurina sp. & 0.00 & 0.00 & 0.00 & 0.00 & 0.00 \\
\hline Globobulimina pacifica & 0.00 & 0.00 & 0.00 & 0.00 & 0.00 \\
\hline Globocassidulina subglobosa & 0.28 & 0.00 & 0.00 & 0.00 & 0.07 \\
\hline Gyroidinoides zelandica & 0.00 & 0.00 & 0.32 & 0.44 & 0.19 \\
\hline Haeuslerella parri & 6.82 & 19.34 & 37.18 & 34.06 & 24.35 \\
\hline Hoeglundina elegans & 4.83 & 5.47 & 1.28 & 8.73 & 5.08 \\
\hline Lagena sp. & 1.14 & 1.82 & 0.64 & 0.00 & 0.90 \\
\hline Lenticulina sp. & 4.55 & 4.01 & 4.17 & 1.75 & 3.62 \\
\hline Marginulina sp. & 0.00 & 0.36 & 0.00 & 0.00 & 0.09 \\
\hline Martinottiella communis & 0.00 & 0.00 & 0.00 & 0.00 & 0.00 \\
\hline Melonis zeobesus & 0.57 & 0.36 & 0.00 & 0.00 & 0.23 \\
\hline Nodosaria sp. & 0.00 & 0.00 & 0.00 & 0.44 & 0.11 \\
\hline Nonionellina flemingi & 0.00 & 0.00 & 0.00 & 0.44 & 0.11 \\
\hline Notorotalia finlayi & 7.10 & 5.84 & 4.81 & 5.24 & 5.75 \\
\hline Notorotalia kingmai & 0.00 & 0.36 & 0.00 & 0.00 & 0.09 \\
\hline Notorotalia zelandica zelandica & 0.00 & 0.36 & 0.00 & 0.00 & 0.09 \\
\hline Oolina sp. & 0.00 & 0.00 & 0.00 & 0.87 & 0.22 \\
\hline Oridorsalis tenera & 0.00 & 0.00 & 0.00 & 0.00 & 0.00 \\
\hline Oridorsalis umbonatus & 0.85 & 0.00 & 0.00 & 0.00 & 0.21 \\
\hline Parafusulina sp. & 0.00 & 0.00 & 0.00 & 0.00 & 0.00 \\
\hline Plectofrondicularia pellucida & 0.00 & 0.00 & 0.00 & 0.00 & 0.00 \\
\hline Proxifrons sp. & 0.00 & 0.00 & 0.00 & 0.00 & 0.00 \\
\hline Pullenia bulloides & 0.00 & 0.00 & 0.00 & 0.00 & 0.00 \\
\hline Pullenia quinqueloba & 0.00 & 0.00 & 0.00 & 0.00 & 0.00 \\
\hline Rectobolivina striatula & 0.00 & 0.36 & 0.00 & 0.00 & 0.09 \\
\hline Saracenaria italica & 0.00 & 0.00 & 0.00 & 0.00 & 0.00 \\
\hline Sigmoidina sp. & 0.00 & 0.00 & 0.00 & 0.00 & 0.00 \\
\hline Siphonaperta macbeathi & 0.28 & 1.46 & 0.64 & 2.62 & 1.25 \\
\hline Siphotextularia wairoana & 0.00 & 0.00 & 0.00 & 0.44 & 0.11 \\
\hline Sphaeroidina bulloides & 0.00 & 0.00 & 0.00 & 0.00 & 0.00 \\
\hline Trifarina bradyi & 0.00 & 0.00 & 0.00 & 0.00 & 0.00 \\
\hline Vaginulina sp. & 0.00 & 0.00 & 0.00 & 0.00 & 0.00 \\
\hline Zeoflorilus parri & 0.00 & 0.00 & 0.00 & 0.00 & 0.00 \\
\hline
\end{tabular}




\begin{tabular}{|c|c|c|c|c|c|c|}
\hline CLUSTER 5a & WS52 & WS54 & WS55 & WS57 & WS58 & Mean \\
\hline Amphicorya hirsuta & 2.09 & 0.66 & 1.97 & 0.35 & 0.00 & 1.02 \\
\hline Anomalinoides parvumbilia & 0.00 & 6.31 & 5.59 & 3.82 & 5.23 & 4.19 \\
\hline Anomalinoides sphericus & 1.67 & 3.65 & 0.66 & 4.51 & 6.40 & 3.38 \\
\hline Anomalinoides subnonionoides & 0.00 & 0.00 & 0.00 & 0.00 & 0.29 & 0.06 \\
\hline Astrononion parki & 0.42 & 1.66 & 5.92 & 5.56 & 8.72 & 4.46 \\
\hline Biloculina anomala & 0.00 & 0.00 & 0.00 & 0.00 & 0.00 & 0.00 \\
\hline Bolivinita pliozea & 34.31 & 0.66 & 5.59 & 12.15 & 10.76 & 12.69 \\
\hline Bolivina sp. & 0.00 & 0.00 & 0.00 & 0.00 & 0.00 & 0.00 \\
\hline Bolivina cacozela & 0.00 & 0.00 & 0.00 & 0.00 & 0.00 & 0.00 \\
\hline Bolivina petiae & 0.00 & 0.00 & 0.00 & 0.00 & 0.00 & 0.00 \\
\hline Bolivina silvestrina & 0.00 & 0.00 & 0.00 & 0.00 & 0.00 & 0.00 \\
\hline Bolivina spathulata & 0.00 & 0.00 & 0.00 & 0.69 & 0.29 & 0.20 \\
\hline Bolivina subcompacta & 0.00 & 0.00 & 0.00 & 0.00 & 0.00 & 0.00 \\
\hline Bolivina subexcavata & 0.00 & 0.00 & 0.00 & 0.00 & 0.00 & 0.00 \\
\hline Bolivina wanganuiensis & 0.00 & 0.00 & 0.00 & 0.00 & 0.00 & 0.00 \\
\hline Bulimina marginata & 11.72 & 10.30 & 35.53 & 20.83 & 9.30 & 17.54 \\
\hline Cassidunlina neocarinata & 0.00 & 0.00 & 0.00 & 0.00 & 1.16 & 0.23 \\
\hline Cibicides deliquatus & 2.51 & 4.65 & 0.33 & 1.04 & 0.00 & 1.71 \\
\hline Cibicides molestus & 0.00 & 0.00 & 0.00 & 0.00 & 0.00 & 0.00 \\
\hline Discorbidae sp. & 0.00 & 0.00 & 0.00 & 0.35 & 0.29 & 0.13 \\
\hline Elphidium charlottense & 0.00 & 0.00 & 0.00 & 0.00 & 0.58 & 0.12 \\
\hline Elphidium excavatum & 0.00 & 0.00 & 0.00 & 0.00 & 0.00 & 0.00 \\
\hline Elphidium novozealandicum & 0.00 & 0.00 & 0.00 & 0.00 & 0.00 & 0.00 \\
\hline Euuvigerina pliozea & 10.46 & 21.59 & 0.66 & 7.99 & 8.14 & 9.77 \\
\hline Evolvocassidulina orientalis & 0.84 & 2.66 & 2.63 & 2.43 & 0.87 & 1.89 \\
\hline Fissurina sp. & 0.00 & 0.00 & 0.00 & 0.00 & 0.00 & 0.00 \\
\hline Globobulimina pacifica & 0.00 & 0.00 & 0.00 & 0.00 & 0.00 & 0.00 \\
\hline Globocassidulina subglobosa & 0.00 & 0.00 & 0.00 & 0.00 & 0.29 & 0.06 \\
\hline Gyroidinoides zelandica & 0.00 & 0.00 & 0.00 & 0.00 & 0.87 & 0.17 \\
\hline Haeuslerella parri & 20.92 & 32.23 & 20.39 & 23.26 & 21.80 & 23.72 \\
\hline Hoeglundina elegans & 0.84 & 1.00 & 0.00 & 0.00 & 0.00 & 0.37 \\
\hline Lagena sp. & 2.93 & 0.66 & 1.97 & 0.35 & 2.33 & 1.65 \\
\hline Lenticulina sp. & 5.86 & 2.66 & 3.29 & 1.74 & 0.00 & 2.71 \\
\hline Marginulina sp. & 0.00 & 0.00 & 0.00 & 0.00 & 0.00 & 0.00 \\
\hline Martinottiella communis & 0.00 & 0.00 & 0.00 & 0.00 & 0.00 & 0.00 \\
\hline Melonis zeobesus & 0.00 & 0.00 & 0.00 & 0.00 & 0.00 & 0.00 \\
\hline Nodosaria sp. & 0.00 & 0.00 & 0.00 & 0.00 & 0.00 & 0.00 \\
\hline Nonionellina flemingi & 0.42 & 0.00 & 4.93 & 2.78 & 4.65 & 2.56 \\
\hline Notorotalia finlayi & 4.18 & 10.30 & 9.87 & 11.11 & 15.12 & 10.12 \\
\hline Notorotalia kingmai & 0.00 & 0.66 & 0.00 & 0.00 & 0.00 & 0.13 \\
\hline Notorotalia zelandica zelandica & 0.00 & 0.00 & 0.00 & 0.00 & 0.00 & 0.00 \\
\hline Oolina sp. & 0.00 & 0.00 & 0.00 & 0.35 & 0.00 & 0.07 \\
\hline Oridorsalis tenera & 0.00 & 0.00 & 0.00 & 0.00 & 0.29 & 0.06 \\
\hline
\end{tabular}




\begin{tabular}{|l|c|c|c|c|c|c|}
\hline CLUSTER 5a & WS52 & WS54 & WS55 & WS57 & WS58 & Mean \\
\hline Oridorsalis umbonatus & 0.00 & 0.00 & 0.00 & 0.00 & 0.00 & 0.00 \\
\hline Parafusulina sp. & 0.00 & 0.00 & 0.00 & 0.00 & 0.00 & 0.00 \\
\hline Plectofrondicularia pellucida & 0.42 & 0.00 & 0.00 & 0.35 & 0.87 & 0.33 \\
\hline Proxifrons sp. & 0.00 & 0.00 & 0.00 & 0.00 & 0.29 & 0.06 \\
\hline Pullenia bulloides & 0.00 & 0.00 & 0.00 & 0.00 & 0.29 & 0.06 \\
\hline Pullenia quinqueloba & 0.00 & 0.33 & 0.00 & 0.35 & 0.00 & 0.14 \\
\hline Rectobolivina striatula & 0.00 & 0.00 & 0.00 & 0.00 & 0.00 & 0.00 \\
\hline Saracenaria italica & 0.00 & 0.00 & 0.00 & 0.00 & 0.00 & 0.00 \\
\hline Sigmoidina sp. & 0.00 & 0.00 & 0.00 & 0.00 & 0.00 & 0.00 \\
\hline Siphonaperta macbeathi & 0.00 & 0.00 & 0.00 & 0.00 & 0.58 & 0.12 \\
\hline Siphotextularia wairoana & 0.00 & 0.00 & 0.00 & 0.00 & 0.00 & 0.00 \\
\hline Sphaeroidina bulloides & 0.42 & 0.00 & 0.00 & 0.00 & 0.29 & 0.14 \\
\hline Trifarina bradyi & 0.00 & 0.00 & 0.00 & 0.00 & 0.00 & 0.00 \\
\hline Vaginulina sp. & 0.00 & 0.00 & 0.00 & 0.00 & 0.29 & 0.06 \\
\hline Zeoflorilus parri & 0.00 & 0.00 & 0.66 & 0.00 & 0.00 & 0.13 \\
\hline
\end{tabular}

\begin{tabular}{|l|c|c|c|}
\hline CLUSTER 5b & WS60 & WS61 & Mean \\
\hline Amphicorya hirsuta & 0.68 & 0.00 & 0.34 \\
\hline Anomalinoides parvumbilia & 0.00 & 1.82 & 0.91 \\
\hline Anomalinoides sphericus & 6.42 & 6.36 & 6.39 \\
\hline Anomalinoides subnonionoides & 0.00 & 0.00 & 0.00 \\
\hline Astrononion parki & 1.35 & 1.36 & 1.36 \\
\hline Biloculina anomala & 0.00 & 0.00 & 0.00 \\
\hline Bolivinita pliozea & 0.68 & 2.27 & 1.47 \\
\hline Bolivina sp. & 0.00 & 0.45 & 0.23 \\
\hline Bolivina cacozela & 0.00 & 0.00 & 0.00 \\
\hline Bolivina petiae & 1.35 & 0.00 & 0.68 \\
\hline Bolivina silvestrina & 0.00 & 0.00 & 0.00 \\
\hline Bolivina spathulata & 0.00 & 0.00 & 0.00 \\
\hline Bolivina subcompacta & 0.68 & 0.00 & 0.34 \\
\hline Bolivina subexcavata & 0.00 & 0.00 & 0.00 \\
\hline Bolivina wanganuiensis & 0.00 & 0.00 & 0.00 \\
\hline Bulimina marginata & 9.46 & 11.82 & 10.64 \\
\hline Cassidunlina neocarinata & 1.35 & 1.82 & 1.58 \\
\hline Cibicides deliquatus & 5.41 & 3.18 & 4.29 \\
\hline Cibicides molestus & 0.00 & 0.00 & 0.00 \\
\hline Discorbidae sp. & 0.00 & 0.00 & 0.00 \\
\hline Elphidium charlottense & 0.34 & 1.36 & 0.85 \\
\hline Elphidium excavatum & 0.00 & 0.00 & 0.00 \\
\hline Elphidium novozealandicum & 0.00 & 0.45 & 0.23 \\
\hline Euuvigerina pliozea & 30.07 & 17.27 & 23.67 \\
\hline Evolvocassidulina orientalis & 0.00 & 1.36 & 0.68 \\
\hline Fissurina sp. & 0.00 & 0.00 & 0.00 \\
\hline & & & \\
\hline
\end{tabular}




\begin{tabular}{|l|c|c|c|}
\hline CLUSTER 5b & WS60 & WS61 & Mean \\
\hline Globobulimina pacifica & 0.00 & 0.00 & 0.00 \\
\hline Globocassidulina subglobosa & 0.00 & 0.00 & 0.00 \\
\hline Gyroidinoides zelandica & 8.78 & 0.45 & 4.62 \\
\hline Haeuslerella parri & 17.91 & 27.27 & 22.59 \\
\hline Hoeglundina elegans & 1.69 & 0.91 & 1.30 \\
\hline Lagena sp. & 0.00 & 2.73 & 1.36 \\
\hline Lenticulina sp. & 2.03 & 1.82 & 1.92 \\
\hline Marginulina sp. & 0.00 & 0.00 & 0.00 \\
\hline Martinottiella communis & 0.00 & 0.00 & 0.00 \\
\hline Melonis zeobesus & 0.68 & 0.00 & 0.34 \\
\hline Nodosaria sp. & 0.00 & 0.00 & 0.00 \\
\hline Nonionellina flemingi & 2.70 & 1.82 & 2.26 \\
\hline Notorotalia finlayi & 6.08 & 10.00 & 8.04 \\
\hline Notorotalia kingmai & 0.00 & 0.00 & 0.00 \\
\hline Notorotalia zelandica zelandica & 0.00 & 0.00 & 0.00 \\
\hline Oolina sp. & 0.00 & 0.00 & 0.00 \\
\hline Oridorsalis tenera & 0.00 & 0.00 & 0.00 \\
\hline Oridorsalis umbonatus & 0.00 & 0.00 & 0.00 \\
\hline Parafusulina sp. & 0.00 & 0.45 & 0.23 \\
\hline Plectofrondicularia pellucida & 0.00 & 0.45 & 0.23 \\
\hline Proxifrons sp. & 0.00 & 0.00 & 0.00 \\
\hline Pullenia bulloides & 0.00 & 0.00 & 0.00 \\
\hline Pullenia quinqueloba & 0.00 & 0.45 & 0.23 \\
\hline Rectobolivina striatula & 1.69 & 1.36 & 1.53 \\
\hline Saracenaria italica & 0.00 & 0.00 & 0.00 \\
\hline Sigmoidina sp. & 0.00 & 0.00 & 0.00 \\
\hline Siphonaperta macbeathi & 0.68 & 2.27 & 1.47 \\
\hline Siphotextularia wairoana & 0.00 & 0.00 & 0.00 \\
\hline Sphaeroidina bulloides & 0.00 & 0.00 & 0.00 \\
\hline Trifarina bradyi & 0.00 & 0.00 & 0.00 \\
\hline Vaginulina sp. & 0.00 & 0.00 & 0.00 \\
\hline Zeoflorilus parri & 0.00 & 0.45 & 0.23 \\
\hline
\end{tabular}

\begin{tabular}{|l|c|c|c|c|c|c|}
\hline CLUSTER 5c & WS63 & WS65 & WS66 & WS67 & WS69 & Mean \\
\hline Amphicorya hirsuta & 0.00 & 0.00 & 0.00 & 0.00 & 0.00 & 0.00 \\
\hline Anomalinoides parvumbilia & 0.66 & 0.59 & 1.66 & 0.65 & 0.36 & 0.78 \\
\hline Anomalinoides sphericus & 0.33 & 0.00 & 0.00 & 0.00 & 0.00 & 0.07 \\
\hline Anomalinoides subnonionoides & 0.00 & 0.00 & 0.00 & 0.00 & 0.00 & 0.00 \\
\hline Astrononion parki & 10.53 & 16.18 & 12.29 & 14.33 & 12.41 & 13.15 \\
\hline Biloculina anomala & 0.00 & 0.00 & 0.00 & 0.00 & 0.36 & 0.07 \\
\hline Bolivinita pliozea & 3.62 & 6.47 & 9.63 & 11.73 & 5.47 & 7.38 \\
\hline Bolivina sp. & 0.00 & 0.00 & 0.00 & 0.00 & 0.00 & 0.00 \\
\hline Bolivina cacozela & 0.00 & 0.00 & 0.00 & 0.00 & 0.00 & 0.00 \\
\hline
\end{tabular}




\begin{tabular}{|c|c|c|c|c|c|c|}
\hline CLUSTER 5C & WS63 & WS65 & WS66 & WS67 & WS69 & Mean \\
\hline Bolivina petiae & 0.00 & 0.00 & 0.00 & 0.00 & 0.00 & 0.00 \\
\hline Bolivina silvestrina & 0.00 & 0.00 & 0.00 & 0.00 & 0.00 & 0.00 \\
\hline Bolivina spathulata & 0.33 & 0.00 & 0.00 & 0.65 & 0.00 & 0.20 \\
\hline Bolivina subcompacta & 0.00 & 0.00 & 0.00 & 0.00 & 0.00 & 0.00 \\
\hline Bolivina subexcavata & 0.00 & 0.00 & 0.33 & 0.00 & 1.09 & 0.29 \\
\hline Bolivina wanganuiensis & 0.00 & 0.00 & 0.00 & 0.00 & 0.00 & 0.00 \\
\hline Bulimina marginata & 3.62 & 5.29 & 5.98 & 14.33 & 6.93 & 7.23 \\
\hline Cassidunlina neocarinata & 1.32 & 4.12 & 2.33 & 4.56 & 8.76 & 4.22 \\
\hline Cibicides deliquatus & 1.32 & 0.00 & 0.66 & 0.00 & 0.36 & 0.47 \\
\hline Cibicides molestus & 0.00 & 0.00 & 0.00 & 0.00 & 0.00 & 0.00 \\
\hline Discorbidae sp. & 0.66 & 0.88 & 1.00 & 0.00 & 0.00 & 0.51 \\
\hline Elphidium charlottense & 9.21 & 2.35 & 2.33 & 0.33 & 4.38 & 3.72 \\
\hline Elphidium excavatum & 0.66 & 0.00 & 0.33 & 0.00 & 1.46 & 0.49 \\
\hline Elphidium novozealandicum & 0.00 & 0.00 & 0.00 & 0.00 & 0.00 & 0.00 \\
\hline Euuvigerina pliozea & 11.84 & 12.35 & 13.29 & 12.38 & 7.66 & 11.51 \\
\hline Evolvocassidulina orientalis & 2.63 & 2.65 & 1.99 & 1.63 & 2.55 & 2.29 \\
\hline Fissurina sp. & 0.33 & 0.00 & 0.00 & 0.33 & 0.36 & 0.20 \\
\hline Globobulimina pacifica & 0.00 & 0.00 & 0.00 & 0.00 & 0.00 & 0.00 \\
\hline Globocassidulina subglobosa & 0.00 & 0.00 & 0.00 & 0.00 & 0.00 & 0.00 \\
\hline Gyroidinoides zelandica & 1.97 & 0.00 & 0.00 & 0.00 & 0.00 & 0.39 \\
\hline Haeuslerella parri & 30.59 & 20.00 & 21.59 & 20.20 & 15.33 & 21.54 \\
\hline Hoeglundina elegans & 0.33 & 2.06 & 0.33 & 3.58 & 3.65 & 1.99 \\
\hline Lagena sp. & 4.28 & 0.59 & 1.00 & 2.61 & 2.92 & 2.28 \\
\hline Lenticulina sp. & 1.97 & 6.76 & 4.32 & 1.95 & 5.47 & 4.10 \\
\hline Marginulina sp. & 0.00 & 0.00 & 0.00 & 0.00 & 0.00 & 0.00 \\
\hline Martinottiella communis & 0.00 & 0.00 & 0.00 & 0.00 & 0.00 & 0.00 \\
\hline Melonis zeobesus & 0.33 & 0.00 & 0.00 & 0.00 & 0.00 & 0.07 \\
\hline Nodosaria sp. & 0.00 & 0.00 & 0.00 & 0.00 & 0.00 & 0.00 \\
\hline Nonionellina flemingi & 0.33 & 5.00 & 5.32 & 2.28 & 4.74 & 3.53 \\
\hline Notorotalia finlayi & 10.20 & 13.53 & 13.95 & 7.82 & 14.23 & 11.95 \\
\hline Notorotalia kingmai & 0.00 & 0.00 & 0.00 & 0.00 & 0.00 & 0.00 \\
\hline Notorotalia zelandica zelandica & 0.00 & 0.00 & 0.00 & 0.00 & 0.00 & 0.00 \\
\hline Oolina sp. & 0.00 & 0.00 & 0.00 & 0.00 & 0.00 & 0.00 \\
\hline Oridorsalis tenera & 0.00 & 0.00 & 0.00 & 0.00 & 0.00 & 0.00 \\
\hline Oridorsalis umbonatus & 0.00 & 0.00 & 0.66 & 0.00 & 0.00 & 0.13 \\
\hline Parafusulina sp. & 0.00 & 0.00 & 0.00 & 0.00 & 0.00 & 0.00 \\
\hline Plectofrondicularia pellucida & 1.97 & 0.00 & 0.00 & 0.00 & 0.00 & 0.39 \\
\hline Proxifrons sp. & 0.00 & 0.00 & 0.00 & 0.00 & 0.00 & 0.00 \\
\hline Pullenia bulloides & 0.00 & 0.00 & 0.00 & 0.00 & 0.00 & 0.00 \\
\hline Pullenia quinqueloba & 0.66 & 0.00 & 0.33 & 0.00 & 0.00 & 0.20 \\
\hline Rectobolivina striatula & 0.33 & 0.00 & 0.00 & 0.00 & 0.00 & 0.07 \\
\hline Saracenaria italica & 0.00 & 0.00 & 0.00 & 0.00 & 0.00 & 0.00 \\
\hline Sigmoidina sp. & 0.00 & 0.00 & 0.00 & 0.00 & 0.00 & 0.00 \\
\hline
\end{tabular}




\begin{tabular}{|l|c|c|c|c|c|c|}
\hline CLUSTER 5c & WS63 & WS65 & WS66 & WS67 & WS69 & Mean \\
\hline Siphonaperta macbeathi & 0.00 & 0.00 & 0.33 & 0.00 & 0.00 & 0.07 \\
\hline Siphotextularia wairoana & 0.00 & 0.88 & 0.33 & 0.65 & 1.09 & 0.59 \\
\hline Sphaeroidina bulloides & 0.00 & 0.29 & 0.00 & 0.00 & 0.36 & 0.13 \\
\hline Trifarina bradyi & 0.00 & 0.00 & 0.00 & 0.00 & 0.00 & 0.00 \\
\hline Vaginulina sp. & 0.00 & 0.00 & 0.00 & 0.00 & 0.00 & 0.00 \\
\hline Zeoflorilus parri & 0.00 & 0.00 & 0.00 & 0.00 & 0.00 & 0.00 \\
\hline
\end{tabular}

\begin{tabular}{|c|c|c|c|c|c|c|}
\hline CLUSTER 6 & WS70 & WS72 & WS73 & WS75 & WS76 & Mean \\
\hline Amphicorya hirsuta & 0.00 & 0.00 & 0.00 & 0.00 & 0.00 & 0.00 \\
\hline Anomalinoides parvumbilia & 0.00 & 0.00 & 0.00 & 0.31 & 0.36 & 0.13 \\
\hline Anomalinoides sphericus & 0.00 & 0.00 & 0.00 & 0.00 & 0.00 & 0.00 \\
\hline Anomalinoides subnonionoides & 0.00 & 0.00 & 0.00 & 0.00 & 0.00 & 0.00 \\
\hline Astrononion parki & 6.41 & 13.25 & 15.16 & 4.69 & 5.01 & 8.90 \\
\hline Biloculina anomala & 0.00 & 0.00 & 0.00 & 0.00 & 0.00 & 0.00 \\
\hline Bolivinita pliozea & 8.19 & 4.90 & 2.89 & 2.19 & 10.02 & 5.64 \\
\hline Bolivina sp. & 0.00 & 0.00 & 0.00 & 0.00 & 0.00 & 0.00 \\
\hline Bolivina cacozela & 0.00 & 0.00 & 0.00 & 0.00 & 0.00 & 0.00 \\
\hline Bolivina petiae & 0.00 & 0.00 & 0.00 & 0.00 & 0.00 & 0.00 \\
\hline Bolivina silvestrina & 0.00 & 0.00 & 0.00 & 0.00 & 0.00 & 0.00 \\
\hline Bolivina spathulata & 0.36 & 0.54 & 0.00 & 0.00 & 0.00 & 0.18 \\
\hline Bolivina subcompacta & 0.00 & 0.00 & 0.00 & 0.00 & 0.00 & 0.00 \\
\hline Bolivina subexcavata & 0.00 & 0.00 & 0.00 & 0.00 & 0.00 & 0.00 \\
\hline Bolivina wanganuiensis & 0.00 & 0.00 & 0.00 & 0.00 & 0.00 & 0.00 \\
\hline Bulimina marginata & 40.21 & 25.95 & 49.46 & 30.94 & 50.98 & 39.51 \\
\hline Cassidunlina neocarinata & 12.46 & 7.80 & 6.50 & 30.94 & 0.54 & 11.65 \\
\hline Cibicides deliquatus & 0.00 & 0.18 & 0.00 & 0.00 & 0.00 & 0.04 \\
\hline Cibicides molestus & 0.00 & 0.00 & 0.00 & 0.00 & 0.00 & 0.00 \\
\hline Discorbidae sp. & 0.00 & 0.00 & 0.00 & 0.00 & 0.00 & 0.00 \\
\hline Elphidium charlottense & 0.00 & 0.00 & 0.00 & 0.31 & 0.18 & 0.10 \\
\hline Elphidium excavatum & 0.00 & 0.00 & 0.00 & 0.00 & 0.00 & 0.00 \\
\hline Elphidium novozealandicum & 0.00 & 0.00 & 0.00 & 0.00 & 0.00 & 0.00 \\
\hline Euuvigerina pliozea & 11.74 & 8.71 & 2.89 & 3.44 & 2.15 & 5.79 \\
\hline Evolvocassidulina orientalis & 0.71 & 2.36 & 0.72 & 2.50 & 1.43 & 1.54 \\
\hline Fissurina sp. & 0.00 & 0.00 & 0.00 & 0.00 & 0.00 & 0.00 \\
\hline Globobulimina pacifica & 0.00 & 0.00 & 0.00 & 0.00 & 0.00 & 0.00 \\
\hline Globocassidulina subglobosa & 0.00 & 0.00 & 0.00 & 0.00 & 0.00 & 0.00 \\
\hline Gyroidinoides zelandica & 0.00 & 0.00 & 0.00 & 0.00 & 0.00 & 0.00 \\
\hline Haeuslerella parri & 1.78 & 0.18 & 2.53 & 2.50 & 2.33 & 1.86 \\
\hline Hoeglundina elegans & 0.00 & 0.00 & 0.00 & 0.00 & 0.36 & 0.07 \\
\hline Lagena sp. & 1.07 & 0.00 & 0.36 & 0.31 & 0.89 & 0.53 \\
\hline Lenticulina sp. & 1.78 & 0.18 & 0.72 & 0.00 & 1.43 & 0.82 \\
\hline Marginulina sp. & 0.00 & 0.00 & 0.00 & 0.00 & 0.00 & 0.00 \\
\hline Martinottiella communis & 0.00 & 0.00 & 0.00 & 0.00 & 0.00 & 0.00 \\
\hline
\end{tabular}




\begin{tabular}{|l|c|c|c|c|c|c|}
\hline CLUSTER 6 & WS70 & WS72 & WS73 & WS75 & WS76 & Mean \\
\hline Melonis zeobesus & 0.00 & 0.00 & 0.00 & 0.00 & 0.00 & 0.00 \\
\hline Nodosaria sp. & 0.00 & 0.00 & 0.00 & 0.00 & 0.18 & 0.04 \\
\hline Nonionellina flemingi & 0.71 & 12.89 & 3.61 & 7.50 & 10.20 & 6.98 \\
\hline Notorotalia finlayi & 14.23 & 23.05 & 15.16 & 14.38 & 13.60 & 16.08 \\
\hline Notorotalia kingmai & 0.00 & 0.00 & 0.00 & 0.00 & 0.00 & 0.00 \\
\hline Notorotalia zelandica zelandica & 0.00 & 0.00 & 0.00 & 0.00 & 0.00 & 0.00 \\
\hline Oolina sp. & 0.00 & 0.00 & 0.00 & 0.00 & 0.00 & 0.00 \\
\hline Oridorsalis tenera & 0.00 & 0.00 & 0.00 & 0.00 & 0.00 & 0.00 \\
\hline Oridorsalis umbonatus & 0.00 & 0.00 & 0.00 & 0.00 & 0.00 & 0.00 \\
\hline Parafusulina sp. & 0.00 & 0.00 & 0.00 & 0.00 & 0.00 & 0.00 \\
\hline Plectofrondicularia pellucida & 0.00 & 0.00 & 0.00 & 0.00 & 0.00 & 0.00 \\
\hline Proxifrons sp. & 0.00 & 0.00 & 0.00 & 0.00 & 0.00 & 0.00 \\
\hline Pullenia bulloides & 0.00 & 0.00 & 0.00 & 0.00 & 0.18 & 0.04 \\
\hline Pullenia quinqueloba & 0.00 & 0.00 & 0.00 & 0.00 & 0.00 & 0.00 \\
\hline Rectobolivina striatula & 0.00 & 0.00 & 0.00 & 0.00 & 0.00 & 0.00 \\
\hline Saracenaria italica & 0.00 & 0.00 & 0.00 & 0.00 & 0.00 & 0.00 \\
\hline Sigmoidina sp. & 0.00 & 0.00 & 0.00 & 0.00 & 0.00 & 0.00 \\
\hline Siphonaperta macbeathi & 0.00 & 0.00 & 0.00 & 0.00 & 0.00 & 0.00 \\
\hline Siphotextularia wairoana & 0.36 & 0.00 & 0.00 & 0.00 & 0.18 & 0.11 \\
\hline Sphaeroidina bulloides & 0.00 & 0.00 & 0.00 & 0.00 & 0.00 & 0.00 \\
\hline Trifarina bradyi & 0.00 & 0.00 & 0.00 & 0.00 & 0.00 & 0.00 \\
\hline Vaginulina sp. & 0.00 & 0.00 & 0.00 & 0.00 & 0.00 & 0.00 \\
\hline Zeoflorilus parri & 0.00 & 0.00 & 0.00 & 0.00 & 0.00 & 0.00 \\
\hline
\end{tabular}

\begin{tabular}{|l|c|c|c|}
\hline CLUSTER 7 & WS78 & CLUSTER 8 & WS80 \\
\hline Amphicorya hirsuta & 0.00 & & 0.00 \\
\hline Anomalinoides parvumbilia & 1.85 & & 0.00 \\
\hline Anomalinoides sphericus & 0.00 & & 0.00 \\
\hline Anomalinoides subnonionoides & 0.00 & & 0.00 \\
\hline Astrononion parki & 6.48 & & 3.73 \\
\hline Biloculina anomala & 0.00 & & 0.00 \\
\hline Bolivinita pliozea & 15.74 & & 0.00 \\
\hline Bolivina sp. & 0.00 & & 0.00 \\
\hline Bolivina cacozela & 0.00 & & 0.00 \\
\hline Bolivina petiae & 0.00 & & 0.00 \\
\hline Bolivina silvestrina & 0.31 & & 0.00 \\
\hline Bolivina spathulata & 0.00 & & 0.00 \\
\hline Bolivina subcompacta & 0.00 & & 0.00 \\
\hline Bolivina subexcavata & 0.00 & & 0.00 \\
\hline Bolivina wanganuiensis & 0.00 & & 5.33 \\
\hline Bulimina marginata & 9.57 & & 0.27 \\
\hline Cassidunlina neocarinata & 0.00 & & 1.33 \\
\hline Cibicides deliquatus & 0.00 & & 2.40 \\
\hline
\end{tabular}




\begin{tabular}{|l|c|c|c|}
\hline CLUSTER 7 & WS78 & CLUSTER 8 & WS80 \\
\hline Cibicides molestus & 0.00 & & 0.00 \\
\hline Discorbidae sp. & 0.00 & & 6.67 \\
\hline Elphidium charlottense & 5.86 & & 30.93 \\
\hline Elphidium excavatum & 0.00 & & 2.13 \\
\hline Elphidium novozealandicum & 0.00 & & 0.00 \\
\hline Euuvigerina pliozea & 27.16 & 12.53 \\
\hline Evolvocassidulina orientalis & 1.54 & & 1.33 \\
\hline Fissurina sp. & 0.00 & & 0.00 \\
\hline Globobulimina pacifica & 0.00 & & 0.00 \\
\hline Globocassidulina subglobosa & 0.00 & & 0.27 \\
\hline Gyroidinoides zelandica & 0.00 & & 0.00 \\
\hline Haeuslerella parri & 1.85 & & 0.80 \\
\hline Hoeglundina elegans & 0.00 & & 0.27 \\
\hline Lagena sp. & 2.47 & & 0.53 \\
\hline Lenticulina sp. & 1.23 & & 0.00 \\
\hline Marginulina sp. & 0.00 & & 0.00 \\
\hline Martinottiella communis & 0.00 & & 0.00 \\
\hline Melonis zeobesus & 0.00 & & 0.00 \\
\hline Nodosaria sp. & 0.31 & 0.00 \\
\hline Nonionellina flemingi & 0.00 & & 0.00 \\
\hline Notorotalia finlayi & 0.32 & \\
\hline Notorotalia kingmai & 20.99 & 0.00 \\
\hline Notorotalia zelandica zelandica & 0.00 & 0.00 \\
\hline Oolina sp. & 0.00 & & 0.00 \\
\hline Oridorsalis tenera & 0.00 & & 0.00 \\
\hline Oridorsalis umbonatus & 0.00 & & 0.00 \\
\hline Parafusulina sp. & 0.00 & & 0.00 \\
\hline Plectofrondicularia pellucida & 0.00 & & 0.00 \\
\hline Proxifrons sp. & 0.00 & & 0.00 \\
\hline Pullenia bulloides & 0.00 & & 0.00 \\
\hline Pullenia quinqueloba & 0.00 & & 0.00 \\
\hline Rectobolivina striatula & 0.00 & & 0.00 \\
\hline Saracenaria italica & & & 0.00 \\
\hline Sigmoidina sp. & & & 0.00 \\
\hline Siphonaperta macbeathi & & \\
\hline Siphotextularia wairoana & & \\
\hline
\end{tabular}




\section{Appendix D}

Specimen and site palaeomagnetic directions estimated via PCA analysis and remagnetisation great circle analysis. PCA analysis was not anchored to the origin. NRM is natural remanent magnetisation. The locations and stratigraphic depths of sites are in Appendix A.

\section{Appendix D Table 1: Specimen and site calculated palaeomagnetic directions}

\begin{tabular}{|c|c|c|c|c|c|c|}
\hline \multirow{2}{*}{$\begin{array}{l}\text { Site } \\
\text { Specimen }\end{array}$} & \multicolumn{2}{|c|}{ WS3 } & \multicolumn{4}{|c|}{ WS7 } \\
\hline & $2 a$ & $3 a$ & $2 b$ & $3 a$ & $3 b$ & $4 a$ \\
\hline NRM intensity $(\mathrm{A} / \mathrm{m})$ & 0.002875 & 0.0002953 & 0.0002668 & 0.005201 & 0.004566 & 0.000521 \\
\hline $\begin{array}{l}\text { Maximum } \\
\text { demagentisation } \mathrm{T}\left({ }^{\circ} \mathrm{C}\right)\end{array}$ & 290 & 290 & 290 & 250 & 290 & 290 \\
\hline PCA declination $\left({ }^{\circ}\right)$ & 44.3 & 44.7 & 19.9 & 17.5 & 9.3 & 31 \\
\hline PCA inclination $\left({ }^{\circ}\right)$ & -53.1 & -57.8 & -63 & -41.5 & -52.7 & -54 \\
\hline \multicolumn{7}{|l|}{$\begin{array}{l}\text { (pole to) Great Circle } \\
\text { declination }\left({ }^{\circ}\right)\end{array}$} \\
\hline \multicolumn{7}{|l|}{$\begin{array}{l}\text { (pole to) Great Circle } \\
\text { inclination }\left({ }^{\circ}\right)\end{array}$} \\
\hline Site mean declination $\left({ }^{\circ}\right)$ & & & 19.2 & & & \\
\hline Site mean inclination $\left({ }^{\circ}\right)$ & & & -53.1 & & & \\
\hline $\begin{array}{l}\text { a95 ( } 95 \% \text { confidence } \\
\text { interval) }\end{array}$ & & & 11.7 & & & \\
\hline Polarity & $?$ & & $\mathrm{~N}$ & & & \\
\hline
\end{tabular}

\begin{tabular}{|l|c|c|c|c|c|c|c|}
\hline Site & \multicolumn{3}{|c|}{ WS11 } & \multicolumn{3}{c|}{ WS15 } \\
\hline Specimen & $2 a$ & $3 a$ & $4 a$ & $2 c$ & $3 a$ & $3 b$ & $4 a$ \\
\hline $\begin{array}{l}\text { NRM intensity } \\
(\mathrm{A} / \mathrm{m})\end{array}$ & 0.000266 & $\begin{array}{c}0.00508 \\
9\end{array}$ & 0.003043 & $\begin{array}{c}0.00019 \\
9\end{array}$ & $\begin{array}{c}0.00204 \\
5\end{array}$ & $\begin{array}{c}0.00197 \\
4\end{array}$ & $\begin{array}{c}0.00247 \\
4\end{array}$ \\
\hline $\begin{array}{l}\text { Maximum } \\
\text { demagentisatio } \\
\mathrm{nT}\left({ }^{\circ} \mathrm{C}\right)\end{array}$ & 290 & 250 & 290 & 290 & 250 & 250 & 250 \\
\hline $\begin{array}{l}\text { PCA declination } \\
\left(^{\circ}\right)\end{array}$ & & & & 22.6 & 34.6 & 5.7 & 9.1 \\
\hline $\begin{array}{l}\text { PCA inclination } \\
\left(^{\circ}\right)\end{array}$ & 131 & 101.2 & -67.1 & -51.6 & -61 & -65.4 \\
\hline $\begin{array}{l}\text { (pole to) Great } \\
\text { Circle } \\
\text { declination }\left(^{\circ}\right)\end{array}$ & -27 & -27.9 & -9.7 & & & & \\
\hline $\begin{array}{l}\text { (pole to) Great } \\
\text { Circle } \\
\text { inclination }\left(^{\circ}\right)\end{array}$ & & & & & & & \\
\hline
\end{tabular}




\begin{tabular}{|l|c|c|c|c|c|c|}
\hline Site & \multicolumn{2}{|c|}{ WS11 } & & & \\
\hline $\begin{array}{l}\text { Site mean } \\
\text { declination ( }\end{array}$ & 178.6 & & 19.3 & & \\
\hline $\begin{array}{l}\text { Site mean } \\
\text { inclination ( }\end{array}$ & 52.4 & & -61.8 & & \\
\hline $\begin{array}{l}\text { a95 (95\% } \\
\text { confidence } \\
\text { interval) }\end{array}$ & 7.8 & $\mathrm{R}$ & & 11 & & \\
\hline Polarity & & & $\mathrm{N}$ & & & \\
\hline
\end{tabular}

\begin{tabular}{|c|c|c|c|c|c|c|c|c|}
\hline Site & WS19 & & & & & WS23 & & \\
\hline Specimen & $2 b$ & $3 a$ & $3 b$ & $4 a$ & $4 b$ & $2 a$ & $2 b$ & $3 b$ \\
\hline $\begin{array}{l}\text { NRM intensity } \\
(\mathrm{A} / \mathrm{m})\end{array}$ & 0.01137 & 0.003487 & 0.000499 & 0.003251 & 0.006742 & 0.003093 & 0.00022 & 0.00266 \\
\hline $\begin{array}{l}\text { Maximum } \\
\text { demagentisation } \\
\mathrm{T}\left({ }^{\circ} \mathrm{C}\right)\end{array}$ & 250 & 250 & 290 & 250 & 290 & 250 & 290 & 210 \\
\hline $\begin{array}{l}\text { PCA declination } \\
\left({ }^{\circ}\right)\end{array}$ & 28.5 & 10.1 & 0.4 & 333.5 & 359.9 & 30.8 & 11.4 & 24.8 \\
\hline $\begin{array}{l}\text { PCA inclination } \\
\left({ }^{\circ}\right)\end{array}$ & -52.8 & -62.6 & -71.5 & -68.9 & -61.2 & -64.5 & -70.4 & -69.2 \\
\hline \multicolumn{9}{|l|}{$\begin{array}{l}\text { (pole to) Great } \\
\text { Circle } \\
\text { declination }\left({ }^{\circ}\right)\end{array}$} \\
\hline \multicolumn{9}{|l|}{$\begin{array}{l}\text { (pole to) Great } \\
\text { Circle inclination } \\
\left({ }^{\circ}\right)\end{array}$} \\
\hline $\begin{array}{l}\text { Site mean } \\
\text { declination }\left({ }^{\circ}\right)\end{array}$ & 5.7 & & & & & 21.2 & & \\
\hline $\begin{array}{l}\text { Site mean } \\
\text { inclination }\left({ }^{\circ}\right)\end{array}$ & -64.5 & & & & & -66.7 & & \\
\hline $\begin{array}{l}\text { a95 (95\% } \\
\text { confidence } \\
\text { interval) }\end{array}$ & 10.9 & & & & & 4.7 & & \\
\hline Polarity & $\mathrm{N}$ & & & & & $\mathrm{N}$ & & \\
\hline
\end{tabular}

\begin{tabular}{|l|c|c|}
\hline Site & WS23 & \\
\hline Specimen & $4 a$ & $5 b$ \\
\hline $\begin{array}{l}\text { NRM intensity } \\
(\mathrm{A} / \mathrm{m})\end{array}$ & 0.00266 & 0.000236 \\
\hline $\begin{array}{l}\text { Maximum } \\
\text { demagentisation } \\
\mathrm{T}\left({ }^{\circ} \mathrm{C}\right)\end{array}$ & 250 & 290 \\
\hline $\begin{array}{l}\text { PCA declination } \\
\left({ }^{\circ}\right)\end{array}$ & 22.7 & 13.8 \\
\hline $\begin{array}{l}\text { PCA inclination } \\
\left({ }^{\circ}\right)\end{array}$ & -60.8 & -67.8 \\
\hline
\end{tabular}




\begin{tabular}{|c|c|c|c|c|c|c|c|c|c|}
\hline Site & WS72 & & & WS78 & & & & \multicolumn{2}{|c|}{ WS79.5a } \\
\hline Specimen & $1 b$ & $2 a$ & $2 b$ & $1 a$ & $2 a$ & $2 b$ & $3 a$ & $1 a$ & $2 a$ \\
\hline $\begin{array}{l}\text { NRM intensity } \\
(\mathrm{A} / \mathrm{m})\end{array}$ & 0.001838 & 0.001083 & 0.000135 & 0.001261 & 0.001628 & 0.00018 & 0.001812 & $9.56 \mathrm{E}-05$ & 0.000876 \\
\hline $\begin{array}{l}\text { Maximum } \\
\text { demagentisati } \\
\text { on } \mathrm{T}\left({ }^{\circ} \mathrm{C}\right)\end{array}$ & 250 & 210 & 290 & 210 & 250 & 290 & 250 & 290 & 290 \\
\hline $\begin{array}{l}\text { PCA } \\
\text { declination }\left({ }^{\circ}\right)\end{array}$ & 14.3 & 13.8 & 5.5 & 24.2 & 347.6 & 11.6 & 6.2 & & \\
\hline $\begin{array}{l}\text { PCA } \\
\text { inclination }\left({ }^{\circ}\right)\end{array}$ & -62.1 & -67.4 & -64.6 & -76.2 & -62.1 & -65.8 & -79.3 & & \\
\hline $\begin{array}{l}\text { (pole to) } \\
\text { Great Circle } \\
\text { declination }\left({ }^{\circ}\right)\end{array}$ & & & & & & & & 93.8 & 264 \\
\hline $\begin{array}{l}\text { (pole to) } \\
\text { Great Circle } \\
\text { inclination }\left({ }^{\circ}\right)\end{array}$ & & & & & & & & 9.4 & -36 \\
\hline $\begin{array}{l}\text { Site mean } \\
\text { declination }\left({ }^{\circ}\right)\end{array}$ & 11.2 & & & 4.6 & & & & & \\
\hline $\begin{array}{l}\text { Site mean } \\
\text { inclination }\left({ }^{\circ}\right)\end{array}$ & -64.8 & & & -71.4 & & & & & \\
\hline $\begin{array}{l}\text { a95 ( } 95 \% \\
\text { confidence } \\
\text { interval) }\end{array}$ & 5.1 & & & 11.1 & & & & & \\
\hline Polarity & $\mathrm{N}$ & & & $\mathrm{N}$ & & & & ? & \\
\hline
\end{tabular}

\begin{tabular}{|c|c|c|c|c|c|c|c|c|c|}
\hline \multirow{2}{*}{$\begin{array}{l}\text { Site } \\
\text { Specimen }\end{array}$} & \multicolumn{2}{|c|}{ WS79.5b } & \multicolumn{2}{|c|}{ WS81 } & \multicolumn{3}{|c|}{ WS81.5d } & \multirow[b]{2}{*}{$3 a$} & \multirow[b]{2}{*}{$3 b$} \\
\hline & $1 a$ & $2 a$ & $1 a$ & $3 a$ & $1 a$ & $2 a$ & $2 b$ & & \\
\hline $\begin{array}{l}\text { NRM intensity } \\
(\mathrm{A} / \mathrm{m})\end{array}$ & $\begin{array}{c}8.07 \mathrm{E}- \\
05\end{array}$ & 0.001001 & 0.001099 & $\begin{array}{c}8.52 \mathrm{E}- \\
05\end{array}$ & 0.000134 & 0.000862 & 0.000313 & 0.000537 & 0.00313 \\
\hline $\begin{array}{l}\text { Maximum } \\
\text { demagentisation } \\
\mathrm{T}\left({ }^{\circ} \mathrm{C}\right)\end{array}$ & 290 & 290 & 290 & 250 & 290 & 250 & 290 & 250 & 250 \\
\hline $\begin{array}{l}\text { PCA declination } \\
\left({ }^{\circ}\right)\end{array}$ & & & & & 310.9 & 333.3 & 128.2 & 48.4 & 273.6 \\
\hline $\begin{array}{l}\text { PCA inclination } \\
\left({ }^{\circ}\right)\end{array}$ & & & & & -32.8 & -67.3 & -68.4 & -11.2 & -29.7 \\
\hline $\begin{array}{l}\text { (pole to) Great } \\
\text { Circle } \\
\text { declination }\left({ }^{\circ}\right)\end{array}$ & 94.1 & 90.9 & 147.7 & 256.7 & & & & & \\
\hline $\begin{array}{l}\text { (pole to) Great } \\
\text { Circle inclination } \\
\left({ }^{\circ}\right)\end{array}$ & -2.4 & -1.8 & -22.7 & -8.9 & & & & & \\
\hline $\begin{array}{l}\text { Site mean } \\
\text { declination }\left({ }^{\circ}\right)\end{array}$ & 181.9 & & 184.2 & & & & & & \\
\hline $\begin{array}{l}\text { Site mean } \\
\text { inclination }\left({ }^{\circ}\right)\end{array}$ & 15.6 & & 62.5 & & & & & & \\
\hline $\begin{array}{l}\text { a95 ( } 95 \% \\
\text { confidence } \\
\text { interval) }\end{array}$ & $\mathrm{NaN}$ & & $\mathrm{NaN}$ & & & & & & \\
\hline Polarity & $\mathrm{R}$ & & $\mathrm{R}$ & & $?$ & & & & \\
\hline
\end{tabular}




\begin{tabular}{|c|c|c|c|c|c|c|c|c|}
\hline \multirow{2}{*}{$\begin{array}{l}\text { Site } \\
\text { Specimen }\end{array}$} & \multicolumn{3}{|c|}{ WS81.5h } & \multicolumn{5}{|c|}{ WS82 } \\
\hline & $2 a$ & $2 b$ & $5 a$ & $1 a$ & $2 a$ & $2 b$ & $3 a$ & $5 a$ \\
\hline $\begin{array}{l}\text { NRM intensity } \\
(\mathrm{A} / \mathrm{m})\end{array}$ & 0.001451 & 0.002022 & 0.001594 & 0.003909 & 0.003703 & 0.004825 & 0.000266 & 0.002864 \\
\hline $\begin{array}{l}\text { Maximum } \\
\text { demagentisation } \\
\mathrm{T}\left({ }^{\circ} \mathrm{C}\right)\end{array}$ & 250 & 250 & 250 & 250 & 250 & 290 & 290 & 250 \\
\hline $\begin{array}{l}\text { PCA declination } \\
\left({ }^{\circ}\right)\end{array}$ & 9.2 & 4.3 & 34.7 & 35.2 & 8.4 & 354.4 & 11.4 & 346.9 \\
\hline $\begin{array}{l}\text { PCA inclination } \\
\left({ }^{\circ}\right)\end{array}$ & -60.4 & -68 & -67 & -66.4 & -52.3 & -61 & -75.3 & -50.1 \\
\hline \multicolumn{9}{|l|}{$\begin{array}{l}\text { (pole to) Great } \\
\text { Circle } \\
\text { declination }\left({ }^{\circ}\right)\end{array}$} \\
\hline \multicolumn{9}{|l|}{$\begin{array}{l}\text { (pole to) Great } \\
\text { Circle inclination } \\
\left({ }^{\circ}\right)\end{array}$} \\
\hline $\begin{array}{l}\text { Site mean } \\
\text { declination }\left({ }^{\circ}\right)\end{array}$ & 15.6 & & & 4.4 & & & & \\
\hline $\begin{array}{l}\text { Site mean } \\
\text { inclination }\left({ }^{\circ}\right)\end{array}$ & -65.7 & & & -62 & & & & \\
\hline $\begin{array}{l}\text { a95 }(95 \% \\
\text { confidence } \\
\text { interval) }\end{array}$ & 11.9 & & & 12.9 & & & & \\
\hline Polarity & $\mathrm{N}$ & & & $\mathrm{N}$ & & & & \\
\hline
\end{tabular}

\begin{tabular}{|c|c|c|c|c|c|c|c|}
\hline Site & WS87 & & & WS89 & & & \\
\hline Specimen & $1 a$ & $1 b$ & $2 a$ & $1 a$ & $2 a$ & $4 a$ & $5 b$ \\
\hline $\begin{array}{l}\text { NRM intensity } \\
(\mathrm{A} / \mathrm{m})\end{array}$ & 0.000828 & $6.32 \mathrm{E}-05$ & 0.00135 & 7.09E-05 & 0.001162 & 0.000807 & 0.001331 \\
\hline $\begin{array}{l}\text { Maximum } \\
\text { demagentisation } \\
\mathrm{T}\left({ }^{\circ} \mathrm{C}\right)\end{array}$ & 250 & 290 & 210 & 290 & 250 & 250 & 250 \\
\hline $\begin{array}{l}\text { PCA declination } \\
\left({ }^{\circ}\right)\end{array}$ & 15 & 22.8 & 3.7 & & & & \\
\hline $\begin{array}{l}\text { PCA inclination } \\
\left({ }^{\circ}\right)\end{array}$ & -55.1 & -63.7 & -62.6 & & & & \\
\hline $\begin{array}{l}\text { (pole to) Great } \\
\text { Circle } \\
\text { declination }\left({ }^{\circ}\right)\end{array}$ & & & & 268 & 289.8 & 276.7 & 119.6 \\
\hline $\begin{array}{l}\text { (pole to) Great } \\
\text { Circle inclination } \\
\left({ }^{\circ}\right)\end{array}$ & & & & -20.5 & -17.5 & -13.8 & 10.4 \\
\hline $\begin{array}{l}\text { Site mean } \\
\text { declination }\left({ }^{\circ}\right)\end{array}$ & 13.8 & & & 41.9 & & & \\
\hline $\begin{array}{l}\text { Site mean } \\
\text { inclination }\left({ }^{\circ}\right)\end{array}$ & -60.7 & & & -61.4 & & & \\
\hline
\end{tabular}




\begin{tabular}{|l|c|l|l|l|l|l|}
\hline Site & WS87 & & WS89 & & \\
\hline $\begin{array}{l}\text { a95 (95\% } \\
\text { confidence } \\
\text { interval) }\end{array}$ & 10 & & & 10.6 & & \\
\hline Polarity & $\mathrm{N}$ & & & $\mathrm{R}$ & & \\
\hline
\end{tabular}




\section{Appendix E}

Individual zircon fission-track data are displayed in the table below (counted and calculated by Diane Seward). From left to right: Ns and Ni are counted spontaneous and induced fission tracks respectively, $\mathrm{A}$ is area, RhoS and Rhol are spontaneous and

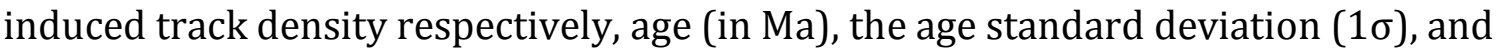
Uranium content (ppm).

Appendix E Table 1: Individual zircon crystal fission-track data

Eagle Hill 1.zir $\quad * \star *$ TRACKKEY DATAPRINT *** 11 Jun. 14

Eagle Hill EH1 Magnaweka Mudston

16 Zircon crystals Sum. Ns: 114 Sum. Ni: 799

Zeta: $120+-5$ Micr. grid.: 100

Glass: CN_1 Irrad. code: VUW021 RhoD: 3.186 Nd: 2383

Cryst Ns $\mathrm{Ni}$ A RhoS Rhol Age +- 1s Uran.

$\begin{array}{rrrlrrrrr}1 & 5 & 33 & 24 & 2.083 & 13.750 & 2.90 & 1.40 & 136.898 \\ 2 & 5 & 26 & 24 & 2.083 & 10.833 & 3.68 & 1.80 & 107.859 \\ 3 & 6 & 50 & 18 & 3.333 & 27.778 & 2.29 & 1.00 & 276.562 \\ 4 & 8 & 74 & 14 & 5.714 & 52.857 & 2.07 & .77 & 526.259 \\ 5 & 2 & 19 & 4 & 5.000 & 47.500 & 2.01 & 1.50 & 472.922 \\ 6 & 10 & 80 & 30 & 3.333 & 26.667 & 2.39 & .81 & 265.500 \\ 7 & 2 & 23 & 6 & 3.333 & 38.333 & 1.66 & 1.23 & 381.656 \\ 8 & 10 & 87 & 16 & 6.250 & 54.375 & 2.20 & .74 & 541.371 \\ 9 & 9 & 64 & 12 & 7.500 & 53.333 & 2.69 & .96 & 531.000 \\ 10 & 5 & 37 & 12 & 4.167 & 30.833 & 2.58 & 1.24 & 306.984 \\ 11 & 8 & 69 & 25 & 3.200 & 27.600 & 2.22 & .83 & 274.792 \\ 12 & 11 & 57 & 70 & 1.571 & 8.143 & 3.69 & 1.23 & 81.072 \\ 13 & 14 & 58 & 20 & 7.000 & 29.000 & 4.61 & 1.39 & 288.731 \\ 14 & 5 & 30 & 16 & 3.125 & 18.750 & 3.19 & 1.55 & 186.680 \\ 15 & 11 & 78 & 20 & 5.500 & 39.000 & 2.70 & .88 & 388.294 \\ 16 & 3 & 14 & 10 & 3.000 & 14.000 & 4.09 & 2.61 & 139.387\end{array}$


The table below lists the major element data collected by Juliet Sefton and Brent Alloway (data recalculated by Brent Alloway).

Tephra sample localities are listed in the table 2 below. The stratigraphic depths are from the top contact of the Mangaweka Mudstone from the Rangitikei River (Journeaux et al., 1996) and Tiriraukawa (see also Chapter 4 and Appendix A).

Appendix E Table 2: Tephra locality and stratigraphic positions.

\begin{tabular}{|l|c|c|c|c|}
\hline & Tephra name & Latitude & Longitude & $\begin{array}{c}\text { Stratigraphic } \\
\text { depth (m) }\end{array}$ \\
\hline $\begin{array}{l}\text { Rangitikei River } \\
\text { (Journeaux et al., } \\
1996 \text { stratigraphy) }\end{array}$ & Eagle Hill & -39.8131 & 175.8202 & 270 \\
\hline & Kowhai & -39.8124 & 175.8238 & 567 \\
\hline $\begin{array}{l}\text { Tiriraukawa section } \\
\text { (this study) }\end{array}$ & Tiri Tephra-2 & -39.7723 & 175.6754 & 562 \\
\hline & Tiri Tephra-1 & -39.7726 & 175.6755 & 5 \\
\hline
\end{tabular}

\section{Appendix E Table 3: Major element data from tephra glass shards}

\begin{tabular}{|c|c|c|c|c|c|c|c|c|c|c|c|c|c|}
\hline & $\begin{array}{c}\text { Probe } \\
\text { mount and } \\
\text { number of } \\
\text { analyses }\end{array}$ & $\mathrm{SiO}_{2}$ & $\mathrm{Al}_{2} \mathrm{O}_{3}$ & $\mathrm{TiO}_{2}$ & $\mathrm{FeO}$ & MgO & Mno & $\mathrm{CaO}$ & $\mathrm{Na}_{2} \mathrm{O}$ & $\mathrm{K}_{2} \mathrm{O}$ & $\mathrm{Cl}$ & Total & $\mathrm{H}_{2} \mathrm{O}$ \\
\hline \multirow[t]{21}{*}{ Tiri Tephra-1 } & 14J1_4_1 & 77.803 & 12.824 & 0.085 & 1.407 & 0.000 & 0.013 & 0.872 & 3.430 & 3.379 & 0.186 & 100 & 6.260 \\
\hline & 14J1_4_2 & 77.766 & 12.720 & 0.101 & 1.332 & 0.028 & 0.018 & 0.865 & 3.482 & 3.532 & 0.155 & 100 & 5.898 \\
\hline & 14J1_4_3 & 77.928 & 12.879 & 0.100 & 1.345 & 0.119 & 0.051 & 0.874 & 3.115 & 3.389 & 0.201 & 100 & 7.281 \\
\hline & 14J1_4_4 & 77.817 & 12.694 & 0.093 & 1.383 & 0.050 & 0.033 & 0.857 & 3.355 & 3.536 & 0.182 & 100 & 6.165 \\
\hline & 14J1_4_5 & 77.556 & 12.694 & 0.142 & 1.295 & 0.000 & 0.000 & 0.901 & 3.750 & 3.495 & 0.168 & 100 & 5.819 \\
\hline & 14J1_4_6 & 75.231 & 12.505 & 0.088 & 1.284 & 0.184 & 0.038 & 0.887 & 5.680 & 3.907 & 0.197 & 100 & 2.933 \\
\hline & 14J1_4_7 & 76.419 & 12.413 & 0.085 & 1.411 & 0.000 & 0.040 & 0.914 & 4.493 & 4.043 & 0.183 & 100 & 4.842 \\
\hline & 14J1_4_8 & 75.727 & 12.571 & 0.089 & 1.270 & 0.083 & 0.053 & 0.899 & 5.012 & 4.108 & 0.189 & 100 & 4.800 \\
\hline & 14J1_4_9 & 75.550 & 12.489 & 0.060 & 1.322 & 0.099 & 0.047 & 0.936 & 5.247 & 4.062 & 0.189 & 100 & 4.082 \\
\hline & 14J1_4_10 & 75.710 & 12.677 & 0.066 & 1.322 & 0.088 & 0.013 & 0.879 & 4.915 & 4.155 & 0.175 & 100 & 5.007 \\
\hline & 14J1_4_11 & 76.281 & 12.505 & 0.092 & 1.435 & 0.158 & 0.035 & 0.899 & 4.372 & 4.034 & 0.189 & 100 & 6.706 \\
\hline & 14J1_4_12 & 75.615 & 12.485 & 0.095 & 1.396 & 0.147 & 0.036 & 0.844 & 5.071 & 4.126 & 0.183 & 100 & 3.866 \\
\hline & 14J1_4_13 & 75.786 & 12.475 & 0.106 & 1.377 & 0.049 & 0.023 & 0.864 & 5.153 & 3.997 & 0.170 & 100 & 3.659 \\
\hline & 14J1_4_14 & 75.655 & 12.567 & 0.100 & 1.258 & 0.033 & 0.039 & 0.878 & 5.214 & 4.079 & 0.178 & 100 & 4.108 \\
\hline & 14J1_4_15 & 76.309 & 12.611 & 0.080 & 1.352 & 0.000 & 0.033 & 0.864 & 4.760 & 3.826 & 0.166 & 100 & 4.166 \\
\hline & 14J1_4_16 & 76.213 & 12.597 & 0.093 & 1.304 & 0.137 & 0.065 & 0.846 & 4.597 & 3.987 & 0.162 & 100 & 3.943 \\
\hline & 14J1_4_17 & 75.985 & 12.594 & 0.111 & 1.188 & 0.077 & 0.008 & 0.877 & 4.920 & 4.049 & 0.193 & 100 & 3.950 \\
\hline & 14J1_4_19 & 76.493 & 12.626 & 0.094 & 1.345 & 0.122 & 0.035 & 0.904 & 4.403 & 3.782 & 0.196 & 100 & 5.100 \\
\hline & 14J1_4_20 & 76.061 & 12.538 & 0.069 & 1.375 & 0.146 & 0.011 & 0.887 & 4.683 & 4.058 & 0.172 & 100 & 3.141 \\
\hline & Average & 76.416 & 12.603 & 0.092 & 1.337 & 0.080 & 0.031 & 0.881 & 4.508 & 3.871 & 0.181 & 100 & 4.828 \\
\hline & $1 \sigma$ & 0.895 & 0.122 & 0.018 & 0.062 & 0.060 & 0.017 & 0.023 & 0.743 & 0.267 & 0.013 & 100 & 1.234 \\
\hline
\end{tabular}




\begin{tabular}{|c|c|c|c|c|c|c|c|c|c|c|c|c|c|}
\hline & $\begin{array}{c}\text { Probe } \\
\text { mount and } \\
\text { number of } \\
\text { analyses }\end{array}$ & $\mathrm{SiO}_{2}$ & $\mathrm{Al}_{2} \mathrm{O}_{3}$ & $\mathrm{TiO}_{2}$ & $\mathrm{FeO}$ & MgO & Mno & $\mathrm{CaO}$ & $\mathrm{Na}_{2} \mathrm{O}$ & $\mathrm{K}_{2} \mathrm{O}$ & $\mathrm{Cl}$ & Total & $\mathrm{H}_{2} \mathrm{O}$ \\
\hline \multirow[t]{22}{*}{ Tiri Tephra-2 } & 14J1_5_1 & 74.316 & 14.259 & 0.407 & 2.801 & 0.502 & 0.032 & 2.213 & 2.826 & 2.510 & 0.135 & 100 & 5.806 \\
\hline & 14J1_5_2 & 74.515 & 14.502 & 0.409 & 2.656 & 0.536 & 0.051 & 2.239 & 2.593 & 2.353 & 0.147 & 100 & 6.968 \\
\hline & 14J1_5_3 & 74.440 & 14.097 & 0.424 & 2.924 & 0.319 & 0.054 & 2.207 & 2.861 & 2.536 & 0.138 & 100 & 7.820 \\
\hline & 14J1_5_4 & 74.331 & 14.223 & 0.399 & 2.882 & 0.468 & 0.052 & 2.232 & 2.780 & 2.444 & 0.189 & 100 & 6.916 \\
\hline & 14J1_5_5 & 73.943 & 14.289 & 0.392 & 2.757 & 0.367 & 0.040 & 2.069 & 3.258 & 2.746 & 0.140 & 100 & 5.514 \\
\hline & 14J1_5_6 & 73.712 & 14.260 & 0.428 & 2.730 & 0.345 & 0.045 & 2.258 & 3.479 & 2.579 & 0.164 & 100 & 5.669 \\
\hline & 14J1_5_7 & 74.277 & 14.388 & 0.400 & 2.806 & 0.336 & 0.063 & 2.326 & 2.709 & 2.548 & 0.146 & 100 & 6.277 \\
\hline & 14J1_5_8 & 73.377 & 14.337 & 0.424 & 2.873 & 0.503 & 0.064 & 2.293 & 3.370 & 2.602 & 0.157 & 100 & 6.162 \\
\hline & 14J1_5_9 & 74.669 & 14.402 & 0.408 & 2.819 & 0.389 & 0.077 & 2.139 & 2.507 & 2.439 & 0.151 & 100 & 8.359 \\
\hline & 14J1_5_10 & 73.942 & 14.024 & 0.427 & 2.733 & 0.362 & 0.076 & 2.224 & 3.391 & 2.652 & 0.168 & 100 & 5.759 \\
\hline & 14J1_5_11 & 74.184 & 14.235 & 0.409 & 2.684 & 0.278 & 0.074 & 2.291 & 3.186 & 2.489 & 0.170 & 100 & 5.712 \\
\hline & 14J1_5_12 & 74.125 & 14.308 & 0.409 & 2.754 & 0.386 & 0.058 & 2.315 & 2.952 & 2.537 & 0.156 & 100 & 7.559 \\
\hline & 14J1_5_13 & 74.423 & 14.372 & 0.419 & 2.728 & 0.387 & 0.079 & 2.160 & 2.891 & 2.393 & 0.148 & 100 & 6.352 \\
\hline & 14J1_5_14 & 73.304 & 13.990 & 0.413 & 2.719 & 0.400 & 0.021 & 2.235 & 3.997 & 2.752 & 0.168 & 100 & 4.128 \\
\hline & 14J1_5_15 & 74.245 & 14.233 & 0.427 & 2.691 & 0.368 & 0.053 & 2.115 & 3.141 & 2.597 & 0.130 & 100 & 5.866 \\
\hline & 14J1_5_16 & 74.502 & 14.386 & 0.389 & 2.684 & 0.467 & 0.055 & 2.253 & 2.611 & 2.496 & 0.156 & 100 & 7.772 \\
\hline & 14J1_5_17 & 74.329 & 14.282 & 0.411 & 2.768 & 0.428 & 0.050 & 2.544 & 2.319 & 2.715 & 0.153 & 100 & 6.813 \\
\hline & 14J1_5_18 & 74.480 & 14.280 & 0.419 & 2.847 & 0.353 & 0.091 & 2.293 & 2.600 & 2.441 & 0.197 & 100 & 7.696 \\
\hline & 14J1_5_19 & 74.228 & 14.105 & 0.422 & 2.918 & 0.433 & 0.062 & 2.261 & 2.916 & 2.495 & 0.159 & 100 & 6.685 \\
\hline & 14J1_5_20 & 74.991 & 14.287 & 0.394 & 2.897 & 0.339 & 0.057 & 2.231 & 2.187 & 2.470 & 0.148 & 100 & 7.170 \\
\hline & Average & 74.217 & 14.263 & 0.412 & 2.784 & 0.398 & 0.058 & 2.245 & 2.929 & 2.540 & 0.156 & 100 & 6.550 \\
\hline & $1 \sigma$ & 0.406 & 0.129 & 0.012 & 0.084 & 0.068 & 0.017 & 0.097 & 0.434 & 0.112 & 0.017 & & 1.021 \\
\hline \multirow[t]{19}{*}{ Eagle Hill } & 10-06_3_1 & 75.566 & 14.523 & 0.388 & 2.701 & 0.406 & 0.057 & 2.329 & 1.512 & 2.375 & 0.142 & 100 & 5.707 \\
\hline & 10-06_3_2 & 74.750 & 14.108 & 0.402 & 2.849 & 0.404 & 0.064 & 2.324 & 2.425 & 2.487 & 0.188 & 100 & 6.339 \\
\hline & 10-06_3_3 & 74.221 & 14.208 & 0.407 & 2.759 & 0.382 & 0.067 & 2.296 & 3.205 & 2.287 & 0.167 & 100 & 6.635 \\
\hline & 10-06_3_4 & 75.348 & 14.305 & 0.425 & 2.856 & 0.363 & 0.072 & 2.266 & 1.630 & 2.587 & 0.149 & 100 & 7.441 \\
\hline & 10-06_3_5 & 75.551 & 14.313 & 0.395 & 2.942 & 0.290 & 0.048 & 2.309 & 1.750 & 2.195 & 0.205 & 100 & 11.320 \\
\hline & 10-06_3_6 & 74.919 & 14.337 & 0.398 & 2.910 & 0.425 & 0.038 & 2.193 & 2.136 & 2.500 & 0.145 & 100 & 7.412 \\
\hline & 10-06_3_8 & 74.997 & 14.179 & 0.387 & 2.936 & 0.346 & 0.070 & 2.290 & 2.169 & 2.464 & 0.161 & 100 & 7.420 \\
\hline & 10-06_3_9 & 74.723 & 14.057 & 0.396 & 2.898 & 0.463 & 0.057 & 2.264 & 2.472 & 2.517 & 0.153 & 100 & 7.063 \\
\hline & 10-06_3_10 & 73.695 & 14.117 & 0.384 & 2.829 & 0.365 & 0.026 & 2.201 & 3.992 & 2.230 & 0.160 & 100 & 5.193 \\
\hline & 10-06_3_11 & 74.075 & 14.064 & 0.426 & 2.723 & 0.204 & 0.033 & 2.059 & 3.491 & 2.775 & 0.151 & 100 & 4.667 \\
\hline & 10-06_3_12 & 74.753 & 14.075 & 0.388 & 2.930 & 0.467 & 0.066 & 2.235 & 2.474 & 2.481 & 0.130 & 100 & 5.581 \\
\hline & 10-06_3_13 & 74.167 & 14.260 & 0.398 & 2.709 & 0.370 & 0.041 & 2.189 & 3.061 & 2.646 & 0.159 & 100 & 4.996 \\
\hline & 10-06_3_14 & 74.873 & 14.254 & 0.410 & 2.752 & 0.374 & 0.052 & 2.138 & 3.115 & 1.873 & 0.159 & 100 & 7.280 \\
\hline & 10-06_3_15 & 74.696 & 14.047 & 0.388 & 2.738 & 0.372 & 0.062 & 2.308 & 2.851 & 2.399 & 0.139 & 100 & 5.583 \\
\hline & 10-06_3_16 & 74.603 & 14.193 & 0.431 & 2.878 & 0.297 & 0.042 & 2.234 & 2.647 & 2.523 & 0.153 & 100 & 6.230 \\
\hline & 10-06_3_18 & 74.330 & 14.163 & 0.424 & 2.786 & 0.483 & 0.038 & 2.231 & 2.931 & 2.485 & 0.128 & 100 & 5.487 \\
\hline & 10-06_3_20 & 75.325 & 14.206 & 0.390 & 3.141 & 0.295 & 0.066 & 2.282 & 1.823 & 2.349 & 0.123 & 100 & 9.171 \\
\hline & Average & 74.741 & 14.201 & 0.402 & 2.843 & 0.371 & 0.053 & 2.244 & 2.570 & 2.422 & 0.154 & 100 & 6.678 \\
\hline & $1 \sigma$ & 0.530 & 0.125 & 0.016 & 0.113 & 0.072 & 0.014 & 0.072 & 0.691 & 0.203 & 0.021 & & 1.660 \\
\hline \multirow[t]{6}{*}{ Kowhai } & 10_06_4_1 & 78.293 & 12.701 & 0.108 & 1.289 & 0.093 & 0.026 & 0.865 & 3.416 & 3.030 & 0.178 & 100 & 4.476 \\
\hline & 10_06_4_2 & 77.391 & 12.474 & 0.098 & 1.359 & 0.071 & 0.049 & 0.878 & 3.903 & 3.603 & 0.174 & 100 & 3.621 \\
\hline & 10_06_4_3 & 76.834 & 12.624 & 0.090 & 1.337 & 0.155 & 0.029 & 0.885 & 4.127 & 3.739 & 0.181 & 100 & 1.854 \\
\hline & 10_06_4_4 & 78.255 & 12.659 & 0.091 & 1.231 & 0.038 & 0.026 & 0.902 & 3.215 & 3.407 & 0.176 & 100 & 3.283 \\
\hline & 10_06_4_5 & 77.895 & 12.776 & 0.126 & 1.328 & 0.103 & 0.023 & 0.940 & 3.365 & 3.256 & 0.189 & 100 & 3.465 \\
\hline & 10_06_4_6 & 77.123 & 12.529 & 0.077 & 1.458 & 0.091 & 0.030 & 0.911 & 4.006 & 3.612 & 0.163 & 100 & 2.278 \\
\hline
\end{tabular}




\begin{tabular}{|c|c|c|c|c|c|c|c|c|c|c|c|c|c|}
\hline & $\begin{array}{c}\text { Probe } \\
\text { mount and } \\
\text { number of } \\
\text { analyses }\end{array}$ & $\mathrm{SiO}_{2}$ & $\mathrm{Al}_{2} \mathrm{O}_{3}$ & $\mathrm{TiO}_{2}$ & $\mathrm{FeO}$ & MgO & Mno & $\mathrm{CaO}$ & $\mathrm{Na}_{2} \mathrm{O}$ & $\mathrm{K}_{2} \mathrm{O}$ & $\mathrm{Cl}$ & Total & $\mathrm{H}_{2} \mathrm{O}$ \\
\hline \multirow[t]{16}{*}{ Kowhai } & 10_06_4_7 & 77.827 & 12.617 & 0.075 & 1.313 & 0.017 & 0.034 & 0.892 & 3.596 & 3.456 & 0.176 & 100 & 4.953 \\
\hline & 10_06_4_8 & 78.017 & 12.693 & 0.092 & 1.349 & 0.175 & 0.042 & 0.899 & 3.269 & 3.282 & 0.182 & 100 & 3.943 \\
\hline & 10_06_4_9 & 76.717 & 12.962 & 0.116 & 1.439 & 0.081 & 0.023 & 1.025 & 4.208 & 3.273 & 0.156 & 100 & 2.524 \\
\hline & 10_06_4_10 & 77.788 & 13.140 & 0.131 & 1.569 & 0.244 & 0.036 & 1.083 & 2.833 & 3.007 & 0.168 & 100 & 5.376 \\
\hline & 10_06_4_11 & 77.861 & 12.477 & 0.092 & 1.446 & 0.055 & 0.027 & 0.901 & 3.693 & 3.253 & 0.194 & 100 & 3.848 \\
\hline & 10_06_4_12 & 76.522 & 13.077 & 0.158 & 1.537 & 0.054 & 0.001 & 1.252 & 3.750 & 3.458 & 0.190 & 100 & 3.377 \\
\hline & 10_06_4_13 & 78.392 & 12.619 & 0.117 & 1.357 & 0.038 & 0.038 & 0.828 & 3.163 & 3.269 & 0.180 & 100 & 4.290 \\
\hline & 10_06_4_14 & 78.603 & 12.696 & 0.083 & 1.335 & 0.022 & 0.027 & 0.947 & 3.028 & 3.074 & 0.185 & 100 & 4.786 \\
\hline & 10_06_4_15 & 77.957 & 12.456 & 0.092 & 1.464 & 0.000 & 0.031 & 0.895 & 3.645 & 3.291 & 0.168 & 100 & 4.209 \\
\hline & 10_06_4_16 & 78.082 & 12.601 & 0.097 & 1.228 & 0.044 & 0.027 & 0.908 & 3.531 & 3.299 & 0.182 & 100 & 4.765 \\
\hline & 10_06_4_17 & 77.432 & 12.495 & 0.102 & 1.358 & 0.000 & 0.039 & 0.913 & 3.955 & 3.521 & 0.185 & 100 & 3.938 \\
\hline & 10_06_4_18 & 78.097 & 12.634 & 0.108 & 1.412 & 0.071 & 0.006 & 0.834 & 3.484 & 3.180 & 0.173 & 100 & 4.386 \\
\hline & 10_06_4_19 & 78.151 & 12.675 & 0.080 & 1.323 & 0.176 & 0.027 & 0.831 & 3.335 & 3.218 & 0.183 & 100 & 4.700 \\
\hline & 10_06_4_20 & 78.109 & 12.483 & 0.098 & 1.343 & 0.098 & 0.016 & 0.892 & 3.389 & 3.406 & 0.167 & 100 & 4.036 \\
\hline & Average & 77.767 & 12.669 & 0.102 & 1.374 & 0.081 & 0.028 & 0.924 & 3.546 & 3.332 & 0.177 & 100 & 3.905 \\
\hline & $1 \sigma$ & 0.580 & 0.193 & 0.020 & 0.090 & 0.064 & 0.011 & 0.098 & 0.369 & 0.195 & 0.010 & & 0.916 \\
\hline
\end{tabular}

The table below lists the trace element data, collected and recalculated by Brent

Alloway.

Appendix E Table 4: Trace element data from tephra glass shards

\begin{tabular}{|l|c|c|c|c|c|c|c|c|}
\hline & $\mathbf{R b}$ & $\mathbf{S r}$ & $\mathbf{Y}$ & $\mathbf{Z r}$ & $\mathbf{N b}$ & $\mathbf{C s}$ & $\mathbf{B a}$ & La \\
\hline Tiri Tephra-1 & 143.813 & 79.364 & 34.718 & 146.859 & 9.540 & 4.741 & 1086.565 & 28.123 \\
\hline & 148.613 & 94.980 & 43.343 & 183.399 & 8.969 & 7.423 & 1178.304 & 41.373 \\
\hline & 145.330 & 77.539 & 33.531 & 157.781 & 8.320 & 5.650 & 1015.613 & 30.339 \\
\hline & 158.859 & 71.294 & 37.452 & 127.876 & 7.963 & 5.705 & 1006.607 & 30.504 \\
\hline & 154.806 & 71.543 & 35.851 & 125.854 & 8.056 & 6.086 & 1048.763 & 28.631 \\
\hline & 144.294 & 94.429 & 36.829 & 224.695 & 9.484 & 5.976 & 1016.630 & 31.265 \\
\hline & 162.002 & 80.043 & 39.585 & 170.502 & 9.067 & 5.994 & 1153.322 & 36.077 \\
\hline & 146.401 & 66.548 & 32.203 & 128.195 & 8.241 & 6.349 & 995.670 & 28.449 \\
\hline & 152.133 & 67.462 & 34.923 & 127.064 & 9.188 & 6.674 & 1048.854 & 31.738 \\
\hline & 148.686 & 67.620 & 35.431 & 130.400 & 9.458 & 6.389 & 1045.979 & 31.279 \\
\hline & 149.148 & 68.692 & 36.767 & 125.555 & 9.043 & 5.767 & 1088.448 & 30.935 \\
\hline & 152.175 & 69.593 & 33.908 & 133.627 & 8.616 & 5.697 & 1030.340 & 29.398 \\
\hline & 152.525 & 126.843 & 43.990 & 130.421 & 8.783 & 6.104 & 1082.885 & 39.745 \\
\hline & 179.829 & 81.722 & 31.621 & 125.556 & 9.223 & 7.677 & 1018.740 & 29.466 \\
\hline & 162.514 & 75.249 & 37.217 & 128.469 & 8.706 & 6.687 & 1081.146 & 29.171 \\
\hline & 150.074 & 80.743 & 41.145 & 145.104 & 9.602 & 6.445 & 1177.232 & 35.267 \\
\hline & 131.264 & 117.849 & 42.103 & 165.236 & 8.043 & 6.349 & 1231.827 & 46.780 \\
\hline & 149.841 & 95.201 & 39.261 & 133.156 & 7.254 & 6.632 & 1145.792 & 31.352 \\
\hline & 146.806 & 71.009 & 32.538 & 122.485 & 9.198 & 6.205 & 990.311 & 27.486 \\
\hline & 158.768 & 81.404 & 38.651 & 142.620 & 9.157 & 5.891 & 1161.944 & 35.668 \\
\hline
\end{tabular}




\begin{tabular}{|c|c|c|c|c|c|c|c|c|}
\hline & $\mathbf{R b}$ & $\mathrm{Sr}$ & $\mathbf{Y}$ & $\mathrm{Zr}$ & $\mathrm{Nb}$ & Cs & $\mathrm{Ba}$ & La \\
\hline Tiri Tephra-1 & 158.679 & 77.359 & 38.710 & 133.081 & 9.606 & 7.318 & 1142.192 & 33.783 \\
\hline Average & 152.217 & 81.737 & 37.132 & 143.235 & 8.834 & 6.274 & 1083.198 & 32.706 \\
\hline $1 \sigma$ & 9.330 & 15.773 & 3.495 & 24.524 & 0.628 & 0.652 & 69.142 & 4.820 \\
\hline \multirow[t]{22}{*}{ Tiri Tephra-2 } & 118.261 & 159.463 & 32.480 & 253.987 & 9.200 & 5.399 & 831.529 & 26.642 \\
\hline & 126.023 & 137.020 & 34.324 & 265.644 & 9.299 & 5.352 & 905.698 & 25.020 \\
\hline & 123.993 & 179.119 & 36.244 & 277.201 & 9.921 & 5.502 & 922.580 & 28.147 \\
\hline & 131.891 & 162.520 & 32.216 & 250.759 & 9.631 & 5.846 & 813.733 & 24.508 \\
\hline & 126.203 & 156.636 & 32.369 & 262.452 & 9.664 & 5.780 & 853.943 & 27.237 \\
\hline & 131.461 & 165.099 & 36.374 & 252.675 & 10.286 & 5.946 & 862.052 & 26.377 \\
\hline & 129.797 & 149.158 & 31.145 & 245.155 & 8.449 & 5.542 & 776.638 & 22.397 \\
\hline & 129.717 & 156.407 & 31.147 & 238.411 & 8.467 & 5.975 & 779.272 & 24.534 \\
\hline & 133.858 & 164.225 & 33.563 & 240.412 & 8.902 & 6.261 & 834.156 & 25.163 \\
\hline & 131.180 & 167.396 & 34.017 & 274.266 & 10.684 & 5.789 & 926.667 & 29.170 \\
\hline & 129.493 & 161.625 & 34.156 & 262.062 & 8.847 & 6.090 & 812.559 & 24.967 \\
\hline & 132.103 & 160.813 & 34.547 & 269.206 & 9.250 & 5.730 & 840.356 & 28.725 \\
\hline & 125.850 & 173.990 & 33.790 & 280.134 & 9.318 & 5.025 & 868.094 & 27.396 \\
\hline & 125.605 & 165.677 & 38.517 & 272.488 & 9.587 & 5.449 & 820.389 & 25.658 \\
\hline & 136.120 & 164.104 & 31.663 & 249.818 & 9.292 & 5.634 & 792.314 & 23.718 \\
\hline & 120.196 & 160.184 & 33.719 & 254.547 & 9.226 & 5.711 & 839.524 & 25.967 \\
\hline & 122.115 & 165.596 & 33.498 & 265.036 & 8.467 & 5.468 & 797.778 & 24.648 \\
\hline & 177.866 & 49.885 & 32.882 & 200.576 & 9.142 & 5.624 & 889.908 & 26.797 \\
\hline & 190.585 & 45.234 & 36.928 & 191.205 & 10.748 & 5.284 & 879.033 & 27.507 \\
\hline & 103.193 & 138.750 & 28.605 & 218.033 & 7.917 & 4.521 & 705.911 & 21.794 \\
\hline & 123.708 & 175.218 & 34.629 & 278.354 & 9.905 & 5.094 & 888.994 & 27.112 \\
\hline & 178.119 & 202.797 & 39.002 & 312.296 & 10.279 & 7.366 & 1000.708 & 28.599 \\
\hline Average & 133.970 & 152.769 & 33.901 & 255.214 & 9.385 & 5.654 & 847.356 & 26.004 \\
\hline $1 \sigma$ & 20.396 & 35.727 & 2.394 & 26.272 & 0.716 & 0.529 & 61.364 & 1.930 \\
\hline \multirow[t]{14}{*}{ Eagle Hill } & 105.795 & 163.345 & 34.652 & 286.032 & 7.645 & 4.634 & 849.511 & 26.134 \\
\hline & 118.926 & 168.254 & 38.668 & 299.761 & 9.561 & 5.352 & 852.284 & 27.692 \\
\hline & 121.462 & 190.674 & 40.935 & 328.775 & 9.217 & 4.942 & 903.722 & 31.302 \\
\hline & 118.849 & 169.226 & 35.913 & 296.152 & 9.232 & 5.125 & 818.619 & 26.654 \\
\hline & 113.272 & 200.484 & 38.806 & 307.740 & 8.824 & 4.954 & 831.197 & 28.867 \\
\hline & 119.262 & 151.993 & 36.807 & 271.035 & 8.872 & 5.426 & 786.541 & 24.764 \\
\hline & 107.582 & 221.928 & 30.785 & 251.284 & 8.567 & 5.111 & 767.342 & 23.371 \\
\hline & 121.125 & 174.160 & 41.022 & 299.559 & 10.331 & 4.928 & 883.909 & 27.037 \\
\hline & 116.787 & 174.140 & 38.427 & 313.605 & 8.817 & 5.068 & 857.169 & 29.007 \\
\hline & 114.531 & 190.023 & 38.132 & 327.112 & 10.002 & 4.862 & 878.900 & 29.998 \\
\hline & 115.721 & 172.518 & 36.514 & 294.944 & 9.659 & 5.074 & 842.624 & 26.981 \\
\hline & 122.788 & 187.310 & 39.495 & 314.070 & 9.426 & 5.813 & 902.735 & 27.964 \\
\hline & 111.833 & 201.148 & 45.288 & 352.639 & 9.235 & 5.285 & 926.908 & 32.652 \\
\hline & 122.073 & 159.372 & 32.274 & 254.594 & 8.069 & 5.698 & 872.838 & 23.970 \\
\hline
\end{tabular}




\begin{tabular}{|c|c|c|c|c|c|c|c|c|}
\hline & $\mathbf{R b}$ & Sr & $\mathbf{Y}$ & $\mathrm{Zr}$ & Nb & Cs & $\mathrm{Ba}$ & La \\
\hline \multirow[t]{7}{*}{ Eagle Hill } & 119.839 & 166.156 & 34.796 & 271.805 & 9.029 & 5.046 & 796.623 & 25.979 \\
\hline & 122.738 & 170.481 & 37.010 & 288.810 & 9.305 & 5.458 & 819.780 & 27.163 \\
\hline & 125.329 & 161.548 & 36.172 & 290.534 & 9.751 & 5.658 & 805.270 & 28.387 \\
\hline & 122.274 & 186.181 & 40.611 & 306.109 & 9.399 & 5.484 & 907.463 & 32.054 \\
\hline & 117.012 & 202.562 & 43.407 & 335.507 & 10.865 & 5.591 & 901.774 & 29.075 \\
\hline & 116.449 & 192.178 & 41.502 & 321.605 & 9.791 & 5.248 & 927.705 & 31.345 \\
\hline & 105.788 & 180.977 & 36.742 & 284.524 & 8.831 & 5.264 & 769.099 & 25.708 \\
\hline Average & 117.116 & 180.222 & 37.998 & 299.819 & 9.258 & 5.239 & 852.477 & 27.910 \\
\hline $1 \sigma$ & 5.499 & 17.011 & 3.401 & 25.166 & 0.703 & 0.300 & 49.086 & 2.513 \\
\hline \multirow[t]{22}{*}{ Kowhai } & 143.356 & 88.040 & 33.122 & 210.473 & 10.057 & 6.320 & 979.329 & 30.004 \\
\hline & 158.262 & 85.350 & 45.182 & 183.735 & 11.130 & 6.830 & 1286.205 & 40.841 \\
\hline & 146.838 & 78.002 & 41.083 & 162.308 & 9.220 & 5.717 & 1144.953 & 37.043 \\
\hline & 145.066 & 117.641 & 34.420 & 129.222 & 9.131 & 6.333 & 962.533 & 30.528 \\
\hline & 141.418 & 98.355 & 40.773 & 236.854 & 11.260 & 5.644 & 1078.080 & 33.952 \\
\hline & 151.976 & 76.939 & 36.573 & 169.569 & 10.161 & 6.083 & 1049.333 & 34.261 \\
\hline & 149.124 & 76.865 & 39.849 & 173.483 & 9.172 & 5.770 & 993.683 & 32.936 \\
\hline & 136.174 & 94.994 & 40.086 & 192.957 & 10.601 & 6.306 & 1082.817 & 34.565 \\
\hline & 161.712 & 80.853 & 41.674 & 197.672 & 10.205 & 5.975 & 1104.716 & 35.077 \\
\hline & 160.652 & 70.918 & 39.691 & 141.346 & 9.761 & 6.649 & 1031.626 & 31.609 \\
\hline & 151.756 & 66.806 & 36.998 & 134.626 & 8.447 & 6.135 & 997.119 & 33.069 \\
\hline & 149.621 & 100.628 & 40.448 & 152.171 & 9.900 & 6.472 & 1106.760 & 37.363 \\
\hline & 150.527 & 64.713 & 34.414 & 135.895 & 9.388 & 6.238 & 957.590 & 29.640 \\
\hline & 151.479 & 78.445 & 41.358 & 151.687 & 8.669 & 6.278 & 1088.854 & 35.755 \\
\hline & 157.440 & 62.426 & 30.660 & 136.788 & 8.809 & 5.842 & 861.264 & 28.249 \\
\hline & 161.961 & 77.840 & 38.495 & 146.372 & 9.791 & 6.650 & 1039.044 & 34.447 \\
\hline & 157.979 & 74.097 & 39.146 & 160.096 & 10.481 & 6.989 & 1052.668 & 35.247 \\
\hline & 157.813 & 67.502 & 33.849 & 126.920 & 8.576 & 6.709 & 985.870 & 30.242 \\
\hline & 159.159 & 72.796 & 37.154 & 143.583 & 9.164 & 6.110 & 1041.638 & 34.047 \\
\hline & 153.367 & 70.144 & 35.453 & 146.312 & 9.042 & 6.473 & 997.492 & 33.519 \\
\hline & 149.181 & 63.062 & 34.228 & 127.416 & 9.117 & 5.802 & 954.312 & 30.690 \\
\hline & 150.630 & 60.393 & 31.911 & 119.840 & 8.628 & 5.943 & 897.566 & 27.285 \\
\hline Average & 152.068 & 78.491 & 37.571 & 158.151 & 9.578 & 6.239 & 1031.521 & 33.199 \\
\hline $1 \sigma$ & 6.735 & 13.962 & 3.629 & 29.640 & 0.799 & 0.370 & 87.765 & 3.147 \\
\hline
\end{tabular}

\begin{tabular}{|l|c|c|c|c|c|c|c|}
\hline & Ce & Pr & Nd & Sm & Eu & Gd & Tb \\
\hline Tiri Tephra-1 & 63.797 & 7.723 & 32.306 & 5.060 & 0.827 & 7.875 & 0.932 \\
\hline & 73.604 & 8.092 & 39.402 & 11.267 & 1.290 & 8.868 & 1.215 \\
\hline & 62.642 & 6.791 & 28.168 & 9.004 & 0.767 & 2.797 & 0.968 \\
\hline & 62.413 & 7.513 & 25.951 & 6.499 & 1.081 & 6.782 & 0.802 \\
\hline & 60.858 & 7.679 & 25.836 & 6.725 & 0.845 & 5.259 & 0.664 \\
\hline & 61.705 & 7.049 & 26.950 & 6.045 & 0.863 & 7.185 & 1.235 \\
\hline
\end{tabular}




\begin{tabular}{|c|c|c|c|c|c|c|c|}
\hline & $\mathrm{Ce}$ & $\mathrm{Pr}$ & Nd & Sm & $\mathrm{Eu}$ & Gd & Tb \\
\hline \multirow[t]{15}{*}{ Tiri Tepha-1 } & 64.986 & 7.598 & 28.648 & 7.235 & 1.088 & 5.698 & 1.268 \\
\hline & 59.008 & 7.060 & 25.724 & 7.627 & 0.523 & 8.206 & 1.054 \\
\hline & 67.332 & 7.315 & 27.560 & 4.634 & 1.013 & 5.338 & 0.937 \\
\hline & 61.642 & 7.431 & 29.627 & 5.890 & 0.789 & 6.035 & 0.749 \\
\hline & 64.322 & 6.916 & 31.029 & 9.344 & 0.706 & 3.780 & 1.036 \\
\hline & 60.798 & 6.921 & 29.031 & 6.022 & 0.789 & 5.415 & 0.834 \\
\hline & 70.585 & 10.040 & 41.205 & 7.964 & 0.925 & 6.153 & 1.085 \\
\hline & 61.006 & 7.411 & 30.580 & 5.354 & 0.538 & 6.953 & 0.757 \\
\hline & 65.125 & 6.250 & 30.688 & 6.719 & 0.343 & 7.535 & 1.214 \\
\hline & 68.779 & 8.182 & 36.159 & 5.011 & 0.809 & 10.025 & 1.019 \\
\hline & 80.329 & 9.949 & 38.136 & 9.017 & 1.719 & 10.148 & 0.863 \\
\hline & 70.963 & 8.031 & 28.904 & 8.351 & 0.684 & 8.412 & 1.132 \\
\hline & 61.019 & 6.138 & 29.156 & 3.763 & 0.908 & 9.134 & 1.105 \\
\hline & 71.941 & 7.032 & 31.728 & 6.076 & 0.653 & 5.274 & 1.285 \\
\hline & 68.415 & 7.721 & 36.401 & 7.158 & 1.302 & 7.841 & 1.136 \\
\hline Average & 65.775 & 7.564 & 31.104 & 6.894 & 0.879 & 6.891 & 1.014 \\
\hline $1 \sigma$ & 5.262 & 0.948 & 4.467 & 1.768 & 0.297 & 1.887 & 0.181 \\
\hline \multirow[t]{22}{*}{ Tiri Tephra-2 } & 51.933 & 6.472 & 23.735 & 12.108 & 0.752 & 6.469 & 0.902 \\
\hline & 56.897 & 5.983 & 25.211 & 7.209 & 0.563 & 8.453 & 0.864 \\
\hline & 60.362 & 6.179 & 27.141 & 7.449 & 0.980 & 5.936 & 0.927 \\
\hline & 53.978 & 6.354 & 25.879 & 5.748 & 1.197 & 5.035 & 0.856 \\
\hline & 55.523 & 6.344 & 25.813 & 7.196 & 1.148 & 5.937 & 1.058 \\
\hline & 57.001 & 6.810 & 25.559 & 6.440 & 0.984 & 4.864 & 0.966 \\
\hline & 53.245 & 5.757 & 27.284 & 4.261 & 1.244 & 4.854 & 1.094 \\
\hline & 54.366 & 5.427 & 28.102 & 5.715 & 0.774 & 4.486 & 0.683 \\
\hline & 54.878 & 6.078 & 22.887 & 4.296 & 1.269 & 6.709 & 0.908 \\
\hline & 57.167 & 5.911 & 26.778 & 4.470 & 1.055 & 4.571 & 0.871 \\
\hline & 54.448 & 5.798 & 25.528 & 6.738 & 0.934 & 11.025 & 0.760 \\
\hline & 56.454 & 6.184 & 24.481 & 6.380 & 1.028 & 4.582 & 1.053 \\
\hline & 57.479 & 6.300 & 26.160 & 6.727 & 1.078 & 5.242 & 0.882 \\
\hline & 54.068 & 6.307 & 23.323 & 6.904 & 1.069 & 6.857 & 0.810 \\
\hline & 53.623 & 6.790 & 20.560 & 7.335 & 0.468 & 6.345 & 1.087 \\
\hline & 52.953 & 6.167 & 29.540 & 6.129 & 1.061 & 6.466 & 0.838 \\
\hline & 53.747 & 6.065 & 24.974 & 6.806 & 1.311 & 5.876 & 1.062 \\
\hline & 56.065 & 6.048 & 23.005 & 5.319 & 0.471 & 6.482 & 0.850 \\
\hline & 56.549 & 6.132 & 27.662 & 6.936 & 0.925 & 6.127 & 1.123 \\
\hline & 45.304 & 6.150 & 16.809 & 3.457 & 1.000 & 5.629 & 0.646 \\
\hline & 53.970 & 6.570 & 26.794 & 5.510 & 1.372 & 4.449 & 0.863 \\
\hline & 56.205 & 7.875 & 32.101 & 6.300 & 1.055 & 6.012 & 1.542 \\
\hline Average & 54.828 & 6.259 & 25.424 & 6.338 & 0.988 & 6.018 & 0.938 \\
\hline $1 \sigma$ & 2.794 & 0.471 & 3.040 & 1.665 & 0.245 & 1.451 & 0.183 \\
\hline
\end{tabular}




\begin{tabular}{|c|c|c|c|c|c|c|c|}
\hline & $\mathrm{Ce}$ & $\mathrm{Pr}$ & Nd & Sm & Eu & Gd & $\mathrm{Tb}$ \\
\hline \multirow[t]{21}{*}{ Eagle Hill } & 49.640 & 6.224 & 28.953 & 4.697 & 0.958 & 5.022 & 0.939 \\
\hline & 54.543 & 7.354 & 28.911 & 5.764 & 1.331 & 7.727 & 0.968 \\
\hline & 59.636 & 6.802 & 28.674 & 5.354 & 1.195 & 7.733 & 1.509 \\
\hline & 52.680 & 6.529 & 27.335 & 6.144 & 0.793 & 7.126 & 0.991 \\
\hline & 57.961 & 6.979 & 28.483 & 7.082 & 0.807 & 5.043 & 0.978 \\
\hline & 50.234 & 5.881 & 22.757 & 4.866 & 1.008 & 7.231 & 0.919 \\
\hline & 52.242 & 6.082 & 27.755 & 6.631 & 0.793 & 7.363 & 0.918 \\
\hline & 61.410 & 6.856 & 32.297 & 7.300 & 1.051 & 5.731 & 1.381 \\
\hline & 56.270 & 6.790 & 29.415 & 6.392 & 0.983 & 7.246 & 0.705 \\
\hline & 59.745 & 7.200 & 26.700 & 5.571 & 1.676 & 8.183 & 1.272 \\
\hline & 56.606 & 6.885 & 28.782 & 5.278 & 1.033 & 7.137 & 0.975 \\
\hline & 60.381 & 7.076 & 31.052 & 5.473 & 1.073 & 5.141 & 1.059 \\
\hline & 62.547 & 7.045 & 30.161 & 10.043 & 1.256 & 10.152 & 1.076 \\
\hline & 51.468 & 6.313 & 27.600 & 7.326 & 0.679 & 6.959 & 0.916 \\
\hline & 52.344 & 6.103 & 26.873 & 6.390 & 1.014 & 3.610 & 0.905 \\
\hline & 52.234 & 6.110 & 25.365 & 5.358 & 0.990 & 7.194 & 0.892 \\
\hline & 54.439 & 6.653 & 26.633 & 5.433 & 1.392 & 7.465 & 1.000 \\
\hline & 60.411 & 6.675 & 36.455 & 7.213 & 1.473 & 7.710 & 1.110 \\
\hline & 57.059 & 7.594 & 32.329 & 3.675 & 1.706 & 8.334 & 0.742 \\
\hline & 63.007 & 8.055 & 29.063 & 4.834 & 1.391 & 8.103 & 1.006 \\
\hline & 47.410 & 5.414 & 23.684 & 6.362 & 0.696 & 4.091 & 1.164 \\
\hline Average & 55.822 & 6.696 & 28.537 & 6.056 & 1.109 & 6.871 & 1.020 \\
\hline $1 \sigma$ & 4.457 & 0.600 & 2.938 & 1.294 & 0.291 & 1.525 & 0.185 \\
\hline \multirow[t]{19}{*}{ Kowhai } & 64.350 & 7.287 & 27.158 & 6.417 & 1.128 & 6.652 & 1.072 \\
\hline & 78.189 & 9.350 & 33.338 & 6.875 & 0.996 & 8.894 & 0.919 \\
\hline & 70.158 & 7.150 & 29.615 & 9.121 & 0.844 & 7.146 & 1.416 \\
\hline & 60.120 & 6.029 & 27.615 & 6.677 & 0.514 & 6.674 & 0.871 \\
\hline & 70.366 & 7.842 & 35.745 & 6.692 & 1.109 & 6.221 & 1.155 \\
\hline & 66.537 & 7.762 & 30.904 & 6.817 & 0.454 & 7.831 & 0.963 \\
\hline & 63.591 & 7.481 & 33.746 & 6.273 & 1.010 & 8.265 & 0.930 \\
\hline & 68.146 & 7.946 & 33.775 & 6.503 & 1.137 & 7.765 & 0.914 \\
\hline & 67.531 & 7.533 & 33.611 & 6.455 & 0.692 & 7.048 & 1.314 \\
\hline & 68.774 & 7.411 & 30.546 & 7.319 & 0.854 & 4.839 & 0.923 \\
\hline & 67.618 & 7.488 & 30.962 & 6.111 & 0.263 & 5.619 & 1.209 \\
\hline & 70.669 & 8.274 & 29.302 & 8.330 & 1.229 & 8.790 & 1.427 \\
\hline & 62.854 & 7.061 & 27.706 & 4.354 & 0.599 & 4.611 & 1.303 \\
\hline & 64.043 & 7.061 & 29.909 & 5.637 & 0.569 & 9.106 & 0.964 \\
\hline & 59.742 & 6.460 & 22.115 & 5.668 & 1.124 & 4.526 & 0.721 \\
\hline & 67.475 & 7.987 & 27.997 & 7.205 & 0.735 & 3.367 & 0.852 \\
\hline & 68.420 & 7.011 & 31.457 & 6.928 & 0.855 & 7.670 & 1.385 \\
\hline & 64.227 & 6.990 & 26.891 & 6.784 & 0.514 & 5.857 & 0.936 \\
\hline & 65.862 & 7.253 & 31.525 & 8.377 & 0.837 & 4.546 & 0.962 \\
\hline
\end{tabular}




\begin{tabular}{|l|c|c|c|c|c|c|c|}
\hline & Ce & Pr & Nd & Sm & Eu & Gd & Tb \\
\hline Kowhai & 66.853 & 7.134 & 25.732 & 7.833 & 0.781 & 5.150 & 1.177 \\
\hline & 64.136 & 6.211 & 28.824 & 6.873 & 0.731 & 8.446 & 0.975 \\
\hline Average & 58.340 & 5.884 & 26.119 & 4.974 & 0.953 & 6.536 & 0.802 \\
\hline 10 & 6.273 & 7.300 & 29.754 & 6.737 & 0.815 & 6.616 & 1.054 \\
\hline
\end{tabular}

\begin{tabular}{|c|c|c|c|c|c|}
\hline & Dy & Ho & $\mathrm{Er}$ & $\mathrm{Tm}$ & $\mathrm{Yb}$ \\
\hline \multirow[t]{21}{*}{ Tiri Tephra-1 } & 7.847 & 1.265 & 4.528 & 0.878 & 3.047 \\
\hline & 7.303 & 1.424 & 5.184 & 0.575 & 6.302 \\
\hline & 4.377 & 1.457 & 4.028 & 0.457 & 4.119 \\
\hline & 6.176 & 1.828 & 4.209 & 0.702 & 2.840 \\
\hline & 5.480 & 1.095 & 3.070 & 0.756 & 3.133 \\
\hline & 6.268 & 1.425 & 3.715 & 0.568 & 4.978 \\
\hline & 7.218 & 1.675 & 3.706 & 0.598 & 5.132 \\
\hline & 6.571 & 0.966 & 4.439 & 0.487 & 4.204 \\
\hline & 6.808 & 1.049 & 3.164 & 0.821 & 3.716 \\
\hline & 6.075 & 0.785 & 3.273 & 0.628 & 4.167 \\
\hline & 5.684 & 1.541 & 4.923 & 0.650 & 2.808 \\
\hline & 5.842 & 1.548 & 2.753 & 0.647 & 3.822 \\
\hline & 7.741 & 1.273 & 4.965 & 1.134 & 3.798 \\
\hline & 4.739 & 1.343 & 4.704 & 2.158 & 3.607 \\
\hline & 7.583 & 1.429 & 5.090 & 0.448 & 2.988 \\
\hline & 7.124 & 1.752 & 3.950 & 0.356 & 3.725 \\
\hline & 10.217 & 1.656 & 3.446 & 0.379 & 8.683 \\
\hline & 6.245 & 0.903 & 4.699 & 0.227 & 5.065 \\
\hline & 7.836 & 1.175 & 3.510 & 0.428 & 3.467 \\
\hline & 7.052 & 1.702 & 5.587 & 0.676 & 5.304 \\
\hline & 5.535 & 1.373 & 4.616 & 0.749 & 4.493 \\
\hline Average & 6.653 & 1.365 & 4.169 & 0.682 & 4.257 \\
\hline $1 \sigma$ & 1.247 & 0.283 & 0.773 & 0.384 & 1.334 \\
\hline \multirow[t]{12}{*}{ Tiri Tephra-2 } & 5.343 & 1.162 & 2.978 & 0.593 & 2.666 \\
\hline & 5.319 & 1.147 & 4.126 & 0.550 & 4.488 \\
\hline & 7.571 & 1.007 & 4.509 & 0.539 & 3.752 \\
\hline & 5.185 & 1.082 & 3.560 & 0.559 & 4.011 \\
\hline & 5.787 & 1.098 & 5.170 & 0.611 & 4.478 \\
\hline & 5.921 & 1.568 & 4.828 & 0.515 & 3.973 \\
\hline & 6.143 & 0.920 & 4.425 & 0.591 & 3.632 \\
\hline & 5.726 & 1.142 & 3.942 & 0.432 & 3.908 \\
\hline & 6.424 & 1.500 & 3.701 & 0.607 & 3.454 \\
\hline & 5.418 & 1.378 & 3.345 & 0.514 & 3.616 \\
\hline & 7.150 & 1.423 & 3.466 & 0.655 & 3.310 \\
\hline & 6.317 & 1.121 & 3.699 & 0.585 & 4.002 \\
\hline
\end{tabular}




\begin{tabular}{|c|c|c|c|c|c|}
\hline & Dy & Ho & $\mathrm{Er}$ & $\mathrm{Tm}$ & $\mathrm{Yb}$ \\
\hline \multirow[t]{10}{*}{ Tiri Tepha-2 } & 7.647 & 1.604 & 4.276 & 0.474 & 4.520 \\
\hline & 6.799 & 1.314 & 4.456 & 0.759 & 4.186 \\
\hline & 4.614 & 1.439 & 3.477 & 0.401 & 3.614 \\
\hline & 5.281 & 1.331 & 4.305 & 0.644 & 3.573 \\
\hline & 5.805 & 1.633 & 3.131 & 0.400 & 2.914 \\
\hline & 6.543 & 1.503 & 4.739 & 0.672 & 3.634 \\
\hline & 7.224 & 1.075 & 4.369 & 0.843 & 3.312 \\
\hline & 4.508 & 0.831 & 3.248 & 0.487 & 2.900 \\
\hline & 7.076 & 1.367 & 4.046 & 0.705 & 4.022 \\
\hline & 6.084 & 1.174 & 4.990 & 0.559 & 3.693 \\
\hline Average & 6.086 & 1.265 & 4.036 & 0.577 & 3.712 \\
\hline $1 \sigma$ & 0.878 & 0.221 & 0.613 & 0.108 & 0.490 \\
\hline \multirow[t]{21}{*}{ Eagle Hill } & 6.014 & 1.360 & 3.545 & 0.806 & 3.704 \\
\hline & 7.044 & 1.456 & 5.027 & 0.586 & 4.685 \\
\hline & 7.877 & 1.604 & 3.970 & 0.600 & 4.645 \\
\hline & 7.040 & 1.459 & 4.459 & 0.398 & 4.257 \\
\hline & 8.083 & 1.142 & 4.291 & 0.745 & 3.434 \\
\hline & 6.798 & 0.935 & 4.095 & 0.409 & 2.926 \\
\hline & 5.384 & 1.179 & 3.473 & 0.592 & 3.611 \\
\hline & 7.001 & 1.510 & 3.527 & 0.717 & 3.782 \\
\hline & 7.772 & 1.663 & 4.650 & 0.718 & 4.436 \\
\hline & 7.014 & 1.422 & 4.340 & 0.791 & 3.506 \\
\hline & 7.252 & 1.439 & 4.414 & 0.601 & 4.770 \\
\hline & 7.797 & 1.264 & 3.228 & 0.529 & 4.504 \\
\hline & 8.995 & 1.652 & 5.165 & 0.721 & 5.343 \\
\hline & 6.266 & 1.350 & 2.886 & 0.461 & 3.892 \\
\hline & 6.853 & 1.440 & 3.741 & 0.573 & 3.855 \\
\hline & 5.681 & 1.472 & 4.519 & 0.480 & 3.909 \\
\hline & 6.522 & 1.336 & 3.973 & 0.610 & 2.907 \\
\hline & 6.412 & 1.271 & 5.108 & 0.519 & 4.190 \\
\hline & 6.766 & 1.344 & 5.543 & 0.695 & 4.330 \\
\hline & 7.060 & 1.801 & 4.589 & 0.725 & 3.952 \\
\hline & 7.201 & 1.522 & 3.412 & 0.401 & 3.889 \\
\hline Average & 6.992 & 1.410 & 4.188 & 0.604 & 4.025 \\
\hline $1 \sigma$ & 0.811 & 0.189 & 0.685 & 0.125 & 0.585 \\
\hline \multirow[t]{6}{*}{ Kowhai } & 6.212 & 1.741 & 3.922 & 0.453 & 4.217 \\
\hline & 6.018 & 1.509 & 6.211 & 0.895 & 4.243 \\
\hline & 6.792 & 1.144 & 3.393 & 0.612 & 4.737 \\
\hline & 5.670 & 1.177 & 3.381 & 0.576 & 3.047 \\
\hline & 6.954 & 1.779 & 4.926 & 0.843 & 4.921 \\
\hline & 5.877 & 1.711 & 4.580 & 0.696 & 3.691 \\
\hline
\end{tabular}




\begin{tabular}{|c|c|c|c|c|c|}
\hline & Dy & Ho & Er & $\mathrm{Tm}$ & $\mathrm{Yb}$ \\
\hline \multirow[t]{16}{*}{ Kowhai } & 5.575 & 1.175 & 3.672 & 0.563 & 4.743 \\
\hline & 7.962 & 1.748 & 4.818 & 0.793 & 3.603 \\
\hline & 8.304 & 1.519 & 3.865 & 0.563 & 4.344 \\
\hline & 7.628 & 1.822 & 4.646 & 0.763 & 4.364 \\
\hline & 6.784 & 1.560 & 4.009 & 0.456 & 4.249 \\
\hline & 6.969 & 1.559 & 4.240 & 0.583 & 5.216 \\
\hline & 5.993 & 1.283 & 3.333 & 0.693 & 4.027 \\
\hline & 5.976 & 1.192 & 3.244 & 0.852 & 4.099 \\
\hline & 6.332 & 1.218 & 2.967 & 0.480 & 3.647 \\
\hline & 6.856 & 1.527 & 3.660 & 0.737 & 4.513 \\
\hline & 8.098 & 1.402 & 3.848 & 0.995 & 3.836 \\
\hline & 5.713 & 1.405 & 3.015 & 0.464 & 2.728 \\
\hline & 7.933 & 1.163 & 4.878 & 0.896 & 4.422 \\
\hline & 7.377 & 1.032 & 4.214 & 0.747 & 4.558 \\
\hline & 6.774 & 1.457 & 2.850 & 0.573 & 3.333 \\
\hline & 5.948 & 1.189 & 4.137 & 0.519 & 4.115 \\
\hline Average & 6.716 & 1.423 & 3.991 & 0.671 & 4.121 \\
\hline $1 \sigma$ & 0.841 & 0.237 & 0.782 & 0.158 & 0.591 \\
\hline
\end{tabular}

\begin{tabular}{|c|c|c|c|c|c|}
\hline & Lu & Hf & $\mathrm{Ta}$ & Th & $\mathbf{U}$ \\
\hline \multirow[t]{21}{*}{ Tiri Tephra-1 } & 0.449 & 4.848 & 1.211 & 16.313 & 4.338 \\
\hline & 0.783 & 9.005 & 0.345 & 19.263 & 3.821 \\
\hline & 0.624 & 6.099 & 0.831 & 13.968 & 4.513 \\
\hline & 0.549 & 4.470 & 0.662 & 16.052 & 4.536 \\
\hline & 0.537 & 5.507 & 1.079 & 16.416 & 3.946 \\
\hline & 0.680 & 8.803 & 0.808 & 17.426 & 4.235 \\
\hline & 1.252 & 3.601 & 1.097 & 18.841 & 3.609 \\
\hline & 0.505 & 5.619 & 1.054 & 15.454 & 3.652 \\
\hline & 0.504 & 3.767 & 0.911 & 18.816 & 8.428 \\
\hline & 0.608 & 4.750 & 0.719 & 16.123 & 4.050 \\
\hline & 0.403 & 4.295 & 0.639 & 15.528 & 3.648 \\
\hline & 0.450 & 3.680 & 1.048 & 15.859 & 4.749 \\
\hline & 0.761 & 5.440 & 0.930 & 23.622 & 29.872 \\
\hline & 0.854 & 6.209 & 1.090 & 17.179 & 4.243 \\
\hline & 0.934 & 4.909 & 0.975 & 17.783 & 3.991 \\
\hline & 0.691 & 5.093 & 1.247 & 17.765 & 5.020 \\
\hline & 0.682 & 9.304 & 0.815 & 23.958 & 13.707 \\
\hline & 0.325 & 4.404 & 1.228 & 19.695 & 4.358 \\
\hline & 0.706 & 5.913 & 0.643 & 15.590 & 4.381 \\
\hline & 1.437 & 5.793 & 1.330 & 19.702 & 5.048 \\
\hline & 0.600 & 4.245 & 1.178 & 19.914 & 5.207 \\
\hline Average & 0.683 & 5.512 & 0.945 & 17.870 & 6.160 \\
\hline $1 \sigma$ & 0.261 & 1.626 & 0.244 & 2.509 & 5.736 \\
\hline
\end{tabular}




\begin{tabular}{|c|c|c|c|c|c|}
\hline & Lu & Hf & $\mathrm{Ta}$ & Th & U \\
\hline \multirow[t]{22}{*}{ Tiri Tephra-2 } & 0.664 & 7.199 & 0.668 & 11.709 & 2.978 \\
\hline & 0.733 & 7.816 & 0.708 & 13.541 & 3.488 \\
\hline & 0.987 & 7.799 & 0.696 & 14.258 & 3.662 \\
\hline & 0.532 & 8.168 & 0.546 & 13.365 & 3.983 \\
\hline & 0.584 & 9.159 & 0.677 & 12.389 & 4.096 \\
\hline & 0.568 & 8.296 & 1.091 & 13.145 & 3.360 \\
\hline & 0.532 & 6.652 & 0.832 & 11.633 & 3.746 \\
\hline & 0.394 & 6.861 & 0.547 & 12.070 & 3.463 \\
\hline & 0.771 & 8.233 & 0.852 & 11.861 & 3.837 \\
\hline & 0.454 & 7.251 & 0.743 & 13.784 & 2.858 \\
\hline & 0.443 & 6.694 & 0.789 & 11.652 & 4.363 \\
\hline & 0.566 & 8.659 & 0.885 & 11.892 & 3.649 \\
\hline & 0.510 & 7.834 & 0.729 & 12.004 & 3.133 \\
\hline & 0.607 & 7.659 & 0.949 & 14.426 & 3.955 \\
\hline & 0.350 & 7.774 & 0.761 & 11.906 & 3.408 \\
\hline & 0.539 & 6.919 & 0.736 & 10.971 & 3.142 \\
\hline & 0.447 & 7.758 & 0.798 & 11.811 & 3.121 \\
\hline & 0.576 & 7.488 & 0.670 & 13.853 & 3.595 \\
\hline & 0.637 & 6.804 & 1.047 & 13.960 & 3.885 \\
\hline & 0.587 & 6.986 & 0.650 & 9.685 & 2.527 \\
\hline & 0.679 & 9.141 & 0.863 & 13.405 & 3.049 \\
\hline & 1.017 & 9.193 & 1.465 & 14.748 & 2.856 \\
\hline Average & 0.599 & 7.743 & 0.805 & 12.640 & 3.461 \\
\hline $1 \sigma$ & 0.162 & 0.782 & 0.197 & 1.252 & 0.456 \\
\hline \multirow[t]{18}{*}{ Eagle Hill } & 0.613 & 7.196 & 1.029 & 12.223 & 2.668 \\
\hline & 0.731 & 7.609 & 0.788 & 13.846 & 3.282 \\
\hline & 0.502 & 8.063 & 0.751 & 13.190 & 3.030 \\
\hline & 0.757 & 7.748 & 0.469 & 12.727 & 3.379 \\
\hline & 0.558 & 7.985 & 0.980 & 14.173 & 2.801 \\
\hline & 0.478 & 6.583 & 0.755 & 12.366 & 3.010 \\
\hline & 0.738 & 7.006 & 0.935 & 12.096 & 2.864 \\
\hline & 0.651 & 8.762 & 0.761 & 14.543 & 3.724 \\
\hline & 0.697 & 8.477 & 0.870 & 13.680 & 3.313 \\
\hline & 0.926 & 7.879 & 0.689 & 13.760 & 3.251 \\
\hline & 0.658 & 8.721 & 0.622 & 14.056 & 3.123 \\
\hline & 0.485 & 9.116 & 1.125 & 13.758 & 3.734 \\
\hline & 0.625 & 9.697 & 0.906 & 16.020 & 2.915 \\
\hline & 0.828 & 7.960 & 0.511 & 13.756 & 3.543 \\
\hline & 0.378 & 9.945 & 0.591 & 13.514 & 3.747 \\
\hline & 0.735 & 7.313 & 0.776 & 12.796 & 2.892 \\
\hline & 0.941 & 6.706 & 0.784 & 12.874 & 3.613 \\
\hline & 0.498 & 8.113 & 0.368 & 12.728 & 3.625 \\
\hline
\end{tabular}




\begin{tabular}{|c|c|c|c|c|c|}
\hline & Lu & Hf & $\mathrm{Ta}$ & Th & $\mathbf{U}$ \\
\hline \multirow[t]{3}{*}{ Eagle Hill } & 0.708 & 9.417 & 0.660 & 14.339 & 2.445 \\
\hline & 0.985 & 8.967 & 1.127 & 14.864 & 3.510 \\
\hline & 0.582 & 7.639 & 0.610 & 11.954 & 2.208 \\
\hline Average & 0.670 & 8.138 & 0.767 & 13.489 & 3.175 \\
\hline $1 \sigma$ & 0.158 & 0.924 & 0.200 & 0.990 & 0.427 \\
\hline \multirow[t]{22}{*}{ Kowhai } & 0.490 & 7.085 & 0.819 & 16.252 & 4.772 \\
\hline & 0.781 & 5.966 & 0.928 & 22.758 & 3.974 \\
\hline & 0.511 & 6.274 & 1.115 & 19.324 & 4.160 \\
\hline & 0.412 & 5.230 & 0.984 & 17.497 & 12.683 \\
\hline & 0.854 & 7.553 & 1.146 & 19.243 & 4.368 \\
\hline & 0.407 & 6.226 & 0.915 & 17.735 & 4.483 \\
\hline & 0.710 & 5.508 & 1.077 & 18.211 & 4.151 \\
\hline & 0.759 & 5.363 & 1.171 & 18.322 & 4.809 \\
\hline & 0.904 & 7.311 & 1.393 & 21.372 & 5.198 \\
\hline & 0.729 & 7.232 & 0.972 & 18.610 & 4.650 \\
\hline & 0.880 & 5.243 & 1.030 & 18.165 & 5.152 \\
\hline & 0.794 & 5.217 & 0.907 & 20.086 & 8.317 \\
\hline & 0.421 & 5.145 & 0.902 & 16.615 & 4.515 \\
\hline & 0.696 & 5.070 & 0.646 & 17.151 & 3.931 \\
\hline & 0.676 & 5.742 & 1.151 & 16.005 & 4.222 \\
\hline & 0.992 & 4.995 & 0.958 & 18.703 & 4.456 \\
\hline & 0.825 & 6.181 & 1.339 & 17.887 & 4.943 \\
\hline & 0.706 & 5.161 & 0.862 & 17.153 & 5.030 \\
\hline & 0.761 & 6.136 & 1.089 & 18.182 & 4.711 \\
\hline & 0.597 & 4.811 & 0.937 & 17.531 & 4.749 \\
\hline & 0.463 & 4.024 & 0.538 & 16.601 & 4.707 \\
\hline & 0.373 & 4.058 & 0.855 & 15.997 & 4.083 \\
\hline Average & 0.670 & 5.706 & 0.988 & 18.155 & 5.094 \\
\hline $1 \sigma$ & 0.179 & 0.953 & 0.193 & 1.639 & 1.866 \\
\hline
\end{tabular}

